norman t.j. bailey and mark thompson editors
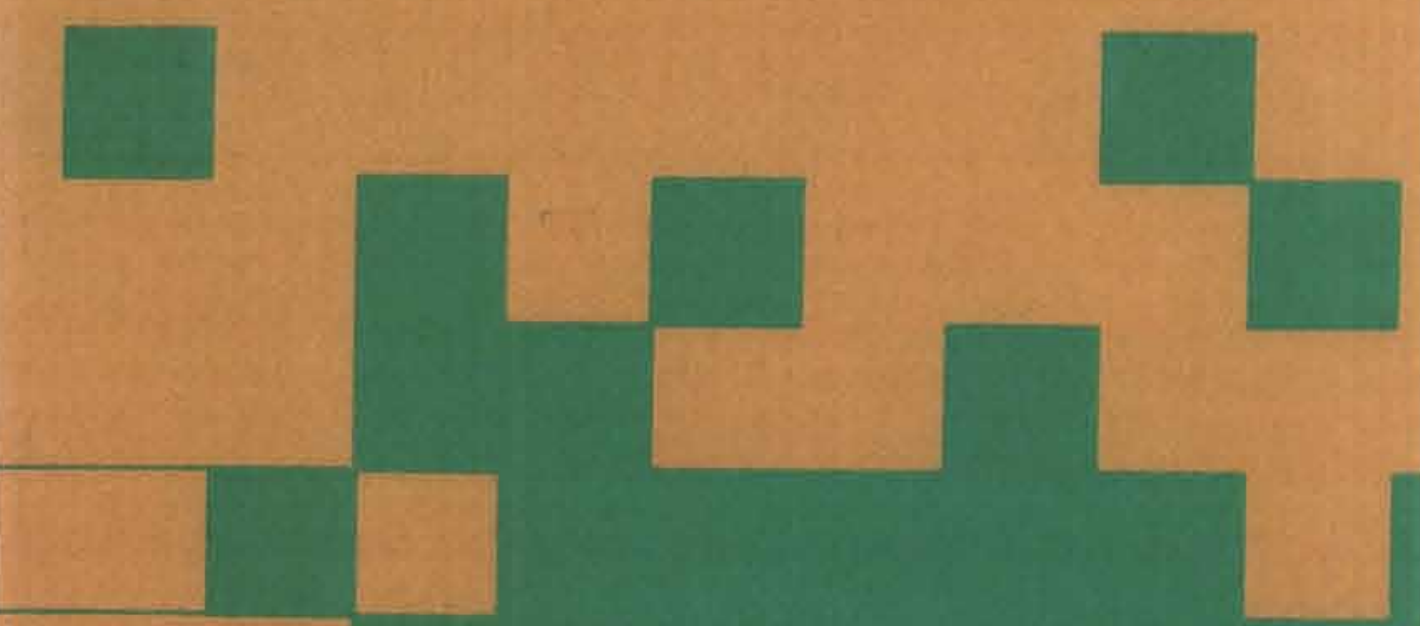

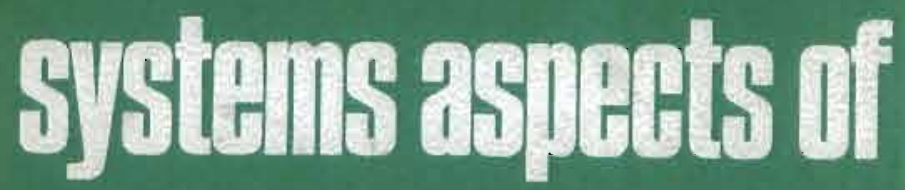
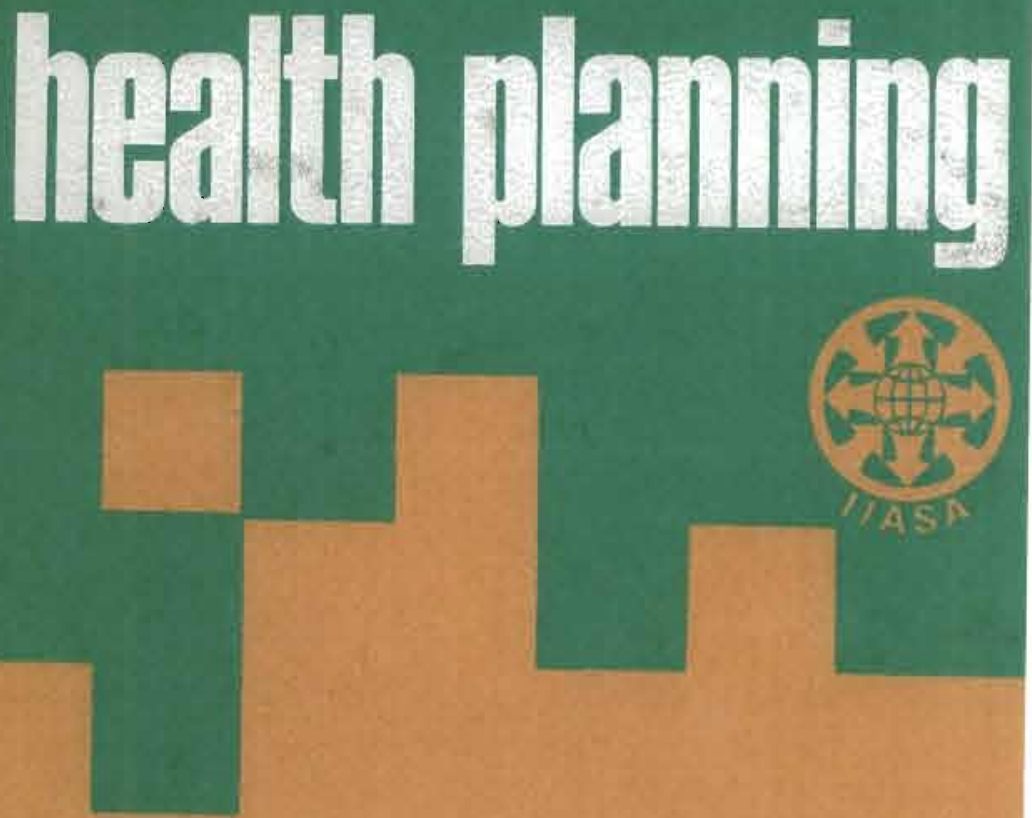

north-hollarid/american elsevier 



\section{Systems Aspects of HEALTH PLANNING}

Proceedings of the IIASA Conference, Baden, Austria, August 20-22, 1974

edited by

Norman T.J. Bailey

World Health Organization

Geneva, Switzerland

and

Mark Thompson

International Institute for Applied Systems Analysis

Laxenburg, Austria

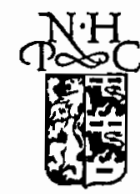

1975

NORTH-HOLLAND PUBLISHING COMPANY - AMSTERDAM - OXFORD AMERICAN ELSEVIER PUBLISHING COMPANY, INC. - NEW YORK 
All rights reserved. No part of this publication may be reproduced, stored in a retrieval system, or transmitted, in any form or by any means, electronic, mechanical, photocopying, recording or otherwise, without the prior permission of the copyright owner.

\author{
Library of Congress Catalog Card Number 7428994 \\ ISBN North-Holland 0270428300 \\ ISBN American Elsevier 0444108416
}

\author{
Publishers: \\ NORTH-HOLLAND PUBLISHING COMPANY - AMSTERDAM \\ NORTH-HOLLAND PUBLISHING COMPANY, LTD. - OXFORD
}

Sole distributors for the U.S.A. and Canada:

AMERICAN ELSEVIER PUBLISHING COMPANY, INC.

52 VANDERBILT AVENUE

NEW YORK, N.Y. 10017

PRINTED IN THE NETHERLANDS 


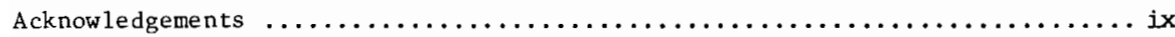

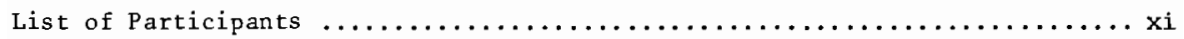

Foreword $\ldots \ldots \ldots \ldots \ldots \ldots \ldots \ldots \ldots \ldots \ldots \ldots \ldots \ldots \ldots \ldots \ldots \ldots \ldots \ldots \ldots \ldots \ldots$

PART I. INTRODUCTION

Morning, Tuesday, August 20, 1974

Research on Bio-Medical Systems in IIASA

Introductory Remarks by Howard Raiffa $\ldots \ldots \ldots \ldots \ldots \ldots \ldots \ldots$

Systems Modelling in Health Planning

Dr. N. T. J. Bailey .........................

Activities and Perspectives of the European Regional

Otfice of WHO on Health Planning

F. A. Bauhofer ............................ 13

Field Studies of Health Planning in Several European

Countries

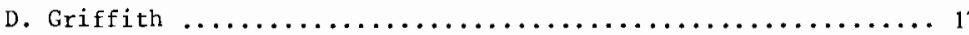

Systems Analysis of Health Services

D. D. Venediktov ............................. 19

Systems Analysis of the Development of Bio-Medical

Science and Methods of Its Coordination at National

and International Levels

D. D. Venediktov

PART II. DEFINITION OF HEALTH PROBLEMS

Morning and Afternoon, Tuesday, August 20, 1974

Forecasting Demand and the Planning of Health Services

J. P. Newhouse ...........................45

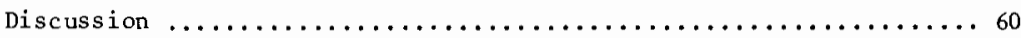

The Determination of Acute Care Bed Requirements for

Provincial Acute Care Hospital Regions

Douglas $\mathrm{W}$. Paine and Lawrence $\mathrm{L}$. Wilson $\ldots \ldots \ldots \ldots \ldots \ldots$

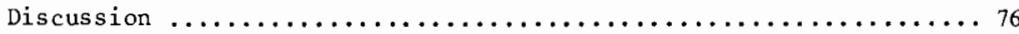

Complex Long- and Short-Term Planning on Health

Development in the USSR

V. V. Golovteyev ......................... 77

Forecasting the Development and the Territorial Distribution of Health Services in the People's Republic of Bulgaria

A. Cenov

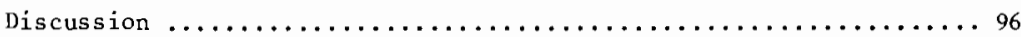


PART III. MEDICAL INFORMATION SYSTEMS

Morning, Wednes day, August 21, 1974

The Czechoslovak Health Care System and Its Computerization J. Rusnák, M. Popper, A. Rehảk, and J. Lelovský ........... 103

PlanningA National Medical Information System:

A Systems Approach

K. Atsumi and $S$. Kaihara ....................... 111

Discussion $\ldots \ldots \ldots \ldots \ldots \ldots \ldots \ldots \ldots \ldots \ldots \ldots \ldots \ldots \ldots \ldots \ldots \ldots \ldots$

PART IV. RESOURCE ALLOCATION

Morning and Afternoon, Wednesday, August 21, 1974

Health Manpower Planning in a Market Context:

The Case of Physician Manpower

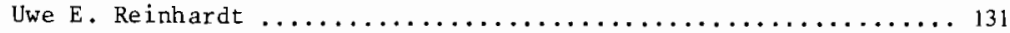

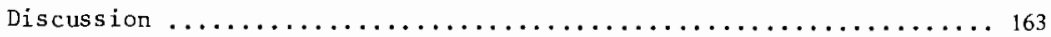

Systems Analysis for the Evaluation of Bio-Medical

Research

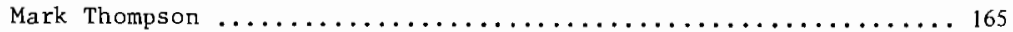

Discussion $\ldots \ldots \ldots \ldots \ldots \ldots \ldots \ldots \ldots \ldots \ldots \ldots \ldots \ldots \ldots \ldots \ldots \ldots$

The Role of the Systems Analysis in Medical Information

and Management of Bio-Medical Research

Yu. P. Lisitzyn and Yu. N. Chistyakov ................ 179

The Systems Analysis of Bio-Medical Research and the

Role of Scientific Medical Information

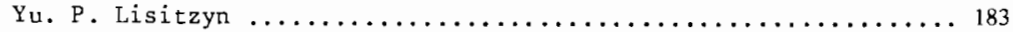

Discussion $\ldots \ldots \ldots \ldots \ldots \ldots \ldots \ldots \ldots \ldots \ldots \ldots \ldots \ldots \ldots \ldots$

Computer Simulation Studies of Alternative Population Screening Policies

E. G. Knox ............................... 191

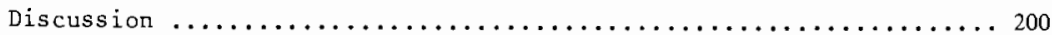

Economic Aspects of the Prevention of Down's Syndrome (Mongolism)

N. Glass ............................... 203

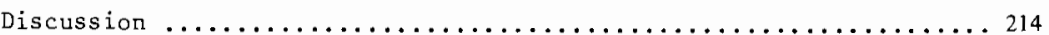

PART V. PLANNING AND MANAGEMENT IN THE HEALTH SECTOR

Afternoon, Wednesday, August 21, 1974

Morning and Afternoon, Thursday, August 22, 1974

The Public Health Planring System in Sweden

Gunnar Wennström ................................. 219

Uses of Epidemiology in the Planning and Evaluation of Health Care Systems

Dr. Jan Kostrzewski ............................ 227 


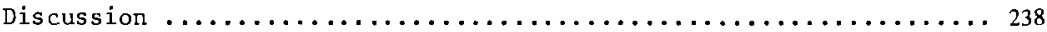

An Integrated Model of the Austrian Health Care System Peter Fleissner .............................. 241

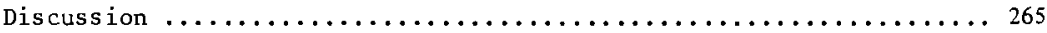

Some Aspects of the Relationships Between Mortality, Environmental Conditions, and Medical Care

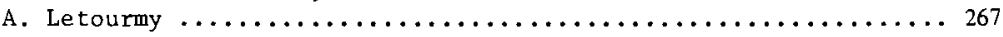

Discussion $\ldots \ldots \ldots \ldots \ldots \ldots \ldots \ldots \ldots \ldots \ldots \ldots \ldots \ldots \ldots \ldots \ldots \ldots$

On the Logic of Standard Setting in Health and Related Fields

G. Majone ................................ 279

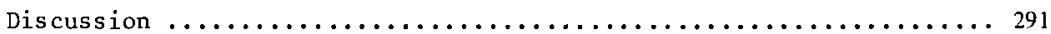

Health Care Delivery System Without Physicians

D. Koch-Weser .................................... 293

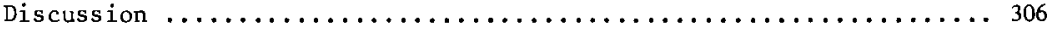

A System Approach to Health Care Planning in Czechoslovakia

J. Bouka1 ............................... 307

Discussion $\ldots \ldots \ldots \ldots \ldots \ldots \ldots \ldots \ldots \ldots \ldots \ldots \ldots \ldots \ldots \ldots \ldots \ldots \ldots$

Methods to Select Problems in Medicine

K. Fuchs-Kittowski, S. Rosenthal, and G. Schlutow ......... 319

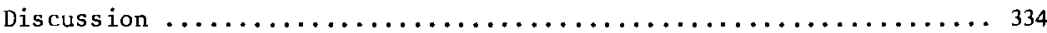

Summarization of the Conference:

Vital Tasks for Systems Analysis in Health $\ldots \ldots \ldots \ldots \ldots \ldots \ldots \ldots \ldots \ldots \ldots \ldots \ldots$

Some Terminalogy Revisited

A. A. Afifi, J. H. Bigelow, and N. Glass .................... 341

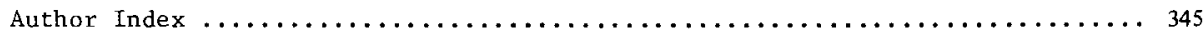





\section{EXPLANATION AND ACKNOWLEDGEMENTS}

Early in 1974, the International Institute for Applied Systems Analysis called for nominations from its thirteen national member organizations (NMO's). for a conference on "Systems Aspects of Health Planning." The purposes of the Conference were:

1) to obtain a more unified picture of the concrete ways in which systems analysis was being used initially as an aid to planning in the health sector; and

2) to define further the future role of the Bio-Medical Project of IIASA.

Every one of the NMO's nominated and sent at least one participant. The roster of conference nominees was supplemented by special invitations and by members of the World Health Organization. The goal was a slate of participants at once broad enough to provide cross-cultural and interdisciplinary coverage and yet small enough to encourage active discussion by all present.

In editing the proceedings, our primary goal has been simplicity of style and clarity of presentation. In presenting discussion, we have recorded precisely the gist of the remarks made. We hope, in so doing, to have omitted no important substantive points. We have followed the format of attributing remarks only when the role of the speaker--as the author of a paper, as its discussant, or as the purveyor of a national perspective--would have made the absence of attribution artificial. The rationale behind this policy was encouragement of more candid and informal interchange of ideas.

To be timely and to present this material in a form permitting its optimal distribution, compromises were essential. Through the meticulousness of all who aided us, we hope that the compromise quality made with speed was minimally to the detriment of the former. To achieve reasonable length, many of the papers presented had to be condensed. For this task, we relied exlusively upon our scientific editors: Messrs. Afifi, Bigelow, Glass, Majone, and Page of IIASA's Bio-Medical Project. They sought to achieve the necessary shortening of material at minimal loss in analytic substance. We must also in this connection express our gratitude for the understanding attitude of the papers' authors. To implement the instructions of the scientific editors and to polish the prose of writers with native languages other than English, the services of Elizabeth Thompson and Maria Sachs were invaluable.

The list of those to whom we are indebted is long: Ilse Ziegler performed heroically in producing verbatim transcripts of the discussions; Hamilton Brown, Terry Seal, Jannalee Smithey, and Margo Sweet provided the editorial supervision that made our deadlines attainable; Ilse Beckey organized the Conference; Patricia Bartos, Patricia Davy, Elfriede Herbst, Maureen Holm, and Ann Wadia supplied the care in the typing, and Helmut Frey, the care in draftmanship; Barbara Hauser was in charge, from beginning until end, of remedying all the myriad of procedural problems that arose in Conference planning, in routing participants, and in preparing the proceedings.

Norman Bailey

Geneva, Switzerland

Mark Thompson

5 November 1974

Laxenburg, Austria 



\section{INTERNATIONAL INSTITUTE FOR APPLIED SYSTEMS ANALYSIS}

\section{LIST OF PARTICIPANTS}

for the IIASA Conference

\section{"SYSTEMS ASPECTS OF HEALTH PLANNING"}

20 to 23 August, 1974

20 to 22 August, 1974

23 August, 1974

MODERATOR

NOMINATIONS BY NATIONAL MEMBER ORGANIZATIONS

AUSTRTA

The Austrian Academy of Sciences

BULGARIA

The National Center For Cybernetics and Computer Techniques

CANADA

The Canadian Committee for IIASA
Hotel Gutenbrunn, Baden near Vienna

Schloss Laxenburg, Laxenburg

Prof. N. T. J. BAILEY

Health Statistical Methodology

Who, Headquarters

Geneva

Dr. P. FLEISSNER

Austrian Academy of Sciences

Institute for Socio-Economic

Development Research

F1eischmarkt 22

Vienna

Dr. A. CENOV

c/o Prof. L. Iliev

The National Center for Cybernetics

and Computer Techniques

Slavjanska 8

Sofia

Dr. D. MIRCHEVA

Institute of Social Hygiene

as interpreter

Mr. D. W. PAINE

Hea1th Systems

Hea1th and Welfare Canada

Brooke Claxton Building

Ottawa

Mr. L. L, WILSON

Alberta Hospital Services

Commission

9912107 th Street

Alberta 


\section{CZECHOSLOVAKIA}

The Committee for IIASA of the Czechoslovak Socialist Republic

FEDERAL REPUBLIC OF GERMANY The Max-Planck Society

\section{FRANCE}

A.F,D.A.S.

GERMAN DEMOCRATIC REPUBLIC The Academy of Sciences

ITALY

Italian Committee for

Liaison with IIASA

\section{JAPAN}

The Japan Conmittee for IIASA

POLAND

Polish Academy of Sciences

SWEDEN

Ministry for Foreign Affairs

\section{UNITED KINGDOM}

The Royal Society
Dr. J. BOUKAL

Ministry of Health

Wilhelm Beack St. 98

Prague 2

Prof . A. REHÁK

Research Institute of Medica 1

Bionics

Opavska cesta 6

88346 Bratislava

Prof. Dr. P. REICHERTZ

Department for Biometrics and

Medical Information Theory

The Medical School

University of Hanover

Karl Weichert Allee 9

3000 Hanover-Kleefeld

Mrs . SCHNEIDER

Federal Ministry for Youth, Family, and Health

Mr. Alain LETOURMY

CERE BE

140, Rue du chevaleret

75013 Paris

Prof. K. FUCHS-KITTOWSKI

Humboldt University

Berlin

Academician Prof. S. M. RAPOPORT GDR Academy of Sciences

Leipziger St.

108 Ber 1 in

Prof. G. MAJONE

University of Rome

(present1y working as a Research Scholar to the IIASA Bio-Medical Project)

Dr. K. AT SUMI

University of Tokyo

Bunkyo-Ku

Tokyo 113

Prof. J. KOSTRZEWSKI

Medical Sciences Department

Polish Academy of Sciences

Palace of Culture and Sciences

Warsaw

Dr. G. WENNSTRÖM

National Board of Health and

planning Affairs

Prof. E. G. KNOX

Department of Social Medicine

University of Birmingham

Birmingham 
U.S.A.

The National Academy of Sciences

U.S.S.R.

The Academy of Sciences
Dr. U. E. REINHARDT

Woodrow Wilson School of

Public and International Affairs

Princeton University

Princeton

Prof. D. D. VEnEDIKTOV

Deputy Minister of Health

The Academy of Sciences

State Comititee for USSR

Council of Ministers for Science and Technology

11 Gorky st.

Moscow

Dr. V. V. GOLOVTEYEV

address as above

Prof. YU. P. LISITZYN

address as above

Dr. NOVOSELTSEV

The Academy of Sciences

State Conmittee for USSR

Council of Ministers for Science and Technology

11 Gorky St.

Moscow

Prof. A. M. PETROVSKY

Institute of Control Sciences

Pr of guznaya St. 81

Moscow

Dr. ZILOV

The Academy of Sciences 


\section{OTHER INVITED PARTICIPANTS}

AND OBSERVERS

WORLD HEALTH ORGANIZATION, GENEVA

WORLD HEALTH REGIONAL OFFICE, COPENHAGEN

Dean H. HIATT

Mr. S. HONOKAPOHJA

Prof. T. KENNER

Dr. D. KOCH-WE SER

Dr . W. MEYER-JUNGNICK

Dr. J. G. MILLER

Dr. J. P. NEWHOUSE

Dr. W. SPENCER

Prof. M. THRALL

$\mathrm{Mr}$. R. TUCH

Dr. M. WEINSTEIN
Dr. DeBOECK

Project Systems Analysis

WHO

Geneva

Dr. F. A. BAUHOFER

Director of Health Services

WHO

Copenhagen

Dr . GR IFF ITH

WHO

Copenhagen

Harvard School of Public

Health

677 Huntington Avenue

Boston, Massachusetts

University of Helsinki

Helsinki

Physiological Institute

University of Graz, Austria

Harvard University

Medical School

Department of Preventive Medicine Boston, Massachusetts

SYSTEC

System Planning and Industrial

Consultants

Wildenbruch Street 18

4000 Dusseldorf

University of Louisville

Kentucky, USA

The Rand Corporation

Santa Monica

California

Baylor College of Medicine

Texas Medical Center

Houston, Texas

Rice University

Houston, Texas

Laxenburger St. 130

Vienna

Harvard School of Public Health

677 Hunt ington Avenue

Boston, Massachuset ts 
Professor H. RAIFFA .................... Director

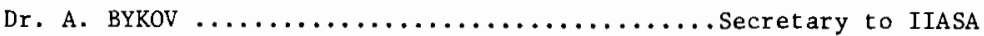

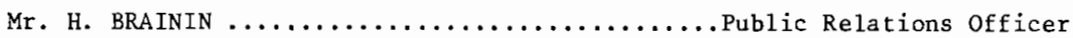

\section{RESEARCH SCHOLARS}

Dr. S. CHATTERJEE

Dr. J. COLLINS

Mr. N. GLASS

Dr. J. GROS

Mr. J. PAGE

Dr. M. THOMPSON

Dr. H. UZAWA
Methodology

Management of Urban and Regional Systems

Bio-Medical Systems

Energy/Methodology

Bio-Medical Systems

Bio-Medical Systems

Envir onmental/Water 



\title{
FOREWORD
}

\author{
Howard Raiffa
}

Director of IIASA

With pleasure and pride, we welcome the appearance of this book--the first to be published by the Bio-Medical Project of IIASA. The Conference, "Systems Aspects of Health Planning," which it describes touched upon many important themes of the Institute: how interdisciplinary systems science should best be organized and directed; how analytic experts and real world practitioners should combine efforts to address most effectively the difficult policy problems of current relevance; and how leading representatives of many nations--in socialist and non-socialist lands-might learn from the experiences of one another.

The book may be valuable for a number of possible reader purposes. On the most evident level, it presents in its papers a series of good examples of what systems analysis is and how it should be applied within the context of health system planning. The student of comparative health systems will find the book rewarding for its description of alternative systems and the rationale which underline them. These descriptions are invaluable as candid statements--and critical selfanalysis--by the very people who make the systems work. The English language literature has been regrettably deficient in descriptions of health systems in the Eastern countries written from the viewpoint of their managers. On still another plane, the book may be read with attention upon the dialogue that followed paper presentations. Here especially can be seen frank discussions of the issues with highest importance to the analysis of health systems in the mid-1970's.

The conference itself was noteworthy for the open exchange between representatives of different health systems and between practitioner and analyst. Our participants were not inhibited in expressing their admiration or their disapproval of aspects in their own health systems and in the systems of other nations. When I see such debate take place constructively and without rancor, I cannot help feeling that this was exactly what the founders of IIASA had in mind.

Discussion between scientist and health system administrator was equally frank and useful. In part, this owed to a fortunate numerical balance between the two groups of conference participants. The analysts presenting papers were not bashful in pointing out instances of inconsistent or ineffective management strategies. The many managers present in turn did not hesitate to bring to light important factors that had been excluded from the analyses or that might prevent inplementation of the analytic recommendations. Among the most valuable commentary made by the practitioners concerned the presentation of the analysis: how it should be couched, ordered, or introduced to achieve maximal impact and benefit.

In my own reading and attendance of the conference I was struck most by the overall flux and change in the field of health analysis. Here, as meh as in any area of applied analysis, no axiom--including those that have stood for centuries-is exempt from challenge. Critical examination is being given to the roles played by doctors and hospitals, patients and mangers in the quest to $f$ ind better ways of delivering health care to the population. Analysis itself is not immune from such scrutiny. The analytic gadfly shooting barbed and witty but unconstructive observations about the shortcomings of systems mangers is no longer tolerated. The analyst must prove his utility through ultimate policy benefits. Analysts themselves are examining carefully the resources which they consume. The discussions in this book show concern both for the possibly exorbitant costs of information-gathering and for excessive drain upon top management talent. 
The conference was useful to IIASA in our continuing and sequential process to determine our most appropriate role. By eliciting from many countries examples of applied analysis in health planning, this conference has provided extensive input for the survey upon the state of the art in systems analysis now being carried out by the Institute. We have discovered--as a careful reading of this volume bears out-- that systems analysis has different meanings for observers in different contexts. For the managers of complex health systems, the discipline focuses upon ways of optimizing system operation. Among the several papers in this volume which discuss such optimization, special emphasis has been placed upon the information subsystem and the ways in which it should be structured to enhance overall system performance. Other papers interpret systems analysis more closely to its operant definition within IIASA: as the application of a rational way of thinking and of scientific methodology to resolve conplex decision problems. Such problems addressed by papers within this volume include: determining the proper supply of acute care hospital beds, improving guidance of bio-medical research, and evaluating possible iarge-scale screening programs.

Another perspective on the nature of systems analysis is provided by the methodologies employed in the papers presented. Three papers show the potential of econometric regression analysis: one in identifying the minimal information set needed for health planning, a second for aid in modelling a national health system, a third in resolving a difficult question on the cumulative effects of health expenditures. The role of precise numerical modelling is displayed and discussed in a number of problem-oriented papers. Still other authors have emphasized the role of scientifically based projections and of prognosis in health planning.

The purely selfish role of the Conference for the Bio-Medical Project of IIASA can be seen in these proceedings. Of utmost importance was the mere bringing together of decision-makers and analysts of different lands. This group identified the types of systems analysis now being carried out to assist health planning, those types where more methodologicai work is needed, and those types which are most critical to systems management. The Bio-Medical Project--like all applied projects of IIASA--seeks to perform analysis that will affect decisions of the real world. To do this, contacts and discussions of the type provided by this conference are essential.

To have impact on international systems of health, the Bio-Medical Project must maintain close working contact with the World Health Organization. We were thus pleased that both the World Headquarters and the European Regional office of WHo were ably represented at the Conference. Their perspective deriving from experience provided a useful temper to our discussions which were superbly chaired by Prof. Norman Bailey of WHO World Headquarters. From the point of view of the Project, I must agree with the Finding of our newly appointed Project Leader, Prof. Venediktov, Deputy Minister of Health of the USSR, who felt that the Conference had laid out well the tableau of what systems analysis can do in health; it now remains for us to initiate work toward the partial realization of this potential. 
PART I. INTRODUCTION 



\author{
RESEARCH ON \\ BIO-MEDICAL SYSTEMS \\ IN IIASA
}

WELCOME

Professor Howard Raiffa, Director of IIASA, opened the conference with a welcome to all participants. He recalled the stimulating and productive planning conference for the Bio-Medical Project held approximately one year earlier. Professor William Schwartz of Tufts University Medical School chaired that meeting which also was attended by many of the persons in the room.

\section{PROJECT BEGINNINGS}

The result of the planning conference was a long list of attractive research topics for the Bio-Medical Project. Unfortunately, adequate treatment of all the subjects would have required scientific resources far greater than those available. As a result, the Project would restrict its ambition by focusing upon a smal1 number of research tasks that would be: 1) bounded in scope; 2) feasible; and 3) not requiring vast amounts of nonanalytic input--such as data gathering and clinical expertise. In addition, the Project would extend its 1 imited internal manpower through collaboration with the World Health Organization (WHO) and national ministries of health.

The initiation of research in the Bio-Medical area has lagged behind other IIASA projects. This was partly a conscious strategy: a11 research areas could * not--because of resource constraints--be simultaneously built up. The choice of the Bio-Medical Project for delayed development derived also from the 1ack, until just recently, of a Project Leader. Professor Raiffa was proud to announce a most satisfactory resolution of this problem in the appointment of Professor Dmitri Venediktov, the Deputy Minister of Health of the Soviet Union, as Project Leader. With the last barrier to rapid development of the Project thus removed, Professor Raiffa envisioned for 1975 a long crescendo of increasing activity.

\section{PROJECT ORGANIZATION}

Organizationally the Project will be run by a Deputy selected by Professor Venediktov. Although Professor Venediktov must reside in Moscow to attend to his other duties, he will make frequent visits to Laxenburg and will maintain close contact with the Project through telecommunications. The Bio-Medical Project Advisory Committee will give advice on short- and long-term planning of the Project. (The first meetings of the Bio-Medical Project Advisory Comittee took place during the evenings of the Conference week.) The Committee members are Professor Raiffa and Professor Venediktov (both ex officio), Professor Bailey, Dean Hiatt, and Professor Rapoport.

The strategy of the Project to extend its limited resources through collaboration with internal IIASA projects and external organizations has already begun. Proof of initial successes in external liaison could be seen at this Conference. Professor Bailey, the Conference Chairman, has been appointed by Director General Mahler of WHO World Headquarters to be liaison officer for IIASA. He was accompanied to the Conference by Dr. Guido Deboeck. The European Regional Office of WHO in Copenhagen was represented by its Director of Health Services, Dr. F.A. Bauhofer, and the head of its unit on Health Planning and Evaluation, Dr. D. Griffith. 


\section{OVERVIEW OF IIASA ACTIVITIES}

The scientific activities of IIASA fall under four main headings:

1) in-house research;

2) extramural collaboration;

3) information expedition; and

4) conference sponsorship.

The Conference, convened to address questions of importance to a11 IIASA members, is intended to contribute toward each of the categories above. It should guide the internal research program, facilitate external liaison, and promote the more rapid exchange of internationally needed information.

Within IIASA, the research program is organized according to the matrix format presented in Figure 1 .

\begin{tabular}{|c|c|c|c|c|c|c|}
\hline & \multicolumn{6}{|c|}{ App $I$ i ed Projects } \\
\hline $\begin{array}{l}\text { Supporting } \\
\text { Projects }\end{array}$ & $\begin{array}{l}\text { Bio-Medical } \\
\text { Systems }\end{array}$ & $\begin{array}{l}\text { Ecology and } \\
\text { Environmental } \\
\text { Systems }\end{array}$ & $\begin{array}{l}\text { Energy } \\
\text { Systems }\end{array}$ & $\begin{array}{l}\text { Industrial } \\
\text { Systems }\end{array}$ & $\begin{array}{l}\text { Urban } \\
\text { Systems }\end{array}$ & $\begin{array}{l}\text { Water } \\
\text { Resources }\end{array}$ \\
\hline $\begin{array}{l}\text { Computer } \\
\text { Sciences }\end{array}$ & & & & & & \\
\hline Methodology & & & & & & \\
\hline $\begin{array}{l}\text { Organization } \\
\text { and Manage- } \\
\text { ment }\end{array}$ & & & & & & \\
\hline
\end{tabular}

Figure 1. The Matrix Origin of IIASA Research.

It is planned that each of the eighteen boxes shall be filled with interactions between the supporting and applied projects. In addition to its service functions, each of the support projects will pursue more theoretical themes of its own choosing not necessarily related to the applied work of the Institute. The applied projects will coordinate among themselves on overlapping themes of interest. The problem of waste heat, for instance, will receive attention from the Ecology, Energy, and Water projects. The possible points of contact between the Bio-Medical group and other IIASA researchers will now be described in detail.

\section{POSSIBLE INTERACTIONS OF THE BIO-MEDICAL PROJECT WITH OTHER IIASA PROJECTS}

\section{ENERGY SYSTEMS}

The Energy Project is presently investigating the comparative risks deriving from all of the main alternatives as primary energy sources. In the nuclear donain, this will focus upon the biological, genetic, and other effects that result from releases of radioactivity. The radiation hazard could result from unintentional releases or from human malevolence. In applying cost-benefit analysis to these phenomena, both actual risks and the risks perceived by the population will be taken into account. The major effort of the Energy Project to assess hazards is now proceeding in collaboration with the Bio-Medical Project and with the International Atomic Energy Agency. 


\section{ECOLOGY AND ENVIRONMENTAL SYSTEMS}

The Ecology group has recently completed a successful study into the management of a particular forest pest, the spruce budworm. Using detailed data compiled over decades, the group was able to model mathematically the course of the epidemics as the function of the weather and forest management. The computer simulation runs resulting enabled the Ecology Project to specify guidelines for the two primary tools of forest operation: spraying and cutting. In hopes of extending this methodology to related situations, the United Nations Environmental Program (UNEP) has been discussing with IIASA the possibility of performing a similar study on such maladies as Chagas' disease, malaria, or schistosomiasis. Here the goal would be to judge the mix of biological, ecological, economic, and sociological policies best combating the diseases. Bio-Medical Project personnel would be essential collaborators in such an effort.

Another topic considered as a possible focus for joint exploration by the Bio-Medical and Ecology groups 1 ies in the area of environmental standards and monitoring. So little is presently understood about the causal relationship between pollutants and human health that delicate statistical analysis will first be required to estimate the strength of such linkages. Using this information, the Ecology Project--in coordination with the Hydro-Meteorlogical Institute of the USSR, the Scientific Committee on Drohlems on the Fnvironment, and INEP--would develop methodology for setting appropriate environmental standards and would prescribe a strategy of monitoring for their enforcement.

\section{WATER RESOURCES}

A main focus of the Water Resources Project has been upon the management of river systems to achieve conflict resolution. Conflicts have centered upon the withdrawal and the impairment of flowing waters--each of which may effect environmental perturbances and, in turn, health hazards. With the Ecology and Bio-Medical groups, the Water Project will seek to gauge these hazards and to devise policies for managing them. A related effort may study the effect of water hardness upon . ischemic heart disease. In the more distant future, the water Project may consider the combined effects of energy, environment, and water upon food and nutrition and in turn upon health.

\section{MANAGEMENT OF URBAN SYSTEMS}

The Urban Project has centered its attention upon two main themes: municipal services and national settlement policies. In the former area, emergency services have been singled out for immediate consideration. These include fire control, police, transportation, ambulance service, mobile coronary care units, and the hospital emergency room. An extension of this analysis may in the future cover international emergency services for such natural disasters as droughts, famines, floods, and earthquakes.

National settlement policies deal both with the delicate population equilibria along the spectrum between urban and rural areas, and with the development of such inhospitable regions as the Arctic, the desert, and the tropical jungles. In both cases, components of the studies performed will address the problem of providing an adequate medical infrastructure. A less tractable goal will be to design settlements for the maximum of psychological well-being.

\section{INDUSTRIAL SYSTEMS}

The Industrial Systems Project of IIASA will study in its first year the control of integrated steel production: the environmental effects, recycling processes, effluent control, and interconnected usage of residuals. Its interconnection with the Bio-Medical Project will lie initially in considering the health effects of steel plan effluents. It is subsequently planned to investigate the health effects of such industrial materials as asbestos and lead. 


\section{METHODOLOGY}

The IIASA experts in general systems methodology will be engaged in two theoretical pursuits of direct consequence to Bio-Medical analysis. These are 1) examining intergenerational tradeoffs and 2) incorporating multiple objectives-including fragile values and such arduously quantifiable effects as morbidity, mortality, and environmental harm--into an optimized decision procedure. More applied work that will buttress the collaboration between the Bio-Medical and Energy areas on radiation hazard is a more general methodology of risk with emphasis upon safety engineering.

\section{ORGANIZATION AND MANAGEMENT}

The Large Organizations Project will initiate its work with a cross-cultural and cross-disciplinary comparison of organization and management. Part of its focus will be upon hea1th systems, hospitals, emergency services, and the management of bio-medical research and development. It will also examine:

a) the implementation of international agreements--through UN agencies and multinational commissions;

b) retrospective case studies of such integrated p1anning projects as the TVA and the development of a Siberian region; and

c) practical ways to bridge the chasm between analyst and decision maker.

\section{COMPUTER SCIENCES}

In addition to the purely service-oriented Computer Systems group, the Computer Sciences Project of IIASA will work to harness modern information processing technology to the needs of systems analysis. A combined theoretical and practical study is underway to examine the potential of computer networking. This study will cover: the specific Laxenburg situation, the more general perspective, teleconferences, hardware and software needs, and the effect upon society. Possible social spin-offs include applications to bio-medical engineering, increased use of paraprofessionals, and remote diagnosis. A future activity of the Computer Sciences Project will center upon artificial intelligence. Among other aspects, computer-aided diagnosis and treatment, prostheses, and bio-medical engineering will be studied.

\section{GENERAL ACTIVITIES}

In addition to the organized and ongoing projects of IIASA, a more flexible section of General Activities has been established. Scientists appointed to this group will provide expertise on important topics peripheral to, but linked to, the areas of applied work and will investigate whether these topics should be proposed to the IIASA Council to become full-fledged projects. The most advanced of the General Activities is a state-of-the-art survey upon applied systems analysis, tentatively entitled the IIASA Handbook of Applied Systems Analysis. Other General Activities topics already under study include food and agriculture, climatology, and methodological evaluations of the major efforts in global modelling. 


\author{
SYSTEMS MODELLING \\ IN \\ HEALTH PLANNING
}

\author{
Dr, N. T. J. Bailey
}

World Health Organization, Geneva

\title{
INTRODUCTION
}

The purpose of this introductory paper is not to present either a specific technical contribution on the delivery of health care, or to outline an overall comprehensive systems analysis of the whole area of health planning. It is, rather, to highlight a number of prominent features that seem constantly to crop up in current discussions about the value of systems approaches and the need for quantitative methods, especially the use of systems modelling. These themes will occur again and again in the papers presented to this conference (either implicitly or explicitly), and I believe that we shall frequently be referring to them in discussion.

It is clear from the agenda before us that we have quite a wide range of technical subjects to consider, including forecasting, information systems, resource allocation, system dynamics and simulation, and standard setting. In addition, there are the wider strategic-level problems of regional and national planning, involving much broader questions of policy analysis, which will come up in the special session involving planning techniques.

The terms of reference for this conference were indicated in Attachment $A$ to the official letter of 21 June 1974, giving the draft agenda at that time. They are as follows:

The stress throughout this conference will be on the discussion and evaluation of systems methods which have been or are presently being used to plan and to manage specific existing health systems. Purely theoretical papers are strongly discouraged as are diffuse narrative papers not addressed to actual systems approaches.

I hope that we shall be able to fulfill the spirit of this charge, even if occasionally enthusiasm for a particular theoretical point manages to defy the official discouragement!

What follows in this paper is therefore very much a personal viewpoint of what constitutes some of the major issues in the use of systems approaches in the health field, though it is based on discussions in which I Find myself involved on an almost daily basis.

\section{MATHEMATICAL MODELLING}

Almost all quantitative thinking and analysis entails some kind of mathematical modelling. I believe that this is a truism that need not be debated in the present company of experts. In the current context, the important questions are what kinds of models are appropriate for understanding and control, and what kinds of mathematics will facilitate the required manipulation.

The range of applications is considerable. Thus we can model the population dynamics of the incidence and prevalence of a given disease at a technical epidemiological level, or we can concentrate on the dynamic structure of health service activities at the management and organizational level using some form of systems analysis. However, such work inevitably employs simulation procedures, operational research techniques, computer facilities, special computer program packages, as well as being intimately connected with various forms of health statistics and the use of statistical methodologies. Moreover, all these activities, to be really 
effective, must be seen as essential inputs to health information systems and policy analysis operations.

Now, the purpose of all this modelling is essentially to facilitate the achievement of agreed objectives. It may encompass anything from the clarification of thought to the computation of optimal resource allocation strategies. The basic approach is that of common sense, $\log i c$, quantitative argument, and scientific method. In accordance with the well-known principle of William of Occam's razor, namely that "concepts should not be multiplied without necessity," the degree of complexity adnitted should be the minimum required to attain the objectives in question. In some cases simple verbal discussion, using a few measurements, rates, or percentages, is all that is required. In other cases, high-powered computing may be essential to disentangle complex problems--especially in the typical interactive, time-lagged, multiple feedback type of system, where actual behavior may be markedly counterintuitive. At all events, what is appropriate all depends on circums tances.

There is, in my opinion, a special reason for placing major emphasis on the whole subject of modelling as such, that is on the philosophical status of the activity. Most of us with an academic, scientific, or mathematical background find an enormous fascination in the business of trying to epitomize interesting phenomena in the real world in terms of mathematical formulations. On the other hand, those whose training has not been specifically scientific, but who have a good intuitive and operational grasp of the major issues involved in decisionmaking and political bargaining, may simply find the minutiae of exact analysis uninteresting, irrelevant, and time-wasting.

The ultimate practical successes of a scientific approach to achieving near-impossible objectives are unquestionable, e.g. the harnessing of atomic energy or putting men on the moon (setting aside any questions of what is socially and economicaily desirable). We may therefore ask where lie the fundamental difficulties of communication between mathematical formulations of phenomena and practical interventions in the real world. I am personally convinced that the concept of modelling is the clue to the problem. A really effective model must be interpretable in everyday common sense terms and be acceptable to an epidemiologist or health decision-maker, for example, at the same time as it is capable of logical manipulations of a possibly very high order using intricate mathematical methods and high speed computation. From this point of view the model is the interface between the real world in all its ramifying complexity and our simplif $\overline{\text { ied schema- }}$ tized investigations of it.

If the modelling--and in our specific context, systems modelling--is truly to be a unifying principle between two different though interacting spheres-between thought and action, between theory and practice, or in whatever terms you choose to see it--then it must be developed consciously and deliberately with this role in mind.

Conversely, this implies that modeling must not be pursued as a purely academic exercise, after which some health-related problem is forced into an uncomfortable posture in an attempt to provide a practical illustration. When this happens, especially in a decision-oriented context, modelling is liable to be regarded by health authorities as an irrelevant and expensive waste of time.

Real, ongoing, decision-oriented problems must be faced, and solutions must be attempted that are socially significant within whatever financial, cultural, or political constraints that may be operating. This means that the systems analysis must always grow out of real-1ife problems and be directed toward their solution, and not be a merely ingenious way of looking at things. 


\section{TYPES OF MODELS}

It may be convenient at this point to refer briefly to one way of classifying models. Although discrete classes are used, there is in practice a good deal of overlap, and it may well be that a continuous spectrum could be envisaged.

\section{a) Technical Models}

These comprise a range of models incorporating detailed technical aspects. In the context of the program of the World Health Organization, it has involved mainly the population dynamics of commnicable diseases such as tuberculosis, malaria, typhoid fever, tetanus, and cholera. This modelling is aimed, first, at providing a more precise scientific understanding of the population behavior of the disease in question; and, secondly, at making forecasts and comparisons of the probable outcomes of feasible strategies of public health intervention, with a view to identifying an optimal intervention strategy.

We can also include under this heading various forms of demographic models, involving birth, death and migration, with or without disease categories; heaith manpower models; various family health models, etc.

\section{b) Systems Models}

Systems models are not intrinsically different in logical form from the technical models above, but the term is conventionally applied to complicated systems of interacting components, where the latter are of technical type. The overall "system" then relates more to organizational patterns and processes, and is more closely connected with management and decision-making.

\section{c) Information Systems Mode1s}

In some usages, information systems are regarded as practically synonymous with systems models. In other usages, information systems may deal in principal with the flow of information within an organization for the purposes of facilitating decision making. The use of flow charts and network analysis for scheduling, programing, and planning come under this heading.

\section{d) Policy Analysis Models}

This type of modelling is very much in its infancy. Basically, it involves using a careful logical analysis of a complex of difficult problems at the policy level, e.g. broad public health planning, for the purpose of making all assumptions more explicit, recognizing constraints more clearly, drawing conclusions from the assumptions in a more reliable manner, and so on. Use is often, but not always, made of technical models, systems models, and information systems.

I believe that it is also important to distinguish, in any particular context, whether we are operating deductively or inductively. That is, we must know whether we are simply elucidating the quantitative models implicit in our verbal thinking and discussion, with a view to deducing the consequences of our assumptions quickly and accurately, and detecting any unrealized contradictions, or, whether we are trying to design a sufficiently realistic model of the external world that is simple enough to be manipulated and which we can subject to scientific verification, using appropriate statistical criteria.

Very often, I am afraid, we embark on enormously expensive computerized investigations of purely deductive a priori models in the belief that they represent the real world and can safely be used to choose between alternative practical strategies. But in fact the models have never been verified, and may, at least for the time being, be unverifiable, because of the lack of relevant data and the absence of opportunities to collect and process the information required. 


\section{SCOPE OF SYSTEMS MODELLING}

With the foregoing conceptual framework as a guide, I should now like to make a few remarks on the general scope of systems modelling. The ultimate purpose is, or in my opinion should be, to expedite the delivery of health care to actual people in existing countries. In order to ensure that this over-riding objective is kept clearly in mind, it seems to me that far more emphas is needs to be placed on policy analysis.

The World Health Organization has of course long been involved in promoting and carrying out all kinds of public health activities at both technical and administrative levels. And it is now beginning to play an increasingly important role in the coordination of activities that occur of necessity on an international basis. Let us take one example in the area of the provision of drugs and insecticides. World-wide programs of malaria control are estimated to need some 50,000 metric tons of DDT per year. WHO's direct control of DDT through specific projects amounts to only about 100 tons a year, a mere fifth of one percent. But the supplies are becoming more difficult to obtain, fewer manufacturing companies are involved, and delivery times are getting longer. Those manufacturers who could supply the world will in fact only be able to do so if some kind of guaranteed market can be established and properly scheduled over several years. International coordination between a variety of interests will be essential, though not sufficient.

Broad quantitative analyses dealing with a variety of interlocking policy mechanisms will also be needed as a basis for discussion. This single problem has a very high priority. Some $350 \mathrm{million}$ people still live in areas where malaria is highly endemic and where as yet no specific anti-malaria control programs have been instituted. The supply of drugs and insecticides for fighting world-wide disease on an astronomical scale must be one of the highest priority issues in public health today.

Although the control of parasitic diseases is largely of importance in developing countries, similar problems on an overall policy level occur in the area of cancer control which is certainly of great importance in developed countries, and of continually increasing concern to developing countries as well.

The major objectives can and should be set on a policy level. As clearer policy statements emerge, it will become correspondingly easier to determine the size and type of efforts required at the lower hierarchical levels of systems analysis and technical modelling. This means that more effort must be put into systems developments for planning at regional and national levels, in order to stimulate, organize, and develop the appropriate supporting work at more technical levels.

Some writers have claimed that systems analysis has been a more or less total failure so far in regional health planning. Shuman, Wolfe, and speas (Operations Research, 22, 234-248, 1974), advocating this point of view, and using the term "operations research" in the wider sense of systems analysis, suggest a variety of causes. For example, no one has really used the approach to aid in the kinds of decisions that current planners are making. A great deal of the quantitative work is mere mathematical modelling, with poorly formulated problems, naively constructed objective functions, neglecting behavioral variables, and including politically and socially infeasible alternatives. The authors comment that such approaches of ten lead to journal articles, but rarely to implementable solutions.

On the contrary, emphasis must be given to identifying real problems of high priority, developing appropriate measures of effectiveness and objective functions that properly reflect the wide range of variables that planners must consider. And finally it is essential to face squarely the policy decisions that lie at the heart of all regional and national planning. 
It is hoped that the multifarious papers presented to this conference will help to make it easier to overcome some of the difficulties outlined above, and to point the way to substantial advances in the practice of health planning. 



\section{ACTIVITIES AND PERSPECTIVES OF THE EUROPEAN REGIONAL OFFICE OF WHO ON HEALTH PLANNING}

Mr. Bauhofer began by reviewing the recent activities of the European Regional Office of who in the field of health planning. In 1966, concerned with the problem of improving nanagerial techniques, the office organized a meeting on the efficiency of health services. This was followed by meetings a year later on evaluation of public health programs and in 1969 on health operations research. The latter subject was pursued in a more general meeting held in 1970 on applications of operations research.

The office has now channeled its efforts to improve the techniques of health planning into three themes:

1) Training. The scarcity of analytically trained health planners encouraged the office to organize a series of training courses. These were held in English, French, and Russian and two former course directors, Messrs. Cenov and Wennstrbm, were present in. the Conference;

2) The European Conference on Health Planning. This was preceded by a series of preparatory meetings and was held in March, 1974 in Bucharest (the report has not yet been published); and

3) A series of field studies. Preparations for the European Conference on Health Planning revealed unsatisfactory understanding of the planning processes in many nations. To remedy this lack of informaticn and to provide rudimentary outlines of the overal1 planning picture, the European Regional office undertook a series of field studies. The effort was made to compare and contrast organizing activities-or the lack of such--and to develop a series of planning models applicable under different situations. Mr. Griffith, a protagonist in these studies, would describe them further.

Mr. Bauhofer moved on to describe the results achieved in the Bucharest Conference. Health planning itself was defined as:

a part of the decision making process whereby sets of related decisions can be looked at together. Further, health planning is intended to prepare for the future in a systematic way by allocating scarce resources in the most effective and acceptable fashion. In doing this it gives the decision makers (politicians, administrators, or managers) a view of possible alternative lines of action, taking into account priorities, costs, benefits, constraints and likely outcomes.

The economic necessity for efficient health planning to provide for systematic allocation of scarce resources was established. Planning seen in this light had no opponents and it was felt that opposition generally arose from confusion over the aims of planning.

Three prerequisites for adequate planning were identified:

1) an administrative structure,

2) a system of information flows, and

3) a pool of interdisciplinary skills. 
With this basis, a number of phases in the planning cycle were spelled out:

1) projection of problems and resources into changing future situations;

2) review of policy options in the light of resource constraints;

3) policy choice;

4) creation of programs to effect policy goals;

5) implementation of evaluative procedures measuring achievement of policy goals; and

6) feedback of lessons learned to the next cycle of planning.

The delegates agreed upon the epigram that planning information is never sufficient, never of the right kind, and never available when needed. This should not, however, be accepted as pretext for not planning. Instead it was argued that the art of planning inheres largely in extracting maximally useful guidance from not wholly adequate information. Four types of data where improvement was urged included:

1) demographic and epidemiological indices for measuring health sector output,

2) risk factors,

3) resources, and

4) service utilization.

The importance of the multidisciplinary approach for planning was stressed. This includes not only improving the quantitative skills of the medical bureaucrat, but also broadening the health problem perspectives of economists and systems analysts. Only when the many disciplines share a common core of understanding and trust will health planning succeed.

\section{CONCLUSIONS AND RECOMMENDATIONS ${ }^{\star}$}

Health planning is a systematic, multidisciplinary method for dealing with health problems.

Health plaming is necessary in any country, irrespective of its politicoeconomic system.

To carry out planning it is essential to have a special team responsible to the technical chief of a health department. Others also plan at different administrative levels, but those at the apex of the planning pyramid should be "staff" and not "line."

Senior planners should not be restricted within the limits of their own ministry. They must be allowed freedom to communicate directly with other ministries and public or private enterprises.

Planning for health needs a proper information system. However, plans should be prepared without waiting until such a system is fully opera+ional.

\footnotetext{
* "Summary Report" of the European Conference on National Health Planning, Bucharest, 12-16 March 1974; WHO Document EURO 4107, 23 April 1974, pages 5 and 6.
} 
Not only the planners and decision makers but the whole community should be involved in the plannning process.

Planning can vary widely from sophistication to simplicity. There is no single blueprint. Nevertheless, there are a number of techniques of value, adapted from other disciplines, for example, from operational research, economics, statistics, social anthropology, and general management science.

Evaluation is part and parcel of the whole planning process. It runs throughout in the form of monitoring. It ends one cycle and starts the next.

Training for planning calls for the education of specialists from and outside the health professions. It calls also for a general knowledge of planning and management by all levels of administration. Formal and informal training can be given. The best training is planning by doing.

Research plays an important part in planning. Its main feature should be aspects related to epidemiology, to management, and to the consumer.

Studies in health planning now proceeding in different countries in the European Region should continue.

There is a need to aid communication between the different groups engaged in planning by standardizing many of the terms used and making health personnel familiar with these. The reverse applies to other disciplines.

There is a need to collect information on legislation in different countries relating to health planing and evaluation and to make this generally available.

Countries should collect, assemble, and make available material for the training of health planners. WHO has an important role to play in co-ordinating this and in making available countries' norms, standards, and definitions for the benefit of other countries.

WhO has a prominent part to play in helping to strengthen institutions engaged in teaching and carrying out research in health planning and evaluation, including epidemiological research. 

Systems Aspects of Health Planning. N.T.J. Bailey/M. Thompson, eds. North-Holland Publishing Company, 1975

\title{
FIELD STUDIES OF HEALTH PLANNING IN SEVERAL EUROPEAN COUNTRIES
}

\author{
D. Griffith
}

Mr. Griffith carried out many of the field studies on health planning mentioned by $\mathrm{Mr}$. Bauhofer. The goal was to identify the common planning components in diverse health care systems. The investigatory team was itself multidisciplinary - which resulted in a continual broadening of the members' perspectives as well as a wider basis for examining systems.

Time permitted mention of but a few of the findings:

1) planning systems--both forma 1 and informal--exist in all countries;

2) economists and other quantitatively trained experts have provided the impetus for planning but they now are receiving support across a broader base;

3) the pluralistic nature of many governments--consisting of various levels culminating in the national--allows many alternative entreses for planning;

4) regional governments--for example, the Land governments in Austria-are often the true implementers of planning;

5) planning takes on a multitude of forms--direct allocation of resources, manipulation of incentive structures, and intervention by broad-based insurance societies (as in the Federal Republic of Germany and Austria) to ensure efficient use of resources. 



\author{
SYSTEMS ANALYSIS \\ $\mathrm{OF}$ \\ HEALTH SERVICES
}

D. D. Venediktov

\title{
1. INTRODUCTION
}

Because of its unique status, the International Institute for Applied Systems Analysis (IIASA) should concentrate on those applications of systems ana1ysis to biology and medicine that interest the IIASA Member States and other countries, and that do not duplicate existing projects. IIASA can work to coordinate scientific efforts and to collaborate extensively with other organizations in the sphere of health services and medicine, e.g. WHO, IACR, international medical research societies, and the national institutions of various countries. We should do our best to stimulate cooperation with these organizations, and to encourage their use of the promising systems methodology recommended by IIASA in their daily activities.

The three basic trends in the use of systems analysis in medicine are:

a) analysis of health services and systems in different countries to determine similarities among them;

b) analysis of the development of biomedical science, and of methods of national and international coordination;

c) analysis of specific problems in biology and medicine (control of biological functions in the organism, mechanisms of compensation, mechanisms of higher nervous activity, control at the cellular and subcellular leve1, interaction of the organism with the environment, etc.).

Let us discuss the first trend.

\section{DEFINITIONS}

After the Second World War, mankind faced the task of "the attainment by a11 peoples of the highest level of health" (WHO Manual). Health services mean all measures taken by a human society to protect and improve or restore the health of the individual and of the population as a whole.

Hea1th is a difficult concept to define. It is "life, not restricted in its freedom..." (K. Marx), "...a state of complete physical, mental, and social wel1-being and not merely the absence of disease or infirmity..." (WHO Manua1), "...equilibrium of the organism with the environment..."; it is vital for the harmonious development of the personality. Health is both a basic gaal of socioeconomic progress and one of its indispensable conditions. It thus involves not only biological, but also sociological and psychological considerations, and hence must be analyzed within the framework of society rather than in isolation from it.

The fifth wHo long-term program for 1973-1977 reads: "Hea1th services occupy a very important place in the rapidly forming complex of political, economic, social, cultural, technical, and psychological systems, basing on the geophysical structure of the environment. Public health is represented in each of the above systems, and, being an integral part of the general structure, affects it by its own dynamism" (World Health Assembly Doc. 24.58, p. 3). The program al so emphasizes that "Instead of being considered merely as a complex of solely medical measures, public health services are being recognized as an important component of socio-economic systems, combining all the economic, social, political, preventive, therapeutic, and other measures which human society, in any country and at any stage in its development, is using to protect and constantly improve the health of every individual and of society as a whole." 
Each system is characterized, first, by its own goals, without which one cannot properly determine the "boundaries" of the system. All the diverse tasks and functions of health services as a social dynamic system can be grouped in the following way:

a) medical research and accumulation of medical and biológical knowledge;

b) comprehensive individual and community measures for prevention of disease, with special emphasis on infant and child care and environmental health;

c) timely diagnosis of diseases and their adequate treatment and cure.

It should be noted here that the indivisibility of these tasks, not only in theory but in practice, has been recognized with difficulty, particularly in countries where they were traditionally separated from each other and where health protection was considered a private affair between patient and practitioner.

\section{COMMON CHARACTERISTICS}

Modern health protection systems are characterized by their complexity and are an integral part of community life. All segments of the society are affected by the system for protecting the life and health of human beings, and in turn affect its operation. No community system could be formed or analyzed without a human being as a primary structural element. The relation of health protection to all aspects of community life is recognized by a number of scientists

(F. Brockington, 1967; M. G. Candau, H. Mahler, V. Cobson, 1963; etc.), who stressed the importance of various factors significant for the protection of life and health, e.g. geographical conditions, cultural level and customs, family structure, dynamics of population, nature of labor, nutritional habits and conditions, etc. Figure 1 illustrates this thesis.

As another consequence of its complexity, we must include as important elements in the system all available groups in any way involved with health protection, regardless of their institutional affiliation. We know that in many countries the types of medical establishment and the nature of their activities differ from those in the Soviet Union (private doctors' practices, hospitals, nursing homes, independent laboratories, pharmaceutical firms, and even chiropractitioners' offices); but even in these countries their combination will represent a definite system. For instance, a report from one of the highly developed courtries, published in 1967, reads: "Medical care in ... is more a collection of pieces and scratches (with great breakthroughs, high cost and lost efforts) than an integrated system in which requirements and efforts are closely interrelated"; but even such a "nonsystem" of health protection may be analyzed as an objectively formed and functioning system. However, under these conditions, a conscious and purposeful management is replaced by a spontaneous one.

That the health protection system is dynamic is shown by the fact that its tasks, methods and structure, and the coordination of its elements are directly responsive to the continuously changing environment--i.e. al1 spheres of community life--and its internal state: accumulated knowledge, availability or shortage of resources, manpower, etc. Of special importance is the functional nature of the health protection system; it is a servicing system capable of commandeering other community elements to help achieve its goals.

\section{SYSTEMS APPROACH}

Much has been done of 1 ate with regard to systems-structural analysis of health protection. We refer you to a number of booklets of WHO; seminars of the Regional office for Europe on the utilization of contemporary methods of management and electronic computers in the health field; and technical discussions at a 


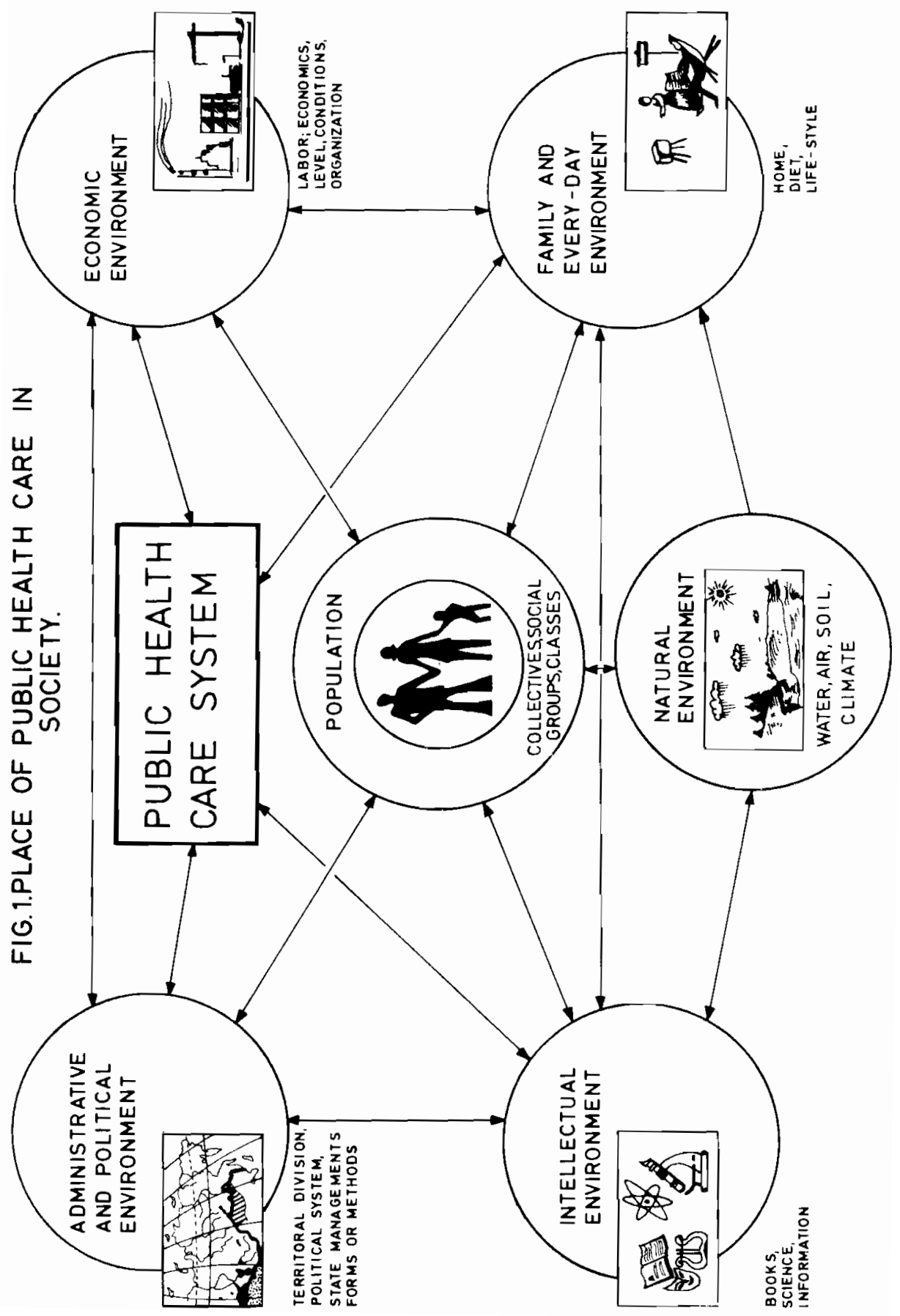


special World Health Assembly Symposium of 1971 on the problems of systems analysis in the health field, held by the Panamerican Sanitary Bureau. In 1973 wHo experts Grandy and Reinke published a monograph on the application of management methods and the study of health practice in various countries. Also pertinent are, e.g., the reports of the Johns Hopkins University in Baltimore on their permanent Courses on Social Medicine and Health Organization and their 1970 Joint Conference on Health Management. Other attempts to evolve "models of health protection" for urban areas and certain states include that of J. Acton and R. Levien (1971), who tried to form health models for the state of Illinois, and various economic analyses in the health field. Thus, it may be considered that applying the systems approach to health protection provokes no objections of principle.

Moreover, it is generally recognized that for the successful development and functioning of health care as a social system we have definite external and internal conditions. The external socio-economic and organizational conditions are: health protection as the most important task of the community and the state rather than a private affair between patient and doctor; a high level of economic and technological development as the only possible basis for the effective development for the health of the population; and, finally, training of qualified medical personnel and the continuous growth of the educational, cultural, and sanitary level of the entire community. Internal conditions for the formation of an effective system of health care are: the planned interrelation of its elements; its scientific basis; preventive trends; medical care for the entire population; etc. WHO resolution 23.61 recommends these principles to all Member States for planning and establishing national health protection systems and services, taking into account mational, historical, socio-econonic, and other conditions, as "the most effective and proved in practice by a number of countries."

\section{PROBLEMS OF COMPLEXITY}

We must admit in all sincerity that numerous systems-analytic attempts to analyze the economics and administration of health protection systems have not yielded the expected results. Hopes that contemporary "management" or the use of electronic computers would easily solve the complicated problems of modern health care have largely vanished.

In our opinion, the failure of many of these attempts is due to the fact that the real complexity of the problems was not realized. As an example we recall here the WHO attempt of 1968-1972 to construct a mathematical model of health services at the international level, which was undertaken by RECS (Division of Research in Epidemiology and Communications Science). In my view this experiment failed, not owing to a lack of talented and clever people (at that time K. Newell, N. Bailey, and other outstanding specialists were working on this problem), but because the staff of the Division underestimated the complexity of the task and thus tried to solve particular problems of health services without an adequate analysis of the general problems. In particular, there was no proper study of the experiences of the Member States and of other Divisions of WHO. Only the analysis and generalization of this accumulated experience, with the help of contemporary computer technology and application of the methods of systems analysis and cybernetics, may turn out to be fruitful.

While analyzing health services systems in different countries, we should take into consideration that they function under rapidly changing conditions, both external and internal. While such shifts may be specific for this or that country, they also have much in common. We shall illustrate this thesis by several external and internal conditions decisively affecting the activities of health bodies in many countries.

\subsection{External Shifts}

a) Economic progress (in industry and agriculture); complication of 
economic relations; industrialization; acceleration of communication and transportation; scientific-technological revolution; aggravation of social and class contradictions.

b) Urbanization and growth of the urban population; increase of educational level; increase of mass information; psychological stress caused by the increased tempo of 1 ife.

c) Growth of the population; involvement of women in the labor process; acceleration of the development of children and adolescents; relative "aging" of the population.

d) Environmental pollution (water, soil, air); ecological shifts.

e) Fluctuations in the state of health, structure of morbidity and mortality of the population; fluctuations in the nutritional level and "chemization" of the population; harmful habits.

\subsection{Internal Shifts}

a) Progress in biomedical science, prerevolutionary state of the number of branches of science; increase in the complexity of and expenditure on research.

b) Success in the control of epidemic and communicable diseases, and changes in the conditions of their global spread; progress in sanitary control.

c) Increase in the cost of medical care; elaboration of new methods of treatment of terminal and grave diseases; improvement of equipment and enlargement of medical establishments.

d) Shortage (in many countries) of qualified medical researchers and slow tempo of their training; development of team methods in rendering medical care; effect of the "brain drain" from developing countries into highly developed ones.

e) Uneven coverage of the population with medical care (urban and rura1 population; and in many countries various social strata and groups); the need for equalizing the volume and quality of curative-preventive care.

\section{PROGRESS IN SOCIAL PLANNING}

We must remember that in many countries the problems of health services are analyzed with special social and political care; governments and legislative bodies are forced to participate actively in the solution of the problems outlined, as well as in disputes and discussions. This is demonstrated by legislative reforms of health services recently implemented in many countries.

Thus, for instance, the Fundamentals of Legislation on Health Services in the USSR, adopted in 1969, summarized the development of the health system for more than 50 years and outlined further perspectives. Important governmental decisions on health systems have also been adopted in Czechoslovakia, Bulgaria, Hungary, the GDR, and other socialist countries.

In 1968, Sweden approved the Draft Project on Health Services, which divided responsibility between the Ministry of Health and Social Affairs and the National Committee on Health Services and Welfare. 
Norway in 1969, 1971, and 1973 adopted decrees on organization and planning of hospital care, social insurance, improvement of primary medical care and preventive measures.

Italy in 1969 passed a Law on Hospital Care Planning.

Canada in 1969 changed its laws on family planning, and the Province of Quebec legislated to reorganize medical and social services.

France in 1970 approved a law radically. changing methods of hospital care and the system of medical financing.

Switzerland in 1971 introduced new laws on environmental control and on the prevention of communicable diseases.

Denmark in 1971 approved legislation on insurance in case of disease and on the establishment of new curative-preventive medical centers.

Finland in 1972 adopted decrees on the reorganization of the basic health services at the provincial level.

The Netherlands in 1971 adopted a law on hospital care plamning at the provincial and national level.

A number of legislative acts dealing with prevention of communicable diseases, TB control, and control over foodstuffs, was adopted in Belgium in 1971 1972 .

Great Britain in 1973 approved a law on the interrelation of the three basic health services and planning in the health field.

A new system of hospital care planning is being introduced in the Federal Republic of Germany; Austria is starting to plan polyclinic care.

Heated debates on health reforms are taking place in the USA. Radical changes are being made in Latin America, Africa, Asia, and other areas. All this illustrates the need for further development of national health services and systems, which should be taken into account in the scientific analysis.

\section{NEED FOR INTERNATIONAL COOPERATION}

The complexity of the analysis of health systems is aggravated by the fact that a number of theoretical and practical medical problems formerly of interest only to a few specialists and the governments of certain countries have outgrown national borders and turned into international and global problems requiring the efforts of many governments and international organizations.

Such international problems are:

a) The coordination and stimulation of scientific medical research, the correct social orientation of science, and the use of its achievements in the practice of hea1th services.

b) Global surveillance of epidemiological processes in epidemic diseases (smallpox, plague, cholera, yellow fever, etc.), taking account of such factors as high-speed transport.

c) The study of methods of attack on widespread major diseases, e.g. cardiovascular disorders, cancer, congenital disorders, and virus infections.

d) Medical aspects of the improvement of the external environment, including the establishment of international standards for maximum permissible 
concentrations of various substances in the air, water, and soil, and protection of the oceans and of the air.

e) In connection with the development of the pharmaceutical and chemical industries and of international trade, effective control over the quality, safety, and side effects of drugs, and steps directed against abuse of various medicines.

f) Study of the dynamics of population and changes in its age structure, birth rate, death rate, and liability to illness in different countries with the aim of working out a new health strategy. This is closely linked with the problem of ensuring a sufficient and balanced food supply and with the struggle against illnesses connected with malnutrition and starvation.

Problems such as these make international cooperation in the field of health and medicine absolutely essential.

\section{PROGRESS IN INTERNATIONAL COOPERATION}

In. the past ten years, international cooperation in the health field has become extremely diverse. Thus we may speak of international health legislation or of an exchange of experience and information in the health field among different countries. Further development of this collaboration requires great effort, and, in particular, mutual understanding between countries (including unique or similar terminology), compatibility between certain elements of the national health systems, and in future, a new international methodology aimed at the solution of the most pressing problems. We see the most important role of WHo, IIASA, and other international, inter-governmental and non-governmental organizations to be the facilitation of collaboration in the health field, and elaboration of its methodology. We attach special importance to the joint efforts of WHO and IIASA. However, we should be aware that a long time will pass between recognition of health services as a functional system and determination of the principles of its optimal activity.

\section{GENERALIZED MODEL OF HEALTH SERVICES}

In our opinion, one of the first steps might be the formation of the generalized model of health services as a functional system, and its logica 1 , mathematical, and organizational description. Initially, we might construct a health management model for a definite administrative-territorial unit (state, republic, city, etc.). Each such unit has a network of health bodies, including research institutions (medical schools, laboratories, etc.); higher and secondary medical establishments; sanitary-anti-epidenic establishments for preventive control and anti-epidemic measures; curative-therapeutic in and outpatient establishments, providing medical care; pharmaceutical, technical, supply, repair, and other services. Finally, each territory has one or several health bodies which are subordinate to 1 ocal governmental bodies as well as to the higher-standing health body.

Al1 medical establishments in the given territory, independent of their subordination, should not only provide medical care to the population of that territory, but also meet the requirements of the whole network of the national health system and function in accordance with its standards. Each establishment may and should contribute to the various system subfunctions: medical science, education, sanitary-epidemiological services, curative and therapeutic services, health management services, etc. Proper combination of all functions of the various establishments to meet the requirements of each geographical location will yield an optimal strategy for carrying out the basic tasks facing health services.

The experience of several years has shown that the coordination and planning of research, and the training of medical personnel, are the most important functions and are of a centralized nature. Preventive and anti-epidemic services should be 
brought close to the population and be capable of rapid mobilization at the nationa1 and international levels. General medical care should be provided not only to the local population, but also to the migrant population. As has already been said, health management, in being subordinate both to local governmental bodies and to higher-standing health bodies, can participate in taking the necessary medical measures, as well as coordinate local and regional actions within the framework of the whole health system of the given country.

Modelling is a very complicated affair, and the model proposed by us is an abstract one. However, it is sufficiently universal and could be easily applied in any country. In the course of discussions at WHO we emphasized the necessity of adopting a generalized model in the health field which would stipulate the basic units and their interrelations, without which the given system will not function. Such a generalized model would not impede but rather promote the elaboration of different models applicable to specific conditions.

\section{SPEC IF IC MODELS}

The proposed generalized model of the health system may serve as the basis for the elaboration of more detailed health models, increasing in complexity according to their territorial (up to a specific medical establishment) and administrative characters (the whole network of health services). However, this model is not free of shortcomings: it is a static and nonoperative one; it does not contain the efficacy criteria for the various functions and organizations; it does not yield a method to determine the optimal centralization and decentralization of the system. Therefore, for the further elaboration and clarification of the model within the framework of WHO and IIASA, we may propose the following:

a) We wish to describe in terms of the general model the existing health services and systems in comparable territorial units of 10-12 countries. Our aim is to detect principal differences and common features of medical institutions and their functions. Here we have to take into consideration that the great variety of establishments and functions will make qualitative descriptions of health services difficult, even with the aid of health administrators and wHO staff, who are specialists in this field. These descriptions should include such qualitative indices as the number per capita of medical personnel, auxiliary personne1, hospital beds, sanitary establishments, etc., for different countries.

b) We hope to carry out a more detailed analysis of each basic function of health services, including specifying that function's requirements and detailing a method to evaluate its effectiveness. Interrelations among the basic functions should also be dealt with. The analysis should probably be specific to one country, although analyses of this kind for different countries would have many similarities.

Of relevance to this proposal are the results of the WHo Regional office for Europe Working Group, which met in Stockholm in June 1972 and was devoted to the problems of health planning within the framework of national development. This Working Group divided all countries of Europe into three groups: the first consists of Bulgaria, Hungary, Poland, Romania, USSR, Czechoslovakia, and parts of Yugoslavia--the countries with centralized systems of health services where health development plans are integral parts of the state plans for socio-economic development. The second group consists of Belgium, the Netherlands, Great Britain, Turkey, France, Sweden, and other countries characterized by sufficiently wide planning processes, but where the results of planning are used as basic indications of general trends and not to create a detailed plan which would be approved by the government. The third group consists of Austria, Italy, and Spain, where the elements of planning of the health services exist, but on a smaller scale compared with the other groups. 
c) The comparison of the health services and functions in different countries should take into account the historical evolution of each function and contemporary legislation. This will allow us to determine the similarity of health bodies and establishments which in different countries have different designations, structures, etc.

\section{ADJUSTMENT OE MODELS}

It is desirable to identify the most important 8-10 problems at present facing the health field in different countries, examine the difficulties that impede their solution, and see what efforts are planned or in progress to solve them. Where these countries have specific long-term or short-term programs, it would be interesting to find out what economic and social calculations they are based on.

It would also be useful, jointly with wHO and the staff of the national health systems, to simulate--possibly using "gaming" techniques--the response of the system's elements in different countries to mass calamities (inundation, accidents, earthquakes, etc.) and to epidemic outbursts. These extreme cases might highlight similarities in the functional interrelations of the various health systems.

All this will enable us to switch over from the first "primitive" health model to a more detailed block-diagram of health services and its description in mathematical formulas and system-structural terms, and to modelling of the activity of health services in different countries.

\section{HEALTH INFORMATION}

The joint attention of WHO and IIASA should focus on the information flows within contemporary health services and systems, particularly with possible means of using electronic computers in mind. At present health systems in many countries generate great volumes of diverse data. Very often these data flows are interlaced. with each other in complicated ways, making it difficult to separate that information necessary to solve a particular problem from the rest. Much medical, epidemiological, statistical, and other information is lost because to those who generate it, it is just "noise." Thus investigations are inclined to register their data selectively, which does not al ways yield sufficiently reliable indices and results.

For many years health bodies and health establishments in many countries cherished exaggerated hopes that the electronic computer would make practical the storage, classification, and retrieval of all such information. Indeed, certain successes were achieved. In a number of countries, such as the USA, Great Britain, France, Japan, Sweden, USSR, GDR, Bulgaria, Poland, and others, electronic computers are widely used for the solution of health problems, mainly by constructing local information-computing systems covering the activities of a few medical establishments. Plans exist to increase and unify the existing computing systems into regional and even national computer centers in certain branches of health services. A number of capacious computer centers service hospitals and medical establishments. Books, articles, and conferences are devoted to the problems of the utilization of electronic computers and systems technology in the health field, e.g. symposia in Kiel (September, 1967), Bucharest (September, 1969), Copenhagen (February, 1970), Bratislava (February, 1970), Geneva (September, 1971), Luxembourg (July, 1972), Washington D.C. (April, 1973), etc.

At present we are witnessing two basic trends in the use of electronic computers in the health field: one, the analysis and management of biological systems (modelling of biological systems, automation of clinical and laboratory tests, automated diagnosis, prolonged follow-up of patients and prognosis of the course of the disease); the other, the management of various elements of the health system as a social system (processing of statistical data and primary carriers of scientific and medical information, hospital management, economic analysis, and health prognosis, etc.). 
Along with this, even today, there is confusion in the methods of utilizing electronic computers in the health field, incomparability of data and incompatibility of the systems of computer processing of medical information.' Therefore, we suggest that WHO and IIASA elaborate standards for information processing to $f a c i l-$ itate cooperation and exchange of information among different countries.

We should consider a variety of approaches to this problem. In the USSR we try to create a single multilevel automated system of management of the health service for the whole country ("OASU-Health"). The main levels at which the system works are: All-Union, Republican, oblast or city, and institutional or hospital.

The development of OASU will lead to improvement in the following areas: treatment and prophylaxis network in urban and rural areas, including specialized types of medical care; prevention and eradication of epidemics, and development of the sanitary-epidemiological service; management of the drug supply system and the pharmaceutical industry; training of medical staff, distribution and utilization of medical and pharmaceutical staff of the health service; network planning and activities of medical establishments; financing operations,-registration, and finance control; and analysis of medico-statistical, medical-research, and medicotechnical information.

Electronic computers are necessary for the creation of an international system of medical and medico-technical information. This system will participate in global sanitary-epidemiological control, coordination of medical research, and control over the quality and efficacy of pharmaceutical products and the study of their side effects.

\section{SYSTEMS ANALYSIS AND ECONOMY OF HEALTH SERVICES}

The problems of health economy also deserve serious investigation and systems analysis. They fall into two main groups: how much effort should we spend to meet the requirements of the health service; and how should we spend the available resources with maximum efficacy. Much information has been published of late on the economic analysis of the activities of certain medical establishments and health services, comparing the effects obtained with the efforts expended. The questions of applying direct economic criteria to the assessment of the activity of health services, and of what economic aspects of health services should be developed and to what extent, are debated heatedly. From our point of view, the theoretical aspects of the economics of health are of primary importance, as their direct application in practice is rather dangerous (choice of therapeutic methods depending on their cost, economic justification of the care of the aged or of hopeless patients, etc.).

We agree with those economists who state that even economics as such cannot be analyzed from a purely economic viewpoint. This is also true of heal th service, where the value of the life and health of a human being cannot be directly expressed in monetary units. Such a viewpoint would seriously undermine the prestige of a health service. However, it is quite evident that at the national level we should register all the available resources and plan for their most effective use. While recommending a careful and serious approach to the problems of health economics, we agree with S. M. Danyushevsky (1967), V. V. Golovteyev (1972), and others who, when speaking of the health system's contribution to the economy of the country, emphasize that no one so far could separate the numerous socio-economic and biological factors affecting the health of the population from purely medical ones. Therefore, the many analyses of expenditure are of only limited value. The paper by $v$. V. Goloyteyev in these proceedings will more fully discuss these points. 
1) The analysis we do may show a real necessity for national health systems to undertake various forms of international cooperation, perhaps including bilateral and regional or global collaboration. It may also show at which levels (non-governmental, inter-institutional, inter-state, etc.) it would be desirable to exchange information in the health field.

2) The final goal of the bio-medical project of IIASA should be to evolve optimal recommendations on national health systems with consideration given to the particular conditions of each country. This will require the serious participation of specialists in systems analysis. The recomendations will cover socio-hygienic problems and methods of management of the complex dynamic health system. They will also deal with the system and subsystem hierarchy and the interrelation of their elements, taking into account organizational and economic aspects of management, optimum level of centralization, etc. This problem is exceedingly complicated and does not admit a simplified approach by either health administrators or management theoreticians; it can be solved only through the comprehensive understanding of scientists and health adminstrators, and close contacts with WHO and IIASA.

3) The next goal of the bio-medical project should be to develop methods for long-term planning and health prognosis, taking into consideration objective trends and forecasts of community development. At present, scientists in many countries, such as the USSR, GDR, Bulgaria, Poland, CSSR, USA, France, Japan, Great Britain, etc., are making projections of development in such sectors as the economy and science and technology, covering all aspects of social and community life up to 1980,1990 , and 2000 . However, as was observed at the UNITAR conference in Moscow in June 1974, the methods of making such predictions are varied, some being overloaded with mathematical calculations while others appear more as guesswork and "prophecy." The resulting prognoses thus cover a wide spectrum, from rather optimistic to gloomy.

We feel that it is desirable to draft prognoses in the health field along three principal lines. First, account must be taken of the development of biomedical science, including possible scientific discoveries and estimates of their practical applications. Second, we must try to predict the conditions under which health systems will function in the coming decades, with due account taken of economic, social, demographic, psychological, and other shifts in the life of the community. We should mention here that such prognoses should not be made by doctors alone, but in close cooperation with other specialists, in particular those on the systems analysis of community development. The third direction should be the projection of the future development of health systems as such, which are called upon not only to maintain but to improve their efficacy under rapidly changing conditions. The joint activity of WHO and IIASA in this respect will be of great interest and paramount importance.

4) In addition to IIASA and WHO, national establishments of the Member States of those organizations should participate in these tasks. It would be desirable to identify what institutions will evince interest in one or another aspect of our analysis, what obligations they are ready to assume, how much time is necessary to address specific problems, and what kind of help they expect from their partners and colleagues.

In the USSR the following institutions will be involved in the development of the bio-medical project: Institute of Health Organization and Social Hygiene, Institute of Scientific Information, Institute of Experimental and Clinical Oncology, Institutes of Cardiology, Epidemiology, etc., and Institute of Management Problems of the USSR Academy of Sciences. Soviet specialists are interested in establishing contacts with other national and international establishments and in collaborating with them on studies of health systems. All concerned should agree soon on the forms of cooperation and information exchange, including conferences, symposia, and 
exchange of methodological papers and results.

5) The development of systems analysis of health service may be successfully combined with other projects of the International Institute for Applied Systems Analysis and, in particular, with the study of the problems and perspectives of city planning, ecology and ecological systems, development of artificial intel1igence studies, and others. 


\title{
SYSTEMS ANALYSTS OF THE DEVELOPMENI OF BIO-MEDICAL SCIENCE AND METHODS OF ITS COORDINATION AT NATIONAL AND INTERNATIONAL LEVELS
}

\author{
D. D. Venediktov \\ Ministry of Health, USSR
}

\section{INTRODUCTION}

Systems analysis of bio-medical science presents great interest as only science can be the basis for any complex of measures aimed at protecting and promoting the health of every individual and of the community as a whole, i.e. any health system. But science is a complex, multilevel phenomenon. On one hand, it is a systematized complex of knowledge about the essence of Iife on all of its levels, about the structure and functions of a human organism in its indissoluble relations with the environment, about the laws of heredity, and abcut possible causes of the development of diseases and methods of their prevention, detection, and treatment. On the other hand, science is a continuous process of clarification and prom duction of such knowledge (with the generation of qualitatively and quantitatively new information).

\section{IHE ADVANCEMENT OF BIO-MEDICAL SCIENCES}

Medical science became an important social institution not only because it is the basis for the national and international health service, but because of its complexity and requirements in resources, and because of its social significance. Bio-medical science requires the discovery and use of the basic laws governing complex social systems, effective coordination of research efforts, and active international scientific cooperation.

During the past decades medicine, and especially biology, has been enriched with new data and discoveries made by scientists and physicians in different countries. These advances have been continuously analyzed in the course of the wide international exchange of experience and ideas, methods and results. In coordination with other branches of science, medicine and biology today investigate nearly al1 the existing and possible points of contact of man with the environment. On one hand, the united scientific front of medicine and biology has already been formed, but on the other, this front has split into innumerable specialized trends, sectors, and areas. The advancement of the scientific front, when man continuously discloses one secret of nature after another, is rather sporadic, and therefore we must analyze the three basic aspects of this irregularity.

\section{DIFFERENCES BETWEEN THE NATURAL SCIENCES}

The first aspect is the acceleration of the tempo of the development of medicine and biology compared to other branches of natural science. For the past years many scientists have been inclined to think that immediately after the remarkable discoveries and achievements in physics, chemistry, and energetics, biology and medicine may take the first place among other sciences (V.D. Timakov, 1972; N.P. Dubinin, 1972; V.A. Engelgart, 1970; P.K. Anokhin, 1970; B.M. Kedroc, J. Ti1ling, Smith, Mattis, 1970; and others).

D. King-Hilley (1969) writes, that if "at present governmental financial support is enjoyed by physics, mathematics, and technology, in the coming twenty years this situation will not remain unchanged--the first place may be taken by medicine and biology." This was also emphasized by G. Taylor (1968): "We rather vaguely start to realize the fact that we are at the initial stage of the Biological Revolution-- the revolution of the twentieth century, which will affect the life of a human being to a greater extent than the great Mechanical Revolution of the nineteenth century or the industrial revolution of the present days." The XxV World Health Assembly (WHA), which took place in May 1972, stressed in its resolution 
WHA 25.60 that "in the course of the accelerated scientific-technological progress, science turns into a productive force of the community and we have every ground to believe that, in the nearest future, all significant discoveries in the field of biology and medicine may have essential social and economic imporfance."

\section{DIFFERENCES BETWEEN BRANCHES OF BIO-MEDICAL SCIENCE}

The second aspect of irregularity in the development of medicine and biology is the unequal tempo of development of certain trends. If certain trends develop rather quietly, then in other branches of biology and medicine we observe a high concentration of scientific means, unexpected events, and such paradoxical conclusions that, in our opinion, we might expect a possible "pre-breakthrough" or even "pre-revolutionary" state of the above scientific trends. The uneven development comes from the complexity of interrelations and mutual influences of various biomedical disciplines on each other and on adjacent branches of natural science.

Comparison of the governmental and international scientific documents about medicine and biology proves that in the majority of countries the basic efforts of scientists and research institutions in the bio-medical field are presently concentrated to a large degree on certain important areas and problems, the "diseases of the century": cardiovascular disorders, cancer and other malignant neoformations, infectious, viral and bacteria infections, genetic defects and congenital diseases, the dependency of man's health on enviromental and numerous other factors (Table 1).

All these problems are being studied on different methodological levels, each of which in itself represents an important stage of analysis and investigation of the biological processes, in addition to being an independent field of knowledge and branch of science. The most important levels are: molecular biology and cellular genetics, organization of intact and functional biological systems, general and particular immunology, the study of the individual development of the human organism, the study of psychology and behavioral sciences, and finally, the socio-hygienic aspects of each medical problem and the problems of the scientific management of health and of science itself.

We have examined many scientific-technological and bio-medical prognoses and have noticed that the prognoses of Soviet specialists on the most probable scientific achievements in the next fifteen to twenty years coincide, in principle, with the predictions voiced in other countries. Often, however, these prognoses are presented as a sensation, or as a "prophecy," and are often associated not with the benefit that the new discoveries may give to practical health service but, rather, are fraught with harmful consequences for the community. The form of such prognoses varies from primitive assumptions to various cypes of diagrams and charts. The probable dates of discoveries are rather argumentive, but the diagrams present definite cognitive and theoretical interest.

\section{DIFFERENCES BETWEEN REGIONS AND COUNTRIES}

The third aspect of the uneven advancement of bio-medical science is the difference in the degrees of development of theoretical and applied research in different countries. This could be connected with the differences in their economic and scientific-technological potential, and also with the attention given to medical science and health service by their national governments.

According to UNESCO (1970) all over the world fifty billion dollars is spent on research, with researchers numbering from three and one-half to five million. It has been repeatedly emphasized that during the past decades expenditures on science increased greatly. This is true also of bio-tnedical research, for which, according to WHO, the expenditures approximate four billion dollars a year--i.e., according to other sources, from five to ten per cent of the total expenditures on science. 


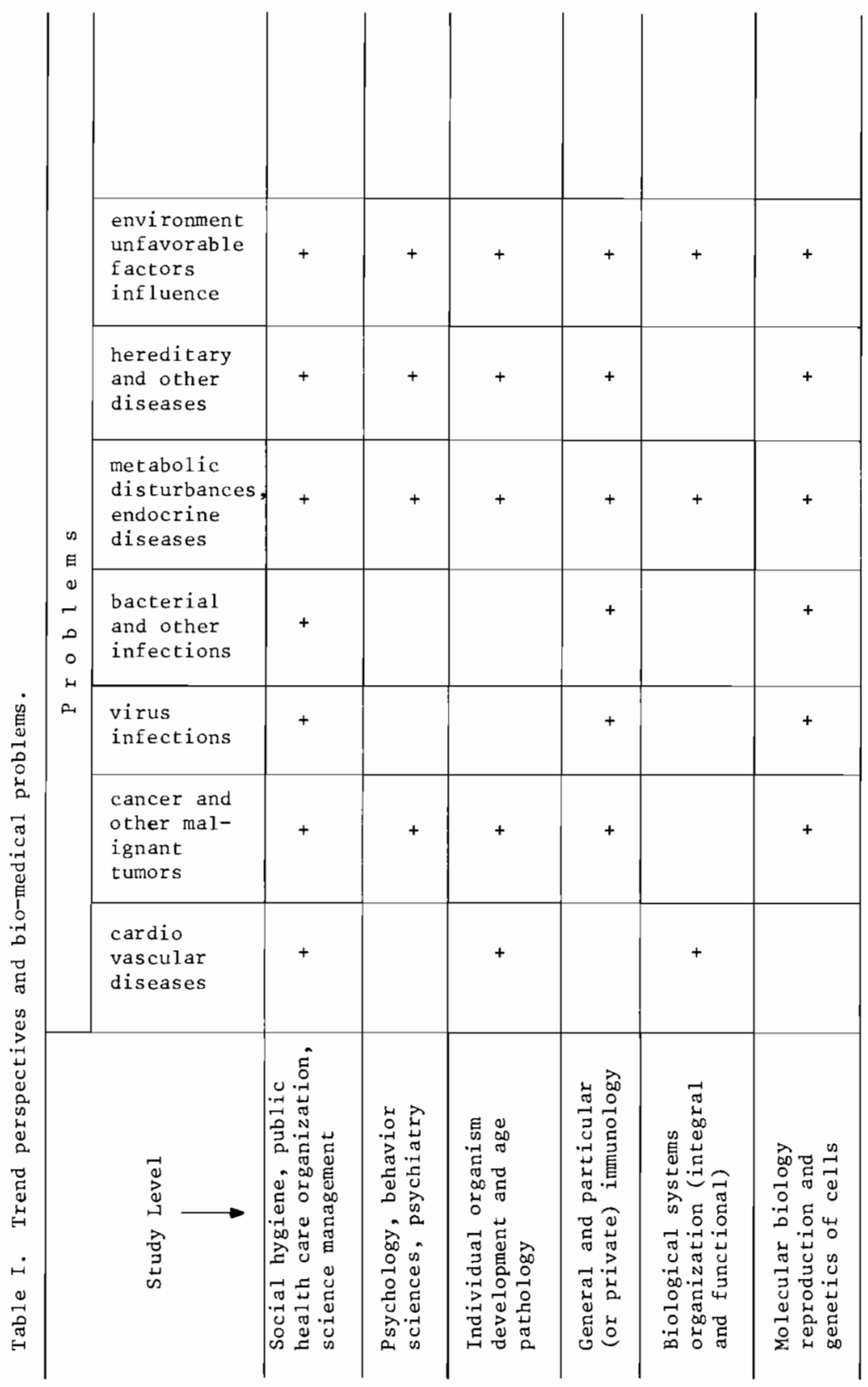


It thus becomes more evident that even highly developed countries will not be able successfully to develop the necessary future bio-medical research--basic and applied--through their own efforts alone. This could be explained not only by huge expenses, but more basically by the complexity of the problems facing, science and requiring united efforts not only of individual scientists and teams of scientists, but of many countries as well. International scientific cooperation is "profitable for all countries, as not even the most developed can take the advanced positions in all the scientific trends and technology. Historical experience proves it", (V.A. Kirillin, 1973).

\section{BARRIERS TO INTERNATIONAL COOPERATION}

However, the development of genuine international cooperation in the biomedical field is a complicated matter, and, at present, this cooperation is impeded by three "barriers"--informational, methodological, and socio-ethical. It is quite evident, that this comparison is purely conditional. It would be more proper to speak of the complex of problems connected with information and data collection, with the methodology of international cooperation, and with the importance of the increasing social responsibility of science and scientists.

\section{INFORMATION BARRIEF}

Much has been said of the "information barrier," "crisis," or "explosion," and of the difficulties of orientation in the "ocean of knowledge." The difficulty lies with the practical impossibility for scientists to follow the changing situation even in their own fields. The process of production and consumption of information is so fast and the interval between them so small, that completely new problems arise.

In the past, information was passed "in time" and basically provided communication between different generations of scientists. Nowadays, we exchange information "in space," i.e. between scientists working at different establishments or in different countries (here we should like to remind you of the well known assumption, voiced by D. Pryce (1968) that "from eighty to ninety per cent of all the scientists who ever lived in this world, are alive now").

\section{METHODOLOGICAL BARRIER}

The second barrier to the development of international cooperation is the "methodological barrier." It is due to the problems of scientific information, but at the same time has its own specific aspects originating in the history of the development of medicine. Other branches of science (for instance nuclear physics or the study of space) developed simultaneousiy in many countries of the world, thus forming a common terminology and similar methodological approaches. Medicine, however, developed over a number of centuries from primitive empiricism in science, with man and his diseases as the only object of investigation. The complexity of this study greatly exceeds the techniques of the past and contemporary methods of investigation which have been developed in different countries in their own way. Even today, medicine uses a great number of empirical methods of therapy which gradually receive scientific explanation. As a result, the same terms designate in cifferent countries various forms of diseases or phases of their development (according to WHO, contemporary medicine uses more than 20,000 terms the majority of which are archaic). On the other hand, practicaily similar pathological processess and diseases are described with different terms.

To illustrate this thesis, the frequency of similar situations and the complexity of overcoming terminological and methodological differences, we would like to mention here an important investigation by wHO experts. Their goal was the unification of pathoanatomical classification of phases of the arterosclerotic process in aorta and coronary vessels (A.I. Vikhert, Z. Pfeifer et al.), and the histological classification of various forms of malignant neoformations. Only 
because of the coordinated efforts of the leading scientific centers and the assistance of WHO, pathoanatomists of different countries started to "use one language" and were able to compare the results of their investigations, rendering valuable assistance to clinicists and theoreticians.

On the other hand, using the same "dominator," specialists could not but draw their attention to great differences in morbidity indices in different countries of the world. This in turn led to the fruitful development of the so-called "contemporary epidemiology," medical geography, or geographical pathology. Thus, A.P. Avtzyn (1972), Z. Pfeifer, I.K. Skhvatzabaya, L.V. Metelitza, V. Raab, P.D. White, and others noticed great differences in the incidence of atherosclerotic lesions of blood vessels in different countries. A.I. Serebrov, A.V. Chaklin (1955), J. Higginson, Maroyama, Tiyins, L.M. Shabad (1970), J. Kmet and E. Mabubi (1972), S.N. Nugmanov (1970), and others also noticed great differences in the incidence of various forms of malignant neoformations among the population of different countries. The verification of geographical pathology data (by unification of the methodology) cannot be considered the final goal. But on this basis, it becomes possible to go on to the next phases of investigation aimed at clarifying the correlative mapping of diseases. This can be done using multifactor analysis and also other methods, including experimental, to discover, for example, the causes of the comparative incidence of a given form of the disease, and to disclose its pathology and pathogenetic mechanisms.

\section{SOCIO-ETHICAL BARRIER}

The third obstacle--the socio-ethical barrier--arose as the scientific-technological revolution disclosed the increased role of science as a social institution and as an important factor of community development, as well as its inherent difficulties and contradictions. This led to the increased responsibility of scientists, and to heated and broad discussions about the role of science in society and the interconnections and impact of scientific-technological and social progress. This is directly reflected in medical science, which is not only a theoretical field, but also a practical applied discipline. And as the social conditions in every country are of paramount importance, then it is of no small importance that at present there exists a great gap between the what could be done by science today to protect and promote health and what is done in practice.

Another aspect of the socio-ethical barrier is the problem of "free" theoretical investigations in contrast to applied investigations. Recently, great interest has been aroused by the problem of permissible limits of experiments carried out on human beings in the process of bio-medical research. A number of declarations and codes of medical ethics are dedicated to this problem (e.g. Nuremberg Code, Helsinki Declaration, Sidney Declaration). This question was also covered by numerous international symposia and conferences (SIOMS symposia in 1972 and 1973, "CIBA" fund in 1971, and many others). ECOSOS, UNO, UNESCO, and WHO deal with the problem of the rights of a human being in the process of bio-medical research (within the framework of WHO there is a Special Secretariat on Moral and Ethic Aspects of All Scientific Investigations which are carried out under the auspices of WHO). However, the problem remains acute, especially since lately scientists have denanded the revision of the code on medical ethics to deal with the questions of prolongation of life for grave and chronic cases and of euthanasia for hopeless patients.

And finally we have the serious problems of the further perspectives and remote consequences of bio-medical discoveries (e.g. manipulations of the genetic code, functions of the human brain) and the social responsibility of science. Some scientists voice pessimistic ideas and nihilism about the future: they consider the social problems which may derive from future achievements of medicine and biology as acute, insoluble, extremely dangerous, and even ominous (G. Taylor; P. Harper; S.F. Powel1, 1969; 0. Toffler and others) and propose ceasing a number of biomedical investigations or decreeing a "moratorium" on research (J. Pickering, 1966; M. Burnett, 1971; and others). We do not share this pessimism, but emphasize once 
again the importance of the pronounced assumption--also voiced by the World Health Assembly--that "the achievements of medicine and biology, the most humane of all the sciences, should be useíl only to benefit and never to destroy the mankind."

\section{THE NEED FOR INTERNATIONAL COOPERATION IN RESEARCH}

lnternational cooperation in the health field is not only a desirable condition of its further development, but also a real, irreversible fact of contemporary life. We do not only desire a mere recognition of this fact. We are advocating here an increase in international scientific collaboration, development of its methodology and voluntary participation of all countries, without external interference or pressure upon national scientific establishments. Thus it is expedient to analyze the logic of the research process. There are many diagrams depicting this process. Figure 1 divides the research process, from an organizational point of view, into consecutive stages: a) determination of the research purpose, b) selection of the adequate method, c) planning of necessary efforts and means, d) process of research, e) control over the results with amendments if necessary, and finally, f) implementation of the results.

Figure 1 also shows that under contemporary conditions any research may be efficient only if it is coordinated with investigations, past and present, carried out simultaneously at other research centers and even in other countries. It seems to us that coordination of scientific research implies two important factors or stages: it is necessary 1) to know WHO carries out whAT type of research, and WHERE, 2) to want and be able to unite one's own research efforts with the efforts of other specialists in this field. The solution of the first task lies with the activities of contemporary systems of scientific information. To solve the second task, one has to be in contact with other scientists and have the necessary skill; i.e. the methodology of scientific cooperation should be worked out within one research institution, as well as within one country and at the international level.

\section{INFORMATION EXCHANGE}

We may distinguish several basic levels of international exchange of scientific and technological information and coordination of research. These exchanges occur at the level of individual scientists and certain research centers, and also at the level of inter-governmental, bilateral, multilateral, and international agreements. Each level is characterized by peculiar--from the point of view of efficacy--expedient forms of scientific and scientific-technological cooperation.

Informal personal communication. Between individual scientists--apart from the exchange of books, reprints, and preprints of the articles--are important exchanges such as informal interpersonal communications, formation of "invisible colleges," and so on. To a greater degree, similar functions are carried out by national and international medical research societies ard associations.

Contacts between institutions. At the level of research institutions, centers and laboratories, the most widespread forms of cooperation have been the exchanges of scientific information on the trends and nature of research, publications, scientific plans, descriptions of research methods. The cooperation has also taken the form of mutual coordination of research and carrying out of joint research according to agreed plans, preparation of joint publications, scientific symposia, and conferences, mutual exchange of research fellows for a prolonged periods of time, and finally, other forms of mutual cooperation between various establishments.

International exchanges. Direct contacts and cooperation between research centers of different countries at present are the most effective and expedient forms of coordination. These contacts are widely used between the socialist countries and are approved by corresponding agreements between Health Ministries and the Academies of Sciences of socialist countries, and also by the agreements between the USSR and other countries, in particular with France, Finland, Sweden, 


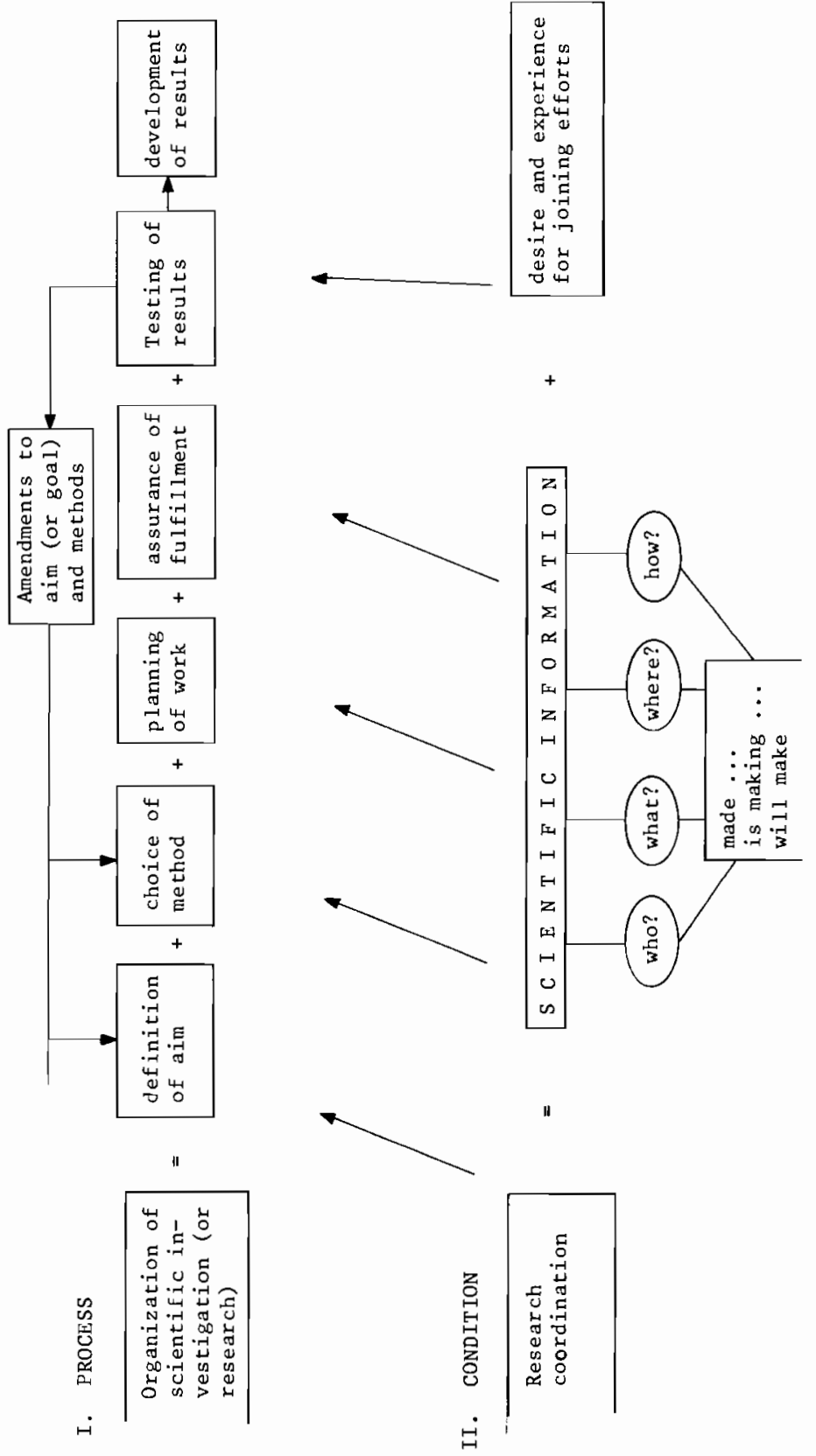


and the USA. Apart from bilateral agreements on cooperation in the health field there is also multilateral cooperation. This cooperation has been successfully implemented between the socialist countries--members of CMEA. Widely known are the multilateral forms of cooperation in the health field between the countries of Western Europe (within the framework of the "European Council"), and Scandinavia, Latin America, and Africa.

\section{THE WORLD HEALTF ORGANIZATION (WHO)}

The most open form of international cooperation in the field of health cnd biology are the research programs of WHO. In accordance with its Manual and longterm program, WhO is called to execute "coordination of research on the most actual and perspective problems of biology, medicine and health, carried out at national and international levels, aimed at the achievement of the maximum efficacy of the above research" (WHA resolution 23.59 ).

WHO has great experience in organizing scientific bio-medical information exchange. This organization is based on the scientists, representing 143 member states, which make up the forty-four Expert Comtritees including the Consultative Council on Medical Research. More than 200 research institutions and laboratories from the Reference wHo Centers; an even greater number of institutions develop, according to agreements with WHO, specific research and practical problems.

We consider that in the future WHO will play a greater role in the development of scientific medicine. However, WHA resolution 25.60 "On the role of WHO in the development and coordination of bic-medical research" states that who will:

1) promote the development of promising areas of research in bio-medical science;

2) develop and improve methods of international cooperation in bio-tnedical science, and standardize nomenclature and terminology;

3) coordinate research efforts in countries able to provide opportunities and staff for joint work on important problems;

4) collect and disseminate information about practical uses of research results in health programs; and

5) provide methodological training for bio-nedical researchers, and help assess their research.

\section{METHODOLOGY OF INTERNATIONAL COOPERATION}

The efforts of WHO and other international organizations clearly should be aimed primarily at medical research problems of great interest and significance to all the countries, and should be supported by the specific (in contrast to national) methodology of international coordination. The basic methodological principles of international research programs should be:

a) establishment of the priority of bio-medical problems requiring international cooperation;

b) analysis of ideas and proposed solutions for those problems;

c) planning for coordinated study of those problems; and

d) provision for systematic recording and assessment of research results in order to improve future plans.

This approach may make it possible not only to study, but to solve important biomedical and socio-hygienic problems of great international interest.

Here, the International Institute for Applied Systems Analysis (IIASA), working jointly with WHO, might greatly contribute to the solution of methodological problems from the systems analytical point of view. The most interesting problems in this regard are: the analysis of the contemporary potential in medical research; the compariscn of prognoses of the development of biomedical science; the study of research information systems; and systematic and mathematical provision of research programs. 
By the study of the "research potential," we mean the analysis of those data which characterize the potential of bio-medical science, the state of its development, i.e. that which could be scientifically analyzed and admit wide systematic comparison (G.M. Dobrov, 1966; I.G. Gerasimov, 1972; D. Gvishiani, R. Marston, and others). Among the parameters which determine the potential of science to solve problems of the scientific technological development are: the: supply of cadres, scientific information, material-technical provision, and, finally, optimum organization of the scientific system. There are additional factors (e.g. the educational background of the researcher) which at present are not subject to precise measurement, but influence the potential of science to raise and solve problems.

\section{BIO-MEDICAL FORECASTING}

Of great interest is the comparison of bio-medical prognoses developed in different countries. WHO plans to "take up the development of the long-term perspectives and prognosis of the activities of the Organization for a prolonged period of time, having in mind national and international prognoses of the scientific-technological, social, and economic development to the end of the twentieth century, and also the expediency of the determination of the most probable ways of the development of medical science and practice and possible role of WHo in solving the most pressing problems of health in future" (WHA resolution 23.59). IIASA cou1d make a great contribution to the solution of this problem.

\section{INFORMATION PROVISION}

The problems of information provision are also of great interest. According to the Working Group of the WHO Executive Board on Medical Literature (1971), al1 over the world 6,000-9,000 medical journals and periodicals are published. These publications are primary (general and specialized, local and central journals), secondary (essays) and tertiary (reviews, educational and didactic journals). Additionally, thousands of medical books, textbooks, essays, proceedings of congresses and conferences, dissertations, governmental and non-governmental reports, collections of rules and regulations, advertising materials, booklets, and technical reports are published annually.

Inevitably, the scientific front suffers an information lag (Table 2). This is caused by the imperfection of the form (details of scientific methods often cannot be described in detail) and the enormous volume, in our opinion, is the basic drawback of this form of information. On the other hand, its basic advantage is its long standing nature and reliability and wide coverage (more than 90-95\% of all the results of interesting research are published). However, literature falls behind not only before publication but even after publication, i.e. it must find the necessary "consumer."

One of the most important measures aimed accelerating the search of scientific information is the wide use of electronic computers. This methodology is well developed at the National Medical Library of the USA, where with the help of the "MEDLARS" system they publish the monthly "Index Medicus," which is also published in many countries of the world; simultaneously this information is stored and can be retrieved at any moment. Similar information-search systems are being developed in France (INSERM), in Great Britain (The International Research Communication System--ICRS), Holland (Excepta Medica), and other countries. The basic role in this field in the USSR is played by the All-Union Scientific-Research Institute of Medical and Medical-Technological Information. It develops the subsystems of the scientific medical and medical-technological information within the framework of "OASU-Health" (Yu. P. Lisitzyn, Yu. V. Vu1, and others).

Many national and international confererces have been dedicated to the problems of "bio-medical communications." Such international organizations as who and UNESCO actively participate in research information activities. UNESCO experts studied and published in 1971 a special report on the state of storage and flow of scientific and technological information in different countries and on the role 
Table 2. Scientific information provision.

\begin{tabular}{|c|c|c|}
\hline & Interpersonal Communicatjons & Literature \\
\hline Goals : & \multicolumn{2}{|c|}{$\begin{array}{l}\text { To know today WHO is doing WHAT, } \\
\text { How he is doing it, and WHERE, }\end{array}$} \\
\hline Means: & $\begin{array}{l}\text { Visists to other institutions } \\
\text { Contacts at confererces } \\
\text { Correspondence } \\
\text { Exchange of working notes } \\
\text { and reports }\end{array}$ & $\begin{array}{l}\text { Journal articles, books, } \\
\text { reviews, references, } \\
\text { surveys }\end{array}$ \\
\hline Volume and Coverage: & $\begin{array}{l}\text { Varies; perhaps } 10-15 \% \text { of } \\
\text { researchers in the field }\end{array}$ & $\begin{array}{l}\text { Great; probably } 90-95 \% \\
\text { of the researchers in } \\
\text { the field }\end{array}$ \\
\hline Reliability: & $\begin{array}{l}\text { Relative--can be subjective } \\
\text { or misleading }\end{array}$ & Acceptable \\
\hline $\begin{array}{l}\text { Delay in reaching } \\
\text { "consumer": }\end{array}$ & None & $\begin{array}{l}\text { Great and unavoidable-- } \\
\text { perhaps } 6 \text { months to } 2 \frac{1}{2} \\
\text { years after completion } \\
\text { of research. }\end{array}$ \\
\hline
\end{tabular}


various services and organizations intermediate between the "creators" and "consumers" of information. This report gives the preliminary proposals on the creation of the international system of scientific-technological information (UNISYST). This system would make possible information exchange between national information systems (using tapes, microphotographs, fijms, etc.) and thus facilitate international scientific-technological cooperation and reduce the duplication of research.

We also consider the second level or type of information, represented by international medical research contacts--"interpersonal communications"--which essentially supplement scientific literature and partially compensate its drawbacks. This was emphasized by many Soviet and foreign specialists (D. Pryce, 1963, 1967; R. Orr, E. Coy1, A. Leeds, 1964; G. Menze1, 1966; A. Kottre1, 1962; E.Z. Mirskaya, 1971; and others). Beyond the traditional exchanges of books, reprints, and preprints, and personal meetings, interpersonal commuications also are in the form of exchanges of new, non-traditional materials and documents (scientific-organizational documentation, methodological documentation, reviews, statistical reports, various references).

From the information point of view, interpersonal communications are characterized by a smaller coverage when compared to literature and to the specific "mosaic" of the results when information cn details of the research combines with scattered data in other fields and with complete absence of information. To get the comprehensive idea of the research, this "mosaic" would be compensated for in the future by fantasy or by comparison with other data. Apart from that, information obtained from interpersonal commication is occasionally unreliable and subjective, perhaps even sensational or consciously misinformative.

However, the drawbacks of informal communications are eliminated by their basic advantage--extreme operative nature and practically "zero" time lag from today's, or this very minute's, situation at the front of scientific research. A scientist visiting another laboratory may quickly realize what has been done in this laboratory earlier, what is being done at the present moment, and what is planned for the future. This is the basic purpose of scientific information.

The combination of literary scientific information and information from interpersonal communications enables us to assess what is being done in the various fields of medical science all over the world. Making such assessments is one of the basic tasks of information establishments. It does not supersede all other specific forms of literary, organizational, and other scientific information; rather, it is a natural generalization, the result of their logical analysis. Such assessment is not the end in itself, but is the necessary basis of the perspective prognosis and planning of research.

In this connection we want to emphasize that the problems of scientific information are far frcm being solved, and we are seeking possible ways of overcoming the "information barrier." According to some scientists, with the further development of electronic computers and means of reproduction, we sha11 witness new forms of conferences whose participants will not be onlookers, but active participants. We may now think of the further "symbiosis" of the researcher and the electronic computer. Other advances in information provision could include: development of inter-departmental cooperation of scientists; radical reforms in the activities of universities and research centers; changes in the nature of scientific publications; and gradual substitution of traditional published forms of comnunication by such communicatior carriers as special carriers, which will be stored centrally to be retrieved instantly by different scientists of the world ( 0 . Helmer and others).

\section{CONCLUSION}

The ideas presented above are important for the development of the systems and mathematical provision of international research programs. The first program of that kind may be the program of international cooperation in the field of onco- 
logy which is developed in accordance with WHA resolution 26.61 under the auspices of WHO, IACR, IOU, and other international bodies. The problems of the elaboration of the international oncological program were widely discussed at the Twenty-seventh World Health Assembly (Ceneva, May 1974). In the course of discussion the delegates emphasized the importance of IIASA participation in the program.'

We shall not analyze the details of the methodology of the international oncological program: they are discussed in the Report of the Director-General, H. Mahler, and in the papers of the Assembly, but we shall refer you to the who memorandun summarizing the program. This Memorandum emphasizes the important role which could be played by IIASA in the third and fourth stages of the development of the cancer program, i.e. in the development of its systems information and mathenatical provision. If the conference participants and the IIASA members agree with these proposals on the role of the Institute in the development of the systems analysis and coordination of bio-medical science, we might then analyze specific proposals for such activity. 
PART II. DEFINITION OF HEALTH PROBLFMS 



\title{
FORECASTING DEMAND AND THE PLANNING \\ OF HEALTH SERVICES
}

\author{
J. P. Newhouse \\ Rand Corporation, Santa Monica, \\ California, USA
}

\section{ABSTRACT}

This paper addresses the question of predicting demand for health services and in particular how complex a model is needed to predict demand. 1 The intellectual importance of this question is based on a standard Occam's Razor argument; the practical importance is that it costs significantly more money to obtain the information that the more complex model calls for. In particular, it is costly to obtain information on insurance coverage. Unfortunately, the results show that omission of insurance coverage resulted in poor prediction of demand changes for physician services.

\section{INTRODUCTION}

The practice of health planning in the United States is somewhat schizophrenic. Some approach the subject with what I have elsewhere called the "production function" approach (Newhouse, 1971). Their objective is to maximize the health of the population, subject to some overall resource constraint. In more global versions of this approach, health may be traded off with other goods or services to find the desired level of the resource constraint. This approach is consistent with a "needs" approach to the health sector in which the health planner attempts to determine the health "needs" of the population at some future point in time and provide the resources to meet these needs.

The production function approach to health planning can be criticized on at least two grounds: 1) although the resources provided may improve the health of the population if used (i.e. they may be needed), there is no guarantee they will be used, and unused resources are wasted resources; 2) the link between medical services at the margin and readily measured indices of health such as life expectancy is tenuous, especially in developed countries. Although the average unit of medical setvice can be presumed to have a considerable effect on measured health status, additional units will probably not have such an effect. Rather, additional medical services are more likely to alleviate anxiety, relieve symptoms, and provide prognostic information, none of which is easily measured. As a result, the production function is quite difficult to estimate.

A different approach to health planning can be called the "market signal" approach (Newhouse, 1971). The essence of the market signal approach is to predict the demand for some medical service at a given point in the future. The task of the health planner is then to ensure that resources exist to meet this demand. Implicit in this criterion is that enough resources should be on hand so that money, prices, and/or queues are at a desired level. Alternatively, the problem might be to ensure that no more resources than necessary exist to meet the projected demand; for example, that there are not "too many" (i.e. under-utilized) open-heart surgery units. ${ }^{2}$

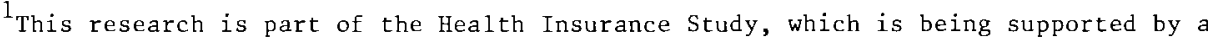
grant from the US Office of Economic Opportunity.

2 This approach is particularly relevant to those operating a hospital or hospitals, such as a local government, who need to predict demand at their facilities.
} 
The market signal approach meets the first objection to the production function approach head on; if the resources are demanded, they will be used. 'l'he market signal approach meets the second objection by assuming that if the resources are demanded, they are being used to improve health status, including subjective elements, in an optimal fashion. But it is precisely this assumption which is doubted by those favoring the production function approach. For a variety of reasons, including consumer ignorance and the private incentives of the physician, one can argue that demands in the medical care market do not call into play that combination of resources which a fully informed consumer would demand.

Thus, both approaches are probably imperfect. Measurement of a production function is beset with error, and the market signals may well be distorted. 3 The obvious question is which approach--the production function or the market signal-comes closer to generating the demand that a market of fully informed consumers would generate. Because such demand is difficult to measure 4 a definitive answer probably cannot be given, yet an answer is given implicitly each time a health planner plies his trade.

Even if one opts for a production function approach, however, market signals can be useful. If, for example, a service could be shown to be medically efficacious and a health planner thought the benefits exceeded the costs, it would be important to know how to ensure that demand for the service is at an appropriate level.

In this paper, I take up some problems in implementing the market signal approach. I therefore assume that the planner has decided that information on demand is necessary, and the question at hand is how to obtain that information.

\section{THE MARKET SIGNAL APPROACH TO HEALTH PLANNING}

The forecasting of demand, when actually put into practice in the United States, typically uses a rather naive model. Frequently, demand is assumed to grow at the rate of population, as in the case of projections of medical school places

${ }^{3}$ Several individuals (Roemer and Shain, 1959; Feldstein, 1969) have concluded that demand is not independent of supply. If by this is meant that the demand schedule shifts in response to supply variation, the market signal approach loses much claim to normative significance. The theoretical explanation for this phenomenon is not presented and the empirical evidence for the simplest version in which demand is solely a function of supply does not support the proposition. In the first place, it is important to distinguish between the effect of additional supply on demand and the effect on utilization. There may be no effect of additional supply on a demand schedule (i.e. a function relating demand to money and time price) but an effect on utilization through the lowering of time price, as sketched below. Feldstein's evidence that utilization correlates with supply in the National Health Service can be plausibly explained through general excess demand for hospital beds. (No hospital beds had been built in twenty-five years and queues for elective surgery were very long.) The notion that supply can always create demand is not consistent with the general downward trend in occupancy rates in the United States (now down to 75 percent for short-term general hospitals), nor with the anecdotal evidence that there is a surplus of beds (which has led to "certificate-of-need" legislation to limit construction of new beds).

${ }^{4}$ See Bunker and Brown (1974) for an interesting analysis of surgery rates among physicians, as opposed to other professional groups. This article made the reasonable assumption that physicians were fully informed consumers, and found that surgery rates among physicians were comparable to other professional groups. 
or hospital beds which adopt the criterion that physician/population or bed/population ratios should remain constant. 5 Occasionally, demand is adjusted for certain demographic changes (for example, Fein, 1967). But the economic theory of demand for medical services has now been well developed by Grossman (1972) and Phelps (1973), and has progressed considerably beyond a "naive" model. In addition, there have been a number of attempts (Grossman, 1972; Newhouse and Phelps, 1974, in press) to implement the theoretical models of demand. Unfortunately, to apply these models to problems of demand forecasting in the United States is expensive. Data on variables--such as health status and insurance coverage--are necessary, and it is usually possible to obtain these data only through special surveys. This paper explores how much is lost by using a simple model to forecast demand, one which makes use only of demographic characteristics that should be readily available. If this approach is viable, that is, if it is nearly as good as the model deduced from economic theory, then considerable resources might be saved in the planning process.

\section{THE MODEL DEDUCED FROM ECONOMIC THEORY}

Because the economic theory underlyirg the demand for medical services has been developed elsewhere, there is no need to develop it here. A few remarks are, however, in order. It is assumed that there are two reasons for seeking medica1 services. First, medical services can reduce the number of days lost to sickness in the future (or the degree of activity limitation). Such a reduction may occur either through standard kinds of preventive services, or through curative services when the disease is not self-limiting. Grossman (1972) calls the model which focuses on this phenomenon the investment model, because the consumer "invests" in future productive time. And second, medical services can improve utility in the present (and also the future), for example through relief of anxiety, provision of prognostic information, or some kinds of symptomatic relief. The consumer "feels better," even though there is no change in the total amount of sick time. The model which focuses on this phenomenon Grossman (1972) calls the consumption model.

Both the investment and the consumption models specify a similar set of variables as affecting demand for care. They differ in the following ways: 1) non-wage income is predicted to have no effect on demand for care in the investment model, while it is predicted to have a positive effect in the consumption model; and 2) the predicted direction of the effect of education and wage income are ambiguous in the consumption model. For our purposes these differences are minor; what is important is that the same set of explanatory variables (with the exception of non-wage income) enters each model.

These explanatory variables include: 1) health status, ideally measured directly; if not, then using age as a proxy; 2) the price of time of those in the economic unit, measured by wage income for those in the labor force, otherwise by an imputed value; 3) non-wage income (consumption model only); 4) the money price of medical care services; 5) education; 6) marital status; and 7) the supply of medical services. The supply of services can be reasonably assumed to be predetermined for the individual (that is, not influenced by his demand and therefore exogenous). This variable is given the interpretation of affecting the proportion of time the local medical care system exceeds capacity, as well as the length of any queue. Because supply in this interpretation has a diminishing effect, it is entered as a square root. In this interpretation supply affects demand by changing the time price.

Sex, race, and age are also entered to control for demographic variation attributable to these variables. This is not a complete 1 ist of variables that affect demand; for example, the actual amount of time spent receiving services is

5 The assumption of no technological change also must be made. 
not included. Such omissions are made for lack of data; I do not feel that the omissions substantially affect the results.

\section{THE SIMPLIFIED MODEL}

Data sets which contain information on all the variables 1 isted above by individual are expensive to generate. As has been pointed out, measures of health status will generally require special surveys; in addition, in the American context-where there is no uniform insurance plan--data on insurance are extraordinarily difficult to obtain. Even survey data typically do not contain enough data on insurance policies to define price, because detailed information on insurance coverage must usually be obtained from the employer or insurance company. This is time-consuming and expensive. One can reasonably ask the question: How good an approximation to demand would a model which omitted these difficult-to-measure variables attain?

I have therefore focused on the subset of the variables 1 isted above that can be readily measured from census data. This subset includes age, sex, race, marital status, and education, which are taken over from the model deduced from economic theory. Measures of price and insurance, as well as health status, are omitted. In their place is a measure of labor force participation, interacted with sex and marital status. In addition, wage and non-wage income have been aggregated to total income, because they are usually aggregated in census data. It is assumed that information on the supply of medical services is also readily available. (A complete list of explanatory variables may be found in the Appendix.)

These explanatory variables are used to predict the following variables: 1) use or no use of the hospital or ambulatory system (i.e. an admissions equation); the dependent variable takes the value one if there is any use and zero if there is none; and 2) amount of use, conditional upon some use, measured by hospital days and physician visits.

The functional form employed is a step function; that is, the continuous variables such as age, education, and so forth are broken up into discrete intervals with a dumny variable for each interval. The method of estimation used is Ordinary Least Squares (OLS) rather than simultaneous equation methods. Although OLS is inconsistent when estimating the model deduced from economic theory (because insurance may be a function of expected use), it gives reasonable results, while simultaneous equation methods appear quite inefficient (Newhouse and Phelps, in press). 6 Another reason to employ ols is that I. use the coefficient of determination as one measure of how well the equation predicts. To use simultaneous equation methods for the model deduced from economic theory and oLS for the simplified model would render the coefficients of determination non-comparable. Because the use or no-use equations have a dichotomous dependent variable, they have been estimated by logit methods. In this case the coefficient of determination is the square of the correlation coefficient between the actual value (zero or one) and the predicted value.

The sample used to estimate these equations is the 1963 survey of the Center for Health Administration Studies of the University of Chicago. This survey is a national probability sample of the United States population; the survey (and the questionnaire used) is described in Andersen and Anderson (1967). I have used the subsample who have no insurance or whose insurance has been verified with the insurance company and who have no hospital or medical deductible in their

${ }^{6}$ The inconsistency occurs because of possible adverse selection in the distribution of insurance; however, estimates using simultaneous equation methods do not appear to be strongly identified. 
policy. ${ }^{7}$ Those with unverified insurance are excluded. In the use or no-use equations, this subsample of those with no insurance or verified insurance consists of 3897 individuals or 50 percent of the total sample. 8 Those excluded are not random. They tend to be in larger firms and at higher incomes; the results are weighted to eliminate any bias from this factor.

\section{HOW GOOD IS THE SIMPLIFIED MODEL RELATIVE TO THE MODEL} DEDUCED FROM ECONOMIC THEORY?

Because interest centers upon the ability of the equations to predict utilization and not on the equations themselves, the actual estimated equations are presented in the Appendix. A comparison of the correlation coefficients of the simplified model and the model deduced from economic theory is shown in Table 1. The major point of interest is the amount of degradation in the simplified model. The results show that there is substantial degradation in most equations.

Table 1. Comparison of correlation coefficients of the simplified model and the model deduced from economic theory.

\begin{tabular}{|c|c|c|c|}
\hline$\underline{\mathrm{R}^{2}}$ & "Simplified" & "Deduced & Irom Theory" \\
\hline $\begin{array}{l}\text { Admissions } \\
\qquad(n=3897)\end{array}$ & .01 & & .05 \\
\hline $\begin{array}{l}\text { Length of stay } \\
\qquad(n=267)\end{array}$ & $\begin{array}{l}.20 \\
.06(\text { corrected })\end{array}$ & & .25 \\
\hline $\begin{array}{l}\text { Use } \\
\qquad(n=3897)\end{array}$ & .07 & & .11 \\
\hline $\begin{array}{l}\text { Visits } \\
\qquad(n=2062)\end{array}$ & $\begin{array}{l}.05 \\
.002(\text { corrected })\end{array}$ & & $\begin{array}{l}.16 \\
.14(\text { corrected })\end{array}$ \\
\hline
\end{tabular}

The implication of these results is that it may well be worth considering health status and insurance coverage when attempting to forecast demand in the United States. However, there are two related reasons why this result can only be suggestive of that conclusion. First, predictive power in a cross-section is not the same as predictive power in a time series. Health status in particular may have considerably greater interpersonal variation than intertemporal variation, and what intertemporal variation there is may not be very predictable. Thus, explanation of cross-section variation does not guarantee the ability to forecast interpersonal variation. Second, one cannot judge the "goodness" of the $\mathrm{R}^{2}$ 's reported in Table 1. On the one hand, they may appear low. Alternatively, the apparently substantial additional precision of the model based on economic theory may be merely more gloss on an already shiny finish, and even the simplified model

7 The exclusion of those with deductibles is a restriction of the model based on economic theory (Keeler, Newhouse, and Phelps, 1974).

${ }^{8}$ There are some very minor exclusions, in addition to those listed in the text, as described in Newhouse and Phelps (1974). The vast majority of those excluded do not have a verified insurance policy; around 14 percent of the sample is excluded because of a deductible. The remaining exclusions exclude fewer than one percent of the observations. 
may be able to predict intertemporal variation well. In order to resolve these issues, it is necessary to use the equations estimated from cross-section data to predict intertemporal variation, and 1 now turn to that task.

\section{INTERTEMPORAL PREDICTIVE ABILITY}

Ideally, one would test the ability to predict future utilization for both the simplified model and the model based on economic theory. Unfortunately, I have therefore been able to test only the intertemporal predictive power of the simplified model, because there are no data on insurance coverage and health status in a later period.

A test of even the simplified model is difficult because it predicts demand, which is not observed. Rather utilization, or the interplay between supply and demand, is observed. To predict utilization also requires a model of supply, and I have not attempted to construct such a model. (See, however, Feldstein and Friedman, in press.) Utilization will equal predicted demand only if the additional services that are demanded can be supplied without any $r$ ise in price (money price or time price). In technical terms, a change in demand will equal a change in utilization only if supply is perfectly elastic.) Because this condition does not hold in the short run, the actual change in utilization will be less than the predicted change in demand. (Some individuals who would have. demanded services at the given money and time price will not do so when the price rises.) If the actual change in utilization exceeds the predicted change in demand, there is evidence of an important misspecification of the demand equation. The importance of this test will soon become clear.

The test of the simplified model I employ is its ability to predict 1970 utilization. The details of the test are as follows. There are data from the 1970 United States Census on the demographic characteristics of the population in 1970 . There are also hospital utilization data from 1965 and 1970 and physician utilizaation data from 1964 and 1970 that have been collected in the United States National Health Survey. I have used the 1963 survey data (a national probability sample) to obtain values for the explanatory variables in 1963 and then use these values in the estimated equations (shown in the Appendix) to obtain an estinate of hospital days and physician visits. I then adjusted the intercept of these equations so they predict 1965 hospital days and 1964 physician visits exactly. 9 I then use this modified equation together with values from the 1970 US Census of Population for explanatory variables, to predict 1970 utilization.

In symbols I let:

$$
\mathrm{Y}=\mathrm{X} \beta+\alpha
$$

where $\mathrm{Y}$ is either estimated hospital days or physician visits, $\beta$ is the vector of coefficients estimated in the Appendix, $X$ is the vector of values of the explanatory

\footnotetext{
${ }^{9}$ I do not have data from 1964 and 1965 for the explanatory variables, and therefore must use 1963 data. Apart from the temporal discrepancy between 1963 and 1964-65, the intercept should be adjusted to account for differences in definitions and techniques of data collection between the 1963 survey and the National Health Survey. For example, the 1963 survey does not include a telephone consultation in its definition of physician visits, while the National Health Survey does. This difference in definition makes the results subject to some error; that error is considered to be relatively low, however.
} 
variables 1 isted in the Appendix, and $\alpha$ is an adjustment to the intercept computed so that the equation predicts 1964 physician visits and 1965 hospital days perfectly.

Values of physician visits and hospital days for 1970 are then predicted by observing $X$ from the 1970 census data and using Equation (1). 10 The predicted value of $Y$ is then compared with the actual value for 1970. In addition, the results from the "simplified model" are compared with the even simpler "naive mode1," which assumes that the rate of utilization per person remains constant, so that total utilization increases at the same rate as population. In order to see that some gain might be expected from taking into account changes in demographic variables (i.e. using the simplified rather than the naive model), we show in Table 2 the change in selected demographic variables between 1960 and 1970.11

Table 2. Changes in selected demographic variables, 1960-1970.

\section{Characteristic}

Married male

Single male

Single female

Married female working

Married female not working

White

Non-white

Rural

Urban

Age $0-5$ years

Age 6-17 years

Age 18-44 years

Age 45-64 years

Age $65+$ years

Education, $0-8$ years

Education, 9-11 years

Education, 12 years

Education, 13-15 years

Education, $16+$ years
1970

(percentage)

.23

.08

.07

.09

.14

.83

.17

.27

.73

.08

.26

.35

.21

.09

.19

.17

.21

.08

.06
1960

(percentage)

.24

.07

.05

.08

.16

.89

.11

.30

.70

.12

.26

.31

.21

.1

.26

.16

.18

.06

.05
Difference (1970-1960)

$-.01$

.01

.02

.01

$-.02$

$-.06$

.06

$-.03$

.03

$-.04$

0

.04

0

$-.01$

$-.07$

.01

.03

.02

.01

Source: 1960 and 1970 US Census of Population.

$10_{1970}$ income has been deflated to 1963 values, so that income is in real terms. The Gross National Product deflator was used.

11 The change in income groups is not shown because income in census data is, of course, measured in current dollars, whereas in the simplified model it is measured in constant dollars. 
HOSPITAL DAYS

The expected number of hospital days is found by predicting the probability of hospital admission for each person, multiplying the probability of admission by the expected length of stay for that person and sumning over the population. The "base period" for this calculation was 1965, when the total number of hospital days was 228.4 million. The results of this calculation are shown in Table 3 .

Table 3. 1970 hospital days (in millions).

$\begin{array}{ccc}\begin{array}{c}\text { Predicted by } \\ \text { "Simplified" Model }\end{array} & \begin{array}{c}\text { Predicted by } \\ \text { "Naive" Mode1 }\end{array} & \text { Actual } \\ 235.7 & \frac{244.4}{234.0}\end{array}$

Sources: "Hospital Utilization," United States Vital Health Statistics, Series 13, No. 2, Tables 2 and 3 , and Series 13, No. 14, Table 3 Values of 189.8 and 203.1 million have been used for population in 1965 and 1970 in order to derive the prediction of the "naive mode1."

As can be seen, the prediction error associated with the simplified model is considerably less than the prediction error associated with the naive model, and comes within 1 percent of the actual total.12 All is not as well as it may seem, however. Table 4 shows predicted demand by age group.

Table 4. 1970 hospital days by age group (in millions).

$\begin{array}{crr}\text { Age } & \begin{array}{c}\text { Predicted by } \\ \text { "Simplified" Model }\end{array} & \text { Actual } \\ \text { Under } 65 & 183.3 & 156.9 \\ 65+ & 52.4 & 77.2\end{array}$

Sources: (same as for Table 3).

The actual number of hospital days in the 65 and over age group is considerably underpredicted, while the hospital days in all other age groups are considerably over-predicted. This pattern of error is not surprising, for the advent of public health insurance for the aged in 1966 (Medicare) considerably improved the insurance coverage of the aged and thereby increased their demand for hospital services relative to other age groups. As a result, the aged's share of hospital days rose, as shown in Table 5. Because insurance coverage is omitted from the simplified model, that model could not be expected to pick up this change in the pattern of demand by age group due to changes in insurance coverage. However, in the aggregate the change in insurance coverage was not large; the average portion of the hospital bill paid out of pocket fell from 0.185 to 0.133 between 1965 and

${ }^{12}$ It would have been desirable to present standard errors so that formal confidence intervals might be calculated. However, there are no good estimates of the intertemporal variance. As a result, I present only point estimates. 
and 1970 (computed from data in Cooper and Worthington, 1973, Table 1). This relatively small change in insurance in the total population is quite consistent with the relatively small change in the number of hospital days.

Table 5. 1965 and 1970 hospital days (in millions) by age.

\begin{tabular}{|c|c|c|c|c|}
\hline & $\begin{array}{l}\text { Total } \\
\text { Days } \\
1965 \\
\end{array}$ & $\begin{array}{l}\% \text { of } \\
\text { Tota1 } \\
1965 \\
\end{array}$ & $\begin{array}{l}\text { Tota1 } \\
\text { Days } \\
1970 \\
\end{array}$ & $\begin{array}{l}\% \text { of } \\
\text { Total } \\
1970 \\
\end{array}$ \\
\hline Under 65 & 168.1 & 73.6 & 156.9 & 67.0 \\
\hline 65 and Over & 60.3 & 26.4 & 77.2 & 33.0 \\
\hline
\end{tabular}

Sources: (see Table 3. 0.4 percent of the persons had an unstated age, and these have been allocated in the same proportion as the persons with known age.

\section{PHYSICIAN VISITS}

Although the simplified model was relatively close to the actual number of hospital days, this is not the case for physician visits, as shown in Table 6 .

Table 6. 1970 physician visits (in millions).

\author{
Predicted by \\ "Simplified" Model
}

840.6

\section{Predicted by \\ "Naive" Model}

923.0
Actua1

926.9

The "base" period is 1964 , when physician visits were 844.3 million. As can be seen, the prediction of the "naive" model is very close to the actual value, while the "simplified" model yields a very large underestimate.

What is the reason for the "failure" of the "simplified" model? It is not likely to be an unmeasured deterioration in health status. Table 7 shows various measures of health status. The measures indicate that there was, if anything, an improvement in health status in this period, so that omission of health status is not likely to account for the under-prediction. ( $I$ assume that the causal flow is for the most part from these measures of health status to demand, and that the slight improvement in these measures of health status is not caused by the additional physician visits.) Rather, the reason for the underestimate is almost surely the omission of insurance coverage in the "simplified" model. Between 1964 and 1970, there was a very substantial improvement in the coverage of physician services, as shown in Table 8.13 This change in the coverage of physician services

\footnotetext{
13 Physician services as defined by these data include inpatient physician services. This is unfortunate, because one cannot know exactly how coverage for ambulatory services changed. It is nevertheless likely that there was a substantial change in the coverage of outpatient services. Because inpatient services represent only about one-third of total physician services (Newhouse, Phelps, and Schwartz, 1974, Appendix B), it is very unlikely that out-of-pocket payments for all physician services could have changed this much without a substantial change in the coverage of outpatient services.
} 
generated a considerable increase in demand. Given estimates of the responsiveness of demand to insurance that I have made elsewhere, this increase could well have been in the range of 15 to 20 percent (Newhouse, Phelps, and Schwartz, 1974). Omission of this large change in demand would account for the large underprediction of the "simplified" mode1.14

Table 7. Health status.

\begin{tabular}{lcc}
$\begin{array}{c}\text { Measure } \\
\begin{array}{c}\text { Rates per } \\
100 \text { Persons) }\end{array}\end{array}$ & $\begin{array}{c}\text { Measures } \\
1964-65\end{array}$ & $\begin{array}{c}\text { Measures } \\
1970\end{array}$ \\
\cline { 3 - 3 } Number of Acute Conditions & 212.7 & 203.4 \\
Restricted Activity Days & 16.4 & 14.6 \\
Bed Days & 6.2 & 6.1 \\
Work Loss Days & 5.7 & 5.4
\end{tabular}

Sources: National Center for Health Statistics, "Current Estimates," Vital and Health Statistics, Series 10, No. 25, Tables 1 and 14; Series 10, No. 72, Tables $A$ and $B$.

Table 8. Proportion of expenditures on physician services paid out of pocket.

$$
\begin{array}{ll}
1964-65 & 0.634 \\
1969-70 & 0.435
\end{array}
$$

Source: Computed from data in Cooper and Worthington (1973), Table 6.

\section{SUMMARY}

In this paper I implemented a "simplified" version of a model to predict the demand for hospital and physician services. The simplification involved making demand a function of only demographic variables, which can be readily obtained from census information, and omitting measures of health status, price, and insurance coverage. For the United States, at least at the present time, this simplification comes at too great a price. Changes in insurance exert too great an influence over demand to be left out of predictive equations, even if labor force participation, income and education are available as explanatory variables. These latter variables are not satisfactory proxy variables. Nor is it likely that a simple measure of the percentage insured, which might be obtained through a survey, will be of much assistance, because the variation in the amount of coverage within the insured population is quite large (that is, individuals have varying degrees of partial coverage). Over time, as the insurance coverage of the population approaches completeness, insurance may cease to be as critical in predicting demand, but at least for the next several years in the United States, it is likely to remain important.

14 Because utilization will not change as much in demand, the change in demand due to a change in insurance coverage will be larger than the actual 10 percent change in utilization. 


\section{REFERENCES}

Andersen, R. and Anderson, O.W. (1967). A Decade of Health Services. (University of Chicago Press, Chicago).

Bunker, J.P., and Brown, Jr., B.W. (May 9, 1974). The Physician-Patient as Informed Consumer of Surgical Services. New England Journal of Medicine, 290:19, 1051-1055.

Fein, R. (1967). The Doctor Shortage. (The Brookings Institution, Washington, D.C.).

Feldstein, M.S. (1969). Economic Analysis for Health Services Efficiency. (Amsterdam, North Holland).

Feldstein, M.S. and Friedman, B. (1974). The Effect of National Health Insurance on the Price and Quantity of Medical Care. (Paper presented at the Universities-NBER Conference on the Role of Health Insurance in the Health Services Sector).

Grossman, M. (1972). The Demand for Health. (Columbia University Press, New York).

Keeler, E.B., Newhouse, J.P., and Phelps, C.E. (forthcoming). Deductibles and Demand. The Theory of the Consumer Facing a Variable Price Schedule Under Uncertainty. R-1514-OGOINC. (The Rand Corporation, Santa Monica, California).

Newhouse, J.P. (Winter, 1971). Allocation of Public Sector Resources in Medical Care: An Economist Looks at Health Planning. Economic and Business Bulletin, 23, No, 2, 8-12.

Newhouse, J.P. and Phelps, C.E. (1974). Price and Lncome Elasticities for Medica1 Care Services. Economics of Health and Medical Care. (Mark Perlman (ed.); Macmillan Press, London).

Newhouse, J.P. and Phelps, C.E. (in press). New Estimates of Price and Income Elasticities. (Paper presented at the Universities-NBER Conference on the Role of Health Insurance in the Health Services Sector).

Newhouse, J.P., Phelps, C.E., and Schwartz, W.B. (June 13, 1974). Policy Options and the Impact of National Health Insurance, New England Journal of Medicine, 290 , No. $24,1345-1359$.

Phelps, C.E. (July, 1973). The Demand for Health Insurance: A Theoretical and Empirical Investigation. R-1054-0EO. (The Rand Corporation, Santa Monica, California).

Roemer, M.J. and Shain, M. (1959). Hospital Utilization Under Insurance. (American Hospital Association, Chicago). 

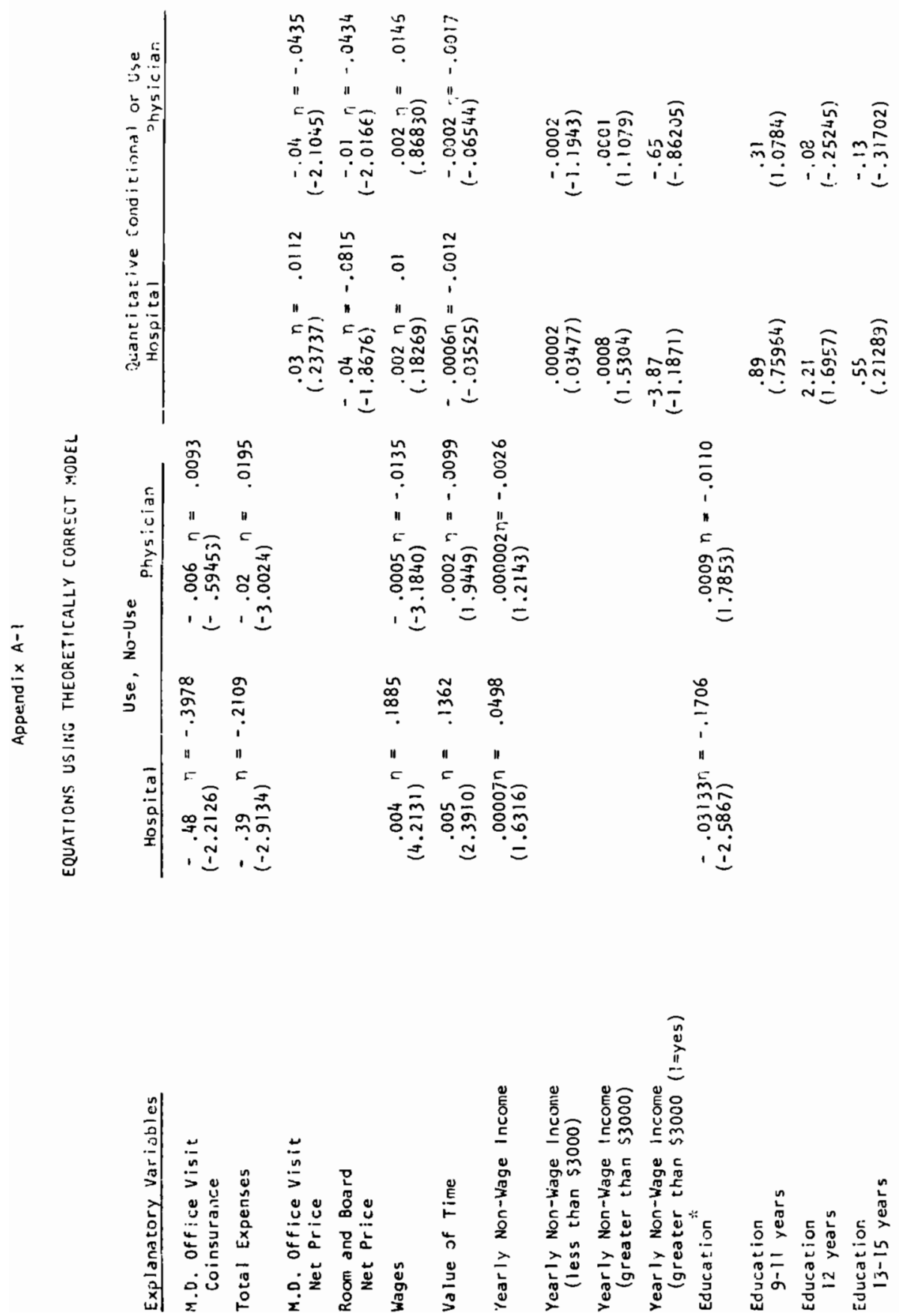


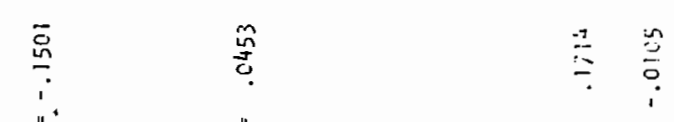

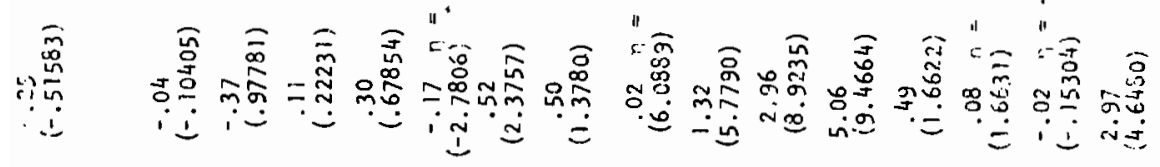

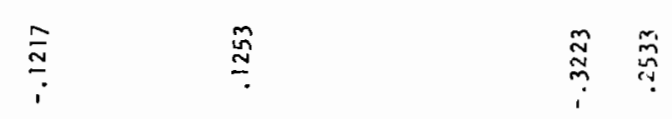

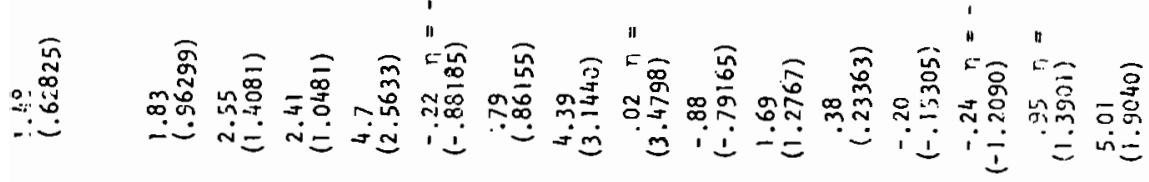

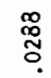

尊高

ถู่

亳亳
항

"

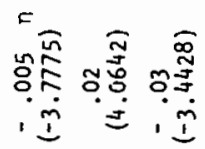

縞

iI

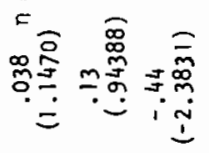

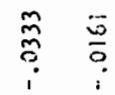

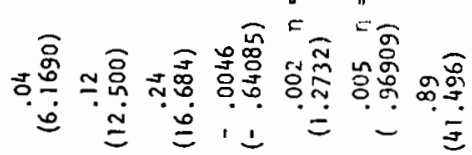

举

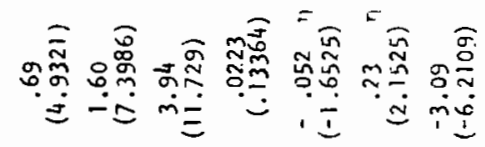

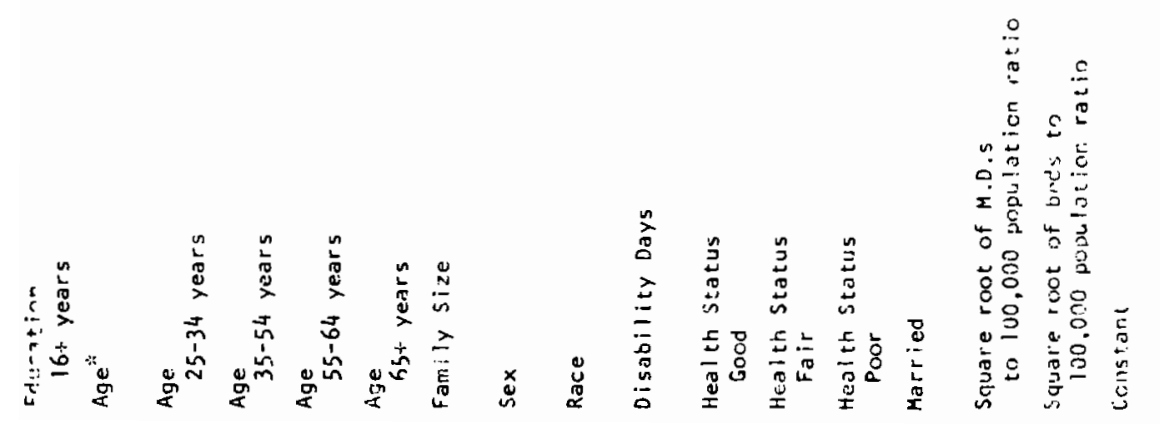




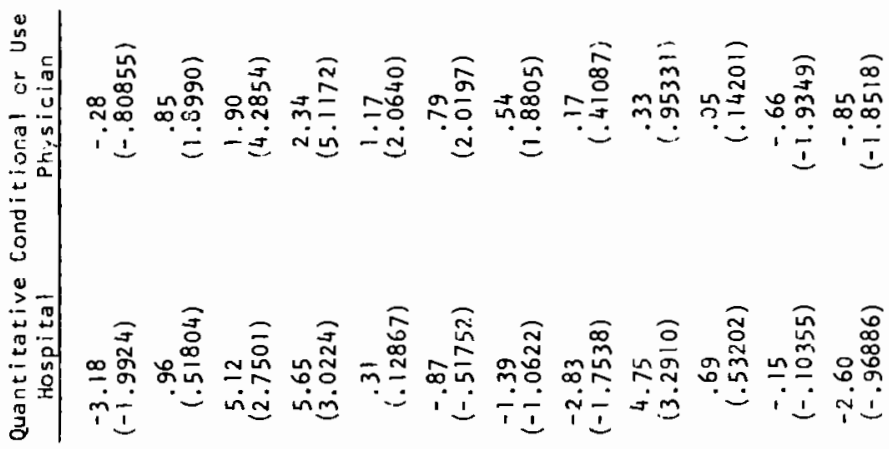

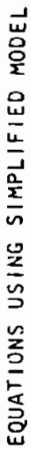

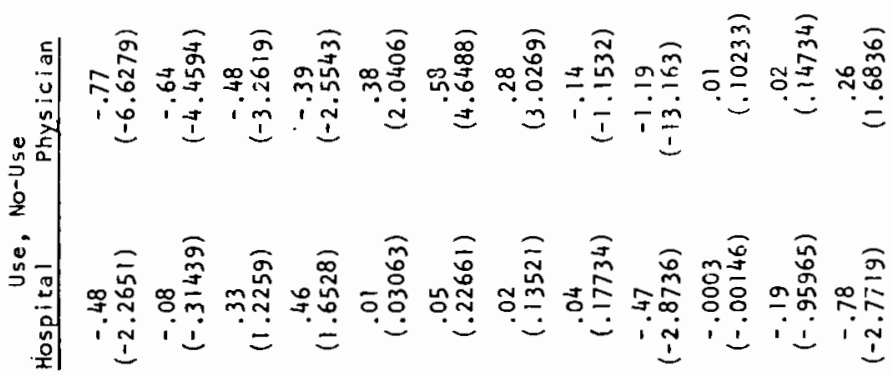

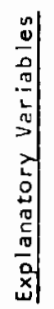

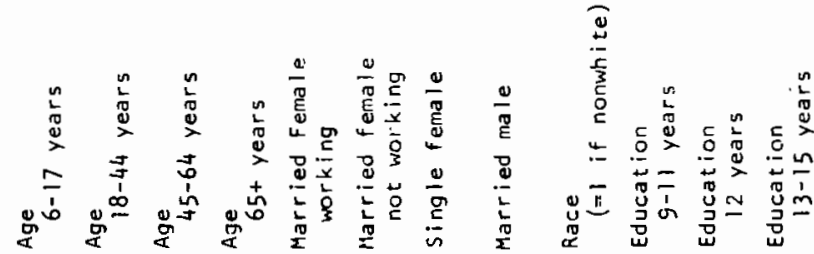




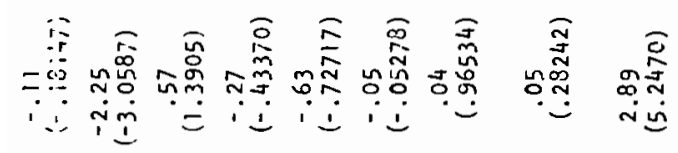

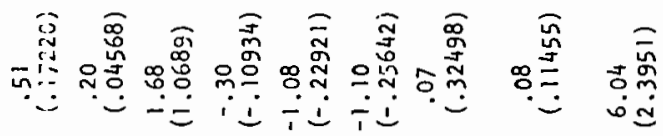

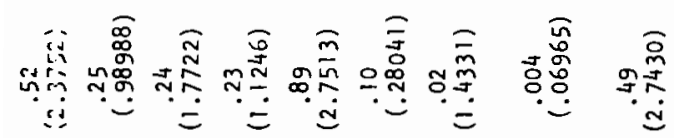

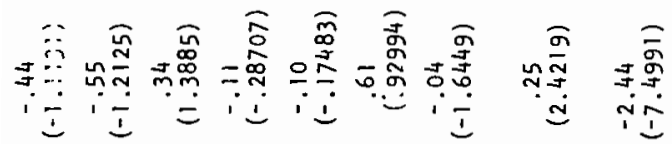

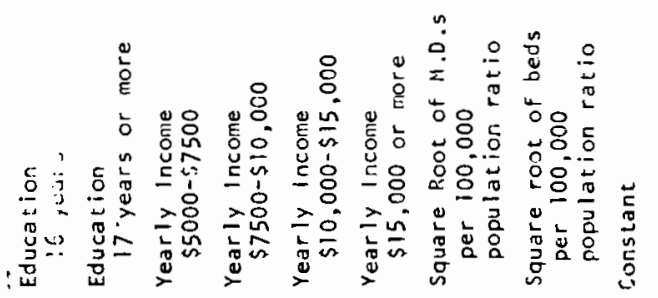


Comments of the Discussant, Mr. Chatterjee

The main problem to which Mr. Newhouse has addressed himself may be stated as follows: given a full linear model

$$
y_{i}=\beta_{0}+\beta_{1} x_{1 i}+\cdots+\beta_{p} x_{p i}+\beta_{p+1} x_{p+1 i}+\beta_{q} x_{q i}+\varepsilon_{i} \text {, }
$$

how do we establish the hypothesis that

$$
\mathrm{H}_{\mathrm{o}}\left(\beta_{\mathrm{p}+1}=\beta_{\mathrm{p}+2}=\cdots=\beta_{\mathrm{q}}=0\right) \quad ?
$$

In the language of the paper $\left\{x_{p+1}, x_{p+2}, \ldots, x_{q}\right\}$ are insurance and other variables which are difficult to measure. Mr. Newhouse shows that the hypothesis does not hold for the US in the present historical period. The insurance variables have significant effects and consequently have to be retained in the equation. The test statistic as we know, al though $\mathrm{Mr}$. Newhouse does not do it exactly this way, is the usual F statistic with $(p-q),(n-p-1)$ degrees of freedom and is given by

$$
F_{p-q, n-p-1}=\frac{\left(R_{p+q}^{2}-R_{p}^{2}\right)}{\left(1-R_{p+q}^{2}\right)} \cdot \frac{n-p-1}{p-q},
$$

where $n=$ number of observations.

$$
\mathrm{R}_{\mathrm{p}+\mathrm{q}}^{2}=\text { multiple correlation coefficient based on }(\mathrm{p}+\mathrm{q}) \text { variables. }
$$

The reason I go through all this is to put the problem in a clear setting and also to arrive at my first point, namely, that I am not very happy at Mr. Newhouse's use of the terms "theoretically correct model" and "the market signal approach." I think Grossman's work has not taken us to the place where we have a unified theory which explains the demand for health services universally; instead, we have a postulated linear model which has been validated by data primarily from the American experience. I would be much happier with the term "postulated full model" and the "reduced model."

Secondly, the term "market signal approach" smacks, if I may be allowed to say so, too much of Wall Street. The proposed approach uses a good old-fashioned linear socio-economic model, the type which we are all very fond of. There is nothing wrong with it, so why introduce a much abused term ("market signal"), whose use has led to financial losses for many innocent and gullible people. Do people (consumers) generate demand for hospitals or is it the doctors who generate it? In planning for health services should we be predicting demand--which for an economist must always be at a price--or health "needs?" I would have thought that the health administrators might be concerned with predicting "needs." I know this is a difficult point and I for one would like to be enlightened on it.

I would also like to know why, in health planning, we are always planning for sickness. How do we plan for demands on the prevention and early detection of disease? How do we plan for demands on the type of vaccines that might be needed for an outbreak of "flu" or "mumps," about whose timing and intensity there is some uncertainty? Some of these diseases I am told have a periodic component. To predict need for services in those cases, should we not include these periodic 
components and any other epidemiological properties that have been already established about a particular disease?

In the problem on selecting variables to predict demand, Mr. Newhouse says leaving out insurance variables leads to a considerable loss of accuracy. But in these problems there has to be a tradeoff between the cost of measuring a variable and the increase in precision which the variable contributes. I am afraid that the statisticians have not paid much attention to this aspect of the problem. Most of the guidelines given for the variable selection procedure never consider the cost of measuring the variables. There are situations where the inclusion of a variable might lead to a significant increase in the value of the multiple correlation coefficient, but the cost of measuring the variable is so high that the increase in the multiple correlation coefficient is not sufficient to justify its inclusion in the forecasting model. What is the situation here?

Now I come to the forecasting aspects of the paper. Let me make some specific remarks first and then I will make some general remarks. The specific remarks concern tables $2,3,5$. In order to judge the performance of the models even in the narrow sense as Mr. Newhouse has done, we should have the predicted figures from the "full model." In Table 3 it would also be nice to have the prediction Irom the "naive models." Judging by the low multiple correlation coefficients reported, I do not expect the forecasts from the full model to be much different from the forecasts from the reduced model. Mr. Newhouse explains the poor performance of the reduced model by the $f$ act that during this period Medicare and Medicaid, forms of health insurance, came into existence. If that is the case, then the whole regression system has changed and we should recalculate the coefficients using the more relevant period.

Now about the more general point. Let us consider Table 2. Mr. Newhouse claims that a "simplified model does considerably better than the naive model," presumably because in one there is a forecasting error of -4.1 , and in another there is an error of +10.4 , both figures in millions of units. I do not see why there is evidence of misspecification if only the estimated predictions are greater than the actual values. Now suppose somebody says that the "naive model" is better because it errs on the safe side. If we are planning facilities it is better to have some unused capacity: better a few empty beds than inhuman, overcrowded facilities. I hope you see what I am driving at; namely, when making forecasts it is essential to know to what use the forecasts are going to be put, and work out the expected loss from the forecasting errors. Without a loss function it is difficult and almost impossible to judge which of the methods give better forecasts--is it better to err on the large positive side or on the small negative side? In forecasts which are to be used for planning purposes, it is essential, I feel, to work with loss functions, if not explicitly, at least implicitly. Single point estimates without standard errors such as given in Tables 2, 3, 5 are not very informative and can be misleading. I would be very pleased if some of you spoke on this point.

\section{Clarifications}

Mr. Newhouse clarified two issues raised by Mr. Chatterjee. First, the full model predictions requested by the latter could not be provided because the necessary data do not exist. Secondly, he had implicitly assumed a symmetric loss function for the model user. Another conference member pointed out that the Newhouse model should not at this phase apply estimated loss functions as that should occur only at the decision stage. Newhouse, he argued, had legitimately concentrated upon providing best point projections together with the estimations of associated error.

Information Costs

One participant took up the question raised by Mr. Chatterjee about the 
cost of measuring variables needed by planning models. Information searches should, perhaps, begin with such a model as that proffered by Mr. Newhouse and should base their collection of specific data upon their value to planners and to other decision makers and upon their cost of acquisition. A second speaker felt that too much emphasis was being placed upon obtaining the ideal, but too often most expensive, figures required by models or planners. Instead there should be greater attempts to infer or to tease more information for planning from such existing data pools as the periodic census.

\section{Level of Explained Variance}

Questioned about the apparently low level of variance explained by his regressions, Mr. Newhouse stated that this arose because the dependent variables were individual household annual expenditures for medical services. Much of the household variance inhered in the chance nature of disease incidents and could not be eliminated. The proper confidence measures for the regressions was not the variance explained but was the standard F-test.

\section{Demand And Need}

Mr. Venediktov brought out the distinction between demand and need for medical services as he asked Mr. Newhouse to define the two. Demand, Newhouse felt, was an economically precise term specifying the amount of medical services that would be consumed at a given price. Need, on the other hand, represented a usually subjective imputation upon the amount of medical services that a person or a population should have. It was not equivalent to demand at zero money price, as recent work has shown the importance of such non-monetary factors as the time price of medical care. Both need and demand could be influenced by health education. 
THE DETERMINATION OF

ACUTE CARE BED REQUIREMENTS FOR PROVINCIAL ACUTE CARE HOSPITAL REGIONS

Douglas W. Paine, Acting Director

Health Systems Directorate, Department of Health and Welfare, Ottawa, Ontario, Canada
Lawrence L. Wilson, Commissioner for Hospitals, Alberta Hospital Services Commission, Edmonton, Alberta, Canada

\section{INTRODUCTION}

In view of the recent intense interest in Canada in the rising cost of providing health care--an average of approximately $12.8 \%$ a year over the period 1962 to 1971--it has become extremely important to assess and improve the effectiveness and efficiency of the health care delivery system, while at the same time ensuring that an adequate standard or quality level of care exists. Consequently, the determination and allocation of health care resources has become paramount. To this extent, this paper deals with a very costly resource--acute care hospital beds--within the acute care hospital component of the overall health care system. At present, approximately $78 \%$, or $235.4 \mathrm{million}$ dollars, of the budget of the Alberta Hospital Services Commission (AHSC) is allocated to the operation of acute care hospitals within the province. Further, the average cost of construction of an acute care hospital bed is roughly $\$ 70,000$. Needless to say, it is of the utmost importance to determine as accurately as possible the number of acute care hospital beds that are needed as well as ascertaining whether or not a surplus or deficiency exists and where.

\section{OBJECTIVES}

One of the principal objectives of the systems analysis that was done in the Province of Alberta was to determine the number of acute care hospital beds that should be provided in the various provincial acute care hospital regions. It is toward this objective that this paper is directed.

\section{PROVINCIAL ACUTE CARE HOSPITAL REGIONS}

In order to meet the above objective it was necessary to determine how many acute care hospital regions existed in the Province of Alberta. There are undoubtedly several methods that can be used for identifying health care regions. For example, they can be identified arbitrarily without using hospital data. The use of electoral districts to define acute care hospital regions is an example of the arbitrary method. However, such a choice is normally a result of administrative expedience rather than a result of systematic analysis. It is not our purpose, here, to discuss the advantages and disadvantages of the various methods that can be used but rather to describe the manner in which, or method by which, the acute care hospital regions in the province of Alberta were determined.

The acute care hospital regions were identified by analyzing patient-flow patterns. In order to determine the patient-flow a computer program was written in COBOL (Common Business Oriented Language) that identified the geographic area of origin of patients and the hospital that serviced these patients which, in turn, identified the area of hospitalization. Actually, the computer program provides the following information:

1) number of cases;

2) total length of stay in days;

3) age; 
4) sex;

5) diagnostic classification according to the eighth edition of the International Classification of Diseases;

6) geographic location of cases;

7) geographic location of acute care hospitals; and

8) the average length of stay of various. case types, based upon a case mix specification, that consists of aggregated diagnostic classifications.

The data used by the computer program was extracted from the information stored on the 1971 hospital computer tapes. In addition, because such data are used by the Alberta Hospital Services Commission for administrative purposes, they were considered to be quite reliable. This permitted a patient-flow matrix to be constructed that reflected the patient-flow pattern of the eighty-one geographic areas or census subdivisions in the province of Alberta.

Subsequently, the acute care hospital regions were determined in two phases. Phase one established the regional centers and phase two the regional boundaries. In order for an area to qualify as a regional center various criteria were used. First, 90\% of the 1971 caseload serviced by a hospital or hospitals in a specific geographic location must have been resident cases. Second, at least 6,000 cases (approximately $1.6 \%$ of the total 1971 caseload attributable to the 117 hospitals that were analyzed) of the total area caseload must have resided in that geographic area. Third, each regional center must have had adequate transportation access routes. Fourth, each regional center should, to some extent, have reflected physician referral patterns. Additional criteria were also used such as natural market areas as well as the future plans of the Alberta Hospital Services Commission with respect to the possible future distribution of health manpower and facilities.

In view of the above qualification criteria six geographic areas out of a total of eighty-one were identified. The acute care hospital regional centers were:
1) Calgary;
2) Edmonton;
3) Grande Prairie;
4) Lethbridge;
5) Medicine Hat; and
6) Red Deer.

In addition, the sensitivity of the $90 \%$ criterion mentioned previously was investigated in order to determine how many areas would have qualified as regional centers if at least $80 \%$ or $70 \%$ of their total 1971 caseload had been resident cases. On the basis of the $80 \%$ criterion eleven areas were identified, and using the $70 \%$ criterion twenty-eight areas would have emerged as acute care hospital regional centers. However, the $80 \%$ and $70 \%$ criteria revealed that a small number of cases were involved. For example, in the improvement district of Drumheller $82.5 \%$ of the 1971 caseload of the Drumheller general hospital were resident cases; however, this percentage represented 1,675 cases or less than one-half of one percent of the total caseload attributable to the 117 acute care hospitals studied. Similarly, in the improvement district of Blairmore $71.9 \%$ of the Crows Nest Pass municipal hospital's total 1971 caseload were local cases. But this percentage only 
represented 1,000 cases. The above examples point out the significance of the second criterion that was used in order for a geographic area to qualify as a regional center.

Also, with regard to the identification of regional centers the $90 \%, 80 \%$, and $70 \%$ criteria were analyzed when an additional patient inflow component was considered. That is, each area was examined on the basis of local patient-flow and the largest single element of patient inflow that was serviced in that area did not represent resident cases. With this additional flow component added to the $90 \%$ criterion there was no change in the number of regional centers identified; that is, the number of acute care hospital regional centers remained at six. However, with the additional flow component added to the $80 \%$ criterion 23 regional centers emerged which was 12 more than when the additional flow component was not considered. Further, 46 geographic areas qualified as regional centers when the additional flow component was added to the $70 \%$ criterion, compared to 28 areas when the additional flow component was ignored. In general, however, even with the additional patient-flow considered, the number of cases involved in each of the areas were small ranging from 533 cases in the special area of Consort to 4,710 cases in the area of Fort McMurray-Lac La Biche. Therefore, even when consideration was given to additional flow, it was decided the $90 \%$ criterion should be used in order for a geographic area to qualify as a regional center.

Consequently, the six regional centers initially identified remained as the acute care hospital regional centers for the province of Alberta.

In order to determine the regional boundaries patient or case-flow was again examined. Those geographic areas whose patient outflow was primarily serviced by any one of the six regional centers were added to the area in which the respective regional center was located. This procedure enabled us to establish the geographic boundary of each of the six acute care hospital regions. The exceptions were the geographic areas of Consort, Castor-Coronation, and Stettler. These three areas were placed in the Red Deer region rather than the Edmonton region because of a new developing arterial highway and a recent change in health personnel and facilities in this region.

In view of the above, Table 1 below indicates the number of regions, the regional center, and the number of each geographic area or census subdivision that is included in each region.

Table 1 .

Region Regional Center

1
Calgary

Edmonton

Grande Prairie

Lethbridge

Red Deer
Medicine Hat

\section{Census Subdivision Number}

$52,53,54,55,56,57,58,59,60$, $61,62,63,64,65,66,67,68,76$.

$1,2,3,4,5,7,11,12,13,14,15$

$16,17,18,19,20,21,22,23,24$,

$25,26,27,28,29,30,31,32,33$, $34,35,36,37,38,39,40,41,42$, 43,44 .

$6,8,9,10$.

$69,70,71,72,73,74,75$.

$77,78,79,80,81$.

$45,46,47,48,49,50,51$. 
Once again, it is important to realize that these acute care hospital regions are based upon patient-flow analysis for the calendar year 1971, and are no way intended to remain fixed. However, the computer program permits a flow analysis to be undertaken at various time intervals say, every two or three years or whenever a major change is anticipated to have an effect upon the delivery of health care in the province. Depending on the outcome of such an analysis the health care delivery decision makers can decide whether or not the acute care hospital regions should be changed.

Furthermore, since hospital choice is affected by choice of physician, the physician's relationship to a hospital, local loyalties, referral patterns, and general market patterns, one might consider that there is sufficient reason to use the acute care hospital regions as an indicator of health care service regions in the province of Alberta.

\section{ACUTE CARE HOSPITAL REGIONAL BED REQUIREMENTS}

The identification of the provincial acute care hospital regions enabled us to determine the number of acute care beds that appeared to be adequate for each region. Once again, just as for the establishment of acute care hospital regions, there are no double various methods that could be used for determining the number of beds required. Three methods were considered based upon:

1) ratios,

2) hospital group performance, and

3) current mode of practice with respect to various occupancy rates.

\section{Method 1--Based upon Ratios}

In the past, and in fact even today, some hospital "planners" use a ratio of 4.5 acute care beds per 1,000 population. However, the first question that arises is, how was the figure 4.5 determined? The second question that appears is, what population is being considered? That is, is it the census population or is it the population that is actually being served (the catchment area population) by hospital or hospitals located in a specific geographic location? Further, if the $r$ atio is based upon the catchment area population, how was that population figure derived? Without providing the answers to these questions, one could very well view with scepticism any result based upon the ratio method that suggest the number of beds required in each provincial acute care hospital region.

In view of the above, we determined how many acute care beds would be required in each region based upon 4.5 beds per 1,000 census population and 1,000 catchment area population. The results are shown in Tables 2 and 3 .

Catchment area population. The catchment area population takes into consideration actual patient-flow patterns. Therefore, its main purpose is to indicate the net population served by any hospital or hospitals located in a specific geographic area and indicate how this differs, if at all, from the census population. Even though the catchment area population of each geographic area wil1, in general, vary from the census population, the total catchment area population--i.e. the sum of individual catchment area populations--should equal the actual census population of the province. For example, in Table 3 the total catchment area population of the province is shown to be $1,628,185$ and the actual 1971 census population was $1,628,280$. The difference which represents 95 people is simply a rounding error that arises in the course of calculating the catchment area population figures for each area in the province. 

follows:

The formula used to determine the catchment area population was as

\author{
Catchment area population $(\mathrm{CAP})=$ Census population \\ - population attributable to resident \\ caseload outflow \\ + population attributable to non-resident \\ caseload inflow.
}

The calculation of the population attributable to resident caseload out-flow from each geographic area is relatively simple. This merely involves dividing the caseload outflow by the case/population ratio applicable to the area under consideration. However, the calculation of the population attributable to non-resident caseload inflow is more arduous. It involves dividing the number of cases flowing into any one geographic area from all other areas by the appropriate case/population ratio that corresponds to the area from which the cases originated. Consequently, when there is a large amount of patient flow into an area from numerous other areas in the province the calculation becomes more complex. Therefore, a computer program was written to calculate the actual catchment area population as well as the population attributable to non-resident caseload inflow. As mentioned previously, if the catchment area populations have been calculated correctly for each geographic area the sum should equal the census population of the province: the calculation involves giving credit in population terms for non-resident cases that are treated in a specific geographic area of the province, and ascribing a debit in population terms to the same specific area for not treating some of its resident cases (resident caseload outflow). Hence, a balancing process is in effect. Moreover, no double-counting of population arises and the total catchment area population will equal the actual census population of the province.

Table 2. Acute care hospital bed requirements.

(Method 1 - based upon 4.5 beds per 1,000 census population)

\begin{tabular}{|c|c|c|c|c|}
\hline $\begin{aligned} & \text { Region } \text { and } \\
& \text { Regional } \text { Center } \\
&\end{aligned}$ & $\begin{array}{l}1971 \text { Census } \\
\text { Population } \\
\end{array}$ & $\begin{array}{c}\text { Numer of Acute Care } \\
\text { Beds Required }\end{array}$ & $\begin{array}{c}\text { Existing Number of } \\
\text { Acute Care Beds }\end{array}$ & $\begin{array}{l}\text { Surplus or } \\
\text { (Deficiency) }\end{array}$ \\
\hline 1- Calgary & 529,470 & 2,383 & 3,433 & 1,050 \\
\hline 2- Edmonton & 834,425 & 3,755 & 5,857 & 2,102 \\
\hline 3- Grande Prairie & 40,095 & 181 & 234 & 53 \\
\hline 4- Lethbridge & 95,125 & 428 & 733 & 305 \\
\hline 5- Medicine Hat & 39,155 & 177 & 250 & 73 \\
\hline 6- Red Deer & 90,010 & 405 & 553 & 148 \\
\hline
\end{tabular}


Table 3. Acute care hospital bed requirements.

(Method 1 - based upon 4.5 beds per 1.000 catchment area population)

Region and Catchment Area Number of Acute Care Existing Number of Surplus or $\underline{\text { Regional Center Population Beds Required }}$ Acute Care Beds (Deficiency)

1- Calgary $532,851 \quad 2,398$ 3,433 1,035

2- Edmonton $849,901 \quad 3,825$ 5,857 2,032

3- Grande Prairie

32,128

145

234

4- Lethbridge

94,522

5- Medicine Hat

36,229

163

\section{Province}

$$
1,628,185^{1}
$$

7,329

11,060

3,731

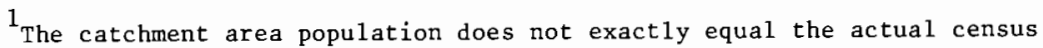
population because of rounding error.

Deriving a ratio. The reader will notice that we have still not answered one question: how was the ratio of 4.5 per thousand derived? This figure was used in the Hospital Survey and Construction (Hi11-Burton) Act in the United States in 1946. However, the method used to arrive at this number was not indicated. Furthermore, many studies 1 have been undertaken in the past showing the ratio of acute care beds per 1,000 population to vary from 2.4 to 6.0 in different geographical areas of a country. Consequent1y, as a general rule, it would appear reasonable to assume that acute care bed requirements vary as a result of area differences in the characteristics that affect hospital utilization. In addition, utilization differences are normally results of many factors: age and sex distribution, morbidity rate, economic status, climate, environment, customs and mores of various ethnic groups, level of preventative and curative care, regional development, distribution of social welfare services, and the effectiveness of outpatient and home care programs. In view of this, the degree of confidence attached to the number of acute care beds for the provincial acute care hospital regions in the province of Alberta shown previously in Tables 2 and 3 is at the discretion of the decision maker. Furthermore, until this question is satisfactorily answered, Method 1--based upon a fixed ratio--is subject to severe criticism.

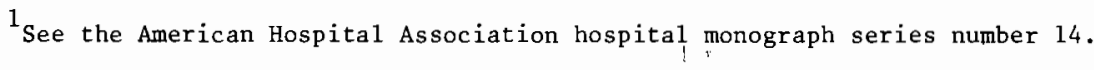




\section{Method 2--Based upon Hospital Group Performance}

This method grouped the 117 hospitals analyzed into five groups according to rated bed capacity as follows:

Group

1

2

3

4

5
Rated Bed Capacity

\author{
$1-24$ \\ $25-49$ \\ $50-99$ \\ $100-299$ \\ 300 and over
}

Subsequently, the caseload of each hospital was aggregated into surgery, obstetric, pediatric, and general medicine case types according to surgical and diagnostic codes contained ir the eighth edition of the International classification of Diseases. In addition, the pediatric cases (ages 0 to 14 inclusive) were divided into two sub-categories, pediatric surgery and general medicine cases. The average length of stay of these different case types was calculated for each hospital within each hospital group. The analysis revealed that the average length of stay varied considerably. Consequently, the average length of stay of each case type applicable to each hospital group was taken as the norm to be applied to all cases treated in each of the various case types by individual hospitals in accordance with their respective hospital group. The results are shown in Table 4 .

Just as the average length of stay varied considerably between hospitals within their respective hospital group so did the occupancy rates. Therefore, an acceptable occupancy rate applicable to each hospital group was stipulated by the Alberta Hospital Services Commission. These were as follows:

Hospita1 Group

1

2

3

4

5 $\underline{\text { Rated Bed Capacity }}$

$$
1-24
$$$$
25-49
$$$$
50-99
$$

$100-299$

$300 \&$ over

\section{Acceptable Occupancy Rate}

75

75

80

85

90

We now had the following information:

1) the hospital group average length of stay for each case type (surgery, obstetrics, pediatric surgery, pediatric general medicine, and general medicine);

2) the number of cases each hospital treated with respect to the above case types;

3) an acceptable occupancy rate for each hospital group; and

4) the number of hospitals in each hospital group within each acute care hospital region in the province. 
The above data enabled us to determine the number of acute care hospital beds required in each hospital region based upon Method 2--hospital group performance. The formulas used to calculate the bed requirements were as follows:

Table 4. Average length of stay by case type.

\begin{tabular}{ccccccc} 
& & \multicolumn{4}{c}{ Average Length of Stay per Case in Days } \\
\cline { 5 - 7 } Hospital Group & $\begin{array}{l}\text { Rated Bed } \\
\text { Capacity }\end{array}$ & Surgery & Obstetrics & $\begin{array}{l}\text { Pediatric } \\
\text { Surgery }\end{array}$ & $\begin{array}{l}\text { Padiatric } \\
\text { General } \\
\text { Medicine }\end{array}$ & $\begin{array}{l}\text { General } \\
\text { Medicine }\end{array}$ \\
1 & $1-24$ & 8.1 & 5.7 & 4.4 & 5.7 & 9.8 \\
2 & $25-49$ & 7.2 & 5.5 & 3.6 & 5.7 & 8.0 \\
3 & $50-99$ & 9.1 & 5.6 & 4.7 & 6.7 & 8.2 \\
4 & $100-299$ & 9.4 & 5.8 & 5.4 & 6.9 & 9.1 \\
5 & $300 \&$ over & 12.9 & 5.6 & 7.0 & 6.4 & 9.6
\end{tabular}

Number of beds required $=$ Total number of patient-days provided

365 (acceptable hospital group occupancy rate)

Total number of patient days = Number of cases treated in each case type (hospital group average length of stay for each case type).

The results of the application of Method 2 based upon hospital group performance are given in Table 5.

Method 3--Based upon Current Mode of Practice

The number of acute care hospital beds required based upon the current mode of practice of each of the 117 hospitals studied was undertaken in order to determine at various occupancy rates whether a bed surplus or deficiency existed. However, in order to ascertain whether a bed surplus or deficiency existed within each acute care hospital region the acceptable occupancy rates stipulated by the Alberta Hospital Services Commission were applied to each hospital. That is, the current mode of practice of all group 1, 2, 3, 4, and 5 hospitals within each region was evaluated on the basis of a $70 \%, 75 \%, 80 \%, 85 \%$, and $90 \%$ occupancy rate respectively. The results are shown in Table 6 .

\section{CONCLUSIONS}

The following conclusions are based on the analysis of 117 acute care hospitals that are under direct control of the Alberta Hospital Services Commission, and 81 geographic areas (sequence codes or census subdivision) within the province of Alberta. Excluded from the analysis are contract and federal hospitals. Furthermore, sanatoriums and mental hospitals that operate under the provincial Department of Health and Social Development were not considered. 
Table 5. Acute care hospital bed requirements.

(Method 2--based upon hospital group performance)

\begin{tabular}{lccc}
$\begin{array}{c}\text { Region and } \\
\text { Regional Center }\end{array}$ & $\begin{array}{c}\text { Number of Acute Care } \\
\text { Beds Required }\end{array}$ & $\begin{array}{c}\text { Existing Number of } \\
\text { Acute Care Beds }\end{array}$ & $\begin{array}{c}\text { Surplus or } \\
\text { (Deficiency) }\end{array}$ \\
\cline { 2 - 3 } 1 - Calgary & 2,836 & 3,433 & 597 \\
2 - Edmonton & 5,331 & 5,857 & 526 \\
3 - Grande Prairie & 230 & 234 & 149 \\
4 - Lethbridge & 584 & 733 & 30 \\
5 - Medicine Hat & 220 & 250 & 7 \\
6 - Red Deer & 546 & 553 & 1,313
\end{tabular}

Table 6. Acute care hospital bed requirements.

(Method 3--based upon current mode of practice)

\begin{tabular}{|c|c|c|c|}
\hline $\begin{array}{r}\text { Region and } \\
\text { Regional Center } \\
\end{array}$ & $\begin{array}{r}\text { Number of Acute Care } \\
\text { Beds Required } \\
\end{array}$ & $\begin{array}{c}\text { Existing Number of } \\
\text { Acute Care Beds }\end{array}$ & $\begin{array}{l}\text { Surplus or } \\
\text { (Deficiency) }\end{array}$ \\
\hline 1 - Calgary & 2,999 & 3,433 & 434 \\
\hline 2 - Edmonton & 5,121 & 5,857 & 736 \\
\hline 3 - Grande Prairie & 206 & 234 & 28 \\
\hline 4 - Lethbridge & 644 & 733 & 89 \\
\hline 5 - Medicine Hat & 228 & 250 & 22 \\
\hline 6 - Red Deer & 502 & 553 & 51 \\
\hline
\end{tabular}


In view of the above we have made the following conclusions.

1. On the basis of patient-flow patterns there are six acute care hospital regions in the province of Alberta.

2. The acute care hospital regional centers are:
1) Calgary;
2) Edmonton;
3) Grande Prairie;
4) Lethbridge;
5) Medicine Hat; and
6) Red Deer.

3. The geographic areas (sequence code or census subdivision numbers) within each region are as follows:

\begin{tabular}{|c|c|c|}
\hline Region & $\underline{\text { Regional Center }}$ & $\begin{array}{c}\text { Sequence Code or Census } \\
\text { Subdivision Number }\end{array}$ \\
\hline 1 & Calgary & $\begin{array}{l}52,53,54,55,56,57,58,59,60,61, \\
62,63,64,65,66,67,68,76 .\end{array}$ \\
\hline 2 & Edmonton & $\begin{array}{l}1,2,3,4,5,7,11,12,13,14,15,16, \\
17,18,19,20,21,22,23,24,25,26, \\
27,28,29,30,31,32,33,34,35,36, \\
37,38,39,40,41,42,43,44 .\end{array}$ \\
\hline 3 & Grande Prairie & $6,8,9,10$ \\
\hline 4 & Lethbridge & $69,70,71,72,73,74,75$ \\
\hline 5 & Medicine Hat & $77,78,79,80,81$ \\
\hline 6 & Red Deer & $45,46,47,48,49,50,51$ \\
\hline
\end{tabular}

4. When bed/population ratios are used to determine acute care hospital bed requirements it is imperative to be able to ascertain how the ratio was derived and what population base the ratio pertains to.

5. The number of acute care hospital beds required and the surplus or deficiency that exists within each hospital region in the province based on Method 1 using the ratio of 4.5 beds per 1,000 census population is as follows: 
Region and Regional Center

1 - Calgary

2 - Edmonton

3 - Grande Prairie

4 - Lethbridge

5 - Medicine Hat

6 - Red Deer

\begin{tabular}{c}
$\begin{array}{c}\text { Number of Acute Care } \\
\text { Beds Required }\end{array}$ \\
\hline
\end{tabular}

2,383

3,755

181

428

177

405
Existing Surplus or (Deficiency)

1,050

2,102

53

305

73

148

Provincial Total

7,329

3,731 surplus

6. The number of acute care hospital beds required and the surplus or deficiency that exists within each hospital region in the province based on Method 1 using 4.5 acute care beds per 1,000 catchment area population is as follows:

Region and $\underline{\text { Regional Center }}$

1 - Calgary

2 - Edmonton

3 - Grande Prairie

4 - Lethbridge

5 - Medicine Hat

6 - Red Deer

\author{
Number of Acute Care \\ Beds Required
}

$$
\begin{aligned}
& 2,398 \\
& 3,825
\end{aligned}
$$

Existing Surplus or (Deficiency)

$$
1,035
$$

2,032

307

87

181

Provincial Total

7. If the ratio method is used for determining acute care hospital bed requirements the population base that should be used is the catchment area population. The reason is that patient flow patterns are considered in the calculation of the catchment area population. Consequently, differences in the number of acute care hospital beds required in each region will arise as indicated in conclusions 5 and 6 . However, the total provincial acute care hospital bed surplus or deficiency will remain the same. But, it is the proper allocation of acute care hospital beds to each hospital region that is of the utmost importance.

8. The number of acute care hospital beds required and the surplus of deficiency that exists within each hospital region in the province based on Method 2, hospital group performance, is as follows: 
DOUGLAS W. PAINE, AND LAWRENCE L. WILSON

\begin{tabular}{lcc}
$\begin{array}{c}\text { Region and } \\
\text { Regional Center }\end{array}$ & $\begin{array}{c}\text { Number of Acute Care } \\
\text { Beds Required }\end{array}$ & \multicolumn{2}{c}{$\begin{array}{c}\text { Existing Surplus } \\
\text { or (Deficiency) }\end{array}$} \\
\cline { 2 - 3 } 1 - Calgary & 2,836 & 597 \\
2 - Edmonton & 5,331 & 526 \\
3 - Grande Prairie & 230 & 4 \\
4 - Lethbridge & 584 & 149 \\
5 - Medicine Hat & 220 & 30 \\
6 - Red Deer & 546 & 7
\end{tabular}

Provincial Total

9,747

1,313 surplus

9. The number of acute care hospital beds required and the surplus or deficiency that exists within each hospital region in the province based upon Method 3--current mode of practice within each hospital--is as follows:

Region and

$\underline{\text { Regional Center }}$

1 - Calgary

2 - Edmonton

3 - Grande Prairie

4 - Lethbridge

5 - Medicine Hat

6 - Red Deer

\author{
Number of Acute Care \\ Beds Required
}

$$
\begin{array}{r}
2,999 \\
5,121 \\
206 \\
644
\end{array}
$$

502
Existing Surplus or (Deficiency)

434

736

51

Provincial Total

9,700

1,360 surplus

10. As shown in conclusions $5,6,8$, and 9 , the number of acute care hospital beds required in each acute care hospital region, and the surplus or deficiency that exists within each region varies in accordance with the method used to calculate the bed requirements. We have rejected the results of Method 1--use of a fixed bed-to-population ratio applied to all geographic areas that constitute a region--because bed needs vary as a result of area differences in the characteristics that effect hospital utilization. Also, we have considered the results based upon Method 3--current mode of practice--to be inappropriate simply because this method assumes that all hospitals have an appropriate average length of stay per case and therefore an acceptable flow or turnover rate (cases/bed/year). The analysis indicated that this was far from true. Therefore, we have accepted the results based upon Method 2--hospital group performance--primarily because hospitals of equivalent bed size have in general, the same resources to treat their respective caseloads. 
11. Method 1--based upon a fixed bed/population ratio to determine bed requirements cannot be used to ascertain the number of different types of beds required. For example, if a hospital is located in a geographic area that has a census population of 20,000 people it would be allocated 90 beds on the basis of 4.5 beds per 1,000 census population. But, out of this total number of beds how many surgery, obstetric, pediatric, and general medicine beds are required? One certainly cannot use the ratio of 4.5 beds per 1 , 000 census population to determine the number of different types of beds required.

12. The admission and discharge policy of a hospital can also affect acute care bed requirements. For example, our bed requirement estimates were based upon an acceptable occupancy rate for each hospital group. Further, this occupancy rate was to be maintained, on average, for 365 days of the year. However, if a hospital follows a practice of admitting patients at the beginning of the week (Monday) and discharging at the end of the week (Saturday) there will be a number of days throughout the year that the hosptal will be operating at a low occupancy rate. Even if the occupancy rate is above the stipulated average throughout the remaining days of the year, situations can arise whereby the average acceptable occupancy rate for the entire year is not maintained. Consequently, this has an effect upon the number of acute care beds that are required.

13. The estimate of the number of acute care beds required could be further refined if clinicians could agree on specific standards that should be used in the provision of health care. For example, in our analysis we would not have needed to use hospital group averages if an acceptable range in the average length of stay pertaining to surgery, obstetric, pediatric surgery, pediatric general medicine, and general medicine cases had been available. However, it would appear that if such standards ever come into existence they should not be based solely on the qualitative judgment of some peer group. Information must be provided to peer groups on the basis of detailed systems analysis. The end result would be standards that are based upon the best quantitative and qualitative information available at the time.

14. Information concerning other factors that affect hospital utilization-e.g. age and sex distribution, transportation routes, c1imate, topography, enviroment, customs and mores of various ethnic groups, level of preventative and curative care, regional development, and the distribution of other types of health care facilities--must be considered before a definite number of acute care beds for any acute care hospital region can be ascertained.

15. Systems analysis should not be looked upon as trying to replace the decision making process but rather as additional information intended to aid health care decision makers.

Finally, the reader will no doubt realize from this paper that we consider systems analysis to be a scientific method of problem solving, utilixing the tools of description, investigation, research, creativity, and judgment, with the analyst attempting to answer six basic areas of inquiry: What? Why? When? Where? Who? and How?

"I keep six honest serving men (They taught me all I knew) Their names are What and Why and When And How and Where and Who." 
Points Raised by the Discussant, Mr. Collins

Mr. Collins addressed three questions to Messrs. Paine, and Wilson:

1) Did the modelling exercise presented constitute part of a larger, integrated planning system?

2) What provisions are made for future events that might invalidate the present planning model? and

3) Does the model play any role in encouraging people to minimize their own hospitalization?

On the latter point, Mr. Collins feared that demand too often grows to fill the beds available. He wondered whether careful distinction was made between chronic and acute care patients. He noted that he was again raising the delicate difference between demand and need that had been mentioned in the morning.

\section{The Need for Standards}

Mr. Paine felt that Mr. Collins' third question hit a vital subject for planners. He conceded that beds provided for acute care patients were taken by chronic care patients. The methodological problem of providing for an appropriate level of need was not trivial. As an example, he cited the difficulty in deciding the proper length of stay for surgical patients. This can vary widely and thus introduces a wide margin of uncertainty for planning. With the advent of standards for lengths of stay, planning will be relieved of a discretionary element and will be given greater precision. For the Alberta study, the data obtained from group practice was adopted as the most reliable yardstick of appropriate usage: 


\author{
COMPLEX LONG- AND SHORT-TERM \\ PLANNING ON HEALTH \\ DEVELOPMENT IN THE USSR
}

\author{
V. V. Golovteyev
}

National economic planning in the USSR is carried out within the framework of the state system under the State Planning Comittee of the USSR Council of Ministers (Gosplan of the USSR). Below this committee are the State Planning Committees of the Union Republics. In smaller geographical units--i.e. in krais, oblasts, cities, and districts--there are Planning Commissions of the Executive Committees of the Soviets of Workers' Deputies.

Health planning is the elaboration, for a definite period of time, of the complex of interconnected measures for providing medical care to the population. The health plan is aimed at fulfilling the tasks of promoting the health of the population. The State classifies as a branch of the national economy the field of "health, physical culture, and social securicy." Thus, under the USSR Ministry of Health, we plan the activities of the health system: curative-preventive centers (e.g. hospitals, polyclinics, dispensaries, maternity homes, first aid centers, sanatoria for children and TB cases) and sanitary-preventive centers (e.g. sanitary-epidemiological stations, health education centers, disinfection centers). The planning also includes the activities of other ministries and health bodies (their activity is not so broad, as their hospitals have only about $4 \%$ of all the hospital beds in the country). The same plan envisages: 1) the construction and use of sanatoria under the control of the trade unions, which have about $75 \%$ of all beds in the sanatoria of the country, 2) boarding houses for the aged and invalids, which are under the Ministry of Social Security and other ministries, 3) rest homes, 4) boarding houses, 5) summer and mountaineering camps, and 6) physical culture and sport organizations (e.g. skating rinks, stadiums, swimming pools, sport schools, sport-technical clubs).

Thus this branch of the national economy--health, physical culture and social security--is a system, within the framework of which we carry out the complex planning of measures aimed at protecting and promoting the health of the population. In planning, the functions of the USSR Ministry of Health are not limited to purely medical tasks or to those tasks in the hranch of the national economy called "education, culture, and health."

The national economic plan provides for the development of medical science, for construction of health centers, for provision of the network of curative establishments, for provision of medicines to the population, and for medical equipment and staff. These provisions can be found in such sections of the national cconomic plan as the development of science and technology, industrial production, capital construction, and labor resources. These provisions in the section of the plan on "Health" are consistent with the available material, labor, financial, and other resources.

In the USSR we carry out both short- and long-term economic planning. Long-term planning envisages the further development of the economy for a number of years (5-10-20), foresees the solutions of the most important problems, and determines the tempo of development of the national economy. Details of the national economic plans are set by the Government.

Each branch of the economy has a branch planning service which develops a branch plan and submits it to higher planning bodies. The service responsible for health planning is within the Ministry of Health. Therefore, the Ministry of Health and Ministries of Health of the constituent Republics have their own Planning and Finance Boards. In some constituent Republics and at the Ministries of Health of Autonomous Republics, Krai, Oblast, and City Health Boards, there are Sections or Officers responsible for planning. 
The long-range plan is developed in two stages. During the first stage we develop the basic trends of national economic development on the basis of which the directives are approved by the Government. In accordance with these directives, we elaborate long-term plans at the second stage. The short-range,plans are compiled, as a rule, for one year and are based on the long-term plans of development. These plans are developed according to the territorial division of the country, including the entire USSR, Constituent Republics, Autonomous Republics, krais, oblasts, cities, districts, and medical establishments.

Indices for describing the plans are approved by the USSR Council of Ministers (Republican Council of Ministers) and are of a directive nature; these indices are included into all plans at all levels. The basic approved health plan indices for 1971-1975 are:

a) the total number of hospital beds (including beds for psychiatric cases and TB cases). This number is divided into rural and urban hospital beds;

b) the construction of new hospitals and polyclinics with the help of centralized capital investments; and

c) the total number of sanatoria beds, including beds for TB cases.

The USSR Ministry of Health gives more detail on the approved indices--concerning, for example, the development of inpatient care, for estimating the number of fersonnel, expenses for nutrition, medicinal preparations, bed clothes, etc. The Ministry is presently considering additional indices--e.g. for the development of the network of sanitary-epidemiological stations, pharmacies, crèches, assistantmidwife posts--taking into consideration the number of medical posts and the visit rate to polyclinics.

After the Plan is approved by the USSR Council of Ministers and ratified by the Supreme Soviet, the Plan becomes law and must be implemented. The apfropriate bodies are responsible for implementing the various sections of the Plan and for controlling the activities of health bodies and organizations. At the same time our plans are rather flexible and, in case of necessity, our Management Bodies may appropriately amend them. Long-range plans are corrected during the approval of the annual plans, and in executing the annual plan the Head of the Body may introduce changes within the scope of his authority.

The Ministries and Departments which have hospitals plan the develpment of hospitals and other provisions for medical care with the help of the Gosplan bodies. However, the construction of new hospitals and medical establishments is coordinated with local health bodies. The overwhelming majority of health establishments--hospital beds (96\%), medical staff (88\%) and paramedical personnel ( $87 \%$ )--are under the system of the USSR Ministry of Health, Health Ministries of the Republics, and their health bodies. Thus other Departments contribute relatively little to direct health care.

At the time of the Great October Socialist Revolution, the material basis of health services was rather feeble. Therefore, the most important tasks of health services during the first five years' plans (1928-1940) were the maximum development of the health network in the country and the training of medical personnel to solve the problems of primary medical services for workers and peasants and to promote maternal and child health. Thus, the network of crèches and kindergartens was increased four to five times, which permitted a radical increase in the employment of women in the national economy.

During the years of the first post-war five years' plans (1946-1950 and 1951-1955), attention was concentrated on reconstructing the destroyed national industry and the material-technical basis of health services to further increase the capacity of health establishments. 
In the sixties, our country reached the level of the economically developed countries in the number of doctors and hospital beds. In 1960 we had 20 doctors and 80 hospital beds per 10,000 population. By then, the problem of meeting the requirements of the population in medical care was basically solved, and the next important problem was to improve the quality of medical care. This complicated the tasks of planning and required improvement in the methodology of planning.

The following methods have been used in the planning effort:

a) Economic analysis, for assessing the degree of health development and the reasons for the state of health care indices in certain planning territories, and for determining the means and pace of eliminating irregularities;

b) The standard method--the role of which in planning has greatly increased due to the wide involvement of the research institutions--for the setting of standards and technico-economic indices for determining the personnel and material resource requirements of health services; and

c) The balance method, for establishing the proper proportions between the requirements of health services and resources, and also for detecting irregularities and measures for their elimination.

In 1975 our country will complete the fulfillment of the ninth five-year plan of the national economic development. The plan of health development for this period envisaged the further improvement of the quality of specialized medical care and more comprehensive health care service for the population. Under this plan construction continues of large specialized multi-profile hospitals, polyclinics, dispensaries, and sanitary-epidemiological stations. The network of first aid centers has been extended and strengthened and we are also carrying out measures aimed at enlarging and improving health centers. We also foresee further improvement of our ability to provide medicinal preparations to the population and to health establishments. In addition to constructing new establishments in the current five-year. period, we have built many large clinical hospitals with polyclinics $(1,000$ and more beds), oncological dispensaries ( 450 beds) with boarding houses (100 additional beds), first aid hospitals with rehabilitation centers (800-900 beds), hospitals for rehabilitative treatment for adults (520 beds) and children (420 beds), psychiatric hospitals (500 and more beds), large sanitary-epidemiological stations, and also plans and work shops for medical equipment maintenance and repair. Moreover, by the end of 1975 there will be 3 million hospital beds, or 11.7 beds for each 1,000 people, and 830,000 doctors, or 32.5 doctors for each 10,000 people.

The tenth five-year plan (for 1976-1980) should become a specific expression of the socio-economic policy of the Soviet State for a prolonged period of time. This plan will determine the goals and means of the continued construction of the material-technical basis of Communism, and further improvement of living standards and production relations. We attach great significance to the increase of the scientific basis of planning in this effort. Preparatory activities are being pursued along four basic lines:

1) The USSR Academy of Sciences and the State Committee of the USSR Council of Ministers on Science and Technology, basing their activity on research carried out by the leading research institutes of the country, are compiling the complex program of scientific-technological progress and its socio-economic consequences;

2) Ministries and Departments of the USSR are preparing the proposals to the Gosplan of the USSR on the basic trends of the development of the corresponding branches of the national economy, and clarifying--jointly with scientific research institutes--standards and other initial data for predicting branch development; 
3) The State Planning Committee and Republican Councils of Ministers are elaborating proposals on the development of their respective territories; and

4) The State Planning Committee of the USSR elaborates the proposals on the most important national economy problems, social, economic, and scientific-technological problems, which the country has to solve by 1990 .

Through these activities the Draft Projection of the basic tendencies of the national economic development for 1976-1990 will be compiled, taking into consideration the proposals of scientists, Ministries and Departments of the USSR, and Republican Councils of Ministers.

The present activities of planning and prognosis of health services are based 1) on the deep analysis of the dynamics of the health of the population, morbidity tendencies, demographic processes, and 2) on the evolution of the organizational methods and health management. Contemporary science allows for the prognosis of such health parameters as: the state of the environment, demographic shifts, the level and nature of morbidity, eradication and reduction of communicable diseases, the state of health and its separate contingents, development of organizational forms and perspective norms and standards of medical and medicinal care, sanitary-epidemiological services, further specialization of medical care and differentiation of medical specialties, extension of the network of health establishments, and training of medical personnel. The increase in the size and and complexity of healch services makes the health system more complicated. This in turn requires contemporary econometric methods and the use of electronic computers in branch management.

In accordance with this view, we are creating in our country the Automated System of Health Management--"OASA Health." The main Levels at which the system wor': re: All-Union, Republic, oblast or city, and institutional or hospital. This "ork 1 , carried out by a wide network of branch Computer Centers at all the Level of magrament. The Main Computer Center, which heads the work on this prob , belongs to the USSR Ministry of Health. In the Constituent Republics the Computer Centers function now or will soon begin to function. Computer Centers also exist in some oblast and city health boards and in many medical establishments.

"OASA Health" is constructed as a complex of subsystems, one of which is "Planning and Financial Activity". The basic purpose of this subsystem is to develop and introduce econometric methods, based on the use of electronic computers, into health planning. In the first stage, the "Planning and Financial Activities" subsystem will provide for the collection and processing of information necessary for the development of planning and financial indices which characterize the level of health development. This will allow us to compare the indices for different adninistrative territories with similar union and optimum planning indices, chus promoting improved planning and health management. Later, the scope and nature of the problems addressed, and the planning methods used by the "Planning and Financial Activities" subsystem can be expanded. One method we hope to implement is multifactor analysis for assessing the degree of influence of demographic, socio-economic, climatic-geographical, and other factors on the requirements of health services in resources. We expect these measures to allow us to produce better plans while absorbing fewer resources. This approach will, moreover, help us to eradicate errors and mistakes and to create conditions for analyzing numerous variants with the purpose of making optimum planning decisions.

We consider that this system of planning meets the requirements of the present time. It aids the solution of important social and economic problems, while meeting the requirements of material and cultural needs of the population. This, in its turn, requires effective utilization of the economic resources of the country. Plaming as the central element of the national economic management is the basic means of ensuring the most rapid development of the national economy. We therefore now face the task of perfecting our planning methodology. 


\section{FORECASTING THE DEVELOPMENT AND THE TERRITORIAL DISTRIBUTION OF HEALTH SERVICES \\ IN THE PEOPLE'S REPUBLIC OF BULGARIA}

\author{
A. Cenov \\ Institute of Social Hygiene \\ and Public Health Organization, \\ Bulgaria
}

\section{INTRODUCTION}

Public health is a complex dynamic system of medical, social, economic, and other measures for protecting, rehabilitating, and promoting the health, work capacity, and creative longevity of man. This system consists of interrelated and interdependent parts that must be systematically developed in the right proportions. Public health is also a constituent element of the whole social and economic life. Human health is conditioned not only by health services activity, but also by many economic, social, cultural, and other factors. For this reason, public health must be developed in exact correlation with all the other systems.

The assessment of the quality and quantity of health measures depends on three factors: the need of the population in medical care, the available national resources at a given stage, and the entire health policy. To solve these problems rationally, it is necessary 1) to collect, process, and analyze a large volume of information, 2) to counterbalance the needs with the possibilities, and 3 ) to find the most effective means of achieving the main goals. Satisfactory results can be obtained only in the case when public health is developed and improved in accordance with the other systems covered by the uniform social and economic plans--1ong, medium, and short term.

Long ago, socialist countries adopted public health planning, and it is a part of the total national economic planning. But, nevertheless, it needs gradual improvement and introduction of new methods and approaches. For two years in the People's Republic of Bulgaria, the General Scheme for territorial distribution of production powers, as well as the Uniform System for improvement of complex public attendance, have been worked out in accordance with a decree by the Council of Ministers. The methodological approaches used are of great value for explaining the methods of general planning and of public health planning. This is why it is appropriate to inform the Conference about them.

In fulfilling this task, a complex approach has been implemented. The projected developments of all branches were worked out. The separate developments were then integrated into a uniform model of national economy and services up to 1990. The task was distributed among separate research institutes, organizations, and State organs, according to their competence. The activity of all these institutions was directed by the chief scientific organizations--authorized by the Government-in conformity with a general coordinating program.

The task of working out a model for improving health services and the General Scheme for territorial distribution of health services was assigned to the Scientific and Research Institute of Social Hygiene and Public Health organization (as a responsible executor), to several scientific and working institutions, and to the local health organs.

In solving the problem, we kept to the following approach:

- Elaboration of a uniform economic, territorial, and demographic basis;

- Development of a standard system on scientific principles; 
- Assessment of the parameters of each health care division and of the health services;

- Rebuilding the material and technical base; and

- Improvement of the managerial system in health care.

UNIFORM ECONOMIC, TERRITORIAL, AND DEMOGRAPHIC BASIS OF PUBLIC SERVICES

On one hand the economy is influenced in its development by human resources, but on the other, it influences considerably the migration processes and the settlement structure. The structure of settlements depends also upon geographic and climatic conditions, but its main factor is the development and location of production powers. This factor also influences the living enviroment.

Working out a uniform econonic, territorial, and demographic basis for public services is a complex task. Therefore, it was assigned to several state organs and scientific organizations, keeping rull correlation among them. Implementing this task required:

1) Determination of the basic territorial units in view of complex public services.

2) Determination and typification of the prospective settlements.

The People's Republic of Bulgaria is divided into 27 regions plus the capital of the country. The population of the regions ranges from 180,000 to 600,000 inhabitants, with an average of about 300,000. No district subdivision exists, except for the capital which consists of seven districts. The smallest administrative unit is the municipal people's council, including three or four settlements, and the people's city council. The basic territorial unit, is a social and economic unit. Public services, including basic health care, must be provided within the territorial unit boundaries.

As a result of industrialization and mechanization of agriculture and stockbreeding in our country, there has been a strong migration of the population from the small villages to central settlements and towns. The number of inhabitants in many villages, therefore, is decreasing. The functions of these settlements are gradually changing, converting them into "dormitories" or into places for short-term recreation. The population of other settlements is increasing; they are enlarging their functions and becoming prospective.

The basic territorial units and the prospective settlements were defined by the following factors:
a) geographic--climate, landscape;
b) geological--underground resources, soil characteristics;
c) economic--industry, agriculture, and stock-breeding;
d) social--population, daily labor investigations, housing, schools, health centers; and
e) miscellaneous--administrative, historical, political, traditions, archi- tecture, monuments, frontier areas.

Through systems analysis and complex evaluation of these factors and criteria, the basic territorial units were defined and the prospective settlements typified. 
There are more than 100 basic territorial units with populations ranging from 20,000 to 100,000 . It must be kept in mind that these units are dynamic and may be subject to changes in accordance with the economic and social development. The prospective settlements were classified into the following eight types:

1) Zero Type--the capital, Sofia, with national, social, and economic importance as a coordinating, administrative, and political center.

2) First Functional Type--a multifunctional center with regional and crossregional importance with respect to public service. The population of the area of such a center must be ensured full medical care of the highest range. Only a few rare cases, demanding special competance, have to be treated on the national level.

3) Second Functional Type--a multifunctional center with eccnomic and social importance on a regional level. Medical care there must be excellent, but some special profiles of public health would not be developed (e.g. neurosurgery, toxicology).

4) Third Functional Type--the centers of the basic territorial units belong chief $1 y$, but not exclusively, to this group. The population is given from $70 \%$ to $85 \%$ of the necessary medical care in accordance with the capacity of the local health services.

5) Fourth Functional Type--settlements with a limited functional importance. They are usually the secondary centers of the basic territorial units. In some cases they may be also the centers of the basic territorial units.

6-8) Fifth, Sixth, and Seventh Types--these are prospective villages with small populations and more limited functions.

The remaining small villages and hamlets-those gradually losing their functions-are not included in this classification. They are called settlements with changing functions.

The main characteristic of the process of building up an economic, territorial, and demographic basis is that it includes not only the evaluation of the existing situation, but also the envisaged development of the above-mentioned factors, making it possible to project future demands for health care. Moreover, the strict classification of the territorial structure of settlements and their functional dependence and interrelations gives the opportunity to build up and improve the total system for public services, including health services and the more important health measures.

\section{NORMATIVE BASIS (STANDARDS) FOR HEALTH SERVICE}

The second working phase in devising the General Scheme consisted of drawing up the dynamic standards for development and improvement of health services. The main goals of this standardization are: 1) to put the projection of different sections of public health on a scientific base; 2) to distribute proportionally all health services throughout the country; and 3 ) to coordinate this activity with all the other branches of social and economic 1 ife.

Standards were elaborated after a careful investigation of the population demands for different types of medical care. All the socialist countries, together with the Soviet tnion and many capitalist countries, have undertaken such investigations. We have also studied morbidity and population demands for medical care in the People's Republic of Bulgaria. Our investigations included a thorough analysis of health needs of the population in relation a) to the volume and structure of morbidity, b) to the age, sexual, professional, and territorial structure of the 
population, and c) to economic and geographic peculiarities of the region.

Dynamic standards were first worked out by the Ministry of Pubiic Health and then confirmed by the Council for Standardization at the State Planning Committee. These standards were:

1) for the scope of services,

2) for the degree of satisfaction, and

3) for the material base.

1. Scope of services. These standards determine the kinds of medical care that must be provided for every functional type of settlement. The standard scope of outpatient and polyclinic medical care is shown on Table 1 , and the standard scope of hospital medical care on Table 2. Similar standards exist for all kinds of medical care. The standards for sanatorium and balneotherapeutic care, of course cannot be reckoned with the types of settlements. In this case the main criteria are the type to care provided and the location of the health resorts (Table 3 ).

2. Degree of satisfaction. The standards for this somewhat overlap the above standards for assuring the population different kinds of medical care. Extracts of the standards for outpatient and polyclinic medical care are shown on Table 4, and for the hospital medical care on Table 5. Further standards for such aspects of health care as balneotherapeutic care, hospital personnel, the number of places in nurseries, and pharmaceutical services have also been worked out. The volume of medical care can be thus calculated. The majority of the standards are designed for national purposes; when applying them to territorial planning, therefore, the specific peculiarities of the region must be kept in mind.

3. Material base. These standards are worked out according to the type of the health services and to the type of settlements. They determine the necessary capital investments in thousands of levas (Table 6).

\section{MORBIDITY--PRESENT SITUATION AND PROGNOSIS}

Data about the present state and prognosis of morbidity are the most important part of the information needed to assess the type and volume of the projected medical care. The prospective analyses of morbidity undertaken to date in our country are not sufficient.

In 1965, in addition to the research investigations in the field of prognosis of some diseases (e.g. tuberculosis, diabetes), a full prognosis for total morbidity was worked out for the first time by scientific committees. Now we are projecting morbidity of all classes of diseases by combining extrapolation and the Delphi method. In such a way the future trends of development of morbidity in our country were also briefly outlined. As a result of the increasing welfare and the cultural level of the population, as well as the new achievements of medical science we expect, as in many other countries, that the morbidity of many diseases--e.g. communicable diseases, tuberculosis, malnutrition, and several endocrine and stomatological diseases--will decrease. But, on the other hand, changes in the way of living of the population, environmental pollution, and the aging of the population lead us to expect increased morbidity due to other diseases--e.g. cardiovascular diseases, malignant neoplasms, poisonings, diseases of the nervous system, diabetes, drug addiction, accidents, and traumas.

In building up health services, local pathology must also be kept in mind. For example, in the regions of Vratza and Mihajlovgrad many cases of proendemic nephritis were recorded, and some parasitosis is characteristic in the regions of Blagoevgrad, Smoljan, Shumen, and Pazgrad. These factors were taken into conside$r$ ation when the General Scheme for development and territorial distribution of 
health services was worked out.

\section{ANALYSIS AND EVALUATION OF THE PRESENT STATE OF MEDICAL CARE SERVICES}

The next data necessary for the General Scheme reflected the present state of medical care services for the population. The adequacy of health services to the present and future changes in the life of the country was examined. Many factors were taken into consideration: for example, the degree of satisfaction of population demands for medical care, availability of the necessary health personnel, state of the material base, and eventual territorial disproportions.

The results of the investigations have shown that in the People's Republic of Bulgaria there is an orderly system of health services, ensuring medical care on different levels. The scope of medical care and the degree of qualification of the health personnel are proportional to the level of the health services. (Scheme No. I). The structure of the health system tends to follow the pattern of the national administrative structure. But this is not always achieved. Basic medical care is delivered at the regional level from the regional service and its sub-units--i.e. from rural health services, town and factory health services.

The regional level is divided into two sub-levels: a) regional health services (regional hospitals, sanitary and epidemiological Inspectorates of the second category, stomatological polyclinics, etc.), and b) regional health services with interregional functions (first-rate regional hospitals, sanitary and epidemiological inspectorates of the first category, specialized dispensaries, etc.). Every health service of the higher level cumulates the functions of the corresponding health services of the lower level.

In order to investigate the state of the material base, the buildings of the health services were investigated. Data were collected about the fitness of the buildings, the possibility for renovation, the degree of overpopulation, and so forth. These investigations are reflected in health certificates for the larger. buildings and are summarized (according to the type of the health services and their territorial distribution) for the smaller ones.

In general outline the present health system is proportionately distributed throughout the country. But the analysis and evaluation of the health system have revealed many weak points. The chief points of the system are described below.

a) The number of health services with regional functions is very large (12 of every type), and they serve a relatively small portion of the population (500,000 to 600,000 inhabitants). Their capacity, therefore, is underdeveloped and they cannot ensure medical care with full volume and of the highest level. Their number does not correspond to the number of the First Functional Type centers (i.e. the centers with interregional functions, according to the functional typing of settlements).

b) The population is insufficiently provided with hospital beds. Moreover, the number of beds in sanatoria and nursing homes is insufficient. There is a shortage of nursing and midwifery staff as well as of the auxiliary personnel. The material basis is unsatisfactory- $-4-5$ square meters per bed, the standard being 7-8 $\mathrm{m}^{2}$. There is a high percentage of buildings--about 18\%--which are not fit for use.

c) Serious disproportions became evident in the health service of the separate regions. For example in the Kurgjaly region, the number of hospital beds of the general type--excluding the beds in the specialized medical establishments--is only half the number provided in the region of Sofia. These disproportions are considerably greater for certain specialities as ophthalmology and neurology. 
In accordance with the Party and government policy, the Ministery of Health has worked out in the past few years a conception for the development of public health. This document makes clear the basic trends along which the public health in our country will be improved. The following basic tasks are set in this document:

1) an increase of the reproduction of the population and the productive forces and an improvement of the health of the nation;

2) an improved control of the most widely distributed pathological processes in the population and a restriction of the incapacity for work;

3) an optimal satisfaction of the needs of the society for health care; and

4) a perfection of the public health system in accordance with the level of the productive forces, the socialist relations of production, the social development of the country, and the scientific and technical progress.

For the fulfillment of these basic tasks, and on the basis of analysis of the initial information, the following trends of development were included in the model:

a) realization of rational structural changes in the health service;

b) maximal increase of the prophylactic measures;

c) optimization of the outpatient clinics systems;

d) expedient concentration of the inpatient clinics;

e) increase in the number of hospital beds up to $12 \%$, of sanatorial beds up to $4.5 \%$, and of the places in the child care centers up to insuring $30 \%$ of the children aged up to three years;

f) perfection of the drug supply of the population;

g) optimal increase of the medical staff and an improvement of the state of the different categories;

h) decisive improvement of the material basis; and

i) decrease and gradual elimination of the disproportions in the distribution of medical care in the different regions.

DEFINITION OF THE PARAMETERS OF THE SEPARATE KINDS OF HEALTH SERVICE AND OF THE MED ICAL ESTABLISHMENTS

A plan of development of the health service system in the whole country was elaborated. We shall mention the seven principal decisions here.

\section{Structural Changes}

It became evident that structural changes are not necessary on the district level nor the lower levels. A more narrow link should exist, however, between the sanatorial establishments and the pharmaceutical service on one side, and the rest of the health service system on the other. An integration is planned for a number of places between certain territorial outpatient clinics and the respective resort outpatient clinics or the medical establishments for the workers. In some of the basic territorial social service urits, it was inexpedient and medically and 
economically inefficient to create a basic medical service on the district level because of the small population. These territorial units were attached to neighboring district health establishments.

The most important problem was the adaptation of the health establishments with interregional functions to the functional typing of the inhabited places, especially of the first functional type. Two variants were suggested in this respect. The first reflects more accurately the present tendencies of the migration of the population to the bigger centers and better corresponds to the opinion of the local authorities. However, it does not ensure the proper concentration of the medical care because of the division of north Bulgaria into a greater number of such centers. Neither does it provide a sufficient number of patients for the interregional medical centers; thus, it was not possible to open all the necessary departments. In the southern part of the country, on the contrary, one such center, Plovdiv, is planned for two million inhabitants.

For these reasons a second variant is proposed, giving a better distribution of the population--one million on the average for the interregional centers. But to a certain extent it does not take into consideration the present migration tendencies of the population and contradicts the opinion of some authorities.

In any case, the model clearly provides for the creation of medical establishments with interregional functions, as an independent, wel1-defined stage in the development of public health. Furthermore, the formation of a complex of medical establishments with interregional functions is foreseen for the centers of the first functional type, in all the different spheres of the medical service, which allows a high level of planning and management of the public health of that region of the country.

The creation of medical faculties in four of the eight centers of the first functional type, and their comparatively correct territorial distribution, permits a still better optimizing of the structure of the health service system.

\section{Hygienic and Epidemiological Service}

The accent on prevention in the public health system was ensured in the model first of all with a correct organization and structure of the hygienic and epidemiological service system. Its basic function is to work out, put into practice, and contro1' the observation of norms, rules, and criteria for a safe, normal working and living environment. To this end, the model provides for instituting hygienic and epidemiological inspections, capable of ensuring sanitary and prophylactic measures at the highest level.

\section{Outpatient Clinics}

There was a significant number of problems arising with respect to the outpatient clinics, starting from the village health service and up to outpatient clinics in the big cities. The village health service presently is characterized by the great number of small health centers with doctor's assistants in charge.

Following the standards these should be created in places with 500 to 1,500 inhabitants. Health centers with doctors in charge are provided for the places with 1,500 to 4,500 inhabitants and rural outpatient clinics for more than 8,000 inhabitants. A considerable number of inhabited places with fewer than 500 inhabitants have no local health service.

The changes planned for the period up to 1990 in the structure of the villages include about a $50 \%$ increase in the number of places with fewer than 500 inhabitants, and a decrease in the number of the bigger villages and the small towns. This raises the question of reducing the number of the rural health establishments and increasing the number of places lacking local medical care. At the same time, 
we have the general political task of bringing services offered to the rural population closer to those ensured for the urban population.

In the model these problems are solved by providing dactor's assistants to all places or groups of neighboring places with 500 to 2,000 inhabitants in the plains, and with 300 to 1,500 inhabitants in the mountain districts. Qualified doctors are provided in places with more than 2,000 inhabitants in the plains and with more than 1,500 inhabitants in the mountain districts. A concentration of the medical service is carried on into district services. These include one doctor and one dentist and the corresponding nursing and midwifery staff. More of ten in rural health services, they include two doctors--a pediatrician and an internist--and a stomatologist. Some village outpatient clinics have a greater number of physicians: an internist, a pediatrician, an obstetrician, and so on. Besides these, services should be visited by other specialists from the district outpatient clinic. In this way the district hospital becomes more and more engaged in the health service of rural population, which provides the population with specialized medical care.

For improving the communications between the villages and the district center, radiotelephones were established, and the connection with the district hospital can be obtained at any time. At the same time a number of mobile forms of medical services will be created, for example, pediatric and gynecological counseling, and groups for mass screening.

\section{Hospital Service}

The prognosis for the decreased population in some basic territorial units still further lowers the economical and medical efficiency of some of the district hospitals. The hospital service will be improved mainly 1) by increasing the capacity of the hospitals, 2) by closing the small district hospitals, and 3) by concentrating the available becs in the regional, interregional, and university hospitals. A correct structure of the hospitals regarding the different specialities--e.g. psychiatry, chronic disease--should also be achieved. A better hierarchy of thi hospital service is envisaged in the more backward districts with the aim of eliminating the disproportions.

The specialized hospitals are structured with the view of attempted satisfaction of the needs of most health districts of the interregional level. The model ensures 12 hospital beds per 1,000 inhabitants without increasing and even decreasing the number of general hospitals.

\section{Sanatoria}

The sanatorial system is unevenly distributed, mainly in the southern part of the country. The richness of mineral water sources and of other resorts permits this system to be widened to completely satisfy the needs of the population of Bulgaria and partly to serve the needs of other countries as well. The number of beds in these establishments is planned to amount to $3.5 \%$ and taken together with the beds in the other sanatoria--e.g. phthysiatric, prophylactic--up to 4.5\%. There will be a simultaneous increase in the number of resort establishments and centers for general medical service in the resorts in the so-called peak periods in the sumer months.

\section{Child Care Centers}

The intense occupation of the women in production and in the cultural and social life of the country sets very serious tasks for child care outside the family. Since the needs in this respect are presently satisfied only to a limited extent, the model provides for the widening of the child care system up to 1985 and for the ensuring of $40 \%$ of the children in all places of the first and second functional types with beds in child care homes. This number is $30 \%$ for the areas of the third 
and fourth functional type, and $20 \%$ for the rest. Simultaneously, the so-called mother and child homes should be correctly structured and increased, with a total number of 7,000 beds for the country, where socially endangered, illegitimate, premature, and hypotrophic children are brought up.

\section{Pharmaceutical Service}

The improvement of the medical and sanitary supply of the population is carried out in the model by a correct territorial distribution of the pharmaceutical establishments. The standard is one chemist's shop for 15,000 inhabitants. The pharmaceutical supplies are concentrated in eight interregional centers, corresponding to the concentration of the other medical interregional services.

An increase in the number of the medical staff is planned. The approximate figures are listed below:

1974

$\begin{array}{rr}15,900 & 27,000 \\ 2,900 & 7,400 \\ 1,900 & 5,200 \\ 3,000 & 4,200 \\ 42,000 & 124,000 \\ 68,000 & 140,000\end{array}$

Physicians

Stoma tologists

Pharmacists

Pharmaceutical assistants

Nursing and Midwifery Staff

other staff
68,000

Moreover, a project is elaborated in the model for improving training of the medical staff including the type, capacity, and territorial distribution of the higher and professional medical training schools.

An important part of the model and the General Scheme includes: 1) suggestions for improving the material base and the necessary capital investments, 2) suggestions for the stages of creation of the mode1,3) a program for introducing new forms and organization of the health service, with improved managenent of public health, and 4) a suggestion for the demands to other institutions and organizations to preserve the living environment and to improve the medical service of the population.

Up to now two variants of the model and the General Scheme were elaborated which have been discussed and generalized in the central institutes. Depending on the conceptions concerning the other spheres of the economy, certain corrections are possible by gradual coordination of the opinions.

It is possible that new data may be obtained about the initial information, such as, for example, the demographic processes, the territorial structure, the economic development of the separate regions and basic territorial units. The possibilities of the country regarding the national income should further be evaluated and the respective restricting measures determined for the capital investments, labor resources, and so on. A final variant will be suggested on this base which will serve further on for the more precise planning of the periods 1976-1980, 19801985, and 1986-1990. 
Table 1. Medical care provided in the outpatient medical centers.

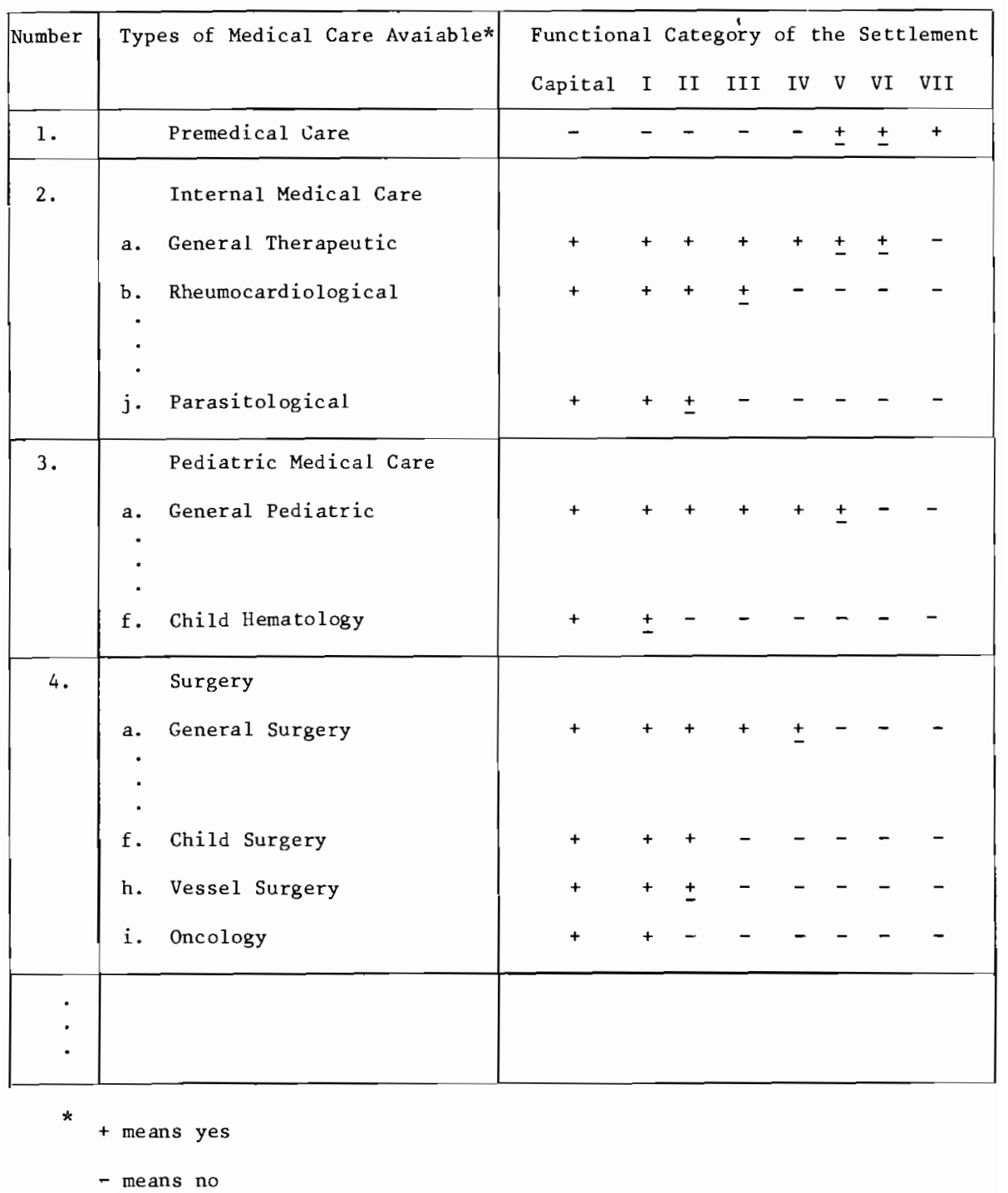


FORECASTING HEALTH SERVICES IN THE PEOPLE'S REPUBLIC OF BULGARIA

Table 2. Medical care provided in the inpatient medical centers.

\begin{tabular}{|c|c|c|c|c|c|c|c|c|c|}
\hline \multirow[t]{2}{*}{ Number } & \multirow[t]{2}{*}{ Type of Medical Care Available* } & \multicolumn{8}{|c|}{ Functional Category of the Settlements } \\
\hline & & Capital & I & II & III & IV & v & VI & VII \\
\hline 1. & General Practice & - & - & - & - & - & - & - & - \\
\hline 2. & $\begin{array}{l}\text { Internal Diseases } \\
\text { Cardiorheumotology }\end{array}$ & + & + & + & + & + & - & - & - \\
\hline 3. & For Adults & + & + & + & \pm & - & - & - & - \\
\hline 4. & For Children & + & + & + & - & - & - & - & - \\
\hline 49. & $\begin{array}{l}\text { Physical Therapy and } \\
\text { Rehabilitation }\end{array}$ & + & + & + & \pm & - & - & - & - \\
\hline
\end{tabular}

*

+ means yes

- means no 


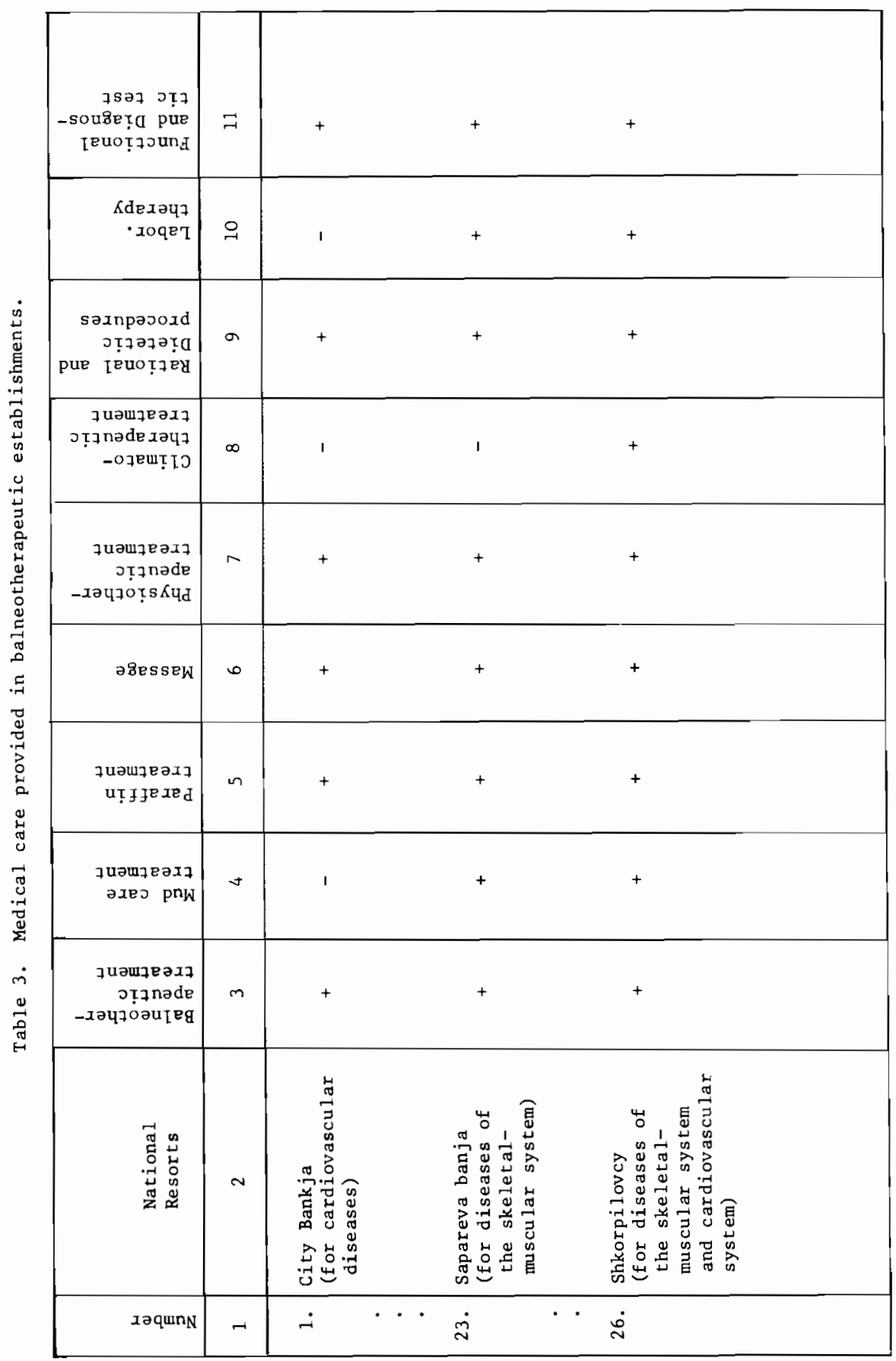


Table 4. Dynamic standards for outpatient care in the different medical specialties.

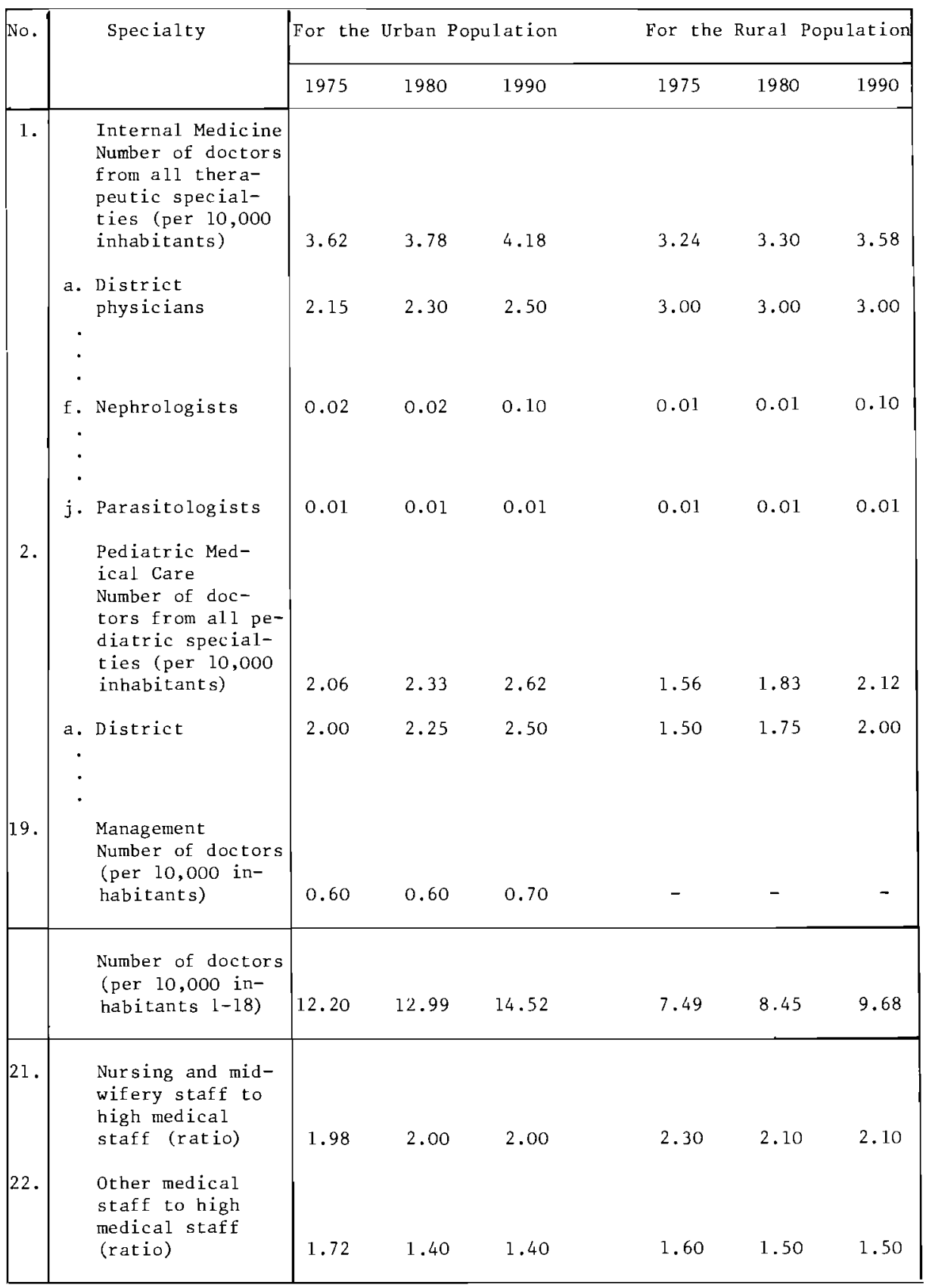


Table 5. Standards for hospital beds supplied per 1,000 inhabitants.

\begin{tabular}{|c|c|c|c|c|c|}
\hline \multirow[t]{2}{*}{ Specialty } & \multirow{2}{*}{$\begin{array}{l}\text { Number of Beds } \\
\text { per } 1,000 \\
\text { inhabitants }\end{array}$} & \multicolumn{4}{|c|}{ I n c l u d i n $g$} \\
\hline & & $\begin{array}{l}\text { District } \\
\text { Hospitals } \\
30,000- \\
100,000 \\
\text { inhab. }\end{array}$ & $\begin{array}{l}\text { Regional } \\
\text { Hospitals } \\
200,000- \\
600,000 \\
\text { inhab. }\end{array}$ & $\begin{array}{l}\text { First-rate } \\
\text { Hospita1s } \\
700,000- \\
1,500,000 \\
\text { inhab. }\end{array}$ & $\begin{array}{l}\text { National } \\
\text { Establish- } \\
\text { ments }\end{array}$ \\
\hline \multicolumn{6}{|l|}{1975} \\
\hline All Specialties & 8.37 & $5.54-2.76$ & $0.90-3.68$ & 0.56 & 1.37 \\
\hline $\begin{array}{l}\text { 1. General Thera- } \\
\text { peutic Beds }\end{array}$ & 1.21 & $1.14-1.10$ & $0.02-0.06$ & 0.03 & 0.02 \\
\hline 21. For Chronics & 0.37 & $0.25-0$ & $0.02-0.27$ & - & - \\
\hline 22. General Beds & 0.04 & $0.04-$ & - & - & - \\
\hline \multicolumn{6}{|l|}{1980} \\
\hline All Specialties & 8.63 & $5,90-2.73$ & $1.08-3.95$ & $0.54-0.84$ & 1.11 \\
\hline $\begin{array}{l}\text { 1. General Thera- } \\
\text { peutic Beds }\end{array}$ & 1.24 & $1.14-1.09$ & $0.06-0.11$ & 0.02 & 0.02 \\
\hline 21. For Chronics & 0.30 & $0.23-0$ & $0.06-0.29$ & 0.01 & - \\
\hline 22. General Beds & - & - & - & - & - \\
\hline
\end{tabular}

\section{0}

\begin{tabular}{llllll}
\hline All Specialties & 11.50 & $7.15-4.09$ & $1.88-4.54$ & $0.71-1.11$ & 1.76 \\
$\begin{array}{l}1 . \text { General Thera- } \\
\text { peutic Beds }\end{array}$ & 1.61 & $1.47-1.41$ & $0.07-0.13$ & 0.04 & 0.03 \\
$\begin{array}{l}\text { 21. For Chronics } \\
\text { For }\end{array}$ & 1.00 & $0.70-0$ & $0.29-0.99$ & 0.01 & -
\end{tabular}

22. General Beds 
Table 6. Standards for developing the material and technical basis of the health service per inhabitant.

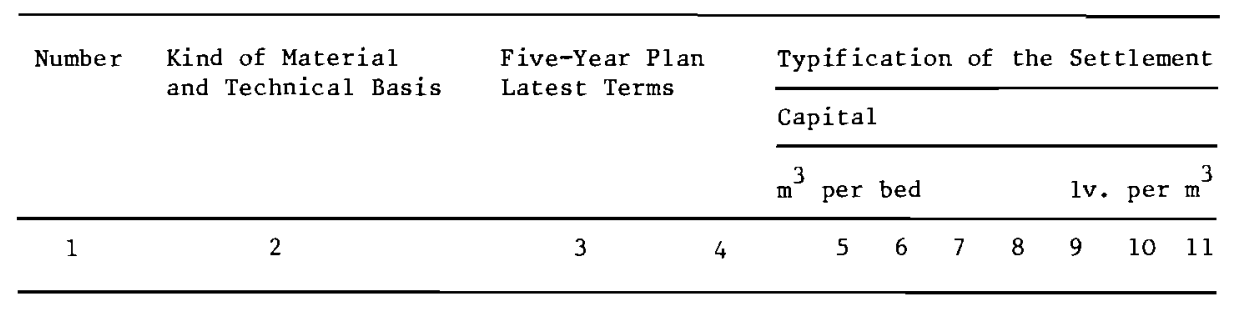

\section{First-rate} Hospital

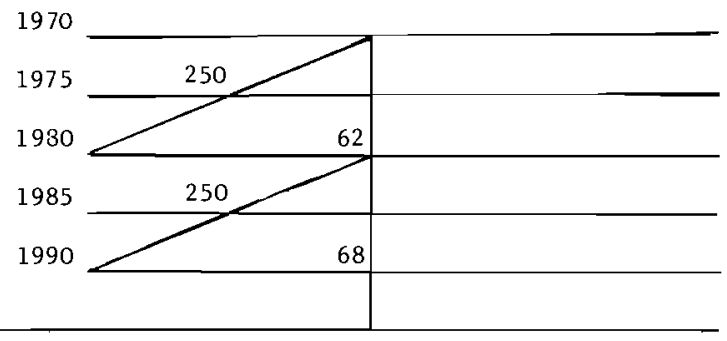

2. Regional Hospital

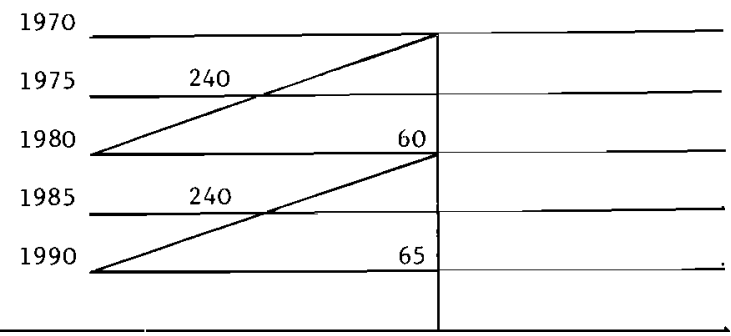


Queries of the Discussant, Mr. Collins

Mr. Collins voiced four questions that had come to mind in reading the papers of Messrs. Golovteyev and Cenov:

1) How extensive must be the investment of analysis and data acquisition before comprehensive planning models of the type used in the USSR and in Bulgaria could be developed?

2) How do such models promote the uniformity of health care?

3) Has actual experience--through unexpected problems or payoffs-altered the models in question?

4) Are the data derived from these planning exercises internationally available?

\section{Uniformity of Care}

Mr. Venediktov stated that unifornity of health care was not an objective of the planning. Village health facilities, for instance, would never offer all the treatment opportunities of a metropolitan hospital. Mr. Golovteyev pointed out that not all villages of the same size had equivalent facilities. This occurred because of the varying health needs of different populations and because villages may be designed as centers for certain treatments for which they would also serve neighboring villages.

\section{Model Flexibility}

A number of speakers pointed out that the models developed are not static and fixed but dynamic and growing. Mr. Venediktov estimated that thousands of unexpected problems had arisen and that these occupy the attention of systems analysts. While the details of the system may change, the underlying principles of model structure are permanent. Mr. Golovteyev related that growth or shifts of population effect immediate changes in the health care system. An extreme example of system flexibility is provided by the mobile health units which accompany railroad construction crews.

Mr. Cenov agreed that there was not simultaneous working out of all facets in the Bulgarian model. Similarly, he felt that the goal of system uniformity was dangerous in that it would tend to make the model sterile and would inhibit investigation into the various branches of public health. Versions of the model were iterated at least every five years to provide current descriptions of the health care system and projections for its improvement over the ensuing five-year plans. Typical of the factors causing adjustments of the model were discrepancies between projected and actual population growth. Further difficulties arose in coordinating model interfaces between different spheres of activity.

Mr. Rehak said that the planning model used for the CSSR closely resembled those described by Messrs. Cenov and Golovteyev. It also contains features of health systems in many non-socialist countries. Far from seeking one omipotent static model, the Czechs are constantiy calibrating and modifying their models through pilot projects carried out in different areas.

Data Availability

Messrs. Cenov, Golovteyev, Rehak, and Venediktov affirmed the availability of their planning data to all nations. Mr. Venediktov urged the beginning of quantitative comparisons across systems so that they might learn from each other. Mr. Rehak reiterated the desire for cross-cultural statistical comparisons and felt 
that problems of data arose not from their insufficiency but from their overabundance. It was not impossible that health agencies would drown in data.

\section{Numbers as Planning Goals}

One questioner asked for a more precise explanation of the roles which target numbers play in the planning and management processes. For instance, the specification that so many doctors or beds are needed per unit population tends to imply that the goals are beds and doctors instead of health. How should preventive health care advances--which might reduce the numbers of physicians needed--be factored into the planning goals?

Mr. Golovteyev said that the technical name for the numerical criteria was optimal normatives. They represent near term goals that have not yet been achieved. The questioner was right in saying that the true goals are not the inputs--doctors and beds--but the output: health. Yet it is by specification of the input numbers that the planner has control over the system. Wel1-determined input numbers will have the effect of improving health. A health administrator who is simply told to improve health will not know what he should best do. But an administrator who is told to increase the number of clinies and doctors to specified levels--determined by the planners sc that they will effect better health --knows exactly what to do.

In this manner, the planners must naturally take into account desirable levels of preventive care. Thus, Mr. Golovteyev noted that the set numbers of trips to clinics were designed to include preventive visits.

Further refinements on the target numbers have been made to reflect the needs of specific areas. Depending upon the climatological, demographic, geographic, and socio-economic conditions, the optimal normatives are adjusted. Mr. Golovteyev and his systems analysts are constantly working to improve these numbers so that they till more accurately show the true needs of the population.

Another shortcoming of the numbers is that they do not reflect appropriate tradeoffs among the inputs. The paper of Mr. Reinhardt shows the importance of this factor in the US. In the USSR it is realized that the proper set of functions for a doctor is constantly changing to reflect the latest technologies. Paramedical assistants are increasingly able to take over tasks formerly done only by physicians. The numerical planning targets should incorporate optimal manpower mixes.

Messrs. Paine and Wilson felt that the comments Mr. Golovteyev had made upon planning in the USSR applied also to Canada. The numbers they established were only goals which might not be reached, yet in being sought would have the effect of improving health. In their work, they had settled upon the number of 4.5 beds per thousand population. To use this number, it was necessary to consider the catchment population over the whole area relying upon a given hospital. They found that hospital needs varied across Canada depending upon the requirements and tastes of the different provincial populations. Case load levels and average lengths of stay are particularly variable. The figure of 4.5 beds per thousand was thus not universal or immutable; it represented simply, at one point in time in Alberta, the goal that would effect the best allocation of hospital resources.

\section{Source and Meaning of Target Numbers}

Another participant bemoaned the exaggerated emphasis placed by planners upon numbers attributed mystical qualities. He noted that, in the UK, the figure of one general practitioner per 2,500 population has acquired the status of a magic and hallowed number. In searching for its basis, he found that this represented the ratio at the time the National Health Service was instituted. The figure was thus three decades out of date and derived from a radically different system of health care delivery. 
Another instance cited was the case of a friend sent to a hospital to rest her nerves. She was placed in a large room of howling and dying people and left the hospital worse off than she arrived. This observer saw irony in the fact that the hospital stay would be recorded as output.

To put the target numbers in their proper perspective, this speaker suggested that close examination be made of the corsequences of changing them slightly. What, for instance, would happen if Alberta had adopted the goals of 4.0 or 5.0 beds per thousand of catchment population? Mr. Chatterjee's question upon payoffs for over- or underprojections seemed relevant here: what actually occurs when too few or too many resources are allocated? How is this reflected in the payoff functions of the administrators?

One speaker felt that modular construction of hospitals reduced the penalties of underestimating need. When greater need is perceived, it often is possible to enlarge the hospital.

Mr. Golovteyev stated that underestimations were generally handled by ad hoc adaptations--such as squeezing more beds into a clinic. Overestimations result in unused resources and reflect badly upon the planner. Sometimes hospital stays are increased to take advantage of excess facilities and thus to make the utilization rate appear better. To avoid behavior of this type, the USSR is instructing its health administrators in the overall planning of the sector. The result has been wiser allocation and fewer false economies in the utilization of resources.

Mr. Wilson stated that insufficient provision of hospital beds leads to long waiting lists for surgery. Public dissatisfaction with such waits prompts the planners and administrators to increase the facilities available.

\section{A Defense of Input Numbers}

One speaker felt that the Conference may have been too harsh in denigrating the importance of input figures. He noted that cuba has set a standard of doctors per population thrice the level in the US. The USSR figure sharply exceeds that for Western countries. A first inference may be that general practitioners in Cuba and the USSR are performing many functions that in other countries might be done by physician assistants. On the other hand, emphasis on high doctor ratios may bespeak a basic priority of the nation--the right of each citizen to easy access to a physician. An assistant may be able to take a pulse reading as easily as a doctor, but he may not give the patient the same sense of trust and security. If such psychological feelings are deemed important--and recent study shows their broad prevalence--then the input numbers are important and cannot trivially be replaced by other technologically equivalent mixes of resources.

Model Validation

A participant regretted that the Conference was not concentrating upon the definition of health problems. He noted also that there was little mention of validating or verifying the models under discussion. No bases had been presented that would enable confident judgment whether the structure of a given predictive model was good or bad or subject to improvement.

\section{Practitioner Grasp of Models}

It was noted that large models have been constructed in Western nations for such fields as the environment or the economy. Too often they failed to influence policy because of the communications failure between the analysts who designed the models and the practitioners who might have used them. Decision makers naturally are suspicious of artifacts they do not understand. Builders of health models should be aware of this possible pitfall. It was affirmed that a similar weakness in communications existed in socialist countries and merited equal attention. 


\section{The Comprehensive System}

One member of the Conference argued that the planning problem inhered in optimally manipulating the entire system of health care providers. In particular, the physician should be focused upon, as it is he who makes diagnoses and prognoses solely for the benefit of his patient population. System managers--by adjusting the incentives available to physicians, by allocating medical resources, and by encouraging technological advance--affect the ability of the individual doctor to meet the needs of his patients.

\section{System Efficiency}

As the session drew to a close, Mr. Venediktov noted that a most important set of numbers had been mentioned but not accorded due attention. He referred to indices upon the efficiency of embracing health systems and of their component parts. With adequate indices, it will be much easier for individual planners and managers to focus upon the most appropriate goal--enhancement of health broadly defined--rather than disperse their efforts in individual specification of inputs. Satisfactory indices will enable managers to assess their own achievements and to discern which parts of the systems they operate are performing relatively better and worse. Cost-benefit analysis offers insights into acquiring suitable indices but it also points out the difficulties to be faced. Mr. Venediktov urged that systems analysts and this Conference devote greater effort to the distillation of such indices. This is a task uniquely suited to the capability of systems analysis and one offering rewards commensurate with difficulties. 

PART III. MEDICAL INFORMATION SYSTEMS 



\section{THE CZECHOSLOVAK HEALTH CARE SYSTEM AND TTS COMPUTERIZATION}

J. Rusnâk, M. Popper, A. Rehäk, and J. Lelovský

In spite of great many differences in distribution of manpower, facilities, priorities, strategy, the goals of health policy throughout the world remain the same, i.e. to reach an optimum relation between the requirements for the health care, the accessible resources, and the performance of the health care systems. The present nationalized health care system in Czechoslovakia can be defined as a unified, large-scale system. It covers a population of a comparatively small nation with 1 imited resources but with a good ratio of medical and paramedical manpower to the size of population and with an evenly distributed network. With the prerequisites for computerization thus achieved, special research institutions with several other medical establishments are exploring the best solutions for a nationwide computerized system. There is no doubt that the existing health care system at its present state of computerization can serve as a suitable model for developing new methods and applications of systems analysis.

The basic structural elements of the health care system are hospitals with outpatient departments, centers of hygiene and epidemiology, pharmaceutical services, transfusion centers, economic and technical services, and units of statistics. All are united under a single administrative management of the regional Institute of National Health. This basic organization is reiterated on two levels according to the administrative division of the nation into territorial regions. The higher regional authorities administer more comprehensive and specialized services and better equipped establishments than those administered on the lower district levels. Nevertheless, the structures on the two levels are analogous. Therefore, nationwide optimization can be uniformly pursued on a nationwide scale using the same organization, programs, software, and hardware.

The part the Ministry plays in managing the whole national health care system is conceptual, calling for statistical data necessary for long-term planning and development. The information supplied by the statistical network pertains mostly to demographic data, morbidity, mortality, epidemiology, social and environmental hygiene, structure of the network, manpower, activities and performance, costs and budget; education and training of present and prospective staff. Collecting statistical data for clinical and scientific purposes rests on the researchers themselves,

The main element with most numerous and closest links with other basic parts of the system and its environment is the hospital with polyclinic. This is the hub where all therapeutic and preventive activicies, information and material flow meet. Therefore the endeavors to computerize and automate the health system are centered first on developing an integrated information system in the hospital with polyclinic.

The other line of research is to develop computerized systems of management in: hygiene and epidemiological services, health statistics, drug output and supply, and planning and management of establishments together with econometric and applied mathematical methods for administration on higher regional levels. The infomation system is to be expanded, and in addition to data necessary for checking the status of the system and its parts, it should provide and store information about individual patients ready for processing and retrieval. This is the objective of the first project being worked upon by the Research Institute of Medical Bionics in Bratislava. It encompasses all problems of computerized collection, storage, and processing of information about sick and healthy subjects: computerized patient interviewing, laboratory test record, medication, hospital admission, discharging, and finally, preparation of statistical data for further evaluation. 
Other activities include: emergency patient monitoring, automated cinical laboratories, computerized Inedical material and drug administration, and incapability of work, feeding, maintenance, planning, and accounting agendas. These activities are the subject of the first research project conducted by the Research Institute of Medical Bionics; the second project is focused on the problem of managing the whole health care delivery system or at least higher regional levels. This makes use of the integrated hospital and polyclinical information system by processing selected data with conventional techniques based on statistical methods for decision making. Moreover, the second project is attempting to solve the mutual communication and compatibility between the particular elements of the whole system and its computerized technology, thus linking them together into a complete national medical information system.

The general concept of the software and hardware for the hospital information system is based on a requirement that the system must be modular and flexible, with back-up possibilities, and able to work in real time, time-sharing, and batch mode in the same time.

The central unit is a dual processor to which dedicated satellite computers are connected (e.g. for intensive care units, ECG interpretation). These satellite computers may be doubled or tripled according to required concurrent activities. While one processor serves as a time-sharing system for multi-user interactive communication with data base, the other processor serves as a back-up for the first, and, under normal working conditions, serves as a real-time processor for various analog signals and small batches in background. During the night shift the second processor should be utilized for extended batch processing.

In order to accommodate the largest number of users, interactive terminals should be installed. But, in addition to the cost, specific technical problems must also be solved in this respect. Therefore a dedicated terminal is being developed in Czechoslovakia based on a design of the Research Institute of Medical Bionics. This terminal will be dedicated to discrete medical data collection. The sets of acquired data are descriptive pre-defined text-strings, numeric figures, curves, and images. This terminal will enable the user to display in a linear or hierarchical format sets of questions to be answered and will collect data in online or off-line modes. The construction is based on an optical screen on which images of problem-oriented questionnaires are projected from a $16 \mathrm{~mm}$ film strip controlled by the computer or by the terminal itself.

Theoretical points of automated patient interviewing may be still open to question, but it is generally agreed that a properly structured questionnaire is the basic requirement for a dialogue with the cumputer. One can define the formal properties of an automated questionnaire with a triplet consisting of a finite set of questionnaire expressions, a finite set of labels, and a finite set of rules attrituting labels to expressions. The utilization of the questionnaire was found to depend upon 1) the properties of the questionnaire, 2) the algorithm depending on the interview conditions and preceding responses of the patient, and 3 ) the set of rules governing the attribution of responses to questions.

The form of labeling of the expressions--i.e. questions, responses, and insertions of narrative statements--results in a tree structure organization of the questionnaire. The contents of one vertex of the structure are usually, but not necessarily, screened from one frame of the film strip. The coding of vertices determines the address of the field (or vertex) which is to be displayed. This structure makes it possible to generate an intelligible dialogue using expressions and phrases familiar in traditional medical communications pertaining to the patient's history, his complaints and health status.

Many minor problems of the computerized questionnaire await solutions. One example is how to determine locations of pathologic changes, or projections of sensations upon the body surface. We have devised a code number approach with logical sematic rules in its composition, in contrast to other coded systems which attribute 
the numbers to individual areas of the body surface arbitrarily. Large parts of body surface are coded by numbers 1 to 10 . Breaking down these areas into a satisfactorily detailed definition of smallest parts is done by adding additional numerals according to precise rules. Exact coding of location thus becomes possible without costly electronic pen equipment.

We expect to implement such systems in Czechoslovakia within one or two decades, and thereby significantly upgrade the capacity and performance of the whole health care system. However, Czechoslovakia, like other small countries with limited resources, must carefully calculate the necessary investments and their payoffs. The computerization project involves expensive sub-projects beyond the resources of small communities and therefore calls for international participation to the mutual benefit of al1. Without this collaboration, further advance becomes problematic. That is why great hopes and expectations are centered on the activities of the International Institute for Applied Systems Analysis.

In the Czechoslovak concept of developing automated systems in health care and medicine several successive phases of research and development are envisaged, with urgent priorities in three areas:

1) An integrated information system of all medical literature including the increasing proportion of papers written in national languages;

2) The education and training of medical personnel. Automation and computerization will spawn allied medical professions for which the systems of education are unprepared. The impact of automation must be taken into account in both the undergraduate and the postgraduate study of medicine and science. The question remains whether the education of electronic computerized medicine should be arranged as a special track of the undergraduate studies or as a part of postgraduate education; and

3) Computerized diagnostic procedures. The integrated medical information system may yield a mass of data necessary for such diagnostics. This could revolutionize our view of the diseased and healthy states. Along with modelling of biologic systems, this circle of problems will probably follow suit only when the basic problems of automated and computerized information and communication are solved. 
APPENDIX:

Groups of Statistical Data

Currently Collected and Processed by

the Present Statistical Information Network

\section{BASIC DATA}

- Numbers of inhabitants

- Territorial distribution of the population

- Age groups

- Marriages and divorces

- Birth rates and mortality rates

- Perinatal mortality

- Abortions

- Mortality caused by coumunicable diseases

- Numbers and distribution of health care establishments

- Numbers of beds and distribution (absolute and ratio per 10,000 inhab.)

- Physicians' posts and their fluctuations

- Numbers of office visits, home visits, examinations, working hours

- Numbers of examinees, treated patients, treatment days, utilization of beds, average bed occupancy

- Numbers of health service employees (in particular sectors)

- Occupational distribution of employees

- Medical and pharmaceutical faculties, schools for allied professions

- Dentists, distribution, population ratio

- Territorial physicians' posts, distribution

- Numbers of inhabitants per health centers, pharmacies, and optician shops

- Ratio of physicians and allied professions

- Office visits in health centers.

\section{DEMOGRAPHIC DATA}

- Territorial and city distribution of population, marriages, divorces, births, overall and perinatal mortality

- Age distribution of parturitions

- Neonatal sex, weight, and length

- Fertility ratio

- Age distribution (overa11, regional, districts)

- Abortions (territorial distribution)

- Interrupted pregnancies and reasons (indications)

- Perinata 1 mortality

- Overall mortality (age and sex distribution) 


\section{STATE-OF-HEALTH DATA}

- Territorial distribution of incidence of communicable diseases (absolute, ratio, mortality)

- Monthly and seasonal incidence of conmunicable diseases (sex, age, depending on the size of residential settlement etc.)

- Incidence and prevalence of venereal diseases and malignant tumors

- Incidence and prevalence of tuberculosis (territorial, ratio)

- Mortality due to malignant tumors of the respiratory tract

- Tuberculosis (incidence according to official classification, sex, age, territory)

- Follow-ups of T.B. (territorial distribution, children and adult groups)

- Venereal diseases (incidence according to clinical classification, age groups, sex, and territory)

- Territorial distribution of malignant tumors, incidence, systems involvements, sex

- Incidence of malignant tumors, ratio, age, sex

- Incapability of work caused by disease or accident (territorial, ratio)

- Incapability of work due to particular groups of diseases, ratio of total incapability

- Invalidity incomes--causes, sex distribution

- Mortality and its causes according to regions

- Infantile mortality--according to causes and regions

- Hospitalization data (average length of treatment, rate of discharges, deaths, departments, sex, and regional distribution of patients, etc.)

- Causes for hospital admission (regions)

- Absolute and average hospitalization length according to age

- Sex distribution of diseases of hospitalized patients

\section{NETWORK OF HEALTH CARE ESTABLISHMENTS}

- Overall data according to types of establishment

- Changes in the fiscal year (manpower, beds depending on regions and types)

- Hygienic service and epidemiology (centers, physicians, allied professionals, distribution in regions and districts)

- Physicians' posts in specialized departments

- Beds in specialized departments

- Territorial areas, physicians' posts

- Types of territorial health centers in particular regions

- Establishments of curative and preventive care (health centers, polyclinics, dispensaries)

- Territorial distribution of specialized polyclinical departments

- Physicians' posts in ambulatory services (general and specialized, absolute and population ratio)

- Physicians' posts in factory health services

- Specialists' posts in factory health services 
- Distribution of physicians' posts in industry according to trade groups

- Laboratory and comnon establishments

- Physicians' posts in the above category

- Physicians' posts in sports medical care, oncology, anti-alcohclic centers, and dispensaries

- Hospital distribition in distinct areas

- Hospital and their bed capacities

- Categories of hospitals throughout the nation

- Structure of hospitals (basic and specialized departments)

- Hospital beds serving special fields--population ratios

- Physicians' posts in specialized departments of hospitals

- Physicians' posts in administrative functions

- Units of pharmaceutical services

- Ambulances, transportation

\section{ACTIVITIES}

- Performance in outpatient establishments and office work hours

- Numbers of therapeutic and investigative actions in territorial establishments--overall and per hour

- Examinations in pregnancy, preventive care of women

- Performance in outpatient care of children

- Performance in school health services

- Performance in dentistry (physicians' activities)

- Performance of dental technicians

- Performance of the sports medical care

- Performance in the psychiatric care and anti-alcoholic services

- Hospitalization data in specialized fields (numbers of inpatients, length of hospitalization, bed occupancy, etc.)

- Ratio of beds and physicians' posts

- Utilization of beds in specialized departments (according to regions)

- Obstetric care

- Care of premature children

- Performance of department of pathology

- Performance of the department of forensic medicine

- Health care in specialized and research institutions, nursing homes, etc.

- Performance in biochemical laboratories

- Performance of X-ray departments

- Performance of rehabilitation establishments

- Performance of emergency and ambulance transportation 
6. RESORT PLACES, SPAS

- Number of sanatoria, beds, indications, children and adult departments

- Numbers of treated patients and therapeutic activities

- Distribution of patients according to residence

- Foreign patients

- Disease groups and average length of stay

- Diseases treated at particular places

- Beds, physicians, utilization, etc, in sanatorial care

7. BUDGET, COSTS, AND INCOME

- Expenditure on health care in different regions (divided into groups--e.g. drugs, feeding, other material, investments, ratio per treatment days, beds, physicians)

- Expenditure in specialized departments (tuberculosis, psychiatrics, nursing homes, children and youth care institutions, etc.)

- Expenditure in outpatient care

- Overall experditure (drugs, blood products, dressing material, etc.)

- Expenditure and income in pharmaceutical services

8. PHYSICIANS, DENTISTS, AND PHARMACISTS

- Numbers of physicians in different sectors, sex, and territorial distribution

- Physicians in specialized fields

- Fluctuations in specialized fields, men and women ratio

- Physicians employed in other sectors and their field of activities

- Age groups of physicians in specialized fields

- Physicians according to years of graduation and specialization

- Territorial distribution of physicians, age groups, sex

- Physicians in postgraduate training for specialization

- Certifications of physicians in specialized fields

- Territorial and age distribution of dentists

- Sectors of employment of dentists

- Regional distribution of pharmacists, sectors of employment, age

\section{ALLIED PROFESSIONS}

- Distribution over sectors and institutions

- Fluctuations in distribution

- Allied manpower in research institutes according professional group

- Allied manpower in health care institutes according professional groups

- Distribution over territorial regions

- Allied manpower in pharmaceutical services

- Allied manpower in specialized institutions 
- Allied manpower in sanatoria and spas

- Physicians and allied professions with part-time and over-time employments

- Fluctuations in numbers

- Female employees on maternity leaves

- Average numbers of substitute employees

- Average salaries in the main groups with regard to territorial regions

- Employees in administrative health care functions

10. MEDICAL AND PARAMEDICAL EDUCATION

- Medical and pharmaceutical faculties (students, teachers, graduates)

- Particular faculties, tracks of study, numbers of graduates

- Pharmaceutical faculties (students, graduates)

- Nurses and technician schools (regional distribution, students, teachers)

- Studies by correspondence

- Professional specializations and distribution of students

- Students by correspondence and their specializations

- Hostels for paramedical students

- Physicians and pharmacists in medical postgraduate institutes

- Physicians and pharmacists going for certification of specialist

- Participants on postgraduate courses for allied staff

\section{DEMOGRAPHY OF DISTRICTS AND DISTRICT HEALTH CARE}

- Fluctuation of demographic data in district areas

- Institutes of national health throughout the nation, their territorial areas

- Structure of the particular health care institution throughout the nation 
PLANNING A NATIONAL

MEDICAL INFORMATION SYSTEM:

A SYSTEMS APPROACH
K. Atsumi

Institute of Medical Electronics

University of Tokyo, Japan
S. Kaihara

Hospital Computer Center

University of Tokyo, Japan

\section{THE BASIC PRINCIPLE OF THE MEDICAL INFORMATION SYSTEM}

Recent1y, demands for medical services have been rapidly increasing in both variety and scope. Needs for highly technical medicine; the search for ways to cope with incurable diseases; hospital care which does not have long waiting 1 ists; more substantial rehabilitation programs; emergency care; remote area services; preventive medicine; health administration; all clamor for endless development in medical service and administration. Reasons for these demands abound: increased population, environmental pollution from intense industrialization and urbanization, increased individual incomes that allow demands for better medical care, improved medical technology, and ever-expanding national needs for medical services through the national health programs.

However, the greatest social factor which calls for such increased demands is the change in the people's concept of the absolute value of life itself. Human life now has more dignity than before, and people feel entitled to more rights. Their health, meaning of living, and demand for equality in living are more guaranteed than in previous ages. The basic principle of medical services of a nation which aims to promote the welfare of its people can be expressed as the desire for every person to receive the ultimate medical care of the time, wherever the person is, whenever he needs it.

This term, "ultimate medical care," includes not only the treatment of a disease but also broader aspects of health care: disease prevention, health administration, and rehabilitation, as well as the patient's safe return to a healthy and normal life (Figure 1). This is what we call "comprehensive medicine," covering the whole life course of health of all the individuals "from the cradle to grave." Comprehensive medicine demands practical, interrelated programs to involve medicine and health administration activities at the community level. This we might call "the regional medical service." Unless such a regional medical system is we11-established, a national medical program cannot function wel1, and in this sense a community-level medical program is the core of the national medical service network.

With nearly endless demands for medical care but only limited resources to match them, our efforts will best be aided by systematizing resource utilization. This can be achieved by creating a "pipeline" in the form of a medical information system (MIS) to link the branches of medical services. To form such a system, a systematized community medical service plan will be made. The information network will then cover the system. In practical applications, however, this procedure will not always be necessary. Many existing structures can well be clarified to a great degree simply by having a single pipeline of information through them.

\section{PLANNING THE MEDICAL INFORMATION SYSTEM}

The initial incentive to create a medical information system is born from the conflict between "ideal" medical service programs and the reality of existing social conditions. The first step is the collection and analysis of information about the existing medical system. Then comes the basic planning which is further subdivided into more specific purposes and studied in relation to technical and social aspects (Figure 2). Out of modelling experiments and study of various suggested plans, a medical information.system will evolve. Then the possible impact of the 


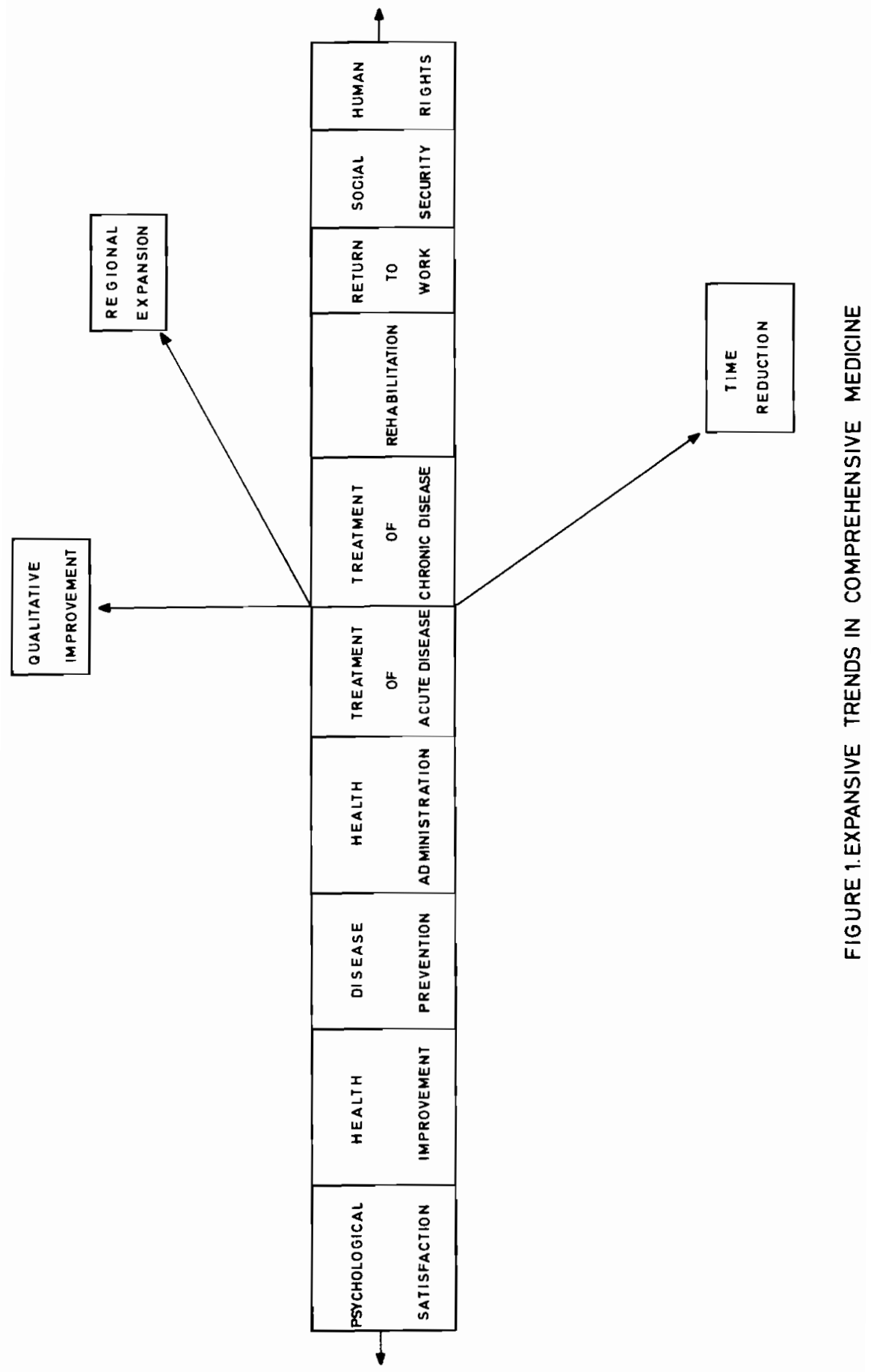




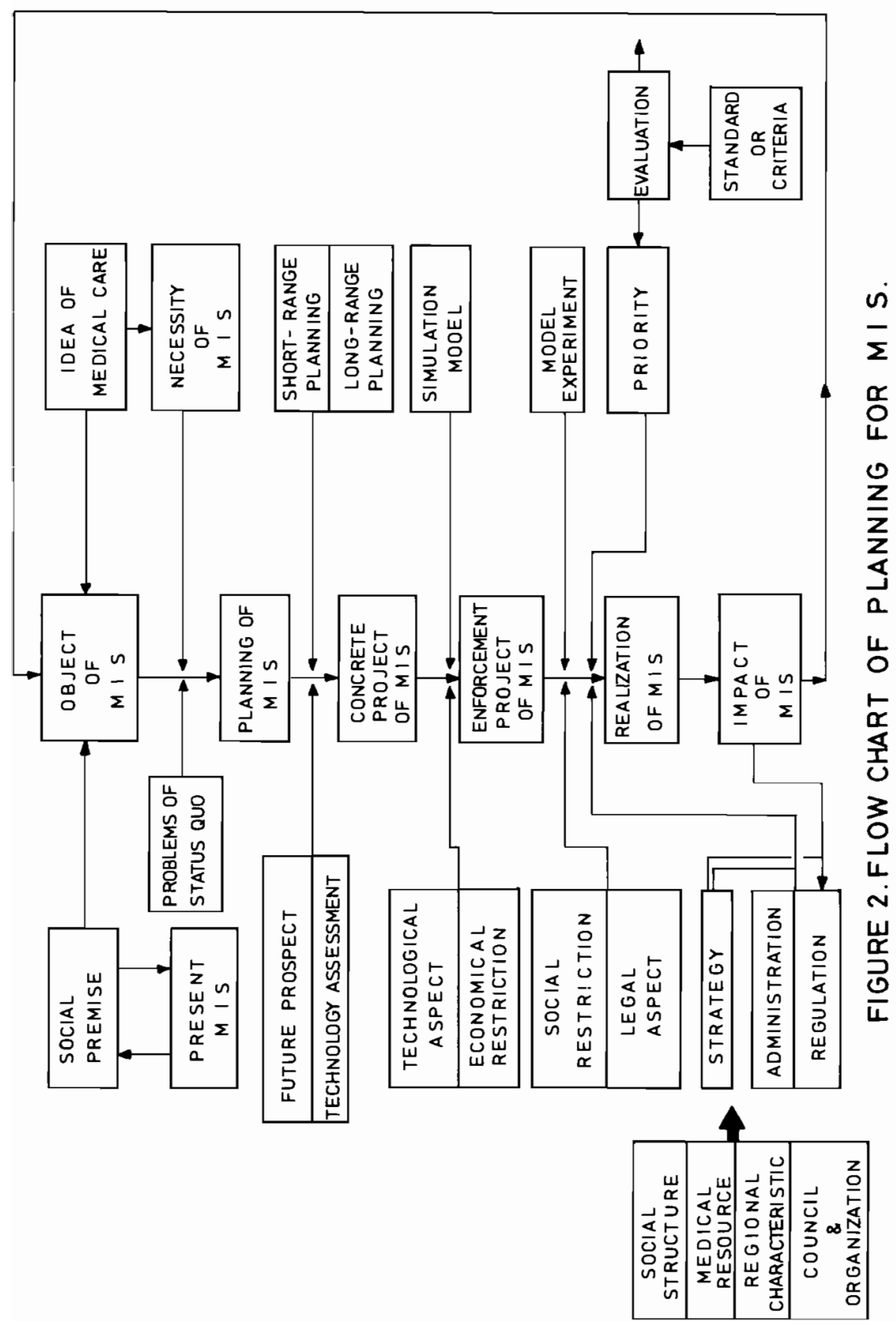


MIS on society will be visualized and evaluated. Through this process, the initial aims of the system will be adjusted to create a feasible system.

The plan should be both practicable and socially acceptable. Therefore priorities among subsystems must be decided and measures taken to implement, adjust, and operate the system smoothly. The medical information system will always try to meet current demands by absorbing new technologies; thus, the system must be flexible. However, for the sake of efficiency, the setting of a module as its function unit, and specific planning of the module is important for maintenance of the system.

The medical service system is a sub-system of the whole social system and, therefore, a macroscopic view of the society is also important for the solution of medical problems. Incorporating this view into the design of the medical system will require the participation not only of medical and administrative personnel, but also of experts in engineering, economics, political science, and psychology, to name but a few.

Depending on differences from one country to another, the social system, and consequently the medical service system, also vary. In planning a medical system for Japan, it is not enough just to copy any of the systems of other countries as those do not properly fit our realities. The system for Japan must be compatible with its history, economy, laws and regulations, social habits and thought patterns, customs, and resources.

First of all, the maximum medical service possible in this country under all the social conditions should be listed. Next the minimum service that the country can guarantee must be established with full consideration paid to the people's demands for medical service. And between the maximum and the minimum, all possible varieties of service must be discussed.

It is important to emphasize the regional medical service to meet specific requirements in each local area. However, it is also true that a basic plan for a nation-wide MIS must be established. Care must be taken to strike a balance between decentralization and centralization of the administrative authority or flow of information. The time factor is also important. More realistic shortterm planning (i.e. five year term) must be blended with and long-term aims (i.e. ten year pattern) based on ideal medical service theory.

\section{OBJECTIVES OF THE MEDICAL INFORMATION SYSTEM}

One aim of the MIS is to distribute eifectively the limited medical service resources. This includes the following sub-objectives:

1) to meet the existing demands for medical service with the minimum resources available;

2) to satisfy the increasing demands with a minimum increase in use of the resources; and

3) to be able to improve the quality of medical services with minimum consumption of resources.

More specificaliy, the goals of the MIS are:

1) to improve health care delivery--better emergency care and remote area services; reduced waiting lists for admission to hospitals and clinics; better diagnosis and treatment; improved prevention and rehabilitation;

2) to improve medical personnel--improved medical education, more research made possible; 
3) to promote the progress of medical science--better data collection and analysis; improved information searches; and

4) to improve health care administration and planning.

\section{EVALUATION, ESTIMATION, ASSESSMENT OF THE MEDICAL INFORMATION SYSTEM}

Before the MIS can be implemented, considerable problems must be solved. Some are technical: System engineering theories and methods must be developed; peripheral instruments essential for medical services must be perfected and standardized.

other problems are more complex. We must be aware, for example, of the possible impact of the MIS on all aspects of society. In our technology assessments we must plan now for ways to confront problems arising from:

- future technological developments

- changes in social attitudes

- standards and methods for information evaluation

- over-centralization or misuse of information (including threats to individual privacy).

The planning and implementation of the MIS should be carried out by the responsible medical personnel. Ideally, however, the people who receive the services should also participate in their operation. Realistically, though, many problems will occur.

To make easier the promotion of medical service and health programs it is essential that a central place of discussion be provided. This will permit feedback from the users--the sine qua non of successful operation of the medical information system. The Government conceives of a central medical information center as a sort of "think tank." Among its many tasks, it would: make future estimations of medical service resources (personnel, materials, money), plan education and training programs and test the plans using simulation models, make technology assessments, and collect and analyze overseas information. We must study this concept thoroughly.

THE NATIONAL PROJECTS ON MIS

In Japan, the national projects on MIS were started in 1973 by the Ministry of Health and Welfare (MHW) and the Ministry of Industry and International Trade (MITI). Although MHW has been in charge of software on MIS, and MITI in charge of hardware, these projects have developed in cooperation since early 1974 . Here we will give brief overviews of the two national projects.

\section{The MHW Project}

The MHW project on MIS is constructed from three projects--regional MIS, hospital automation, and coding and thesaurus--each connected with a fourth project on basic problems in which basic problems common to all three projects are studied. This fourth project is in turn divided into two major sub-projects on 1) the total plan of MIS and 2) the development of technology. (Topics studied in the projects are listed in Table 1).

The regional MIS project is the core of the MIS project. It is divided into three sub-projects concerned with conception of regional MIS, 2) development of various information systems in regional MIS, and 3) basic design of regional MIS in model areas. 
In the project on hospital automation, the general hospitals that will become centers of regional medical care are modernized and automated. This project is divided into two sub-projects on general and special problems.

Table 1. Planning of research and development of MIS (Ministry of Health and Welfare.

I. Project on Basic Problems

A. Total P1an of MIS

1) Basic philosophy

2) Analysis of reports on MIS published in Japan and foreign countries

3) Medical data bank

4) MIS in plan of development of regional community

5) Legal and economic problems

6) Standards of evaluation for MIS

7) Survey of opinions by questionnaire

8) Management problems

B. Development of Technology

1) Analysis of MIS using system dynamics

2) Simulation analysis for evaluating MIS

3) Forecast survey and technology assessment of MIS

4) Survey of technology to analyze MIS

5) Development of hardware in MIS

II. Project on Regional MIS

A. General Problems

1) Conception of regional MIS

2) Regional medical data banks

3) Regional MIS based on clinical laboratory centers

4) Health care systems

5) MIS in remote doctor-less areas

6) Emergency medical care systems

7) Analysis of methods to promote projects of regional MIS

8) Transmission technology in regional MIS

B. Basic Design of Regional MIS in Model Areas

III. Project on Hospital Information Systems (HIS)

1) Role and function of hospitals in regional MIS

2) Investigation of Applications of Computers and Automatic Instruments in Hospitals

3) Studies of methods to evaluate hospital functions 
4) Evaluation of function of general hospitals in regional medical care

5) Systematization of medical care for outpatients and hospital business

6) Systematization of patient monitoring

7) Role of clinical laboratory in hospital

8) Data communication in HIS

9) Cashless system in hospital automation

10) Administration system of patient history in medical centers

11) Evaluation of development of technology in hospital automation

12) Studies on design of transportation systems in hospitals

13) Design, technology, and evaluation of HIS

IV. Project on Coding and Thesaurus

1) Studies on utilization of MeSH [sic]

2) Analysis of medical terminology and collection of basic data on this field

3) Acquisition and analysis in medical coding

4) Computer applications in thesaurus administration

5) Survey on network of medical reference information

6) Automatic tranlation system from Japanese to English on classification of diseases and deaths

\section{The MITI Project}

The main object of the MITI project is to develop the hardware which will be required in MIS. The MIS was conceived as a multi-satellite system consisting of a center, satellites, and terminals of medical institutions. The design of the MIS must take into account the role of the MIS in:

1) assistance and back-up functions for general physicians,

2) emergency medical care,

3) health administration,

4) medical consultation,

5) supply of medical knowledge and information for medical and paramedical staffs,

6) health education for the public, and

7) administration of medical resources.

Table 2 outlines the five sub-projects for development of technology and instrument for the future MIS. 
Table 2. Five sub-projects on methods, hardware, and softward to be developed for MIS (Ministry of Industry and International Trade).

I. Multiplex and Modulation Transmission

1) Transmission by multiplex and modulation

2) Antennae

3) Mobile and portable radio devices

4) Control technology for networks

5) Milliwave transmission

6) Transmission technology utilizing satellites

7) Facsimile for medical use

8) Bilateral transmission on free-writing images

9) Software for message collection

II. Storage, Access, and Protection of Privacy in Medica1 Information Retrieva1

1) High-speed and large capacity data processing

2) Special terminals for medical use

3) Individual identifier and privacy protection

4) Digital image processing

5) Portable terminals

6) Software for controlling the medical data base

7) Software for task management

8) Software for communication contro1

III. Medical Image Storage

1) Image filing for medical microfilm retrieval

2) Terminals for image filing

3) Retrieval files for medical analog information

4) Request movie devices

IV. Color Image Transmission
1) Image transmission with high resolution
2) Digital image transmission
3) Tele-diagnosis by TV

V. Electronic Medical Devices and their interfaces with Computers
1) Device for computer-aided automatic diagnosis
2) Device for patient monitoring
3) Device for multiphasic testing
4) Automatic cytoscreener
5) Device for analyzing bio-medical information (simplified level)
6) Device for analyzing bio-medical information (high level) 
7) Devices and software for medical emergencies

8) Software for health care

9) Portable devices for medical treatment

10) Medical device for tele-control

11) Device to collect bio-medical information

12) Portable X-ray devices

13) Devices for simplified chemical testing

14) Devices for simplified medical treatment

15) Portable medical devices

16) Portable de1ivery monitoring devices

\section{EXAMPLES OF THE SYSTEMS APPROACH IN NATIONAL PROJECTS}

In the previous section we described the ongoing national medical projects in Japan. The systems approach has always been the methodological base in carrying out these projects. Although not always effective in solving practical questions encountered, systems engineering has contributed guidelines or leading concepts in project planning and evaluation. For example, the systems approach showed how to establish objectives, how to analyze means of achieving goals, how to estimate time and cost, and how to evaluate the experiment results. The suggested guidelines are mostly only qualitative and sometimes vague; nevertheless without these techniques, it would have been impossible to carry out these big projects. Here we will discuss briefly quantitative applications of the systems approach in the national projects. These quantitative approaches are still iumature and thus demand caution in interpreting their results. However, we believe that these methods will contribute tremendously in improving future medical care.

One of our goals was to build a mathematical simulation model of Japanese medical and health care. The model would simulate the complex network system of commodities, personnel, information, money, and services in the health care system. It would also take into account health administration, insurance, and education. Analysis of the model may make it possible to forecast the future trends of medical care or to choose the best policy among many in the field of medical care. However, the studies have just been started at the present time. Only part of the model has been formed and tested. Some of the results already obtained are described below.

\section{Forecast of Demand for Medical Care}

A study is in progress to form a simulation model to forecast the demand for medical care in Japan. Figure 3 shows the factors related to this demand. People with illnesses are obviously those who require medical care; however, they do not necessarily all appear as patients. In this model it was assumed that there are two levels before the people with illnesses become patients: 1) the leve1 of needs, and 2) the level of wants. At the level of needs, people do not yet know their illnesses and consequently do not visit physicians as patients. At the level of want they now know they are ill but for various reasons do not yet seek treatment.

Various factors which affect the transitions between levels are shown in the figure. Illnesses were classified into eighteen categories (based on the international classification of diseases). The population was classified into twelve categories by age and sex. As a factor of education, the rate of entering high school was used. The influence of insurance coverage on the number of patients visiting physicians was taken into consideration using the results of a past study. 


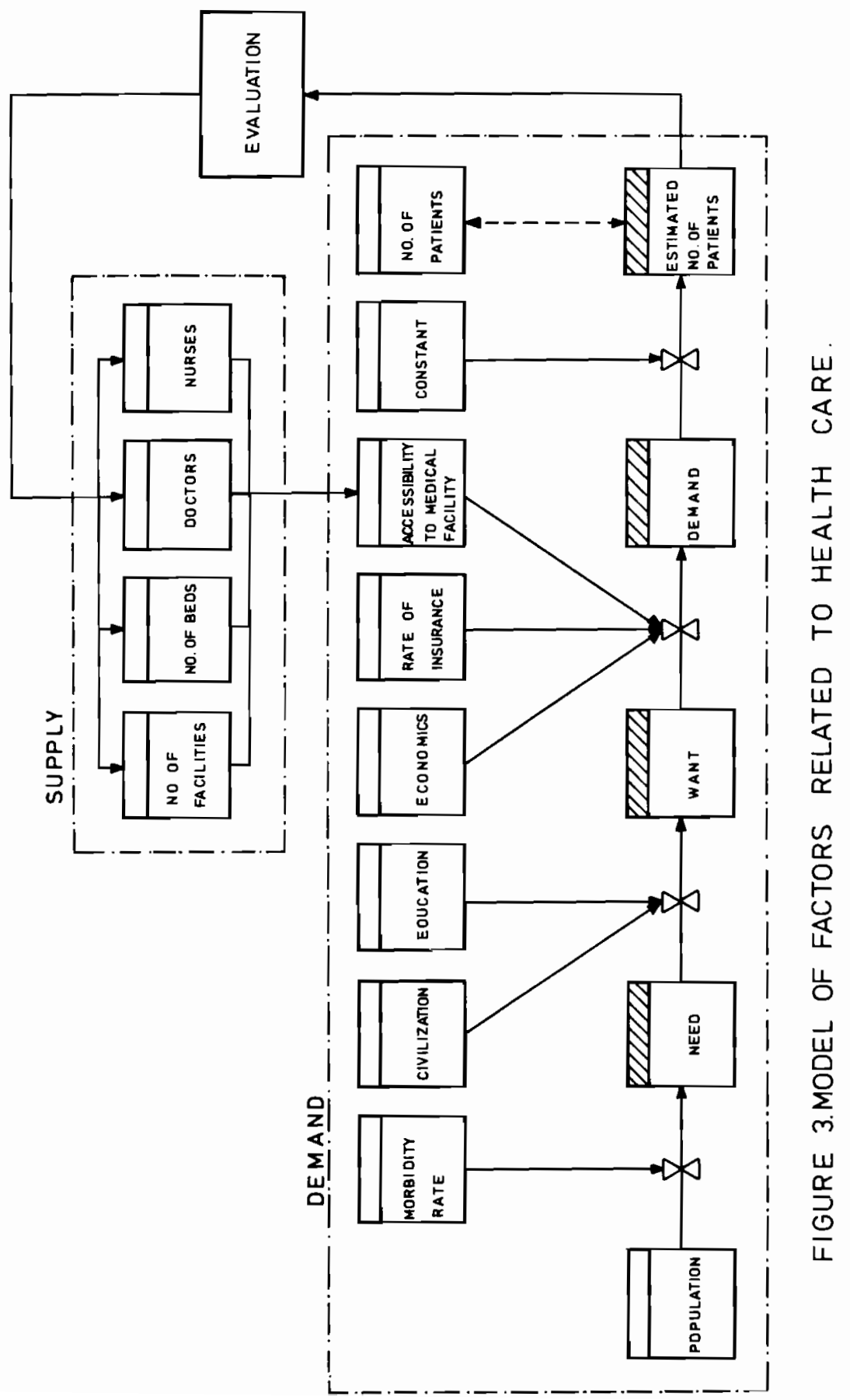




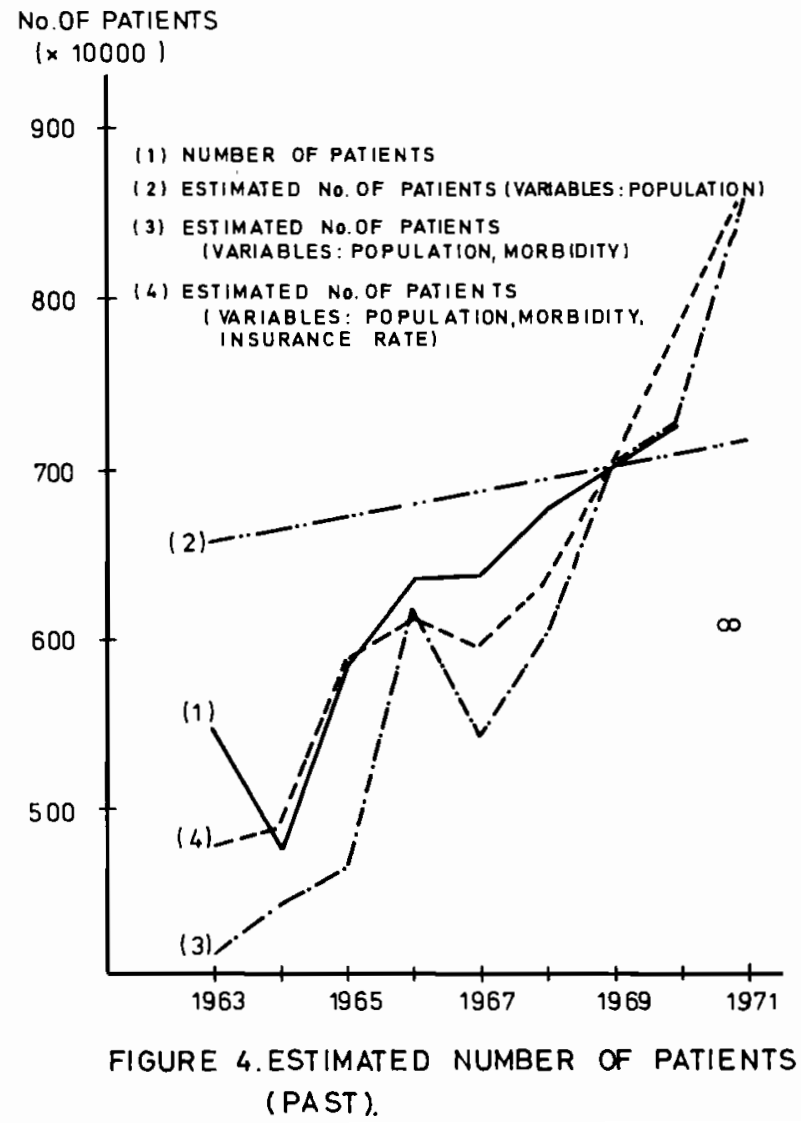




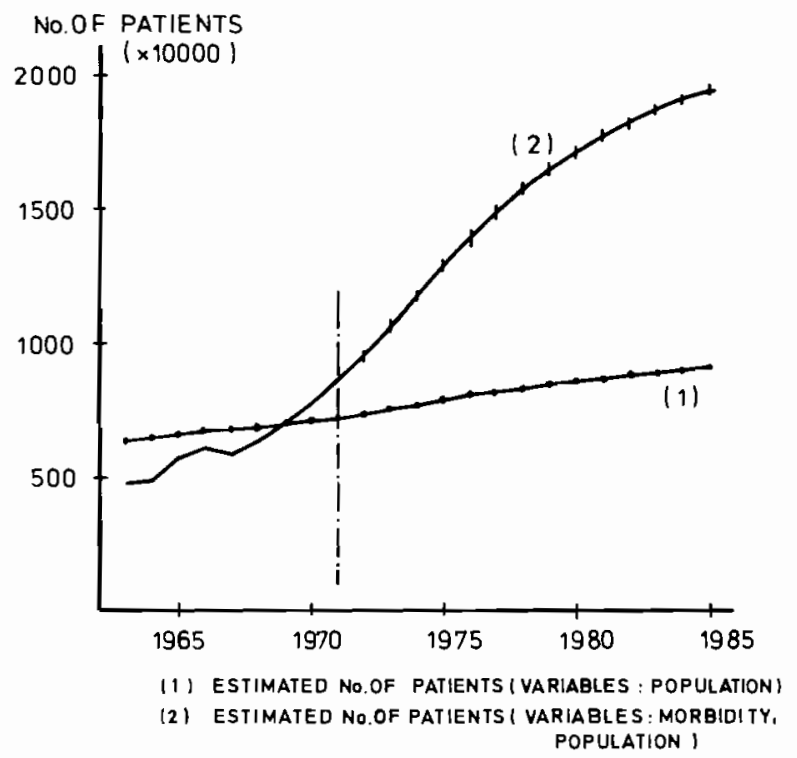

FIGURE 5. ESTIMATED FUTURE NUMBER OF PATIENTS.

Figure 4 shows the result of the calculations performed on the model. The estimated number of patients was compared with the real number in the past ten years. In this figure each line represents the result of calculation when the number of factors was increased one by one. Line 2 is the estimated value when only the change of population structure was included in the model. By taking into consideration the factors described above, the calculated value approaches the real value.

Figure 5 shows the future forecast of the medical demand in Japan obtained from the same model. In Japan the percentage of the aged in the population will gradually increase in the future. Line 1 of the figure shows the medical demand if only this change of population structure was included. Even when the other factors do not change, the number of patients will gradually increase because of this aging process. If other factors are counted, the number of patients rapidly increases (1ine 2). This may overestimate the real value because the change of morbidity inthe future was calculated from the past trends. More investigations are necessary to interprete these preliminary results. 


\section{Effects of Multiphasic Screening}

A similar approach was taken in the study of automated multiphasic health testing. The number of multiphasic screening centers has rapidly increased since the first center was established in 1969: twenty-nine are now in operation (1974). However, the role which these centers play in Japanese medical and health care is controversial: Is it really possible to get all the population of Japan screened by this method? Is it possible to give good care to those who were found ill by screening? Does the screening really contribute to the improvement of health status of the nation?

The following study performed by Professor Ikeda attempted to answer these questions by using systems dynamics methods. Figure 6 shows a flow diagram of a health screening center. In this study the components of the model were:

1) healthy people;

2) latent patients--those who have illnesses, but have not known it by themselves;

3) direct patients--those who know their illnesses and are getting medical care;

4) patients found by hospital visits--those who were found to be ill by hospital visits;

5) patients found by center visits--those who were found to be $i 11$ by center visits; and

6) suspected patients-those who were suspected to be $i 11$ and advised to visit the center regularly.

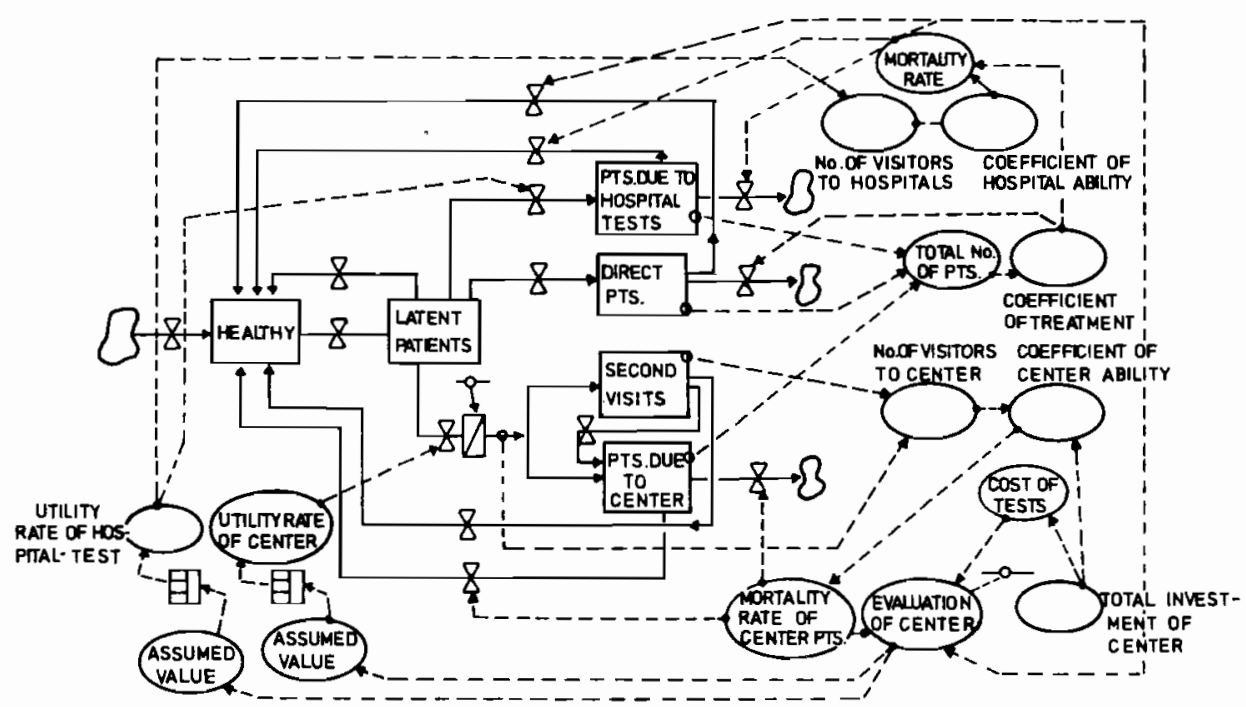

FIGURE 6. FLOW DIAGRAM OF A HEALTH SCREENING CENTER. 
The parameters introduced were: recovery from illnesses, mortality, testing ability of the centers, utility of hospitals, utility of screening centers and so on. Assumed parameters substituted for the parameters which could not be estimated directly. Some of the results obtained from this model are shown in Figures 7 and 8 .

Figure 7 shows the number of healthy persons and patients projected over the next ten years with no health screening center. The number of patients will increase in ten years as the population of Japan increases and ages. This result is the same as that obtained by the previous demand model. The numbers of latent and hospital visitors also increase at the same rate.

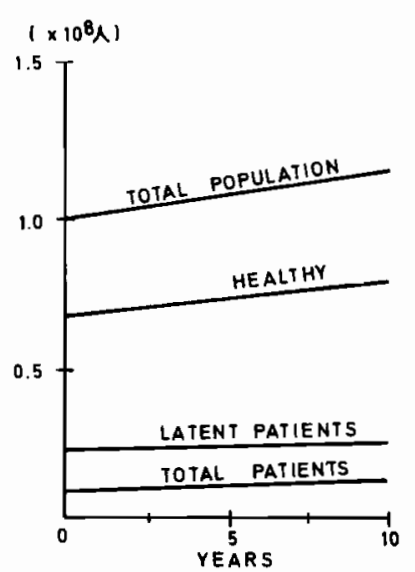

(a)

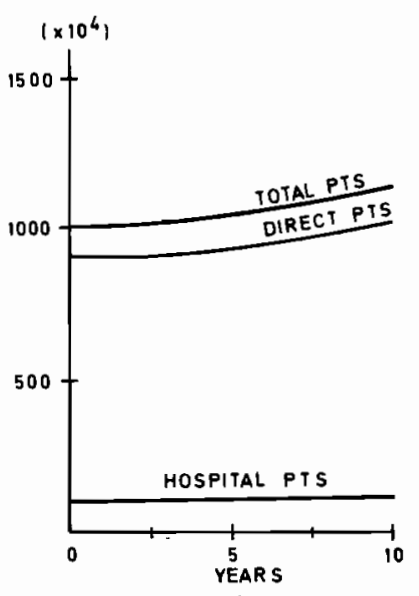

(b)

FIGURE 7. NO HEALTH SCREENING CENTER.

Figure 8 shows the results when screening centers function at the maximum rate. In this calculation, it was assumed that the number of people who visit screening centers is $50,000,000$ per year--approximately half of the total population of Japan. The model results showed that many latent patients are found and the number of patients increases for a couple of years after the start of screening. However, if hospitals have sufficient capacity to treat properly all these patients found by the screening centers, the number of patients decreases gradually and the number of healthy persons increases to reach a better health status in the country. 


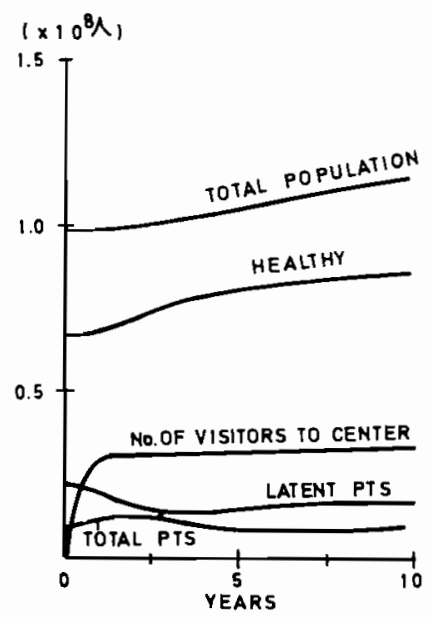

(a)

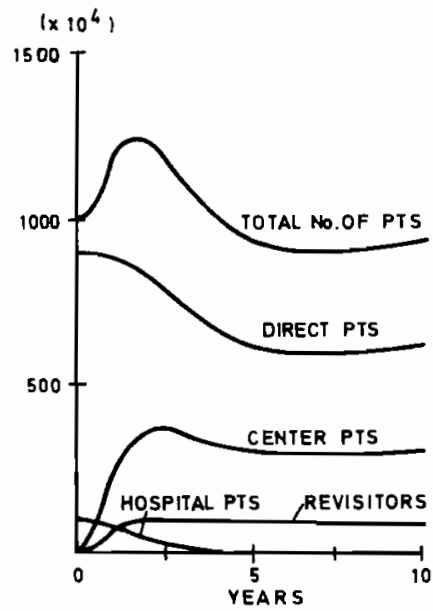

(b)

FIGURE 8. HEALTH SCREENING CENTER ESTABLISHED.

Since there are so many assumptions in these calculations, it is still too early to predict the future role of screening centers or medical demand solely from the results of these studies. However, we believe that these simulation studies will play an increasingly important role in the future in performing broad studies like the national projects described in this paper. 
Comments of the Discussant, Mr. Page

Mr. Page felt that the conference would hardly be able to do justice to the topics--the role of computerization and of information systems within the health context--that had been raised by Messrs. Rehak and Atsumi. Instead he proposed that attention should be directed to the role which systems analysis could play in tailoring information processing to the needs of the health sector. To do this, lessons can be learned from the experience with management information systems and with scientific and technical information systems. Even so, the different objectives for medical information systems must clearly be recognized. Consideration should be given to deciding what parts of the system can, must, or must not be mechanized. Should the system be composed of many self-sufficient modules or should it be structurally integrated? What standards of reliability should be applied? If the systems require interactive capability, attention must be given to the adequacy of the telecommunications facilities. A significant result of management information systems which may be duplicated in the medical area is that their implementation has led to the reshaping of the entire decision structure.

\section{Information System Purpose}

Mr. Bailey felt that one more critical question deriving from experiences with information systems generally should be addressed to systems designers for the health sector: what specific purpose the system is to have. He noted two broad classes of systems that may be differentiated by their level of purpose. On the one hand are specific systems designed to provide well-defined information sets to policy-makers faced with a given and limited series of decisions. On the other hand are the multi-purpose sytems that bring together broad sets of information for comprehensive projections into the future. These differences of purpose can lead to huge disparities in system size and ambition.

\section{Unity of Information Systems}

Mr. Venediktov noted that Mr. Page referred to information systems for management, for scientific and technical purposes, and for the health sector as separate entities. Would there not be significant gain in melding the different attributes of these systems into one system that would combine scientific and technical inputs so that better management could be achieved in the health sector?

\section{System Obsolescence}

One speaker felt that a critical oversight in establishing health information systems was that their limited lifetimes were not recognized. User needs change and the technology improves. Both these factors limit the period of utility for information systems. Instead of ambitiously trying to satisfy eternal needs, emphasis should be placed upon user acceptability in the short term. One way to combat the inevitable obsolescence of information systems is to design them to be modular and extensible. He found modularity to be a popular figure of speech, but in practical applications a concept generally ignored.

\section{Costs and People}

It was pointed out that much talk is directed to the glowing potential of information systems but all too little attention is given to their costs. Information systems should be critically examined to discover which less essential components can be eliminated to effect cost savings. When reckoning up the costs, the hidden drain in terms of user time and reporting demands of personnel should not be overlooked if a concept of total system performance is to be obtained. Mr. Atsumi stated that the design of the medical information system described in his paper paid constant heed to the three interrelated constraints of money, men, 
and time. It was suggested that, to these constraints, should be added a fourth of user convenience. Too many health information systems have failed because the burden of inconvenience in inputing data discouraged use. The result was that essential data bases were not maintained.

One participant saw the origin of these problems in the human system components. The enthusiasm and impetus for ambitious information systems has come from computer experts who too often leave shortly after their ideas have been implemented. In their absence, the technical know-how for maintaining the systems and adapting them to changing conditions is missing. This point was reinforced by a scientist who urged realization that the components of the information system are just as vital to its success as its hardware and software.

Another speaker agreed with these comments but saw a laudable trend in praxis. At first, health information systems were established to demonstrate proudly the new technological capacity. With increasing experience and familiarity with the problems, technology is now being more efficiently channeled into the solution of specific problems. It was urged that a preliminary evaluation now be invoked to show in just what areas computerization has been most successful and where problems remain to be ironed out. Scheduling was cited as an area where computer systems have proven clearly cost-effective. 

PART IV. RESOURCE ALLOCATION 

Systems Aspects of Health Planning, N.T.J. Bailey/M. Thompson, eds. North-Holland Publishing Company, 1975

\title{
HEALTH MANPOWER PLANNING IN A MARKE'T CONTEXT: THE CASE OF PHYSICIAN MANPOWER
}

\author{
Uwe E. Reinhard $t^{*}$ \\ Associate Professor of Economics \\ and Public Affairs \\ Department of Economics \\ and Woodrow Wilson School of Public \\ and International Affairs \\ Princeton University \\ Princeton, N.J., ITSA
}

\section{INTRODUCTION}

One can think of two extreme approaches to the design and implementation of a nation's health manpower policy. At one extreme, that policy may be formulated as an integral part of full-fledged health sector planning. At the other extreme, the public sector may decide to leave the health industry to its own devices, intervening in that industry only in the face of an acute crisis--for example, a critical shortage of health services.

Much of the scholarly literature on the subject of health policy has been oriented toward the first of these approaches. Among the explicit or implicit assumptions embodied in that literature are (1) that health manpower forecasters can accurately project health manpower requirements one or two decades into the future and (2) that health planners have the political clout to make the nation's health resources available in the planned amount, where needed, and when needed. In some of the more rigorous mathematical planning models, it is additionally assumed (3) that health planners can and will allocate scarce health resources so as to maximize a fully articulated social objective function. [For examples of such models, see Feldstein (1970a) and Maki (1967).]

Political contexts exist in which these rigorous, comprehensive planning models find practical application. In many of the industrialized Western nations, however, these models have remained academic exercises. These nations--particularly the United States and Canada--have long suffered from a mild schizophrenia in matters of health policy. On the one hand, it is believed that resource-allocative decisions in the health-care sector are best made if left to the myriad of individual economic agents in the market system. Although the medical profession has understandably been the most vigorous proponent of this thesis, the view appears to be shared by many policymakers, by many economists, and by the public at large. On the other hand, however, citizens in these nations have increasingly come to look to their governments for assurance that adequate health services are available everywhere, and at anytime. If, as sometimes happens, the health care sector fails to own up to society's expectations--for example, leaves some communities totally without access to health services-responsible leaders of that sector, notably the medical profession, are usually the last to profess responsibility for these private market failures. Public wrath in these instances is almost invariably channelled toward the public sector, which is called upon "to do something."

The "something" public policymakers in these nations have typica11y "done" in the area of health manpower is to guess what manpower shortages the otherwise unfettered health-care sector would be likely to register ten or twenty years hence in the absence of public intervention, and to assist that sector in avoiding these

* This paper was written while the author was a Visiting Scholar at the Department of Economics, Harvard University. The author wishes to thank Martin S. Feldstein for the invitation to Harvard and the Robert Wood Johnson Foundation for providing financial assistance to this visiting-scholar program. 
shortages. The preferred modus operandi of public policy has been to intervene beneficently in the markets for health professional training, with grants to health professional schools and/or direct financial assistance to the trainees. Because of either faith in the market or fear of the medical profession, or both, there has been a manifest reluctance on the part of policymakers to exert any direct influence over the organization of health-care production. As a result, public policy in this area has, in effect, amounted to a tacit ratification of whatever use-efficient or inefficient--the providers of health services choose to make of the resources available to them.

It may seem that, in comparison with full-fledged health sector planning, the design and implementation of health manpower policy in this peculiar market context is relatively simple. The opposite is more nearly the case. First, here, as elsewhere, the success of public policy is crucially dependent on the availability of accurate manpower forecasts. In a more or less free market context preparation of these forecasts involves enormous methodological difficulties. Quite aside from these methodological difficulties, however, the implementation of health manpower policy in this context is almost invariably frustrated by the economic behavior of the health industry. Because policy makers either cannot or will not exert any direct influence over the manner in which health manpower is deployed, their policies labor under the motto: Plus fa change, plus c'est la même chose.

This paper concentrates almost wholly on the problems of health manpower forecasting in a market context, although some problems of policy implementation in that context are touched on as well. To keep the discussion within reasonable bounds, it is developed against the economic and political backdrop of the United States, and focuses primarily on the demand for and supply of physician services. Furthermore, to avoid undue overlap with a separate paper on the demand for health services, the present paper places relatively greater emphasis on the supply side.

The remainder of this paper is organized around the two major features of a health-care system: (1) the technology underlying the health-care production process, and, indeed, the health production process; and (2) the behavior of individuals or institutions in the health delivery system. Approaches to characterizing the technology underlying the health-care system are discussed in the next section. By and large, these methodological issues transcend the particulars of alternative economic systems. What distinguishes health manpower policy in a centrally planned health-care sector from that in a market environment are the behavioral aspects of the system. These are explored in Section III of the paper. The paper concludes with some observations on the future of health manpower forecasting and policy in the United States.

\section{HEALTH MANPOWER FORECASTING AND THE UNDERLYING PRODUCTION FUNCTION}

The basic ingredients of a health manpower forecast are everywhere the same. The forecast begins with a projection of future changes in the size and in the socioeconomic and demographic composition of the population to be covered by the health system in question. Next, the population forecast is translated somehow into (a) the corresponding future supply of health manpower (augmented perhaps by net additions from outside) and (b) a projection of the corresponding future "demand" for or "need" of health services (hereafter referred to simply as health-service "requirements"). Insertion of these projected health service requirements into a technology matrix yields the corresponding projected health manpower requirements, which are then compared to the supply forecast to identify potential imbalances calling for remedial policy. This activity, of course, need not take place in quite so recursive a fashion as may be inferred from the above description. As will be suggested further on, there are enough feedbacks in the health system to call for a simultaneous equations approach to health manpower forecasting.

The technology matrix used to translate projected health-service requirements into projected health-manpower requirements is in ef ect a set of 
health-service production functions. At the most general level, these functions may be represented as

$$
\mathrm{S}_{i}=\mathrm{f}_{\mathrm{i}}\left(\underline{\mathrm{L}}_{\mathrm{i}}, \underline{\mathrm{x}}_{\mathrm{i}}, \underline{\mathrm{Z}}_{-\mathrm{i}}\right), \quad \mathrm{i}=1,2, \ldots, \mathrm{n},
$$

where $S_{i}$ is the rate of output of the ith health service (for example, ambulatory patient ${ }^{1}$ visits to physicians in a particular specialty, or hospital inpatient days for a given case mix), element $L_{i j} \varepsilon \underline{L}_{i}, j=1,2, \ldots, m$, is the amount of the $j$ th type of health manpower used in the production of type $i$ services, element $x_{i j} \varepsilon \underline{x}_{i}, j=1,2, \ldots, s$, is the amount of the $j$ th non-labor input into the production of $S_{i}$, and vector $\underline{Z}_{i}$ contains a set of factors not properly regarded as bona fide inputs and yet capable of influencing the rate $S_{i}$, ceteris paribus. 1ncluded $\overline{\text { in }} \underline{Z}$ might be an index of technical progress, or variables characterizing the spatial and organizational setting of the production process.

In the bulk of the literature on health manpower planning, it is assumed-either explicitly or implicitly--that the underlying health-service production functions can be properly represented by a fixed-coefficient technology matrix. If element $a_{i j}$ of matrix A denotes the anount of the $j$ th manpower required to produce one standifd unit of the ith health service, in period $t$, then the projected health manpower requirements for period $t$ are obtained from the set of equations

$$
\underline{\mathrm{L}}_{\mathrm{t}}=\underline{\mathrm{AS}}_{\mathrm{t}},
$$

where $L_{j t} \varepsilon L_{t}$ denotes the total amount of the $j$ th manpower required in period $t$ and $S_{i t} \varepsilon \underline{S}_{t}$ is the projected requirement of type $i$ health services in that period. occasionally one sees attempts made to project changes in the input coefficients $a_{i j}$ as functions of time. 1 More commonly, they are treated as constants, which amounts to denying the possibility of any future gains in health manpower productivity.

In proceeding via a technology matrix such as A above, few forecasters actually believe that the elasticity of substitution among the inputs into the health-care production process is zero for any pair of inputs and for any service, an assumption that seems implicit in the matrix. Rather, the coefficients of that matrix are thought to reflect a compound of the underlying technology with economic behavior. If one believes, for example, that whatever the true production functions for particular health services may be, they are generally characterized by constant returns to scale, and if one further believes that the input coefficients in matrix A are derived from input configurations that are in some sense optimal, then it may not be unreasonable to proceed in one's forecast via a technology matrix such as A. If "optimal" in this context is thought to be "least-cost," however, one is clear assuming that the relative prices (or relative real resource costs) of the inputs remain constant over the forecast horizon (or that the elasticities of input substitution are zero after all). One also assumes that the underlying production functions are not likely to shift, either as a result of technical progress or for still other reasons. These are clearly stringent assumptions.

In proceeding with technology matrix A one may, of course, simply believe that regardless of whether or not A reflects an optimal input configuration, force of habit in the health care sector, combined with a lack of economic pressure on

${ }^{1}$ See, for example, Maki (1967). 
the producers of health services, will somehow preserve the resource deployment reflected in the current technology matrix, so that one's best estimates of future health manpower requirements are obtained from these institutionally determined input coefficients. If so, there is great merit in providing policymakers not only with one's best estimate of the health manpower mixes likely to be required in the future, but also with estimates of alternative, technically feasible input combinations, $\underline{L}_{t}$, capable of producing the required vector of health services, $\underline{S}_{t}$. Given a set of input prices (or data on the relative real resource costs of these inputs) it would be an easy matter to associate with each of the technically feasible manpower configurations a cost figure, and thus to identify the least-cost combination, $\underline{\mathrm{L}}_{\mathrm{t}}{ }^{*}$, capable of producing the projected future health-service requirements, $\underline{S}_{t}$. If policymakers wish to help allocate society's resources efficiently, and if they have the will or political power to exert direct influence over the organization of health-care production, they might implement policies likely to deflect the health-care sector from the predicted $\underline{L}_{t}$ toward the optimal $\underline{L}_{t}{ }^{*}$.

A first step in the direction of this more flexible approach to health manpower forecasting is clearly the empirical estimation of health-service production function. In the United States, this research effort has been underway for a number of years. Although the state of the art in this area is still in the development stage, the research so $f$ ar has nevertheless been fruitful ${ }^{2}$ and encourages one to recommend sustained effort in this direction.

For the most part, analyses of the health-care production process have attempted to capture the essence of the underlying technology in a simple, non1 inear equation that is continuously variable in the inputs. 3 Since the algebraic form of that equation must be specified prior to estimation of its parameters, and because there is always the risk of specification error, some researchers have preferred to approximate the true underlying production function not in terms of a single equation but instead by a finite number of alternative processes (or "activities"), each characterized by a linear, fixed-coefficient production function. 4 Thus, if superscript $r$ denotes the $r$ th of $k$ technically feasible alternative processes that can be used to produce services of a given type, then the overall production function ( $f_{i}$ in equation (1) above) for the ith service is defined by the relationship.

$$
\mathrm{S}_{\mathbf{i}}=\min \left[1_{\mathbf{i}}, \mathbf{x}_{\mathbf{i}}\right]
$$

where element $1_{i j}$ of vector $\underline{1}_{i}$ is further defined as

$$
1_{i j}=L_{i j} / \sum_{r=1}^{k}\left[p_{i}^{r} \cdot a_{i j}^{r}\right]
$$

${ }^{2}$ For a survey of production-function estimates for hospital services, see Berki (1972). Production-function estimates for ambulatory services are surveyed in Reinhardt (1973).

${ }^{3}$ See, for example, Boaz (1972), Feldstein (1967, Ch. 4), Maurizi (1967), or Reinhardt (1972).

${ }^{4}$ See Dowling (1972), Smith, Miller, and Golladay (1972), and Uyeno (1971). 
In addition to the already familiar symbols, ${ }_{a_{i j}}^{r}$ in equation (4) is the amount of the jth manpower required to produce one standard unit of the ith service via the rth process, and $p_{i}^{r}$ is the proportion of the output rate $s_{i}$ actually produced with the rth process. (The elements of vector $x_{i}$, reflecting the non-labor inputs $x_{i j}$,
are analogously defined.) Although within each process the elasticity of substitution among inputs is assumed to be zero, health manpower substitution does become technically feasible by switching partly or wholly from one process to another--that is, by varying the $p_{j}^{r}$.

Specification of health-services production functions ( $f_{i}$ in equation (1) above) by a set of linear activities has the advantage of permititing one to work with multidimensional output indices. The parameters of these functions are typically estimated from operational statistics of particular provider facilities--for example, medical practices or hospitals--and such facilities are really in the nature of multiproduct firms. There is, therefore, something to be said for disaggregating the overall output index "ambulatory patient visits" or "patient days" into major diagnostic categories. On the other hand, it is clear that use of a linear activities model requires one to estimate the myriad of input coefficients $a_{i j}^{r}$, which is an enormous $1 y$ complex and costly undertaking. Furthermore, given the programming methods with which linear activity models are usually operated, even small estimation errors in the individual $a_{i j}^{r}$ can have serious consequences.

Approximation of the production function by even a fairly complex single, nonlinear equation involves immensely fewer parameters to be estimated. Although the limitations of available statistical methods had, until recently, confined researchers to a very narrow set of overly simple algebraic specifications, nonlinear estimation techniques are now available that enable one to posit much more plausible prior specifications. Single-equation production functions do, unfortunately, require one to measure output by a one dimensional index, although even here there has been some experimentation with multidimensional output measures. 4a A more penetrating review of these and related methodological issues can be found in Reinhardt (1973).

If reasonably accurate production function estimates were available, in whatever form, for all types of health services considered in one's health manpower projections, it would not be too difficult to develop a suitable algorithm to identify alternative, technically feasible, and technically efficient manpower mixes capable of producing some projected vector of future health service requirements. At the present time the empirical information in health care production is still too sketchy to permit such comprehensive forecasting exercises. One can at most indicate the potentially feasible manpower trade-offs that seem feasible within particular health-care provider facilities. Table 1 below is a modest illustration of such a forecasting exercise. The trade-offs considered in that table are confined to two types of health manpower: physicians in office-based, private practice (solo or single-specialty partnerships and groups) and their support personnel in that practice setting.

The basic unit of output underlying Table 1 is the patient visit to the physician's office, an output index widely used by United States health experts (and, one gathers, by those in other nations as we11). 5 The first row in the table

${ }^{4 a}$ See Mundlak (1964).

${ }^{5}$ See, for example, Rozenfeld (1963), describing health sector planning in the USSR. 
Table 1. Estimated tecinically feasible trade-offs between office-based M.D. 's and support personnel.

United States, 1970 and 1990.

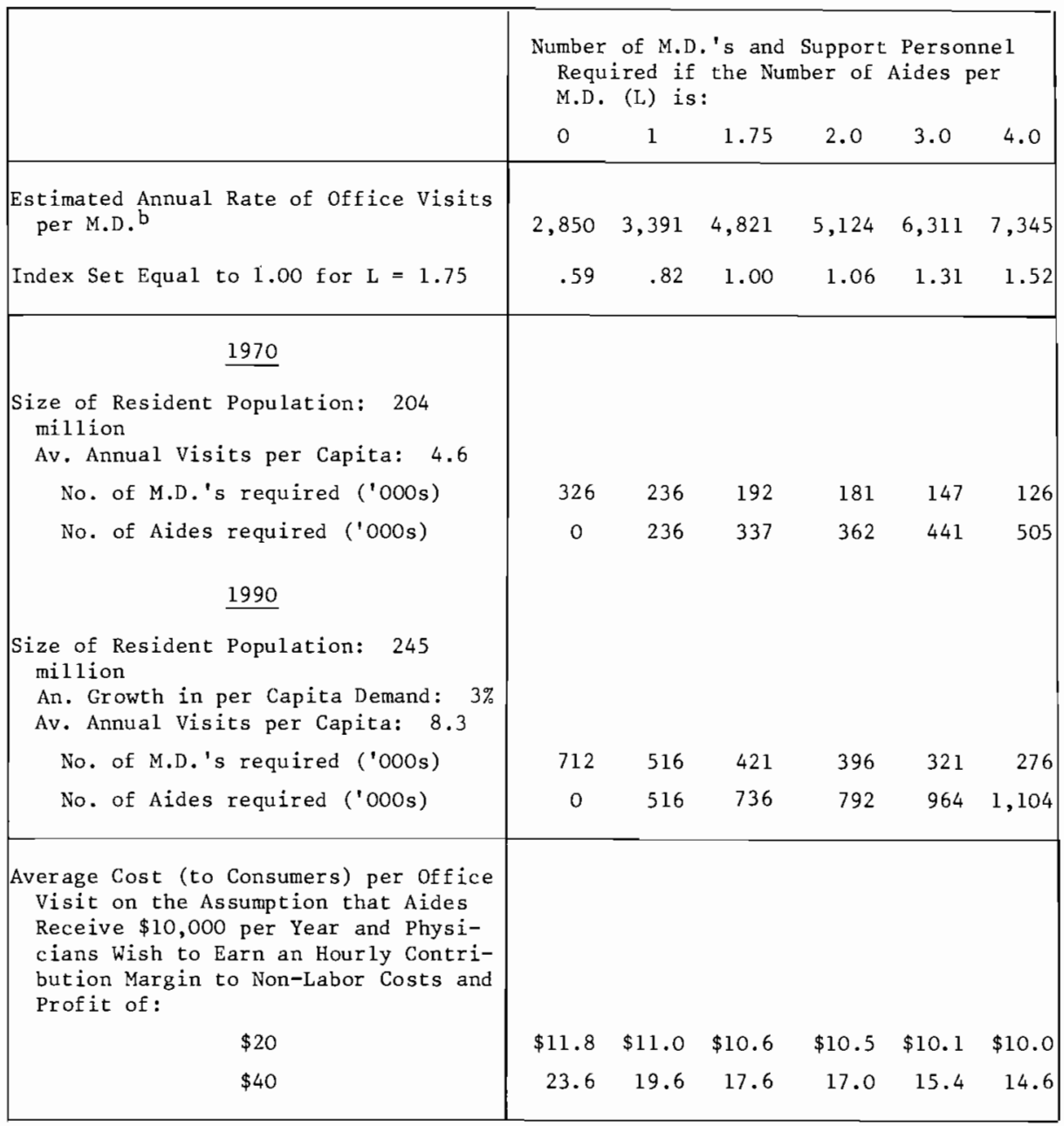

Source: Reinhardt (1974), table 7-5. 
indicates the estimated number of patient visits produced by office-based physicians with a support staff ranging from zero to four assistants per physician. These estimates are based on the production function

$$
\mathrm{Q}=\mathrm{C} \cdot \mathrm{H}^{.695} \cdot \mathrm{K}^{.045} \cdot \mathrm{e}^{.347 \mathrm{~L}-.028 \mathrm{~L}^{2}},
$$

where $Q$ denotes the physician's annual rate of office visits, $H$ is the annual number of hours devoted to the office-based part of his practice, $k$ is an index of the capital (mainly floor space and equipment at his disposition), L denotes the number of aides employed per physician, and $\mathrm{C}$ is a constant set to yield the observed average number of 4,821 office visits per physician that were actually produced by American physicians in 1970 with an average, ful1-time equivalent support staff of 1.75 aides per physician. The parameters of equation (4a) were estimated from data retrieved by a nationwide survey of self-employed American physicians and appear to be consistent with similar estimates independently derived from a different sample of physicians. For a fuller description of this and alternative estimates of physician-service production functions, see Reinhardt (1972) and (1974, ch. 6).

The remaining rows of Table 1 indicate alternative combinations of physicians and physician-support personnel that should, according to the underlying production-function estimate, be able to produce the aggregate visit rates shown in the first column of the table. The first pair of rows shows alternative manpower combinations that could have produced the number of office visits actually produced in 1970. The actual manpower combination used in that year included 192,000 officebased physicians supported by 337,000 assistants. As already noted, this combination resulted in an estimated annul average of 4,821 office visits per physician. The next pair of rows indicates manpower requirements in 1990 on the assumption that, between 1970 and 1990, the per capita demand for office visits in the United States will grow at an average annual rate of 3 percent, perhaps as a result of more comprehensive health insurance coverage for ambulatory care. Finally, the third pair of rows indicates the average cost per office visit (charged to patients or third-party payers) on the assumption that physician support personnel is paid an annual salary of $\$ 10,000$ (including fringe benefits, and in 1970 do11ars) and that the physician wishes to earn a contribution to non-labor costs and profits of $\$ 20$ or $\$ 40$ per hour he devotes to his office-based practice. 6 It is assumed, also, that the number of hours physicians devote to the office-based part of their practice will remain' constant over the forecast horizon.

The policy implications emerging from Table 1 are two-fold. First, the table suggests that, contrary to popular opinion, an unanticipated drop in the future supply of American physicians need not engender a health-care crisis if the average American physician could be induced to engage in more extensive delegation of tasks to paramedical assistants and if patients could be persuaded to accept that task delegation. ${ }^{7}$ Although this point may be brushed off as a mere artifact of a regression equation, it does find support in the data presented in Tables 2 and 3 below. As these tables suggest, regional differences in physician density

6 The average net income of American physicians is currently between $\$ 45,000$ and $\$ 50,000$. The hourly contribution margin (revenue minus the cost of auxiliary personnel per hour) varies enormously among physicians. For some physicians, the figure may be as low as $\$ 20$. The national average is likely to be between $\$ 30$ and $\$ 40$.

${ }^{7}$ Although the average number of aides per physician in medical practice is less than 2, a good number of physicians employ as many as four or even five aides per physician with highly positive effects on their hourly rate of patient visits. 
appear to be compensated to a large extent by what appears to be differences in physician productivity. 8

The gains in physician productivity suggested in Table 1 do, of course, come at the price of substantially higher numbers of physician-support personnel. Even so, the underlying technology appears to be such that, at current relative rates of remuneration, more extensive task delegation in medical practice would tend to reduce the average cost of office visits--at least up to a point--if physicians were content with a fixed hourly contribution margin of either $\$ 20$ or $\$ 40$ and thus passed on the economic benefits from task delegation to consumers (or taxpayers) in the form of lower prices. The second policy implication to be drawn from Table 1 is therefore that American physicians should be encouraged to engage in more task delegation than has hitherto been customary, even in the absence of an acute physician shortage. Whether or not the typical American physician actually has any incentives to do so is, unfortunately, another matter to which we shall turn shortly.

Although Table 1 is based on and is consistent with actual us data, it bears emphasizing that the table is intended to be merely illustrative and offered here to suggest the potential utility of the more flexible approach to health manpower forecasting proposed earlier. The obvious next step in this exercise would be to disaggregate the projections by medical specialty, which could be done with empirical information already available at this time. Next, the exercise should be extended to the hospital-based part of the physician's practice and, ultimately, to include all of the health services covered by one's health manpower forecast. Finally, to indicate more completely the full range of technically feasible alternatives open to society, one should, in principa1, extend one's analysis to the health productions process itself. This point is illustrated in Figure 1 .

At the conceptual level, the need of or demand for health services can be viewed as a derivative of a health production process which is managed by the patient, often (though not always) in consultation with his management consultant in health matters--the physician. It is widely appreciated that "medical interventions" constitute but a small subset of the inputs going into that production process, and that trade-offs between these other inputs and medical care are not only technically feasible, but highly desirable from an economic viewpoint.

Not the least important of the non-medical inputs into the health production process is the patient's own managerial acumen in this area, and that acumen can be enhanced through consumer education on health matters. Unfortunately, the educational system in the United States tends to train students in the management of virtually anything but their own health-production process. It has long been felt by some students of the health sector that significant net savings could be achieved simply by devoting more resources to consumer education in health matters. 9 In a systems-analytic perspective on health sector planning, these potential tradeoffs should not be overlooked.

Quite aside from technically feasible trade-offs between health services, on the one hand, and non-medical inputs into health production on the other, trade-offs are feasible also within the category of health-services. International comparisons of health-care utilization patterns, for example, suggest that there are large differences in the mix of ambulatory and inpatient services going into the treatment of we11-defined medical conditions, without corresponding differences

\footnotetext{
${ }^{8}$ It must, of course, be kept in mind that the patient visit is an imperfect measure of physician output. Patient visits in New England may represent services of a superior quality, although this assertion would need to be demonstrated empirically, and, in any event, the extra quality may not be worth its cost.
}

${ }^{9}$ See, for example, Anne Somers (1971). 


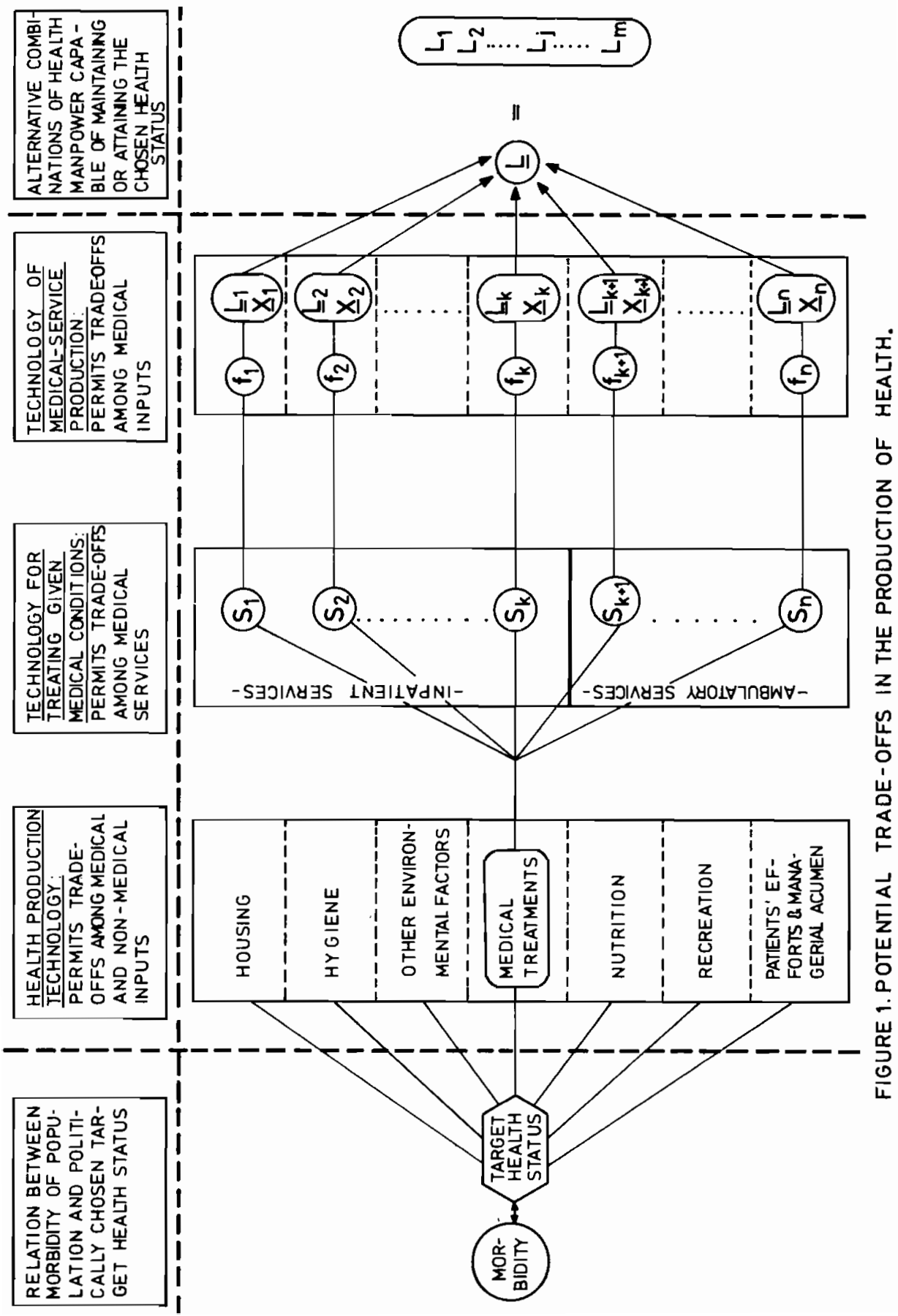


Table 2. Regional differences in certain health-care statistics. United States, $1969-1970$

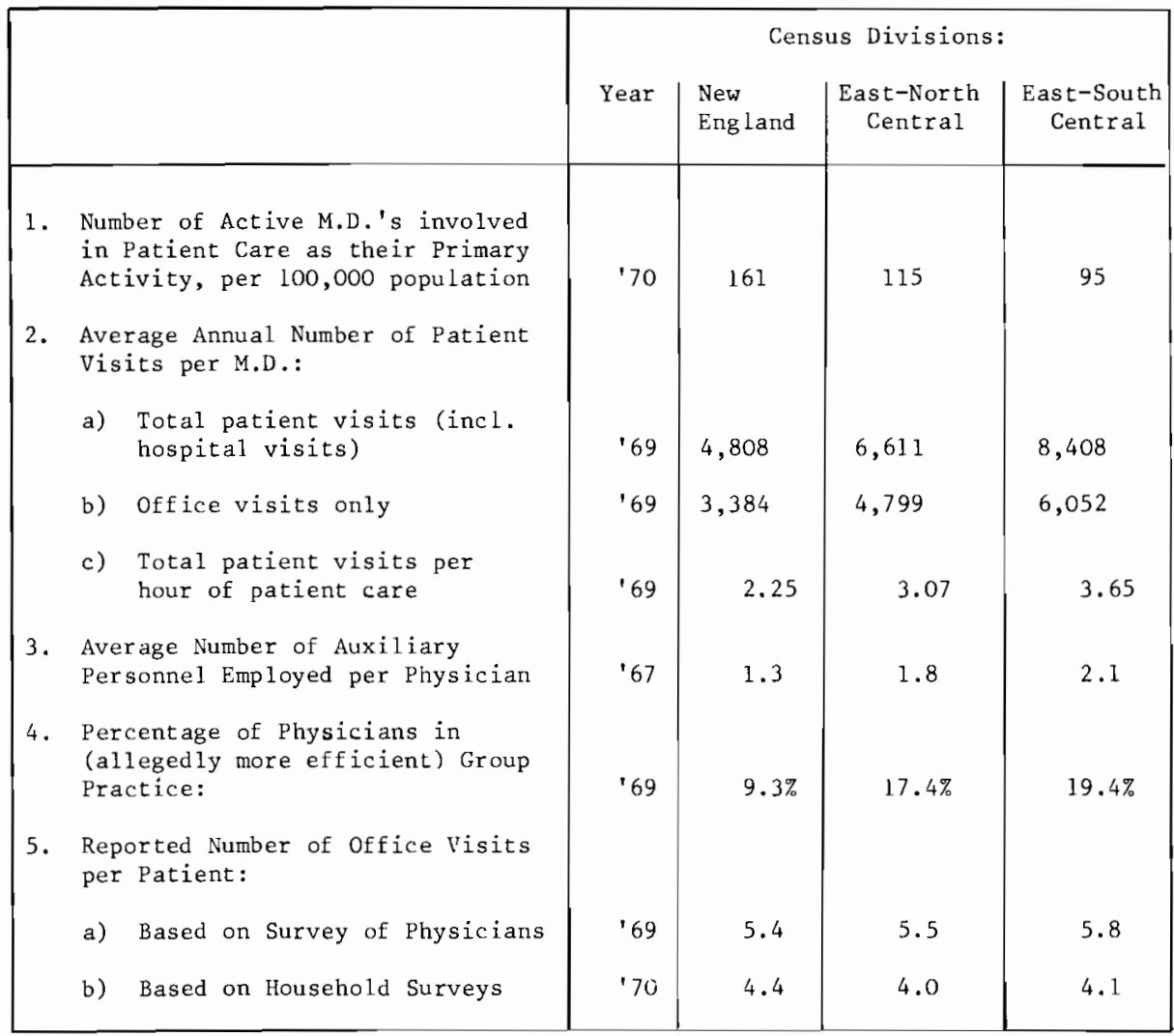

Source: Reinhardt (1974), table 2-5. 
Table 3. Physician-population Rations, patient loads, and medical fees by size of county

United States, 1970

\begin{tabular}{|c|c|c|c|c|}
\hline \multirow[t]{2}{*}{$\begin{array}{c}\text { Demographic County } \\
\text { Classification }\end{array}$} & \multirow{2}{*}{$\begin{array}{l}\text { Physician- } \\
\text { Population } \\
\text { Ratiob }\end{array}$} & \multicolumn{2}{|c|}{ Weekly Patient Visits } & \multirow{2}{*}{$\begin{array}{l}\text { Fee for an } \\
\text { Initial } \\
\text { Office Visit }\end{array}$} \\
\hline & & Total & Office & \\
\hline \multicolumn{5}{|l|}{ NON-METROPOLITAN: } \\
\hline $10,000-24,999$ & 51 & 223 & 167 & 7.15 \\
\hline $25,000-49,999$ & 64 & 217 & 164 & 7.13 \\
\hline 50,000 or more & 87 & 192 & 153 & 7.96 \\
\hline \multicolumn{5}{|l|}{ METROPOLITAN : } \\
\hline $50,000-499,999$ & 107 & 194 & 150 & 8.65 \\
\hline $500,000-999,999$ & 141 & 167 & 140 & 9.33 \\
\hline $1,000,000-4,999,999$ & 150 & 138 & 114 & 9.00 \\
\hline $5,000,000$ or more & 191 & 124 & 109 & 10.34 \\
\hline
\end{tabular}

a Numbers refer to inhabitants.

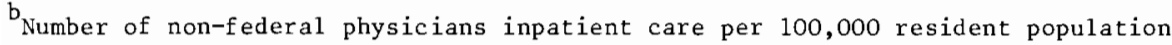
as of December 31,1970 .

Source: American Medical Association (1973), tables 55, 56, and 58 . 
in observable health status. Such differences are observed even within the United States, not only among disparate regions but, more significantly, anong distinct health-care provider systems that differ primarily with respect to the economic incentives faced by health-care providers. 10 Trade-offs are, of course, feasible also between health care in regular hospitals, on the one hand, and health care in nursing homes or the patient's home, on the other. Finally, there undoubted 1y exist potential trade-offs between professional health services, on the one hand, and pharmaceuticals on the other.

In short, then, if one truly wished to identify the entire range of alternative, technically feasible health manpower combinations capable of achieving some politically determined target level of national health status, one's set of alternatives would be based not on a single projected vector of health service requirements, $\underline{S}_{t}$, but instead on an entire menu of alternative combinations $\underline{S}_{t}$ capable of generating the target level of health status in the short and long run. It is clear that so far flung an analysis is quite infeasible at this time, if only for want of the requisite empirical information. But even if such information were one day to become available--and research into the various trade-offs alluded to above is currently underway--it can be doubted that it will ever be feasible to implement a national health policy based on such an analysis. For one, attainment of the globally optimal resource configuration suggested by the analysis might require the public sector to intrude quite forcefully into the individual's management of his/her own health. In some societies it may be politically feasible to carry public policy to so personal a level, particularly in the area of child health care. In the United States, however, the approach is unthinkable. The maximum intrusion likely to be tolerated ever in the United States would be policy measures designed to induce efficiency on the part of health-care producers, and even such policies are still viewed as politically adventurous. In the foreseeable future, health manpower policy in the United States will undoubtedly continue to concentrate on providing whatever health manpower requirements are generated by the otherwise uncontrolled healthcare sector. We now turn to some of the more vexing forecasting problems this policy approach engenders.

\section{BEHAVIORAL ASPECTS OF THE HEALTH SECTOR}

The preceding discussion has focused solely on efforts to identify the technology underlying the health- and the health-services production processes. Such information indicates the range of technical opportunities faced by society. We now turn to the problem of predicting the health system's probable response to these opportunities.

In societies where the behavior of individuals and institutions can be influenced through officially decreed health-care consumption standards, output quotas and staffing patterns in health-care facilities, such predictions need not be insurmountably difficult. They are enormously complex in the more loosely organized health market systems of the United States, Canada, and some of the Western European nations. In these matters individual consumers have the right to consume whatever health services they can afford (or, not infrequently, to go without whatever care they cannot afford); health-care providers-notably physicians--are free to locate their facilities where they see fit, to staff them how they see fit, and to work as hard as they please; and individuals are free to apply the human capital they have accumulated during vocational or professional training in any manner they see fit-even not to use it at all. In that context, a truly comprehensive health manpower

${ }^{10}$ In general it is found that populations covered by comprehensive prepaid health plans--such as the Kaiser Foundation Medical Plans in California--exhibit lower rates of surgery and hospitalization than do similar populations covered by fee-for-service insurance plans. In this connection, see Donabedian (1969). For an imaginative interpretation of this phenomenon, see Monsma (1970). 
forecast ultimately becomes a far-flung, dynamic, simultaneous-equations model constructed around at least three distinct sets of markets: the markets for health services, the markets for health manpower, and the markets for health vocational or professional training.

Figure 2 presents a schematic overview of these markets and of the interrelationships among them. An arrow from one block in that schema to another should be read as "partially determines." Most of the causal flows shown in the diagram are perfectly straightforward and require no additional comment. They would, in fact, be compatible with the economic organization around any ordinary commodity produced and sold in the context of a market system. Some of these flows, on the other hand, are peculiar to the health care system. They reflect the fact that consumers in the health-service markets do not enjoy the same degree of sovereignty consumers enjoy in markets for more ordinary commodities, and the observation that prices in the health-care sector do not seem to move freely to equilibrate markets, thus giving rise to various forms of non-price rationing, in case of shortages, or to artificially induced shifts in demand, in the case of a surplus.

Although Figure 2 is fairly general, it will be convenient for purposes of exposition to narrow our focus to the supply of physician services. In the United States (and in Canada) the bulk of these services are produced by self-employed physicians in private medical practice and sold on a fee-for-service basis. Although a small mirority of physicians practice in large multi-specialty groups or clinics-occasionally even on a salaried basis--the norm continues to be the solo practice or small, two-to-three-man partnership, in which physicians are supported by an auxiliary staff of one or two assistants per physician. The typical physician also has access to one or several hospitals in the vicinity which he can use, free of charge, for procedures involving surgery or treatments involving complex equipment.

\section{THE MARKETS FOR PHYSICIAN SERVICES AND THE MANPOWER USED IN MEDICAL PRACTICE}

The market for physician services has long held the fascination of American health economists, not only because that market is the cornerstone or any healthsector model, but also because it offers researchers some interesting challenges. Research on the behavior of this market has quite logically divided itself into the demand for physician services, the determinants of physician fees, and questions relating to the precise shape of the physician-service supply curve. Research on the related markets for health manpower has focused primarily on the demand for physician support personnel and on the number of hours physicians work per week or year. Given the economic characteristics of medical practice, it is not useful from an analytic viewpoint to treat the practice's demand for physician labor as a distinct research focus. The supply of physician support personnel, on the other hand, has drawn little attention from researchers, because that personnel comes from the much larger labor pool physicians share with the hospital sector. Since the hospital sector dominates in that market, the supply of physician support personnel faced by a medical practice has hitherto been treated as perfectly elastic at an exogenously determined wage rate. The recent emergence of specialized physician support personnel (the so-called "physician extenders") will eventually generate more research interest in the supply side of that market.

A very excellent, comprehensive survey of research in health economics has recently been completed by Martin S. Feldstein (1973). Our purpose here is not to repeat that survey. Rather, we shall draw selectively from the available literature in commenting on some of the hypotheses embodied in Figure 2 (and in Figure 3 further on).

\section{A. The Demand for Physician Services}

As noted in the introduction to this paper, our discussion deemphasizes the demand for health services to avoid overlap with a separate paper on the subject. Probably the only points worth special mention are embedded in the hvonthesized 


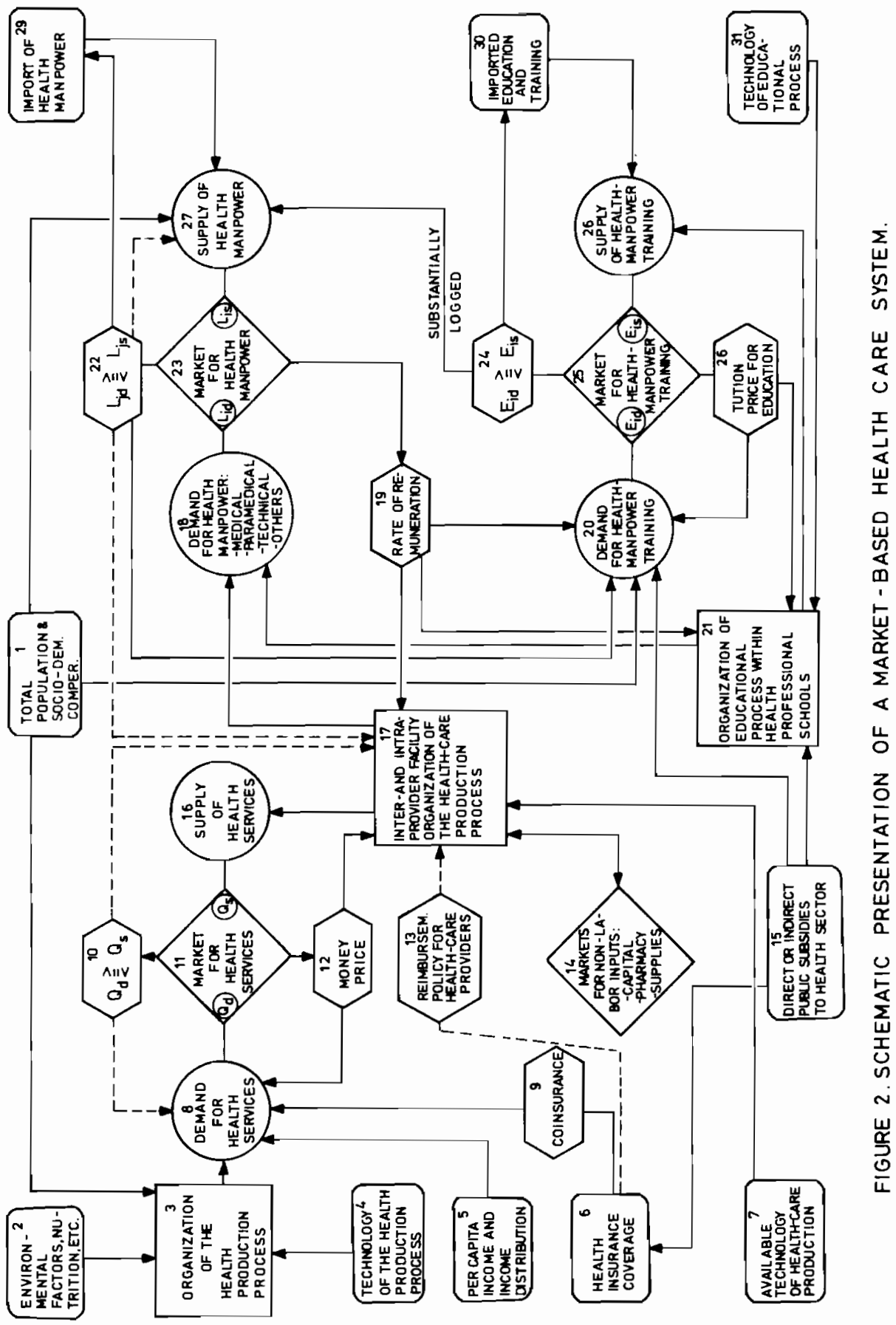


causal flow from box 10 to box 8 of Figure 2 .

It is reasonable to suppose that a potential excess supply of physician services $\left(Q_{d}<Q_{S}\right)$ will not generally trigger a market-equilibrating decline in physician fees. Instead, physicians are likely to induce upward shifts in the demand for their services until equilibrium is restored. The physician's ability to induce such shifts originates in the dual role he plays in the market for his own services. on the one hand, the physician acts as the consumer's management consultant and agent in determining the demand for the health services going into the treatment of a medical condition. On the other hand, however, he is typically also one of the suppliers who meet that demand, and in that role he acts as a profit-oriented businessman, albeit a professional one. On the face of it, this peculiar circumstance creates an economic conflict of interest to which individual physicians may succumb in the face of potential excess supply. There is some evidence--controversial to be sure, but suggestive nevertheless--that, in the United States, demand is occasionally induced in this way in the relatively overstaffed specialty of general surgery.

Shifts in the demand for physician services may occur also under conditions of excess demand $\left(Q_{d}>Q_{S}\right)$. There is evidence that under these circumstances physicians do not generally raise their fees to clear the market (Feldstein (1970)). Instead, physicians appear to resort to various forms of non-price rationing, a phenomenon also represented by the arrow from box 10 to box 8 in Figure 2. The analytically most tractable form of non-price rationing is an increase in the time costs patients must bear to gain access to physician care. This can be accomplished simply by letting queues build up. The more recent empirical work on the demand for physician services (see, for example, Feldstein and Friedman (1974) and Phelps and Newhouse (1974)) has formally incorporated these time costs of health-care consumption into the underlying models. By virtue of his influence over the demand side the physician may, of course, also reduce the number of services rendered per medical case, perhaps to make basic medical care available to a larger number of patients. In modelling the physician's behavior one should never overlook that physicians practice medicine not only for the money.

\section{B. The Pricing of Physician Services}

In the unfettered market environment still characteristic of private medical practice in the United States, individual physicians are free to set their own fees, subject only to the constraints of the market, if any. In the previous section, it has been repeatedly suggested that physicians may not set fees so as to equilibrate the market for their services. Precisely what determines their fees, however, is still a much debated question among students of the health sector.

A variety of alternative theories on physician pricing has been suggested in the literature. With some simplification, these theories order themselves into the following grid: 


\begin{tabular}{|c|c|c|}
\hline & $\begin{array}{l}\text { A } \\
\text { FEES } \\
\text { Clear the Market for } \\
\text { Physician Services }\end{array}$ & $\begin{array}{l}\text { B } \\
\text { FEEs } \\
\text { Do Not Clear the Market } \\
\text { for Physician Services }\end{array}$ \\
\hline $\begin{array}{l}\qquad \text { I } \\
\text { Physicians are } \\
\text { Price-Takers }\end{array}$ & $\begin{array}{l}\text { The physician sells his } \\
\text { services in a competitive } \\
\text { local market and reacts to } \\
\text { market-determined local fee } \\
\text { schedules. }\end{array}$ & $\begin{array}{l}\text { There are price ceilings, } \\
\text { or fee schedules which are } \\
\text { set by third-party payers, } \\
\text { and the individual physi- } \\
\text { cian reacts to these fees. }\end{array}$ \\
\hline $\begin{array}{l}\text { II } \\
\text { Physicians are } \\
\text { Price-Setters }\end{array}$ & $\begin{array}{l}\text { The physician enjoys a } \\
\text { monopoly in the market for } \\
\text { his services and sets his } \\
\text { fees as a single-price } \\
\text { (fixed fee-schedule) or } \\
\text { price-discriminating } \\
\text { (sliding-scale fee- } \\
\text { schedule) monopolist. }\end{array}$ & $\begin{array}{l}\text { The physician takes what- } \\
\text { ever cases he likes, or- } \\
\text { ganizes his practice to } \\
\text { suit his tastes, and sets } \\
\text { his fees so as to generate } \\
\text { a given target income, } \\
\text { related, presumably, to } \\
\text { the income distribution } \\
\text { in his locality. }\end{array}$ \\
\hline
\end{tabular}

These alternative theories clearly have varying implications for economic models of physician behavior and, in particular, for models of the supply of physician services. The subject matter is therefore of great interest to health manpower forecasters.

In so-called target-incone models (type II-B) the physician is assumed to work under conditions of chronic excess demand (Feldstein (1970)), which ipso facto imputes to him discretionary power over his fees. If the physician uses a single fee schedule applied to all of his patients, the fees for individual services are probably determined on the basis of some full-cost pricing formula with a profit margin set to yield the desired overall income (Reinhardt (1970), Appendix A). Alternatively, it may be assumed that the physician uses his discretionary power to tailor his fees to his individual patients' ability to pay--that he uses a socalled sliding-scale fee system. On the surface such a system may strike one as price discrimination. Under conditions of excess demand, however, it is more akin to a user-tax system under which the individual user's taxes are a function of his or her ability to pay and taxes are set at levels to yield a given target take. Incidentally, under target-income pricing, an increase in a region's physician population ratio would be expected either not to affect physician fees at all, or to push them upward. The strong positive correlation between physician fees and physician density in the United States is thus consistent with the target income hypothesis, although the phenomenon also sustains rival theories.

Excess demand models may well be descriptive of the real world, especially of the 1950's and 1960's when the overall physician supply was indeed rather taut. Economists find such theories troublesome from an analytic viewpoint. The problem is that, whatever his pricing formula may be, the individual physician in these models is not subject to an effective market constraint on the demand side. His choice of the input-output rates for his practice are thus likely to be based on a mixture of personal, social, and medical considerations, and may not be linked at all to observable economic variables. Similarly, it is anybody's guess how the target income is chosen. Within the context of such models the economist's analytic tools tend to lose much of their cutting edge. The fact that these models may in fact be descriptive of past periods furnishing the empirical record for current research on physician behavior is probably one reason why economists have so far 
had relatively little success in obtaining robust estimates of the supply of physician services at the individual practice level.

Models positing the condition of perennial excess demand are more tractable if the individual physician is a pure price-taker, as would be the case in type I-B models. As far as the physician's input-output decision is concerned these models are identical to the type I-A model, and empirically testable relationships can readily be derived from them after one has specified a concrete objective function for the physician.

In principle, the same can be said also of type II-A models, although here the entire demand function for the individual physician's services must be specified and estimated in an analysis of the physician's input-output and pricing decisions. Models of type I-A or II-A must also be reconciled somehow with the notion that physicians can induce additional demand for their services at will, a notion that is incompatible with the hypothesis that physicians are market constrained in their pricing behavior. One assumption one could make is that, in equilibrium, the physician will have induced any additional demand for his services that can safely be induced. In that case one would have to posit implicitly fairly high physician-population ratios. An alternative hypothesis, recently suggested by Pauly (1973) is that the demand function to which the physician reacts has not necessarily been pushed by him as far up as it could safely be pushed on purely medical and legal grounds, because physicians may have some moral qualms about inducing the demand for their services for pecuniary reasons. If so, the position of the demand curve to which the physician reacts is a function of the number of colleagues with whom he shares a given patient pool. The notion underlying this theory is that if the local physician-population ratio rises and the physician's share of the local patient pool (and his income) falls, his moral qualms about inducing demand will be thereby eroded (because moral sentiments tend to be a normal good) and he will seek to shift the demand curve to which he reacts further upward. On this theory, physicians may feel subject to a market constraint (partially fixed by their own moral standards) even at fairly low physician-population ratios.

It may be the case that, from a policy standpoint, the economists' focus on the past and current pricing behavior of American physicians is somewhat misplaced, because the United States can be expected to follow the lead of other nations and soon introduce a national health insurance system. Under such a system, American physicians would most probably continue to be reinbursed on a fee-for-service basis, but according to fee schedules negotiated between regional medical associations and third-party payers--perhaps the government itself. The individual physician would therefore find himself in a market environment of type I-B, and it would be operationally meaningful to speak of a supply function for his services. Figure 3 further on depicts the physician's supply response to the exogenously given price vector schematically. That diagram is simply an enlargement of certain microeconomic sections in Figure 2 .

\section{The Supply of Physician Services}

A narrowly focused forecasting equation designed to project some aggregate index (e.g. physician-patient visits) of the number of physician services available in some future year $t$, in medical specialty $i$, would be

$$
S_{i t}=\left[\frac{1}{N} \underset{v=1}{N}\left(q_{i v t}\right)\right] \cdot \sum_{j=t-r-e}^{u}\left(z_{i j t} M_{i j t}\right) \text {, }
$$




$$
N=\sum_{j=t-r-e}^{u}\left(z_{i j t} M_{i j t}\right)
$$

In this expression, $q_{\text {ivt }}$ denotes the rate of output produced by the vth practitioner in specialty $i$ in period $t, M_{i j}$ is the number of physicians who entered medical school $j$ years prior to $t$, who redeived specialty training in specialty $i$, and who remain alive during period $t$, and $z$ is the proportion of that cohort who are actually practicing medicine, part-time or full-time, in specialty i. Proportion $\left(1-z_{i j t}\right)$ may either have retired by time $t$, practice medicine in some other specialty in period $t$, be engaged in full-time research, or even hold a purely administrative job. The bracketed term on the right side of equation (5) may be referred to as the "average annual physician productivity."

$$
\begin{aligned}
& \text { Variables } q_{i v t} \text { and } M_{i j t} \text { in equation (5) may be further defined as } \\
& q_{i v t}=f_{i}\left(H_{v t}, \underline{L}_{v t}, \underline{x}_{v t}, \underline{\Omega}_{v t}\right)
\end{aligned}
$$

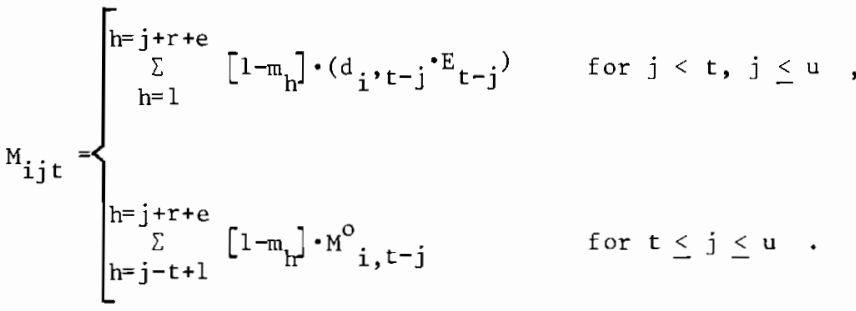

Equation (5a) is the already familiar production function with input rates defined for the vth physician, $\underline{L}_{v t}$ denoting his support personnel and $H_{v}$ the input of his own time. Henceforth we shall refer to the input configuration ${ }_{\mathrm{H}}{ }_{v t}, \underline{\mathrm{L}}_{\mathrm{v} t}, \underline{\mathrm{x}}_{\mathrm{v} t}, \stackrel{\Omega}{\mathrm{v} t}$ ) as the "organization of the physician's production process" as distinct from the technology constraining his production decisions, a constraint represented as before by the function $f_{i}$ and assumed to hold for all physicians in specialty $i$.

In equation ( $5 b), \mathrm{E}_{t-j}$ denotes the number of students who entered medical school in calendar year $t-j, d, i, j$ is the percentage of these students opting for residency training in specialty ${ }_{1}, \mathrm{M}_{\mathrm{i}, \mathrm{t}-\mathrm{j}}^{\mathrm{O}}$ is the number of physicians who entered medical school $j$ years prior to $t$ and were alive at time $t=0$ (the base year in which the forecast is made), and $m_{h}$ is the percentage of medical students or physicians who are alive h-l years after entering medical school but do not survive the hth year. Since medical students are of roughly the same age upon entering medical school, $m_{h}$ is readily linked to age-specific mortality rates. Finally, parameter $e$ in equations (5) and (5b) denotes the number of years students are in medical school and $r$ the number of years they are in residency training. Equation (5b), incidently, could be refined by accounting explicitly for dropouts from medical school or residency training. In practical applications, $M_{i j t}$ should also be adjusted for net emigration or immigration of medical manpower. These refinements, however, would add little to our present discussion.

It is clear that to forecast the future time path of $M_{i j t}$, one must explore and forecast the behavior of the market for medical education and the market for residency training. Some comments on these markets will be offered further on, in a separate section. The specialty-specific labor force participation rate, $z_{i j t}$, is part of the supply side in the market for health manpower. In the United States, 
where physicians remain at least partially active until a fairly advanced age, this rate varies primarily with the age of the $j$ th cohort. The rate may, however, fluctuate also in response to market conditions. For example, a perceived excess supply of physicians in the ith specialty might induce many of the physicians in that specialty to switch to another specialty (even if that requires additional specialist training), or even to seek out administrative or research positions. In Figure 2 above, that kind of shift is alluded to by the arrow running from box 22 to box 27.11 Since some medical specialties in the United States--especially surgical specialties--are rapidly becoming overpopulated, variable $z_{i j}$ will undoubtedly attract the attention of researchers before long. So far, that aspect of the supply side has been virtually overlooked in the literature.

Variable $q_{i v t}$ in equations (5) and (5a) represents the individual physician's annul output (or productivity). Table 1 above illustrates the crucial role this variable plays in the projection of future health manpower requirements. As was noted in the section on physician fees, it is difficult to come to grips with the determinants of this variable if the typical physician can in fact price his services so as to attain some target income. The problem is more readily tractable if the physician's pricing decisions are market constrained (type I-A or II-A pricing models), or if he otherwise reacts to exogenously determined price (fee) levels (type I-B models). Figure 3 below is drawn on the latter assumption.

Figure 3 is based on the theory that, in managing the production decision process for his practice, the physician seeks to maximize a utility function (or "happiness-production" function)

$$
U=U(R, Y, L, D ; \underline{Z}),
$$

subject to the time constraint

$$
\overline{\mathrm{H}}=\mathrm{R}+\mathrm{H} \text {, }
$$

the production function

$$
\mathrm{q}=\mathrm{f}(\mathrm{H}, \mathrm{L}, \mathrm{K} ; \underline{\Omega}) \text {, }
$$

the definition of net income

$$
\mathrm{Y}=[1-\mathrm{t}(\pi+\mathrm{I})][\pi+\mathrm{I}],
$$

the definition of pretax profits

$$
\pi=\mathrm{pq}-\mathrm{wL}-\mathrm{rK},
$$

\footnotetext{
11 It has been estimated, for example, that a large proportion of general surgeons in the United States perform not more than two surgical procedures per week and devote the remainder of their time to the practice of general medicine.
} 


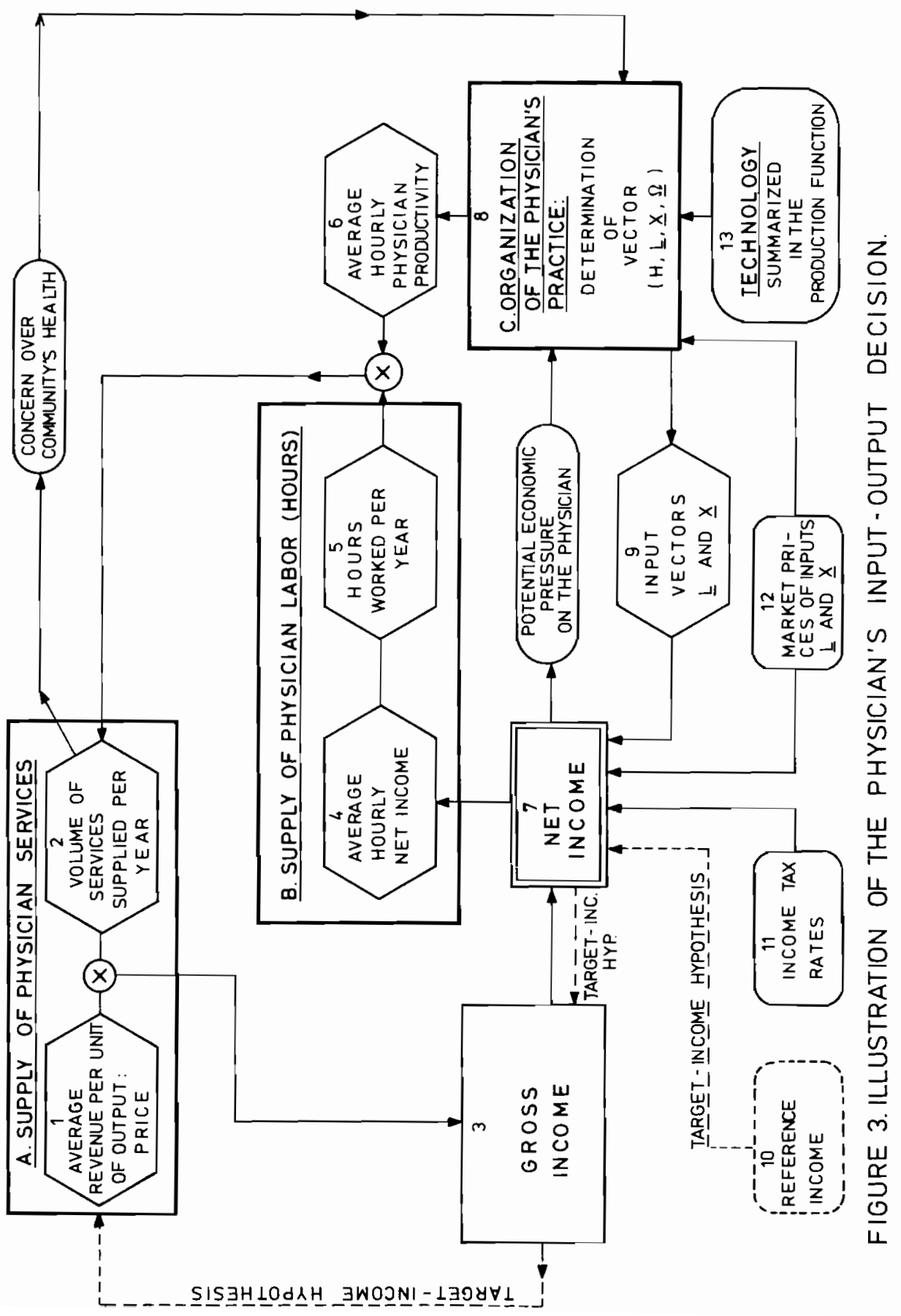


and an index D relating the physician's perception of the per capita consumption of physician services by consumers in his immediate neighborhood to his own output rate $\mathrm{q}$. For the sake of expositional convenience, one may assume that the physician's output can indeed be measured by the one dimensional index $q$, that a meaningful, exogenously given price, $p$, can be associated with that output index (p could readily be made to vary as a function of $q$ ), that there is only one type of physician support personnel whose rate of input per period (e.g. man-hours per period) is denoted by $L$ and whose cost to the physician (salary and fringe benefits) is $w$ per unit, and that the physician's use of non-1abor inputs can be represented by the one-dimensional index, $K$, the cost of which to the physician is $r$ per unit and per period. In addition to these and the already familiar symbols

$$
\begin{aligned}
& \mathrm{H}=\text { the number of hours the physician works per period, } \\
& \mathrm{R}=\text { his number of leisure hours (non-work hours) per period, } \\
& \overline{\mathrm{H}}=\mathrm{a} \text { total-time constraint, } \\
& \mathrm{I}=\text { income not derived from his practice, } \\
& \mathrm{t}=\mathrm{t}(\pi+\mathrm{I}) \text { is a progressive income-tax rate, }
\end{aligned}
$$

and vectors $Z$ and $\Omega$ are other variables entering the utility and the production function respectively. The elements of $\Omega$ have already been discussed earlier in this paper. Vector $Z$ may include the physician's age, variables describing the income distribution in his own neighborhood and/or within his peer group, and certain professional aspects of the practice to which the physician attaches significance.

In this particular model of the physician's production decision process, the input of physician support personnel, L, is entered directly into the physician's utility function on the notion that the typical physician dislikes the administrative headaches associated with the employment of a large auxiliary staff and that he attaches certain non-monetary, purely psychic costs to the employment of aides. It is furthermore assumed in this model that the typical physician derives satisfaction from the thought that patients in the immediate community with which he identifies receive adequate health care. It is hypothesized that, if the physician perceives unmet health-care needs in his community, he will work longer hours than he otherwise would be inclined to work. It is thought that by working extra hours, or by raising his own productivity through more extensive task delegation to aides (by raising L), the physician believes to make a perceptible contribution to the per capita consumption of physician services, D, in his community. This hypothesis is fully consistent with the observable behavior of American physicians in certain underdoctored areas in the United States, especially in the rural South.

Equations (6) to (10) have been presented here to flesh out Figure 3 and to underscore certain methodological difficulties one encounters in developing an analytic framework for projecting the future time path of the average annual physician productivity (or, more specifically, the output indices $q_{i v t}$ in equation (5) above). In principle, the supply of physician services (block A in Figure 3) can be developed from the production function (8) above and the additional first-order conditions generated by the model, namely:

$$
\begin{aligned}
& \frac{\partial U}{\partial H}=-U_{R}+\left[U_{Y} p\left(1-t^{\star}\right)+U_{D} D_{q}\right] \cdot f_{H}=0, \\
& \frac{\partial U}{\partial L}=U_{L}+\left[U_{Y} p\left(1-t^{\star}\right)+U_{D} D_{q}\right] \cdot f_{L}-\left(1-t^{*}\right) w=0,
\end{aligned}
$$




$$
\frac{\partial U}{\partial K}=\left[U_{Y} p\left(I-t^{*}\right)+U_{D} D_{q}\right] \cdot f_{K}-\left(1-t^{*}\right) r=0,
$$

where, in general, a letter-subscript to functions $U, D$, or $f$ signifies the $f$ irst partial derivative of that function with respect to the variable identified by the letter-subscript, and $t^{k}$ is the marginal tax rate faced by the physician. For any exogenously given set of prices $\overline{(p, w, r)}$, that set of equations yields a solution vector ( $\hat{q}, \hat{\mathrm{H}}, \hat{\mathrm{f}}, \hat{\mathrm{R}}$ ), so that cne could, in principle, trace out the functional relationship between $p$ and $q--$ the supply of physician services. ${ }^{t}$

This analytic derivation of the physician-service supply curve would, of course, be possible only if the precise form and the parameters of the production function (f), the physician's utility function (U) and of function D were known. In practice that information is simply not available. It is difficult to imagine that it would ever be available. And even if one reduced the model to the version in which such models are traditionally given--by eliminating $L$ and $D$ from the utility function--the utility function would still have to be known to obtain the shadow price of the physician's own time,

$$
\mathrm{U}_{\mathrm{R}} /\left[\left(1-\mathrm{t}^{*}\right) \cdot \mathrm{U}_{\mathrm{Y}}\right]
$$

One way of overcoming these difficulties in empirical work is, of course, simply to bypass the structural equations (8) and (11) to (13) and to estimate the supply of physician services directly by relating observed output rates, $q$, to observed prices, $p$, and other variables the model suggests as potential determinants to the supply curve.

One of the earliest and best-known attempts to estimate a physician-service supply function (block A in Figure 3) is Martin Feldstein's paper, "The Rising Price of Physicians' Services'(1970). From the viewpoint of health manpower policy the most significant conclusion in that paper is that the supply of physician services is backward bending over the empirically relevant rate--that is, that $\mathrm{dq} / \mathrm{d} p<0$ on the estimated portion of that supply curve. This result is perfectly compatible with the preceding model of physician behavior. In that model a price increase generates a (positive) income change, ceteris paribus, and by itself that income gain should induce the physician to consume added leisure, considered here a normal good. On the other hand, a price increase also raises the rate at which the physician can translate leisure hours into income. By itself, this effect should induce the physician to substitute added income for leisure. Feldstein's result simply suggests that the income position of the typical American physician is sufficiently high to permit the "income effect" of a price increase to outweigh its "substitution effect." The policy implications of that conclusions are obvious.

Sloan, in a recent paper (1973), has attempted to estimate the physician's labor supply function (block B in Figure 3) by regressing hours worked (H) on hourly remuneration $(\mathrm{Y} / \mathrm{H})$ and other variables likely to affect $\mathrm{H}$. In effect, Sloan's analysis is an attempt to estimate the relationship for the solution value $\hat{H}$ one would derive from the simultaneous solution structural equations (8) and (10) to (13) for vector $(\hat{\mathrm{H}}, \hat{\mathrm{L}}, \hat{\mathrm{K}}$, ). Sloan finds the observed values of $\mathrm{H}$ to be $\mathrm{f}$ airly unresponsive to the physician's observed hourly remuneration, suggesting an almost vertical labor supply curve over the empirically relevant range. This result, incidentally, can readily be reconciled with Feldstein's backward-bending supply of physician services,

For a graphical illustration of this equilibrium solution, see Figure $A-1$ in the appendix to this paper. 
if one includes L (the size of the physician's auxiliary staff) in the physician's utility function. In that case, a decrease in the price of physician services might not affect the number of hours, $H$, the physician works, but lower the psychic costs of employing aides-- $\mathrm{U}_{\mathrm{L}} /\left[\mathrm{U}_{\mathrm{Y}}\left(1-\mathrm{t}^{*}\right)\right]-$-by depressing income and raising $\mathrm{U}_{\mathrm{Y}}$. Consequently, the physician would be induced to increase his auxiliary staff at given monetary wage $w$, in order to raise his hourly productivity (and income) through more extensive task delegation. Such behavior would tend to generate a backward bending supply of physician services even if the physician's labor supply were unresponsive to hour ly remuneration. 12

To sum up at this point: One of the more crucial variables in projecting the future supply of physician services is the average annual productivity of physicians. In a market system, that variable cannot be fixed by officially decreed quota--its value is a product of the individual physician's production decision process. Empirical research on the part of economists to shed light on the nature of this process is still in its infancy, although progress is being made on that front. In the meantime, health manpower forecasters have little choice but to continue the traditional practice simply of extrapolating past growth in physician productivity into the future, or perhaps even to assume constancy of this variable over time.

\section{THE MARKETS FOR MEDICAL EDUCATION AND RESIDENCY TRAINING}

As noted in connection with equation ( $5 b$ ) above, variable $E$ in that equation (the number of students entering medical school at a given time) and variable $\mathrm{d}_{i}$ (the proportion of medical-school graduates in a given year electing residency training in specialty i) are determined in the markets for medical education and for residency training, respectively. Neither market has received much attention from economists, probably because they seem to be in a perennial state of disequilibrium which, in turn, can be traced to the heavy involvement of public financing in health professional training. In fact, many Americans find it difficult to think of health professional training in terms of markets at all.

A student entering medical school in the United States can expect, with virtual certainty, that successful completion of his/her training will quickly propel him/her into the top tenth or fifth percentile of the nation's income distribution. Paradoxically enough, there has been little sentiment so far to ask the beneficiaries of this propulsion to finance the cost of their education out of their hand some future rewards, As a result of the substantial public subsidies to health professional schools and to medical students, the tuition borne by students currently covers only a fraction of the true average costs identifiable with a medical education--perhaps as little as 10 percent. Given this disparity between the private costs of and returns from an investment in medical education, it is not surprising that the market for medical educations is characterized by substantial excess demand--and has been so for several decades. (In recent years the ratio of qualified applicants to acceptances in American medical schools has been about 2 to 1 .) During the post-war years the time path of the annual number of first-year medical students $(E)$ has been determined solely by the number of medical school places supplied. It may be noted in passing that some of these places have, in effect, been "imported" from European, Canadian, or Mexican medical schools to which candidates rejected by American schools have turned in desperation (see the arrow from box 30 to box 28 in Figure 2).

There is reason to believe that the financial arrangement surrounding the training of physicians will continue unchanged in the foreseeable future. For al1 practical purposes, it is therefore reasonable to equate the future time path of $E$

${ }^{12}$ In empirical work of this nature one can, of course, not rule out the possibility that the statistical results are unreliable. 
with the projected number of medical-school places supplied. Unfortunately, the determinants of the latter are not well understood at this time. In the absence of public intervention, one would expect the supply of medical school places to respond positively to tuition fees, and of course, to the potential pool of qualified applicants (because medical schools would clearly not accept or graduate an unqualified applicant merely because he/she has the wherewithal to pay for a medical education ${ }^{13}$ ). However, since medical schools in the United States have become the virtual wards of the public sector, control over the supply of medical educations now rests almost completely in the hands of public policymakers. In practice, projections of the number of places supplied had best be inferred from the government's own policy statements on the matter.

Although the demand for medical educations can, for practical purposes, be disregarded in projecting the future output of medical graduates, it is nevertheless worth noting that this relationship seems to conform to the conventional human-capital model. In his time series analysis of the number of medical-school applicants--with observations going back into the $1930^{\prime} \mathrm{s}--$ Sloan (1971) found that the annual numbers of applications tends to respond negatively to tuition charges and to incomes in rival occupations, and positively to expected physician income. On the other hand, sloan found that the demand for specialty training tends to be remarkably unresponsive to monetary incentives. His estimates suggest that the rate of return to a general practitioner's investment in specialty training appears to be at best modest, and occasionally negative (see sloan (1970)). Unfortunately, Sloan did not adjust his estimates for differences in hours worked. Since general practitioners in the United States typically work longer hours than do specialists, and also tend to work at a relatively more hectic pace, a rate-of-return calculation based simply on unadjusted income differentials tends to understate the returns to specialty training. 14 It is, however, quite possible that purely professional, nonpecuniary incentives dominate among the determinants of specialty choice.

In exploring the determinants of specialty choice--variable $d_{i}$ in equation (5a)--increasing attention will obviously have to be given to the supply side of the market for residency training. Up to the present time, the supply of residencies in the various medical specialties has been under the effective control of the respective chiefs of staff in teaching hospitals, although in practice the number of places offered requires some negotiation with the hospital administrator. One suspects that, here as in the market for medical services, the suppliers have a strong influence over the demand. side. Since the chiefs of staff in teaching hospitals are in effect medical educators, they undoubtedly can influence their students' specialty choice in a number of subtle ways. In any event, current thinking among students of the health care sector is that the most fruitful starting point for an analysis of the specialty choices of medical students is the behavior of medical educators within the teaching hospital. Here it must be noted that the market for residency training (especially the supply side) is just as heavily dependent on public subsidies as is the market for medical educations. The increasing interest among policymakers in this market springs from the hope that this flow of public funds will offer the potentially most effective levers for policies designed to alter the specialty distribution of Anerican physicians. To date, the supply side of the market for specialty training has remained virtually unexplored.

${ }^{13}$ In his analysis of the demand for Medical Educations, Sloan (1971) concluded that the number of qualified applicants itself may influence the number of places medical schools make available. One would expect this type of behavior in any market for higher education.

${ }^{14}$ For additional criticism of this particular study, see Feldstein (1973, p. 62). 
Before concluding Section III of this paper, brief mention must be made of the geographic distribution of the physician supply--a subject matter we have neglected so far. From the viewpoint of health manpower policy this dimension of the supply side is clearly as important as is the aggregate supply of physician services.

As is shown in Figure 4, the physician-population ratio varies enormously among the regions of the United States. Although the figure is based on state data, a high variance in the ratio is exhibited also among counties within each state. The determinants of this distribution pattern have been explored in a number of econometric studies, conveniently summarized in Feldstein (1973, pp. 57-61). Broadly speaking, these studies suggest that physicians tend to gravitate toward culturally attractive locations, preferably endowed with a medical education complex, and characterized by high per-capita incomes (that is, high ability to pay for physician services). These locational preferences are hardly surprising; they are those of highly educated professionals in general.

Although in the American context the locational preferences of physicians are certainly not shameful, few professionals enjoy quite the market power physicians have to satisfy these preferences. This circumstance confronts health planners in the United States with some vexing problems. First, even though the locational preferences of physicians are understood in broad outline by researchers, it is difficult to incorporate them into a long run manpower forecast disaggregated to the state or county level. Not only is it hard to describe these preferences in terms of quantitative parameters, but such parameters might not be stable over time. Health manpower forecasting at the state or county level has therefore remained a precarious guessing game.

Second, the locational preferences of American physicians also tend to frustrate the implementation of health manpower policy. Although the United States has long enjoyed one of the highest aggregate physician-population ratios in the wor $1 d$--certainly in the non-Socialist world-the fact is that many Americans in rural areas or urban slums lack access to adequate health care because American physicians refuse to practice in these locations. During the last decade or so, policymakers had tacitly hoped to fill these gaps with foreign trained physicans. But the latter typically emulate their American peers af ter establishment of their credentials in the United States. The maldistribution problem has not been solved in this way.

Some policymakers and commentators in the media are persuaded to the view that the persistence of a physician shortage in some localities is evidence of an aggregate physician shortage. On this theory, the logical remedy would be to legislate funds for an expansion of medical-school capacity. Such a policy is, in fact, being proposed at this time, in spite of the fact that the capacity of American medical schools has increased by over 60 percent in the last decade and the aggregate physician-population ratio in the United States will soon exceed 200 physicians per 100,000 population. All available evidence on the production decisions of physicians and on the market for physician services suggests that this policy will fail to reach its stated objective. The proposed additions to the aggregate physician supply are not likely to spill over into the now underdoctored areas. One suspects that they are likely to gravitate toward the traditionally preferred locations as well.

The ultimate result of the proposed policy is that it will aggravate the maldistribution problem as that problem is perceived by the public. It may even trigger renewed calls for a further increase in the aggregate physician supply. Furthermore, it is reasonable to hypothesize that the influx of added medical manpower into the already well-endowed regions will result there in (1) physicianinduced upward shifts in the demand for physician services (see the link from box 


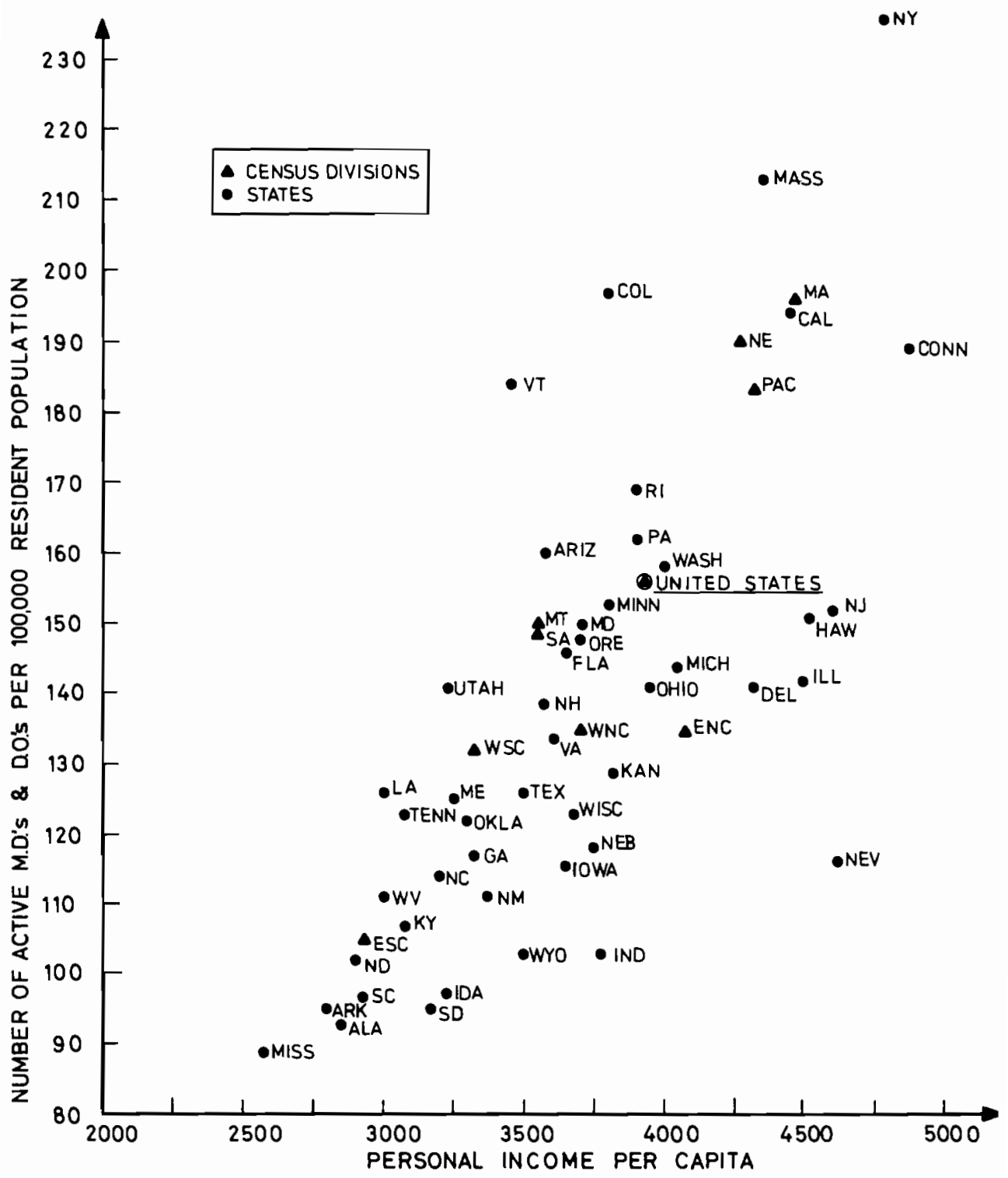

FIGURE 4. PHYSICIAN DENSITY AND PERSONAL INCOME PER CAPITA BY CENSUS DIVISION ANO BY STATES (UNITEO STATES, 1970 ).

SOURCE: REINHARDT [1974], TABLE $1-3$. 
10 to box 8 in Figure 2), (2) increased inefficiency in the use of physician time kacause physicians have little incentive to push the delegation of tasks to assistants to the extent that is technically feasible and economically sound (see the link from box 10 to box 16 in Figure 2), and, to the extent that the target-income theory of physician pricing is valid, (3) increases in the average level of physician fees. These potential side effects are clearly not the impact policymakers wish to achieve with their ostensibly benign stratagem. Under the currect organization of the United States health system, these effects seem virtually guaranteed.

\section{SUMMARY AND CONCLUSIONS}

In the introduction to this paper, the point was made that most of the health manpower planning models presented in the literature are developed on the implicit assumption that they are to be implemented within the context of a command economy. Health planners in a good many non-Socialist countries do not enjoy the implied control over the behavior of the health-care sector. In these nations, the delivery of health services is organized around a set of relatively unfettered markets, and the task of health manpower planning is at once more complex and more frustrating.

In section II and III of the paper we have reviewed the basic building blocks of the kind of model that should, in principle, be used to project future health manpower supplies and requirements in this market context. The discussion was ordered around the basic schema presented in Figure 2, and focused, for the most part, on medical manpower alone. The basic trust of that discussion was that a comprehensive health manpower forecasting model in this context will ultimately have to be a fairly sizable, dynamic, simultaneous equations model, if one wishes to account properly for the many feedbacks in the health sector. Although prototype models of this sort are currently under development, 15 it should have become apparant from our survey that many of the basic building blocks in such a model have remained empty boxes at the empirical level, and that implementation of such models for practical, long-range policy purposes awaits a considerable amount of, empirical research.

It may be asked what form of forecasting model has actually been used in the United States for purposes of health manpower policy. To this date, most forecasting efforts in this area have remained at a highly aggregate level. Furthermore, most of the forecasts actually used as input for policy formulation have been effectively a comparison of projected aggregate supplies of various types of health manpower (developed from data on the capacity of training facilities) with requirements-forecasts based on maintenance of some normative, base-year manpower-population ratio. A very explicit example of this type of model can be found in Edward Yost's The U.S. Health Industry: The Costs of Acceptable Medical Care by 1975 (1969), in which the author projects national health manpower requirements for 1975 with the "basic-need" equation

$$
\mathrm{Y}=\mathrm{X}+\Delta \mathrm{X},
$$

where $Y$ is the ratio of physicians, dentists, nurses, and so on, to the population of Westchester County in New York State (home of many professionals and business executives in New York $\mathrm{City)}, \mathrm{X}$ is the corresponding ratio for the United States as $a$ whole, and $\Delta \mathrm{X}$ is the change in $\mathrm{X}$ required to bring the United States up to Westchester County standards, considered by Yost as an indication of basic need.

${ }^{15}$ For an example of such models, see Feldstein and Friedman (1974) and Yett et a1. (1971). 
The danger of basing health manpower policy in a market context on that type of forecasting technique was hinted at briefly toward the end of Section III. Although the ostensible goal of such a policy might be to provide all Americans with the level of health care now enjoyed by American executives and their families, the procedure also posits the organization of health care facilities (e.g. medical practices) in Westchester County as national norms. As was suggested in Section III, one has no assurance that this organization is, in fact, an efficient one. A priori, one would suspect the contrary. Finally, it was noted also that the geographic distribution of health manpower in the United States would never hold still to permit the rest of the country to catch up with Westchester County. Inequities in the geographic distribution of health manpower will almost surely persist.

In some of the more recent forecasts of physician manpower prepared by econowists--for example, in those by Fein (1967), Jones et al. (1967), and Monsma (1969) --the demand for health services has been projected separately and then converted into manpower requirements. Although these forecasters did not articulate their methodology in terms of a formal model, their approach can be compactly described in terms of the forecasting equation

$$
D_{t}=a_{t} \cdot c_{t} \cdot M_{t}-\left(\frac{s_{t}}{Q_{t}}\right) N_{t} \text {, }
$$

where:

$M_{t}$ is the number of physicians projected to be alive in period $t$,

$a_{t}$ is the proportion of these physicians expected to be professionally active,

$c_{t}$ is the proportion of professionally active physicians expected to be rendering patient care as their primary activity,

$\mathrm{S}_{t}$ is the projected per-capita demand for physicians" services,

$Q_{t}$ is the projected average annual output of physician services per physician (the average annual physician productivity), and

$N_{t}$ is the size of the population to be served.

Finally, $D_{t}$ denotes the projected surplus $\left(D_{t}>0\right)$ or deficit $\left(D_{t}<0\right)$ of physicians in period $t$. In projecting future per-capita demand, $S_{t}$, an attempt is usually made to account for projected changes in the socio-demographic and economic composition of the population. To project the future time path of $Q_{t}$, it is most commonly assumed that future productivity growth will tend to parallel the growth experience of the recent past. (Since $S_{t} / Q_{t}$ is in effect a target physician-population ratio, the assumption of constancy in that ratio is tantamount to assuming that $S_{t}$ and $Q_{t}$ grow at precisely the same rate throughout the forecast period.) It should be obvious that the approach summarized in equation (15) represents a step in the direction of the more comprehensive forecasting models discussed in this paper, especially so if the productivity variable, $Q_{t}$, were expressed formally as a production function.

As $f a r$ as the design and implementation of health manpower policy in the United States is concerned, one doubts that the nation can long continue to afford the passively accommodating policy hitherto pursued. As the methodology of health manpower forecasting progresses, policymakers will sooner or later become persuaded to a systems-analytic perspective on the health sector, a perspective that will sensitize them to the subtle and unintended side effects of their current approach 
to health manpower policy. Signs of some restiveness in this area are already in the offing. Legislators are beginning to toy with the notion that some form of public control over the deployment of national health resources will have to become an integral part of a health manpower strategy, lest the cost of health services in the nation reach intolerable levels. Such controls may take the form of direct regulation as it is now practiced in fully planned health systems. In the American context, policies designed to operate through the manipulation of financial incentives seem preferable. Alternative policy options in this area make fascinating subject matter. Given the focus-and the length--of the present discussion, however, that topic had best be reserved for another paper. 16 


\section{APPENDIX}

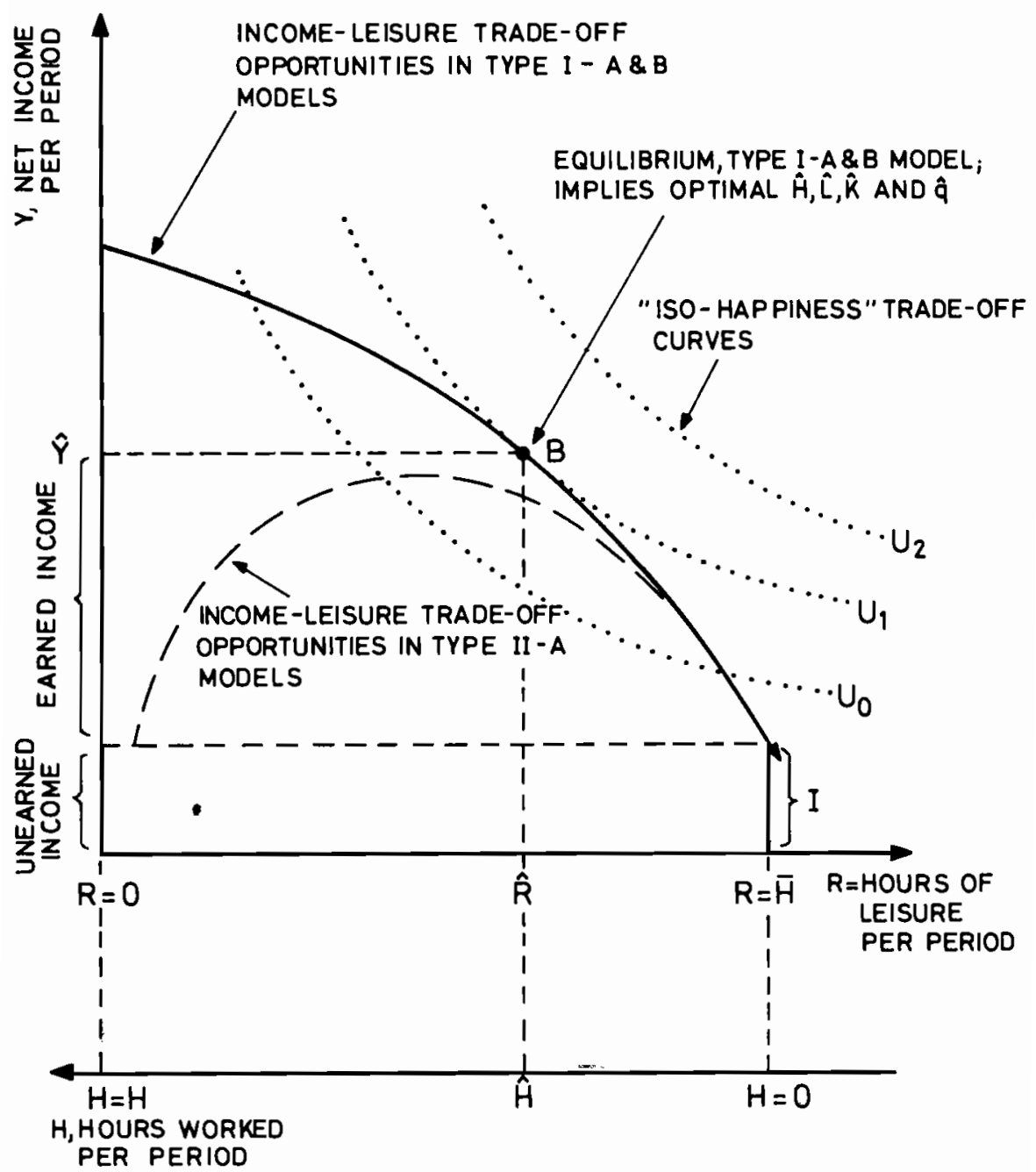

FIGURE A-1. HYPOTHETICAL ILLUSTRATION OFA PHYSICIAN'S INPUT-OUTPUT CHOICE. 


\section{REFERENCES}

Ahamad, B., and Bland, M. (1973). The Practice of Manpower Forecasting. (Amsterdam: Elsevier Scientific Publishing Co.).

American Medical Association (1973). Reference Data on Profile of Medical Practice. (Chicago: American Medical Association).

Bartholomew, D.J., and Smith, A.R. (1971). Manpower and Management Science. (Lexington, Mass.: D.C. Heath and Co.).

Berki, S. (1972). Hospital Economics. (Lexington, Mass.: D.C. Heath and Co.). Blumberg, M.S. (1971). Trends and Projections of Physicians in the United States 1967-2002. (A Technical Report Sponsored by the Carnegie Commission on Higher Education, U.S.A.: The Carnegie Foundation for the Advancement of Teaching).

Boaz, R.F. (Spring, 1972). Manpower Utilization by Subsidized Family Planning Clinics: An Economic Criterion for Determining the Professional Skil1 Mix. Journal of Human Resources, 192-8.

CENTO Treaty Organization (January, 1973). Proceedings from the CENTO Conference on the Methodology of National Health Planning. (Istanbul, Turkey: CENTO Treaty Organization).

Donabedian, A. (September, 1969). An Evaluation of Prepaid Group Practice. Inquiry $6,3-27$.

Dowling, W.L. (1972). A Linear Programming Approach to the Analysis of Hospital Production. (Unpublished Ph.D. dissertation, Ann Arbor: University of Michigan).

Fein, R. (1967). The Doctor Shortage: An Economic Diagnosis, (Washington, D.C.: The Brookings Institution).

Feldstein, M.S. (1967). Economic Analysis for Health Service Efficiency: Econometric Studies of the British National Health Service. (Amsterdam: NorthHolland Publishing Co.).

Feldstein, M.S. (May, 1970). The Rising Price of Physicians' Services. Review of Economics and Statistics, 52, 121-33.

Feldstein, M.S. (May, 1970). Health Sector Planning in Developing Countries. Economica, 37, 139-62.

Feldstein, M.S. (April, 1973). Econometric Studies of Health Economics. (Discussion Paper No. 291, Harvard Institute of Economic Research, Cambridge, Mass., mimeographed).

Feldstein, M.S., and Friedman, B. (May 31, 1974). The Effect of National Hea1th Insurance on the Price and Quantity of Medical Care. (paper presented at the Universitites - National Bureau of Economic Research Conference on the Role of Health Insurance in the Health Services Sector, Rochester, N.Y.).

Hansen, W.L. (March, 1970). An Appraisal of Physician Manpower Projections. Inquiry, VII: $1,102-13$.

Hughes, E.F.X., Fuchs, V.R., and Jacoby, J.E. (1972). Surgical Workloads in a Community Practice. Surgery, 71, 315-72.

Jones, N.H., Jr., Struve, C.A., and Stefani, P. (1967). Health Manpower in 1975 Demand, Supply and Price. (In U.S. National Advisory Commission on Health Manpower). Report of the Commission, 2, 229-63.

Maki, D.R. (1967). A Forecasting Model of Health Manpower Requirements in the Health Occupations. (Ames, Iowa: Industrial Relations Center, University of Iowa, mimeographed).

Maurizi, A. (1967). The Economics of the Dental Profession. (Unpublished Ph.D. dissertation, Stanford University).

Monsma, G.N., Jr. (1970). Marginal Revenue and the Demand for Physicians' Services. (In Klarman, Herbert E. (ed.), with the assistance of Helen H، Jaszi). Empirical Studies in Health Economics (proceedings of the Sécond Conference on the Economics of Health, Baltimore: The Johns Hopkins Press).

Monsma, G.N., Jr. (1969). The Supply of and Demand for Physicians' Services. (Unpub1ished Ph.D. dissertation, Princeton University).

Mundlak, Y. (September, 1964). Transcendental Multiproduct Production Functions. International Economic Review, 5, 273-88. 
Newhouse, J. (October, 1970). A Model of Physician Pricing. The Southern Economic Journa1, $37: 2,174-183$.

Pauly, M.V. (December, 1973). Information and the Demand for Medical Care. (mimeographed).

Phelps, C.E., and Newhouse, J.P. (1974). Coinsurance, the Price of Time, and the Demand for Medical Services, (forthcoming in Review of Economics and Statistics).

Reinhardt, U.E. (1970). An Economic Analysis of Physicians' Practice. (Unpublished Ph.D. dissertation, Yale University).

Reinhardt. U.E. (February, 1972). A Production Function for Physicians' Services. Review of Economics and Statistics, 54, 55-66.

Reinhardt, U.E. (Fa11, 1973). Manpower Substitution and Productivity in Medical Practice: Review of Research. Health Services Research, 200-27.

Reinhardt, U.E. (October, 1974). Physician Productivity and the Demand for Health Manpower, (forthcoming from Ballinger Publishing Co,, Cambridge, Mass.).

Reinhardt. U.E. (January, 1974a). Alternative Methods of Reimbursing Non-Institutional Providers of Health Services. (paper presented to the Institute of Medicine Conference on Regulation in the Health Industry, National Academy of Sciences, Washington, D.C.; forthcoming in Proceedings).

Smith, K.R., Miller, M., and Golladay, F.L. (Spring, 1972). An Analysis of the Optimal Use of Inputs in the Production of Medical Services. Journal of Human Resources, $7,208-25$.

Rimlinger, G.V., and Steele, H.B. (July, 1963). An Economic Interpretation of the Spatial Distribution of Physicians in the U.S. Southern Economic Journal, $\mathrm{xxx}, 1-12$.

Rozenfeld, I.I. (1963). Planning and Allocation of Medical Personnel in Public Health Services, (translated from the Russian and published for the National Science Foundation, Washington, D.C. by the Israel Program for Scientific Translations, Jerusalem, Israe1).

Sloan, F.A. (1970). Lifetime Earnings and the Physicians' Choice of Specialty. Industrial and Labor Relations Review, 24, 47-56.

Sloan, F.A. (Fal1, 1971). The Demand for Medical Education: A Study of Medical School Application Behavior. Journal of Human Resources, 6, 466-89.

Sloan, F.A. (1973). A Microanalysis of Physicians' Hours of Work Decision. (Baper presented at the International Economic Association Conference of Health and Medical Care, Tokyo).

Somers, A. (1971). Health Care in Transition. (Chicago: Hospital Research Education and Trust Fund).

Uyeno, D.H. (1971). Health Manpower Systems: An Application of the Management Sciences to the Design of Primary Hea!th Care Teams. (Ph.D. dissertation, Evanston, Illinois: Northwestern University).

Yett, D.E., Drabek, L., Intriligator, M.D., and Kimba11, L.J. (1971). The Use of an Econometric Model to Analyze Selected Features of National Health Insurance Plans. (Human Researches Research Center, University of Southern California, mimeographed).

Yost, E. (1969). The U.S. Health Industry: The Costs of Acceptable Medical Care by 1975. (New York: Frederick A. Praeger, Publishers).

Zeckhauser, R., and Eliastam, M. (Winter, 1974). The Productivity Potential of the Physician Assistant. Journal of Human Resources, IX, 95-116. 
Points raised by the Discussant, Mr. Thral1

Mr. Thrall found that the paper of Mr. Reinhardt touched upon so many critical issues of health policy that he would be able now to voice his personal reactions to only a limited number of them. He noted that the complex matrix of personnel interchangeability limned by the paper would require highly sophisticated techniques of manpower programing as well as long lead times for establishing the separate training programs. Mr. Thrall felt that a conjugate problem of health manpower planning--that of geographical distribution--was highly important. He had found recently that the flexibility of doctors in selecting sites of practice was being more limited, and especially constraining in the case of specialists. He asked Mr. Reinhardt what measures he would recommend to improve physician distribution. Mr. Reinhardt felt that bold, perhaps drastic, remedies were in order. He personally favored sharp limitations on fees charged in urban areas.

\section{System Feedback}

Mr. Venediktov congratulated Mr. Reinhardt on a clear exposition of the fallacies inherent in assuming fixed technological coefficients for medical activities. He wondered though whether this might not be carried a step further. Conceptually it should be recognized that the matrices for manpower interchangeability presented by Reinhardt were themselves subject to change. A massive organizational change such as the introduction of national health insurance in the US or technological developments could drastically alter the matrix elements. Provision for incorporating this type of system feedback should be made. Mr. Venediktov noted that optimal1y useful feedback depended upon the measurement-or imputation--of physician quality.

Mr. Reinhardt agreed with this point. The analyst can forecast systematic reactions to policy but not the policy itself. For this reason, careful incorporation of feedback is essential. He felt the measurement of physician quality or productivity to be tremendously difficult. Too many important dimensions of output simply lack quantitative handles.

\section{Geographical Distribution}

A participant from the UK stated that his nation was seeking to improve doctor distribution through money grants to physicians who practice in designated areas. It is extremely difficult to judge--in the absence of a control nation for comparison--just how effective this program is. This difficulty is comparable to that in measuring the productivity of general practitioners. Nevertheless, his own rudimentary analysis showed that the grant program was having beneficial effects.

Another participant noted that there are many aspects to the distribution of physicians. One feature is international and reflected in such anomalies as the presence of more Iranian doctors in the US than in. Iran. Nations use various ways to improve their own geographical distribution. In India, young doctors are required to sign contracts agreeing to serve in doctor-poor areas. Norway has established a system whereby doctors start out in rural areas and move later to the cities. Austria represents a curious case in that rural Tyrol--because of the skiing it offers--has no dearth of doctors though other rural areas, lacking such attractions, are short of physicians.

\section{The Swedish Case}

Mr. Wennstrom found Mr. Reinhardt's presentation relevant to the Swedish context. A concerted effort has been made in Sweden to increase the ratio of doctors within the population and considerable improvement since 1960 has been realized. The ultimately appropriate ratio of doctors will depend upon the duties 
that can be performed by other medical personnel. The primary handle upon the numbers of doctors is educational policy. In his paper would be found a description of the means used by Sweden to effect better geographical distribution.

\section{Behavioral Uncertainties}

One member urged that the behavioral aspect should be stressed in ruminations about the health manpower problem. Pure allocation of manpower is not the answer since the individually free elements of the medical profession will react in unknown ways to new conditions and constraints. Instead, greater behavioral inquiry should be made to learn how doctors would or might react to contemplated policy changes.

Mr. Reinhardt agreed with this. His own paper had sought only to explain one set of frustrations--that resulting from the interchangeability between manpower categories--in long-range health planning. Related to the difficult behavioral problems mentioned is the impossibility of constructing a production function for physicians. There is simply too little understanding of the tasks that would be accomplished by physicians under different organizational structures to make even an intelligent beginning.

Extending this point, a participant noted that, if we cannot begin to construct a production function for medical personnel, then we cannot obtain the coefficients of interchangeability required by Reinhardt's model. He doubted whether the coefficients for a neighborhood health center could be derived from existing studies. This implies that the methodology developed by Reinhardt is only arduously applicable. Attention should be given to the types of research that would render the methodology more operable. 


\title{
SYSTEMS ANALYSIS FOR THE EVALUATION OF BIO-MEDICAL RESEARCH
}

\author{
Mark Thompson \\ International Institute \\ for Applied Systems Analysis
}

\section{INTRODUCTION}

Systems analysis has long been attributed great potential for the guidance of research and development efforts. In the bio-medical sphere, systems analysis has been little tried and then without noteworthy success. In large part this is due to the huge, complex, and unmanageable uncertainties that plague the area. It owes also to the paucity of sound models developed for research evaluation.

Considerations that should be addressed by such models are presented in the second section. The rudimentary analytic framework described there discusses how the gains from morbidity reduction, from life extension, and from their consequent externalities might consistently be taken into account.

The third section describes a practical attempt to apply the concepts brought out in the second section. We enumerate a list of difficulties encountered when medical experts were asked to provide the quantitative estimates required by analytic models.

In the final section of the paper, we evaluate the evaluation described in the third section. While concluding that it failed in its main tasks, we find that gains were registered in tangential areas. The most important of these gains may have been an improved understanding of the potential for systems analytic evaluation of research. Ways are indicated for improving future efforts of a similar nature. It is argued that the misgivings of medical reviewers with the model used were largely based upon the failure to allow for and to incorporate uncertainties. The extent of these uncertainties seems so great as to prevent the model in present form from being used to direct the more basic research. We argue finally that systems analysis is essential to a more sensible allocation of research monies and therefore must work to correct the shortcomings here described.

\section{IN THEORY}

\section{The Need for Models}

To differentiate fairly and accurately between the relative values of competing research proposals, a model making clear the basis for those values is needed. The model should transiate the foreseen results of bio-medical research--ultimate improvements in the delivery of health care--into benefits. It should thereby :6." provide a comprehensive and systematic means for gauging the value--ex ante and ex post--of the research.

We will briefly discuss factors to be borne in mind in constructing such a model. Initial consideration will be given to the most basic situation of a contemplated research task with foreknown results and costs. Once an estimation of gross benefits has been obtained, costs may be subtracted to obtain net benefits. If the analysis is sound, projects with negative net benefits ought not to be funded and, of equaliy expensive competing projects, that with the highest net benefit should be preferred.

\section{Benefit Estimations}

Benefits of bio-medical research derive from two fundamental effects: the prolongation of life and the reduction of morbidity--which thereby enhance the 
quality of life. When these effects are consistently accounted for, distinction between advances in therapeutic care and in prophylactic praxis need not be distinguished.

At least two beneficiary groups should be borne in mind in gauging the effects both of extending lives and of reducing morbidity. The first is the population sub-group that is, will be, or would be afflicted by the disease, disorder, or condition in question. The second is the extensive union of individuals--in the family and the community--that become better off because members of the first group live longer or more healthy lives. This second set of benefits thus comprises a far-flung range of externality benefits--from the economic gains in reduction of absenteeism or the loss through death of highly trained personnel to the non-economic satisfaction that one's mother lives longer or with less pain. The difficulties in estimating non-economic externality benefits have led many analysts to exclude them from their models. Economically measurable benefits are most easily incorporated within quantitative analyses. of these, the overal1 societal gain deriving from reduced absenteeism is that most of ten calculated. Other gains that should, at least conceptually, be included are the increased productivity achieved by workers with higher health status and the preservation of the socially sunk investment in training when the working 1 ife of a skilled craftsman is extended.

\section{Cost Estimations}

For most analyses, it suffices to estimate research costs--covering labor, equipment, and management--as a single monetary sum. In exceptional cases, modification is needed to reflect the opportunity cost of scientific resources. When research succeeds, it frequently occasions higher treatment costs to bring to the population the benefits of its advances. These should, in addition to the research costs, be subtracted from the gross benefits to obtain net benefits. When research leads to lower cost treatment, the total societal cost differential should be treated as a benefit.

Less often, successful research requires major reorganization or expenditure before its benefits are realized. These costs include:

1) the acquisition of equipment and other facilities, and

2) the training of personnel.

When significant reorganization of the health care delivery system is required, this should be treated as a cost, estimated, and included within the analysis. Another type of cost to be incurred before benefits are realized is the expense of campaigns--such as those to control disease vectors, to reduce environmental carcinogens, or to warn against habits dangerous to health.

\section{Methodological Considerations}

To estimate benefits and costs according to the framework described above, a number of hampering methodological difficulties must be overcome. These include:

1) Breaking down the population into sub-groups to clarify benefit incidence. Different levels of fineness or coarseness in this breakdown will be required for different studies and purposes. A1though breakdown by age and sex cohorts often suffices, further disaggregation into groups of varying vulnerability may be required;

2) Attributing values to gains in life extension and in morbidity reduction as perceived by the potentially afflicted individuals. Analysts have had almost as much trouble themselves in describing a nethodology for such imputations as they have in coaxing the quantifications 
from others. Their arguments that many governmental decisions-necessarily if implicitly--place money values upon being alive or more healthy do not ease the estimations. Despite the difficulties incurred, these values ought not to be neglected because i) they are needed to differentiate between the work of an artificially prolonged but severely impaired 1 ife and a more healthy and natural existence, and $i i)$ a major gain from morbidity reduction inheres precisely in the internally perceived benefits of a higher health status;

3) Discounting future benefits. For consistent and appropriate weighting of present and future priorities, time discounting is essential. In problens of bio-medical research valuation, large lag times are likely between completion of the research and its effected social benefits. The benefits may then be spread over decades. These factors magnify the importance of the methodology used for gauging intertempora1 tradeoffs. The preeminent technique in such situations has been the simplistic application of a discount rate. Unfortunately, practitioners have frequently had difficulty in selecting the most suitable rates while, for some situations, the discounting methodology itself is inappropriate; and

4) Differentiating between ex ante and ex post benefits. Ex ante expected benefits are no more than the aggregation of possible ex post benefits weighted by their probabilities of occurring. Research funding decisions must be made on the basis of ex ante knowledge and, hence, the ex ante benefits. Evaluation of those decisions cannot be based wholly upon the ex post returns from the research but must take into account the uncertain set of possible results faced by the decision makers. The complex nature of these uncertainties we now consider in greater detail.

\section{Additivity and Uncertainty}

The methodological difficulties described above indicate that net value estimation--even for projects whose results are foreknown and require no further research before achieving their benefits--is not trivial. In fact, the direction of research monies must face such uncertainties as:

1) the broad spectrum of possible results that any project could lead to;

2) the broad choice of possible subsequent steps that might come under consideration for each of the many possible research results; and

3) a vast range of possible pathways by which a given research advance might eventually come to improve health care. 1

The repercussions of basic laboratory research will be more difficult to estimate than those of the more applied clinical or epidemiological research. Thus, research on the mechanisms of cell division could only with great and perhaps prohibitive difficulty be evaluated on the basis of the specific diseases, disorders, or conditions which it could alleviate. Since such research can lay the foundation for so many diverse strands of subsequent research, it has frequently been termed "additive." On the other hand, the possible benefits of an epidemiological study for a specific disease can be imagined with much greater, if still far from perfect, precision. Those benefits, for instance, would most likely be upper bounded by all the good that could be done the population that has contracted or would contract

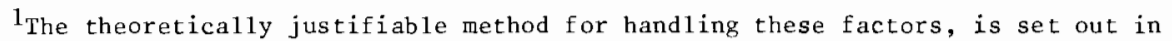
H. Raiffa (1968). Decision Analysis, Addison-Wesley, Reading, Massachusetts. Unfortunately, the extent and complexity of the uncertainties here render such techniques pragmatically inapplicable. 
the disease. ${ }^{2}$ It thus makes sense for grant administrators to prefer, ceteris paribus, epidemiological research into diseases with higher prevalence, incidence, and severity.

Having thus glanced at the theoretical framework that might be used to evaluate bio-medical research and at the lurking difficulties, we turn now to examine an instance in which a multidisciplinary analytic team sought conscientiously to apply that theory to actual research.

\section{IN PRACTICE}

\section{The Evaluation}

In 1971 the evaluation arm of the is Department of Health, Education, and Welfare engaged a team of experts from Harvard University to evaluate bio-medical research performed in Yugoslavia under the cooperative bi-national Special Foreign Currency Program (SFCP).3 The Program, begun in 1961, consisted of 110 projects which were to be individually and summatively assessed. The Harvard team included one biochemist, one clinical researcher, one economist, one public policy analyst, one sociologist, and four physicians. Simultaneously, a similarly constituted Yugoslav team was conmissioned to perform a parallel evaluation of the Program. The Harvard team convened frequently during 1972, held two meetings with the Yugoslav team, and, in a splurge of eleventh hour activity, completed and submitted its report in January 1973 .

\section{The Focus of the Evaluation}

The commissioners of the evaluation had as their goal the construction and implementation of an evaluation model much like that described above. They were not, however, so naive as to believe this an easy task or even one likely of achievement. In the end they received a well-written document that made enough intelligent points that they could be satisfied. In only the loosest way could it be claimed that the Harvard study had made progress toward the original goal of program evaluation--in the sense of ascribing monetary values to the whole program or comparative values to different segments of it.

That the team had consciously striven to apply a model of the type above could be seen in the questionnaire laboriously developed:

a) four separate questions inquired into the project cost magnitudes;

b) one question requested an approximate estimation of the ex ante net research value while another sought the ex post value;

c) four questions elicited the importance, prevalence, and incidence of the disease, disorder, or condition in question;

d) nineteen questions sought information about different types of potential and actual impact; and

e) two questions, by requesting the estimated time to impact in health practice, both enabled finer classification along the spectrum between basic and applied research and provided necessary information for the discounting of benefits.

2 An exception would occur when research into one disease leads to insights about another.

3 Harvard University, An Evaluation Study of the Special Foreign Currency Program in Yugos lavia, DHEW Report HEW-05-71-188. 
Results of the Evaluation

The Harvard team could not be faulted for lack of effort when one considers the conscientiousness with which it developed its questionnaire, tested it in plenary sessions, then applied it to the program. The degree of interdisciplinary harmony and cooperation astounded this observer. And yet, though the team succeeded in many ways, it failed in its central task of evaluation. Before examining the reasons for this, we should look to what the evaluation did achieve.

The evaluation team obtained two pools of information from which it would draw in writing its report:

1) three questionnaire reviews--two US and one Yugoslav--for each of the 110 projects provided by a total of twenty experts; and

2) a mass of documentation and interview reports upon the administration of the Special Foreign Currency Program.

From these sources, the report author extracted near maximal information value to achieve a polished and professional account of the study.

The research report provided:

a) intricate classification of all projects--by granting agency, by budget size, by type of research, and by probable specificity of impact;

b) sumnative commentary of a Delphi nature upon the program though provision and rudimentary interpretation of reviewer response to each of the questionnaire items--concluding, for example, that the total impact would benefit Yugoslavia more than the US and the scientific establishments of both nations more than their health care delivery systems;

c) a series of inferences based upon the classifications and reviewer answers--as, for instance, the finding through correlation analysis that uS non-financial contributions were significantly linked with actual project accomplishments ${ }^{4}$

d) a set of comments upon the administration of the program--the proposa1 review process, the role of the project officer, the publication policy--and how it might have been improved.

Overwhelmingly as a result of the skills displayed by the writer of the report, it: 1) has been accepted with praise by the evaluation arm of DHEW which funded it;

2) has become a necessary addition to the bookshelves of all administrators remotely connected with the SFCP; and 3) has been published commercially.5 Notwithstanding these tokens of success, the evaluation seems, to this writer, in part a failure for having neglected to provide information that could beneficially have guided the management of the program. We now examine why.

${ }^{4}$ From this, the report drew the judgmental conclusion that non-financial contributions--such as the time of the project officer--effected better results. It lacked a sound statistical basis for ruling out the possibility that causation ran in the other direction: that the project officers tended to devote more time to plojects that were developing well.

5erry, R.E., Jr. et a1. (1974). Evaluating Health Program Impact, D.C. Heath, Lexington, Massachusetts. 
PROBLEMS OF ANALYSIS

\section{Retreat from Quantification}

The original version of the fiarvard questionnaire attempted more precise quantification than was achieved in the final instrument. An example of the modifications made can be seen in two questions which originally asked for numerical estimates of the exact prevalence and incidence of the disease, disorder, or condition studied. The reviewers raised objections: they did not want to have to put down hard numbers that could perhaps be proven wrong. In concession to this sentiment, a new response scale was substituted enabling choice among such semi-quantitative 6 terms as "very high," "high," moderate," "low," and "very low." The change filed off one cutting edge of the questionnaire but the new softer and more rounded contours enhanced reviewer comfort.

The result of such modifications could be seen in the delicately balanced language of the final report. One question of highest importance was that inquiring into expected benefits in relation to project cost. The answers here clustered about the rating "great" with dispersion into the categories of "small" and "maximal. At first blush, this appears an important Delphi commendation of the program as the reviewers rejected the opportunity to be more negative. Unfortunately, the professional positions and outlooks of the reviewers made it extremely likely that their median assessment of any program with reasonabiy well-written reports and diligent researchers would impute a "great" ex ante net value. The program administrators should have expected such a rating. 7

In this light, the utility of the evaluation is questionable. It becomes still more questionable when we consider a primary purpose of research evaluation: allocation of men and money to areas of greatest promise for societal benefit. On the assumption that our researchers will be diligent and will write able reports, we must seek to aim them in the most valuable direction. Any evaluation reflecting cnly their diligence and ability does not assist this purpose. If quantified estimates upon the net value of the research had instead been obtained, improved allocation of scientific resources would have been enabled.

A question gauging contribution toward US health objectives ${ }^{8}$ provides another example of the consequences wrought by semi-quantitativeness. For each project, its best contribution toward at least one of the ten health objectives tended to lie between "some" and "maximal." The projects of one agency within the program had an advantage on this scale over those of another thus making a hard comparative judgment apparently possible. When, however, the greater average project cost within the former agency was considered, it was unclear which of the two had sponsored more beneficial research per unit cost. With quantitative estimations of benefit, this difficulty would have been avoided. Far from being an adventitious result of the semi-quantitativeness, it seems linked in a fundamental and causal way. The project reviewers may not have wished to quantify their answers precisely in order to hinder hard and unambiguous judgements that might have put researchers

$6_{A}$ term taken from the as yet unpublished work of H. Raiffa, who found substantial subjective disagreement upon the meaning of such expressions.

${ }^{7}$ In evaluative theory such findings might be valuable as a means by which top-level administrators could obtain information on program effects not biased by passing up through self-serving lower strata. With the SECP, the top administrator knew more before the evaluation started than Harvard was ever to learn. The report may, however, have been valuable in this sense to the office of the Sectretary of DHEW.

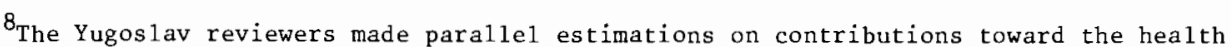
objectives of their nation. 
out of work and relegated their children to the streets. 9

\section{Disciplinary Roots}

The majority of the Harvard reviewers were bio-medical professionals who could identify with personnel in the projects they examined. If the project leader seemed competent--from his record and his writing--the reviewer would be strongly guided by the motive of making the project look good. This inevitably inhibited wholly objective responses. The bulk of the reviewers were in the later stages of their careers, somewhat set in their beliefs, and not amenable to the idea that a new magic called systems analysis could benefit medicine. These factors reduced the utility of the questionnaire data.

\section{The Concept of Value}

The disciplinary rooting of the reviewers induced a number of conceptual difficulties. A typical example lay in their assessment of project worth. Though repeatedly instructed that research value should be perceived in terms of expected societal benefits, the reviewers resolutely rejected this guidance. If a project proposal was well written and assiduously executed, it was rated a good project regardless of its potential or actual consequences. When judging project worth against its budget, the reviewers could not be weaned away from their insistence on comparing the budget not to the probable social results but instead to alternative costs of obtaining the research knowledge.

\section{Probabilities}

Because the expected probabilities of research success varied across projects, we asked our reviewers to estimate the expected net value of the research. Thus a project with a success 1 ikelihood of 0.5 should, ceteris paribus, be funded before one with a likelihood of 0.1 . Our reviewers insisted upon assuming project success and rating the research upon its maximum possible achievement with no consideration of the probabilities involved.

Two arguments were proffered for the neglect of success 1 ikelihoods:

1) that they were difficult to estimate; and

2) that the estimations would duplicate the efforts of the original scientific reviews prior to funding.

While the first objection cannot be gainsaid, the second seems but a specious cover for the first. Surely the original study section review was better qualified than harvard to judge the probabilities of project success. Its approval may, however, have certified only that a project attained a necessary threshold level of success likelihood, say thirty per cent. In this case, no discrimination would be made between two projects with success likelihoods of thirty-five and ninety per cent. The discomfort of the Harvard team when faced with probabilities leads also to a more serious fear. It can be inferred that the study sections themselves--composed of men with similar backgrounds and outlook--were, most likely, similarly daunted by probabilistic concepts and sought to avoid considering their implications.

${ }^{9}$ As we shall argue below, quantified estimates--though attractive in theory--have problems of their own. The precise cost-benefit ratios of the IIS Corps of Engineers are examples of numbers whose precision is camouflage for unfathomable uncertainty. 


\section{Ex Ante and Ex Post Analysis}

Through an error in the commissioning of the evaluation, the research program to be assessed turned out--to the surprise of both commissioners and evaluators--to consist overwhelmingly of ongoing projects. Thus a final impact evaluation from an ex post perspective was rendered impossible. Instead an ex ante estimation of potential impact--implying heavy duplication of the original study section reviews--was performed. 10 This seriously undermined the basic evaluative objectives. 11

\section{Shortcomings of Theory--Probabilities}

The inability of the reviewers to incorporate probabilistic estimates into their project evaluations is matched by the inability of theoretical models explicitly to handle probabilities. There are important chance elements affecting the a priori value of research:

1) the probability that a research project will attain the goals it has set for itself;

2) the probability that the results of a successful research project will be adequately followed up by subsequent research to make possible practical benefits; and

3) the probability that research advances enabling practical benefits can be assimilated into the health care delivery system.

Potential gross benefits may be defined as the value of the research benefits to society assuming that its goals are attained, that adequate follow-up is forthcoming, and that its practical advances are not stymied by system resistance. Expected gross benefits are then the potential gross benefits multiplied in turn by each of the three probabilities above.

Of these probabilities, the most difficult to estimate is that of adequate follow-up. The pathways by which research begets research, in turn broadening knowledge and leading to societal benefits, are multifarious and unforeseeable. Prior predictions will never be able to foretell the serendipitous combination of men, moment, and the chance event that has led to many a research advance. Not only can inspiration and insight not be programmed, but they are likely to suffer when the attempt is made.

These problems proved too much for the Harvard team. The physician reviewers, sensing the magnitude of the problem, escaped it by treating likelihoods difficult to estimate as certainties. Those members of the team more comfortable in dealing with probabilities might have parsed the estimation problems into parts that the reviewers could more easily have handled. They might thus have obtained from the physicians a systematic Delphic estimation of research follow-up probabilities. Such an estimation might not consider all remotely plausible events but it would have enabled a more reliable judgment upon expected research value.

10 This task required delicacy as the Harvard study was explicitly looking for mistakes of the previous reviewers.

11 The ex ante evaluation from an ex post perspective required careful judgment by our reviewers. Decisions had to be rated not on how they turned out but on their reasonableness within the information framework of the moment. Our reviewers --perhaps because as physicians they have internalized an instinctive understanding of decision processes--had no trouble grasping this basic point in decision theory. 


\section{Additivity}

The difficulties in estimating chances of research follow-up are heightened by the tangled additive relationships of projects with related goals. To illustrate, we suppose that research leading from the status quo ante of knowledge, point $A$, to practical value, point $D$, would achieve ten units of benefit. The research is broken down into segments $A$ to $B, B$ to $C$, and $C$ to $D$ as shown below.

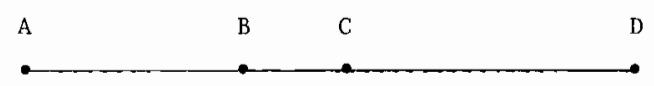

Suppose now that it is necessary to gauge the value of traversing segment $A B$. There are no conclusive a priori reasons for any given set of value assignments. Thus, $\mathrm{AB}$ could be valued at eight units and each of the neyt two segments at one apiece. But BC similarly could be accorded a value of eight and the other segments values of one. If the minimal costs of traversing the segments were given, the difficult problem of value attribution could be reduced but not eliminated. If, for example, these minimal costs are $A B$, two units; $B C$, one unit; and $C D$, four units; it would make sense to conclude that the net value of $A B$ lies between two and five; of $B C$, between one and four; and of $C D$ between four and seven.

One common sense resolution would be to assign the given value ten to $A D$ and to declare that further segmentation of the values is without meaning. The research should be performed only if the cost of achieving point D from point A is no greater than ten.

But this does not solve the reviewer's problem of valuing project $A B$. Should there be four alternative ways of moving to $C$ from $B$, five ways of moving from $C$ to $D$, two additional ways to move from $A$ to $C$ without passing through $B$, and the possibility of performing the research simultaneously in parallel, the problem becomes still more intractable.

In additive situations, both simple and complex, reviewers cannot be blamed for failing to specify a precise research value that, even conceptually, may not exist.

\section{OBSERVATIONS AND CONCLUSIONS}

\section{Rating the Results of the Harvard Study}

We have argued that the final report produced by the Harvard team, for all the kudos granted it, did not fulfill the primary goals of the evaluation. This because:

1) the average rating of project net values as "great"--being unquantified and allowing vast subjectivity of judgment--did not provide a useful sumnative assessment of the program;

2) the comparisons between different segments of the program--again hampered by the lack of quantitativeness and by subjectivity-did not indicate which should be pruned and which expanded; and

3) the examination of internal program operations did not yield information not already known to its administrators. 
Yet the results were not wholly negative. If Harvard's comments about program administration were far from novel, they at least were given stature by their mode of publication and may have effected operational improvements. In a related way, the mere act of the evaluation seems to have energized the program-heightening the motivation of its personnel through a Hawthorne Effect--as it was being scrutinized.

\section{Lessons for the Team}

In the opinion of this observer, the value of the Harvard study lies in the lessons it taught about the application of systems analysis to a difficult area. As is frequently the case with new instruments, first trials teach more about the instrument itself than about the phenomena to be examined.

We have seen in the study defects that can be remedied in future applications of systems analysis. Harvard learned the conceptual stumbling blocks of its non-analytic reviewers and just how they gave rein to their subjective feelings. Certain questionnaire items were too comprehensive and difficult and should have been broken down to more tractable parts. In areas where embracing quantification was not easy, the reviewers should have been provided a simplified series of questions to coax better their judgments. Ways should also have been found to permit expression of their subjective feelings lest they complete the questionnaires with misgivings that the wrong questions were posed.12

\section{Team Composition}

The composition of the Harvard team, though impugned perhaps by implication in the commentary above, could not easily have been improved. The inclusion of several distinguished physicians--leery of numbers and the tricks of analysis-was essential. While the medical expertise of these men gave a necessary ballast and depth to the study, their stature ensured that the final report would be read with care. Any report penned wholly by slick systems analysts could easily have been discredited and disregarded in the very decision forums it was designed to serve.

The team brought together talented individuals whose personalities meshed well and who were devoted to building bridges between disciplines. Even in failing, their efforts indicated possible strategies for linking the disciplines across the gulfs that separate them. No failure whose effort was mighty is altogether without gain. The shortfall of Harvard indicated both limits to the purview of systems analysis and obstacles that need now to be overcome before its full worth will be known.

\section{The Neglect of Variance}

The resistance of the medical reviewers to the matrix forced upon them by the questionnaire may have derived from a fear that the numbers they were asked for could not have the importance or the infallibility attributed them by the analysts. In this, their reluctance may have had grounding. Too many mistakes of policy have been committed because the arguments for them could be expressed in numbers.

${ }^{12}$ Four questionnaire items designed to allow such ventilation of misgivings were insufficient. 
A shortcoming common to both theoretical and practical exercises in evaluation is the neglect of variance. Few quantities called for by models for evaluating research can be estimated with confident precision. The judgments upon the unit values of life extension and of health status enhancement are especially subject to uncertainty. With the subsequent introduction of probabilities and of time discounts, the imprecision of the primary value measure--the expected net value of the research--mounted appreciably.

Any single expert called upon to consult in evaluating future bio-medical research will harbor his own uncertainties that can be roughly expressed as variances of the values estimated. Still another source of variance lies in subjective differences of opinion between experts. The absolute magnitude of the combined variance is so great that special systems methods for dealing with it are bad1y needed.

\section{Dealing with Uncertainty in Guiding Research}

In many areas of endeavor, the application of systems analysis at the managemental level has the effect of so ordering knowledge and expert opinion that perceived variance is minimized and that a small number of action alternatives is thereby shown to be distinctly superior. In the more applied areas of biomedical research, this may be possible. Thus, systems thinking may indicate which epidemiological investigations and which clinical trials promise greatest potential benefit and should therefore be given priority.

In the area of more basic or additive research, this approach is judged impossible. The terrain is so dominated by the unknown and the uncertain that to attempt to draw a consensus from the disparate opinions of one's expert consultants is to misconceive the problem. Instead the entire range of uncertainty and disagreement should be examined to find appropriate opportunities for research. If ninety-five per cent of the experts judge a research path without promise in opposition to five per cent who believe it potentially important, it should not be automatically dismissed. Instead all research themes accorded a minimal probability of reward should be covered. How extensive the coverage would be would depend upon the magnitude of the potential reward and upon the probabilities estimated for success. 13

These arguments imply that precise models inccrporating the considerations of the second section cannot be applied to basic research. The predominant mechanism for passing upon the funding of research in many countries has been that of scientific peer review. This mechanism is not perfect: scientists may be motivated by the desire for intellectual stimulation or be guided by the inertia of their training and past research to the neglect of potential social benefits. Nevertheless, peer reviews do ensure that the work maintains high professional standards and that the knowledge sought is, by scientific standards, important. The greatest potential for improvement in basic research guidance thus seems to lie in modification of the scientific peer review groups rather than in the

${ }^{13}$ Problems of this nature arise in connection with the guidance of national cancer programs. See, for instance:

The National Cancer Program--Report of the Director, January 1973, DHEW Publication Number (NIH) 74-472;

The Strategic Plan, DHEW Publication Number (NIH) 74-569; and

Multilevel Aralysis of NCI Research Grants by Scientific Category-Fiscal Year 1972, prepared by J.H. Schneider of the National Cancer Institute. 
imposition of a comprehensive model that attempts to trace knowledge advances through long and tortuous paths to ultimate social benefit. 14

\section{The Need for Systems Analysis}

One might take the Harvard study as cause to despair of using systems analysis for guiding bio-medical research. This would be premature and wrong. Govermental and foundation sponsorship of research will continue and the donors will be besieged with more requests for funding than they can meet. Every time one request is favored over another, external direction of research takes place. We may permit this direction to be inconsistent and random or we may invoke analysis to systematize its workings. Conscientious application of systems analysis--which requires recognition of its deficiencies--still holds promise of better guiding bio-medical research toward societal benefits. In the world of the unknown, such guidance cannot be precise and without turnings, but it can reduce duplication, fill lacunae of effort, and cut short unpromising endeavor. For these reasons, systems analysis should be strengthened and modified to deal better with the idiosyncratic problems posed by bio-medical research. The critique presented by this paper has sought to aid that adaptation.

\footnotetext{
${ }^{14}$ Similarly, the scientists themselves should be allowed to select the tactical approaches toward the problems they face. In the UK and the US, the trend in the last decade has been to fund grants primarily on the basis of scientific merit. Overal1 strategic redirection of research monies occurs in the cases of major campaigns--such as those against cancer or sickle-cell anemia--and in the selection of projects considered marginal in terms of scientific merit.
} 
Observations of the Discussant, Mr. Spencer

Mr. Spencer recently had participated in an exercise to gauge the value of bio-medical research that resembled closely the project described by $\mathrm{Mr}$. Thompson. Their group too had developed a model to quantify the research benefits that was remarkably similar to the model exhibited in the paper. The major point of difference was that Spencer's group found it desirable to include an additional term for benefits that result solely from the funding of the research. An example is the political gain in allocating research funds to any area salient in the popular mind.

From his experience, Mr. Spencer drew a number of conclusions:

1) that systems analysis provides a set of quantified relationships that may be aggregated into a model;

2) that such models can be aids to decision making but can never be replacements;

3) that a primary result of cost-benefit modelling is its improved statements of program goals; and

4) that a danger in such modelling is the comparison of non-comparables. In their quest to reduce all important factors to numbers, costbenefit practitioners sometimes are excessively zealous. Comparisons of different benefits often depend critically upon value assignments. Since these will vary widely among social groups, analytic reduction of the benefits to numbers inevitably entails subjective judgments.

\section{Hard Models and Soft Phenomena}

Mr. Koch-Weser was a team member of the project described by Mr. Thompson. He concurred in most of the judgments made in the Thompson paper but felt that the criticism there was perhaps too gentle. He would formulate the vital failing of the project as its attempt to apply hard analytic methods to data--subjective judgments of achievement and progress--that were intrinsically soft.

\section{The Communications Gap}

Mr. Venediktov favored the use of systems analysis to evaluate bio-medical research. He, however, found the model as laid out difficult to understand. He urged that such models be carefully presented so that doctors and other non-analysts would more readily comprehend them. As did Mr. Spencer, he felt that a chief problem in applying such a model lay in quantifying the non-quantifiable.

\section{Advice for Model Application}

A participant with experience in related research efforts offered his observations. He felt that formulas provided in Mr. Thompson's paper could be clearly understood by non-technical experts if a series of carefully structured discussion sessions were held. Such sessions should be held before the analysis itself is initiated. He felt that models of this type were more effectively applied to lines of research activity composed in individual projects rather than to the projects separately. He was pleased that the model distinguished between gains in reducing morbidity and in extending life. Recent data show that the number of morbidity episodes has no effect upon life expectancy.

Mr. Spencer agreed wholeheartedly that great efforts should be made to achieve an initial meeting of minds. He related that one program evaluated was 
attributed 350 different effects. Extensive discussion was required to coalesce these into forty-six effects which could more easily be understood and evaluated. The effort required to achieve interdisciplinary harmony and mutual understanding can take years.

\section{Scientific Merit Evaluation}

One speaker described an evaluation of bio-medical research that compared the original scientific merit rating with an ex post merit rating, and with the numbers of citations relating to papers arising from the project. Correlations across all three indices were high. Mr. Thompson felt that this should be expected since all three measures were based on scientific judgment of scientific merit. The study he described was more difficult in that it sought to 1 ink ascribed scientific merit to foreseen social benefits.

\section{Further Remarks upon Cost-Benefit Analysis}

Additional observations upon cost-benefit analysis were proffered:

a) The importance of defining benefits at the initiation of the study was stressed.

b) An area of great confusion is the application of time discounting. In bio-medical research this is critical as there may be a substantial lag until benefits are realized whereupon they may be spread over decades.

c) Benefits can be broken down into the categories of direct, indirect, and intangible. Both of the former two classes can generally be calculated, but the greatest difficulty arises in estimation of intangible benefits which often are highly significant.

d) The limitations of cost-benefit analysis are indicated by frequent selection of projects with poor ratios over those with higher ones. 


\section{THE ROLE OF THE SYSTEMS ANALYSIS IN MEDICAL INFORMATION AND MANAGEMENT OF BIO-MEDICAL RESEARCH}

Yu. P. Lisitzyn and Yu. N. Chistyakov

Medicine, as one of the most ancient sciences and practices of mankind, is analyzed as a systematized complex of knowledge (information) on the essence of life at a11 of its levels, on the structure and functions of a human organism in its indissoluble relation with the environment, on the laws of heredity, on the possible causes of morbidity and methods of its prevention, on recognition of diseases and their therapy, and, on the other hand, as a continuous process of clarification of such information (with the generation of the qualitatively and quantitatively new scientific-medical information).

Thus, the role of scientific-medical information in the hea]th system (including health services and medical equipment) is determined by its content. It is, in itself, the system of knowledge in the health field, medical science, and medical technology. This system of information is complex based, on the one hand, upon the health system and medical science, being its functional derivative and, to a greater degree, its content. On the other hand, this system derives from the composition of the state system of scientific-technological information as a branch of information. The system of scientific-medical information is at the nexus of certain sciences and scientific disciplines, the theory and methods of which are borrowed, interpreted, and widely used in the existing system of scientific-medical information. The functional working of the system depends upon the means and methods of cybernetics, particularly the work of electronic computers. The method of the systems analysis, which will be discussed further, is widely used as a scientific methodology for the management and organization of medical science, which is represented by medical information. The interrelations of scientificmedical information with adjacent disciplines are depicted in Figure 1.

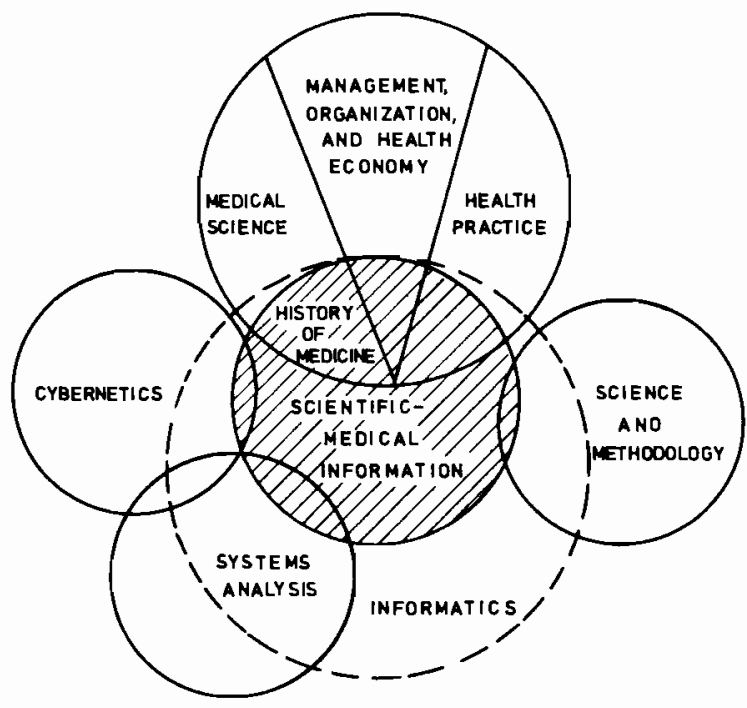

Figure 1. The scheme of interrelations of medical information with adjacent disciplines. 
The system of medical information belongs to the class of large dynamic systems which function on the basis of such global systems as the health system and medical science. As a "large" system, the system of medical information has its own methods of work, its own territorial-hierarchic structure of functional units, and the peculiarities of relationships among its various units. The method of systems analysis could be applied to the medical information system as to any other "large" system whose operation involves massive flows of information. This method, which uses contemporary technological means for processing large information sets, includes the following complex of measures:

1) Analysis of the goals and tasks of the system;

2) Analysis of the: system in connection with organizational, economic, and other systems for the detection of causative and other relations of the above system;

3) Formation of the structural-hierarchic scheme of the system, detection of relations between elements of the system and their correlations;

4) Determination of the functional properties of the system as a whole and of each individual element and group of elements, nested within the given system, formulation of the algorithms by which the system functions;

5) Prognosis of the system's development on the basis of the outlined (or available) parameters of its separate elements or of the system as a whole;

6) Deternination of the technological possibilities of the system with due regard to definite tasks and functions.

When applied to the system of medical information, this method enables us operatively to bring medical information to the point at which it will be possible:

a) to draw conclusions on the state of health services and medical science at the present stage of development;

b) to carry out managemental control over functional correction of the whole system of health services and medical science in case of comprehensive information on the controlled objects or phenomena;

c) to project into the future the state of health services and medical science; and

d) to correct the development of the structural-functional scheme of the health services and medical science by improving the work of their elements, by creating new elements.

In this case, medical information itself is a factor which covers the basic problems of health development and the development of medical science.

The system of medical information determines the problems of long-term planning and prognosis with due reference to the proper understanding of the objective tendencies of community development and the health system as a whole. This understanding derives from objectively existing information on the past and the present states of health services. Thus, the system allows prognosis upon the development of bio-medical science from the point of view of possible scientific discoveries and perspectives of their application for practical medicine, and from forecasts of conditions under which the health system will function (derived using data obtained by other systems of scientific and scientific-technological information). The information circulating in the system is basically of factographic and managemental. origin; it is directly related to the development of the health system itself and to the increase of its efficacy under the changed conditions.

The system of medical information, which covers the necessary amount of scientific management information on health and medical science, may deal with the elaboration of the contemporary methodology of health management using the most common management problems for large dynamic systems--which are developed by other sciences. The flows of medical information, being formed in a definite way, become the basis for the systems-structural analysis of all the formed elements of the health system, activities of its network, and detection of its available and unused reserves. 
The most important tasks in using the medical information system--from the point of view of the development of the health system and of medical science as a whole--are the problems of methodology and the organization of highly effective scientific investigations. For implementation, public health administrators and organizers of medical science should know the basic elements of the activities of the contemporary scientific-medical information systems: the WHO, WHAT, WHERE, and HOW of developments in this specific field of medicine.

Our investigations into the information search process showed the perspective nature of the factographic search for information on research, which is essential to the further scientific development of health practice. Information on research, in combination with information coming from practical medicine, encbles us to correct already planned research work and more effectively to implement the results into health practice. This system is presented diagramuatically in Figure 2.

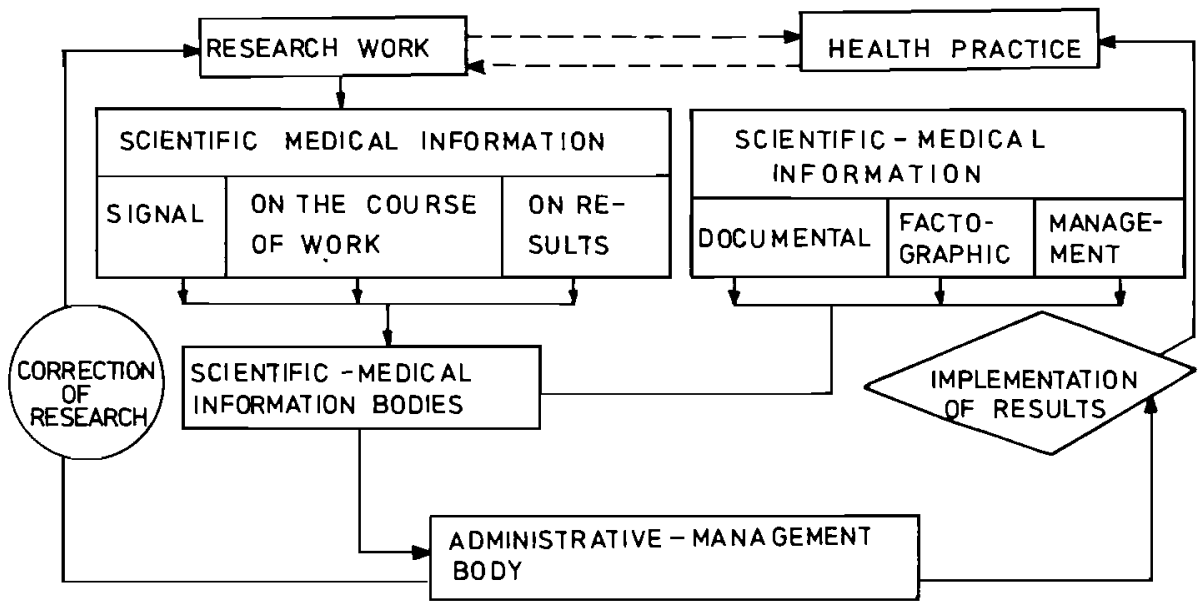

Figure 2.

The factographic systems of information searches, developed in the USSR for research work and scientific establishments, and the application of the systems analysis method during the creation of the above systems enable us to solve a number of problems connected with the effective organization, planning, and registration of research work, and also the implementation of the results of scientific research within medical practice.

The system is a dynamic structure consisting of several facets which have their own specific relations. The subjects of scientific investigations are analyzed and fed into electronic computer storage. Here, we mean to form the data bank on research in the health field which will take into consideration every subject of research. Modern electronic computers enable us to make information searches according to the existing features which interest the user.

This allows us to detect the most characteristic areas in the general storage of research works and to draw corresponding conclusions. The bodies of scientific medical information--using material coming from electronic computers which is the result of the electronic processing of the research subjects--may rapidly compile summary information material and submit it to the administrative-management bodies of health and medical science. These latter bodies are responsible for: 
a) assessment of the material (although the preliminary assessment could be given by the information bodies during the retrieval of information);

b) correction of the research, based upon preliminary information of it;

c) prognosis of further development of research in the specific field of medicine and health services; and

d) planning of research on the: basis of the elaborated prognosis.

Figure 3 shows the diagram of the automation of research management with the help of electronic computers.

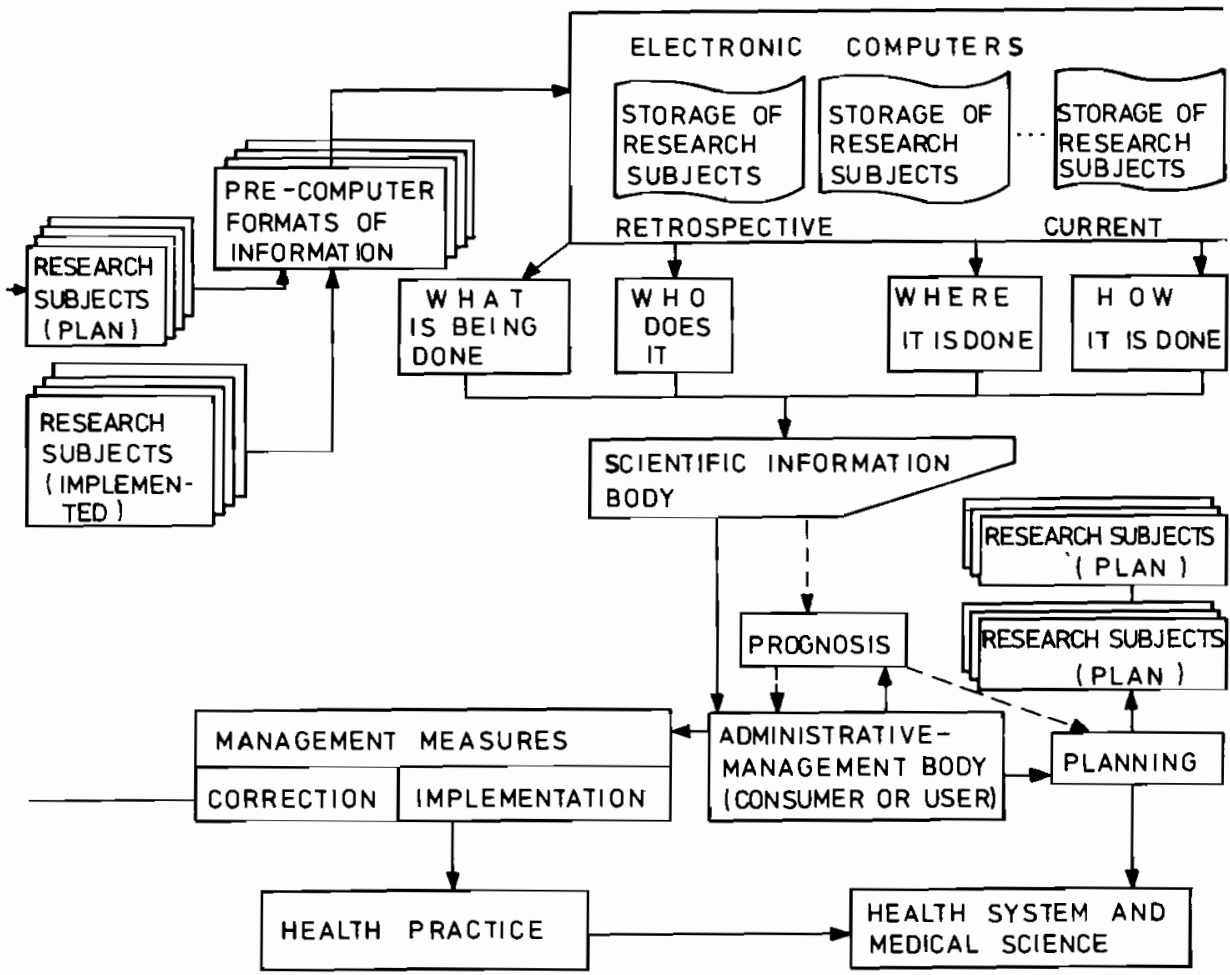

Figure 3. The scheme of the automated management system of research in the health field.

The data upon the work of the system permit us to carry out economic assessment of research and also, with the: help of the Expert Committee, to assess the essence of research.

The above system, according to its functional properties, is the management system of research in the health field and enables us to raise the level of development of medical science, taking into consideration and eliminating the drawbacks in existing research works--such as the improper control over the fulfillment of the subject, subjectivism in planning, ignorance of the requirements of health practice, and duplication of research. 


\author{
THE SYSTEMS ANALYSIS OF BIO-MEDICAL \\ RESEARCH AND THE ROLE \\ OF SCIENT LFIC MEDICAL INFORMATION
}

Yu. P. Lisitzyn

USSR Academy of Sciences

Medical science and bio-medical research--their planning, organization, implementation, and control--may be analyzed as a complex dynamic system. Its complexity derives from diverse interrelations between research centers, groups of research fellows, and intensive flows of information. The system is further characterized by stability in the sense of dynamic equilibria and by probalistic features. The concept of medical science as a dynamic system reflects the regularities of the formation of bio-medical research and the contemporary period of scientifictechnological revolution. Its practical aspect may be seen as the application of scientifically grounded principles to its own management.

The effective management of such complex dynamic systems predetermines the availability of the properly organized hierarchial structure of medical science and its research organizations (RO), each of which has its own structure: "The combination is of RO elements and their correlations, in which the properties of the elements are displayed through their relations." 1 Such structure exists in the Soviet Union, where the organization of bio-medical research is an inseparable part of the national system. It is coordinated by the State Body--the State Comnittee on Science and Technology. RO in the health field (the total number of research medical institutions and higher medical establishments is approximately 500, with more than 60,000 research fellows) have branched subordination: to the USSR Ministry of Health, to the USSR Academy of Medical Sciences, to Republican Ministries of Health, and to local health bodies.

Systems analysis of national health systems and medical science al lows the perfection of the system's structure on the basis of empirical generalizations as well as on the basis of theoretical abstractions and construction of models. The optimization of the structure with the help of systems analysis and the description of the system structures--their analysis, selection, construction of the most rationa1 systems, $i . e$. the synthesis of structures--becomes a very important document of research and realization of medical science management.

The basis for assessing the efficacy of management of the system of biomedical research is the determination of the problems, their priority and hierarchy. Research planning is similarly based upon recognition of high priority problems. Systems analysis may well be enlisted in the determination of these problems, and thereby in the optimization of research. Unfortunately, the solutions to many of these problems cannot be attained on the basis of the present knowledge. The overall task is thus far from achieved.

In the health field, we lack even the generally recognized branches of scientific disciplines--even though the nomenclature of diseases, traumas, and mortality causes dates back more than a hundred years. In practice, we subdivide the huge complex of bio-medical sciences into three or four sections: the so-called theoretical disciplines (e.g. morphology, physiology, general pathology, medical genetics), the clinical disciplines (e.g. internal diseases, surgery, psychiatry), and the hygienic disciplines, including social hygiene. It is quite natural that such division has nothing to do with the problematic principle since this listing of sciences and branches has resulted from the rapid differentiation and integration

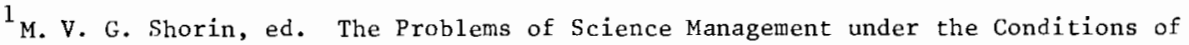
Scientific-Technological Revolution, 1972 , p. 32. 
of scientific knowledge. Interrelated with the problems are the following traditional medical tasks: 1) determination of the causes and the mechanism of development (pathogenesis); 2) diagnostic methods, therapy, and prevention of diseases; 3) creation of conditions for eradication of diseases; 4) increase of the health level of population through combinations of measures; 5) reduction of mortality; 6) increase of longevity; 7) improvement of the harmonic, physical, and moral development; and 8) increase of the "health index," i.e. the number of healthy people

From this point of view, the attempts to classify problems according to the so-called technological principle, are of great interest. This principle identifies the basic tasks to be solved by medicine. One such proposal was to isolate six classes of problems: prevention of diseases, ethio-pathogenesis, methods of diagnostics, therapeutic effects, complex therapy of the nosological forms, and development of medical services and medical science. This technological approach is scientifically grounded since even theoretical investigations of medical science are aimed ultimately at the achievement of such practical tasks as disease prevention.

Such an approach does not, however, meet the basic requirement--the determination of the most pressing and the most significant problems. Both the priority of problems and their likely solubility must be taken into account in the context of the specific socio-economic, geographic, scientific-technological, and political conditions.

Systems analysis should be directed to identify important problem tasks and to indicate lines of problem solution. Problems relatively more important to the entire system and those relatively more amenable to solution should first be tackled. Systems analysis should take into account parameters of the system, their relations, and the encompassing system. The latter aspect is of especial importance since many characteristics and action possibilities are derived only from the system as a whole. Having determined the most urgent problems, the next step is to equip the management with additional means--such as planning, assessment, and control--for their resolution. From this standpoint, systems analysis demonstrates the advantages of complex research methods. (Complex socio-hygienic and clinico-social investigations enable us comprehensively to study the effect of the group of diverse social factors on the health of the individual, in contrast to the limited opportunities of sanitarystatistical methods.)

Systems analysis presently is not widely used in the determination of the pressing problems of bio-medical research. Attempts to use this method have been made and were especially successful where health planning and health management (and management of medical science) is run by the State. Thus, the practice of biomedical planning proves the efficacy of the problem principle-the determination of the most urgent problems for the given period of time, and for the solution of general and particular problems by the health system and inedical science.

At present, for instance, we have distinguished approximately eighty problems, the solutions to which are being worked upon a11 over the country, To coordinate research on the above problems, we have set up Problematic Comissions of the most outstanding specialists.

The Problematic Commissions have as their bases the largest Research Centers in the given field of science (the so-called Head Institutes). The activities of such Problematic Commissions are coordinated by the Presidium of the USSR Academy of Medical Sciences, which, to optimize management, united a number of Problematic Commissions into Scientific Councils (on cardiology, oncology, hygiene, etc.).

The programing, according to the problem principle, is applied at different scales (national and local) in other countries as well. In the USA, for instance, it is coordinated by the National Institute of Health, although this type of planning is inhibited by the absence of the state system of health and medical science. 
Scientific-technological information is required for systems analysis and for the adoption of its identified solutions. Systems analysis starts by obtaining information on the staff, resources, structure, functions, relations and goals, labor conditions, and so on. Information on prognoses in bio-medical research completes the systems analysis--if it is actually aimed at the management of the above problems and their optimization. In this connection, of paramount interest are data on the scope of research and scientific-technological information in many developed countries.

Financial allocations for research now exceed three per cent of the total national income. The extent of these allocations is explained by the fact that the "industry of discoveries" promotes the intensification of the industrial production and, according to economic estimates, yields eighty per cent of the growth of labor productivity which greatly exceeds in value the expenditures on science. Every ten to fifteen years--in several branches, every seven to eight years--the number of researchers doubles. In 1960 , there were a few more than 350,000 researchers in the USSR; at present, their number exceeds one million. 2 This in its turn, has promoted the increase of financial allocations in the science field. The number of research centers and higher educational establishments in the USSR continues to increase (5367 in 1972). 3

The volume of scientific-technological information has grown apace: the doubling of the number of scientific achievements is accompanied by the multifacious growth of the volume of information. The volume of research publications increases annually by eight to ten per cent. At present we publish more than 100,000 journals (of these, 20,000 are in natural sciences and 9,000 in the health field, and contain about nine million articles); the number of books on natural and technical sciences exceeds thirty million titles; the volume of the world patent fund is more than twelve million descriptions. Here we should also take into account that only one-third of the material of scientific-technological interest is published.

It is no accident that the rapidly growing flow of information is a characteristic manifestation of the scientific-technological revolution. In order to bring the necessary information to the consumer, we use information systems incorporating modern electronic computers. The creation of branch and national systems of scientific-technological information (STI) is now being undertaken. Moreover, under the auspices of the UN and its agencies, the international system of information--UNISIST--is being planned. Some automated information systems (AIS) enable us not only to form data banks, but al so to compile such secondary information as bibliographic and reference materials. A further step is to introduce this information into the communication line and terminals, as it is done in the MEDLARS system.

AIS in a number of cases are considered to be the subsystems of the Automated Systems of Management (ASM), which, once again, emphasizes the service orientation of AIS.

The State system of STI was set up in the USSR. It serves and is served by the national, territorial, and local information services of some enterprises, including research organizations. The State Committee on Science and Technology of the USSR Council of Ministers executes the coordination of the information services as well as research at the national level. The largest information service in the world is the All-Union Scientific and Technological Information (AUSTI) which extensively uses electronic computers and other contemporary technological

${ }^{2}$ National Economy of the USSR in 1972. Statistical Annual Report, Moscow, 1973, p. 129 . 
means, and publishes different series of secondary and tertiary (analytic-synthetic) information, including the publication of the Reference Journal (RJ), which contains more than a million reviews annually.

The services of the STI are widely used in the planning and coordination of scientific and bio-medical investigations. However, to optimize research, we need specialized research toward applying AIS in the planning and coordination of research. In medicine this implies creation of the "Medical Science" AIS and the "Medical Science" ASM. To achieve this, we require the corresponding structure of the STI in medicine and health and the creation on this basis of the AIS of biomedical research. Highly important to the solution of this problem is the role of managing bio-medical research. This management should benefit from development of the STI and ASM services.

In the USSR we have the necessary prerequisites for the organization of AIS and ASM in medical science. We have set up a branch service of STI--scientificmedical information (SMI)--as an element of STI. This system now has three levels:

1) Central--The All-Union scientific-research Institute of Medical and Medico-Technological Information (AUIMMTI) and the State Central Scientific-Medical Library (SCSML);

2) Republican--Republican Sections of Scientific-Medica1 Information (RSSMI) and Republican Scientific-Medical Libraries (RSML); and

3) Local--Sections of scientific-medical information at research centers, higher educationsl establishments, large curative-preventive establishments and the network of oblast, city, and other libraries in medicine.

At present, in our country we have about 300 subsections of scientificmedical information and more than 4,000 Medical Libraries with a staff of about 5,000, excluding free-lance fellows.

Reference-information funds (RIF) serve as the basis for all the bodies and establishments of scientific-medical information and compile about forty million primary documents. All these publications are under the unique Reference-Information Fund. The basic task of the scientific-medical information service and the RIF is to supply the customer with information.

As has been stated, this required provision of such traditional forms of service as librarial aid in addition to help provided by information systems is based upon modern equipment. Of decisive importance is the review and bibliographical activity--the so-called secondary information--organized by AUIMMTI. Apart from bibliography, and some reference information materials (prepared at Medical Libraries and Sections of Information), a great volume of the secondary information is published by AUMMT, which has its own publishing house. The Institute publishes bibliographical, reference, review, and current information. The one-time circulation of all publications is about 200,000 copies, which are distributed to numerous individual and collective subscribers. Among the most popular publications of the Institute are News of Medicine and Medical Technology, Express-Information, reviews on the most pressing problems of medical research and health problems, different bibliographical series, and descriptions.

Highly popular and widely known is the Medical Reference Journal (MRJ), which at present is published monthly on sixteen topics. It has a bibliography and reviews on more than 25,000 articles, selected by specialists from 2,300 foreign journals and from more than a hundred domestic journals. MRJ is distributed abroad and is very popular there as in the USSR. UNESCO considers this Journal to be a large and most popular publication--comparable to such Journals as Index Medicus and Excerpta Medica. This popularity is proved by the increasing circulation of this Journal, which in 1957 was 10,000 copies and in 1974 reached 73,000 copies. 
In the course of several years, the Institute has created the Automated System of Scientific-Medical Information (ASSMI) as a part of the unique system of scientific-technological information in the country. The "brain" of this system is two electronic computers, with the help of which we have created a data bank. Bibliographical, reference information and data on research medical centers, topics of their research and personnel are fed into the computers. Until now, electronic computers have had a limited amount of information. However, intensive replenishment of the data bank will enable us to accelerate the processing of required data, including research data, carried out in the field of the most pressing bio-medical problems. ASSMI was developed by the Institute as a complex for electronic technology, for its mathematical provision, for methodological materials, and for massive inputted information. It uses automated storage, accumulation, search and retrieval, and transmission of information. Now it is used as a factographic system for planning and coordinating bio-medical research. In principle we may develop ASSMI for the improvement of management functions, and, in particular, for the development and utilization of methodology for determining research efficacy.

The compilation of the unique rubrics, classifiers, and technological dictionaries is required for the utilization of electronic computers and other modern technological means. The Institute has developed the first variant of the Thesaurus on medicine and at present, in collaboration with the specialists from the Head Institutes, works toward its perfection.

To increase the effective utilization of systems analysis in bio-medical research, it is expedient to develop methods for actively involving international organizations--above all, WHO--in solving this problem. WHO's basic task is 1) the implementation of the extended program of research, which envisages the promoting cooperation with national $\mathrm{RO}$ in carrying out research on the most imminent problems of health (e.g. immunology, oncology, cardiology, medical demography, control of infectious diseases); and 2) cooperation with different regional and international organizations, such as FAO, UNESCO, UNICEF, IACR, and others. The program of research requires specification, determination of priorities, development of superprograms on the basic problems, and consideration of national and international possibilities. One of the positive examples of the development may be the long-term program on planning of international collaboration in the field of oncological research, which was discussed at the Twenty-seventh World Health As sembly.

Systems analysis, even in the field of international cooperation in biomedical research, should be directed toward determination of the most pressing problems with the help of the information systems, WHO information services, and information services of other organizations. 
Mr. Rapoport aired a number of thoughts on the systematization of biomedical information that touched upon points raised in the paper of Professor Lisitzyn. The first points concerned the overwhelming force of contention: the few magic numbers attributed vast policy importance and the focusing of attention upon certain, so-called pressing problems. In the latter category, he felt that heart disease and cancer had been so often cited as urgent concerns that continued mention reduced the areas to trivialities. In addition to sapping meaning from the terms themselves, such overemphasis has obscured other conditions causing much actual suffering. If research can alleviate the suffering of one individual, it can provide great satisfaction to the physician and to the researcher. Unfortunately, much research is so fundanental that its results cannot be realized in practice for many years. A time perspective of twenty years for the evaluation of basic research would allow confident judgments upon its quality.

A way to break the constraining and narrow bounds of convention is through the cross-fertilization of scientists. This would be described in detail by the paper of Mr. Fuchs-Kittowski to be presented in the afternoon. Experts in many fields should consciously identify independent areas of inquiry that may have been neglected because they were not in vogue. The result might be an ordered structure of possibilities that could be followed for many years. Should IIASA become engaged in the prognosis of research activities, its interdisciplinary perspective would enable it to broaden further the tableau of identified and promising lines for scientific exploration.

Cross-fertilization of effort between fundamental and clinical research is particularly to be encouraged. Fundamental researchers tend to develop their disciplines while clinicians are tackling real problems. Each can beneficially stimulate the other: the basic researchers would be guided to more policy-relevant work while clinicians might be enabled to resist the pressures of empiricism. An example of regrettably mischanneled clinical research activity was provided by the intensive trials with radium baths believed to have marvelous curative powers. Subsequently it was realized that, instead of being therapeutic, the baths posed a serious radiological hazard to health.

Mr. Rapoport lauded the emphasis placed by Mr. Lisitzyn's papers upon improving bio-medical information flows. 'Though the volume of these flows has reached avalanche proportions, their utility has not mounted apace. Many scientists express their dismay at the vast amount of information by avoiding it insofar as possible and by relying upon word-of-mouth exchange. What seems required is a purposeful focusing of information. Mr. Rapoport hoped that function of literature reviews described in the Lisitzyn paper would accomplish this end.

\section{Response}

Mr. Lisitzyn agreed with Mr. Rapoport on the force of convention. He saw it reflected in the problem of classifying research targets. At present, there is no satisfying system of classification as research problems are generally bound to disciplines. The proliferation of disciplines complicates the situation without contributing to a solution. Instead of disciplinary perspectives, the classification of research might better reflect the aims and tasks of health services. It is hoped that systems analysis may contribute to a reoriented classification scheme.

Mr. Lisitzyn stated that the details of the information review and condensation scheme had not yet been worked out. Perhaps the system would be based upon critical reviews by scientific experts. He cautioned, however, against narrowing the focus to pureiy scientific uses. Bio-medical information is needed by managers and planners and must also be mixed and matched with social and technological information. The problem here is that these various streams of informaton represent distinct disciplinary languages between which communication has been difficult. 
Systems analysis might itself be a developing common language that would enable better interaction among such diverse persons as economists, laboratory researchers, physicians, and managers. 



\title{
COMPUTER SIMULATION STUDIES OF ALTERNATIVE
}

\section{POPULATION SCREENING POLICIES}

\author{
E. G. Knox
}

Health Services Research Centre

University of Birmingham, UK

\section{INTRODUCTION}

The subject matter of this paper is covered in IIASA's statement on research strategy (1973) by two phrases: "systematic prevention, diagnosis, control and treatment of disease," and "guidance of medical research and development" (Section 6.8). The IIASA statement is an imaginative exposition of its subject, but section 6.8 reflects the fact that applied systems analysis was injected into medicine from the outside, and is associated especially with its technical fringes such as management, epidemiology, statistics, and technology. The report does not explicitly mention the measurement and control of clinical errors, the measurement of the effectiveness of medical care, or a systems approach to studying the natural histories of diseases. Some of these ommissions may result from traditional taboos, but they also reflect a reluctance by doctors to recognize the nature of the modelling process and the extent of its usage in medicine. It is this reluctance which has largely confined the application of systems analysis to the fringes of medicine.

Workers in this field have tended to treat such concepts as natural history, diagnostic error, the acceptability of tests, or the effectiveness of treatment as relatively fixed points in a sea of administrative and economic uncertainties. The latter are then treated as the subjects for study. Yet the systematic examination of one particular type of medical care, screening procedures (Mckeown, 1968), demonstrated that it was precisely in those "medical" areas that the greatest and most significant uncertainties were to be found. There is nothing to suggest that this is limited to screening. The simple checklist approach adopted in the screening study was rewarded with the depressing discovery that serious uncertainties of these kinds existed for almost any proposed procedure. Not only were the essentials for planning often undefined; it was not always easy to see which areas of ignorance mattered most, or where a research investment was most urgently needed. Nor was it always easy to see how the research would be conducted. How, for example, does one compute the natural history of a disease? How can one assess the sensitivity of a test when false negatives remain unidentifiable? These entities cannot be calculated from the data by a reduction process such as we might use for calculating a mean or a proportion or a standard error. They must be formulated by iterative declaration; arithmetic is directed toward computation of the consequences of these declarations and subsequent attempted fittings to complex sets of data. In other words, a simulation approach is as necessary from a scientific point of view as from an administrative one.

It was against this background that the present exercise was developed. It consisted of the construction of a general computer simulation system for manipulating a range of proposed screening procedures in such a way as to examine the conditional consequences of a matrix of factual uncertainties, each combination then being set against a range of feasible levels of investment and different modes of deployment.

\section{THE MODEL SYSTEM}

The program was written in FORTRAN and its global structure is simple (Knox, 1973). It requires the successive inputs of the necessary premises for the mode1, at which point it completes the birth to death process of a cohort of 10,000 persons. The results are printed out stage by stage and terminally, including details of disease onsets and deaths, the prevalences of disease states, and the performances 
of the screening tests. Finally, it invites selective modification of the initial inputs and repeats the computations for as many loops as are required. The required inputs are as follows:

a. Life-Table. Lx data are supplied on a single card and the cohort dies from causes other than the disease in question, at the specified rate.

b. Pathological States. A list of names is required. They are numbered serially as they are input, one state to each card. State No. 1 is always NORMAL; State No. 25 is DEAD OF THIS DISEASE; and State No. 26 is DEAD OF OTHER CAUSE. States 2 - 24 are optional and are designed in such a way as to adapt the program to a particular screming problem.

c. Natura1 History. In systems terms a natural history is a transition matrix. It must be declared in the form of transitions between pairs of serially numbered pathological states. The choice of pairs (up to 50 in the present program) is optional. Each transfer-specification is followed by a series of paired values: the first value of the pair represents the age from which a given transition rate will operate; this is given as the second value of the pair expressed percent per annum. This rate can be changed subsequently by another pair of values and so on. Where the initial pathological state is NORMAL, the age value represents the age of the patient; where the initial state is not NORMAL it represents the age of the lesion.

d. The Screening Procedures. Up to six screening procedures can be

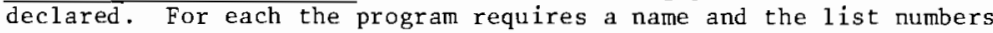
of the pathological states to which it will be made available. For each initial state must be declared the transition state to which the patient will be transferred if the test should be positive. The estimated percentage positive must also be provided for each individual state in order to provide working estimates for the "sensitivity" and "specificity" of the test.

e. Service Provision. Finally, the program must be supplied with the ages at which each of the tests will be offered, an option which subsumes both the total investment and detailed deployment. At each of these ages the program also requires a working estimate of the percentage of patients expected to attend. One additional optional input, attached to stage 2 above, is related to this latest requirement. Each pathological state can be pre-weighted with a percentage attendance value which modifies the overall age-attendance value, so that known selective attendance risks (e.g. as in cervical cancer) can be incorporated into the program.

The outputs of the program include:

a. reprints of the 1 ife-table, the list of pathological states, the transition matrix, the procedural definitions and the service deployment;

b. outputs at desired intervals (another option) of transitions to and from each pathological state, together with current prevalence and incidence estimates. Cumulative and interval estimates of screening procedure performances are also given at these times;

c. a final statement is given to summarize the interval statements under b; 
d. a year by year statement of numbers in each pathological state, per 10,000 born; a repetition of this table giving prevalences per 1,000 still living; and

e. a full matrix of all transitions.

In practice the "life-table" and the "pathological states" inputs give little difficulty. Cross-sectional life-tables are probably adequate in most cases and an agreed list of names is not usually a problem. Names of treated states must be included, and if any (e.g. pre-clinical) states are of doubtful validty and are to be made a subject for subsequent simulation experiments, they they can be included at this stage so that the list remains constant throughout the whole investigation; they do not have to be used at every run and can be omitted from the transition matrix.

The natural history specification is the most difficult input to construct. A moderate number of pathological states generates a large number of one-way transitions and an initial arbitrary selection must be made. Next, while it may be possible to find data to guide the specification of some of the transitions (e.g. incidences of onset, case fatalities following treatment), some data-sets will give only the gross consequences of several sequential steps (e.g. cancer registration, mortality). The intermediate transition arrangement will have to be guessed initially and then adjusted until known age-specific prevalences, or other non-time-dimensioned data, are successfully matched. The construction of a natural history competent to mimic all the known facts is a tedious iterative process. Moreover, in some cases, while it is possible to exlude a large number (an infinite set) of natural histories as incompetent, it may be possible to mimic the available observations with more than one competent natural history (another infinite set?). In this case the natural history becomes one of the uncertainties in the service simulation experiments which will follow and it is necessary to compute a series of predictions on the basis of each of a range of alternatives.

The iterations are carried out in the absence of screening procedures so that it is not necessary to specify the latter in the early stages. The sensitivity/ specificity estimates are the most likely to give trouble through lack of data. Sometimes, where the results of a large-scale planning experiment are available, an iterative fitting process like that above may be feasible. Usually, it will be necessary simply to test a range of values which encompass the most important uncertainties--say the false positive rate in normals and the true positive rate in the most frequently occurring of the pathological states. It may be possible, within the general simulation-space of interest to demonstrate a linear dependence of results upon sensitivity, for example, and this would permit curtailment of the scale of the investigation.

The last input stage, giving the ages of offers of tests, together with attendance estimates, offers little difficulty. These values must be repeated over a range corresponding with the feasible admininstrative alternatives. Each choice, however, has to be run against the range of factual uncertainties already developed. The administrative options are usually arranged as series representing feasible escalations, de-escalations, and modifications from the present position. The results are compared with each other and with the result of offering no screening at all, so that absolute and marginal benefits can be predicted, together with absolute and marginal costs, expressed in terms of numbers of tests performed, numbers of subsequent investigations, numbers of false positives, and numbers of harmful results.

\section{IDENTIFICATION OF A PROBLEM: CERVICAL CYTOLOGY SCREENING}

The problems of cervical cytology screening have been states and denied many times. They arise first because the procedures has never been subjected to a randomized experiment of any kind; second because the progreesive natural history model of carcinoma in situ, on which many cytologists have relied, has never 
been adequately validated; and thirdly because, after many years of assiduous application, there is still no direct and unambiguous evidence that mass screening has reduced morbidity or mortality (e.g. Alhuwalia \& Doll, 1968, Kinlen \& Dol1, 1973).

The possibility of carrying out a randomized general trial has long since disappeared. The resolution of the natural history is difficult because the only reliable criterion for the diagnosis of carcinoma in situ is through its total removal--which effectively blocks direct sequential observation. Effects upon mortality will not easily be solved in the near future, because even when a fall is noted, a number of alternative causes for the fall can be quoted, and when a fall is not noted, a number of excuses can be supplied.

Examples of such arguments are:

a) Mortality has been falling in places not subjected to screening.

b) Differences in the disease experience of successive cohorts, and different cohort sequences in different places, prevent accurate prediction of future trends in the absence of screening.

c) Provision of cytology is accompanied by good therapeutic practice and mortality may have fallen for this reason.

d) Adequate gynecological services, a necessary prior condition for the institution of cytological services, are often followed by high hysterectomy rates, and this alone could explain a fall in mortality.

e) The supposed long duration of carcinoma in situ means that no mortality effect can be expected for many years after the initiation of a screening program.

f) Once a diagnosis of carcinoma of cervix is given it tends to be cited on the death certificate, even when it is not the cause of death, and this tendency masks any beneficial result.

g) We should not be despondent about a failure to reduce mortality, but should congratulate ourselves on having prevented an increase--an expectation which springs from the (alleged) growth of early promiscuity and its demonstrable relationship to the onset of the disease.

Morbidity figures suffer from many of the above difficulties of interpretation and when they are based upon comparisons of clinical cancer rates in "screened" and "unscreened" women fresh problems arise. The complex effects of selfselection, migration, change of name, clerical error, and the effects of cytology screening upon the mode of presentation have prevented hard conclusions from being reached.

Because of the absence of a direct demonstration of the effectiveness of screening programs, rational planning has had to rely excessively upon the natural history model. The basic uncertainties surrounding this model, which arise from the destructive diagnosis procedures, have already been mentioned. In addition it has now been shown that the cumulative incidence of onset of carcinoma in situ --as measured by the occurrence of new disease in initially "negative" women in successive age-groups--substantially surpasses the accumulated prevalence for invasive cancer. The difference is not explained through taking into account the residual prevalence of carcinoma in situ at later ages. Where, then, have the excessive onsets gone? Have some reverted to normal? If some have done so, can we be certain that most have not done so, while the invasive cases developed rapidly from some undetectable or transiently detectable pre-invasive state? To what extent, on the other hand, is that incidence-prevalence gap a consequence of negative errors, the estimate prevalence being too low because of missed cases and 
the estimated incidence being too high because some of the "new" cases were in fact missed old ones? Yet again, might we be dealing with a cohort effect, an artifact of accumulating rates across age groups in cross-sectional data?

At the present time there are no hard answers to any of these questions and yet a number of planning decisions must be taken. These decisions include:

a) Whether to escalate or de-escalate the service, or leave it as it is.

b) Whether to encourage cytology screening at other ages.

c) To decide, upon the basis of the natural history of the disease and the estimated negative error rates of the test, what intervals to recommend between examination.

d) In which areas research resources should most urgently be deployed.

\section{THE SIMULATION OF A CYTOLOGY PROGRAM}

A recent female life-table for England and Wales was used throughout. The names of the recognized pathological states were:

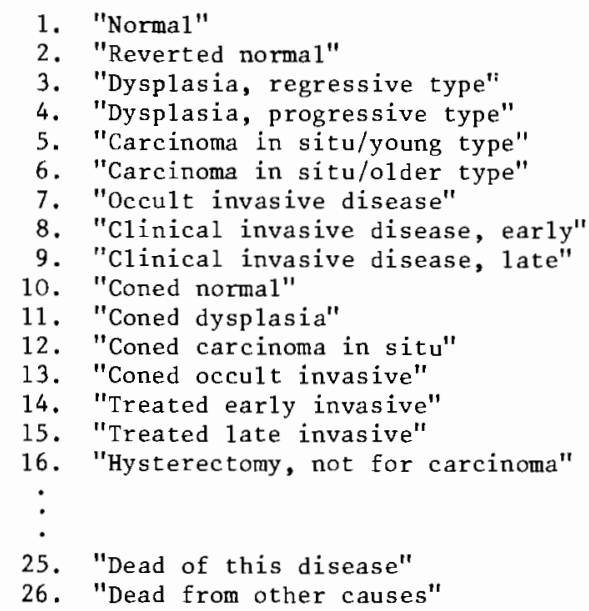

It will be noted that the term "micro-invasive" was not used; it was treated as a subset of "in situ." The regressive/progressive dichotomy of dysplasia was not used in every run, nor was the young/old dichotomy for carcinoma in situ.

Iterations were carried out on the transition matrix to match, so far as was possible, data on the prevalence and incidence of carcinoma in situ and dysplasia (using mainly the British Columbia data of Fidler, Boyes, and Worth, 1968), data on cancer registrations (for the Birmingham region), and mortality rates for England and Wales (Registrar General). This mixture of sources and the cross-sectional nature of each set of data--the simulation operates on a cohort-make this an inexact process. However, it is probably good enough for relatively crude projective work and in any case it it is probably as good as we can get. As might be expected from the intractability of the natural history dilemma described above, it was found more than one natural history could produce reasonable mimicry of most of the observations. In the end two main hypothetical natural histories were constructed and used in parallel throughout the following examinations. They are referred to as the progressive and the dynamic alternatives. 
The two natural histories shared a number of common features. The transfer rate from all pre-clinical conditions to "hysterectomy, not for carcinoma" was the same in each, and this state, once attained, gave immunity from cervical cancer. About six percent of women attained this state by age 40, fifteen percent by age 50, while at later ages it leveled off between nineteen and twenty-three percent. Transfer rates from clinical to treated clinical states were common to both ratural histories, as were case fatalities of treated and untreated clinical conditions. Several of the transfers (to types, 10,11,12,13) occurred only as a the result of screening procedures and the rules were the same in each case.

The main differences between the natural histories were in transfers between the pre-clinical states. Types $2,3,5$ were not used at all in the progressive matrix and the only "reverse" movement was from dysplasia to normal. In the dynamic natural history dysplasia could progress or regress (as in the progressive natural history), but two different relativities were provided for. The same applied to carcinoma in situ of which both sub-types could either progress or regress, but again in different ratios.

The final values chosen, following these iterations, were still to some extent arbitrary. In the progressive natural history, for example, transfers from normal to carcinoma in situ began at age 20 , at 0.02 percent per annum, mounted in two stages to 0.05 at age 30 , and remained at this level until ages 70 and 80 when they were reduced in two steps. This picture differs from notions held by many pathologists to the extent that the onsets continued until quite advanced ages; this arose in the simulation out of necessity. It was not possible to reconcile onsets limited to women under 30 (for example) with latent intervals of 10 to 15 years, and with non-reversibility, and still mimic available observations. The degree of dynamic interchange between reversible states in the dynamic natural history was also arbitrary, but was adjusted until a reasonable mimicry of the gap between the prevalence and accumulated incidence resulted. The gap so engineered was not as great as the gap observed in real life from crosssectional data. This was to allow, so far as possible, for the alternative co-contributors to the gap, namely error rates and cohort effects.

The two natural histories were adjusted so that the yields of each were approximately the same. This is necessary if subsequent experiments on the application of different screening procedures are to permit valid comparisons between the two natural history contingencies in terms of percentage deaths and percentage carcinomas saved. The progressive natural history resulted in 222 invasive carcinomas and 89 deaths, the dynamic natural history in 265 invasive carcinomas and 96 deaths. There were great differences in the production of dysplasias, 170 and 455 respectively, and in the production of carcinomas in situ--262. against 443 .

\section{RESULTS OF SIMULATED SCREENING}

A single procedure was offered in these experiments, namely "cervical scrape." It was assigned a sensitivity of 75 percent in the presence of carcinoma in situ, slightly less for dysplasia, and slightly more for the invasive states. This was intended to cover the total procedure of taking and examining a specimen, and not simply the repeatability of classification at the laboratory level. Early experiments suggested that in typical situations and with relatively low investments ( 5 investigations per woman per life-time, with five-year intervals) overall yields varied linearly with the sensitivity values. The specificity problem was met arbitrarily by assigning a false positive rate, in normals, of 0.1 percent. Easson's data (1973) suggest that in his laboratory this may be rather too high (although this will vary between laboratories); but again the result can probably be corrected linearly in relation to alternative values.

Because of the approximately linear relationship between yields and sensitivities, it appeared that overall results could not be influenced critically by inaccuracy in these assignments at least within the simulation space or practical 
interest. Therefore, further experiments in this respect were not carried out and the sensitivities were held constant for all subsequent examinations. The main bases of experiment were therefore the ages and numbers and frequencies of the screening procedure offers, together with varying estimates of acceptance.

A series of experiments with universal acceptance showed that, for women who attended when asked on a single occasion, the best return in terms of "deaths saved" was between the ages of 40 and 45 . This was true for both natural histories. Natural history assumptions made surprisingly little difference; if the progressive natural history were true, the cost was 390 tests per 1 ife saved, and for the dynamic natural history, 474. For the progressive natural history, 3.5 cervical cone biopsies were carried out for every life saved, and for the dynamic natural history 3.8. These last figures depend critically upon the assigned false positive rate. If the rate were less than the assigned 0.1 percent, then both ratios would have been less, and the proportional difference between the progressive and dynamic natural histories would have been greater.

When the investment was increased successively to 5,10 , and 20 tests per life-time (even1y spread between ages 20 and 70 ), a) the overall results increased, b) the overal1 yields per test fell, and c) the marginal benefits of each increment of investment fe $\overline{11}$ even more rapidly. For the progressive natural history, the incremental cost of each extra 1 ife saved rose across the four steps of escalation for 390 tests to 809 to 2,024 , to 11,289 . The dynamic natura 1 history gave a quite different pattern, rising from 474 to 1,202 to 2,272 and 7,937 .

The percentage deaths saved, if the natural history were progressive, rose from 25.8 to 67.4 to 88.8 to 96.6 ; for the dynamic natural history the percentages were $19.8,45.8,63.5$, and 74.0 . These are interesting and intuitively unpredictable results. Since the present position in Britain is somewhat short of the five-test level, we must assume that our expectations for improvements in the near future depend critically upon what the natural history actually is. If, in fact, it is a dynamic one, we may already be entering the phase of prohibitive costs, whereas if it is progressive, we may have a little distance yet to go. Furthermore, while the progressive natural history offers a prospect of substantial control, say 90 percent saving, for a cost which can be contemplated, the dynamic natural history suggests a much less ambitious target, say 50 percent control, as reasonable.

The alternative way of measuring marginal costs, in terms of positive tests per extra death saved, is of particular interest to the patient since it reflects the relative risks of an unnecessary biopsy and a useful one. These values also arose in patterns which were not readily predictable; the series for the progressive natural history was $3.5,4.6,5.8,16.7$, and for the dynamic natural history $3.8,5.4,5.5,11.1$. It is interesting 1) that the difference between the natural histories is not critical, and 2) that unacceptable rises do not occur until long after we can no longer afford the increasing investment.

A series of examinations was carried out for "five-test" programs deployed alternatively from age 35 onwards, or below the age of 35 . The latter is currently favored by the Department of Health, while the second has been recommended by several groups of pathologists and gynecologists. There was not a great deal of difference between the results. But for both natural histories the current policy gave somewhat better returns in terms of deaths saved than did the proposed innovations. Consideration of life-years saved, however, modified this result and almost erased the difference.

A series of experiments was then carried out upon the effects of varying acceptance levels, short of the 100 percent levels used so far. The range varied between 40 percent and 100 percent. Each level was examined first as for a homogeneous population and secondly with selective weightings according to the 
initial pathological state. These experiments were carried out for both the progressive and the dynamic natural histories and at investment levels of $1,5,10$, and 20 tests.

It was possible, within each level of attendance, to examine the consequences of different patterns. Thus, when the program is assigned a 60 percent attendance rate per of fer, the program treats each offer as independent of the preceding and following offers so that the frequency distribution of all attendances, across the population, will follow a Poisson distribution. At the other extreme it is possible to regard the population as consisting of 60 percent who always attend and 40 percent who never do. The results of this contingency can be calculated by adding together the results of two separate runs with appropriate weightings. It was found that at low levels of investment (e.g. Five tests per life-time) the particular pattern did not make much difference and that deaths saved depended almost 1 inearly upon attendance percentages. For example, with the progressive natural history and a five-test offer, 40 percent attendances (Poisson pattern) saved 29.2 percent of 1 ives and 100 percent saved 67.4 percent. For the dynamic natural history the figures were 21.9 percent and 45.8 percent. The non-Poisson pattern, that is 40 percent attenders and 60 percent non-attenders reduced the 29.2 percent of the progressive natural history to 26.9 percent; the 21.9 percent of dynamic natural history fell to 18.3 percent. These figures refer to percentage attendances unweighted according to initial pathological state. A superimposed loading of attendance of 80 percent attached to carcinoma in situ (or worse), again reduced the results by an almost uniform 20 percent.

However, at high investments, (e.g. 10, 20 tests) the pattern of attendance made a great deal of difference. The Poisson distribution resulted in lifesavings almost twice as high as when the population segregated itself into attenders and non-attenders on a $40: 60$ basis. For example, with the dynamic natural history and a 20 test offer, a 40 percent random attendance resulted in a 52.1 percent saving on deaths, whereas a 40:60 segregation into attenders and non-attenders resulted only in a 29.6 percent saving on deaths. At the 10 and 20 test levels and for both natural histories, substantial investment to assess the unassessed is clearly worthwhile, whereas at the five-test level and below, such investment would produce little improvement. High investment applied to a self-segregating population implies that part of the population is already deep into the zone of diminishing returns; it is only the remaining part which is really worth an increased investment at this stage.

\section{CONCLUSION}

At small levels of investment the consequences of uncertainty, particularly about the natural history, are not too serious. Small resources will pick up the easy cases and the first 10 percent of mortality can be prevented at moderate cost. This is probably done mainly through the detection of already invasive early disease, and the question of the natural history of carcinoma in situ has scarcely yet arisen. The optimal deployment is around age 40.

As investment increases the results will improve, but each extra result is more expensive than the last. This is a continuous process and there is no "natural limit" to investment. In addition, the consequences of uncertainty about the basic factual premises increase as the investment increases, and combinations of unfavorable, but not unduly pessimistic premises are capable of drawing practical limits to the degree of control which can be hoped for. Thus, the cost of ignorance rises with the investment and justification for research to resolve uncertainties must also mount as the investment mounts. This conclusion is the reverse of most intuitive fonmulations of the relationship between research and service, where it is commonly supposed that research might taper of $f$ as the service function takes over. 


\section{REFERENCES}

Alhuwalia \& voll. (1968). Mortality from Cancer of the Cervix Uteri in British Columbia and other parts of Canada. Br. J. Prev. Soc. Med. 22, 161-164.

Easson, E.C. (ed.) (1973). Cancer of the Uterine Cervix (Lond on: Saunders).

Fidler, H.K., Boyes, D.A. and Worth, A.J. (1968). Cervical Cancer Detections in British Columbia. J. Obstet. Gynaec. Br. Commonw. 75, 392-404.

Kinlen \& Do11. (1973). Trends in Mortality from Cancer of the Uterus in Canada and in England and Wales. Br. J. Prev. Soc. Med. 27, 146-149.

Knox, E.G. (1973). A Simulation System for Screening Procedures: Computer Simulations of Cervical Cytology Screening Programmes. In Problems and in Progress in Medical Care. Nuffield Prov. Hosp. Trust.

Mckeown, T. \& Others. (1968). Screening in Medical Care. Nuff. Prov. Hosp. Trust. Oxford Univ. Press. 
Comments of the Discussant, Mr. Chatterjee

Screening is one tool in public health policy which aims at prevention and detection before preclinical symptoms appear. Screening is a medical investigation which does not arise from a patient's request for treatment of specific complaints, but is initiated by a physician or public health authorities and has as its goal the early presymptomatic identification of treatable disease. Since the whole procedure is started by the health authorities rather than the patient, it is necessary to justify the usefulness of such procedures. There are many pitfalls, as has been pointed out by Zelen and Feinleib, Knox, and others, in the evaluation of screening programs. I will not go into this point. Mr. Knox has presented us with a tool to look at different screening policies.

While reading his paper and listening to his talk, I thought how satisfactory it would have been to have a console at my disposal, and to look at some simulation results to see how the variation in the parameters of the problem affect the performance of different screening programs. Would Mr. Knox say that the Health Insurance Program of Greater New York is an attempt at field trials to establish the effectiveness of screening procedures?

It was not clear, to me at least, what the different outputs which Mr. Knox's program produced were. I wonder whether his runs also gave the conventional measures which are looked at in the screening studies--namely, mean lead time, mean age at detection, proportion of cases missed, survival times of detected cases. These quantities must be looked at carefully, and have obvious misinterpretations. Nevertheless, they provide for a layman some measures by which he can grasp and get a feel for the different policies. Mr. Knox, in his simulation program, gives various performance measures for different screening policies. But he has refrained from commenting, and I am prodding him and others in the audience with a question (this might have been discussed yesterday afternoon when I was unable to be present): how does a public official choose among several screening policies given different costs and different performance characteristics? He seems to favor, and here I may be making an inaccurate attribution, a marginal approach. Is it to be a marginal analysis or a utility analysis? Or are the realities of the situation in health fields such that there is never enough money and the screening policy to be chosen is dictated by the budget for the program? Are the medical community and public health officials convinced of the efficacy of screening studies, and its inclusion in the health care package? I hope some of you will address your remarks to these points.

I would like to suggest a procedure which is a variant to complete screening that I feel may have some merit. After some knowledge has been built up from screening studies, this procedure may work. The whole target population is subjected to the first screen. If a particular disease is associated with certain medical histories more often than others, then the people with those medical histories are completely screened in subsequent screens, but only a fraction of those with other medical histories are subjected to successive screening. These individuals may be overlapping, non-overlapping, or partially overlapping. The motivation for the procedure is to save money if national screening programs are instituted and to achieve efficiency. The success of this approach will depend on how much knowledge has been built up about the disease and its associated medical histories.

The last question $I$ will raise is directed particularly toward theoreticallyminded people: can analytical results be obtained by applying the results from the field of Markov Renewal Theory to screening problems? Could it be done, has it been done, or is it worth doing? 


\section{Applying Maximal Theory to Screening}

In response to Mr. Chatterjee's final question, Mr. Bailey said that he knew of no instances in which Markov Renewal. Theory had been applied. In a real world situation, a specific proposal should be taken as a starting point for building up a model. Such a model might or might not be Markovian. It was Mr. Bailey's feeling that maximal models of entire health screening processes would be most complex.

Observations on Large-Scale Screening

A number of remarks on screening were offered:

a) The overall success of a screening program depends critically upon the spacing of tests and upon their accuracy--measured as the frequency of false positives and negatives.

b) The USSR is concentrating upon the possibility of universal dispensarization which is multidimensional screening performed in conjunction with regular check-ups of the entire population.

c) Bulgaria is implementing multi-phasic screening in poly-clinics for all chronic diseases but evaluation of its efficiency is not yet possible.

d) US experience and a study of WHO have both cast doubt upon the efficacy and value of multi-phasic screening.

e) One calculation made in the UK indicates that multi-phasic screening would require a $150 \%$ increase in physicians.

f) Physician assistants can perform many screening tasks and thus reduce the need for additional physicians.

g) International comparison of experience with multi-phasic screening is fraught with dangers because of the vastly different health system contexts in which the screening would be embedded.

\section{Response of Mr. Knox}

Mr. Knox felt that the idea for pre-screening suggested by Mr. Chatterjee was feasible.

The question of optimal spacing he had pondered and found complex. Perhaps an exponential scheme of spacing would be optimal. Mr. Knox warned that in seeking such an optimum a set of complex non-linear equations must be dealt with. 



\author{
ECONOMIC ASPECTS OF \\ THE PREVENTION OF \\ DOWN'S SYNDROME (MONGOLISM)
}

\author{
N, Glass \\ International Institute for \\ Applied Systems Analysis, \\ Laxenburg, Austria
}

\title{
INTRODUCTION
}

Developments in chromosome analysis in recent years have led a number of people to suggest "screening" programs for the detection and prevention of genetic disorders. In particular, Stein et a1. (1973) have outlined the case for the progressive introduction of a comprehensive program to eliminate or, at any rate, to reduce the incidence of Down's Syndrome (Mongolism). The program would involve the detection of the genetic abnormality in utero by amniocentesis and chromosome analysis, combined with the offer of an abortion to those women found to be carrying an affected fetus.

In this article, in the correspondence which followed it, in the document emanating from the WHO Scientific Group (1972), and in the recent work by Milunsky (1973), reference has been made to "economic" aspects of such a program. In particular Stein et a1. and Milunsky have claimed that the program would certainly "pay for itself" for mothers over thirty years old, in the sense that the savings in future institutional care of Mongoloids would more than offset the cost of the scheme. The WHO working party suggested that for mothers over thirty-five years of age, the cost of the program would be less than half the savings it engendered.

Since the medical participants have not feared to tread in this area of "economic" costs and benefits, the rest of us perhaps may be excused the wish, if not to rush in then, at least to sidle in also. In particular, it was not always made clear in the works cited already whether the calculations made were expected to apply to al1 countries or only to the US and, if only to the US, whether conclusions drawn from the US case might need to be altered for other countries. The analysis in this paper confines itself to the situation in the UK.

\section{THE ECONOMICS OF SCREENING--SOME ETHICAL AND ECONOMIC CONSIDERATIONS}

Screening programs are, in principle, capable of being regarded as any other investment project. They usually require an initial capital outlay and incur continuous running expenses. In return they generate a series of effects which can be thought of as benefits or returns and which accrue over time. We11-tested techniryes exist for dealing with this kind of problem and for deciding whether the investment is a "good thing" or not.

In practice, however, this approach has its limitations. These have been summarized by Pole (1968) as follows: "Economic considerations are bound to play a part in determining what screening programmes are put into effect, but can only operate within a framework of valuations which have an obvious moral content and of constraints which are likely to be ethical, political, and administrative as well as financial and medical." In short, many of the costs and benefits of screening prograns are such that there is no technical way of expressing them in terms of a single dimension which would be generally acceptable. Although one can attempt to set out the various factors in terms of a "balance sheet" there is no useful apolitical way of totting both sides up.

Should one therefore carry out any "economic" analysis of such programs at a11? The customary justification for analysis in these circumstances is that since one element in any decision to proceed with a screening program is its impact on the 
use and availability of resources--largely a matter of "fact", and establishment of the "facts" can at least narrow down the area of uncertainty. This view has, however, been attacked.

The nature of the criticism is best summed up by Wiseman (1963): "I am uncomfortable about the notion that better information about one part of an indefinite whole must always make for a better understanding of that whole: it seems at least possible that it might make for difficulty in taking a balanced view of the relative importance of the things that have been quantified and those that have not (the socalled intangibles)." The first part of this argument resolves itself ultimately into a matter of fact: do the decision makers find the type of information provided by an economic analysis helpful or not? To a large extent this will depend on the nature of the decision and the quality of the information--not to mention the character of the decision makers!

The second part of the argument, especially as expounded more recently by Draper (1974) seems to involve the belief that dangerous toys should be kept out of the hands of children, doctors, health administrators, and politicians, who cannot be trusted to put such economic information into its correct perspective alongside medical and moral considerations. Obviously, we shall tend to differ about whether we find this essentially paternalistic attitude attractive.

In any case, whether economists take a vow of abstinence or not, people will hold and air opinions about the economic aspects of screening programs and it seems sensible that these opinions should be based on explicit assumptions and calculations rather than on implicit ones.

At the beginning of the section I drew a comparison between screening and investment. A major similarity is that screening involves an outlay now in order to achieve a benefit in the future. It is, I think, clear that if two outlays of equal size $x$ promised, on the one hand, a benefit of size $y$ in five years time, and on the other, a benefit of size $y$ in 100 years time then, on the whole, we should be inclined to choose the first. This is not simply because we shall not be alive 100 years hence. One could always sell the right to appropriate the benefit to someone else. Forests are planted even though their planters may never live to see them felled.

We are dealing with the complex phenomenon of time preference. How should next year's benefits be valued compared with this year's, and what about benefits in five years' time? A discussion of this issue would take us far afield. What I have done is to use the procedure which H.M. Treasury suggests for public expenditure projects, namely a $10 \%$ discount rate. This means that the value of a benefit or cost decays at a rate of $10 \%$ per year in real terms (i.e. in constant prices). The longer the benefits or costs are delayed the lower their value. The extent of this reduction for the purposes of planning the commnity's activities must be a social (and, ultimately, political) decision.

The notion of discounting future costs and benefits has important implications for screening. The effect of screening relates to the particular cohort screened, and the benefit or cost accrues over the lifetime (or potential lifetime) of the cohort screened. The cost (however defined) of the present mentally handicapped population, for example, is irrelevant to a decision about screening to prevent or alleviate mental handicap. What is relevant is how such costs might be expected to occur over the lifetime of the affected cohort. The importance of this consideration will, I hope, become clearer later.

\section{THE ECONOMICS OF DOWN'S SYNDROME: TWO OBJECTIONS}

objections to carrying out an economic analysis of an amniocentesis/abortion program come under two headings. The first relates to the ethics of abortion. A "prevention" program to eliminate or reduce the incidence of Down's syndrome would 
involve the offer of an abortion to those mothers discovered after amniocentesis and karyotyping to be carrying a Mongoloid child. Many people find the notion of legal abortion--especially in the form of an organized program--abhorrent and may consider arguments about economic gains and losses irrelevant, if not reprehensible. Of this group of people, some would still hold this opinion even if caring for the population of Mongoloids were to absorb $100 \%$ of our national resources. For the remainder there is, presumably, some point between one penny and $100 \%$ of our national resources at which ethical objections would weigh less heavily than the economic burden implied by these objections. For the former group there is no point in reading further. Members of the latter group will, I hope, be interested in being able to weigh the economic considerations in the balance with other more exalted considerations.

There is a potential second group of objectors whose line is, perhaps, best exemplified by a passage from Stein et a1.(1973): "But is a detailed estimate of money cost required? The 1 ifelong care of severely retarded persons is so burdensome in almost every human dimension that no preventive program is likely to outweigh the burden."

The problem with this argument is that it appears not to be true. The number of nurses working in mental handicap hospitals in England and Wales rose from 10,000 to 15,000 between 1959 and 1969. Despite occasional instances of i11treatment there is no reason to believe that these nurses find the "lifetime care of severely retarded persons so burdensome in almost every human dimension," or they would clearly not be willing to do the job. As for the parents of Mongoloid children, there would appear to be conflicting views on the extent to which they find the burden of caring for their children intolerable. But even if it were true that the burden was an intolerable one from the parents' point of view this is not a1together germane. Since the "community" is to provide the resources for a screening program, the question to be decided is whether "the community" regards the burden borne by the affected parents as intolerable. This is clearly a rather different question from that of whether the parents themselves find it intolerable. The evidence, from the UK at least, would appear to be that either 1) the community does not regard the burden as being so great that the resources necessary to provide complete lifetime institutionalization for all Mongoloids could not be better spent elsewhere or 2) parents do not regard the lifetime care of severely retarded persons as so burdensome that they would prefer to institutionalize their children, since only about $10 \%$ of Mongoloid children are currently institutionalized.

However, even if Stein et al.'s statement were self-evidently true--namely, that the burden of caring for Mongoloids far outweighed the cost of any prevention program--this, in itself, does not constitute an argument for not computing this cost. For it may wel1 be that when the cost of "any" prevention program is taken together with possible clinical and ethical objections, not to mention the political "cost" of getting such a program accepted, the combined forces of the various negative factors outweigh the "great" benefits. Unless we know the resource costs and benefits we cannot make an overall judgment on the value of the scheme. For these reasons, I consider it to be a worthwhile task to trace out as fully as I can the resource implications of such a prevention scheme for the UK.

\section{INCIDENCE OF DOWN'S SYNDROME}

Table 1 summarizes the salient features of the incidence of Down's Syndrome. It can be seen that the condition has an overall incidence of about 1 in 600 but that this incidence rate rises greatly with maternal age. Although the incidence is tending to fall with a fall in the number of children born to mothers over 40, prevalence is apparently tending to increase due to increased survival rates among Mongoloids. The hereditary element is not very important in the incidence of the condition. The evidence about survival rates is somewhat conflicting. Stein et al. quote a number of studies to the effect that $54 \%$ of children with the syndrome had died before the age of 7 . Kushlick, however, found that two-thirds were still alive 
at 15 (1974) while Neligan (1974) reports a survival rate at 5 years of over $80 \%$. Since most deaths occur within the first year the differing rates are somewhat confusing. While it is possible that they may reflect the phenomenon of increasing survival noted earlier, the differences seem rather too large to be explained in this way.

Children with Down's Syndrome comprise about $30 \%$ of severely mentally handicapped children ( $\mathrm{IQ}<50$ ). In the Wessex survey (1973) higher-grade Mongoloids comprised just over $3 \%$ of the mildly sub-normal $(50<1 Q<70)$.

Table 1. Estimated age-specific incidence of Down's syndrome, numbers of live births, and estimated numbers of affected infants with percentages, in England and Wales, 1970 .

\section{Maternal}

age (years)
Incidence $/ 1000$

live births

(estimated)
No. of

live births
No. of affected infants (estim.)

$\begin{array}{lccc}\text { al1 ages } & 1.67 & 784486 & 1312(100.0) \\ \text { under } 20 & 0.9 & 80975 & 73(5.6) \\ 20-24 & 1.0 & 289209 & 289(22.0) \\ 25-29 & 1.1 & 238228 & 262(20.0) \\ 30-34 & 2.0 & 114086 & 228(17.4) \\ 35-39 & 5.0 & 48323 & 242(18.4) \\ 40-44 & 15.0 & 12756 & 191(14.6) \\ 45 \text { and over } & 30.0 & 909 & 27\end{array}$

Figures in parentheses are percentages.

Source: Wynne Griffith, 1973.

\section{AMNIOCENTESIS AND KARYOTYPING}

The detection of a Mongoloid child in utero depends on a technique known as anniocentesis which consists of the aspiration of amniotic fluid from the uterine cavity. This is usually done at 14-16 weeks and can be performed normally on an outpatient basis under local anaesthetic. It is, however, thought to be desirable that the placenta should be located by the use of ultrasonic equipment (1973).

The subsequent chromosome analysis to detect the presence of an extra chromosome (the normal genetic characteristic of Down's syndrome) is a laborious process taking two to three weeks for culture and analysis. Antenatal diagnosis of fetal chromosomal abnormalities is still very much an art rather than a routine procedure. Stein et al. claimed a $95 \%$ culture success rate per pregnancy, including repeat cultures the need for which can normally be ascertained after a few days, but this has been disputed by others. There would appear also to be differences of opinion concerning the likelihood of significant technical improvements involving computer technology. The specificity and sensitivity of the test is very high. 
The risks to the mother and fetus attendant upon amniocentesis are a matter of dispute and are currently the subject of a Medical Research Council project. Estimates of the risk of inducing abortions range from $3 \%$ to virtually nil.

In general, before amniocentesis is carried out to detect genetic abnormalities an undertaking is obtained from the mother that she will consent to an abortion in the event of such an abnormality being discovered.

\section{HOSPITAL RESOURCES REQUIRED FOR AMNIOCENTESIS}

Amniocentesis is normally carried out as an outpatient procedure under local anaesthetic. The resources demanded would clearly depend on the size of the program, the participation rate of mothers, the number of repeats required, and the rate at which the procedure can be carried out.

An upper bound to the possible manpower implications of an amniocentesis program can be given using fairly extreme assumptions. If the amniocentesis program were to cover all pregnancies in England, which we shall assume to number 700,000 a year, if all mothers participated, if one procedure in three had to be repeated, if the procedure required a consultant obstetrician, and if each obstetrician carried out four procedures in a session, then such a program would require the services of about 470 whole-time consultant obstetricians. In 1972 there were just over 500 whole-time-equivalent consultant obstetricians in England.

If the size of program and the participation rate were held constant but a repeat rate of one in ten and a work-rate of six procedures per session were assumed, then the number of whole-time consultants required would be about 280 . A lower participation rate would, of course, reduce the number of doctors required but would concomitantly reduce the number of cases detected.

It becomes clear that a program to provide amniocentesis for all pregnant mothers, even using the second set of assumptions above, would imply large increases in medical manpower. Probably for this reason, a phased introduction of such a program has been suggested by Stein et a1. (1973) and by Bain and Sutherland (1973). Given the highly age-related incidence of the condition, the program would initially cover mothers over the age of forty and would gradually be extended to younger age groups.

In 1971 mothers over forty accounted for $1.7 \%$ of all live births a1though this proportion is falling. On the other hand they accounted for an estimated $16.7 \%$ of al1 Mongoloid births. If we take $1.5 \%$ as our best estimate of the proportion of the 700,000 births which will be accounted for by mothers over forty, such mothers will be responsible for 10,500 births. Of these, about 170 might be expected to be Mongoloids. What this will mean in work load is more difficult to estimate. Amniocentesis would need to be carried out by the sixteenth week of pregnancy in order to permit an abortion to be carried out by the twentieth week. The proportion of potential mothers over forty who will have come in contact with a medical agency by the sixteenth week is unlikely to be anywhere near $100 \%$. While this factor is important it should be stressed, on the other hand, that a reduced participation rate principally affects the absolute level of costs and benefits. The ratio of costs to benefits is largely unaffected by such a transformation.

With this in mind an estimate of the hospital cost of an amniocentesis program for the annual cohort of mothers of age 40 and above in a proportion of 700,000 mothers is given below. The detailed estimates on which it is based are described elsewhere. The estimates assume a participation rate of $100 \%$ and should be appropriately scaled down for lower rates. They also include an allowance for subsequent abortions. 
Table 2. Estimated annual clinical cost of an amniocentesis program for mothers aged forty years and above.

\begin{tabular}{|c|c|c|}
\hline Repeat Rate & 4 per session & 6 per session \\
\hline One in Three & $£ 196,000$ & $£ 125,000$ \\
\hline One in Ten & $£ 164,000$ & $£ 114,000$ \\
\hline
\end{tabular}

The foregoing calculations do not include the costs to the patient of attending for the amiocentesis. The size of such an element would depend on the number of centers carrying out the program within a given region and on whether one chose to attribute a cost to the patient's time travelling and at the hospital. A larger number of centers would reduce travelling time and costs but might lead to rather higher unit costs at each center if capital and equipment were under-utilized and if the fewer cases to be handled provided less scope for technical improvement. It might also involve a higher risk of inducing abortions.

A similar scheme for mothers in the 35-39 age group would be about four times as expensive as that for mothers of forty and over, since births to mothers between 35 and 39 might be expected to account for about $6 \%$ of all births. Economics of scale, however, might reduce the cost of this larger program.

The above calculations have also ignored the high abortion rate for older mothers. To the extent that older mothers who currently abort might, under an amniocentesis program, be screened before doing so, the cost of the scheme would be higher. The fact that a proportion of older mothers may currently seek an abortion from fear of bearing a Mongoloid child (a Fear which would be removed by a screening program) provides a further complication.

\section{LABORATORY RESOURCES REQUIRED}

Chromosome analysis on the scale implied by a comprehensive screening program has not hitherto been carried out at any center in the UK although its practice is rapidly increasing. This increases the problem of estimating the cost of such a procedure.

The detailed estimates of staffing and other requirements which have been made are outlined elsewhere. Chromosome analysis is a highly labor-intensive procedure. It is possible that there may be significant technical improvements in the future. The possibility of such technical improvement is only relevant to a current decision, however, to the extent that the implementation of a largescale chromosome-analysis service would be likely to hasten such technical development. If technical development is likely to proceed autonomously at an unchanged rate, then for present purposes it can be ignored. If technical development is likely to be hastened by the presence of a Iarger-scale service comitment, the calculation then becomes much more complex.

In Table 3 the costs of a laboratory program to detect Down's syndrome in the annual cohort of mothers over the age of forty is set out. It is assumed that a service on the scale implied (around 1,000 analyses a year at each regional center) would require purpose built accommodation. 
Table 3. Annual laboratory costs of a screening program for mothers 40 and above.

\begin{tabular}{l|c} 
REPEAT RATE & COST \\
\hline One in Three & $£ 820,000$ \\
One in Ten & $£ 750,000$
\end{tabular}

Once again the cost of extending the scheme to the population of mothers between 35 and 39 would be a sum about four times as large as that for those over 40 .

To summarize, there are various assumptions one can make about the operation of an amniocentesis/abortion program for the prevention of Down's syndrome. On the assumptions outlined above the minimum annual cost of such a scheme for mothers of 40 and over would be $\{850,000$. The maximum figure would be about fl million. These estimates do not include patient costs. A similar scheme for mothers aged 35-39 would cost at present between $\{3.4$, and $\{4.0$ million, assuming no economies of scale. These cost estimates are based on a participation rate of $100 \%$ among mothers and need to be appropriately scaled down for lower rates.

\section{SAVINGS IN INSTITUTIONAL CARE}

An amniocentesis/abortion program for mothers over 40 might expect to prevent about 170 live Mongoloid births, assuming $100 \%$ participation by mothers. To estimate the consequences of this for institutional care one would need to know how many of these children will be institutionalized at what stage in their lives. This requires not simply information about the present state of affairs but a prediction as to likely trends in care over the next fifty years--clearly a tall order:

There has been a tendency in the various articles and letters about screening programs to discuss the "institutional" costs of the trisomic population in an obscure and ambiguous way. In particular it has not been made clear that the relevant "institutional" costs are those that would be caused by a particular cohort of Mongoloids. It is often not clear whether, for example, Stein et al. and the WHO working party are referring to the costs of institutionalizing all Mongoloids or to the costs of institutionalizing that proportion of future cohorts who, given the present or projected provision of institutional places, are likely to be institutionalized.

The first assumption does not conform with what actually happens, in this country at any rate. The second requires a forecast of rates of institutionalization--rates which are probably largely determined by the extent of public provision of hospital and residential places.

For the purposes of this study I have made the following assumptions about the expected average lifetime experiences of a current cohort of Mongoloid births in the absence of an amniocentesis program:

Assumption 1. Fifteen per cent of Mongoloid children die before one year; ten per cent of those left alive are institutionalized for life; and thereafter half of the remainder are institutionalized at age 15 and the other half at age 25 .

Assumption 2. The same as Assumption 1 except that twenty per cent are institutionalized for life. 
Assumption 3. The same as Assumption 1 except that onethird of children die before first year.

Assumption 4. The same as Assumption 2 except that one third of children die before first year.

These assumptions are made with references to the work of Kush1ick (1974) and of Neligan (1974). The important point to note is that under all of the assumptions most of the "savings" in institutional care do not occur for fifteen years after the birth of the cohort. It is this delay which makes the use of a "discounting" procedure imperative.

In estimating the "savings" from the reduction in the need for institutional care I have used as my basic estimate the current cost of a patient-year in a mental subnormality hospital to which I have added a capital cost allowance to give an average figure of $\mathrm{El}, 500$ per year per patient. To the extent that Mongoloids present particular problems this may be a slight underestimate. To the extent that Mongoloids present fewer problems or might be accommodated in community residential accommodation the figure may be somewhat lower. The allowance for capital cost reflects the fact that hospital and residential places for the mentally retarded are in short supply (at zero price!). For the sake of simplicity I have assumed that all places are provided by the public sector and have not tried to incorporate the role of the private and voluntary sectors.

It is not very realistic in a cohort analysis of this kind to assume that expenditure will remain constant in real terms (it is likely, of course, to rise dramatically in money terms!) This is for two reasons: firstly, if the country becomes richer higher standards are likely to be desired for the care of the mentally subnormal and are likely to be implemented; secondly, labor-intensive sectors like the care of the mentally subnormal, where wages probably account for $90 \%$ or more of hospital expenses, are likely to become relatively more expensive as labor productivity increases at a faster rate in the rest of the economy. This latter effect may, however, be offset by a move away from hospital-type care.

With these effects in mind I have estimated expected lifetime "savings" in institutional care for a current cohort of Mongoloids under two assumptions:

(1) That expenditure remains constant in real terms--the first two effects being offset exactly by the third.

(2) That expenditure rises at a real rate of $5 \%$ per annum.

Table 4 gives the results for the various assumptions.

Table 4. Lifetime costs of institutional care for one year's cohort born to mothers of age 40 and above (discounted at $10 \%$ per annum).

Zero Real Growth in Expenditure

As sumption 1 .

Assumption 2 .

As sumption 3

Assumption 4.
$E 567,000$

5\% Real Growth in Expenditure

$£ 1,200,000$

f1, 539,000

E 976,000

$\mathrm{E} 470,000$

$£ 1,248,000$ 
If the amniocentesis program were extended to mothers in the age group 35 to 39 , the savings attributable to this extension would be about one-eighth greater than the above figures. Once again it should be stressed that these calculations assume $100 \%$ participation by mothers and a "success" rate of $100 \%$.

\section{SAVINGS IN TRAINING COSTS}

We have here assumed that all children receive some form of training from age 5 until age 15 or until they are institutionalized, in addition to what they would receive in their institution. We have used Section 6 fees paid by Local Authorities to Special Schools as a first measure of the cost of such training. For one local authority this averaged $£ 700$ a year per pupil in 1973 .

Table 5. Lifetime training costs of annual cohort born to mothers age 40 and above.

\section{Zero Real Growth in Expenditure}

As sumption 1 .

Assumption 2.

Assumption 3 .

As sumption 4 .

The "costs" of the 35-39 cohort would again be about one-eighth greater than
5\% Rea1 Growth in Expenditure

E778,000

E7 58,000

$£ 609,000$

$£ 593,000$

$\begin{array}{ll}£ 450,000 & £ 778,000 \\ £ 440,000 & £ 758,000 \\ £ 354,000 & £ 609,000 \\ E 348,000 & £ 593,000\end{array}$

this.

HOSPITAL AND FAMILY cosTS

A cursory analysis of the data provided by Neligan did not indicate a very. great inpatient cost imposed by Mongoloid children who survived their first year. Only seven of the eighteen survivors examined appeared to have had an inpatient episode in their first Eive years and in general the episodes were not of long duration. Possibly this reflects a reluctance among pediatricians to admit Mongoloid children to acute wards. I have not allowed for home care or outpatient episodes.

The cost to those families who keep their Mongoloid children at home is difficult to estimate. I have used Family Expenditure Survey figures to estimate the cost of rearing a child--in this case the difference in average annul expenditure between a family with one child and a family with two children. Using 1972 data this amounts to $£ 250$ a year or about $£ 300$ in 1974 prices. Assuming a real rise in expenditure of $3 \%$ a year, the discounted value of family expenditure for an annul over-forties cohort, under various assumptions ranges from $£ 283,000$ for Assumption 4 to $\$ 406,000$ for Assumption 1. Due to lack of data no attempt has been made to allow for the extent to which the presence of a Mongoloid child reduced the "employability" of the mother or father.

To summarize: it is possible to make a number of assumptions about the expected lifetime profile of a current cohort of Mongoloid births and about the trend of expenditure both public and private. This gives us a range of estimates of the discounted lifetime costs of an annual cohort. For mothers of forty and over, assuming a 100\% participation and success rate (which would need to be scaled down for lower assumed rates), the values extend from $\mathrm{E} 1.2 \mathrm{million}$ using Assumption 3 and a zero real growth in expenditure to $\$ 2.7$ million with Assumption 2 and a 5\% real growth in expenditure. This compares with a cost of between $\mathfrak{E} 850,000$ and $\mathfrak{E} 1.0$ million. For the cohort of children born to mothers aged 35-39, the maximum "savings" $f$ igure is about $\mathbf{E 3 . 0}$ million, as against a cost of between 
£3.4 million and $54.0 \mathrm{million}$.

\section{CONCLUSIONS}

The purpose of this paper was to trace out as fully as possible, using existing data, the resource consequences of an amniocentesis/abortion program for the prevention of Down's syndrome under a number of plausible assumptions. lmplicit in an exercise of this kind is the belief that information of this kind is useful when taken together with medical and social data (and a person's own value judgments) in coming to a conclusion about the advisability of such a program.

There are some particular points which I wish to stress, however. The first is that under no set of assumptions in the paper is the resource cost of an amniocentesis/abortion program for the 35-39-year-old group of mothers in the UK less than the resource "savings" engendered by such a program, a result which conflicts with the assertions of Stein et al. and the WHO working party.

Much of the explanation for the different results lies in the apparent failure of the other studies to apply a discounting procedure to effects which occur over the lifetime of the affected cohort. However, this is not the full explanation. The cost quoted by both Stein et al. and Milunsky $(1973,1973)$ for an amniocentesis/chromosome analysis in New York ( $\$ 150$ ) would appear to be rather below the estimated current cost of such a procedure in the IK even allowing for intervening inflation, while the cost of caring for Mongoloids is, apparently, much higher in the US. This is simply another instance of the danger of applying results derived in one national context to quite different countries and societies. It should be stressed again that the analysis in this paper does not imply that a screening program should not be extended to mothers in the 35-39 age group in the UK; clearly such a decision depends on many other factors, clinical, ethical, social than could be considered here. The sole implication is that, on the basis of the data and assumptions used in this paper, such a program would not "pay for itself."

The second point is to stress the crucial role playing in the analysis by the discounting procedure. This is a procedure which is often difficult for non-economists to come to terms with and yet it is one which they implicitly use in their everyday lives. If a project promises returns in the future in exchange for present sacrifices, then some means of valuing these delayed effects in relation to present burdens must be found. The use of the Treasury-reconmended discount rate for public expenditure projects seems to the the most reasonable rate to use in a project calling largely for the expenditure of public money.

Lastly, this study has confined itself to an analysis of the proposal to detect Down's syndrome. It is sometimes suggested that the sample of amniotic fluid could be used to detect the presence of other fetal irregularities such as spina bifida. Whatever the merits of this argument it should be noted that the actual amniocentesis procedure forms a comparatively small part of the total cost of detecting the presence of Down's syndrome. 


\section{$\underline{\text { REFERENCES }}$}

Bain, A.D., and Sutherland, G. (February 24, 1973). Letter to the Lancet, 423. Draper, P. (1974). Social Sciences and the Health Services - A Case of Childhood Prostitution. Dept. of Community Medicine, Guy's Hospital, London. Mimeographed.

Kushlick, A. (1974). Personal Communication.

Kushlick, A., and Cox, G. (1973). The Epidemiology of Mental Handicap, Developmental Medicine and Child Neurology, 15, 748-759.

Milunsky, A. (1973). The Prenatal Diagnosis of Hereditary Disorders, C.C. Thomas.

Neligan, G. (1974). Personal Communication.

Pole, J.D. (1968). Economic Aspects of Screening for Disease, in Screening in Medical Care: Reviewing the Evidence: A Collection of Essays. London, Oxford University Press, for Nuffield Provincial Hospitals Trust, 151.

Stein, Z., Susser, M., and Guterman, A.V. (1973). Screening Program for Prevention of Down's Syndrome, The Lancet, i, 305-310.

W.H.O. (1972). Technical Report Series, No. 497.

Williams, A. (1974). The Cost Benefit Approach, University of York, to be published. Mimeographed.

Wiseman, J. (1963). Cost Benefit Analysis and Health Service Policy in A.T. Peacock and D.J. Robertson (eds.) Public Expenditure: Appraisal and Control, oliver and Boyd.

Wynne Griffith, G. (1973). The Prevention of Down's Syndrome (Mongolism): Trends, 5, 59-60. 
Comments of the Discussant, Mr. Thrall

The Glass study, Mr. Thrall pointed out, showed that cost-benefit analysis could exclude as well as justify a contemplated project. In this case, Mr. Glass had shown that the savings in institutional care, which others' had claimed would more than repay the expenses of screening for Down's Syndrome, simply failed to do so. Mr. Glass had considered a broad range of alternative assumptions and had found that the saved institutional costs approximated the screening costs only for the population of women over forty.

Nevertheless, Mr. Glass realized that institutional savings were not the only benefit in reducing the incidence of Mongolism. The screening project might, after all, in weighing other benefits, be justified. Mr. Thrall felt that Mr. Glass had appropriately not embarked upon such an exercise. The values that would have had to be imputed to those benefits should be the values of the decision makers themselves. Lacking entry, to their minds, the modeller should not impose his own values upon the analysis.

The choice of discount rate for a study of this type is, as indicated by Mr. Glass, thorny. This area of systems methodology is currently undergoing careful scrutiny as to facile extentions of basic techniques to problems in which they were not relevant has brought discounting into disrepute. The use of discounting in valuing whale populations is a case in point. Assessing through discounting the future benefits from screening for Down's Syndrome is fraught with danger. Mr. Thrall suggested that a way around this might be to examine the steady state results of an assumed long-term adoption of the policy. In this way, costs and benefits could be compared for the same year. It was pointed out that this scheme effectively implies a discount rate equal to the population growth rate.

\section{Points on the Evaluation of Screening}

Conference participants offered a number of thoughts on topics in the evaluation of screening prompted by Messrs. Glass and Thra1l:

a) that a kind of ethical paralysis sets in when people shrink from the thought of comparing the ineffable benefits of screening for Down's Syndrome with cold, hard lucre;

b) that a recent evaluation of screening for phenylketonuria expressed output in terms of function years and found that the best screening is genetic rather than bio-chemical;

c) that the cost of screening depends critically upon the level of personnel thought capable of performing the amniocentesis; and

d) that the reduction of Mongolism may have vast unknowable externality benefits--invisible to the affected families themselves--making benefit estimation a nugatory exercise.

Response by Mr. Class

The possibility of ethical paralysis was conceded by Mr. Glass. His own analysis represented an attempt to resolve questions about the monetarily measurable benefits whose enumeration might subsequently aid the inevitable religious and ethical debates.

He took issue with one off-hand reference to his work as cost-benefit analysis. The facile deduction sometimes is made that any appearance of the dollar or pound symbol indicates cost-benefit analysis. Mr. Glass stated that the disparaging remark applied to certain cultures appeared to him valid for cost-benefit analysis: that it had passed from a state considered primitive to decadence without any inter- 
vening phase.

Mr. Glass defended his use of discount rates as the best of presently available analytic alternatives. He warned, however, of a danger: that the presentation of alternative discount rates to evaluate proposed and competing projects might enable the decision maker to select first the project he finds personally most appealing and then to choose as the appropriate rate that justifying his project. Discount rates should be determined without reference to specific contemplated projects and should reflect the social attitude toward the future.

\section{Presenting Analysis}

One participant felt that the Glass paper had skirted a danger run by all difficult and delicate analysis: that it is overwhelmingly likely to be misunderstood. To be as clear as possible, analysis ought perhaps to be divided in two parts. The first should compare monetarily quantifiable benefits with costs to obtain net benefits--which may be negative. The second part should enumerate those benefits whose valuation requires discretionary judgment which, as Mr. Thrall argued, can be assigned only by the decision maker.

Mr. Glass said that he had attempted to provide the first part in this suggested estimation of net benefits. He did not consider himself competent to embark upon the second exercise of enumerating such benefits as the social externalities. 

PART V. PLANNING AND MANAGEMENT

IN THE HEALTH SECTOR 



\section{THE PUBI,IC \\ HEALTH PLANNING SYSTEM \\ IN SWEDEN}

\section{$\underline{\text { ABSTRACT }}$}

In my paper I shall present a new system for public health planning which is now being introduced in sweden. Before doing so it is necessary, however, to give, as a background, a short review of the organization of health and medical care in Sweden and the changes taking place in order to meet future demands.

\section{BACRGROUNI-OORGANIZATION AND DEVLLOPMENT}

All medical care available to the public in Sweden--with a population of about 8.1 million--is subject to Government control. However, the state is responsible for only a small proportion of the health and medical care services provided. The twenty-three councils and three local authorities outside the county councils are responsible for most of these. There is also a small private sector consisting mainly of private practitioners and dentists. The pharmacies are also owned by the state.

In the field of health and medical care, the state functions on two levels: 1) the Ministry of Health and Social Affairs, and 2) certain main departments of the civil service, particularly the National Board of Health and Welfare. This division of Government activity between Minisiry and civil service departments is a special feature of the Swedish administrative system with its 300-year old tradition.

The Ministry of Health and Social Affairs--often in cooperation with Parliament--draws up the general lines of operation for the health and medical care services. There is a Permanent Planning Committee on National Health Planning connected with the Ministry. It is the task of this Committee to study the expansion of public health resources in the country and to work for coordination of public health planning.

The National Board of Health is responsible for the planning of health and medical care services on the national level. The Board also has supervisory functions vis-à-vis both public and private medical care institutions. Thus not only the county council hospitals and physicians come under the Board's control; it also supervises the work of private practitioners and dentists. The Board has many administrative functions: it provides health information and constitutes for the benefit of society a pool of expert knowledge in the fields of environmental hygiene, health and medical care, drug distribution, and so on.

Under medical care legislation the county councils are responsible for providing medical services for the population of the county and persons residing temporarily in the county until they can be transferred, without risk, to the medical system in their home county. Medical care must be available both in- and outside the hospital system. The county council is also responsible for planning in its own jurisdiction and, in cooperation with the neighboring counties, also for the regional planning of health services.

County council activities, which are primarily in the health field but also include some educational and social activities, are financed through county council taxation (75\%), Government allocations (8\%), health insurance contributions (9\%), 
fees from patients (1\%), and a number of other sources (6\%). Most of the income thus comes from direct taxation, which is proportional--that is, it amounts to a certain percentage of a person's taxable income, regardless of the size of income. The county council's right to levy taxes is one of the main reasons for its high degree of independence. In this respect it differs from its counterparts abroad, whose freedom is restricted by the sma11ness of their independent income and by their dependence on contributions from the central government.

The public health service in Sweden has up to now been heavily hospitaloriented. In international terms, the number of beds is relatively high and corresponds to roughly 17 beds per 1,000 inhabitants (about 6.2 beds for acute somatic care, 4.5 for long-stay somatic care, 4.0 for psychiatric care, and 2.5 for the mentally retarded). Outside the health organization there are about 7 places per 1 , ooo inhabitants in homes for the aged under the responsibility of primary local governments.

In contrast to the figures for hospital care mentioned, the number of outpatient visits to physicians is relatively low compared to other similar countries, being currently about 2.7 visits per inhabitant per year.

Public health resources have expanded greatly in recent years. The expenses for health services have also risen sharply by $7-8 \%$ a year reckoned in fixed prices, as opposed to an annual increase in the GNP of 3.5-4.0\%. Health services are thus consuming an increasing part of the national resources. The cost of health service now amounts to more than $7 \%$ of the GNP. The major task for the near future is to come to grips with continued increases in expenses for health care. At present, the total cost of public health services amounts to more than Skr 2,000 (US\$ 450) per inhabitant per year.

There are at present about 13,000 physicians in Sweden, corresponding to 1 physician per 640 inhabitants. There is today a great shortage of physicians. The number is expected to increase sharply, however, and by the middle of the $1980^{\prime} \mathrm{s}$ it will amount to about 25,000. Other staff in the health service, such as nurses and physical therapists, are also expected to increase sharply. The total number of nurses will increase by the same time from about 60,000 to about 90,000 .

The rapid rise in the cost of public health service, the increased demand for service (mainly caused by developments in medical technology), the increasing number of elderly people, and the change in availability of trained staff have resulted in a need to reorganize the system for health service. services:

The following efforts will provide a basis for future deveiopments in health

1) Expansion of non-institutional out-patient care service (objective: 4.0-4.5 visits to physicians annually per inhabitant by 1985 , including visits for preventive care);

2) Expansion of long-term care service (the percentage of persons aged 65 years or more in the total population will be $16-17 \%$ by the middle of the $\left.1980^{\prime} \mathrm{s}\right)$;

3) Concentration and reduction in the number of beds for acute somatic care, care differentiation, and specialization (objective: 4.5-4.7 beds per 1,000 inhabitants for acute care by the beginning of the $1980^{\prime} \mathrm{s}$ );

4) Concentration of psychiatric care under and coordination with somatic care--gradually closing down the large mental hospitals; and

5) Increased emphasis on preventive measures and early diagnosis. 
The following is needed in order to obtain efficient measures to meet the growing demand within the framework of limited economic resources:

a) expanded and coordinated public health planning, and

b) assignment of care activities to specified care levels (leve1 of resources).

Public health planning in Sweden (point a) will be described later in a special section. At this point I shall make a few remarks on the restructuring of the health system (point b).

\section{RESTRUCTURING THE HEALTH SYSTEM}

The National Board of Health and Welfare has recently presented a proposal entitled "The Structure of Health Services in the 1980's." The main objective of this proposal was to elucidate the manner in which public health resources should be arranged and located. According to the proposal in the future the health system will have a more pronounced outpatient care profile (primary care) than before and the facilities for primary care will thus be very much improved. The proposal is summarized below.

Discussions of the patient's need for vicinity, continuity, and safety in the health services offered are vital features of the items under study in the proposal.

The need for vicinity is essential when aid is required for acute infection, slight accidental injuries, emotional crises, and long-term illness. There is also a need for close contact with the social welfare service in connection with disorders and disturbances entailing "social consequences."

The need for continuity in care is especially apparent for children and the families of children (mothers in particular) and for the elderly. This continuity. refers not only to the previously mentioned sicknesses and disorders but also to continuity within each care occasion.

The need for safety is related to the quality of service. Patients must be confident that all their problems will receive a qualitatively satisfactory solution.

In accordance with the proposal, the structure of the health services will be divided into three levels, organized in a pyramidal fashion. The first level is the primary care organized for a population of about 8,000-40,000, the second 1evel, the county level, for a population of $250,000-400,000$, and the third level, the regional level, for a population of about 1 million.

\section{Primary Leve1}

Primary care refers to non-institutional health services with access to general practitioners at health centers in cooperation--even at small centers--with specialists, such as gynecologists, pediatricians, and psychiatrists, and to differentiated groups of staff. Primary care is aimed at satisfying demands for vicinity, continuity, and safety. Primary care also includes home service and most of the care in nursing homes for long-stay patients.

Assessments have been made which indicate that staff within "Primary Care," could accommodate $70-80 \%$ of the problems which bring patients to the care organization. 


\section{County Leve1}

The studies also assume that primary care will be supported by other health facilities in the county council's jurisdiction on the county level. Rather markedly differentiated hospitals with mainly medical and surgical units will be required relatively close to the people for emergency cases such as infarction, strokes, accidental trauma, and acute abdominal cases. These hospitals are called county district hospitals ("länsdelssjukhus") in the proposal.

Additional support may be required for complicated cases, especially for examination and for the planning of treatment. This kind of service will be the responsibility of the widely differentiated county hospitals ("länssjukhus") with about twenty specialties. The most important facilities required, in addition to the resources of the county district hospitals, will be units for obstetrics, pediatrics, psychiatry, ophthalmology, and oto-rhino-laryngology.

There will also be a more widely differentiated supply of services within the basic disciplines of medicine and surgery than is available at county district hospitals; this includes services such as cardiology, neurology, pulmonary medicine, care of infectious diseases, orthopedic surgery, and urology. The laboratory service will be led from the county hospital and distributed to primary care and county district hospitals. In its immediate vicinity, the county hospital will also have the same function as a county district hospital.

An important feature of the proposal is that the public health district is to be regarded as a unit with collected skills and common principles for diagnosis and therapy. It is thought that this type of organization will produce enhanced care quality and provide the basis for more rational utilization of allocated resources than is possible at present. The introduction of uniform principles for diagnosis and treatment, i.e. medical action and care programs, should make it easier for the patient to feel at ease in different care units.

In the field of health service it is important that the same material used in the decision making process is used as a basis for all information to the patient. It is also important that this material can serve as a basis for education and for the applied and practical research work.

\section{Regional Leve 1}

Are any other resources required beyond those offered in the field of public health? The regional level is necessary mainly for consultation in rare and difficult cases and for the care of cases making heavy demands on staff and technical resources. Neurosurgery and thoracic surgery are examples of the latter. In addition, the regional hospital will have extensive staff resources, within a limited geographic area, which can be used in collecting and disseminating information to all the medical units in the region. This will create a basis for medical development work which can provide material for qualified basic and post-graduate training of doctors and refresher courses for different categories of staff.

Thus, the number of doctors engaged in primary care is expected to increase rapidly. According to one calculation, approximately 8,500 of the country's 25,000 doctors in 1985 will be employed in primary care, as opposed to about 3,000 at present (1,400 in public health, 1,200 in private practice and 400 in industrial health).

During the spring, opinions were submitted to the National Board of Health and Welfare concerning "The Structure of Health Services in the $1980^{\prime} \mathrm{s}^{\prime}$ by the different county councils and other organizations and agencies in the field of public health. The Board will later issue guidelines for the future structure of the health service on the basis of the proposal and the presented opinions. It is already sure, however, that the Swedish health organization will be more outpatient 
care oriented than before and that the facilities and resources for primary care will accordingly be greatly improved.

\section{PUBLIC HEALTH PLANNING}

As I mentioned previously, health planning in Sweden functions on two levels. National health planning is a responsibility of the National Board of Health and welfare. One of its objectives is to provide plans on a nation-wide basis in order 1) to outline broadly the public health services, 2) to provide for adequate medical services, and 3) to ensure the best allocation of resources with regard to avai1able economic and personnel resources, with the aim of providing all inhabitants in the country, irrespective of place of residence, with health services. The state also influences long-range developments in health and medical care by virtue of its responsibility for education and research.

Health planning on the county level is a responsibility for the county council. Their long-term plans for medical care and its further development must provide the basis for a coordinated system of medical care as well as the related prophylactic care, which also falls within the sphere of the county council.

For health planning purposes (among others) the state and the county councils have jointly established and now finance an Institute for the Planning and Rationalization of the Health Services, SPRI. This institute deals especially with planning methods and techniques.

In view of the rising cost of health and medical care services, it has been regarded as vitally important to coordinate into an organized system of public health plans the various planning instruments which have been in use in public health. This issue has been considered by the Permanent Committee on National Health Planning, connected with the Ministry of Health and Social Affairs. In 1972 the Committee presented guidelines for a health planning system to be used by all county councils. The guidelines were based on work by the SPRI and a special working group. In the opinion of the working group, the purpose of the guidelines should be :

a) to propose tools and basic material to aid public health officials in improving their planning and to devise them such that comparisons between public health areas and regions become possible; and

b) to provide a proposal for a public health planning system with a structure providing a continuous feedback of information to the central authorities.

Continuous feedback of information is important as the basis of educational and investment planning for the entire country and for further development of public health on a national scale. However, the guidelines given by the Permanent Committee on National Health Planning did not cover the proposal or formulation of health policy goals for the country as a whole or for individual public health regions. It was presumed that the health planning system proposed in the guidelines could be used for the different public health policy goals which were, or could, be formulated by county council authorities, by the Government, and by the Parliament.

The Permanent Committee on National Health Planning made clear that the planning and feedback of information to the central authorities provided no guarantee of achievement of the desired changes in the extent and organization of public health services. Nor would any necessary balancing in the expansion of public health costs be a direct result of increased planning alone. The increased activity advocated in public health planning should instead be seen as one of many ways of achieving more purposeful management of the public health services. Other means involved development of administrative and operational planning. However, a 
step-by-step build-up of a system containing comparable public health plans was also considered necessary to obtain basic material for central staff and investment planning.

It should also be mentioned that planning itself results in a changed view of the development of public health services. Insight into necessary changes and new solutions is often a result.

The Permanent Committee on National Health Planning also stressed that public health planning must be regarded as a part of the planning of total county council activities. Consideration should therefore also be given to the plans of other authorities, e.g. primary local authority school health programs and the care of the aged. According to the Public Health Act the county councils should provide general plans for the various branches of public health. However, experience has shown that a comprehensive plan, comprising all public health activities, is more desirable. This should reduce the risk of undesirable overlapping or ga's in the planning.

The trend toward more uniform central responsibility for all public health services and the ability to process large amounts of information by EDP improve the primary conditions for efficient planning. Basic input materials are also improved in step with improvements in planning in other sectors of society.

The following health planning system was proposed by the Permanent Committee on National Health Planning. The system contains three planning levels with thirty-year, fifteen-year, and five-year planning cycles. The system is described very briefly below.

\section{Planning Leve1 1 (Thirty years)}

A development outline for approximately thirty years is devised on the national level. It contains a forecast, or a vision, of society's future development on the basis of data from central, regional, and other authorities. This perspective has something of the character of research into the future. The outline shows alternatives of development which officials should consider in their shortrange planning. A development program should be devised on the county council level with the development outline as the basis. This program shows, for instance, the sub-activities which should be given long-range priority. This makes it possible to give consideration to long-range targets in short-range planning.

\section{Planning Level 2 (Fifteen years)}

The next level in the planning system comprises a fifteen-year perspective. A total plan for all the activities of the county council points to the basic level of ambition. Priorities by sector and the allocation of resources by sector are stated.

A long-range budget or an economic program illustrates the economic targets of the county council for the next fifteen years. This budget should comprise operating costs, investment plans, and financing plans. Targets, emphasis, forecasts of requirements, and forecasts of resources for the different county council activities, especially in public health, are stated in the fifteen-year basic plan. The basic plan indicates the operating structure, i.e. targets and allocation of resources for various activities and services and care facilities in the planning area. The plan also shows the total planned performance volume during the planning period. Estimated total staff requirements (broken down by category) and total annual expenditures and costs are stated for each alternative. Resource demands are consolidated in shell plans, providing dimensioning data for the respective health activities inside and outside hospitals. 


\section{Planning Level 3 (Five years)}

A financing and implementation plan on the county council level is the plan of execution for the first five years of basic and total plans. It should coincide in time with the county council's five-year budget. The allocation of economic resources among different activities and means of financing are reported for each year. By studying the actual annual costs versus budgeted costs, corrections can be made in the five-year budget (and automatically in the long-range budget). This may in turn affect public health planning.

The basic and total plans for fifteen-year periods were presumed to be revised or "rolled" every fifth year. The financing and implementation plans--or rolling prognosis (RUPRO), as they also are called--should be revised or "rolled" every year.

Al1 the county councils have now developed, or are developing, basic and total plans for the period 1975-1985. These plans are sent to the National Board of Health and Welfare, which is not authorized to approve or disapprove the plans but to express its opinions on them. The plans are also used to compare different public health areas and regions and to sum up total expected developments in the health field.

The results of the first basic and total plans for the period 1974-78 (RUPRO 78) have recently been published. The county councils are now working with the RUPRO 79.

Difficulties encountered in obtaining basic material for planning are the reason why major resources have not yet been used for thirty-year development planning. For this, research into the future (futurology) is also necessary. This is also the reason why the first basic plans only comprised ten years instead of fifteen.

To improve a health planning system of the described type the county councils require basic material from the central authorities dealing with population developments, expected changes in the mortality and morbidity rates, changes in the structure of public health, and so on. The central authorities are therefore expected to intensify and coordinate their efforts so that the requisite basic information is accessible in ample time for planning activities.

Estimates and analyses of the anticipated demand as the basis for decisions and priorities must obviously be included in the planning work. Information in these fields is at present incomplete. In-depth planning also calls for better statistics. Therefore, work on the construction of statistical and information systems on a national level and for each public health area is considered essential and is also under way. Work is also in progress to achieve clearer definitions of various concepts and measures.

What guarantee is there that the aims and intentions expressed in planning at the national level will also have an effect on developments at the county council level? As stated before, the county councils in Sweden, which mainly shoulder the responsibility for public health, enjoy a high degree of independence in this respect. As indicated above, the individual county councils approve their health plans without necessary consideration of the views proffered by the state authority-the National Board of Health and Welfare--whose duty is, however, to express its opinion on every health plan. But the state does have certain means-apart from legislation--of influencing the execution of the plans, i.e. by controlling the investment resources and the setting up of new positions for doctors.

In order to use even their own financial resources to build new hospitals or health eenters or to remodel old ones, the county councils must obtain permission from the National Board of Health and Welfare. This instrument of control, which 
was introduced primarily in order to allocate the public building resources to the areas (e.g. geographical areas, industrial sectors) in the greatest need from the point of view of economic trends and employment, has been developed more and more into a planning instrument. As such, it influences expansion in the various sectors of the health and medical care services so as to achievercertain overlapping goals in the community.

Similarly, the county council must have the permission of the National Board of Health and Welfare to open new positions for doctors. These establishment controls originally came about so that the limited supply of new doctors in a situation where there was a great shortage of doctors could be distributed as fairly as possible throughout the various parts of the country. The instrument is still used for this purpose: there is still a very troublesome shortage of doctors in Sweden. But it has also been developed into a planning instrument to funnel, by means of the post-graduate training of physicians, the supply of new doctors into the specialties and other fields of activity (e.g. general practice) found to be most expedient from the point of view of long-range planning. Judged from this starting point, the control of the establishment of new positions for doctors and of their post-graduate training is one of the most important instruments for the steering of developments in the medical profession--both quantitatively and qualitatively (with respect to the content of the training)--in accordance with short-range as well as long-range health planning goals.

The system for piblic health planning in Sweden briefly described above is now in the process of being introduced successively. Much work still needs to be done, however, before the system can be considered to function satisfactorily. In different quarters--both at the national and county council levels--experimental and developmental projects are being set up to secure better basic prerequisites and methods for application of the system. In this way the new health planning system has also come to serve as a uniform and coordinating program for research and education in the health planning field. 


\section{USES OF EPIDEMIOLOGY IN THE PLANNING AND \\ EVALUATION OF HEALTH CARE SYSTEMS}

Dr. Jan Kostrzewski

Chief, Department of Epidemiology, National Institute of Hygiene, Warsaw

\section{INTRODUCTION}

Health protection and the development of health care systems form an integral part of socioeconomic development. The organization, structure and function ing of health services in a given country are governed by the social policies adopted by its government and by the state of development achieved by its scciety. However, not only does the general level of a society's health and health needs vary greatly from one country to another, but there are differences between the various population groups within a country. These depend on social and environmental conditions, living standards, the kind and conditions of labor, age, sex, education level, and a great many other factors.

For the purposes of this conference, I propose to adopt the following definition of health needs: health needs are to be understood as deficiencies in health or social well-being that call for preventive, curative, rehabilitative, or public welfare measures. Irrespective of differences in health level and health needs between various countries and between various groups of their populations, the medical care that is expected by the people from the commuity health service can be divided into four categories, namely:

1) protection of health, that is, prevention of diseases or disabilities,

2) restoration of health by appropriate diagnosis and treatment,

3) assistance in rehabilitation, and

4) public welfare for dependent people and alleviation of suffering where health cannot be restored.

The term "health care system" is to be understood as denoting "any recognizably delimited aggregate of dynamic elements that are in some way interconnected and interdependent and that continue to operate together according to certain laws and in such a way as to produce some characteristic total effect" (WHO, 1973). The main differences in health care systems may be observed in the following features of health services:

1) universality of health care,

2) accessability to health care,

3) versatility or range of operation (e.g. environmental health; preventive, clirative, rehabilitative services; public welfare),

4) forms of payment (by the patient immediately, or indirectly through tax payments, his employer, or government authorities),

5) organizational model of health care (e.g. national health service, selfgovernment organizations, co-operative organizations, private enterprises, or various combinations of the above sectors in various proportions),

6) organizational scheme of health care and the degree of its concentration (local, intermediate, and central level of public health administration), 
7) range and degree of integration of various health service branches (e.g. enviromental health; medical care delivered at intramural, i.e. hospital and sanatorium level, or extramural, i.e. at the outpatient clinic level; rehabilitation - medical, occupational and social; public welfare).

The above list does not cover all the features of a health service that may be essential for the evaluation of its activities; it includes only those believed to be most important in affecting possibilities and ways to meet the health needs of a population.

\section{AREAS OF STUDY FOR THE EVALUATION OF HEALTH CARE SYSTEMS}

We propose to discuss the epidemiological methods that are to be used to evaluate the effectiveness and efficiency of medical service systems and on this basis to assess health care systems. We inust first realize, however, the complexity of the problem and clearly define both the subjects and the aims of studies to be made. We should keep in mind that a health care system forms part of the socioeconomic system of a country, and that it comprises several subsystems that are more or less interconnected, with considerable variation in the degree of their integration.

The evaluation of the effectiveness, and efficiency of health care systems must therefore cover the following aspects:

a) bio-medical, in the fields of preventive, environmental, clinical, and rehabilitative medicine,

b) socio-medical, namely the effects of health and sickness on the general feeling and social position of an individual, family, or community; attitudes of patients and of the community toward public health workers and their organization of health care, and vice-versa, and

c) economic-medical, above a 11 , the means required to put projects into operation, including the degree of use and rational application made of these means; the economic consequences caused by the unsolved health problems in a community; individual and social advantages that may be obtained as a result of solving socially important health problems.

For the purpose of our discussion I propose to adopt the definitions of the terms "effectiveness" and "efficiency" that were given in a document issued by the Fifty-First Session of the WHO Executive Board (cf. Official Records WHO, No. 206, Part I, Geneva, 1973, pp. 114-115): "Effectiveness" - the ratio between the achievement of the progranme activity and the desired level which, during the planning process, the planners had proposed would result from the program activity.

"Efficiency" - the ratio between the result that might be achieved through the expenditure of a specific amount of resources and the result that might be achieved through a minimum of expenditure.

\section{THE PURPOSE OF STUDIES ON THE EFFECTIVENESS OF HEALTH CARE SYSTEMS}

The evaluation of the organization of health services and their activities pertains to the basic responsibilities and activities of the public health administration. The essence of such an evaluation consists in "the systematic and scientific process of determining the extent to which an action or sets of actions were successful in the achievement of predetermined objectives. It involves measurement of adequacy, effectiveness, and efficiency of health services" (WHO, 1973).

The purpose of evaluating the effectiveness and efficiency of health service activities consists therefore in a) obtaining information that may be required to ensure the completion of projects and to check whether the objectives have been 
achieved; and in b) obtaining the information necessary for continuing projects already in operation or for preparing new projects.

Evaluating the effectiveness and efficiency of health care in countries of different socio-economic structure, which are dissimilar in the organization of their health care systems, provides a basis for assessing those systems. Uniform methods and procedures must be used for the studies and surveys to be carried out. The studies in question should be as many-sided as possible and cover a wide range of bio-medical, sociomedical, and economic-medical aspects; they must also be very carefully detailed and objective.

The final aim of evaluation is to furnish information on the effectiveness and efficiency of health care systems to statesmen, state and health administrators, and medical service workers, who could then form their own views on which systems of health care could assure the best results under varying conditions and at various levels of social and economic development. The main persons involved would include:

1) health service workers, i.e. both public health administrators and experts in various fields of health care,

2) politicians and state administrators, i.e. local authorities at various levels and members of government, and

3) the general public, either as individuals or as representatives of the country's population, i.e. members of parliamentary bodies.

No doubt, to people belonging to any of these categories the results of studies will prove interesting in different ways. For instance, the interests of health service workers will focus on the results of their activities; they will want to learn as much as possible about their successes and failures so as to take the measures necessary to improve their work. Politicians and state administrators will also be interested in the results of the studies, while the community is most keenly interested in knowing whether the health care services satisfy their own health needs and fulfill their expectations for the future.

Consequently, presentation of the results of evaluating the activities of medical services and health protection systems should take into account the expectations of people falling into the above three categories. It seems desirable to issue the results of surveys, in three separate forms. Firstly, detailed technical data will be of interest to workers of the medical services. Secondly, the socioeconomic aspects of health protection should be treated for politicians and administrators. Finally, there should be educational reports giving a general picture of the health situation and health needs of a population, the achievements and failures of the health services, and their potentialities and difficulties, and the contributions the community can make in carrying out health protection projects.

\section{METHODS USED FOR EVALUATING THE EFFECTIVENESS AND EFFICIENCY OF HEALTH}

\section{CARE SYSTEMS}

To evaluate health care systems adequately, in terms of their effectiveness and efficiency, which has long been a dream of public health workers, three conditions must be fulfilled: first, the studies and surveys made, as has already been indicated under II, a) - c), should be those of complex character; second, they should be carried out on an international scale, covering countries at different levels of social and economic development and with different health care systems; third, they should be carried out using standardized methods so that results can be compared.

Diseases and disabilities are biological processes lasting, in most instances, a long period of time. Thus, evaluating the effectiveness and efficiency of any 
healtin care project requires a considerable amount of time for observation. What, then, should be the subjects of studies and surveys which would enable us to evaluate various health care systems and compare their effectiveness and efficiency?

In medical and biological problems the most important methods of measurement are comparisons of mortality and morbidity rates, particularly of those diseases that could be avoided by appropriate preventive action.

As a result of the projects carried out, the dynamics of changes which occur should be analyzed with special care. Analyses should cover the changes in: the

- infant mortality rates;

- incidence and mortality rates of the infectious and parasitic diseases that could be avoided through vaccination or improvement of sanitary conditions; controlling infection carriers, improving individual hygiene and environmental sanitary conditions; disease detection and treatment;

- morbidity rates of diseases caused by malnutrition or undernutrition, in particular among children, e.g. protein deficiency, rickets, endemic goiter, caries;

- incidence rates of diseases resulting from unfavorable labor conditions, e.g. occupational intoxications, coniosis, tumors resulting from occupational activities, deafness;

- morbidity rates of malignant diseases and results of their early detection and treatment;

- early detection and appropriate therapy or handing of congenital derects, e.g. congenital dislocation of hip joint, cleft palate, defects of cardiovascular system, hearing and sight defects, metabolic defects such as dia betes, phenylketonuria, etc.

The above list gives but a few examples of health indices that should form the subject of comparative studies and surveys. It must be borne in mind, however, that these problems can easily be recognized, and thus can be more efficiently covered in international comparative studies than numerous other diseases, for instance mental disorders.

In the sociomedical area the main field of study consists in evaluating the social consequences of diseases. Sociomedical measurement of health implies an assessment of a valetudinarian individual's condition in relation to others. The inability to perform in a social role, as parent or spouse, worker or student, as a consequence of illness or disease is a sociomedical measure of the level of health (Elinson, 1973). Social disability may be suggested as the indicator of physical illness as well as for mental disorder.

It must be realized, however, that the performance of one's social role is of ten dependent upon many other variables besides health. Efforts have been made to depict all illnesses in behavioral terms and to apply this measure as the sociomedical index of health care intervention. The "Sickness Impact Profile" (Bergner, 1973) is an attempt to develop a measure, based on behavioral expressions of sickness, to evaluate the effects of outpatient clinic projects. Various categories of behavioral items should be developed for this sort of evaluation: mobility, sleeping, eating, speech and communication, work around the house and outside the house (occupation), and others.

Within the same field of studies particular attention should be devoted to length of absence from educational institutions and working places as a result of illness. 
Another wide area consists in evaluating the amount of care extended to those dependent upon the comminity as a result of a chronic disease, lameness, serious mental disability or senility. Who takes the responsibility to care for these dependent people: the family, a charity organization, or the state? To what extent have these social needs been recognized in a given country, and to what extent are they satisfied? How are the problems of dependent people solved within a community? Are they condemned to vegetation in institutions, or are special arrangements made enabling them to participate in community 1 ife?

Data on the utilization of health services should also be taken into consideration when evaluating health care systems. Indices characterizing both coverage and accessability of services can prove helpful in assessing what action is necessary to achieve a desirable provision of health services for a population. Volume and distribution of health services and medical institutions are connected with accessability and coverage of services. Comparing utilization data with the health needs of a population makes it possible to judge the under- or overutilization of services by various groups. It is a1so desirable to gather information on feelings of satisfaction and social ease in the performance of health services.

In the economic-medical area, the main subject of evaluation should consist in two categories of problems.

The first is evaluating the economic consequences of diseases to the individual, family, and community, as well as the economic advantages that could be achieved by carrying out projects aimed at controlling various diseases. Such analyses were, for instance, carried out with regard to some infectious diseases, e.g. diphtheria, poliomyelitis, measles (Egeberg, 1970). Analyses of this kind are particularly useful in cases of occupational disease, as they make it possible to compare the expenditures for health protection and improvement with the economic consequences of occupational diseases (therapy, pensions, compensation).

The second category of economic-medical problems includes forces, material resources, and financial means that are assigned to various branches of the medical service and health protection projects (Rosh). The health effects evaluated should be those that are achieved as a result of defined expenditures in various branches of health care and owing to various projects. Such analyses should be aimed at obtaining information necessary for the rational and effective use of forces and material resources in the medical service, taking into account the education levels and personal skills of the staff. Such studies would allow one to assess in which public health system doctors, dentists, nurses, and other personnel are utilized in the most effective way.

The number of doctors and other medical personnel required can vary greatly depending upon the total number of the population in a given country, their distribution, the general level of their health, the number and kind of medical institutions available (hospitals, sanatoria, health centers, outpatient clinics, rehabilitation centers, public health laboratories), the organizational scheme of health care service, and its centralization and integration.

"There is no doubt that economists now recognize that expenditure on health leads to an increase in the number of working days, in the working capacity of the individual, and in the size of the potential labor force as a result of the increase in the expectation of 1 ife at birth, and also to reduction in the disability caused by disease. This applies to the practice of medicine as such. Nevertheless, the rational organization of medical expenditure can still lead to an increase in its effectiveness by the coordination of medical activities with those in other sectors. Health as a means of development is thus a cumulative phenomenon, tending to promote social and economic changes that themselves raise the level of health" (Torfs). 
Cooperation between economists and public health workers is thus essential. Public health workers should be responsible for the evaluation and analysis of the health situation in a country and should examine the most effective methods to be used in order to improve it. On the other hand, economists should evaluate the damage caused by the existing situation, and should estimate the cost of the preventive, curative, or rehabilitative measures required.

\section{MEASUREMENTS OF HEALTH STATUS}

In 1952 the United Nations, pursuant to resolutions of the General Assembly and the Economic and Social Council, convened an Experts Committee with the participation of ILO, UNESCO, FAO, and WHO for the purpose of studying the definition and measurement of standards and levels of living. The Experts Committee in its report suggested a list of twelve components whereby the true level of 1 iving could be measured (United Nations Report, 1954). The first item on the list was health.

The WHO Study Group on the Measurement of Levels of Health (WHO Technical Report Series, 1957), divided the health indicators used for measurement into three groups:

a) those associated with the health status of persons and populations in a given area: health statistics and vital statistics;

b) those related to environmental conditions having a more or less direct bearing on the health status of the population of a given area; and

c) those concerned with activities and health services directed to the improvement of conditions: availability of hospitals, doctors, and paramedical personnel.

The indicators of groups a) and b) relate to the evaluation of the health status of a population and environmental health conditions respectively, i.e. to medical aspects. Thus, they can be used for evaluating the effectiveness and efficiency of actions undertaken in the biomedical field.

For evaluating the effectiveness of health protection the health situation projects have been carried out prevailing within a given area before and after may be compared. However, there is also a need to make a thorough study of the change in trends during the realization of projects to be evaluated. For in such a study a number of both demographic and epidemiological indices may be used, in particular:

- crude and age-specific death rates including infant mortality rate;

- crude and age-specific birth rates;

- general and age-specific death rates calculated for various diseases;

- prevalence and incidence rates.

However, an evaluation based on that kind of study is far from perfect, ramely in two respects. First, the epidemiological indices, both mortality rates and incidence rates, lack adequate accuracy and in many instances diverge by far from the real health status of a population. The reliability of these indices depends greatly upon the nature of a disease, accessability of the health care service, number and educational level of doctors, equipment available for medical service, potentialities of laboratory diagnosis, and many other factors.

The other reason for imperfection in such an evaluation is the absence of a control group. While evaluating the effectiveness of projects based on a comparison of the health situation "before and after," we cannot check or exclude the effect of factors beyond our control that could contribute to or represent the chief reason for changes in the health situation. 
A much better method for evaluating effectiveness and efficiency seems to be clinical and eopidemiological controlled trials (Cochrane, 1972). These trials are based on the randomized selection of groups of people; one group is subjected to the activities of the medical service according to a predetermined program, e.g. through the application of an appropriate medicine or preventive method, therapy or rehabilitation; the other group has exactly the same composition but differs from the first in that the medicine or method is not applied to its members.

The randomized controlled trial is a method finding wide application. Every new medicine and method, before it is introduced into wider practice, should be subjected to the randomized controlled trials. Provided the appropriate modifications or adaptations are made, this method can also be used in both sociomedical and economic-medical surveys and studies.

In the field of environmental medicine, the indices characterizing the supplies of drinking water, environmental sanitation, food hygiene, industrial hygiene, individual hygiene, etc., should be used. In sociomedical studies use is made of sociological methods, inquiring into the number of sick and healthy persons at home or at work, in hospitals or outpatient clinics. But, as a consequence, a truly objective viewpoint is very difficult, if not impossible, to derive from such a study. New methods should be sought, permitting an objective evaluation of the effectiveness and efficiency of the health care provided. As another means for evaluating the effectiveness of medical services a number of economic indices characterizing both the development of the medical service and the quality and quantity of services achieved from the defined expenditures can be used. Such indices should relate to: the number of personnel, their education and specialization; number and type of medical institutions such as hospitals and sanatoria, including the number of beds and their use; number of outpatient clinics, health centers, centers of therapy and occupational rehabilitation; number and type of public welfare institutions, e.g. for children exhibiting serious mental disabilities, for old people; equipment and apparatus. These indices should also supply information on the utilization of personnel, equipment, and financial means, thus allowing an assessment of which organizational systems would assure the most effective use of forces and means in the separate branches of the medical service, and what kind of interrelations exist between the development of these branches and the effectiveness and efficiency of their activities.

It is a well-known fact that failures in preventive activities usually make it necessary to increase the expenditures in the therapeutical branch, and inadequate therapy in turn leads to further expenditures for rehabilitation, pensions, and public welfare. From the purely medical and sociomedical viewpoint, the most effective and least costly are the preventive activities; therapy is more expensive, and the greatest economic burden is connected with public welfare. Thus, indices for economic estimates on health and illness should be devised. The preparation of indices characterizing work capacity, and limitations and inability to work, learn or perform any social functions, should lead to evaluations of economic consequences of health and illness on an individual and social scale.

\section{THE ROLE OF EPIDEMIOLOGY IN HEALTH SERVICE PLANNING AND EVALUATION}

Health planning and the evaluation of health programs requires a multidisciplinary approach. The health needs and demands of a population should be taken into account, and consideration should be given to health promotion and protection in all its aspects: prevention, restoration of impaired health, rehabilitation, and social welfare. Adequate information about the health services required should be collected and evaluated; this would include manpower, investment, equipment, financing, and management. It is obvious that planning and evaluation can only be undertaken by a team capable of collecting and evaluating information on the fields mentioned above. 
Based on the report of a working group convened by the Regional office for Europe of the World Health Organization (November 1973), the skills required for health planning are:

1) public health administration (medical care, commuity medicine, environmental health, management techniques, etc.),

2) epidemiology,

3) biostatistics,

4) communication sciences,

5) economics,

6) sociology and other behavioral sciences,

7) legal sciences, and

8) system sciences and operational research.

According to the definition adopted by the International Epidemiological Association, epidemiology is the study of the factors determing the frequency and distribution of diseases in human populations (Lowe, 1973). It is now understood to take within its scope all diseases, whether they are acute or chronic, physical or mental, communicable or non-communicable. In addition, epideniology also deals with various phenomena of human health and development and their distribution in a population.

Epidemiology has three main aims:

1) to describe the distribution and size of disease and disability problems in human populations;

2) to provide the data essential to the planning, implementation and evaluation of services for the prevention, control and treatment of disease, and to the setting up of priorities among those services. This includes information about the services themselves; and

3) to identify etiological factors in the pathogenesis of disease.

Two types of epidemiological study can be applied to health service planning and evaluation:

1) Observational--here the epidemiologist attempts to measure disease and related phenomena as they occur, without altering the way they occur. These studies may be purely descriptive or controls may be used so that hypotheses may be tested.

2) Experimental--here the investigator introduces a carefully controlled change of procedure; thereby, scientifically meaningful conclusions can be drawn.

Epidemiology is a basic discipline for public health administrators and others concerned with national or community health services, health planning, and evaluation of health programs. Epidemiology should be used for the diagnosis and measurement of present health needs, for an estimate of future needs, for the determination of health priorities and for the evaluation of health service activities.

The role of epidemiology in the planning of health services is first of all related to the selection of goals and priorities. It is relatively easy to express what a service is aiming to achieve, but much more difficult to describe the order in which all the components of a plan should receive attention and to ascribe a proper schedule and time-scale to the plan. Epidemiological philosophy is helpful 
in formulating goals and objectives; on the other hand, epidemiological methods and techniques are essential for evaluating achievements, and on this basis describing new problems and indicating when and in which direction future action should be taken.

Epidemiology should describe in exact terms the natural history of disease in the community, taking into consideration not only the total course of untreated disease and its relationship to the environment, but also the changes expected in this course after treatments and other interventions have been used.

It is also the role of the epidemiologist to select relevant measurement units for assessing the size of the problem. These units should be easy to use and suitable for surveillance, and evaluation of changes in the size of the problem once a plan has been put into action.

The description of the natural history of disease as a system should make it possible to select points at which intervention is likely to be successful. Some intervention is of a medical nature, but others would require involvement of the sociologist, economist, or other experts.

When the decision to accept a program has been made, the attention of the epidemiologist should turn to acquiring the information which will be necessary for the implementation of the program. Activities should be properly guided, and suitable methods for obtaining valid measurements should be developed. The team of planners must then design a "system description" of ongoing activities, paying special attention to critical points of the system. The epidemiologist must develop suitable monitoring procedures so that achievement can be appraised. He should organize an adequate information collection and play the role of an analyst producing relevant information which permits ongoing control.

How to select the indices for such a control?

Variables and indices used for measurement should help the planners to determine what should be done and which are the most suitable intervention points. With this end in view the variables to be measured can be grouped under the following head ings:

- measurẹment of ill health

- measurement of need for medical care

- measurement of demand for medical care

- measurement of the use of health services

- measurement of effectiveness and efficiency.

The amount of ill health perceived in a population should be determined from the knowledge of the prevalence of all diseases in that population. As this is very difficult to achieve, the planners must rely on indices such as need, and demand for, and use of services.

The definition of a health need is given in the introduction. Satisfaction of health needs in their totality is what is required of the effective and efficient health service.

Health demands are best measured by sample surveys. One must remember, however, that the demand is highly subjective and strongly education- and culturedependent. For a given disease it can vary considerably, not only between countries but also within countries.

The use of health services is the result of need and demand on the one hand, and on the other, depends on availability and accessability. To measure ill health 
and medical care, health statistics such as morbidity and mortality data need to be routinely collected.

The sources of information for morbidity evaluation can be classified under three headings:

- organization of existing service records,

- creation of special service records, and

- special field studies.

The first group of data, on existing service records, can routinely be related to a defined population. This information is collected at a point of contact with the system, and is the most valuable for that reason. For this purpose, special service records can also be created by introducing notification or registration procedures.

Special field studies, while constituting another very important source of information, can be very expensive and protracted. They should therefore be undertaken only after very careful consideration.

To be effective and to serve their purpose all these studies and records must be accurate and complete, which is not easy to achieve.

\section{VIT. CONCLUSION}

In the course of discussion at the Fifty-First Session of the WHO Executive Board on "Methods of Promoting the Development of Basic Health Services" an opinion was expressed that populations in both highly developed and developing countries were dissatisfied with their health services; that heaith services had failed to meet the expectations of the population and to deliver an adequate national coverage; and that there was a wide gap in health status between countries and between different groups within countries." Opponents of the above statement expressed the view that there do exist health care systems capable of effectively solving the health problems of a country and meeting the health needs of its population. As an example the model of the socialist medical service was quoted (organizational Study, 1973). No doubt, both sides are right in their opinions; however, a series of studies should be carried out, allowing one to evaluate the organizational model and the health care system from the point of view of its effectiveness and efficiency. 


\section{REFERENCES}

Bergner, M. (April 13, 1973). Presentation Before Seminar on Sociomedical Health Indicator. (Columbia University. In the paper of J. Elinson [4]).

Cochrane, A.L. (1972). Effectiveness and Efficiency. (The Nuffield Provincial Hospitals Trust).

Egeberg, R.0. (December 1970). Economic Impact of Immunization Programs in the Developed Countries. International Conference on the Application of Vaccines against Viral, Rickettsial, and Bacterial Diseases of Man. (PAHO, WHO, Washington).

Elinson, J. (August 1973). Toward Sociomedical Health Indicators. International Conference of Medical Sociology. (Warsaw).

Lowe, C.R., and Kostrzewski, J. Eds. (1973). Epidemiology A Guide to Teaching Methods Methods. (London and New York, Churchill and Livingston).

Organizational Studv on Methods of Promoting the Development of Basic Health Services (1973). (Twenty-Sixth World Health Assembly, Doc. A 26/20).

Rosh, G. Measurement of Effectiveness and Efficiency. (WHO/HS/Nat. Com./71, 270 ).

Torfs, M. Principles of the Integrated Planning of National Health Services. (WHO, $\mathrm{CHa} / 72.3$ ).

United Nations Report on International Definition and Measurement of Standards and Levels of Living (1954). (New York: E/CN.3/179-E/CN.5/299).

WHO Official Records (1973). No. 206, Part I, Geneva, 114-115.

WHO Regional Office for Europe (November 1973). Report - Working Group on the Application of Epidemiology to the Planning and Evaluation of Health Services. (Copenhagen).

WHO Technical Report Series (1957). Study Group on the Measurement of Levels of Health. No. 137. 
Questions of the: Discussant, Mr. Glass

Noting that the Swedish health system is partially based upon local taxation, Mr. Glass wondered if this did not imply unequal health care deriving from the variation in affluence across regions.

For many years, other countries have been pointing to Sweden as proof that high health status could be maintajned without a high density of physicians. Now Eweden has decided that it needs more doctors. Was this decision based upon comparison with doctor-population ratios of other countries or were there other indicators? It would be ironic if Sweden were trying to match the ratios of other nations who simultaneously were seeking to duplicate the Swedish results.

\section{Health Monitoring}

Mr. Bailey was struck by the similarity between the indices and evaluations which Mr. Kostrzewski had urged to maintain effective health care and a parallel emphasis in the environmental. field. The United Nations Environmental Program is especially interested in establishing a global monitoring network for which large sums of money have been made available. Given the many linkages between health and the environment, might it not be efficient to combine the two projected monitoring efforts?

\section{$\underline{\text { Rehabilitation }}$}

One Conference member felt that Mr. Kostrzewski had brought fresh air to the often submerged problem of impaired populations in need of rehabilitation. The overwhelming emphasis of health care to date has been upon treatment for acute incidents. Effective rehabilitation can restore functional capacity to many individuals. Despite the economic implications of improved rehabilitative care, most nations remain impervious to its possibilities. One reflection of this is that accurate statistics on disabled populations are often impossible to obtain. The recognition that dependency costs can far outweigh those of rehabilitation should be taken to heart in health planning.

A second speaker picked up this point, remarking that Poland and Sweden are two nations that have taken most seriously the problem of disability. He argued, however, that the major obstacle to effective rehabilitation policy is incomplete understanding of its social effects. This points up again the necessity for adequate health information systems. Technological solutions to disability are well known as are in some cases the sizes of the disabled populations. Universally lacking, however, is a grasp of the social effects of rehabilitation and the organizational understanding to manage these effects optimally.

\section{Dangers of Limited International Comparisons}

It was pointed out that contrasting aspects of health systems in different nations can be misleading. An example of this is the meaninglessness of hospital bed numbers without understanding the relationships between hospitals and clinics or outpatient care. The organization of auxiliary health services and of social services influences that health system. In the case of Sweden, it was observed that the low density of physicians seemed linked to a compensatory increase in the number of hospital beds.

\section{Changing Physician Açtivities}

Long-term projections of the need for physicians should, as indicated by Mr. Reinhardt, take into account the changing nature of their activities. If future accent is to be placed upon rehabilitation, then the ratio of physicians to 
paramedical personnel will drop. One suggested role for the doctor is that of manager. If doctors were, like managers in industry, in charge of teams of auxiliary personnel instead of being posted on the front line, total system efficiency might rise.

\section{Future Questions}

Mr. Venediktov asked Mr. Wennström a number of questions about the planning system he had described.

1) What, in his opinion, were the negative aspects of the system?

2) Are the plans linked to schemes for their implementation, or are they forecasts?

3) If implementation is the goal, what forces affect it?

4) How and at what level are the various sub-systems of health planning linked together?

Another participant, noting that a drop is projected in the ratio of nurses to doctors, asked how non-physician personnel were integrated into the health care system. Mr. Kostrzewski was asked to define the range of problems for which he felt a broad epidemiological approach suited.

\section{Response by Mr. Wennström}

To the queries raised by Mr. Glass, Mr. Wennström replied first. The differing economic levels of various local councils are counteracted by national government subsidies to the poorer councils. In this way, a roughly even national equilibrium level of care is achieved.

Perception of a doctor shortage was obtained not only from international comparison, but also from internal indicators. The difficulty in filling posts for physicians taken together with the average physician work week of fifty hours point up the shortage.

Many negative aspects in the Swedish health system might be identified by a resolute critic. The richer nations, for example, prefer more patient freedom and less intervention by the state than is the case in Sweden.

The plans described in the paper are intended for implementation. The national government will be the prime force for implementation as well as provider of nexus between the various sub-systems. The government itself is guided by popularly elected councils in many localities. The councils are instrumental in applying pressure for high quality health care. Between the central government and the councils is extensive communication with occasional problems. The National Ministry of Health is responsible for coordination of the comprehensive planning. It currently is adapting the health planning system for application tc the management of welfare.

The Swedish system has always relied heavily upon well-trained auxiliary professionals, Nurses, for instance, have performed many tasks reserved in other nations for physicians. Figures that have been quoted in this regard may, however, be misleading. Thus only one-half of the 90,000 nurses in the population are economically active. The ratio of physicians to all active health personnel should move from the present 1 to 16 to 1 to 12 in 1985.

The relationship between physicians and auxiliary personnel must be seen in terms of the continuing trend toward higher quality care. One example is delivery care. Only a decade ago, most births occurred in small hospitals or in the home under the guidance of midwives. Today virtually all babies are born in we11-equipped clinics with mary resident specialities. The result of this reorganization for higher quality care has been an increase in the number of physicians required. Marginal increases in quality of care may be inexpensively achieved. A point, however, 
is reached when better care car only come through expensive reorganization, capital outfitting, and improved staffing. This partly explains the impetus to increase the number of doctors in Sweden.

\section{Response by Mr: Kostrzewski}

Mr. Kostrzewski agreed with Mr. Bailey's statement on monitoring and stressed that it was of especial importance for rehabilitation. The numbers of handicapped persons are growing in every community. In part this is an effect of improved medical care which saves the lives of children with handicaps.

The definition of problems suitable for an epidemiological approach should, Mr. Kostrzewski urged, be flexibly made. Epidemiology itself covers a broad range of activities starting with identification of disease distribution but covering also other health phenomena and factors affecting health.

Mr. Kostrzewski agreed that needed numbers of physicians could not be gauged in isolation from the systems of other health workers. Medicine is properly not an individual activity but a team effort. Effectiveness of health care depends critically upon our ability to train and use paramedical personnel as complementary teams to the physician. 


\author{
Peter Fleissner \\ Austrian Academy of Sciences, \\ lnstitute of Research for Social-Economic Development \\ Vienna, Austria
}

\title{
INTRODUCTION
}

In close cooperation with the Institute for Socioeconomic Development Research of the Austrian Academy of Sciences, the Health Care Project of the Institute for Advanced Studies has developed a simulation model which, similar to Meadows' model (Meadows, 1972), is based on an integrated approach. It thus goes beyond the traditional area of health care planning, whose ultimate aims are detailed and directly applicable programs almost always confined to 1 imited aspects of health care (Attinger, 1970). Our model applies instead to medium or long-term periods. The interpretation of this mathematical simulation model, however, depends on the theoretical understanding obtained in working out this model.

\section{SOME BASIC ASSUMPTIONS}

Despite this century's craze for "medical progress" (general increase of life expectancy, extinction of infectious diseases), the morbidity and mortality statistics indicate that the average life expectancy in many highly industrialized countries remains the same and even shows a retrograde tendency. In the ERG, for example, male 1 ife expectancy--infant mortality excepted--generally declined in the $1960^{\prime} \mathrm{s}$. These statistics have been adjusted with regard to the deaths in the two World Wars; the same applies to the USA, Sweden, and Switzerland. The rate of infectious diseases (e.g. tuberculosis) in Austria has remained high, and less serious infectious diseases (e.g. acute pharyngitis, tonsillitis) that account for one-third of all sick leaves are increasing. Moreover the age of cardiac infarctions on the average has become lower. The state of health of the population varies greatly within social stratum: female employees in vienna reach only about $90 \%$ of the average age of death, and more than one third of the farmers in Lower Austria and Styria show more than four symptoms simultaneously that need medical treatment.

If impairments of health are described in terms of "morbid episodes" (Kosa and Robertson, 1969) (i.e. subjective/objective impairments to exercise one's social and individual functions) rather than by the professional concept of "disease" as reflected in given disease groups, it is demonstrated that only about one-quarter of all such impairments are covered by the institutionalized health care system. The remaining $75 \%$ are left to non-professional treatment. Our criticism, therefore, is aimed at the very concepts of health and non-health: an international comparative analysis that we carried out showed that the interpretation of health and non-health depends on the state of productive forces and the relations of production.

In Austria, the distinction between health and non-health depends on a person's ability to work. This view is typical of a society where many concepts are reduced to the needs of capitalist production (Lüth, 1972). Furthermore, nonhealth is being considered primarily as a disturbance of biological functions. This scientific concept of non-health--which goes hand in hand with the development of medical-technological industries--is largely oriented toward the curative aspects. Only symptoms are treated. In a Vienna Casualty Ward, for example, alcoholic workers admitted with bone fractures are discharged as cured and rehabilitated--until they are hospitalized again; their chronic alcoholism is ignored.

The current concept of non-health separates the disease from the environment in which it develops, i.e. living conditions in general, and the specific working 
conditions in particular. So-called occupational medicine differentiates among the organs and orifices of the human body and the measures taken to remedy impairments (e.g. auditory or visual defects) are completely isolated, not directed against the overall causes. As with machines, this branch of medicine simply meets repair requirements of the production agents.

Only when economic requirements such as the petrol crisis necessitate certain measures do the respective authorities take action (e.g. by lowering speed limits). The results--decreased numbers of accidents and casulties--are praised as favorable; usual appeals to humanism are more or less in vain. On-the-job accidents show a similar phenomenon. There, cure and rehabilitation involve an enormous technological apparatus and the whole body of medical knowledge, while accident prevention campaigns are rather half-hearted.

In the opinion of the Project the health care system is not oriented toward the needs of the population--this being a non-system--but in many respects toward the principle of profitable private production of health as a commodity. This principle prevails upon public health insurances via private general practitioners, the pharmaceutical industry, and so on. Private health insurances are increasingly influencing parafiscal health care supply systems. On the one hand, this leads to a decrease in the quality of public health care performance; on the other hand, it also brings about a long-tern allocation of resources into luxury medicine. Premiums of private health insurances are high. Moreover, insurance policies do not cover some diseases at all, and prolonged diseases may involve the cancellation of the policy. As a resuit, the needs of the top strata are met but not those of the broad masses.

The hospital serves as leader in scientifically-oriented individual medicine. Hospitalization in acute cases means that the patient is suddenly separated from his environment: the causes of his condition are reduced to factors that can be medically diagnosed; the patient becomes a passive object. The great demand for beds shortens his stay in the hospital and the patient is again referred to the general practitioner.

The strain upon the general practitioners system is thus growing steadily, and the number of general practitioners shows a downward trend, particularly in rural areas (Schober, 1971). Physicians have at best two or three minutes for an average diagnosis. Therefore, a program for the early recognition of diseases (screening programs) that is based on the system of general practitioners is bound to fail. Traditional reform measures (hospital expansion, more outpatients departments) end up in a vicious circle, consuming tever more resources, but decreasingly able to remedy new health disturbances.

\section{THE MODEL}

\section{CHARACTERISTICS}

On the basis of the above considerations, the simulation model was designed to describe the health care system in its interrelations with the economic system, rather than as a separate social sphere. Non-health, to a large extent, is being understood as a product of living and working conditions. Filtering effects that vary depending on the social strata concerned produce the differences in non-health behavior. Since our living and working environments create new types of diseases, pre-treatment and morbid episodes are increasing together with the growth of economic productivity. These new patterns, however, have not yet been integrated into the health care system as they do not correspond to the prevailing concept of non-health.

Being based upon the paradigm of curative medicine, traditional models are often confined to a purely immanent optimization of aspects such as hospital organization and use of medical-technological devices. In contrast, the present 
model accounts for the most important interdependencies among the individual branches of the health care system and for their relation to the population and to the national economy. The model allows us:

a) to estimate health/non-health in Austria from 1961 to 1995, under the assumptions of both conservative and reform policies;

b) to explicate the political interest groups, their powers, and their influences upon the socio-economic model structure;

c) to illustrate the political genesis, specific effects, and necessary cost requirements for reforms of the health care system on the basis of health indicators and the overall economy; and

d) to analyze the effects of changes of economic parameters, the public revenue and expenditure policy, as well as such effects upon, and the changes within, the population structure.

Thus, the model necessarily consists of four subsystems:

1) the economic system, with its latent conflicts between the employed, the public sector, and the private capital, functioning as the driving force of sociological development;

2) the population system, from which the economic system derives its labor potential, and which draws upon the resources of the hea1th care system;

3) the health care system itself, with various hea1th or nonhealth indicators and related staff and capital expenditures; and

4) the political subsystem of health care, in which the interplay between individual interests is represented.

Sections 1), 2), and 3) provide the socio-economic foundations, and the political subsystem forms the second level of the model, which is connected with the socioeconomic level by feedback process. Thus, we have a hierarchical two-level model (Figure 1).

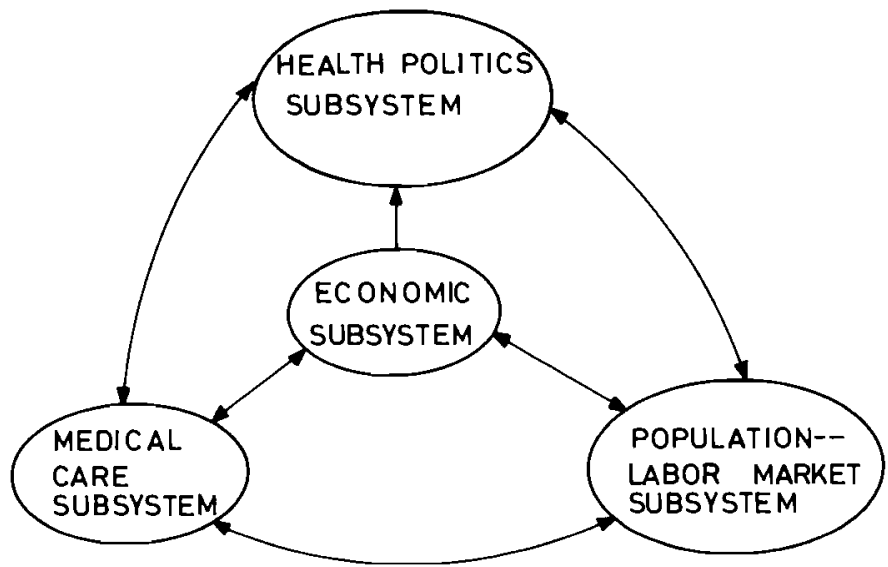


For the economic system a statistically significant set of alternative economic hypotheses has been developed. Here, an empirical approximation of the average profit rate in Austria evolved as the central variable. This theory allows the demonstration not only of the "wage struggle" of labor unions, but also of the causes of inflation or the dependence of the private economic sector on public economic activities.

It should be emphasized that this model uses a social stratification concept to take into account the inequality of the people with regard to income, health care and other factors such as differences of sex and their potentially strong influence upon the labor market. While the assumption of an average worker in usual macroeconometric models (Klein and Goldberger, 1955, Fleissner, 1970, 1971) tends to obscure the problems of income distribution and private property, the present model at least attempts to explicate these problems.

The introduction of a political sector for the health care system makes it possible to study and assess the effects of alternative political power constellations upon the health care of the population. The mechanisms of this sector are based on theoretical assumptions, supported by related literature (Naschold, 1967). The purely technocratic models now in use allow for any manipulation of their parameters, irrespective of whether or not such a change would be at all feasible. In our model, however, the model structure tends to react to voluntaristic interference with an increase in political power group activities; conversely, the interference with the structure may under certain circumstances be balanced by the very logic of the model.

Because of this novelty and of the limited manpower, the model is only a prototype of a new generation of models: it contains examples of all the essential features and properties but does not consistently apply them to all sections of the model. Nevertheless, it is possible to illustrate with the model the development of important variables over time. This model cannot only be used for planning but can also serve as a future-oriented, logically consistent data bank in which individual data series are not independent and isolated but are instead interconnected by statistically significant hypotheses. Moreover, the model allows for alternatives of economic and socio-political assessments. Their effects can be computerized, taking into account the interdependence between important sections, with the results printed out diagramnatically or numerically.

\section{LIMITS OF THE MODEL SIMULATION}

In addition to the new assumptions that were elaborated, the present study also points to the limitations of the simulation technique. Since the quantitative data base employed is derived from the status quo of our social system, existing structures can, at best, be extrapolated in a modified way. Although it is easier to depict reality by means of this model than by traditional ones, its forecasts are nevertheless conditional. The results of this report largely correspond to the overall project tean estimates, but represent only a small sample of possible models generated by a variation of structural relations and coefficients. The great variety of possible model variants in general can be reduced to five basic types of alternative sociological development, which differ with respect to the conception of the political system.

1) The "reform" variant. The reform variant is characterized by a higher degree of collective financing and a tendency toward preventive indices. The political power of social bureaucracy is particularly weighted, with mass loyalty as its premise.

2) The "conservative" variant. Here in a cure-oriented health care system the tendency toward individual financing is strengthened. Social bureaucracy enters into an objective liaison with medical class-specific interests, which is supported by medical capital utilization interests. 
3) The "revolutionary" variant. As the production and distribution of health services no longer are subject to the logic of capital, the health requirements of the population become the guideline for the development of the social patterns. In politically activated groups, the population itself changes and shapes its living and working conditions in the direction of primary prevention.

4) The "reactionary" variant. After the abolition of social bureaucracy, purely capital utilization interests exert their control by means of the politicaladministrative system. The health care system is narrowed down to low-quality curative medicine. Marginal groups are excluded from health care.

5) The "standard" variant. The political system is not explicitly considered. The socio-economic seems unaffected by political powers. On the basis of statistical tests of relations of the past, system developments are simply extrapolated. The underlying hypotheses enjoy the status of unchangeable laws of nature. Most of the current simulation models fall under this heading (Mesarovic, 1972).

In the present development of the political power constellation and the resulting level of development of the theory of social upheaval, it seems to be impossible to represent the revolutionary variant. The problems in dealing with gaps in the social development make it difficult to represent the reactionary variant. Therefore, the present simulation model has been developed in a reform version and a conservative version which yields the standard variant as a kind of "waste product."

\section{THE POPULATION SUB-MODEL}

In this population model, differentiations are made according to age (100 one-year classes) and sex. As there are absolutely no strata-specific data on life expectancy, birth, and death rates in Austria, it was not possible to differentiate between individual strata. For similar reasons, migrations have not been taken into account. The mortality tables for $1959 / 61$ and the population census of 1961 formed the empirical basis of the model.

The birth rates of 20-40 year-old women are shown to be influenced by economic growth. Trends for the probability of death under the age of 60 are extrapolated according to sex and age (0-20, 20-60) on the data base of 1961-1971. The probability of death for these groups decreased in the $1960^{\prime} \mathrm{s}$. persons:

Death rates of the age group 0-20: $T=1$ in 1961, deaths per 1,000,000

$\begin{aligned} \text { Male: } \quad \text { TM1 } & =-\begin{array}{r}.652 \\ (22)\end{array} \text { T } \begin{array}{r}32.595 \\ (2)\end{array} \\ \text { Female: } & \mathrm{TF} 1=-.462 \mathrm{~T}+23.863\end{aligned}$

(24)

Death rates of the age group 20-60:

Male: TM2 $=-1.348 \mathrm{~T}+57.550$

Female: $\quad \mathrm{TF} 2=-.709 \mathrm{~T}+31.837$

$$
\begin{aligned}
& \mathrm{R}^{2}=.708 \\
& \text { D.W. }=2.240 \\
& \mathrm{R}^{2}=.680
\end{aligned}
$$

With older persons (over 60 years) there is an inverse trend; the correlation is very bad because of great data fluctuations. An example of this is shown by the equation:

$$
\begin{aligned}
& \text { Male: } \quad \text { TM3 }=3.350 \mathrm{~T}+602.15 \\
& \mathrm{R}^{2}=.213 \\
& \text { D.W. }=2.343 \text {. }
\end{aligned}
$$


Concluding from developments in other countries, the mortality increase can be expected to shift from older age groups to younger ones (the cardiac infarction age becomes lower) and, therefore, the present trend of increasing life expectancy will be weakened or inverted. For this reason the death probabilities of the 60 year-old group were coupled with a downward trend which is, however, superimposed by an upward process that is slowly shifting from older to younger age groups.

\section{THE ECONOMIC SUB-MODEL IN THE HEALTH MODEL}

Current models of the economic sectors, as far as they are available in a quantitative form, neglect important functional principles of the capitalistic economic system, and therefore cannot satisfactorily explain the way it works. This is why the Health Project has developed an alternative theoretical model on the basis of classical political economics. To obtain a wide range of terms for national income accounting, the model includes inventory quantities such as capital funds and employment rates, price indices, and above all, an empirical estimate of the profit rate in Austria.

The following variables of consumption have been taken over from national income accounting:

- private consumption

- private investments

- public consumption

- public investments

- exports

- imports

- changes of stock, statistical difference.

over:

On the distribution side, the following items, among others, have been taken

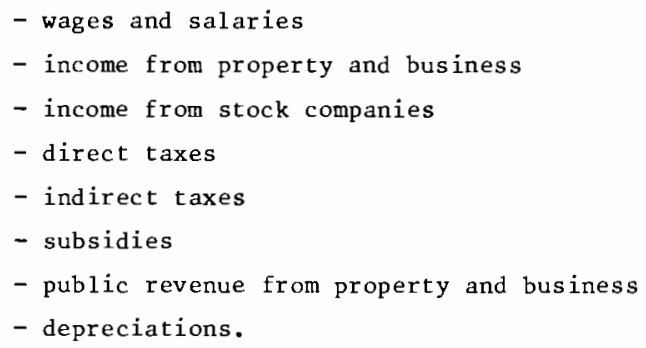

In addition, the public budgetary policy is explicitly introduced into the model, so that terms like "transfers to private households," "social security contributions," "depreciations in the public sector," occur as separate variables in the model. The national sector was included in a "closed form," i.e. public income and expenditure were used, the national budget deficit being regarded as an endogenous quantity. Thus, the model allows for the study of the effects of alternative public policies, and it can be shown in which way governmental interventions affect the private sector of the economy.

The price indices chosen are:

- consumer

- inves tment 
- import

- gross national product (approximate).

The time sequence used for capital funds was calculated on the basis of estimates made by the Institute for Advanced Studies, Vienna, and on the basis of my own calculations with respect to net investments and changes of stock. Even if the numerical value of this quantity is not very accurate, the description of the increase of capital funds over this time period is fairly appropriate.

An approximation of the profit rate is calculated from the capital fund. It is the quotient of the sum of the net non-wage incomes (net incomes from propert. and business, net incomes of stock companies) and the total annual capital advance to be made by all entrepreneurs at the beginning of the year. The capital fund, as evaluated at current prices of capital goods, serves as an approximation for the constant capital; the variable capital consists of the gross aggregate wages of the current year, and of investments and changes of stock.

Thus, the profit rate may drop--with higher taxation of private enterprises by the state, with higher prices for capital goods, with an increase of stock, with increases in the value of building and equipment capital. But it may also rise with higher net profits, with increasing technological progress.

\section{The Functional Relations of the Sub-Sector}

Within the model, it is assumed that the fixing of consumption and investment prices constitutes an important strategic parameter of private enterprises. This assumption proved to be statistically compatible with the available data (1954-1970). Prices rise both with a drop in the profit rate and with an increase in real demand. Traditional econometric models frequently neglect this important parameter, and often prices are explained only by a mark-up factor, or exclusively by the price-enhancing effect of demand.

The price index for consumer goods, together with the wages earned in individual strata of the working population, determine their real incomes. Then, together with the incomes from property and business, the demand for private consumption can be calculated using a consumption function.

The private investments at constant prices of 1964 are understood in terms of the interplay between the profit situation of the preceding year (self-financing) and the profit rate. If, for example, the profit rate rises while the profits decrease, the likely effect would be reduced investment activity. The inversion of this statement would lead to the other extreme. The remaining two possibilities are compensatory.

On the one hand, public consumption and public investments are explained autoregressively with respect to many expenditures; but, on the other hand, they are understood in terms of price increases. In the final analysis, however, they are seen through the role that the state plays in counteracting the downward trend of the profit rate. Individual budget items on the income side of the public budget are calculated as shares of the respective taxable basic quantities.

Imports are calculated both from the price-correct economic activities within the overall national economy, and from the increase of the gross national product.

The aggregate wage in a broader sense is obtained from the product of the strata-specific wage rate times the strata-specific labor force and its surmation over all strata. This is then adjusted by a mark-up factor which relates the average basis of valuation for health insurances to the average wage level of the employed, including all employers' contributions. 
Since the national product can be calculated from the consumption side, the non-wage income is determined by deduction of various taxes and wages.

At this point the circle is closed, since by tax dedyction from the nonwage income, we obtain the profit rate defined above, together with the capital fund at the beginning of the period and the terms for the variable capital.

Most of these relations have simultaneous and non-1inear influence upon each other (Figure 2).

\section{Sectoral Simulation Results}

An increase in governmental intervention may slow the drop of the profit rate, but cannot stop it completely. Even so, the national product in the reform variant run on the model is much higher than that in the conservative run, the main reason being a much higher rate of inflation. The real income of the working population in the reform run is only slightly higher than that in the conservative run. The means necessary to finance higher public expenditure partly come from a higher deficit.

There are only two exogenous variables in the sub-model which may influence the economic development; all the other variables are endogenously calculated from the model structure. At current prices, exports are assumed to increase by $10 \%$ each year and are extrapolated accordingly while the import price index, the second exogenous variable, grows annually by $5 \%$.

The model makes it also possible explicitly to simulate foreign trade crises--e.g. export impediments, excessive import prices--and to study their effects on the economy. Moreover, it is possible to carry out a so-called sensitivity analysis of the structural coefficients of the model--the structural coefficients and a study of the resulting changes in the development of the variables in time-which may give additional information on structural changes within the national economy.

\section{THE HEALTH CARE SUB-MODEL}

In this central section of the model an attempt has been made to develop indicators of health/non-health for the population and to make the widest possible strata-specific distinctions among them. In addition, the model covers topics such as the full use of the present health care system (Figure 3), the demand for and the resources of manpower of various qualifications, and budgetary means and investments necessary for health care. As the relevant data were scarce and incomplete, expert estimates were frequently used.

\section{The Variables and Functional Inter-Relations of the Sub-Model}

Following the theoretical concept of the Project Group, a non-professional health/non-health indicator--morbid episodes--was introduced into the model to deal with subjective/objective afflictions. Morbid episodes were represented by indicators of their intensity and number. Of all the cases of morbid episodes, however, only about one quarter are covered by the professional health care system, while the remaining $75 \%$ must be suffered without treatment.

Another indicator is the number of cases of panel doctor attendance. It was impossible, however, to make exact stratum-specific differentiations; due to a lack of statistics of doctors' consultations, reference could be made only to doctors' certificates. Yet model runs show that the number of panel doctor attendance increases over time. 


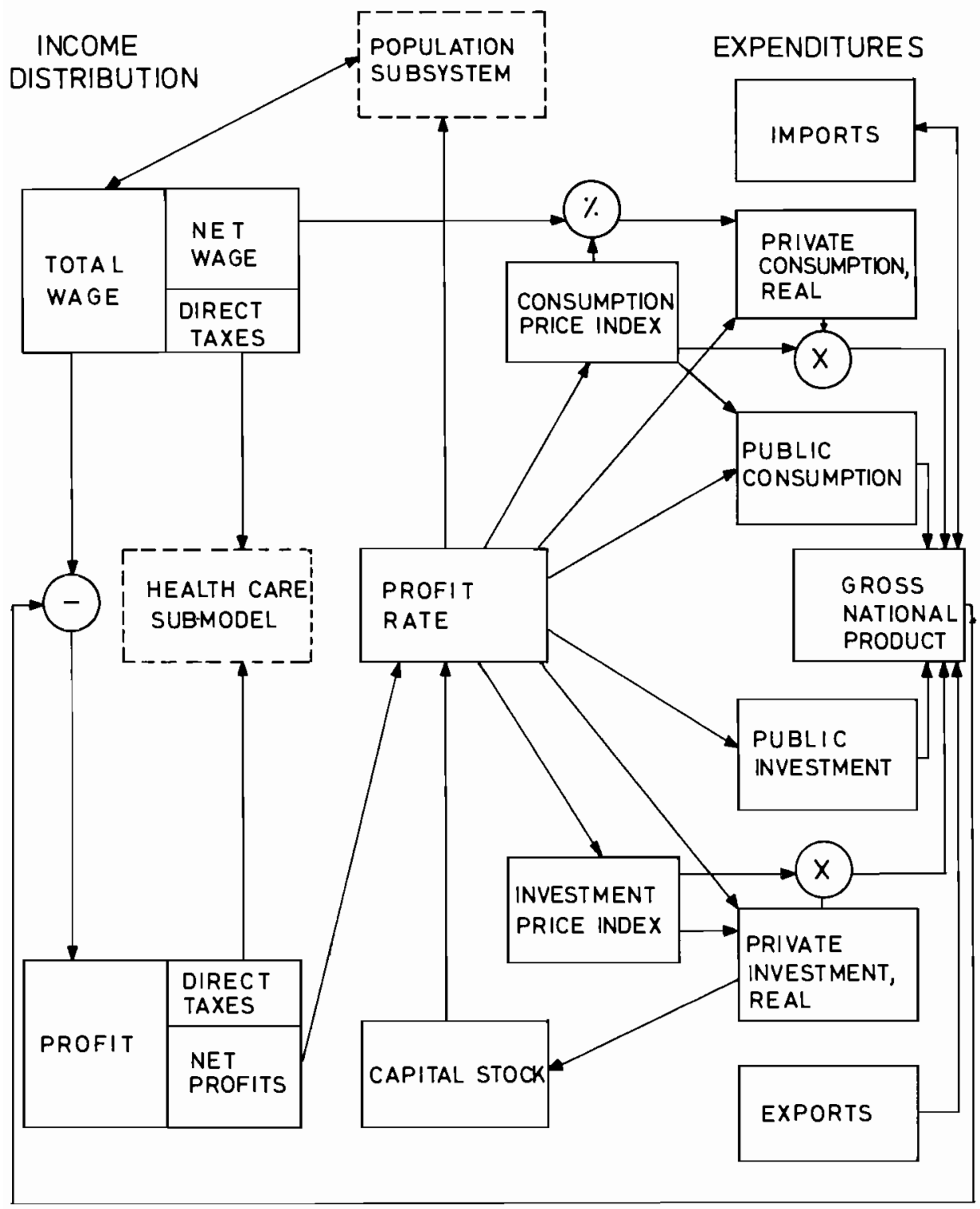

FIGURE2. THE ECONOMY SUB-MODEL (SIMPLIFIED). 


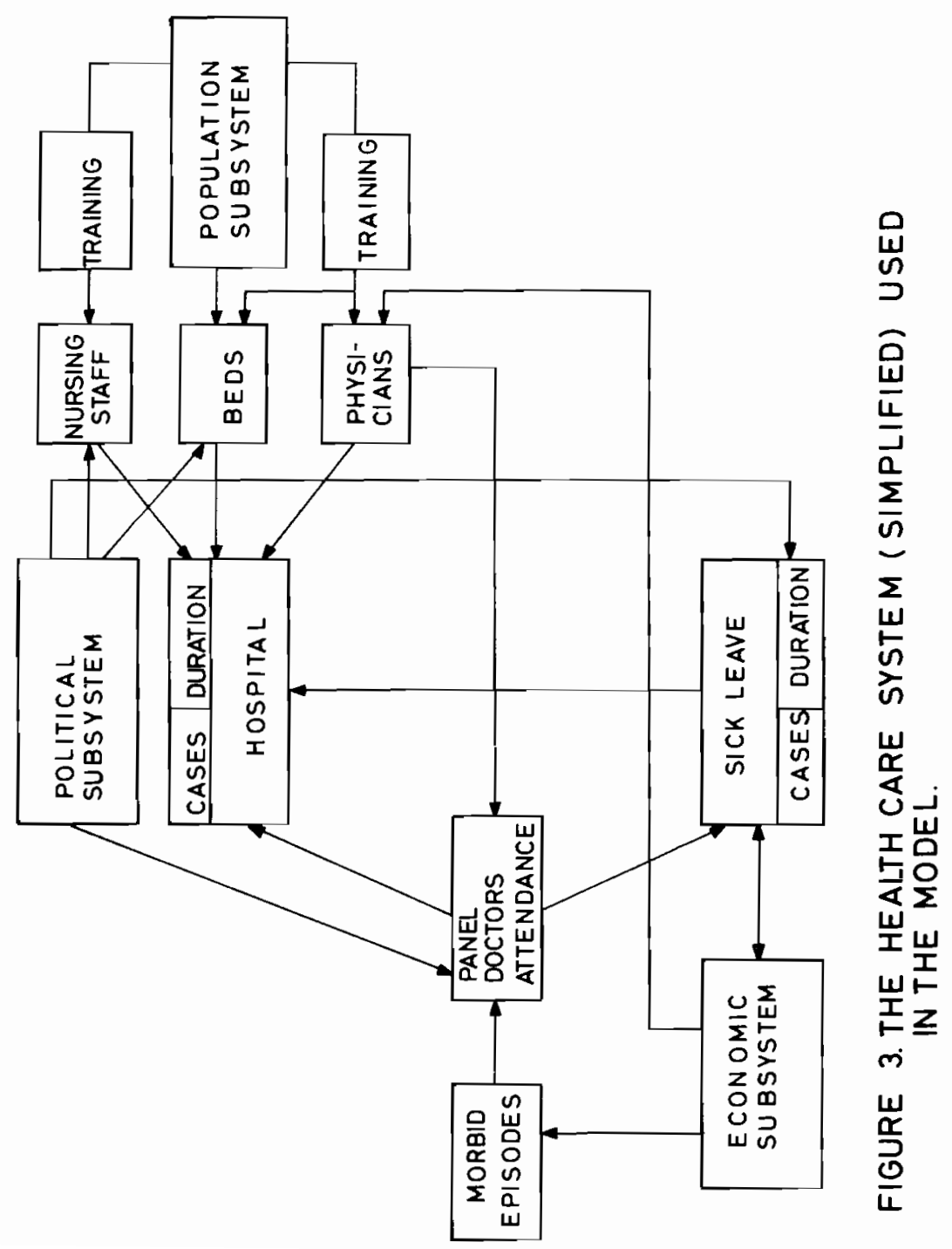


For the description of sick leaves, a system of indicators was established that immediately bears upon the economy. Such leaves were recorded according to manual and non-manual workers, males and females, and an analysis was made of the number of cases per capita and of the duration of sick leaves as distributed among eight disease groups. These groups, which are an aggregate of the 32-code of the Hauptverband der Osterreichischen Socialversicherungsträger, ${ }^{1}$ are the following:

1) cancer (disease groups 6 and 7 in the Association's code),

2) cardiac and circulatory diseases $(10,11,12,14)$,

3) afflictions of the respiratory organs (19),

4) afflictions of the digestive system (20, 21, 22),

5) on-the-job-accidents and injuries due to external causes $(29,31)$,

6) affliction of the locomotive and supporting systems (27),

7) infectious diseases $(1,2,3,4,18)$, and

8) neuroses (13).

A statistical analysis of each disease group would have been too time consuming, but all data are at the disposal of the project team.

The model includes the following indicators for resources in the health care system:

- physicians, total

- residential doctors

- nursing staff, total

- beds available, total

- beds used by health insurances

- income from health insurance

- income from contributions by employees

- income from contributions to old-age insurance

- expendiţure for medical attendance

- expenditure for drugs

- expenditure for institutional care

- investments and current expenditures for hospitals by self-governing bodies, etc.

In this analysis, the costs per medicine prescribed, the development of hospital care rates, as well as the fees per consultation by a panel doctor received special attention and were linked to the rate of inflation.

Following the hypothesis that working and living conditions play an important part in the emergence of diseases, morbid episodes were connected to productivity, an indicator which to some extent reflects the working and living conditions. Low productivity implies a low economic level, high on-the-jobaccident rates, and possibly a great number of infectious diseases and diseases caused by poverty. However, with an increase in productivity over time, the pattern of non-health changes and new non-specific, multifactorial chronic diseases develop, while the number of on-the-job-accidents, for example, tends to remain high.

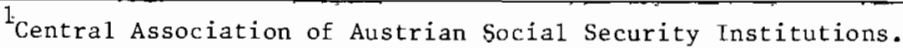


Under this assumption, the sick leaves per capita and the duration per case have been analyzed statistically for each disease group. With regard to hospitalizations and their duration, other factors such as the number of panel doctor consultations were also introduced, as far as this was statistically permissible. When the number of cases of panei doctor attendance increases, more people are transferred to hospitals, and the hospitalized cases per capita increase.

Following the saying, "We do not die of the diseases we suffer from" (Schäfer and Blohmke 1972), mortality was regarded as being dependent on the working and living conditions in general rather than on the health care system. Secondary preventive measures are an exception, but this influence is favorable only with respect to the middle and upper strata of the population. In many cases the lower strata and the self-employed are unable to go to screening check-ups.

A forecast of the numbers of qualified staff in the health care system takes into account the population trend, the average length of training, the dropout rate, and the reduction of the staff available by attrition or retirement. This method was applied to both physicians and nursing staff. In this respect, the addition of educational aspects seem to allow for an extension of the simulation model.

In the standard run, the increase in beds was considered autoregressive and a function of productivity. As long as the number of hospital beds available meets the demand, the period of hospitalization is simply extrapolated using the regression equations in the model. If the number of hospital beds available becomes smaller than the demand, the period of hospitalization is reduced so that the increase in demand can be met--thus leading to longer waiting lists for hospital beds. In accordance with the results obtained in the model, an increase in hospital beds would considerably increase hospital expenditures. It appears that--at least for the next twenty years--the demand for hospital beds can be met only by reducing the length of hospitalization. However, along with this measure, efforts must be made to extend semi-inpatients and outpatients institutions.

\section{Health Care Sub-Model Equations}

\section{Sick Leave}

The number of sick leaves per capita--differentiated according to manual workers, non-manual workers and officials, males and females separately--were related to economic variables (gross national product, productivity).

For the equations of the percentages of each of the eight diagnosis groups of sick leaves per capita (Table 1), dependent on productivity, the coefficients $\alpha, \beta$ and $\gamma$ were obtained,

$$
\operatorname{PKSD}(s)=\alpha+\beta(Q / E)_{-1}+\gamma \operatorname{PKSD}(s)_{-1},
$$

where:

PKSD(s) is the percentage of each diagnosis group in sick leaves/ per capita of the stratum s:

$s=1 \ldots$ manual workers, male

$\mathbf{s}=2$ manual workers, female

$s=3$ non-manual workers, male

$\mathrm{s}=4$ non-manual workers female; 
Q/E is the productivity of labor (gross national product/employed); and $\cdots-1$ indicates that the variable with this index is delayed by one year.

The coefficients refer to the period 1960-70 and were calculated by least squares. The last column gives the determination index $\mathrm{R}^{2}$, which indicates the percentage rate of the variance of the dependent variables that is accounted for by the linear statement.

Table 1. Ratios of diagnosis groups in sick leave cases per capita.

\begin{tabular}{|c|c|c|c|c|c|}
\hline Disease Group & Stratum & $\alpha$ & $\beta$ & $Y$ & $\mathrm{R}^{2}$ \\
\hline 1) Cancerous Diseases & $\begin{array}{l}1 \\
2 \\
3 \\
4\end{array}$ & $\begin{array}{r}.085 \\
1.017 \\
1.197 \\
1.025\end{array}$ & $\begin{array}{c}0 \\
-.003 \\
-.007 \\
-.004\end{array}$ & $\begin{array}{r}.507 \\
-.164 \\
-.161 \\
-.086\end{array}$ & $\begin{array}{l}.527 \\
.610 \\
.786 \\
.817\end{array}$ \\
\hline $\begin{array}{l}\text { 2) Cardiac/Circulatory } \\
\text { Diseases }\end{array}$ & $\begin{array}{l}1 \\
2 \\
3 \\
4\end{array}$ & $\begin{array}{l}4.84 \\
4.323 \\
8.279 \\
4.055\end{array}$ & $\begin{array}{l}-.014 \\
-.006 \\
-.033 \\
-.005\end{array}$ & $\begin{array}{c}-.101 \\
.248 \\
.124 \\
0\end{array}$ & $\begin{array}{l}.689 \\
.219 \\
.660 \\
.161\end{array}$ \\
\hline $\begin{array}{l}\text { 3) Respiratory } \\
\text { Diseases }\end{array}$ & $\begin{array}{l}1 \\
2 \\
3 \\
4\end{array}$ & $\begin{array}{l}9.137 \\
5.842 \\
8.177 \\
6.327\end{array}$ & $\begin{array}{r}-.025 \\
.010 \\
-.023 \\
.011\end{array}$ & $\begin{array}{l}-.163 \\
-.262 \\
-.177 \\
-.128\end{array}$ & $\begin{array}{l}.718 \\
.333 \\
.711 \\
.297\end{array}$ \\
\hline 4) Digestive Diseases & $\begin{array}{l}1 \\
2 \\
3 \\
4\end{array}$ & $\begin{array}{l}10.195 \\
18.134 \\
15.591 \\
22.277\end{array}$ & $\begin{array}{r}.029 \\
.003 \\
.017 \\
-.039\end{array}$ & $\begin{array}{l}-.050 \\
-.367 \\
-.223 \\
-.385\end{array}$ & $\begin{array}{l}.290 \\
.148 \\
.095 \\
.339\end{array}$ \\
\hline 5) Accidents & $\begin{array}{l}1 \\
2 \\
3 \\
4\end{array}$ & $\begin{array}{c}38.533 \\
12.722 \\
18.87 \\
9.980\end{array}$ & $\begin{array}{l}-.027 \\
-.003 \\
-.004 \\
-.009\end{array}$ & $\begin{array}{l}-.181 \\
-.092 \\
-.277 \\
-.154\end{array}$ & $\begin{array}{l}.112 \\
.020 \\
.070 \\
.246\end{array}$ \\
\hline $\begin{array}{l}\text { 6) Locomotive } \\
\text { Diseases }\end{array}$ & $\begin{array}{l}1 \\
2 \\
3 \\
4\end{array}$ & $\begin{array}{r}10.325 \\
4.983 \\
3.085 \\
2.145\end{array}$ & $\begin{array}{l}.002 \\
.002 \\
.025 \\
.001\end{array}$ & $\begin{array}{r}-.089 \\
.421 \\
+.235 \\
.597\end{array}$ & $\begin{array}{l}.032 \\
.224 \\
.535 \\
.369\end{array}$ \\
\hline $\begin{array}{l}\text { 7) Infectious } \\
\text { Diseases }\end{array}$ & $\begin{array}{l}1 \\
2 \\
3 \\
4\end{array}$ & $\begin{array}{l}18.286 \\
22.350 \\
29.133 \\
32.738\end{array}$ & $\begin{array}{l}.095 \\
.103 \\
.103 \\
.089\end{array}$ & $\begin{array}{l}-.176 \\
-.239 \\
-.184 \\
-.149\end{array}$ & $\begin{array}{l}.221 \\
.295 \\
.150 \\
.212\end{array}$ \\
\hline 8) Neuroses & $\begin{array}{l}1 \\
2 \\
3 \\
4\end{array}$ & $\begin{array}{l}0.563 \\
2.202 \\
1.787 \\
2.599\end{array}$ & $\begin{array}{r}.061 \\
-.004 \\
-.005 \\
-.007\end{array}$ & $\begin{array}{l}-.286 \\
-.181 \\
-.005 \\
-.090\end{array}$ & $\begin{array}{l}.381 \\
.265 \\
.510 \\
.610\end{array}$ \\
\hline
\end{tabular}


A similar stratum-specific table was worked out for the duration of sick leaves (Table 2). From the sick leaves/per capita $K(s)$, the ratios $K(i, s)$ of the duration of sick leaves $\mathrm{D}(\mathrm{i}, \mathrm{s})$ and the number of the insured $\mathrm{E}(\mathrm{s})$, the total loss of production $\mathrm{P}$ can be calculated. For a stratum

$$
P(s)=E(s) \sum_{i} \frac{K(i, s)}{100} K(s) D(i, s),
$$

the loss of production in days is obtained. Therefore, the total loss of production is

$$
P=\sum_{s} P(s)
$$

\section{Morbid Episodes and the Outpatient Area}

Empirical references as to the size and number of morbid episodes were taken from a special analysis based upon an all-Austrian random sample of 2000 persons. Special emphasis was laid on the subjective component of morbid episodes. On the basis of the results obtained from studies of the Osterreichischen Bauernkrankenkasse (Austrian Farmers Health Insurance), from the stratum-specific morbidity statistics of the Hauptverband, and from the occupational mortality analysis (Popper, 1961), the Project Group was able to assess objective and subjective components and to aggregate them into a crude indicator which determined the per stratum average intensity of morbid episodes for 1961. Over time, the indicator was determined to be parallel to the number of cases of panel doctor attendance (aggregated).

The stratum-specific distribution was assessed on the basis of another special analysis for manual workers, non-manual workers, children, elderly people, farmers. In order to calculate the empirical interrelation between the economic development and the state of health of the population--in spite of the lack of better empirical data--a regression of productivity with the cases of panel doctor attendance was used. In accordance with the model, the number and intensity of morbid episodes were retroactively added as an intervening variable.

The original equation which was empirically tested was

$$
\text { FVAHE }=\underset{(11)}{2.969}+\underset{(17)^{-1}}{.019 /(\mathrm{Q})}-\mathrm{R}^{2}=.823 \text {, }
$$

where:

FVAHE are the cases of panel doctor attendance/employed, and

$\mathrm{Q} / \mathrm{E}$ is productivity of labor.

The intensity of morbid episodes, e.g. of manual workers, was represented in such a way that for 1961 a pre-set initial value is assumed, and that, despite an increase in the level of morbid episodes with productivity as estimated by the Project group, the ratio of cases of panel doctors attendance in morbid episodes decreases. Thus, the equation for the intensity of morbid episodes, manual workers, is 


$$
\mathrm{SME}=\left(2.969+0.19(\mathrm{Q} / \mathrm{E})_{-1}\right) \cdot(.5-.001 \mathrm{~T}) \text {, }
$$

where:

SME = Intensity of morbid episodes, and

$\mathrm{T}=$ Time, $1961=0$.

Table 2, Average duration per disease group (coefficients).

\begin{tabular}{|c|c|c|c|c|c|}
\hline Disease Group & Stratum & $\alpha$ & $\beta$ & $\gamma$ & $\mathrm{R}^{2}$ \\
\hline 1) Cancerous Diseases & $\begin{array}{l}1 \\
2 \\
3 \\
4\end{array}$ & $\begin{array}{r}150.416 \\
37.551 \\
167.749 \\
62.585\end{array}$ & $\begin{array}{r}-.405 \\
.223 \\
-.588 \\
.261\end{array}$ & $\begin{array}{r}.046 \\
.232 \\
-.130 \\
-.327\end{array}$ & $\begin{array}{l}.750 \\
.581 \\
.572 \\
.397\end{array}$ \\
\hline $\begin{array}{l}\text { 2) Cardiac/Circulatory } \\
\text { Diseases }\end{array}$ & $\begin{array}{l}1 \\
2 \\
3 \\
4\end{array}$ & $\begin{array}{l}66.028 \\
36.435 \\
55.53 \\
12.778\end{array}$ & $\begin{array}{c}-.297 \\
-.074 \\
-.214 \\
0\end{array}$ & $\begin{array}{l}.282 \\
.224 \\
.342 \\
.622\end{array}$ & $\begin{array}{l}.644 \\
.247 \\
.543 \\
.396\end{array}$ \\
\hline $\begin{array}{l}\text { 3) Respiratory } \\
\text { Diseases }\end{array}$ & $\begin{array}{l}1 \\
2 \\
3 \\
4\end{array}$ & $\begin{array}{r}3.596 \\
23.941 \\
29.087 \\
21.850\end{array}$ & $\begin{array}{c}0 \\
-.052 \\
-.128 \\
-.048\end{array}$ & $\begin{array}{r}.800 \\
-.110 \\
.013 \\
-.284\end{array}$ & $\begin{array}{r}.718 \\
.394 \\
.813 \\
.517\end{array}$ \\
\hline 4) Digestive Diseases & $\begin{array}{l}1 \\
2 \\
3 \\
4\end{array}$ & $\begin{array}{l}16.765 \\
23.805 \\
29.983 \\
12.864\end{array}$ & $\begin{array}{l}-.071 \\
-.091 \\
-.045 \\
-.047\end{array}$ & $\begin{array}{r}.466 \\
.184 \\
.174 \\
+.504\end{array}$ & $\begin{array}{l}.837 \\
.694 \\
.837 \\
.776\end{array}$ \\
\hline 5) Accidents & $\begin{array}{l}1 \\
2 \\
3 \\
4\end{array}$ & $\begin{array}{l}19.593 \\
16.682 \\
13.234 \\
17.055\end{array}$ & $\begin{array}{l}.010 \\
.017 \\
0 \\
.075\end{array}$ & $\begin{array}{r}.026 \\
.209 \\
.406 \\
-.114\end{array}$ & $\begin{array}{r}.157 \\
.426 \\
.156 \\
.808\end{array}$ \\
\hline $\begin{array}{l}\text { 6) Locomotive } \\
\text { Diseases }\end{array}$ & $\begin{array}{l}1 \\
2 \\
3 \\
4\end{array}$ & $\begin{array}{l}19.295 \\
25.960 \\
17.824 \\
30.316\end{array}$ & $\begin{array}{l}-.078 \\
-.063 \\
-.064 \\
-.009\end{array}$ & $\begin{array}{r}.398 \\
.157 \\
.436 \\
-.338\end{array}$ & $\begin{array}{r}.818 \\
.584 \\
.784 \\
.118\end{array}$ \\
\hline $\begin{array}{l}\text { 7) Infectious } \\
\text { Diseases }\end{array}$ & $\begin{array}{l}1 \\
2 \\
3 \\
4\end{array}$ & $\begin{array}{l}3.627 \\
4.268 \\
3.575 \\
4.146\end{array}$ & $\begin{array}{l}0 \\
0 \\
0 \\
0\end{array}$ & $\begin{array}{l}.677 \\
.639 \\
.640 \\
.583\end{array}$ & $\begin{array}{l}.661 \\
.502 \\
.563 \\
.461\end{array}$ \\
\hline 8) Neuroses & $\begin{array}{l}1 \\
2 \\
3 \\
4\end{array}$ & $\begin{array}{l}43.855 \\
18.659 \\
47.540 \\
23.525\end{array}$ & $\begin{array}{l}-.055 \\
-.011 \\
-.139 \\
-.050\end{array}$ & $\begin{array}{r}-.221 \\
.324 \\
-.155 \\
.287\end{array}$ & $\begin{array}{l}.345 \\
.131 \\
.709 \\
.297\end{array}$ \\
\hline
\end{tabular}


The concept used is extremely crude, but it illustrates a deplorable data situation in this area. Unfortunately, large-scale epidemiological research, especially with regard to social status, occupational group, income and educational levels, is practically non-existent in Austria.

\section{The Inpatients Area}

The sick leave factor was subdivided into 5 strata:

1) manual workers

2) non-manual workers and officials

3) elderly people (over 65)

4) children (under 15)

5) farmers (social insurance).

Hospitalization cases per capita were understood in terms of productivity, of the increase in the gross national product, and of the cases of panel doctor attendance, by means of autoregression or a trend in time.

1) manual workers (hospitalization cases/1000 insured):

$$
\text { FALLK }=\underset{(999)}{-4.013+}+\underset{(76)}{.177(\mathrm{Q} / \mathrm{E})_{-1}}+.883 \text { FALLK }_{-1} \mathrm{R}^{2}=.541 .
$$

2) non-manual workers:

$$
\text { FALLK }=-214.962-5.779 \mid\left(\mathrm{Q}-\mathrm{Q}_{-1}\right) / \mathrm{Q}_{-1}+\underset{(17)}{50.099 \mathrm{FVAHE}_{-1}} \mathrm{R}^{2}=.963 .
$$

3) elderly people:

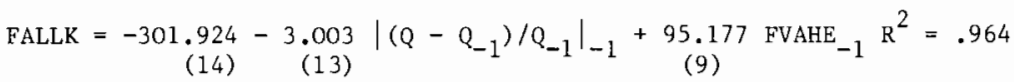

4) children:

FALLK $=\frac{1}{2}$ (FALLK of the non-manual workers).

5) farmers (only as from 1967):

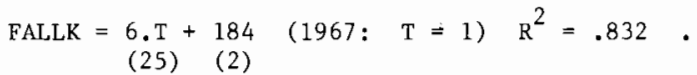

Similar results could be obtained for the average duration of hospitalization. In the model, however, the duration is corrected according to the number of beds available. Therefore the equations given below give only the ratios of hospitalization. 
1) manual workers (period of hospitalization in days):

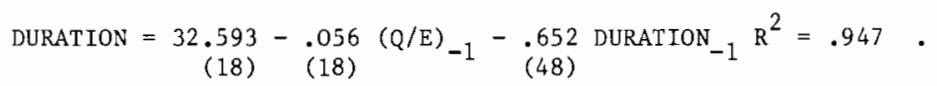

2) non-manual workers:

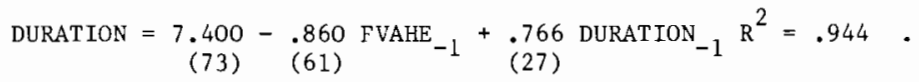

3) elderly people:

$$
\text { DURATION }=\begin{array}{rr}
36.917-2.677 \text { FVAHE }_{-1} \mathrm{R}^{2}=.821 \\
(6) & (17)
\end{array}
$$

4) children:

$$
\begin{aligned}
\text { DURATION }=\text { DURATION (non-manual workers) } \\
\text { 5) farmers: (only as from 1967) } \\
\text { DURATION }=\begin{aligned}
.915 \text { DURATION }_{-1}+\underset{(16)}{.131 \mathrm{R}^{2}=.950}(197)
\end{aligned}
\end{aligned}
$$

The days in hospital/stratum and the total of days spent in the hospital paid by social insurance, TAGSUM, are calculated as

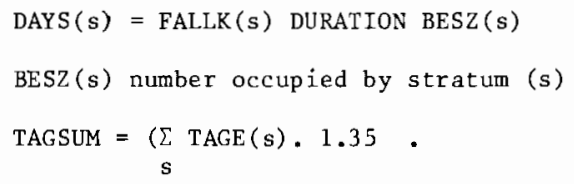

1.35 is the correction factor for residual groups in the hospital who are also entitled to social security.

Using a conversion factor of 1/1.69--derived from the total number of beds to that of beds occupied by health insurance patients--the statistics of beds actually available in Austrian Hospitals are used to calculate the bed-days per year offered by the Hauptverband:

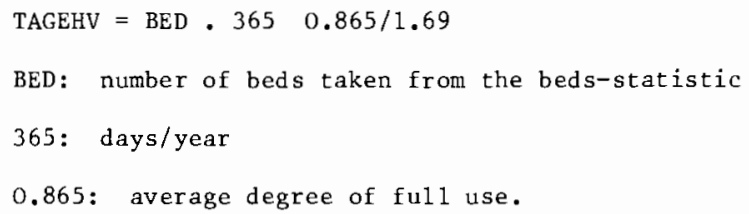


The next step is to compare offer and demand of hospital beds. The quotient of TAGSUM/TAGEHV is used to adjust the period-of-stay figures and thus a balanced "bed market" is obtained. Instead of the simplifications employed--constancy of the "public" bed ratio, homogeneous correction of the period of stay in each strata, constant degree of full use--more realistic assumptions can be replaced by further studies. However, lack of time and capacity made this impossible to accomplish within the framework of this project.

\section{Resources in the Health Care System}

The figures for physicians (total), residential doctors, and for the nursing staff (total) were included in the model. For material resources, some money flows and the bed investments were taken into account. Here the model could be disaggregated as an attempt at expansion, and it would also be advisable to study in more detail those parameters which were assumed to be constant. The numbers of physicians are calculated according to the pattern shown in Figure 4.

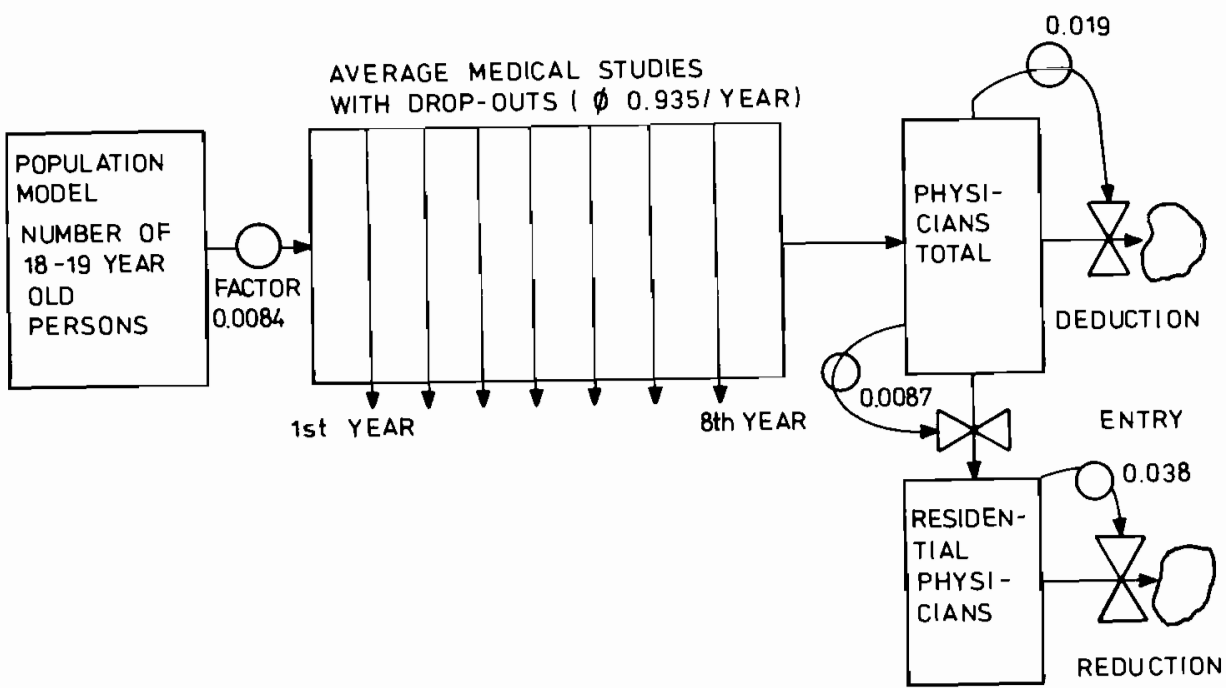

FIGURE 4.

An analogous pattern (Figure 5) may be used for the training of medica1 staff (nurses, male and female, medical/technological assistants).

The bed figures were written out both autoregressively and on the basis of the productivity trend:

$$
\begin{aligned}
\mathrm{DBED} & =\underset{(47)}{44.179+.062(\mathrm{Q} / \mathrm{E})_{-1}-0.638 \mathrm{BED}_{-1}} \mathrm{R}^{2}=.418 \\
\mathrm{BED} & =\mathrm{DBED}+\mathrm{BED}_{-1},
\end{aligned}
$$




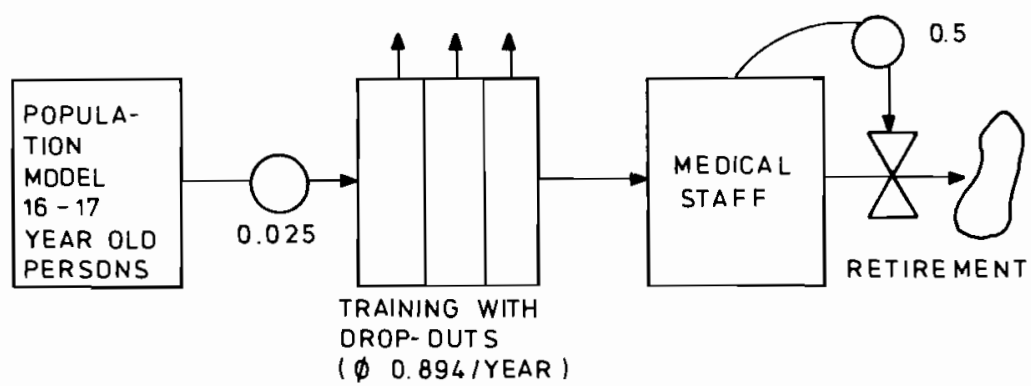

FIGURE 5.

where:

$$
\begin{aligned}
& \text { DBED } \quad \text { changes of the stock of beds, } \\
& \text { BED } \quad \text { stock of beds (beds actually available), and } \\
& (Q / E)_{-1}=\text { productivity, delayed by a year. }
\end{aligned}
$$

For monetary quantities, the following variables and their respective equations were chosen:

a) Total income of the health insurance (KVT) as a function of the tota1 social security contributions (SOzV\$):

$$
\mathrm{KVT}=1.111+.282 \operatorname{SOZV} \$ \mathrm{R}^{2}=.985 ;
$$

b) Income of the KV (see above) from the contributions of the gainful workers (KVE) as a function of KVT:

$$
\mathrm{KVE}=\underset{(11)}{0.456}+\underset{0.642}{0} \mathrm{KVT} \mathrm{R}^{2}=.998 \text {; and }
$$

c) Income of the $\mathrm{KV}$ from old-age pension insurance:

$$
\mathrm{KVP}=-\underset{(11)}{-0.507}+\underset{(2)}{0.318} \mathrm{KVT} \mathrm{R} \mathrm{R}^{2}=.994 .
$$

In order to describe the expenditures of the Hauptverband with respect to its budget for medical attendance, the following statement was chosen: On the basis of general health insurance data (fee per case of panel doctor attendance) the following equation in connection with the consumer price index (PCP), was estimated at:

$$
\text { FVAFK }=-101.483+1.702 \mathrm{PCP} \mathrm{R}^{2}=.992,
$$


so that the inflationary development is considered with regard to fees--a fairly realistic assumption.

from

The budgetary expenditures for medical attendance (YARZḤV) are obtained

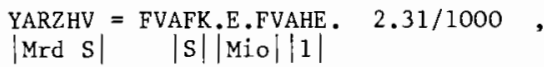

where $E$ is the figure of the employed, 2.31 is a correction factor for other healthinsured residual groups, and 1000 represents a dimensional factor by which million AS are converted into billion AS.

Private household expenditures for medical attendance and the expenditures of private health insurances were assumed to be constant factors of private consumption. This assumption probably underestimates rather than overestimates the actual trend of expenditures.

$$
\begin{aligned}
& \text { YARZPH }=\text { CP } \cdot \text { PCP } \cdot 0.0025 / 100 \\
& \text { YARZPV }=\text { CP } \cdot \text { PCP } \cdot 0.0028 / 100 \\
& \text { YARZTN }=\text { YARZPH + YARZPV + YARZHV, }
\end{aligned}
$$

where:

$$
\begin{aligned}
& \text { YARZPH }=\text { expenditures of private households for medical attendance; } \\
& \text { YARZPV }=\text { expenditures of private health insurances for medical attendance; } \\
& \text { YARZTN }=\text { total gross income for residential physicians; } \\
& \text { CP } \quad=\text { private consumption, real; and } \\
& \text { PCP } \quad=\text { price index of private consumption, } 1964,=100 .
\end{aligned}
$$

From the total gross incomes and the number of residential physicians, an approximate "per-physician income" can be calculated.

Hospital financing in the public, federal, provincial, and local sectors was regarded as proportional to public consumption or investments. Thus, the model shows a rather optimistic situation. The same applies to private expenditures for hospitals.

$$
\begin{aligned}
& \text { SPIGEC }=0.052 \cdot \text { CG } \$ \text { for public consumption of hospitals } \\
& \text { SPIGEI }=0.058 . \text { IG } \$ \text { for public investments for hospitals } \\
& \text { SPIP }=0.0048 . \text { PCP.CP } / 100 \text { private expenditure for hospitals. }
\end{aligned}
$$

The index figures of the general health insurance (KV) provide an indicator SPIKTG for the health insurance (KV) reimbursements per day of expenses for institutional care. Dependent on the consumption price level PCP,

$$
\text { SPIKTG }=-246.908+3.363 \text { PCP R } \mathrm{R}^{2}=.969 .
$$


The hospital expenditures of the Hauptverband are calculated by multiplying the number of hospital days and a correction factor for other health insurers:

$$
\text { SPIHV }=(\text { TAGSUM })(\text { SPIKTG }) \cdot 1.2 / 10^{9}
$$

The sum of SPIHV, SPIGEC, SPIGEI and SPIP gives an indicator for the total expenditures for hospitals in Austria.

The pharmaceutical sector is represented by the index figure "prescriptions insured," and by the various expenditures for medicines.

$$
\begin{aligned}
& \text { prescriptions/insured, in terms of the time trend } \\
& \text { FPHKE }=14.61+0.161 \mathrm{~T} . \quad(\mathrm{T}=1 \text { for } 1962) \text {. }
\end{aligned}
$$

Expenses of the Hauptverband for drugs are calculated as a function of costs/prescription(PHKK), FPHKE of the employed E, and a correction factor:

$$
\text { PHKK }=-19.034+0.351 \text { PCP R }{ }^{2}=.939
$$

PHKHV $=$ PHKK. PCP.E.2.3/1000 .

Private expenditures are assumed as being in a fixed proportion to the expenditures of the Hauptverband--a hypothesis which might be modified by more extensive studies. Therefore, for the total expenditures for drugs, PHKT $=2$. PHKHV applies.

\section{THE POLITICAL SUB-MODEL IN THE HEALTH CARE SYSTEM}

A new assumption was used for this sub-model, which--in contrast to game theory--makes it possible to represent dynamic interrelations, and into which politological opinions can easily be introduced. This assumption reduces value problems to changes of socio-economic factors, whereas in futurological models they are treated in a rather voluntaristic sense. The struggle of political interests groups is represented by a mechanical analogue, which lends to the question of values a materialistic basis. The model could easily be extended to several dimensions; however, the problem is not a formal one but a problem of substance of the theory of the interrelations within the political system. The result of a political power struggle changes a given political indicator, which in turn influences the structural coefficients of the model. The differences in weight attached to the powers of individual interest groups, as well as the orientation of such powers, lead to the above differences between the reform and the conservative variants.

\section{The Variables of the Sub-Model} were chosen:

For the interest groups within the political system, the following headings

1) General capital investment interests, which serve to maintain and modernize capitalistic conditions;

2) Medical capital investment interests of the pharmaceutical construction, and electrical industries; 
3) Medical class interests of residential physicians and pharmacists;

4) Social bureaucracy, well represented by the Hauptverband; and finally,

5) Interests resulting from the health requirements' of the people.

Due to a lack of time, only the first two of the political areas could be represented by the model:

- curative/preventive medicine;

- public/private financing of the HCS;

- equal supply of health services to the population;

- type of payment to physicians; and

- control over medical capital goods.

For these areas the sub-model was arranged in the pattern shown in Figure 6.

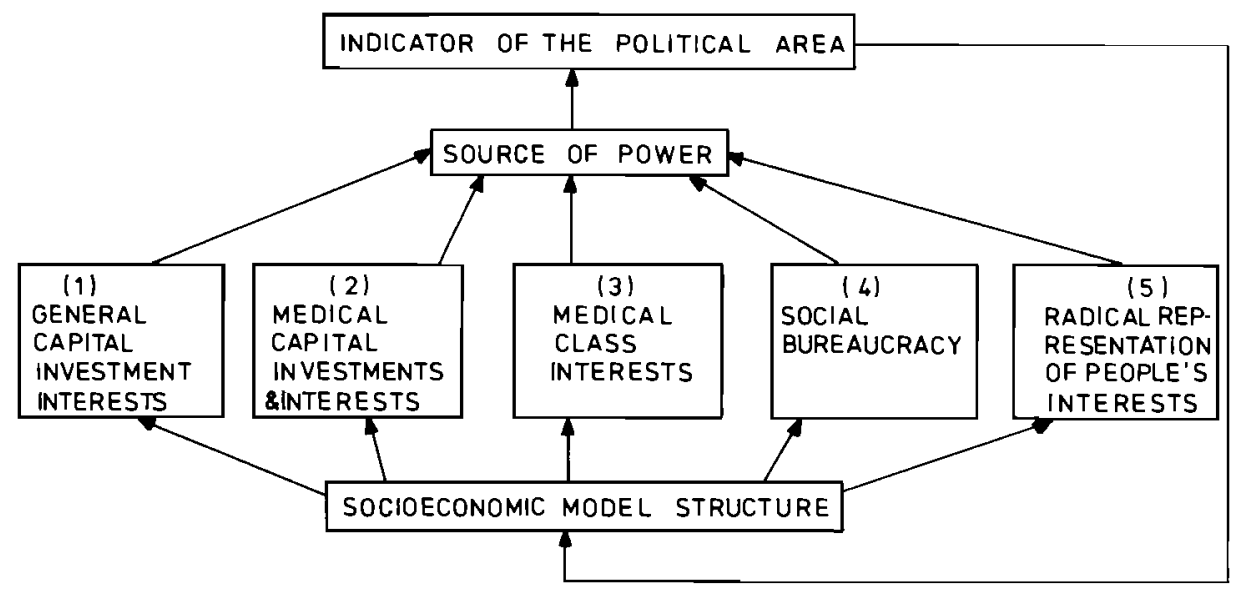

FIGURE 6. THE POLITICAL SUB-MODEL.

\section{Illustration of the Endogenized Political Processes}

For the political area of cure/prevention, there is a variable in the model, the scale of which reaches from 0 (curative medicine as of 1961) to 1 (cumulative value: curative, secondary-preventive and primary-preventive medicine). 0.5 stands for curative medicine, coupled with secondary-prevention and palliative primary-preventive elements.

The introduction of secondary-prevention is, because of the costs involved, of greatest interest to the social bureaucracy. With rising costs, the political power of this group increases. But the social bureaucracy is feeling growing pressure toward prevention by the people (interest group 5) who have not previously been of concern, but who suffer increasingly from the increase in industrial development. When the people's influence upon social bureaucracy does not become too strong over time, social bureaucracy acts repressively as it is not interested in social changes, and the power of group 5 is weakened; this in turn 
comes to affect the power of social bureaucracy with regard to secondary prevention. Over time a wave-like pattern develops.

It is harder to arrive at an adequate description of the behavior of physicians. Before the introduction of a comprehensive secondary-preventive system, physicians favored maintaining the curative system, so that physians and social bureaucracy are in balance. When, in the eyes of social bureaucracy, expenditures for medical attendance tend to become too high, however, doctors may be forced to engage in a secondary-preventive screening system. At this point the behavior of physicians becomes determined by the growth of their incomes. If the latter sinks below a certain level beyond the inflation rate, doctors' behavior ranges from neutral to reluctant. It must also be taken into account that the present organization of production of medical services will not allow them adequately to cope with their demands. This is another infringement of their power--even more so, as it is necessary to introduce medical-technological centers or outpatients departments, which lead away from the residential physician system.

The medico-technologically directed industries, which also enjoy support from general capital investment interests, strongly favor the introduction of secondary-prevention and the accompanying needs for medical technological devices, new buildings, and palliative drugs.

This is a description of a typical reform variant, where social bureaucracy and capital investment interests have the upper hand. The indicator of the political area ranges from 0 to approximately 0.5 in 1995 . If the indicator is varied, changes in the basic structure of the model ensue. These changes cover factors such as:

- probabilities of death

- cases of panel doctor attendance

- budgetary deficit

- higher bed number

- more nursing staff.

Within this area the conservative run means a freeze of the political indicator at the level of 1970; however, because of a more linited access to health institutions, this freeze affects the cases of panel doctor attendance, sick leaves and life expectancy.

The political dimension 2, which considers the issue of public/private finances for the HCS, is again represented in the reform variant. The respective indicator describes the ratio of government spending within the overal1 HCS expenditures. Again social bureaucracy ranks highest in political power. Then follow the people's needs for health care and the medical capital investment interests which can derive private profits from public expenditures. Assuming that social bureaucracy is inclined to favor public financing, general capital investment interests tend to favor limited governmental spending. The opposition to public financing is greatest on the part of the class interests, as their political weight of exclusive control increases with the decrease of physicians. Yet, in spite of a lesser increase in government spending in the conservative rur, the increase in public financing was high in both runs. 


\section{REFERENCES}

Attinger, E.o. ed. (1970). Global Systems Dynamics. (Basel) 263-326.

Fleissner, P., Fürst, E., Löschner, E., Schebeck, F., Schleicher, S., Schwödiauer, G., and Winter, H. (1970). Model1 Österreich I. Ejn makroökonometrisches Prognose- und Entscheidungsmodel1. (Institute for Advanced Studies, Vienna).

Fleissner, P., and Schleicher, S. (1971). Austria 2 Link. (Institute for Advanced Studies, Vienna).

Klein, L.R. and Goldberger, A.S. (1955). An Econometric Model of the United States 1929-1952. (Amsterdam).

Kosa, J., and Robertson, L. (1969). The Social Aspects of Health and Illness in: J. Kosa, A. Antonovsky, and I. Zola, Poverty and Health. (Cambridge, Mass.).

Lüth, P. (1972). Kritische Medizin. (Reinbeck).

Meadows, D. (1972). Die Grenzen des Wachstums. (Stuttgart).

Mesarovic, M., and Reisman, A. (1972). Systems Approach and the City. (Amsterdam).

Naschold, F. (1967). Kassenärzte und Krankenversicherungsreform. Zu einer Theorie der Statuspolitik. (Freiburg).

Popper, L. (1961). Beruf und Lebenserwartung im Spiegel der statistik. (Verlag der ÖGB, Vienna).

Schäfer, H. and Blohmke, M. (1972). Sozialmedizin. (Stuttgart).

Schober, B. (1971). Medizinstudium und Ärztebedarf in Ǒsterreich. (Vienna).

Wolff, K.H. (1970). Versicherungsmathematik. (Vienna). 
To provide a fair critique on a paper presenting a complex model is, Mr. Majone averred, difficult. A satisfactory effort requires thorough familiarity with the problems and objectives faced by the modellers as well with the theoretical propositions they were addressing. Any review of the Fleissner model focusing only upon its final presentational form--for instance criticizing its low R-square values--would likely be missing the point.

Instead then of focusing upon the detailed results of the project, Mr. Majone would speak to the fundamental concepts involved. He found it difficult to see how the thesis of the model could be refuted by experience. It therefore could not claim to prove any behavioral hypothesis. While analysis of power groups has appeal, it is scientifically dangerous in that virtually any phenomenon could be explained by reference to the appropriate power group. In the context of the Austrian model, it would be interesting to examine the limits to the power of groups and to determine why they sometimes are frustrated. An example of power group frustration is found in Norwegian experience where many factions sought to alter the social and geographical composition of the medical community but could not. The lack of hard data on power group phenomena would hamper this type of study.

Mr. Majone expressed sympathy with the study intentions which he saw as breaking away from the narrow bounds of conventional analysis. Its very boldness of approach, however, led it to incur severe methodological problems--for instance, the impossibility of crystallizing the environment at ary point in time. This problem plagues all analysis of utopias. As evidence of change in the disease environment, Mr. Majone cited the trends in iatrogenic diseases, allergies, certain cancers, alcoholism, and drug addiction. Given the inconstancy of the surroundings, dogmatic and timeless statements should be avoided.

\section{Further Remarks upon the Model}

Conference members commented upon:

a) the mention of convergence within the mode1. This could mean purely numerical convergence or might instead refer to inherent stability properties of the system. Clarification was sought;

b) the number of intersectoral models being developed around the world. WHO, the International Labor Organization, and the World Bank were cited as three institutions interested in such efforts; and

c) goal ambiguity. The absence of primary goals which would unite all segments of the model was noted. Perhaps a first stage in modelling should be the identification of primary and secondary goals together with their interlinkages. This would have the effect of unifying the various system components and sub-systems.

\section{Responses by Mr. Fleissner}

Mr. Fleissner stated that the complete study--of which the model was only a "waste product"--ran to 1,400 pages and was presently in print. The model was designed to illustrate a hypothesis by showing a necessary minimum of correspondence with reality. It is a principle of natural science that models can never be finclly verified although they may be proven false. Similarly, it can never be claimed that one and only one model captures reality. Surely models other than the one presented could be derived from the experience of the Austrian health care system.

A chief difference between this and other models is that the starting point and aims have been explicitly spelled out. One important starting point was concern for distribution of goods and services. One can cite other distributional models 
but Mr. Fleissner was struck by the neglect of the distribution factor in the model of Mesarovic and Pestel which was based upon earlier work of Forrester and Klein. This omission, he felt, seriously misrepresented the problems studied.

Both types of covergence phenomena--numerical and structural--were studied in the model. To obtain numerical convergence of various parts, ten to fifteen computer iterations were necessary. Sensitivity checks were performed to investigate the stability of the model. It was found to be more stable than previous econometric models of Austria.

The surprising finding that only one-fourth of Austrian morbidity episodes enter the medical system derives from surveys and from a special investigation performed in connection with insurance for farmers. A similar determination was made by Robinson working with US data.

The absence of an overriding and driving goal within the model reflects the real situation in Austria. Goals vary across time and social class. The approach adopted was to distill a descriptive simulation of reality--in a sense, a status quo analysis. To have posited a hierarchical goal structure would have been to misdepict the system. 


\author{
SOME ASPECTS OF THE RELATIONSHIPS \\ BETWEEN MORTALITY, ENVIRONMENTAL CONDITIONS, \\ AND MEDICAL CARE
}

\title{
A. Letourmy
}

\section{INTRODUCTION}

Recent trends in mortality rates put a new light on the relationships between the medical care expenditures and their presumed outcome: the health of the population. More precisely, in most developed countries, life expectancy has no longer been increasing for ten years whereas medical expenditures have grown at a high and troublesome rate (in France, for instance, at the annual rate of ten percent in real terms). This lone observation does not justify the facile conclusion that medical care has no impact on health. Instead, one may object, first, that life expectancy is a wrong index for this purpose, because medical care is not really concerned with the duration of life but with the reduction of pain and suffering and, secondly, that medical care is not the only contributor to mortality, and more generally to the health of a population. Many factors related to environmental conditions and to the ways of 1 ife of people have effect upon health. It could be claimed that change in these environmental factors (to sum up these nonmedical determinants of mortality) explain this recent trend in life expectancy by offsetting the improved benefits of medical services. This study will be addressed to that claim. The range of questions that should be evoked in order to deal with the first objection is too vast to be resolved with the data which can be gathered from the French health system. Such questions will be mentioned in the conclusion of this paper. The body of the paper will, however, focus on a model formulating aspects of the relationships between mortality, environmental conditions, and medical care: an empirical investigation from cross-sectional data with the purpose of comparing their differential effects on mortality. The first section of this paper will present the basic assumptions of the model; the second will describe the available data; the third will deal with the choice of a specification; the results will be found in the fourth section preceding a conclusion on the possible implications for health planning and subsequent research.

\section{THE MODEL}

Two basic assumptions are involved in the formulation. The first has been suggested in the introduction: the mortality level defined for a population unit $n^{\circ} i$ for year $t$ is viewed as resulting from the action of two kinds of detenninants: the amount of medical services consumed by the population in the year and the environmental conditions--comprising factors generated outside the medical care system--characterizing the population unit in the year. The population unit will be the French département. As all data will refer to the year 1968 , it will be possible to adopt a traditional stochastic formulation:

$$
M(i)=A \prod_{j=1}^{J} M C_{j}(i)^{\alpha} j \underset{k=1}{K} E_{k}(i)^{\beta} k \exp \left[\varepsilon_{1}(i)\right]
$$

where

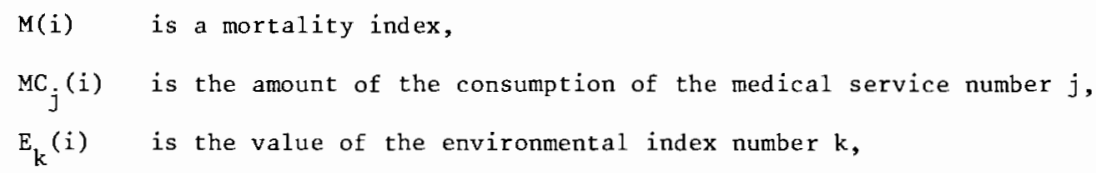




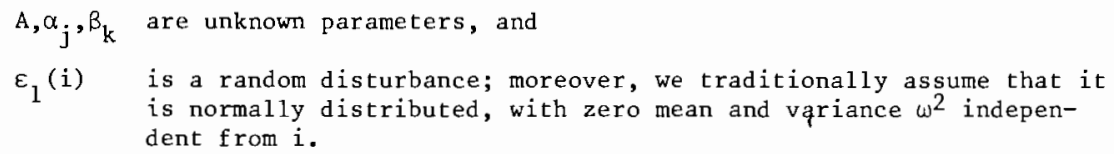

The first equation can be viewed as a production function with mortality appearing as the output of a process in which the inputs are medical services and environmental factors. This is exactly the interpretation given in the study by Auston et al. (1969) on the same subject. In fact, our primary idea was to apply the model of these authors to the French data. However, modifications were introduced to take into account the specificity of the French health system and to use some external information that we had about its mechanisms. For instance, the reason why medical services are treated as endogenous is not the same as in Auston's study; similarly, the introduction of a variable was guided more by epidemiological results than by economic considerations; finally, the interpretation of the estimates--and also the choice of the specification--focused less on the effect of technological improvements in medical care than on the foundations of health planning and medical economic studies.

The second assumption of the model is the specification of medical consumption $\left(\mathrm{MC}_{\mathrm{j}}(\mathrm{i})\right)$ as endogenous. This specification reflects the fact that health is not simply a causal consequence of medical care. Indeed, people are prompted to demand medical services precisely because they do not feel completely healthy. It is more realistic, then, to speak of a "converse causality" between health and medical care. The same argument holds when a mortality index is used as a proxy For the state of health and it implies logically that there is a simultaneous determination of $\mathrm{M}(i)$ and $\mathrm{CM}_{j}(i)$. In the model, this assumption leads us to write supplementary equations, each of them explaining one CMjo(i) by the mortality level $\mathrm{M}(\mathrm{i})$, by the other types of medical services $\mathrm{CM}_{j}(i)$ ( $j \neq j o$ ), and by other factors such as medical supply or socio-economic characteristics of the population (education, income, insurance coverage). Each equation is intended to describe the behavioral components of a process involving individuals, when they demand medical services, or the physicians, when they decide the definite nature and volume of the medical services to be consumed (e.g. X-ray process, drugs, surgery). These equations will be exactly specified in the third section of this paper. Now they will be merely written, using the same Cobb-Douglas formulation:

$$
M C C_{j o}(i)=B_{j o} \prod_{\substack{j=1 \\ j \neq j o}}^{J} M C_{j}(i)^{\gamma j j o} \cdot M(i)^{\lambda} j o \prod_{\ell=1}^{L} x_{\ell}(i)^{\delta} l_{j o} \exp \left[E_{j o+1}(i)\right] \text {, }
$$

where $X_{1}$ is a medical supply or socio-economic factor number 1. ( $B_{j o}, Y_{j j o}, \lambda_{j o}$, $\delta_{\ell j o}$, are unknown parameters.)

Our purpose is to estimate the unknown parameters of these equations from a data bank gathered from eighty-five French départements in 1968. But before turning to the estimation procedure and its results, it is necessary to describe in detail the variables and the concepts they represent.

\section{THE DATA}

We present here the data available for insertion into the model to verify our basic hypothesis. We mention all available variables considered to capture important aspects or effects even though not all are included in the final specification. This listing will justify the heuristic procedures applied before the estimation of the parameters. 
RELATIONSHIPS BETWEEN MORTALITY, ENVIRONMENTAL CONDITIONS, AND MEDICAL CARE 269

THE DATA FOR THE PRODUCTION EQUATION

The Mortality Index (M)

We have suggested that the only available data to represent the state of health were for us the mortality data. The others--morbidity data especially--are partial and not subject to satisfactory aggregation. There is an important interaction between the diagnostic means which an institution is provided with and the nosology it uses to characterize morbidity. More precisely, a hospital using the newest biological tests does not exhibit the same morbidity as a practitioner reluctant to incur additional costs to get supplementary information (Dupuy et al., 1971).

Because no disability data are available in France at the département level our study was forced to focus upon mortality data. We did not seek to disaggregate the medical services consumed by either age or sex and have accordingly used an index of mortality from all causes and for all sex and age groups. Because of the incomparability between different units, we used common demographic procedures to compute an indirect standardized death rate to represent mortality. However, the procedure, if only applied to the explained variable, may lead to a wrong estimation for the elasticities of the inputs--such as medical services--known to be largely dependent upon age and sex. Therefore, most of the variables on which the influence of sex and age was known to be important were also indirectly standardized.

\section{The Medical Services (MC)}

The amount--in volume or in value--of each type of medical service was divided by the population of the département to obtain per capita consumption figures. Six variables were principally used, referring to physicians' visits and consultations (CV), pharmaceutical expenditures (PM), surgery acts (K), radiological acts (R), biological acts (B), and hospitalization days (HOSP).

The first variable represents the demand from the individuals to the medical system, outpatient consultations excepted. The following two represent the therapeutic aspect of medical care (the first excluded hospital, the second one included $i t)$. The fourth and the fifth represent the investigation processes. Only the last four variables result from medical decisions. The sixth is a mixed variable, including demand from individuals (through admissions) and medical decisions (through mean stays).

It was assumed a priori that the effect of these variables on mortality was negative.

\section{The Environmental Factors (E)}

Under this level, we find characteristics of life habits which can be measured at the level of the household, and more general conditions which can only be defined for the entire population--such as pollution, industrialization, urbanization, or climate. More precisely, we at empted to represent: alcoholism, smoking habits, diet, social isolation, individual sanitary conditions, predetermined good health, domestic pollution, industrialization, urbanization, and climate.

For alcoholism, we used an estimated alcohol consumption per capita (ALC) and the standardized death rate from alcoholism and liver cirrhosis (CIR). The elasticities of these variables were expected to be positive.

Smoking habits were represented by the percentage of smokers (SMK) and smoked tobacco's weight (TOB) per capita. 
For diet, we used the average percentage of lipids (LIP), of vegetal protids (VPR), of animal protids (APR), of glucids (GLU) in the food intake of the households.

Social isolation was represented by the percentage of 'persons older than forty-five living alone (LON), and by the percentage of persons older than seventy living in asylums (ASY).

Labor conditions were figured by percentages of family heads in various occupations. The occupations chosen were: farmer (FAR), agricultural worker (AWK), worker (WK), and two aggregate categories that we entitle "white collar occupations" (WCO), and "merchants, craftsmen, and managers" (MAN). From previous studies, it was expected that the first three categories would give positive elasticities and the latter two negative elasticities. Another variable was added: the percentage of workers younger than twenty (YOU) the elasticity of which was assumed positive.

Individual sanitary conditions were represented by the percentage of houses with toilets indoors (TOI) and by an index of overcrowding of the houses (OVC).

Predetermined good health was figured by the percentage of persons older than sixty having migrated into the department during the last four years (MIG). This variable was expected to influence mortality negatively.

Domestic pollution was represented by a per capita consumption of domestic coal (DOM), and industrialization by the percentage of enterprises employing more than twenty persons (IND). These two variables were expected to exhibit positive elasticities.

Urbanization was represented by the percentage of people living in towns with more than 20,000 inhabitants (URB).

Climate was characterized by the number of sunny days (SUN) and frosty days (FRO), and by a dampness index (DAM). The first indicator was assumed to influence mortality negatively, and the two others positively.

\section{THE DATA FOR THE EQUATIONS EXPLAINING MEDICAL CARE CONSUMPTION}

Medical supply was figured by per capita numbers of physicians (PHY), per capita numbers of specialists (SPE), and per capita numbers of hospital beds (BEDS) . We added a dummy variable coded 1 where there was a university hospital in the department and 0 when there was none, to figure the impact of a technologically advanced center. All these variables were assumed to influence medical care consumption positively.

Family characteristics were represented by the average household size (AHS) and the percentage of households with more than four persons $(\mathrm{H}+4)$. The basic assumption was that medical care consumption decreased with household size.

Residency was represented by the variable URB and a more specific indicator of a rural way of life: the percentage of persons living in villages with less than 2,000 inhabitants (RUR).

The educational level was classically figured by the percentage of persons with at least a particular school degree the French B.E.P.C. (ED).

The income level was represented by the average wage rate (AWR) and the percentage of persons earning low wages (LW).

The insurance coverage was represented by the percentage of persons effectively insured (INS). 
We did not make assumptions on the signs of the effects exerted by variables. An exception was RUR, the coefficient of which was supposed to be negative.

\section{THE CHOICE OF A SPECIFICATION}

Before applying an estimation procedure, it was necessary to understand better the data set and to make a selection among the indicators. With only eightyfive observations it was not possible to establish rigorously the valid elasticities between all variables of a priori interest. Instead the exploratory method of Principal Component Analysis (PCA) using Ordinary Least Squares (OLS) was applied. This constituted a heuristic means of drawing out the empirical relationships whereupon Two-Stage Least Squares (TSLS) estimation techniques were applied. With the limited and interrelated data sets, attention had to be given to possible multi-collinearities.

It would be excessive here to present all the intermediate results and their interpretations. We instead focus on the last step of the study: the discussion of the results when assuming one specification of the mode1. As an abstract for the part of the study not reported here, we shall give the main reason why we chose this particular specification. Nevertheless, the specifications do not exclude the possibilities of alternative formulations.

form:

We arrived at the following specification with variables in logarithmic

$$
\begin{aligned}
& M(i)=a_{0}+a_{1} K(i)+a_{2} C V(i)+a_{3} C I R(i)+a_{4} \operatorname{LIF}(i)+a_{5} M I G(i)+E_{1}(i) \\
& C V(i)=b_{0}+b_{1} M(i)+b_{2} P H Y(i)+b_{3} \operatorname{AWR}(i)+b_{4} \operatorname{ED}(i)+\varepsilon_{2}(i) \\
& K(i)=c_{0}+c_{1} M(i)+c_{2} C V(i)+c_{3} R(i)+c_{4} P H Y(i)+E_{3}(i) \\
& R(i)=d_{0}+d_{1} M(i)+d_{2} C V(i)+d_{3} P H Y(i)+E_{4}(i) .
\end{aligned}
$$

Identical stochastic assumptions are retained for the $E$.

\section{THE SPECIFICATION OF THE PRODUCTION EQUATION}

1) Several variables were eliminated from the specification because they either were found statistically insignificant or acquired coefficients in the OLS estimations of opposite sign to the epidemiological expectations. Elimination means only that the expected relationship was not supported by our data.

2) Because of multicollinearity, we used one variable to represent each group in the following cases:

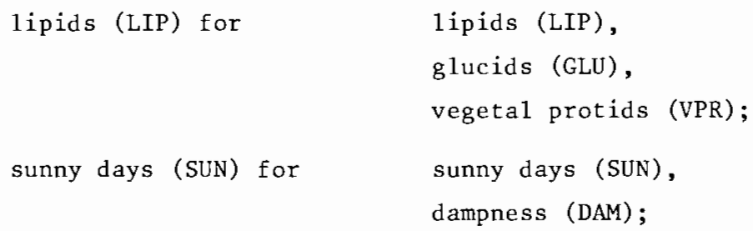




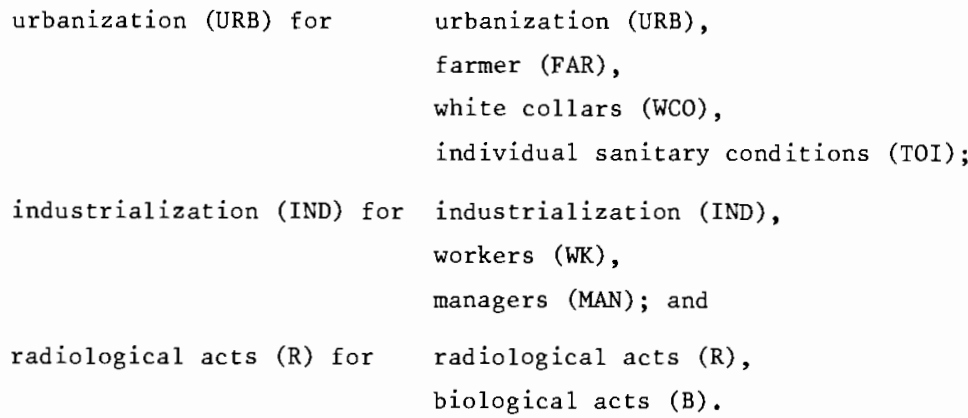

3) The way alcoholism is represented has an important influence on the other coefficients. We computed a per capita alcohol consumption (ALC) but found that it achieved significantly worse correlation values than those obtained with the death rate from alcoholism and liver cirrhosis (CIR). Other elasticities tended to be higher with ALC in the specification than with CIR.

It is interesting to add that in all cases, the elasticity of mortality with respect to urbanization (URB) is close to zero and positive and that the elasticity with respect to "predetermined good health" (MIG) is negative, constant, close to -0.60 , and always statistically significant.

4) From these results, we chose for environmental factors CIR, LIP, and MIG--representing alcoholism, diet, and predetermined good health--and derived partial conclusions about our problem:

a. The importance of alcoholistn in France, already well known from other works, must not be underestimated;

b. This representation of alcoholism through CIR may obscure the actual effect of other environmental factors such as diet, industrialization, isolation, or climate. In fact, all these factors are interrelated with alcoholism. The correlation matrix for these five variables shows particularly high coefficients between CIR and the other four and also between IND and SUN:

\begin{tabular}{c|c|c|c|c} 
& LIP & IND & SLN & ASY \\
\hline CIR & 0.43 & 0.41 & -0.64 & 0.55 \\
\hline LIP & 1 & 0.26 & -0.01 & -0.27 \\
\hline IND & 0.26 & 1 & -0.48 & 0.22 \\
\hline SUN & -0.01 & -0.48 & 1 & -0.27 \\
\hline
\end{tabular}

(A value of 0.21 is significant at the 0.05 level.)

These relationships show the limits of our model if we were to stick to a strict conception of its variables and to estimate separated effects of different environmental factors. The analysis reveals, on the contrary, a network of interrelated variables which would probably be impossible and incorrect to separate. We chose to retain LIP and CIR. In doing so, alcoholism is not presented as the only calamity 
responsible for the mortality level, but as a proxy for more general environmental conditions, another aspect of which is pictured by diet; moreover, the size order of the two elasticities indicates the impact of environmental conditions on mortality relative to the impact of medical actions; and

c. It is reasonable to conclude that urbanization--in the simple sense of urban concentration--has no effect upon mortality. On the other hand, predetermined good health--as represented by net migration (MIG)-exhibits sufficient effect to justify its retention.

5) Among the medical variables, selection was easy, and it is already possible to say that their elasticities are almost zero. But, as our purpose was to maintain both environmental and medical factors, we have chosen the variables which exhibited the most important negative coefficients. HOSP was excluded as always giving a zero elasticity. The drug expenditures also exhibited elasticities close to zero and were highly correlated with physicians visits and consultations (CV). Finally, surgery acts (K) seemed to be the more interesting proxy for the medical actions. We add $\mathrm{CV}$ in order to represent the demand to the medical system. Because of collinearities, a third variable was not introduced. Nevertheless, R was kept in the model in order to obtain a scheme of medical care involving a demand from individuals (CV), a diagnostic search by physicians (R) and a therapeutic process (K).

Recalling that $K, R$, and $C V$ are to be considered endogenous, we shall now justify their corresponding equations.

THE SPECIFICATION OF THE OTHER EQUATIONS

The non-medical data did not give a good explanation (in terms of $\mathrm{R}^{2}$ ) of the level of medical care. This is not surprising when we realize that we had no satisfactory variable--except outcomes of medical practice itself--to characterize the practice at an aggregate level. After trials, we chose to write simple equations, excluding socio-economic factors from the explanation of $R$ and $K$ and keeping them only to explain CV. For these factors, income (AWR) and education (ED) seemed to be the best proxies. It is interesting to notice that no substantial effect on consumption was found for socio-professional categories, household size, and insurance coverage.

Medical supplies were represented in the three equations by the density of physicians (PHY). The number of beds per capita were significant only in the explanation of hospitalization days (HOSP) (not reported here). Surprisingly, the presence of a technologically advanced hospital was not found to influence the level of consumed medical services. To explain surgery acts, we introduced both $\mathrm{R}$ and $\mathrm{CV}$; $\mathrm{CV}$ only was introduced in the equation giving $\mathrm{R}$.

IV. RESULTS AND DISCUSSION

We give here the results of the TSLS estimations:

$$
\begin{aligned}
M(i)= & 2.9135-0.0401 \mathrm{~K}(\mathrm{i})-0.0043 \mathrm{CV}(\mathrm{i})+0.1789 \mathrm{CIR}(\mathrm{i}) \\
& (0.8931)(0.0516) \\
& +0.0540) \\
& (0.1718) \mathrm{LIP}(\mathrm{i})-0.0642 \mathrm{MIG}(\mathrm{i})\left(\mathrm{R}^{2}=0.7\right)
\end{aligned}
$$




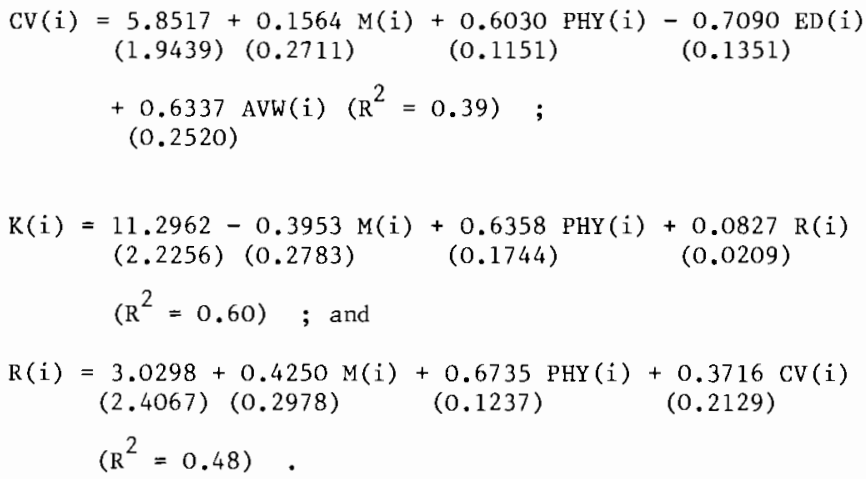

The standard errors put into brackets are the square roots of the estimates for asymptotic variances of the elasticities. It is difficult, therefore, to use them to speak about the statistical significance of the parameters. Nevertheless, in most cases where elasticities are not close to zero, they are substantially lower than the estimated coefficients and there is littie doubt about their signs.

In the first equation, an important difference appears between the proxies for environmental factors and medical factors. This was found in all the specifications tested. Another constant result of our study is the negative value of MIG; so that the idea of a predetermined good health having a substantial effect on mortality level is supported by this finding. But a question may be set about the significance of this predetermined good health: is it environment or medical care which is responsible for it? This question--fundamental to our interpretation of the regression results--is borne upon by three assessments:

1) The indication that our proxy for predetermined good health-internal migration statistics-captures the movement of groups (e.g. schoolmasters, teachers, and white collar workers) whose working lives passed without serious stress and who have been found in other studies (Desplanques et al., 1973) to have greater life expectancy. This indicates that previous working conditions--which we label as a part of the environment--satisfactorily explain the strength of this coefficient;

2) The realization that past, not present, medical care may explain the coefficient; and

3) The justification of crass-sectional application on the basis of stable consumption patterns of medical care across départements when time varies. In this light, inclusion of MIG may be seen, not as capturing an environmental factor, but as adjusting for population differences to enable fairer judgment upon other hypothetical effects.

The results upon the elasticities of mortality with respect to $\mathrm{K}$ and $\mathrm{CV}$ are clear and we conclude that, in our model, medical care appears neutral in the determination of mortality level.

Before concluding that medical care is ineffective in reducing mortality, we must inquire whether a reverse mechanism may be at work: whether health mortality rates induce greater demand for medical services. Consideration of the socio-economic literature indicates the weakness of such a putative mechanism: groups with lowest medical expenditures--such as the farm workers in France--also have lowest life expectancies. Further inference upon this mechanism can be gleaned from examining the coefficients of mortality in other estimated equations. 
From the elasticities of $\mathrm{CV}$, it appears that the socio-cultural or economic factors as well as medical supply are most important determinants of the demand for medical care. We notice also that the elasticity with respect to income is substantially positive, and that the elasticity with respect to education is negative. We suggest that the first result has a classical economic interpretation; the second appears more paradoxical. If we admit the formulation of the equation, with $M$ as a proxy for the state of health, we may suggest that more educated people have another sort of care of their bodies and another idea of their medical abilities which lead them to require a physician's help less frequently.

The coefficient of physicians' density is surprising. The elasticity associated with $M$ is positive and lower than the others. The sign is correct and if we think that this variable is only a proxy for the dimensions of morbidity, its value may not be surprising; if not, it seems difficult to conclude that demand is lower when mortality is higher, when we have such an elasticity!

On the other hand, the estimates for the third equation explaining the surgery acts might lead us to admit this statement. The positive elasticity of $\mathrm{K}$ with respect to $\mathrm{R}$ is not surprising: generally speaking, we infer that more important investigations lead to a rise in therapeutic interventions. The high value found for PHY may be taken as an indication that the density of physicians is an excellent proxy for the importance--in nature and volume--of the medical system in a given area. We shall say that it is an indicator for the "medica1ization" of the area. Such a situation implies--ceteris paribus--a higher level of medical expenditures. This supposes that additional facilities stimulate use. That the elasticity for PHY substantially exceeds that for $R$ may suggest that medicalization is more critical in determining the level of medical intervention than are technical investigations.

The negative elasticity found for $M$ is not so paradoxical as it seems to be at first sight, if we notice that $\mathrm{K}-$-even as it represents an overall level of medical therapeutic action--retains its specific nature. Since all morbid episodes do not lead to surgical intervention, this result suggests merely a negative relationship between the mortality level and the adequacy of surgery to treat the associated morbidity. This interpretation--that the result is caused by the uniqueness of $\mathrm{K}--\mathrm{is}$ reinforced in noting that $\mathrm{M}$ shows positive elasticity in the other equations shown and also when--in an estimation not reported--K was replaced by pharmaceutical expenditures.

The final equation presents no surprises. We find again the influence of "medicalization" and the sign of $C V$ seems normal, reflecting the role of demand. The sign of the elasticity of $R$ with respect to $M$ supports our arguments against the existence of a negative relationship between the utilization of medical facilities and the mortality level.

\section{CONCLUSION}

Our interpretative arguments have stressed our inability to identify the effect of medical care expenditure in reducing mortality. This gives us reason to doubt the simplistic theory of health care delivery whereby discrepancies in the mortality rates are attributed to differential consumption of medical services. We have also argued that our results do not support the supposition that mortality is only a proxy for the state of health. No evidence was found to indicate linkage between a higher mortality level and a lower level of demand for medical care. Physicians' decisions seem influenced by considerations excluded frcm our model, an aspect of which was described as the "medicalization" of an area. Finally, the environment and living habits explained satisfactorily the observed mortality levels. Regional health planning principles deducible from these results can readily be formulated and are omitted here for the sake of brevity. 
We have remarked upon the limitations of our model which derive from its non-dynamic nature. Restricted, as we were, to cross-section data, this shortcoming was inevitable. Straightforward modifications of the model to take advantage of multi-cross-sectional or time series data bases should correct this deficiency. We have also pointed out the ways in which our conclusions might be hedged to reflect doubt in our assumptions.

Nevertheless, we believe the chief vulnerability of the model to lie in another area: the unidimensionality of mortality data and its consequent inability to exhibit the effects of medical care expenditures. Inclusion of accurate morbidity data would improve the situation but would be far from a panacea in that neither of these indices captures psychological and sociological aspects of health. These aspects have been shown to be important in explaining the demand for medical care in the relationship between patient and physician, and in the medical practice itself (Dupuy et al., 1971). Unfortunately, statistical data may be unable to describe these psychological and sociological phenomena.

Although our results do not permit confident espousal of this radically different conception of medical care, they do provide indirect support. More precisely, the hypothesis that medical care deals largely with the psychosociological dimension of health would explain why its consumption is poorly explained by the physical dimension given by mortality data. This conception of an alternative rationality for medical actions can be found in other works from CEREBE in the health field and is supported by psycho-sociological qualitative evidence. The range of the issues suggested by this approach shows the limits of our model. Its exploratory character implies that further investigation will complete its results. This paper only intended to suggest that a traditional approach may not be appropriate for this purpose. 


\section{REFERENCES}

Auston, R., Leveson, J., and Sarachek, D. (first published in 1969). The Production of Health, and Exploratory Study (in V.R. Fuchs: Essays in the Economics of Health and Medical Care, Columbia University Press, 1972).

Dupuy, J.P., Ferry, J., Karsenty, S., and Worms, G. (1971). La Consommation de Médicaments, Approche Psycho-socio-économique. (CEREBE Report, Paris).

Rösch, G., and du Credoc D.E.M. (1973). L'économique Médicale. (Flammarion, Paris).

Desplanques, G. (October 1973). A 35 Ans, Les Instituteurs ont Encore 41 Ans à Vivre, les Manoeuvres 34 Ans Seulement. Economie et Statistique, 49.

Dupuy, J.P. (1973). Rationalité Sociale des Politiques de Santé. (Communication a la conference de Tokio).

Ferry, J., and Karsenty, S. (1974). Pratiques Médicales et Système Hospitalier. (CEREBE Report, Paris).

\section{OTHER STUDIES ON THE SUBJECT}

Silver, M. An Econometric Analysis of Spatial Variations in Mortality Rates by Race and Sex, (in V.R. Fuchs).

Gardener, M.J. (1973). Using the Environment to Explain and Predict Mortality. Journal of the Royal Statistical Society. 
Mr. Letourmy was congratulated by Mr. Thompson for the meticulous fashion in which his results were presented. It has become too much of a fashion in econometrics to brook no doubt about methods used or results obtained. In a discipline with so much leeway for the practitioner, nearly any proposition can be proved by dextrous manipulation of the model--equation specification, weighting or elimination of variables, and choice of regression procedure. In such circumstances, the analyst is behooved to discuss the 1 imitations of his procedures and alternative explanations of his data. This, Mr. Letoumy has done.

The task of the paper was ambitious: to separate the effects of medical expenditures on health from the consequences of differences in the environment and population composition. The data set was limited to cross section statistics derived from the eighty-five French départements in one year. Adequate proxies for many variables in the a priori theoretical models were lacking and thus required innovative experimentation with imperfect surrogates. The large number of related variables inserted within the model introduced problems of multi-collinearity--properly noted by $\mathrm{Mr}$. Letourmy.

Regarding the methodology, Mr. Thompson thought the use of the two-stage least squares (TSLS) regression technique appropriate but disagreed with its description as "elementary and classical." Rigorous tests of significance are not applied to this method. Exploratory data analysis in a study of this type is essential but its dangers must be heeded: when hundreds of equations are examined, onetwentieth on average will be significant at the five percent level. Care must thus be exercised in interpreting the results obtained through Principal Component Analysis (PCA).

The paper represents, in sum, a brave attempt to verify an important hypothesis on imperfect data. The result was the failure to show linkage between increased medical expenditures and better health status. Given the imprecision of the analysis, however, it would be premature also to infer the inverse hypothesis that no connection exists. The immediate policy value of the study inheres in giving the pause to planners who have assumed without question that increased medical payments improved health.

\section{Remarks upon the Analysis}

One participant felt that the negative result obtained by Mr. Letourny could have been expected. Health services, after all, trail air, water, food, and shelter as determinants of health status.

Another conference member argued that nothing had been lost in the lack of data from different periods of time. Health systems are changing so rapidly--both quantitatively and qualitatively--that time series analysis has limited validity.

\section{Response by $\mathrm{Mr}$. Letourmy}

Mr. Letourmy agreed that tremendous complexities plagued his model. Technological progress has made today's health care incomparable with that two decades earlier. A finite econometric model necessarily fails to capture all features of the phenomena studied. 


\author{
ON THE LOGIC \\ OF STANDARD SETTING IN \\ HEALTH AND RELATED FIELDS
}

\section{G. Majone}

University of Rome, Italy, and International Institute for Applied Systems Analysis, Austria

\section{SOME DEFINITIONS}

In its broadest sense, a "standard," the Encyclopaedia Britannica tells us, is anything used to measure. This paper can be viewed as an attempt to explicate this definition in the context of health and environmental policies.

It seems useful, and perhaps necessary, to start with a brief review of the different ways in which such terms as "norms" and "standards" are used in the fields with which we are concerned. For, while most health planners would protably agree that "the establishment of norms and standards is one of the most important of the methods used in planning the development of the health services, "1 these terms, like the concept of planning itself, are open to a variety of different and often contrasting, interpretations.

For instance, attempts have been made to distinguish between norms and standards. An official wHO document refers to norms as rules or indicators which are scientifically determined by research, while standards are supposed to be fixed arbitrarily. ${ }^{2}$ A similar distinction is made in health planning in the USSR, between "scientifically based" norms, and the so-called design norms and standards, developed primarily on the basis of practical experience. Besides being scientifically based, norms relate more directly to the final outputs of the health system, while standards are seen essentially as input variables. Thus, norms refer to "scientifically established indices of environmental conditions and of the medical care required by the community or by various population groups, as well as of the utilization of health facilities." Health standards are "indices relating to the resources required to meet the needs specified by the norms, i.e. indices relating to the public health facilities and the availability of medical care." 3

According to Soviet usage the first category includes: environmental, sanitary, and epidemiological norms; norms for the requirements of the community for medical care; and even "productivity norms," e.g. the work load per hour of doctors in various types of medical care. In the second category we find such indices as: organizational standards; standards for the average length of stay of patients in bed and for the average bed occupancy; construction standards; standards for the number of hospital beds, both in the aggregate and for the various specializations; staffing standards; and so on.

1 G.A. Popov, Principles of Health Planning in the USSR, Geneva: World Health Organization, 1971, p. 129.

2 World Health Organization, Health Planning: Report of the Technical Discussions at the Eighteenth World Health Assembly, Geneva: Document A 18/ Technical Discussion/ 6 Rev. 1, 1965, p. 11.

3 G.A. Popov, op. cit., p. 130. 
"Norm" and "standard" are here used, clearly, in a normative sense, i.e. as rules-usually expressed in quantitative terms--in relation to which a given situation may be gauged and judged good or bad. It is, in fact explicitly asserted that "ideally, al.1 norms and standards should be optimal in character," and the hope is expressed that "as the economy of the USSR develops, it will be possible for design norms and standards to be revised so as to make them approach the optimum more closely." 4

The main part of this paper is devoted to a critical discussion of the assumptions implicit in the above definitions and concepts. Other distinctions are also possible, and have been used. Thus, in functional terms it is possible to identify three major uses of norms and standards:

1) as indicators of need, in terms both of inputs and outputs of the health system, or of a subsystem, and of particular groups of people to whom specific services are directed;

2 ) as rules of action or policy constraints 5 imposed upon a variety of agents, public and private (e.g. environmental and safety standards); and

3) as tools of control, to ensure that plans are carried out according to prescriptions, and to measure the extent of possible deviations between objectives and actual performance.

Applying other taxonomic criteria (e.g. the method used in deriving the standards: statistical sampling, expert opinion, laboratory research), still other classifications are of course possible, but are not immediately relevant to the present discussion. It should, however, be noted that in the western literature the term "standard" (which largely replaces "norn") is of ten used in a much broader sense. This is particularly true in the environmental field, where the term may be applied to any kind of controlling mechanism on the utilization of environmental services, e.g. taxes and subsidies as well as direct controls on emissions or quality deterioration.

\section{STANDARDS AS INDICATORS OF NEED FOR HEALTH}

It seems appropriate to begin a critical discussion of concepts and assumptions employed in the process of standard setting, with an examination of the use of standards as indicators of need. Indeed, in spite of its apparent simplicity, "need" is one of the most ambiguous concepts used in planning and policy analysis. In the first place, it is not usually clear whether the alleged "needs of society" reflect the authoritative decisions of the political authorities, the wishes of a majority of the citizens (perhaps revealed by "manifest demand"), the judgments of a restricted group of experts and administrators, or the values of an enlightened and concerned elite. Also, need can be assessed in (more or less) objective terms 1) when it refers to some minimal prerequisites of individual or societal survival, or 2) when it is expressed as a function of the expectations that are generated by a given level of socioeconomic and technological development. In the first case, standards usually take the form of lower bounds (minimum levels); in the second, minimum levels are often criticized as being too modest and conservative, and discussion focuses on the definition of "optimal" standards.

${ }^{4}$ Ibid., p. 131 .

5 On the concept of policy constraint, cf. G. Majone, "The Feasibility of Social Policies," Policy Sciences, forthcoming. 
The notion of optimality immediately evokes questions of costs, benefits, and constraints. Many discussions of "medical needs" leave the impression that these are needed regardless of financial and social costs, and of institutional and political constraints. One persistent source of confusion is the fact that most doctors and public health planners think about needs in total, rather than marginal, terms. But it is clear that with given resources and technical possibilities, higher levels of one standard (expressing a certain degree of satisfaction of some social need) inevitably imply lower levels for other standards. For instance, high standards of purity for air will entail--except for the possibility of recycling waste material--lower levels of quality for water and land, since waste cannot be destroyed but only transformed in different ways and disposed of through different environmental media. In fact, the stringent regulations recently imposed by air pollution control agencies in many cities have had the consequence of producing tons of additional solid wastes which could not be adequately handled by the sanitation departments.

To make this point completely clear, suppose an environmental agency has to allocate a given budget between water (W) and air (A) protection. of course, restriction to these two media is dictated only by the desire to use a 2-dimensional graphical representation (one could interpret the vertical axis as indicating "other environmental media"). Also for the sake of simplicity, I shall assume that the quality of each of the two media is expressed by a single scalar measure, say, dissolved oxygen concentration (DO) in the case of water. Thus, the scale on the $\mathrm{W}$-axis is defined in terms of Do units (mg/1). With a given budget and technical possibilities, the agency can achieve either the quality level ow for water, or level $\mathrm{OA}$ for air, or any combination of conditions for water and air shown along the possibility boundary AeW (Figure 1).

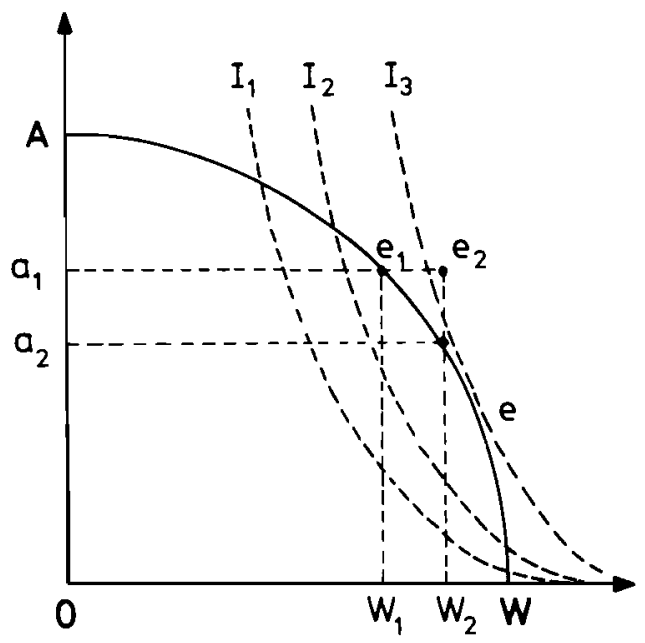

FIGURE 1. 
Suppose that the present quality leve1s for water and air are $w_{1}$ and $a_{1}$, respectively, but that considerable pressure is being exerted on the agency to raise the quality of the water at least to level $w_{2}$. The diagram makes clear that the "need" for clearer water can be satisfied, under the assumed conditions, only by reducing the quality standard for air (from a to $a_{2}$ ). In order to weigh the advantage of purer water against the (opportunity) cost of foregone cleaner air, one would have now to introduce a utility indicator 1 , whose level curves represent alternative combinations of water and air quality levels that are considered equivalent in utility terms. The prescription would then be to choose the combination of standards corresponding to the point on the possibility curve--point e in Figure 1--at which the slope of the highest attainable iso-utility line equals that of the Aew curve.

But even without introducing all the subtleties of utility analysis, we can use our simple diagram to give visual representation to one of the most common errors in standard setting, namely the attempt to achieve the highest possible standard in d certain field, for instance in a particular environmental medium, without regard to its opportunity costs. It is clear that, in our example, the choice of the OW level for the water quality standard would be as disastrous as a choice of oA for air.

Of course, expert health planners are quite aware of this danger. A Soviet expert writes: "A common fault in the preparation of standards for the requirements for medical care is to study the various forms of such care in isolation, e.g. to study hospital care without taking into account the fact that different forms of outpatient care are also available. Standards obtained in this way are unsuitable for use in health planning." 6

What is not so clearly perceived is that the fault is the direct consequence of applying that "method of priorities" which the same author has previously indicated as a necessary tool of health planning. No hierarchy of needs or list of priorities can solve the allocation problein of the decision maker; and, as the preceding discussion suggests, the setting of standards is to a large extent an allocation problem. All needs are simultaneously sensed and the policy maker cannot, and silould not, wait until one need is satisfied hefore beginning to be concerned with the other items on his list of priorities. 7

Many standaris used in health planning, e.g. hospital bed availability and staffing standards, are supposedly determined on the basis of revealed demand (as measured, for instance, by number of hospital admissions or hospital beds used per 1000 population, by increases in the waitirg lists, etc.) The underlying assumption is that the demand for hospitalization is exogenously determined. Now, planning methods based on manifest demand are analytically appealing because they can be dirtctly formulated in terms of well-developed queuing theory models. But these methods are open to a tasic objection: they ignore the effect of available supply on hospital admission rates, and on the average duration of stay per case. This phenomenon is particularly evident in countries whose health systems preciude the rationing of the health resources through the pricing mechanism, while preserving the doctor's professional freedom in the determination of the appropriate treatment of each case.

${ }^{6}$ G.A. Popov, op cit., pp. 131-132.

7 For a good discussion of the ambigujties inherent in the priorities method, and of the special cases in which it is a valid criterion of choice, see C.J. Hitch and R.N. Mckean, The Economics of l)efense in the Nuclear Age, Cambridge: Harvard University Press, 1960, especially pp. 122-123. Also A.J. Culyer, R.J. Lavers, and A. Williams, "Social Indicators: Health," in Social Trends, No. 2, 1971, pp. $31-42$. 


\section{THE COST-BENEFIT APPROACH TO STANDARD SETTING}

The preceding discussion can be summarized by saying that a rational approach to the setting of a standard requires an explicit valuation of the marginal trade-offs between it and other inputs (including other standards) relating to the same indicator, or group of indicators, of state of health. Such valuations correspond to the slopes of the level lines of the indicator as they pass through the possibility boundary (Aew in Figure 1) vertically above each possible level of the standard under discussion.

The important point is that any standard whatsoever--whether it relates to health, to the urban or natural environment, to property damage, or to aesthetic values--can always be expressed as (a function of) a cost-benefit ratio. It is impossible to set standards and norms at such levels as would eliminate any hazard to human health, or satisfy any conceivable need. Even in the most technical fields recourse to human judgment is unavoidable; risks must always be taken, needs have to be matched against resources and technical and institutiona1 constraints, and discount rates for future benefits have to be decided upon. Thus, norms and standards relating to the quality of life necessarily represent a compromise between aspirations and considerations of feasibility. In the last analysis, the setting of a standard is a socioeconomic decision, an implicit valuation of the utility of human life, health, and well-being. 8

Two important consequences follow from a cost-benefit view of standards. First, the distinction between "scientific" and "arbitrary" standards turns out, upon closer examination, to be untenable. No standard or norm can be established on purely scientific or technical grounds (even assuming that a consistent body of relevant and well-tested knowledge is available, which is by no means the usual case in the health and envirommental fields), any more than social goals can be deduced from factual propositions. On the other hand, no standard is actually set in a purely arbitrary fashion, that is to say, without some implicit or explicit evaluation of benefits, costs, and risks.

This brings us to the second point. Standards are set all the time, in the most varied fields of human life and activity. Each of them represents, as I have already indicated, a particular value of a cost-benefit ratio whose terms, in the numerator and the denominator, can be identified with reasonable precision in any specific case. Of these terms, those relating to cost can normally be quantified without too much difficulty, although there may be some uncertainty concerning the appropriate discount rate for capital. Hence, given the particular value $s_{0}$ that has been chosen by the responsible authorities, we can, in principle and often also in practice, solve the equation

$$
s_{0}=f(C / U),
$$

for $U$, in order to get the utility implicitly attached to life, to health, or to whatever other value the standard is supposed to protect.

\footnotetext{
${ }^{8}$ This part of the discussion relies heavily on sections of my paper "The Feasibility of Social Policies," Policy Sciences, forthcoming.
}

${ }^{9}$ World Health Organization, op. cit., p. 11. 
Such calculations have been performed, for instance, in the field of traffic safety, 10 and there is no reason why they cannot be replicated in the health and environmental sectors. Making these valuations explicit can produce consequences of practical significance: a) the decision maker becomes aware of the opportunity costs of setting standards at different levels; and b) it helps to bring the problem of the mutual consistency of different standards--both at the national and at the international level--at least one step closer to a rational solution.

With the proliferation of standards and administrative rules of a similar character, the question of consistency is becoming important and deserves much more attention and systematie investigation than it has received so far. In any given country, one can find enormous variations in the implicit valuations of life and health that are embedded in official and semi-official standards, both over time and across different fields of activity. For instance, in the United States during the Second World War the officers responsible for setting design standards insisted upon heavy armor for bombers, which in turn required larger aircraft. Subsequent analysis revealed that the requirements implied values of several million dollars per life saved. By contrast, in the late sixties, military aircraft were designed almost without any regard to vulnerability, with an implicit value for human life fairly close to zero. Similar variability has been found in the implications of uS Federal Aviation Agency regulations for airline safety, in safety features of highway design, and in public health programs.11

Internationally, the discrepancies are even more striking. A good example here are the standards for maxium concentrations of vinyl chloride monomer (VCM) in industrial plants. The first restrictions--500 parts per million (ppm) in the US and UK--were imposed not because of VCM's toxicity, but rather because of its inflammability. After strong indications began accumulating that VCM may be carcinogenic, and the discovery of a causal link with acro-osteolysis (an apparently reversible disease affecting the skin and bones of toes and fingers), the upper limit was set at $200 \mathrm{ppm}$ in the UK, while the value of 500 ppm remained in force in the United States. In Germany, on the other hand, a maximum workplace concentration of $100 \mathrm{ppm}$ was established on the basis of research carried out at Dow Chemical Co. On the very same scientific evidence, Dow itself set its standard at $50 \mathrm{ppm}$, as early as 1961.12

10 Good examples can be found in H. Levy-Lambertand H. Guillaume, La Rationalisation des Choix Budgetaires, Paris: Presses Universitaires de France, 1971, especially chapters 5 and 7. Also see M. Jones-Lee, "Valuation of Reduction in Probability of Death by Road Accident," Journal of Transportation Economics and Policy, Vol. 3, 1969, pp. 37-47.

${ }^{11}$ Cf. Martin J. Bailey's comments on T.C. Schelling's "The Life You Save May Be Your Own," Public Expenditure Analysis, S.B. Chase Jr. ed. Washington D.C.: The Brookings Institution, 1968. Also, C.J. Hitch and R.N. McKean, The Economics of Defense in the Nuclear Age, op. cit. p. 196; H. A. Thomas, Jr., "The Animal Farm: A Mathematical Model for the Discussion of Social Standards for Control of the Enviroment," The Quarterly Journal of Economics, February 1973.

12 L. McGinty, "Science Paused and 17 Died," New Scientist, 13 June 1974, pp. 675-676. ( $I$ owe this reference to the kindness of Mrs. Gillian Kelley of IIASA.) 


\section{SOME GENERALIZATIONS}

The cost-benefit approach to standard setting represents a significant improvement over current practices. It is not, however, the most general approach to problems of this kind, as has been sometimes asserted. 13

Generalizations can be pursued along different lines. I shall mention here the two extensions of the basic cost-benefit framework that appear most interesting to me, even though the practicality of the first proposal is open to serious doubts, given our present level of knowledge.

The technique of cost-benefit analysis is always applied in the context of a partial equilibrium model. The calculations of the costs and benefits of the consequences of a particular alternative are performed under the assumption that the wider economic and institutional environment remains essentially unaffected by the decision. This assumption is often quite unrealistic. One could, therefore, try to extend the cost-benefit approach to standard setting, by operating with a general equilibrium model which includes also an environmental and health sector. A.V. Kneese and R.C. d'Arge have, in fact, attempted to examine the problem of environmental standards in the setting of a general equilibrium model. They have been able to derive explicit environmental standards via taxes on final products in such a way that, in principle, the externalities due to environmental pollution could be eliminated, while assuring that the Pareto optimum conditions are met everywhere in the economy. 14

The analysis is based on the assumption of competition, with consequent satisfaction of the Pareto conditions (prices equal to marginal social costs) throughout the economy, except for environmental services. While it would be possible, at least in principle, to extend the model by adding the health services, it must be admitted that we do not know enough about the nature of the production functions and of demand-supply relationships holding in the health sector, to make the approach feasible at present. Moreover, the model would not be applicable in countries where the provision of health services has been wholly or partially divorced from the working of the price mechanism and where, as a consequence, the Paretian value judgment has been, in fact, rejected. Thus, even if the numerous efforts now under way to develop econometric models of the healtin system, were to produce practically relevant results in the near future this would not be of much assistance for thẹ kind of generalizations I have been discussing.

A different, and pragmatically more significant, generalization can be achieved by viewing the process of standard setting as a particular type of decision making under uncertainty. As a matter of fact, many environmental standards are expressed in what are essentially probabilistic terms. Air and water quality standards prescribe maximum permitted values for long-term mean concentrations, together with provisions to the effect that the average concentrations over shorter periods must not exceed given levels with more than a certain frequency. For instance, the primary air quality standards for the protection of public health set by the US Environmental Protection Agency on April 30, 1971, put the upper bounds for sulfur oxides at $80 \mathrm{mg} / \mathrm{m}^{3}=0.03 \mathrm{ppm}$ for the annual arithmetic mean, and at $365 \mathrm{mg} / \mathrm{m}^{3}=0.14 \mathrm{ppm}$ for the maximum 24-hour concentration not to be exceeded more than once per year.

\footnotetext{
${ }^{13}$ See, for instance, A.J. Culyer, R.J. Lavers, and A. Williams, op. cit.

${ }^{14}$ A.V. Kneese and R.C. d'Arge, "Pervasive External Costs and the Response of Society," in the Analysis and Evaluation of Public Expenditures: the PPB System, Washington D.C.: US Government Printing Office, 1969, Vol. 1, pp. 87-115. Also, A. Myrick Freenan III, R.H. Haveman, A.V. Kneese, The Economics of Environmental Policy, New York: John Wiley and Sons, 1973.
} 
Water standards have to be met under the average minimum flow for a consecutive period of time (usually one week) to be expected once in every ten years, etc.

Moreover, in the case of certain air pollutants--e.g. carbon monoxide, hydrocarbons, nitric oxide, nitrogen dioxide, nitrogen oxides, oxidant, and sulfur dioxide--statistical distributions of average, median, and maximum measured concentrations have been calculated. 1.5 These estimates allow one to calculate how often the concentrations will exceed given levels, and hence to assess the risk that the concentration temporarily rises to dangerously high levels.

There are many ways of structuring the uncertainty surrounding the process of standard setting. The examples just given suggest a formulation of the problem in terms of a chance-constrained programming model.16

Let $\mathrm{x}_{1}, \mathrm{x}_{2}, \ldots, \mathrm{x}_{\mathrm{n}}$ be decision variables that can be manipulated to attain specified levels of quality standards $s_{1}, s_{2}, \ldots, s_{m}$.

In a case of water pollution control, for example, the standards may express (perhaps in an aggregate way) different characteristics of water quality, such as dissolved oxygen concentration, coliform bacteria density, taste and odor, temperature, radioactivity, and so on. Denote by $a_{i j}$ the effectiveness of $x_{i}$ with respect to $s_{j}$ If the required levels of the $s_{j}$ are stochastically determined-e.g. because of stochastic variations in stream flows, waste flows, weather conditions--one possible version of the standard-setting problem is the following:

$$
\text { minimize } \quad w=\sum_{i=1}^{n} c_{i} x_{i} \text {, }
$$

subject to

$$
\begin{gathered}
\operatorname{Pr} \underset{i=1}{\left(\sum_{i}^{n} a_{i j} x_{i} \geq s_{j}\right)} \geq \pi_{j}, \\
x_{i} \geq 0, i=1, \ldots n ; \quad 0 \leq \pi_{j-1}<j=1, \ldots m,
\end{gathered}
$$

\footnotetext{
${ }^{15}$ For more details, see S.A. Gustafson and K.O. Kortanek, "Mathematical Models for Air Pollution Control: Determination of Optimum Abatement Policies," in Models for Environmental Pollution Control, R.A. Deininger ed. Ann Arbor, Mich.: Ann Arbor Science Publishers, Inc., 1973, ch. 13.

16

To the best of my knowledge, no application of chance-constrained programming methods to standard setting has appeared in the literature, although R.A. Deininger has apparently discussed the relevance of this model in an unpublished doctoral dissertation. Deterministic optimization models for standard setting have, however, been considered; see, for instance, the review paper by W.o. Spofford, Jr., "Total Environmental Quality Management Models," in Models for Environmental Pollution Control, op. cit., ch. 19 and the Gustaf son-Kortanek paper mentioned in the preceding note.
} 
where Pr stands for probability and $c_{i}$ is the unit cost associated with decision variable $x_{i}{ }^{17}$ Using a zero order decision rule (a11 the $x_{i}$ values are assigned ab initio), the problem can be immediately reformulated in a deterministic equivalent version. Let $F_{j}$ be the distribution function of the population from which the values of $s_{j}$ are sampled. Then $F_{j}^{-1}\left(I_{j}\right)$ is the $I_{j}$-fractile of $s_{j}-$-i.e. $\operatorname{Pr}$ $\left(s_{j} \leq F_{j}{ }^{-1}\left(\pi_{j}\right)\right)=\pi_{j}$--and we get the equivalent 1 inear programming problem:

$$
\operatorname{minimize} w=\sum_{i=1}^{n} c_{i} w_{i}
$$

subject to

$$
\begin{aligned}
& \sum_{i} a_{i j} x_{i} \geq F_{j}^{-1}\left(I_{j}\right), \\
& x_{i} \geq 0, i=1, \ldots, n .
\end{aligned}
$$

The dual version of the problem is particularly significant for the logic of standard setting:

$$
\operatorname{maximize} z=\sum_{j=1}^{m} F_{j}^{-1}\left(I_{j}\right)_{j},
$$

subject to

$$
\begin{aligned}
& \sum_{j=1}^{m} a_{i j} y_{j} \leq c_{i}, i=1, \ldots, n \\
& y_{j .} \geq 0, j=1, \ldots, m .
\end{aligned}
$$

The optimal $y_{j}$ values represent the evaluations imputed to the risk indicator or $\pi_{j}$ or, rather to the corresponding fractile. Like the w value for the objective function in the primal problem the $z$ value in the dual is expressed in monetary terms (if the costs are so calculated).

${ }^{17}$ In the water pollution control example, $x_{i}$ could be the amount of waste removed per day in pounds of BOD; $c$, would then be the cost of removal of $x_{i}$. In fact, two more suffixes should be attached to the variables and coefficients of the model to indicate the source of pollution and the point at which the measurement is made; the $a_{i j}$ would represent "transfer coefficients." Given the purely suggestive nature of the present discussion, complete rigor seems out of place. For the same reason, I do not enter into details concerning such practically important issues as the scaling of the quality standards. 
But while the $c_{i}$ refer to treatment costs (or to the cost of whatever actions are needed to attain a given quality standard), the $F_{j^{-1}}^{-1}\left(\Pi_{j}\right.$ ) refer to the fractiles needed to ensure satisfaction of the corresponding quality standard with the preassigned probability $\pi_{j} .18$

The chance-constrained programing model is, of course, linear. The linearity as sumptions hold, for instance, for constraints based on models for dissolved oxygen of the Streeter-Phelps type, but certainly not in many other situations. When serious non-linearities are present, it may be preferable to incorporate the quality standard constraints in the objective function via a penalty function approach. 19

\section{ALTERNATIVES TO STANDARD SETTING}

A qualitatively different type of generalization is introduced in the discussion by asking whether standards are really needed, or are the best way, to achieve a given policy goal. The possibility of regulating essential aspects of social life by administrative rules appeals strongly to the rationalistic bias of the social planner. To him, standards and norms are, in the words of a recent United Nations publication, "an element of quantitative precision in the determination of the goals and means of social policy."20 However, serious doubts have been raised concerning the possibility of coping, by means of standards and administrative regulations, ${ }_{21}$ with the technological and organizational complexities of today's health systems. 21

The conceptual difficulties and ambiguities inherent in the use of standards as indicators of needs have already been discussed in the first part of this paper. As rules of action or policy constraints, standards and norms tend to replace policy objectives in the minds of health planners. There are also serious problems connected with the inflexibility of standards (their formal codification introduces essential discontinuities in the decision process), their excessive uniformity, and the frequent uncertainties about the legal and administrative means of enforcement 22 with a corresponding uncertainty about implementation costs.

The effectiveness of standards as tools of control can also be questioned. Because of socioeconomic growth and technical innovations, standards quickly become obsolete, and thus useless as a device to measure the discrepancy between goals and achievements. If, on the other hand, they are revised frequently, they Iose one of their main advantages, namely that of providing the health planner and the administrator with fixed reference points and benchmarks.

${ }^{18}$ The close connection between chance-constrained programming and cost-effectiveness has been pointed out by A. Charnes, W.W. Cooper, and G.L. Thompson, "ChanceConstrained Programaing and Related Approaches to Cost Effectiveness," Pittsburgh: Carnegie Institute of Technology, Graduate School of Industrial Administration, Management Sciences Research Report No. 39, April 16, 1965.

${ }^{19}$ As As suggested, for instance, by W.0. Spofford, Jr., op. cit.

${ }^{20}$ United Nations European Program for Social Development, Rapport du Groupe d'Experts sur les Methodes Utilisées pour la Détermination des Normes dans la Planification des Secteurs Sociaux, New York: SOA/ESPD/1, 1972, p. 14.

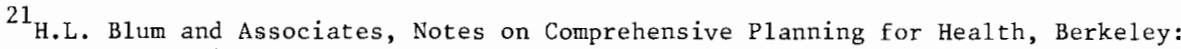
School of Public Helath, U. of Calif. 1968, p. 433.

${ }^{22}$ See, for instance, E.J. Cleary, The Orsanco Story, Bâltimore: The John Hopkins University Press, 1967, especially pp. 56-59. 
When the standard applies to a variety of more or less autonomous agents, the problem of control merges into that of devising suitable incentives, so that the agents will be motivated to adopt types of behavior that are compatible with overall policy objectives. Many standards have built into them features that make their implementation particularly costly, in monetary and/or psychological terms, for the target group whose behavior they attempt to modify. Safety standards provide many examples of built-in disincentives. Industrial safety standards often make the accomplishment of certain tasks so difficult or disagreeable that the operatives have strong incentives to disregard them.

A law requiring every car owner to install expensive safety devices essentially levies a tax to promote the purchase of certain types of safety equipment. Some car owners may have preferred to economize on these devices, perhaps using the savings to purchase a new--and safer--automobile more frequently than would be possible if everybody is forced to invest heavily in safety devices. 23 Similarily, it can be shown that some building standards may actually lower the overall quality of the housing accessible to lower income groups. Again, consider the requirement that all cars be equipped with devices to reduce the level of pollutants escaping from the engine. If the devices shorten the life of the engine and require frequent repairs, car owners have incentives to make the devices ineffective.

The point I wish to make is that standards are not ends in themselves, but only one of many tools that can be used to accomplish particular policy objectives. The spectrum of possibilities ranges from outright prohibition of certain types of activities or behaviors that are considered particularly harmful in individual or social terms, to the provision of a system of penalties and rewards that essentially leaves the final choice to the responsibility, and self-interest, of each decision maker. 24 Standards, administrative regulations, and direct public action should be viewed as discrete, intermediate stages along an essentially continuous spectrum.

Each of these alternatives presents advantages and disadvantages that should be carefully assessed before deciding in favor of a particular solution. In fields as complex as health and environmental control, important policy objectives can probably be achieved only by a mixture of approaches. While the weights to be attached to each element in the combination will probably depend, to a large extent, on the institutional framework in which the decisions are taken, it does not seem wise for any decision maker to rely only on the more direct forms of regulation.

I have restricted my critical remarks to the problem of standard setting because too much faith is put, especially by health planners, in this particular policy tool. Only by dispelling the mystique that surrounds the standard setting process can we rationally evaluate its benefits and costs, both internally and with respect to alternative approaches. The question of the mutual consistency of different standards; the reasons for the significant international differences in standard setting that persist, even when there is a substantial agreement on the scientific data base; the design of flexible standards for systems subject to large stochastic variations; the assessment of policing costs, and of the

${ }^{23}$ H. Demsetz, "Contracting Cost and Public Policy," in The Analysis and Evaluation of Public Expenditures: The PPB System, op, cit., vo1, pp. 169-170. Vo1. 1,

24 F For a good discussion of the role of incentives at every stage of policy making, see C.L. Schultze, "The Role of Incentives, Penalties and Rewards in Attaining Effective Policy," in the Analysis and Evaluation of Public Expenditures: The PPB System, op. cit. 
distributional and efficiency consequences of standards; ${ }^{25}$ public participation in the standard setting process: these are only some of the many interesting problems that nave yet to be systematically explored. However, a necessary prerequisite to any meaningful analysis is the clear realization that standards are neither arbitrarily set, nor uniquely determined by scientific and technical considerations. They represent, rather, socioeconomic decisions whose far-reaching consequences we are only now beginning to appreciate.

25 For example, it has been argued that the emission standards for coal burning power plants set by the US Environmental Protection Agency in 1971, may cause a massive shift to low-sulfur coal in the very near future. It is also possible that utilities may shift to low-sulfur oil and natural gas in order to meet the standards; cf. C.R. Aleta, "A Critique of the New EPA Emission Standards for New Stationary Sources," Ithaca, New York: Cornell Energy Project, Paper no. 71-11, 0ctober 1971. It is clear that a switch to low-sulfur fuels would compound the already serious problem of supply of these fuel sources, but the full implications of these developments, in terms of economic efficiency and even of redistributional effects remain to be worked out. 
Remarks of the Discussant, Mr. Gros

Mr. Majone's paper suggested to Mr. Gros a number of problems in the setting of standarus:

i) the difficulty in catering to uncertainties. The usual phenomenon we observe in standard-setting as further information dispels uncertainty is a tightening of standards. Assuming that mean estimated hazard remains constant, one would expect more stringent standards earlier when the uncertainty is higher;

2) the conflicts of interest among agencies that often have significant impact ufion the standards derived;

3) the observation of Starr that public acceptance of risks is variable. People are more willing to take risks voluntarily upon themselves than they are willing to accept risks exogenously imposed. Advertising campaigns can increase acceptance of reasonable risks;

4) the methodological difficulty in setting separate standards for pol1utants whose chief harm comes through synergistic effects; and

5) the delicate question of whose utility functions should be consulted and used for guidance.

\section{Comments upon Standards}

Conference participants offered a number of reactions to the points brought forward by Mr. Majone:

1) that standards are not scientifically determined and, perhaps, cannot be;

2) that the many considerations for appropriate standard-setting require a good comrinuications system and the application of systems analysis to tailor standards to specific environments;

3) that attitudes toward standards may reflect sociological attitudes toward rules and authority generally;

4) that enforcement costs must be considered. The unenforced standard is no standard;

5) that certain phenomena may not be appropriate for regulation via standards. The new US policy of reviewing all treatments applied to patients raises such questions as whether it makes sense to apply standards to tonsillectomies; and

6) that flexible standards have drawbacks. One member felt that the flexible standard is no standard and that Mr. Majone had been insufficiently meticulous in considering this point.

\section{Responses by Mr. Majone}

Mr. Majone agreed upon the importance of enforcement and of tailoring standards to specific environments. He pointed out that the methodological and philosophical difficulties of assigning utility to the human life has plagued the setting of standards. Mr. Majone characterized standards as one important policy tool for dealing with the complexity of the world and its systems. The simplicity of standards in relation to alternative policy levers enhances their utility. 



\author{
HEALTH CARE \\ DELIVERY SYSTEM \\ WITHOUT PHYSICIANS
}

\author{
D. Koch-Weser \\ Harvard University Medical School, \\ USA
}

\title{
INTRODUCTION
}

At the present time both need and demand for health care delivery clearly exceed the available health manpower in the developing, but also the developed countries. And that is true, even though most health care delivery systems do not provide for equitable distribution, both economical and geographical, of health services. This leaves significant parts of the population needing, but unable to demand, medical attention.

The consumer has received increased knowledge from development programs in literacy and general education, as well as the greater availability of communication media, printed material, radio, and television. One must expect therefore, that the demand for health services will progressively approximate the needs in the underserved and underprivileged populations in all countries.

Generally great reliance is placed on the physician as the provider or, at least, as the leader of the effort to provide adequate services. But even if physicians seriously accepted this challenge, they by themselves could not satisfy the increasing demand, unless the number of medical graduates--in most cases publicly supported during their studies--would be drastically augmented. Many societies do not have the economic resources to accomplish that. And, even if these resources could be applied, economists and health planners are becoming more and more doubtful if, from the cost-effectiveness point of view, physicians are acceptable as the sole or even principal health care providers.

Increasing attention is given to the possibility of transferring most of that responsibility to auxiliary health professionals. So far, however, it is not yet clear how much education and training these require and how many of the health care delivery functions they can perform satisfactorily. Consequently, no really valid cost (of their formation)-effectiveness (of their performance) analyses have been made. Considering the magnitude of this problem for health care policy throughout the world careful systems analytical studies are a prerequisite for implementation of health services compatible with the economic reality in many societies. And this applies to almost all countries, since underprivileged, underserved population groups exist also almost everywhere.

One difficulty of doing such an analysis is caused by the fact that as a rule the health care delivery programs using auxiliary health workers do not stand by themselves. They are, rather, part of physician-oriented activities, in which it would be difficult, if not impossible, to separate the actions and, therewith, the effectiveness of both.

One exception to this rule might be the Kingdom of Nepal. ${ }^{\star}$ It has such a dearth of physicians (one for every 35,000 people, and $95 \%$ of them in the capita1 and a few other urban centers) that for all practical purposes they do not participate in the health care outside these centers.

\footnotetext{
*The information about Nepal was collected during two visits by the author to that country, one of them as a WHO-consultant, as well as from discussions and correspondence with Nepalese graduate students in the health sciences in Boston.
} 
For that reason this country was chosen for an investigation of the possibility of developing a health care delivery system almost entirely without physicians. Such a system then would lend itself very well to a systems analytical approach, because it would be relatively uniform throughout the country--leaving the capital out--and the health care would be essentially delivered only by the health workers to be studied. Many of the results--for instance, a correlation of education and training level with job performance--would have validity for other settings.

\section{NEPAL--GENERAL INFORMATION}

Nepal, a landlocked nation on the foothills of the Himalayas, covers slightly more than $150,000 \mathrm{~km}^{2}$, and borders in the south, east, and west on India and in the north on the People's Republic of China. There are roughly three different geographical regions:

1) The mountainous north, the Himalayan plateau, relatively sparsely populated with small patches of subsistence agriculture, suffers an almost arctic climate. The population is of largely Tibetan origin.

2) The central part, the midlands, or "Mahabharat," consists of fertile plains, cut by deep river valleys, well-populated, with intensive agricultural production in a mostly temperate climate. In the center of the midlands lies the capital, Katmandu, in the valley of the same name, densely populated and intensely cultivated. The relatively few industries are located here, as well as essentially all cultural and historical buildings.

3) The south, "Tevai" or "Siwaliks," consists of tropical rain forest, jungles with tropical animals and plants and also tropical agriculture.

The populations of the midlands and the south are mostly of Indian and Burmese origin, making the Nepalese population of about 11 million people a mixture of languages, religions, and customs.

Eighty percent of the rainfall occurs between June and September, cutting off most of the always inadequate transportation (there are only about $1,000 \mathrm{~km}$. of hard-surfaced all-year-round roads). This creates serious complications for commerce, government services, and also health services. Housing in general, outside of Katmandu, is crowded and usually without ruming water and sewers; clean community water supply is rare, but increasing. Nevertheless, though isolated from the rest of the world until about 1950 , Nepal has since made considerable strides toward modernization.

\section{COMPARATIVE DATA OF NEPAL, THE US, COLOMBIA, AND CUBA}

To make some general statistical data for Nepal more meaningful and to put them into perspective, they are presented together with those from three other countries, widely differing in stage of development and socio-economic-political structure.

Analyzing the data in Table 1 , one recognizes that although Nepal has the highest birthrate, it maintains a moderate population growth rate, because the death rate--mostly due to an extremely high infant mortality--is still twenty-two per thousand. Colombia, reporting a low death rate, in spite of a relatively high infant mortality, has the most marked population growth, while Cuba's birth and death rates have both decreased significantly in the last decade. 
Table 1.

Nepal US Colombia Cuba

$\begin{array}{lcccc}\text { Birth rate/1,000 } & 40 & 15 & 38 & 27 \\ \text { Death rate/1,000 } & 22 & 9 & 11 & 10 \\ \text { Population Growth/year } & 1.95 \% & .8 \% & 3.2 \% & 1.7 \% \\ \text { Infant mortality/1,000 } & 200 & 20 & 80 & 35\end{array}$

Table 2 shows, as a consequence of the high birthrates, a large percentage of people under fifteen (and thus economically dependent and needing economically unproductive services) in Nepal and Colombia. The striking differences in GNP/ capita are naturally translated into enormous differences in health expenditures/ capita. It seems noteworthy, however, that as a percentage of GNP Nepal only spends one tenth the US amount for health, probably due to higher priorities given to different overwhelming needs.

Table 2 .

Total population (in millions)

Percentage of population under 15 years

Population density $/ \mathrm{km}^{2}$

GNP/capita (in US\$)

Health expenditures/capita (in US\$) .51

Health expenditures/GNP

Nepa 1 US

11

$42 \%$

80

70

$$
5,500
$$

400

$7.3 \%$

$.73 \%$

$27 \%$

\begin{tabular}{cc} 
Colombia & Cuba \\
\hline 22 & 9 \\
$47 \%$ & $37 \%$ \\
15 & 69
\end{tabular}

350

7

$2 \%$

The present and Euture physician manpower figures on Table 3 reveal a negligible number in Nepal with no relief in sight. This is due to the absence of a medical school and to the intolerable cost of sending a significant number of medical students for training to foreign countries. Colombia is a country in which the need for health care delivery is greater than the felt need. This is attributable 1) to poor education and ignorance in health matters of a large part of the population, and 2) to the inability--even of those who are aware of the need--to reach and purchase health care. Colombia, therefore, does invest in and put more emphasis on other development programs. Cuba, after a heavy loss of physicians due to emigration, is rapidly recuperating and surpassing its previous physician per population ratio. During the past years Cuba graduated proportionately twice as many physicians as the US, which, however, is now also rapidly increasing the number of physicians. Of great significance for equitable health care delivery planning is the fact that only cuba has been able to move a considerable number of physicians out of the urban areas. 
Table 3 .

Nepa1 US Colombia Cuba

$\begin{array}{llccc}\text { Physicians } & 317 & 250,000 & 9,900 & 8,550 \\ \text { Population/Physician } & 35,000 & 800 & 2,200 & 1,200 \\ \text { Physicians in Urban Areas } & 95 \% & 88 \% & 90 \% & 49 \% \\ \text { Medical School Graduates/Year } & \text { ca. } 25^{*} & 10,000 & 500 & 800 \\ \begin{array}{l}\text { Population/ } \\ \text { Medical School Graduates/Year }\end{array} & 450,000 & 20,000 & 44,000 & 10,600\end{array}$

* Return from foreign countries

These data indicate that the infrastructure, economic situation, demographic distribution, and present as well as future physician manpower all combine to put Nepal in a disadvantaged position. Nevertheless, its government, its planning commission, and its health planners, and educators have begun an energetic, original, and imaginative effort to overcome these difficulties and to organize a health care delivery system, modest, but increasingly effective under the difficult circumstances.

\section{PRESENT HEALTH SERVICES STTUATION}

A. Health care programs in Nepal are administered and delivered by six separate, categorical services with considerable, though varying, success.

1) Malaria. The malaria eradication program almost certainly has been the most successful, reaching essentially all six million people living in malarious areas. The program is expected to enter the "maintenance phase" shortly, which will bring about a reduction in the health manpower requirements for this particular program.

2) Leprosy: In the absence of an infrastructure of uniformly distributed basic health services to provide long-term treatment and follow-up, some progress has been made only in two zones (Bagmati and Narayani) around major centers.

3) Tuberculosis. Even though this disease is one of the two or three main causes of morbidity and mortality in the country, its control program hardly extends beyond the Katmandu Valley. It consists of more or less sporadic and uncoordinated $B C G$ vaccination programs and clinical services, many of them delivered by private charitable organizations and missions.

4) Smallpox. The smallpox vaccination program, sustained by an effective cadre of well-trained "vaccinators," has made considerable gains. It is expected that within the present five-year plan (until 1975) more than $80 \%$ of the population will be vaccinated, probably above the critical level for effective control. 
5) Maternal and Child Health (MCH) / Family Planning. The MCH/FP program in the past five years (during the third five-year plan) has made considerable strides forward. Sixty MCH/FP Centers were opened in the twenty-five districts. Many of them are separated (also with different staffing) from the health posts and district hospitals. While the FP activities are more or less continuous in these MCH/FP Centers, MCH clinics are held in most instances either weekly or bi-weekly, leaving the facilities under-used most of the time. Many patients with acute problems are being treated both in the health posts and the MCH clinic, in an uncoordinated fashion and with separate record-keeping. All health workers on the local level deplore this situation and feel that integrated services would be clearly preferable. In general there cannot be much doubt that the $\mathrm{MCH}$ component in this program plays a secondary role. This policy of stressing the FP component to the detriment of the $\mathrm{MCH}$ component is being abandoned; it is recognized that in Nepal, as in most societies, FP and limitation of family size is only accepted if an improved quality of life--including better health--is assured the other children and therewith the parents in their old age. For that reason FP activities are being integrated with $\mathrm{MCH}$ programs or, whenever possible, with general preventive and curative services.

6) Curative services. Health posts and hospitals dispensing predominantly curative services have increased considerably during the past decade. However, this increase has taken place primarily in the Katmandu Valley and in a few other more populous areas and more prosperous urban areas, making "the facilities for curative services in other parts of the country negligible."

B. These health care programs are mainly staffed by the following categories of health manpower (Table 4).

Table 4. Health manpower in Nepal.

Dentists

Nurses

Asșistant Nurse-Midwives

Auxiliary Health Workers

Ayurvedic Physicians

Sanitary Engineer

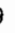

$$
1,222,000
$$$$
61,000
$$$$
43,000
$$$$
20,000
$$$$
<90,000
$$

1

$11,000,000$ 
Peons, Sweepers. The number of these low level, poorly educated or illiterate individuals who, however, perform often useful auxiliary functions in practically all health posts, health centers, MCH/FP clinics and hospitals, cannot be estimated. They often have worked for a long time in the same place and know people, their social and sometimes medical histories, and local conditions better than the professional and semi-professional staff.

Health Aides and House Visitors. It was impossible to determine the exact number of these health workers who, at present, perform a valuable service maintaining continuous patient contact in the various categorical services. With only elementary school training of two to three years, they then undergo three to six month's training aimed almost exclusively at the services they (men and women) are to perform in the specialized program. They then become, for instance, malaria house visitors, spraying insecticide, making blood smears, taking temperatures, and dispensing drugs; or sma11-pox vaccinators, vaccinating and detecting new cases; or family planning motivators, convincing couples to accept family planning and dispensing drugs; or tuberculosis or leprosy workers, following up on drug-taking and defaulters. They make numerous house visits, often walking considerable distances between houses.

The Nepalese government with the help of wHo is at present testing in two areas the feasibility of combining these separate services, transforming the house visitor into a multipurpose primary preventive and curative care deliverer. It will be necessary to compare carefully this alternative with the still-operating categorical program to determine if 1) the decrease in the total number of house visits, 2) the decrease house to house walking time, and 3) the possibly greater acceptance by the consumers make up for the necessity of longer training and perhaps lower efficiency in each activity.

Auxiliary Health Worker (AHW). Admitted to the AHW School in Katmandu after finishing the tenth year of schooling, these men, and in the last two years also women, receive two years multi-disciplinary training, enabling them to perform basic curative and preventive services, as we11 as health education at the community level (Table 4).

Assistant Nurse Midwives (ANM). Three ANM schools, not in Katmandu but in three sma1ler towns in distant "zones," are giving a two-year course to women after eight years of schooling (Table 4). The course is multi-disciplinary with strong emphasis on preventive medicine and public health. Because training facilities for maternity care are insufficient in the provincial towns, midwifery is taught on an interim basis to the ANM candidates in a special course in the School of Nursing in Katmandu. This destroys the advantages of the training in the rural setting, and too many ANM's remain in curative services in the capital instead of providing rural primary care.

Nurses. The nursing school in Katmandu accepts women after ten years of schooling and gives them four years of training in a "university" course leading to a "certificate." Though preventive medicine, public health, and midwifery are included, the training is strongly oriented toward curative, hospital-based medicine. Most of the 160 graduated nurses in Nepal work in hospitals in Katmandu. slightly more than twenty work as public health nurses in government services, the great majority in the Katmandu Valley.

A mission hospital, Shanta Bawan, using essentially the same prerequisites and curriculum, has graduated so far approximately twenty nurses (Table 4 ).

Physicians. 317 Nepalese graduates from foreign medical schools 1ive in Nepal (Table 4). Many others have succumbed to the brain drain and have not returned to their homeland. Even though 272 are in government service, almost all have in addition a private practice in Katmandu and in a few other prosperous urban centers. Fewer than twenty work or live in rural areas. 
Most of the physicians one does meet in the country outside of Katmandu--principally in the Bagmati zone surrounding the capital (Table 5)--are al1 waiting for the first opportunity to return to the capital where, as a rule, they left their family. In addition to the attraction of city life, one must also agree that the type of training, and consequently the interest predominantly in specialized curative medicine, make activities in the large and well-equipped hospitals much more desirable. The exceptions are a few physicians who received special training in public health and who provide new ideas and effective leadership to the health care system.

Table 5 .

\begin{tabular}{lr} 
Physicians/100,000 population \\
in Katmandu & 50 \\
in Bagmati & 15 \\
\hline in Nepa1 & 2.5 \\
in US & 125
\end{tabular}

Ayurvedic Physicians and Practicioners. There is an uncertain, but probably large, number of traditional Ayurvedic practicioners--either self-educated or trained in a "non-academic" setting--who, under the circumstances provide valuable services. Additionally there are Ayurvedic physicians trained in "university controlled" courses on three levels:

1. The "Achavva" obtain their rank after six years of training, including one year internship in the Ayurvedic hospital. This rank is considered equivalent to a physician. More than 122 have graduated so far (Table 5).

2. The "Shastri" study three years.

3. The "Madhvama" study two years.

Al1 three ranks practice separately from the "western" physicians in 82 Ayurvedic dispensaries, many in remote areas, and in one hospital in Katmandu.

C. The programs staffed by these health workers are located in the following health facilities:

1. A large number of health posts constitute the home bases for the house visitors in the categorical programs. The health post also serves as a referral for the house visitors for emergency and primary care. Staffing of the health posts should be by one ANM and/or one AHW, if available. The health post is a strictly ambulatory facility.

2. Nepal is divided into 75 development districts. Each should have a district health office with a few beds for emergency care. originally it was planned to have two primary care physicians (a total of 150, one half of the Nepalese physician manpower) in these offices, but, under the present circumstances, auxiliary health workers do a very good job. 
3. The fourteen zones should each have a well-equipped inpatient and outpatient zonal health office. Not all are established yet, and staffing and quality varies considerably in the existing ones.

4. The ultimate reference center should be the Central Health Office in Katmandu, which can use the various highly sophisticated and specialized hospitals and other health facilities in the capital.

This plan for a network of health facilities, increasing in skill and sophistication from the house visitors to the specialized hospital in Katmandu is very good. It was the feeling in Nepal that the health facilities could be obtained, the health programs organized, but that the health manpower training was the highest hurdle.

\section{PRINCIPAL PROBLEMS}

A. The ratio of health care personnel to population is extremly low. For the effective delivery of basic health services, perhaps more damaging than the low ratio of physicians to population $(1 / 35,000)$ is the that of nurses to population $(1 / 61,000)$, of ANM's to population $(1 / 43,000)$, and AHW's to population $(1 / 20,000)$.

B. Even if the teaching facilities could be built and the existing ones better utilized, the lack of sufficient qualified teachers would make it difficult to increase the health manpower rapidly. It would, however, certainly be more economical to train multi-purpose house-visitors, ANM's, and AHW's, than physicians and nurses.

C. The existing health manpower is concentrated in the Katmandu Valley and to a minor degree in a few other urban centers. More equitable and uniform distributicn of health services requires not only the creation of a health infrastructure, but also a general infrastructure of housing, transportation, schooling, agriculture.

D. There are not enough qualified candidates for health career training, and an unacceptable high number of drop-outs reduces the number of actual workers. One of the reasons for this seems to be the lack of continuity between the various training programs, the absence of a continuous "Health Career," and the feeling that each of the job categories represents a "dead end street" without the prospect of advancement.

E. The separation of curative and preventive services leaves the urgent ly needed preventive programs without prestige with the population and without attraction to the health workers.

F. The categorical, specialized, and relatively uncoordinated disease control programs waste scarce financial and manpower resources.

G. The absolutely necessary control of excessive population growth cannot be achieved without concomitant Maternal and Child Health services which should be part of a basic health care delivery system.

\section{PROPOSED SOLUTIONS OR PARTIAL SOLUTIONS}

In a country like Nepal, with severely limited resources and little prospect of increasing these resources, one cannot plan for a fully satisfactory health care delivery system and one must accept that, at least for the time being, 
many health problems will remain unsolved. One must, however, search for the best equitable solutions obtainable under the circumstances. These solutions, if implemented, should be systematically analyzed from the beginning, to find out if they are either successful and can be implemented elsewhere or unsuccessful and should be either modified or abandoned.

The ultimate goal is the establishment of a fully integrated basic health delivery system evenly staffed and available to all the people in Nepal. The health facilities organization presently adopted would serve this purpose well. It consists of a) the health posts in which, however, all curative and preventive services should be integrated, b) the district health offices in each of the seventy-four districts of Nepal, c) the zonal health offices in the fourteen zones of Nepal, and finally d) the central health services in Katmandu (Table 6).

Table 6. Flow chart of lines of responsibility and communication.

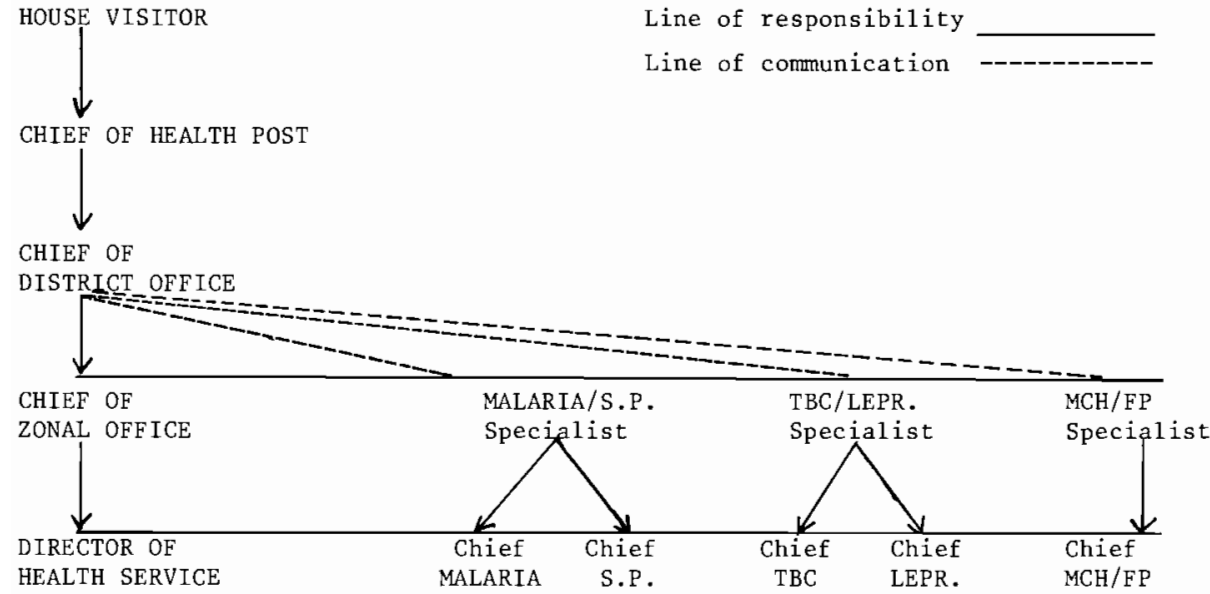

It must be recognized that job satisfaction and good attitude from auxiliary health workers can be expected only if a prestigious career can be offered to those who perform well and who want to make this a life job. The following careers should be established (Table 7).

Health Aides, (men and women) after a minimum of three years' elementary schooling, would be trained at the district and zonal level (on the job), for multi-disciplinary activities, principally as "House Visitors." The training would be given by the staff of the health post and the district level.

Assistant Laboratory Technicians, after seven years of schooling, would be trained in a vocational high school course in the most commonly used laboratory techniques, sufficient to perform principally at the district and perhaps zonal leve1.

Laboratory Technicians would take a two-year "university course" mostly in the Central Health Laboratory under the auspices of the University in Katmandu to become full-fledged Laboratory Technicians. They would enter this course either 
after ten years of schooling, or after having worked as Assistant Laboratory Technician.

Assistant Nurse-Midwives (ANM) would continue to be trained in the ANM schools, but in three years (after seven years of general schooling) which would be considered vocational high school education. Clearly the responsibility for this education must be borne jointly by high school authorities, who could not provide the professional training, however, and by the University in extension courses. Their training should be multi-disciplinary with emphasis on MCH/FP and midwifery, but also including the other disciplines of preventive and curative medicine.

Nurse-Midwives would continue to be trained in a "university course" of four years under the "Institute of Medicine." They should be graduated with a diploma. They would enter the course, oriented both toward curative and preventive medicine, either after ten years of general schooling or after having worked for two years as an Assistant Nurse-Midwife.

Public Health Nurses, Nurse Teachers, and Ward Sisters are three categories of great importance respectively for the development of conmunity services, training courses, and curative services. They would receive one year graduate training. Preferably this would be done in a crash program in Nepal or, if that is not feasible, abroad.

Senior Nurse Education, Senior Nurse Administrators, Senior Public Health Nurses, and Senior Clinical Nurse Specialists in small numbers for top level positions would take M.S. level courses abroad.

Assistant Health Workers (AHW), previously called Auxiliary Health Workers would be trained in the high school vocational system in a parallel fashion to the ANM's. As a matter of fact, much of the AHW's training, with exclusion of midwifery could be given in joint courses and exercises with the ANM's. It should be studied, if the training establishments for this new, but necessary, category should be located jointly with the established and planned ANM schools.

Health Workers would be trained in a two-year "university course" after ten years of general schooling or after having served as Assistant Health Workers. Their training should continue to be given in the present AHW school in Katmandu.

A six-months course for Senior Health Workers should be given in the same school as part of a continuous career for health workers.

Again, to make up for the probably continuing lack of highest level health professionals, courses should be offered of two years for Assistant Health Supervisors (preferably in Nepa1), and of two additional years abroad for Health Supervisors. This training should be multi-disciplinary aiming at the future leaders of the integrated basic health care system, but allowing some specialization in areas of preventive and curative medicine.

Training of Physicians, presently after ten years of schooling and after private colleges in Nepal or abroad, should continue in the same fashion in foreign countries. However, the governinent should also give support for this purpose to a number selected from those who have gone through health careers, who work in Nepal, and who have obtained a university degree in one of the health career fields.

The possibility to make a career should create prestige for the various auxiliary health workers and diminish the switch to other non-medical professions of these, for Nepalese standards, we11-trained individuals. Once these auxiliary health workers are trained in increasing numbers, they would be employed in the following fashion. 


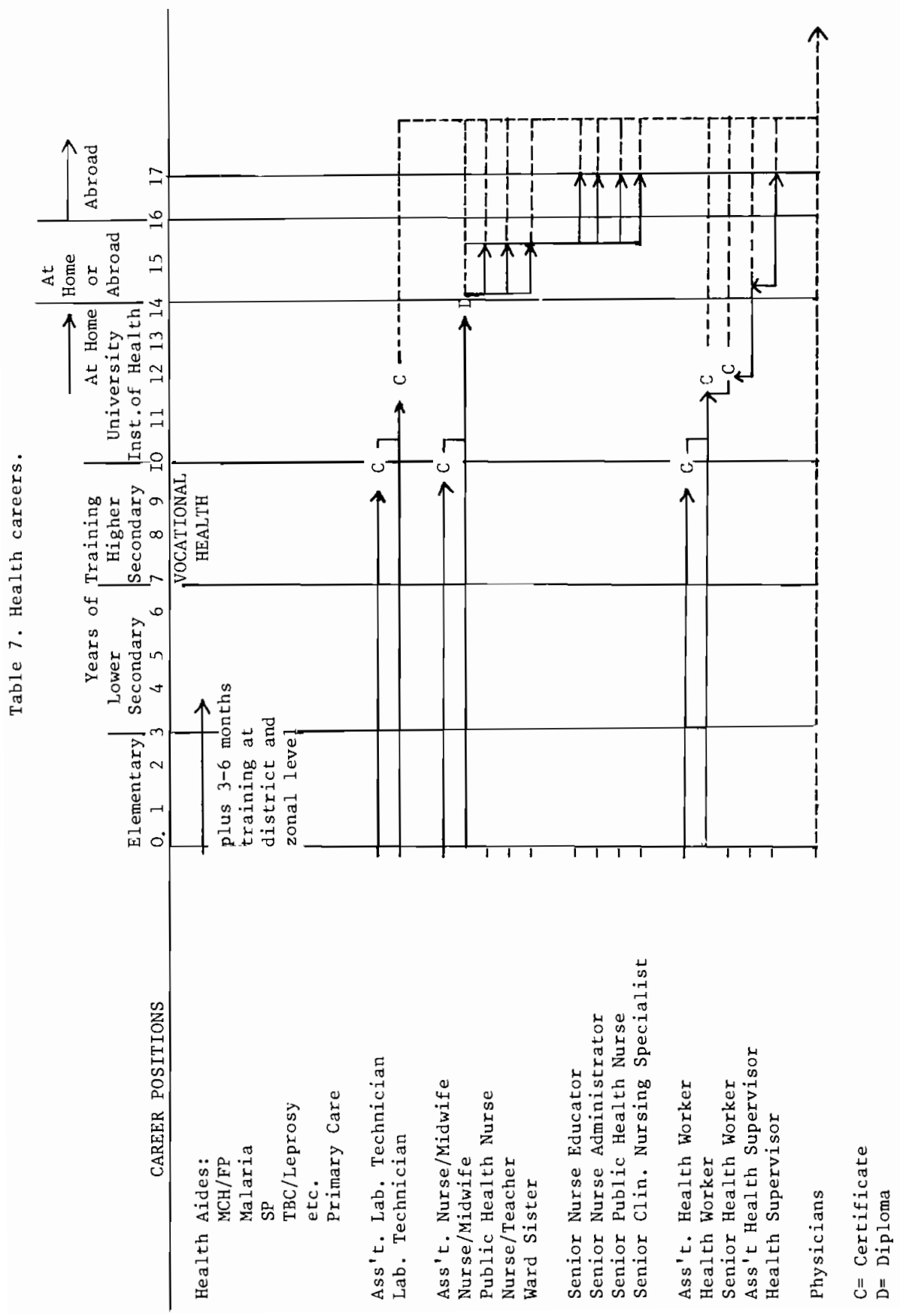


With their home base at the health post there would be two house visitors for each 5,000 people to provide continuity and close follow-up for both the curative and the preventive aspects of the integrated program. The first one would visit each household once a month. He would be responsible, in addition to the malaria program which requires a monthly visit (in the malarious areas), a) for checking a list of clinic visit defaulters (tuberculosis, leprosy, MCH/FP, curative services) which he received from the health post, b) for follow-up on pill-taking for FP, tuberculosis, and other diseases, c) for sending seriously ill people to the health post, and d) for notifying the health post of any serious problem in the household. None of these duties is very time-consuming. The second house visitor would be responsible for those tasks which require longer and more personal contact with the household but do not necessarily have to be performed monthly: smallpox and BCG vaccinations, motivation for FP, evaluation of nutrition and child care, some general health education, household census work, and limited primary curative care. He should also be observant of such regional and temporary problems as epidemics, malnutrition, and goiter, and report them up the line of responsibility for further action. This house visitor would visit each household only about one in four months. Some of the work would also be done by organizing group meetings (even for vaccination programs) and by visiting schcols (for instance, for health education). He will also be used by the chief of the health post to make special visits to households with serious problems, some of them identified by the monthly house visitor.

Such a house visiting program would be the backbone of an integrated health service and would require ca. 5,000 house visitors for a population of 12,500,000 people. These house visitors would be trained as now after three years of elementary school, for three to six months as the lowest level multi-purpose health worker. This goal could be reached within 10 to 20 years, particularly if the several thousand malaria house visitors can be retained. The home base for about five pairs of house visitors is the health post, serving about 25,000 people. Its chief should be at least a Health Worker, hopefully later a Senior Health Worker or Health Supervisor, according to the "New Health Career Plan" (Table 7). He should be responsible for overall direction of the curative and preventive services. He should be assisted by two Assistant Health Workers who would help with curative services and would organize and follow up on the activities of the Health AidesHouse Visitors. Two Assistant Nurse-Midwives would also perform multi-purpose work but would be particularly active in $\mathrm{MCH} / \mathrm{FP}$, including insertion of IUD's. As soon as the general development of resources and manpower make it possible, the health post activities, as well as the activities at all the other levels of the integrated health system, should be upgraded, with more and more higher level health personnel assigned to the periphery of the system.

At the District Health Office level a few beds should be available for direct admission and referral from the (approximately) seven health posts in the district. The District Chief should be a Public Health Nurse, a Senior Health Worker or, if available, an Assistant Health Supervisor. In any event, a Public Health Nurse should be at the district level to coordinate the Public Health Activities.

At the zonal district office the highest category of health worker should be available because the care given there will be primarily referral care. Probably with only fourteen zonal offices it might be possible to attract physicians for this referral work. If physicians are also available for the jobs as "specialist" in the various categorical fields, they should be used. Otherwise Senior Auxiliary Health Workers can perfectly well perform that function. In any event, only at this leve1--and to a large degree for administrative purposes--should specialization and categorical fields enter into the system.

Overall planning and administration, naturally, should remain the responsibility of the Director of Health Services in Katmandu. 
ROLE AND ADVANTAGES FOR SYSTEMS ANALYSIS IN IMPLEMENTING AND EVALUATING THIS HEALTH CARE DELIVERY SYSTEM

1. Cost of training and effectiveness of performance of a number of health professionals at different levels must be compared and analyzed from the beginning to make decisions about continuations, modifications, and terminations.

2. The analyses should be conclusive, because the delivery system is pure in the sense that the care is given by one category of health worker without interference or cooperation by others.

3. As the health care delivery system is a new program--at least in the majority of the health facilities--the analyses could follow the progress from the beginning.

4. There is a reasonable chance that the analysis would clarify the muchdisputed question of the cost-effectiveness of auxiliary health workers, and that these clarifications could be transferred to other settings.

5. An analysis of the activities of the house visitors, which cannot fail to increase the awareness of the consumers in relation to health problems, should reveal if the "need" decreases with improved health status, while the demand increases with knowledge of availability.

6. An analysis of the effect of introducing hospital beds into a setting which did not know them could be revealing.

7. A comparison of the effectiveness of integrated versus categorical health care would be of universal importance.

8. An investigation of the amount of training needed to perform certain health services--or in other words, of the necessity to forgo certain functions because of lack of training--would be of great value for the health professionals, who are chronically overtrained.

9. An analysis could be made of the minimal cost of providing new health facilities for linited functions, another field in which overbuilding and overproviding is the rule.

10. An analysis could compare the effectiveness of health professionals of al1 levels, trained in academic courses and trained "on duty," both modalities being built into this system. 


\section{Commentary of the Discussant, Mr. Griffith: The Nepalese Situation}

The many peculiar problems of improving health care within Nepal were further discussed by Mr. Griffith. Sheer distance is one concern that must be dealt with in ways different from those applied in developed countries. Many Nepalese live a two-week walk distant from the nearest hospital. In the case of fractures or acute disease episodes, this distance becomes prohibitive.

Many problems of Nepal are to be found in other developing nations:

1) Often the continuing struggle for persona $\perp$ status makes it impossible to persuade doctors to relocate.

2) Governmental instability affects health program possibilities.

3) The population does not understand the benefits of family planning with the result that monies donated to this end might better be applied to health programs.

4) Native physicians without training in modern medicine have been persuaded by Western pharmaceutical countries to dispense their drugs. This suggests that this doctor group may be utilized in other health roles.

\section{External Assistance to National Health Programs}

Mr. Griffith saw many lessons in the efforts of external groups to bolster the Nepalese health system. Idealism has led external parties to seek complete coverage of the country with health workers. Mr. Griffith suggested that concentration of these workers in the areas of most fertile soil and highest population would be a more effective policy.

Regarding specific programs, the control of malaria has brought great benefits to Nepal in opening new areas to agriculture. Mr. Griffith believed that careful analysis would show the present proposal to shift anti-malaria personnel into other programs to be dubious. Ongoing efforts to combat smallpox could lead to its eradication within three years. They should be continued.

In the final analysis, comprehensive health programming is likely to be best. An evaluation of this hypothesis at present would probably lead, however, to the opposite conclusion: categorical programs have had to date a better record than integrated programs.

\section{Manpower}

Mr. Griffith agreed with the strategy suggested by Mr. Koch-Weser for the allocation of health manpower: heavy reliance should be placed upon auxiliary personnel and heed given to the career structure required. Attention should be paid to the supervision of workers--a problem exacerbated by the reluctance of most doctors to leave Katmandu for supervisory work. Auxiliaries can vaccinate, diagnose, and provide post-natal care. They might also be used as primary nodes in the health information system: educating the citizenry, collecting data, surveying the needs of consumers and their attitudes toward the care offered, relaying information to other system nodes. 


\title{
A SYSTEM APPROACH TO HEALTH CAKE
} PLANNING IN CZECHOSLOVAKIA

\author{
J. Boukal \\ Ministry of Hea1th, CSSR
}

\section{INTRODUCTION}

The planning of health services is one of the basic ideological principles cn the basis of which the development of the health services in the CSSR is ensured. The planned provision of therapeutic and preventive care is laid down by the Act on the health care of the people which expresses a system concept of comprehensive health care.* This principle implies that health care is a mater for society as a whole and is implemented in a planned way by economic, social, cultural, and health provisions.

Health care is the concern of every citizen as a right and as a duty toward himself and society. An important prerequisite for successfully improving health care is the health consciousness of the citizens. This consciousness is manifested in particular in action: in the adherence to medical principles, in responsible demands for health care and its consumption, and in the active participation of individuals and groups in providing, protecting, and promoting health. Protecting the health of working people and ensuring that work will strengthen physical and mental development is the task of both the state (in particular, the health services) and the working people. Furthermore, care of the young generation is the basis of the nation's present and future health. This involves promoting the population policy, and improved, more extensive care of women-- particularly pre-natal and post-natal care-of preschool children, of school children, and of adolescents. In sum, the Act acknowledges that health care focuses not only on better disease prevention and treatment, but also on the plamed development of physical and mental health and the extension of the creative life span.

Application of these principles of the health care act in a systen approach to the planning and management of comprehensive health services calls for high-standard data and information, indicators which describe the activity of different hea]th institutions and which allow investigation of the results and effectiveness of their activity--i.e. a health information system.

\section{HEALTH SERVICE PLANNING IN THE CSSR}

Czechoslovakia is a federal state. In addition to federal authorities there are national authorities for the Czech and Slovak socialist republics, the territories of which are subdivided into regions administrated by regional committees. The capitals of both republics have their own comnittees with the powers of regional committees. The territory of every region is subdivided into districts under a district committee.

Within a district all health institutions (e.g. health centers, hospitals, polyclinics, pharmacies) are integrated in the District Institute of National Health. Specialized health services (e.g. regional or university hospitals) and health institutions of "above-district-level" importance (e.g. rehabilitation institutes, sanatoria, laboratories), are integrated in the Regional. Institute of National Health in the town of the regional committee. Regional and district health

*Act No. 20, 1966, on health care provides for: the state character of health care, free and generally available care, a high standard of health care, integration of in and outpatient care, planned development of the health services, prevention, preference of working people, maternal and child care, a scientific basis of health services--i.e. close association of science and practice--and active participation of the public in the administration and management of health services. 
institutes are planned and managed by the regional and district committees respectively.

In the two republics (Czech and Slovak) there are separte Ministries of Health with analogons structures; one of the deputy prime ministers of the federal government is responsible for supervising and coordinating their health service activities. Planning--content, organization, and methodology--and supervising the fulfillment and implementation of economic plans (including health service plans) are basically controlled by the federal government of the CSSR. It sanctions federal drafts:

a) of the long-term plan (fifteen to twenty years),

b) of the medium-term plan (five years),

c) of the short-term, operational plan (one year), and

d) of the instructions for preparing the medium- and short-term plans.

The national Ministries of Health plan institutions and organizations they administer directly such as: factories producing medical goods, spas, research institutes, and some special institutions (e.g. the Institute for Postgraduate Training of Doctors and Pharmacists, the Institute for Postgraduate Training of of Paramedical Workers, the Institute for Health Education, the Institute of Medical and Health Statistics). Furthermore, through proposals of national planning commissions, the two national Ministries of Health define the tasks of regional committees and the salaries and numbers of workers in health institutions administered by national cormittees. Instructions are issued for the preparation of long-, mediumand short-term plans. These instructions also include the volume of investments (financial and material) and total numbers of workers allocated to organizations in all branches (e.g. health services, education, social welfare) controlled by national committees. Similarly, regional committees define the activities for implementation by district committees.

For health service planning, the "Main Tasks for Implementing the Resolution of the Congress of the Czechoslovak Communist Party" for different five-year plans are compulsory. This document 1) provides the basic direction for health policy and for activities of all state, economic, and social authorities in the health services, and 2) defines the tasks of society as regards health care and specifically the tasks of the health services.

Thus, the health policy for 1971-1975 (and for subsequent years) emphasizes improvement of the quality of community health services. Local community health centers provide basic services for the community or for several commuities in rural areas and outskirts of towns and in some instances for workers in factories in that area.

Provision of basic health services involves primary care, maternal and child, and dental care. In order to improve the standard it is intended to ensure doctors' services at a ratio of 3.26 doctor's posts per 10,000 population (on average for the CSSR). In addition to the territorial principle of community health services the principle of factory health communities was also introduced. It is foreseen that there will be 1.26 doctor's posts in factory health communities.

\section{PLANNING GUIDELINES USED BY THE NATIONAL COMMITTEES}

\section{The Act on Health Care}

This act contains and defines the activities and duties of the state and of science and technology in providing health services. Moreover, it outlines categories of health service workers, and material provisions to ensure health services and describes the organizational pattern of a uniform system of health institutions 
including spas and natural therapeutic springs. The system of health institutions is based on the following principles:

a) Comprehensive free and available care--laid down in 1966 in the Act on the health care of the people. The principle of availability-from basic health care in health communities to highly skilled care in university hospital/polyclinics--is implemented by a hierarchical regional health system.

b) Integration of prevention and treatment--implemented as uniform preventive and therapeutic care, hygiene (care of the living and working environment), and health education to promote the health consciousness of the population.

c) Integration of inpatient and outpatient care--combination of institutions of in and outpatient preventive and therapeutic care in an organizational and functional unit: the hospital/polyclinic.

d) Differentiation of types of care--1) within a given institution or department, and 2) among functions of different institutions or branches of medicine. The first varies depending upon the severity of the condition or health hazard and comprises different types of intensive care and the system of ambulatory care. The second is important for improving management, planning, and financing. The functions of various institutions and the relations linking them into a system must be differentiated. The regional system of health institutions has three levels (in keeping with the recommendation of WHO):

1) 1ocal: hospital/polyclinic, Type I,

2) interdistrict: hospital/polyclinic, Type II, and

3) regional: hospital/polyclinic, Type III.

e) Differentiation among population areas served--each health institution has a catchment area and a designated part of the population which it serves. The catchment areas are usually not identical with administrative areas. In defining the catchment area natural characteristics are decisive, e.g. general transport conditions; distribution of centers of economic, cultural, and administrative activities; the maximum time 1 imit for providing emergency care; and the optimal size of different functional units in relation to patient use of a given health service branch. The functional capacity of a health institution and its use therefore cannot usually be planned solely in relation to the population of the given political or administrative unit. The same applies to the costs of activities, operation, and development of health institutions and their relationship to the resource constraints upon the appropriate controlling committee.

f) Systematic application of findings of medical science and technology in medical practice--the scientific and technical development in the health services increasingly produces costly special diagnostic and therapeutic equipment whose adoption depends on the economic resources of society. New technology calls for specialized, highly skilled workers. It also calls for large catchment areas to make effective use of its functional capacity. The specialized care for which the complex equipment is designed must thus be concentrated at higher levels of the hierarchy of health institutions. 


\section{Concept of Health Service Branches}

Within the system of health institutions, the goals, structure, and role in the system are defined for each branch of health care (e.g. preventive and therapeutic care, hygiene, epidemiology, balneological care, industrial health care). Additionally, the areas of activities of each institution are defined, directions are given for further developing the health care system, and health worker categories, and equipment needs are stated.

\section{Norms for Predicting Health Care Demands}

The basis for planning inpatient and outpatient services are norms to ensure these services for the population. In particular, these norms aid long-term planning of the development of hospitals and outpatient institutions. The norms are expressed in terms of the number of hospital beds per 1,000 population and of the number of doctors' posts per 10,000 population, in outpatient services. These norms of services are derived from different concepts of medical disciplines and health services and from the persepective of future population growth and health status. The norms also incorporate other factors--varying among the various health services and differing from one region to another--which are important for estimating future needs: e.g. location of institutions, use of beds, length of hospital stays, rate per hour, and number of repeat visits in services, the economic character of the territory for which the services are provided, transport facilities.

The norms for ensuring the future network of institutions providing hospital and ambulatory services indicate to what extent they will be developed. Their gradual implementation accords with economic possibilities, and is incorporated in the long-, medium-, and short-term plans determining the rate at which the goals set in these norms are approached. This rate differs according a) to preferences of disciplines and b) to the health policy and c) economic circumstances (stafí, investments, means of operation) of the given period.

\section{Norms for Planning Personnel and Equipment Needs}

The provision of health institutions with health care personnel is planned in relation to capacity indicators: beds (in inpatient facilities), doctors' post (in outpatient facilities), and places (in nurseries, infants' institutes, and childrens' homes). The criteria are norms for the staffing of health institutions, differentiated according to the type of institution or department, and according to required categories of health workers and their functions.

These staffing norms serve as an aid for fulfilling future health personnel needs. The terms when these norms are to be implemented are determined after comparing these needs with the resources of the national economy. Also taken into account are personnel figures in the annual plans and data on the number of graduates of schools for health workers who will be available. These indicators are useful in assessing the needs and placement of graduates of medical and pharmaceutical faculties and schools for health workers.

\section{Health Statistics for Planning}

Statistics used in planning the future development of the health services include data on:

- causes of death according to the international statistical classification (I.C.D.),

- morbidity of hospitalized subjects and injuries associated with work incapacity, and

- invalidism. 
Based on the dynamics of the development of the population and health status of the population, long-term and retrospective analyses are elaborated as well as analyses of typical features of the present period. From these data are derived hypotheses for the long-term development.

To the above list of statistics must be added the data obtained in investigations made in different medical branches and in surveys of the health status of the population based on direct medical examinations in selected areas.

\section{EMPHASIS ON PREVENTION}

One of the basic principles of the socialist health services is its stress on prevention. The preventive trend of the health services is based on the finding that medicine is not only a biological discipline but also a social science. Health is considered a state of complete physical, mental, and social well-being and not only the absence of disease or physical defects.

Prevention can be primary and secondary. Primary prevention includes provisions for individuals in their living and working environment which are to prevent the development of disease. Primary prevention must be planned during childhood. Secondary prevention involves active detection of the early stages of diseases. This includes outpatient care as an important means of providing therapeutic and preventive care. This implies planned screening of the sick and those threatened with disease, their overall examination and planned treatment, the systematic follow-up of their health status, the maintenance and recovery of their functional capacity, and health education of the people.

Screening is a method of disease detection and identification by periodic examinations. This involves surveillance of the health status of healthy subjects (monitoring of the health status) and surveillance of patients (monitoring of disease). Attention is focused in particular on:

1) Cardiovascular diseases--in particular, hypertension and coronary heart disease;

2) Malignant tumors--in particular, tumors of the female reproductive system and breasts, and of skin and lungs;

3) Endocrine and metabolic diabetes; thyroid disease;

4) Renal and the urinary tract diseases;

5) Pulmonary and circulatory diseases; and

6) Other diseases such as chronic hepatitis and glaucoma.

The objective is to record and store information on critical data in every subject and thus to formulate possible hazard indicators in so-called "risk subjects."

Preventive activity is an integral part of the different medical disciplines. In purely preventive branches such as hygiene, epidemiology, or health education, or those in which preventive activities dominate--e.g. pediatrics, gynecology, and industrial health care--attention is focused on diseases with a mass incidence such as tumors, cardiovascular diseases, metabolic disorders, nephritis, endocrinopathies, and blood diseases.

The approach to planning and implementing preventive measures can be demonstrated in five disease areas: 1) cardiovascular diseases, 2) pediatric diseases, 3) gynecological diseases, 4) malignant tumors, and 5) tuberculosis. 


\section{Cardiovascular Diseases}

In recent years advances have been made in the prevention and control of rheumatic fever and rheumatic heart disease, and of cardiac disprders due to infection. The results in controlling diseases resulting from arteriosclerosis and in controlling hypertension and cerebral complications, however, do not yet correspond to the present possibilities or our health services.

The program of comprehensive care for those threatened with cardiovascular diseases must include provisions which render possible prevention, early diagnosis, treatment and rehabilitation, outpatient care, instruction of health workers and the public, and research methods for evaluating results (including economic evaluation and objective evaluation of work incapacity).

To attain this goal a special group for the control of cardiovascular diseases was established in May 1972 at the CSSR Ministry of Health. This group is headed by workers of the lnstitute for Clinical and Experimental Medicine and includes participants from other research institutes of the Ministry of Health and university departments. The group collaborates with the appropriate departments of the Ministry of Health of the CSSR.

The main task of the group was to transfer into practice as quickly and effectively as possible tested results of research and thereby to reduce mortality, morbidity, and invalidism from cardiovascular diseases. To this end the following objectives were set:

1) to create a model of comprehensive care of subjects threatened or affected with cardiovascular diseases in selected areas of the country; to coordinate their activity and evaluate the results before introducing the new provisions on a nation-wide level;

2) to obtain the cooperation of other departments concerned with research into cardiovascular diseases to promote better care of cardiac patients; and

3) to raise the standard of medical knowledge about cardiovascular diseases, and in particular, to improve the knowledge of health community doctors and specialists in internal medicine at polyclinics.

The program of comprehensive care is already being implemented in selected districts of the CSSR. Based on experience with comprehensive care in these experimental areas, the methods tested will be gradually intraduced into practice. The following have priority: ischemic heart disease (IHD) and myocardial infarction, systemic hypertension, and cerebrovascular accidents.

In the first stage of implementation of the program-before the beginning of the sixth five-year plan--care of subjects with acute myocardial infarction will be ensured. Principles for care have been elaborated which are followed from the first moment of suspected myocardial infarction up to the return of the patient to normal activities. Soon after the development of complaints, patients receive special first aid--in particular, early treatment of frequently fatal disorders of the cardiac rhythm and control of circulatory failure. During hospitalization, every patient with acute myocardial infarction receives intensive care inmediately followed by systematic rehabilitation and lifelong secondary prevention after discharge from institutional treatment. Systematic ambulatory care of all subjects after myocardial infarction is ensured. In model areas outpatient care programs for patients with other manifestations of IHD have been implemented.

Various methods of screening of people with hypertension are being tested and a uniform procedure for examining and treating these patients is being sought, in particular for primary care physicians. Based on experience in these areas recommendations will be prepared for nation-wide outpatient care of hypertensive subjects. 
In model areas a uniform procedure for the diagnosis of early stages of acute cerebrovascular attacks will be elaborated, as well as principles for the treatment of these conditions.

Part of the program of comprehensive care is continuous postgraduate training of doctors and other health workers in modern methods of prevention and control of cardiovascular diseases. In 1973 an extensive program was started for postgraduate courses in cardiology organized in particular for primary care physicians, i.e. health community and factory doctors and specialists in internal medicine at polyclinies.

The scope and comprehensive character of the problem of cardiovascular diseases calls for a multidisciplinary approach and for close collaboration of all departments which participate in the campaign against cardiovascular diseases. It is a long-term program focused on practical problems arising from needs of subjects threatened with or suffering from cardiovascular diseases. It is at the same time, however, a program with the perspective of prevention of the most widespread cardiovascular diseases.

It is important to realize that an orgarization and system are built in advance which will render it possible to introduce gradually throughout the country all provisions for effective control of cardiovascular diseases, as soon as these provisions are tested in model areas. The results of this program will have far-reaching consequences not only for the health of the population but also for the nationa 1 economy.

\section{Pediatric Care}

The organization and provision of basic pediatric care renders it possible to follow-up regularly all children from infancy through fifteen years. Greatest care is devoted to examinations and the follow-up of the physical and psychological development of infants. This is essential for early detection and treatinent of. mild perinatal damage, latent congenital developmental defects, and some genetic diseases.

Of major importance for extensive screening in preschool children are general examinations at the ages of one and three and before entering school (and, where conditions permit, examinations of all preschool children). This is the basis for monitoring the child's physical and psychological development in order to detect hidden disorders. It also makes possible detection of deviations and chronic conditions in their initial stages. A compulsory part of preventive examinations are tests of the child's eyesight, hearing, speech development, and mental level. Before the child enters school, the examination is supplemented by tests evaluating his fitness to attend school.

School children are subjected annually to comprehensive preventive examinations. These are supplemented in older children by examinations of blood pressure, color sense, and physical fitness. In pupils terminating compulsory school attendance, the general evaluation of the health status also includes the evaluation of the ability to work. Children with speech defects detected during preventive preschool or school examinations are referred to the care of speech therapy centers or to phoniatric departments in hospitals with polyclinics.

The results of preventive mass examinations are recorded in the child's health records, children with chronic diseases and developmental deviations are followed up according to thirteen outpatient groups:

1) Inborn and acquired cardiac defects and acute rheumatism,

2) Chronic urinary tract and renal diseases, 


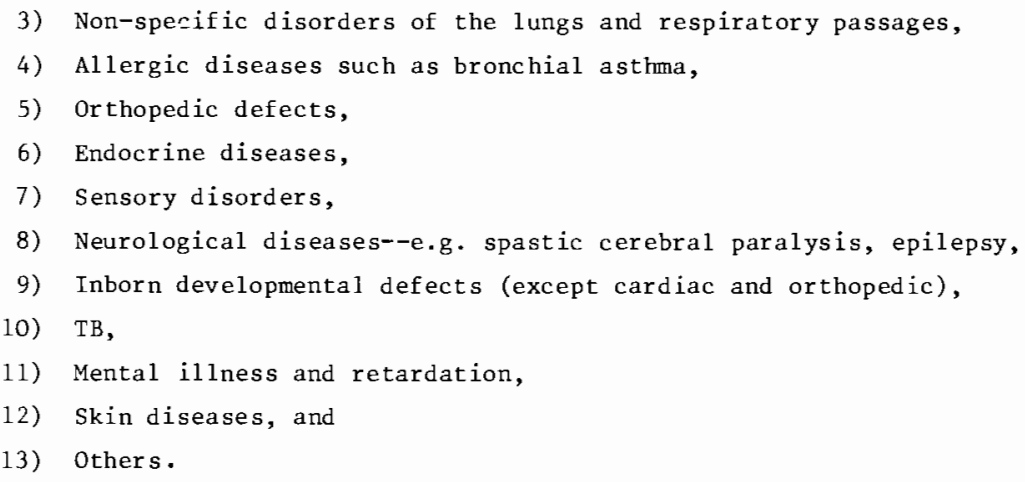

During preventive examinations doctors are assisted by pediatric nurses trained in diagnostic and screening methods. If necessary other specialists (psychologists, teachers) also cooperate with doctors.

In 1973 the mean number of preventive medical examinations per 100 children, according to age group, was:

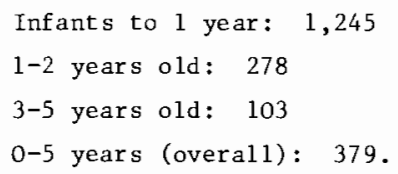

These examinations revealed the incidence in the entire population of children up to five years old of the following disorders:

\section{Disorder Incidence among children $0-5$ years old}

$\begin{array}{lc}\text { Congenital cardiac defects } & 0.42 \% \\ \text { Congenital urinary and renal defects } & 0.08 \% \\ \text { Pyelonephritis } & 0.26 \% \\ \text { Non-specific diseases of the resprir- } & \\ \quad \text { atory tract } & 0.56 \% \\ \text { Bronchial asthma } & 0.18 \% \\ \text { Eczema } & 0.54 \% \\ \text { Dislocations and spinal defects } & 1.69 \% \\ \text { Deaf-mutism } & 0.02 \% \\ \text { Defective hearing } & 0.03 \% \\ \text { Defective vision } & 1.46 \%\end{array}$

\section{Obstetrics and Gynecology}

Preventive care in obstetrics and gynecology takes up a major part of the activity of gynecologists and nurse-midwives. From the total number of medical examinations in outpatient gynecological facilities, $29.7 \%$ are prenatal examinations, and $19.4 \%$ preventive examinations. All pregnant women are regularly examined by a gynecologist and midwife (for each pregnancy there are, on the average, 8.7 medical examinations, 1.5 examinations by a midwife, 1.1 visits of the family 
during pregnancy, and 3.8 visits after discharge from the maternity home). Pregnant women are instructed in courses of prophylactic preparation for childbirth and attend physical exercise courses for expectant mothers.

There are systematic preventive gynecological examinations using bioptic methods, colposcopy, oncological cytology, or histology focused on screening for cancer of the portio vaginalis uteri.

To protect against $\mathrm{Rh}$ isoimmunization, prevention of hemolytic disease of the newborn has been introduced. Since 1974 women who undergo abortions (and are childless or have only one child) are also given protection against Rh isoimmunization.

Among other preventive provisions we can also include contraception. At the end of 1973, 289,605 women were using contraceptives. The expanding use of contraception has reduced the number of abortions: in 1973, 9,615 fewer applications for abortions were submitted than in 1972 .

Health education is part of the daily work of doctors and nurses, and focuses on teaching of parenthood and the health protection of women (including instructions for self-examination of the breasts).

The programs of systematic examinations and screening develop and are adjusted and modified according to needs arising from the population through analysis of its morbidity, structure, and so on.

\section{Prevention of Malignant Tumors}

In the prevention of malignant tumors there are two approaches: 1) primary prevention, and 2) secondary prevention. Primary prevention involves provisions in the living and working environment which will prevent the development of malignant growth. However, our present incomplete knowledge limits the possibilities for this type of prevention.

Secondary prevention includes the detection, the screening, and treatment of precancerous conditions and of early stages of malignant tumors. In order to hasten and improve diagnosis, attention is focused on:

- development of endoscopic examination methods, in particular of the gastrointestinal tract;

- establishment of cytological departments and the development of cytodiagnostics to detect early forms of tumors and possible relapses; and

- development of laboratory screening of malignant tumors.

It is generally known that in recent years mortality from malignant tumors is the second most prevalent cause of death (cardiovascular diseases being the first). The difference, however, is that cardiovascular diseases are mainly diseases of old age, while malignant tumors can occur at any age.

Al1 epidemiological studies and Czechoslovak statistics use as a basis compulsory reporting of malignant tumors. Notification is required not only to record every new case, but also to furnish a signal and information to ensure comprehensive care and follow-up. At the same time it should make it possible to evaluate the standard of screening, diagnosis, and treatment of malignant tumors.

In 1954 in the CSSR the first screening campaign of preblastomatous conditions and early stages of malignant tumors in gynecology was started. This program qualitatively changed working methods. It was gradually expanded by new auxiliary diagnostic methods, particularly cytological diagnosis. The number of women found 
to have malignant tumors of the reproductive system justified this type of gynecological screening and paved the way for the beginning of screening programs in other disciplines, e.g. in dermatology and stomatology.

In preventing malignant tumors the two important links are 1) the team of workers of the health community, and 2) the specialized departments of the hospital/polyclinic. Gynecological screening is the concern of the health community gynecologist. Further screening of certain population groups--determined by age, occupation, etc.--is carried out by workers entrusted with this task by the director of the health institution.

EfFective control--and in particular, prevention--of malignant tumors is impossible without systematically increasing the health consciousness of the population by health education. An example is the program begun in 1969 to teach women self-examination of the breasts to detect precancerous conditions or malignancies at an early stage.

\section{Respiratory Diseases}

In the field of control of tuberculosis and other respiratory diseases, mass examinations of the population are one of the important preventive provisions. These include in particular mass $X-r a y$ examinations (almost 5,000,000 people annually) and large scale tests of tuberculin allergy according to the results of vaccinations against TB.

Compulsory vaccination against TB was introduced in the CSSR in 1953 (decret of the Ministry of Health on Dec. 12, 1953). After five-year intervals allergy to tuberculin is tested in all subjects under 30 years of age. When the above tests are negative revaccination is ensured. Every year in the CSSR 210,000-220,000 newborn infants are vaccinated. Tubercul in tests are made on more than 700,000 children aged 5-14 years and some 150,000-160,000 are revaccinated every year. In the group of 15-year-olds, every year some 10,000-12,000 of a total of 200,000 tested annully are revaccinated.

The importance of these large scale methods is apparent from the developInent of the epidemiological situation as regards TB in the CSSR: during the past two decades the number of new cases and relapses has decreased. As a result the number of beds in sanatoria for TB and respiratory diseases has been reduced, thus freeing the beds for patients suffering from other diseases.

\section{CONCLUSION}

The system approach to planning in the health services is focused on creating a health service system as part of the general social systen. Every health institution as an integral part of this system has its optimal place and role in meeting the different health care needs of the population. This system of health institutions expresses the optimal partial objectives, dynamics of the development of branches of medicine and the need for their cooperation and integration, and defines their interrelations and connection by means of information channels. The localization of the network of institutions in the environment implies the interaction of parameters which characterize the catchment area with parameters of the need of health care, specified according to types of health institutions and according to the specialization of different branches and departments.

For the technology and management of the health care system, a large volume of information is needed about man as a biological system and about the influence of the social and working environment on the health and health care needs and on the social and demographic characteristics of the population. Information is needed not only for planning health care services but also for gauging the costeffectiveness of that care. This requires use of scientific management techniques 
and increased use of computers to improve the productivity of management and the standard of health services.

The complexities of solving the problems of health care systems call for international cooperation. The socialist countries have developed collaboration based on agreements and conclusions of conferences of their Ministers of Health and on symposia on these problems. WHO has also focused projects on these questions. An opportunity for collaboration of socialist countries and other countries also exists in the International Institute for Applied Systems Analysis.

In planning a system of health services it is expedient to focus attention in particular upon four topics.

1) Rationalization of the organization of the system of health institutions and their function.

This is the concept of an integrated system of medical information--a system of the network of institutions and the creation of a data bank. Topics associated with this problem include: a) standardization, b) unification of nomenclature terminology, documentation, and information, and c) centralization and integration of activities. This is the necessary prerequisite of the use of computers in the information system. It is essential to assess the extent and content of information for managing and planning health services at different levels of the regional system of health institutions; computers would be used to assess indicators of quality and effectiveness of the activities of health authorities in hea 1 th institutions of various types.

2) Optimization of the balance between centralized and decentralized planning.

The Ministry of Health must collaborate with local authorities in using local resources and capabilities. Such collaboration would deal, for example, with planning, with training of doctors and paramedical workers, and with the creation of standards and nomenclature of health institutions. The health information system will help develop more fully this collaboration and also help coordinate planning of health services and other branches of government activity.

3) Systematic evaluation of the effectiveness of health services.

When evaluating plans, it is essential that the costs involved be balanced by the effectiveness in fulfilling the aims of the health policy. It is not possible to deal ouly with disorders (pathology); prevention and positive factors which promote health must also be considered. Evaluation must be based upon scientifically founded needs of health care and not only upon consumption of health care. Parameters of evaluation of health service effectiveness must be taken into consideration in planning. Short- and medium-term plans expressed both in medical and in economic terms require quantification of health policy concepts and objectives.

4) Creation of groups of specialist/planners.

Planning of the health services calls for a team of specialists (e.g. economist, mathematician, statistician, system engineer) headed by a physician. These specialists must find a common language and learn to understand each other.

These planning methods which help optimize the organizational structure and functions of health institutions are of basic importance for improving the standard of health care of the people and for effective operation of health institutions. 
Points made by the Discussant, Mr. Venediktov

The main underlying theme which Mr. Venediktov saw in the Boukal paper was the application of the scientific approach to preventive and therapeutic care. The paper gave rise to many observations by $\mathrm{Mr}$. Venediktov:

a) that planning is much more than mere forecasting. The streams of both medical information and health information must simultaneously be applied in order to plan efficiently. Under proper scientific management, the streams may merge;

b) that the trend in al1 nations is toward more comprehensive planning of health care systems. Little by little, the fractionated approach is giving way to planning that takes all available information into account. This is true also for nations considered to have nonsystematic delivery of health care. Centralization of planning is achieved largely through the determination of guidelines and may be best accomplished in hierarchial fashion;

c) that the streams of information upon which systems depend have tremendous effect upon the systems themselves; and

d) that socialist nations now are concentrating upon the optimization of systems management.

\section{The Time for Action}

Mr. Venediktov remarked in closing that comprehensive health care planning will best be achieved when all nations are learning from each other. Many nations have beautiful plans, few have evaluated their system, still fewer have learned from other nations. This Conference represents an opportunity to establish a cross-fertilization of planning ideas. The participants have met and respect each other yet the compliments they have given one another are not enough. The opportunity should be seized to take concrete steps--in conjunction with IIASA and WHO--so that nations may better profit from the world-wide set of experiences in health planning. 


\section{INTRODUCTION}

With the continuously increasing demands upon health services there arises the question of how far medical research is oriented toward the immediate problems of medical practice and which specific research problems result from this practice.

To attain the aims of health policy and to make more tangible progress in the efficiency of medical research as seen in its practical results, it is necessary a) to achieve a greater concentration upon the central tasks in health policy, and b) to improve planning. These tasks can be supported by prognoses, by systems analysis, by statistical methods, and by data processing. This requires working out:

1) long range plans consistent with economic constraints and social needs such as a healthy environment, recreation, and high quality social and medical care; and

2) prognoses of science to aid decision making.

It is obvious that not all scientific disciplines have equal strategic significance. Furthermore it would seem that the consideration of medical disciplines alone would suffice neither for analyzing the problems nor for elaborating a strategy. A comprebensive integration is necessary in a variety of scientific disciplines including molecular biology, psychology, the social sciences--e.g. economics, theory and organization of science--and even philosophy. Therefore complex prognoses are required which involve special methods and procedures.

We set out to make a prognostic study of the development of scientific foundations for the improvement of human life processes (Fuchs-kittowski et al., 1971). We tried to find out whether it is possihle to derive the following ideas from an overall assessment of the foundations of science:

a) to exclude harmful factors;

b) to influence favorably the processes of development and aging, including both physical and intellectual performance; and

c) to choose the scientific fields and problems to be developed.

\section{ABOUT THF METHODOLOGICAL APPROACH}

Our strategy was to determine the main goals and the most important directions of research relevant to these goals. This was done in three stages:

1. Definition of the object of research and its environment;

2. Definition of the interactions (factors); and

3. Search for an appropriate operation to define the relation between the object and the enviroment, by methods of systems analysis and by

${ }^{1}$ This work has heen encouraged and supported in many wavs by Professor S. M. Rapoport. 
representing the relations in a graph of prognosis.

\section{Stage One}

In the first stage it was necessary:

a) to determine the object of the prognostic study hy means of systems analysis, using in particular prognostic graphs and subdivision operators;

b) to arrange and order the factors relevant for the functioning of human life processes; and

c) to work out the structure of relations between external and internal factors of the human organism.

It was necessary to find working definitions of the categories: human life processes, environment, and factors. We took as a point of departure the concept that the human Iife processes and the environment are parts of a ManEnvironment System, and that the human life process must be regarded as a unity of biological, psychological, and social processes. Such a concept leads to the thesis that man's environmert is the sum of processes existing outside the ind $i-$ vidual. However, such definitions are so broad as to be practically useless. Therefore, we have tried to subdivide and simplify the system into two parts (Figure 1):

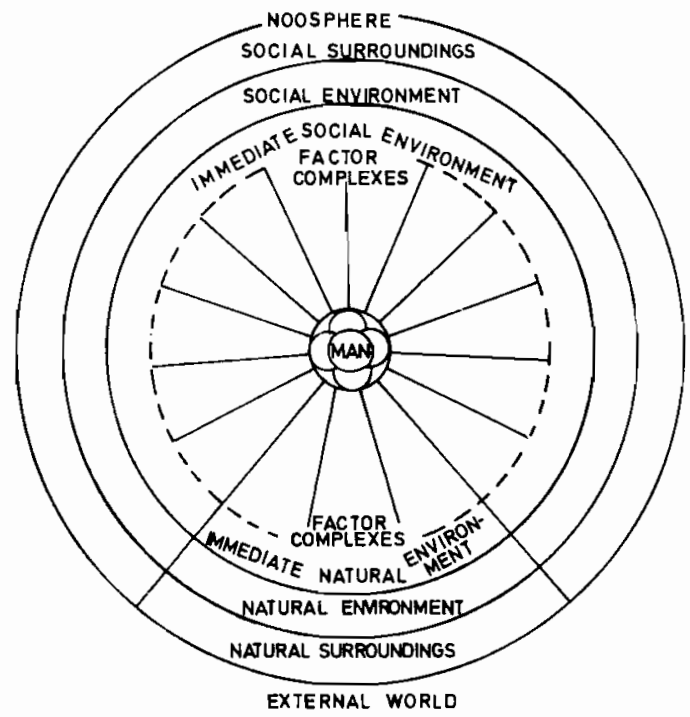

FIGURE 1. MAN AND HIS ENVIRONMENT

MAN AS AN ASSEMBLY OF SOCIAL RELATIONS IN HIS NATURAL AND CONOITIONED ENVIRONMENT. 
1) The external world; and

2) The noosphere
a) the surroundings or the overall natural and social conditions,
b) the environment, and
c) the immediate environment.

The external world is defined as a phenomenon of objects that are prerequisite to human existence, but which are partially or wholly removed from the influence of man. The noosphere is formed by society and by humanized nature that is conditioned by the work of man. It comprises relations between the different spheres of society, relations between society and nature, as well as inside humanized nature. This system interacts with the external world. As the "surroundings" of the Man-Environment system we regard all relations, conditions, and objects that influence man essentially only through the environment. As "environment" we understand the immediate interactions of man with his surroundings. In particular from the viewpoint of health, five domains should be distinguished (Figure 2):
1) the shaped natural environment;
2) the material systems of society;
3) the conditions of work;
4) social group relations; and
5) general social relations.

We have considered primarily the first three domains. Within the domains one can distinguish complexes of factors, each which consists of varicus factors; together they constitute the immediate environment of man.

We call "factors" all elements (of the natural and social environment) influencing man which can be identified and deliminated independent of their structure. They may be part of the natural and social environment or of the human 1 ife processes. Figure 3 shows how the three factor complexes of the shaped natural environment are subdivided into chemical, physical, and biological factors.

Let us now turn to the internal elements--biological and psychological processes--which influence human life processes. For the ordering of the biological factors we followed the structural levels of living systems: molecular, subcelluar, cellular, organism, and population (Figure 4). Through specific physical and chemical processes, these levels are integrated to form a highly complex system. Our knowledge of the importance of the genetic factors is only in its first beginnings.

On the basis of this figure, it was possible to find a point of departure to arrange the multitude of relevant factors and to work out a general structure of their relationships. In this manner we were able to arrange groupings of factors significant for man's physical and psychological activities. They include:

- reproduction, differentiation, growth, development;

- aging, involution; 


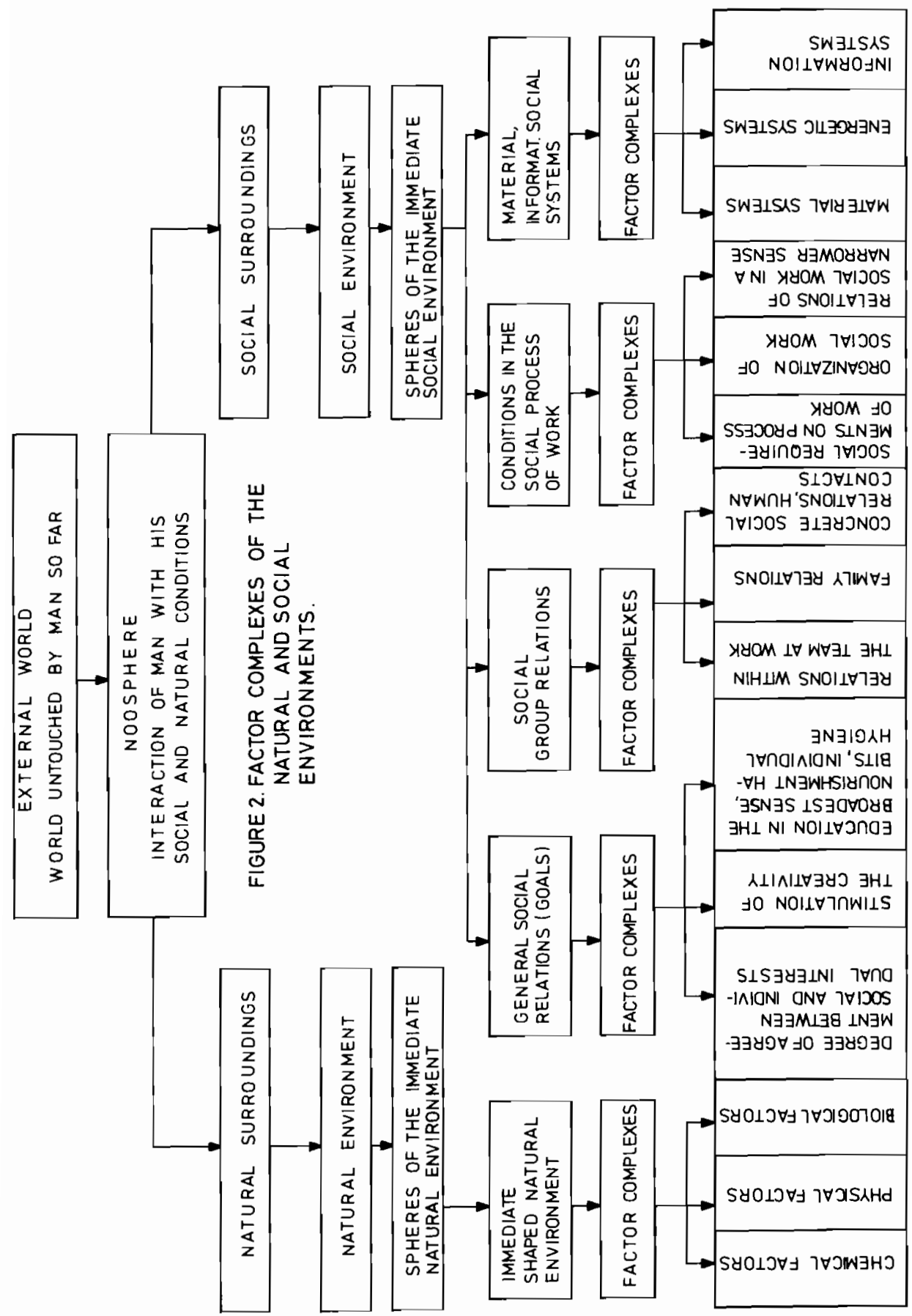




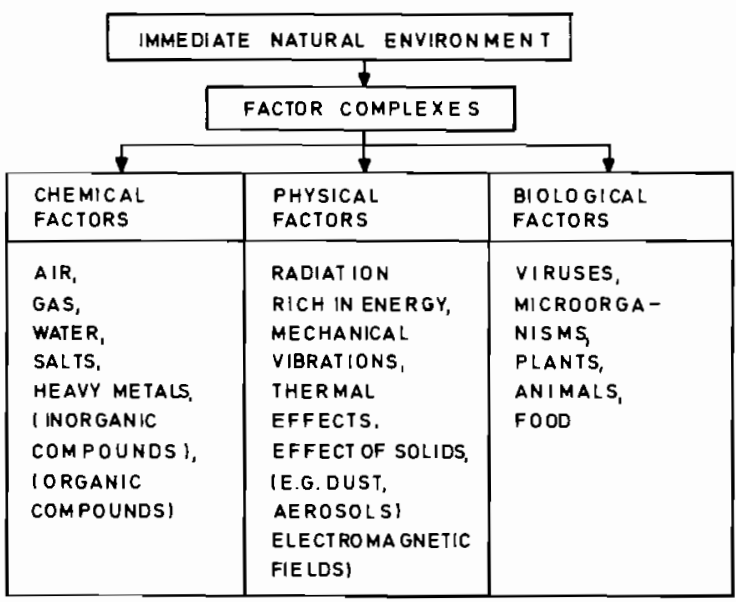

FIGURE 3. SUBDIVISION OF THE THREE FACTOR COMPLEXES OF THE MMEOIATE NATURAL ENVIRONMENT INTO SINGLE FACTORS TO BE MADE MORE PRECISE BY FURTHER RESEARCH.

- defense against infections, immunological reactions;

- protection mechanism against non-antigenous harmful effects;

- organ activities whose limitations essentially determine the overall morbidity;

- physical activities; and

- patterns of behavior.

\section{Stage Two}

The goal of the second stage of the work was to arrive at a weighting of the factors. For this purpose, we compiled a catalogue of factors and worked out a prognostic graph (hierarchy of elements) in order to prepare for numerical analysis. Further details about the methodology and the methods of numerical analysis are given in the appendix to this paper (Schlutow, 1972).

The factors were system- and problem-oriented and were grouped into thirty-five factor groups. The delimitation of the number of factor groups was carried out by a weighting procedure of an expert panel. Table 1 shows a section of an original questionnaire. For psychological reasons, the factors were presented in a random sequence. The highest possible evaluation was 5 , the lowest 1. The evaluation of the factors varied from 4.16 to 2.10 . 


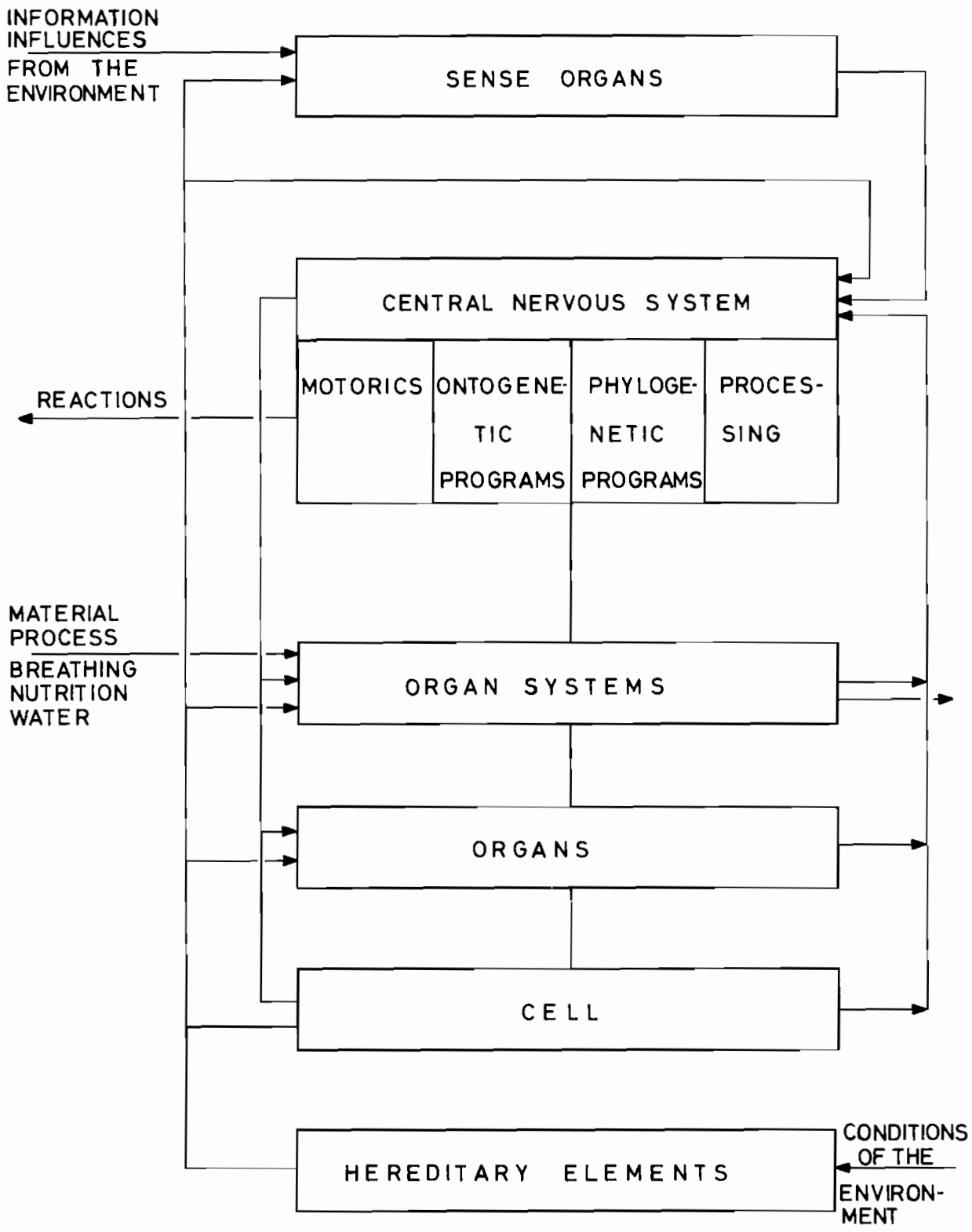

FIGURE 4.INTERRELATIONS OF HIERARCHY LEVELS OF THE HUMAN ORGANISM. 


\section{Table 1.}

Extracts from a questionnaire for weighting factors influencing partial prognostic goa 1 s.

Weighting Grading

2. Influencing factors

2.1 Psychological, sociological, pedagogical

factors of a healthy nutrition

2.2 Chemical (including toxicological) factors of the natural environment

2.3 Factors of the organization of work

2.4 Genetic factors

2.5 Biological, psychological and sociological factors of the landscape

2.6 Traditions and customs

2.7 Migration within the framework of communication processes

2.8 Molecular biological factors of development (reproduction, growth, embryogenesis, differentiation and maturatior)

2.9 Psychological and sociological factors of recreation

2.10 Legal factors

2.11 Regulation factors related to hormones

2.12 Disease frequencies

E: expert; $\ddot{U}$ survey; $N$ : layman with scientific training;

Weighting: 1 (lowest evaluation) to 5 (highest evaluation)

\section{Stage Three}

In the third stage of our work, it was necessary:

a) to formulate and select limited (precise) goals of research; and

b) to assess the contributions of the relevant disciplines for developing the scientific bases for achieving these goals (Rosenthal, 1972). 
A catalogue of limited goals was set up and submitted for consideration to seventyfive experts in the field of biological sciences. This resulted in the selection of four limited goals for improving human life processes:

1) The conservation and promotion of intellectual perfórmance;

2) The conservation and promotion of physical performance;

3) The extension of the age of high effectiveness, with emphasis on the positive influence of favorable conditions for the development period of childhood; and

4) A change of the environment for the benefit of man.

An obvious difficulty in making evaluations lies in the heterogeneity of the factors and in the subjective limitations of the evaluators. We tried a method of numerical analysis which comprised:

1) weighting the factors by a round of evaluations,

2) weighting the significance with respect to the goals of optimization, and

3) weighting with respect to the multiple valency of the factors for several goals of optimizations.

Three rankings were employed ( $3=$ high, $2=$ mean, $1=10 \mathrm{w}$ ). This procedure yielded a much wider spread of differentiations as compared with the ranking procedure of the questionnaire. A weighting of scientific disciplines was carried out. In this way we obtained a matrix which showed all scientific disciplines which have an essential part in the creation of the scientific bases of the goals of optimization.

On this basis two out of thirty-five disciplines--biochemistry and ecology--were selected as having great impact upon the goals of optinization. Table 2 shows the ranking given to these two disciplines with respect to some of the optimization goals. It should be stressed that no single science considered in isolation would be adequate for developing the complex scientific foundations to achieve the goals.

One result of the evaluation was that certain fields of science play a strategic role in the aims of the prognosis because of their multiple valency, even though the experts expected only a limited use of their achievements in the next twenty years.

For the biological foundations of human effectivity, the prognostic study produced recommendations:

1) to establish a system of standards for physical and intellectual performance;

2) to set up a list of endogenous and exogenous risk factors;

3) to increase research in the field of molecular biology of the processes of development;

4) to intensify work in the field of human genetics;

5) to encourage research into the molecular foundations of the processes of learning, fatigue, and recovery; 
6) to study long-range influences of nutrition and different nutritional requirements with respect to age, type of work, and individual constitutions; and

7) to expand efforts in the field of psychological research of early childhood.

Table 2.

Simplified example for a structure of relations between partial aims of optimization.

Partial aim of optimization
Field of knowledge

biochemistry ecology
Conservation and stimulation of intellectual performance

Optimal environment

Organization of work
Biol. f. of fatigue
Information density
Biol. f. of intellectual
performance
Noise
Food - nutrition
Psych. soc. f. recreation
Social rhythms
Biol. rhythms

$\begin{array}{ll}1 * & 1^{*} \\ 3 & - \\ 2 & - \\ 3 & - \\ - & - \\ 3 & - \\ - & 2 \\ - & - \\ 1 & 1\end{array}$

Toxicol f.

2

3

F. of nat. resources

3

Noise

1

F, of industrial conurb.

2

Wastes

Chem. $\mathrm{E}$.

Landscape $f$.

Information density

Organization of work

Physical $\mathrm{E}$.

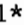

1

.

(1)

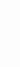


In the field of social sciences, it was recommended to investigate: the role of tradition and subjective views as obstacles to a scientific nutrition; ethical and moral positions with regard to family planning; the place of stimulants; ideological and social aspects of recreation and a healfhy way of 1 ife; and the elaboration of appropriate legal normatives. Research on problems of philosophical studies of the bio-social problems--including the impact of modern genetics and of the revolution in science and technology--calls for a general unity of natural and social sciences.

We had, of course, difficulties in the evaluation, owing to the insufficient number of experts in the GDR. We should like to suggest that a highly complex prognosis would be much improved by international cooperation. The strategy employed for the prognostic study might be applied with advantage to other problems which constitute border regions between medicine and other fields of knowledge (e.g. psychology, ecology, economy, the organization of automated information processing or informatics).

Another possible application may be the problems of multiphasic screening. Hare also external and internal factors must be found and defined in order to decide what kind and how many data are required, and which of the factors considered may be influenced. On this basis it might be possible to set up models for risk groups or of different periods of 1 ife (Friedemann et al. 1970). The method of hierarchies of elements is not only planning and of general classification in very complex fields. Perhaps this method may be useful, whenever it is necessary to make comparable statements by experts from different fields. 


\section{APPENDIX: REMARKS ON THE METHODS OF PROGNOSIS EMPLOYED}

The work on the study "Scientific Foundations of the Optimization" of Human Life Processes" made necessary inquiries into the use of known methods of prognosis or into their further developments (Schlutow, 1972). Science integrating problems are typical of national science prognostics. The problem under consideration--the working out of a complex scientific forecast--is limited according to its contents by the central aim. But according to its structure this problem is characterized by the prognostic methods to be used, and according to each method, it is determined by principles and rules defining the sequence of operations. In solving science integrating problems the scientist will generally proceed only in a manner related to the problem so far as his discipline is concerned. This is unsatisfactory for understanding the problem as a whole and the dialectics of a part and a whole in the problem solving process.

Therefore, the prognostic method must fulfill several functions. First, it must help give the scientist a means of access to the problem as a whole. Wherever the thinking of the individual may be limited, the method must make visible and allow assessment--by a team approach and by technical means--of the variety of interrelations in the hierarchy of the problem. For working out the prognosis "Scientific Foundations of the Optimization of Human Life Processes..." the method of integrated hierarchies of elements appeared to be appropriate. In Figure Al, the position of the method is shown within the overall prognostic study in the GDR.

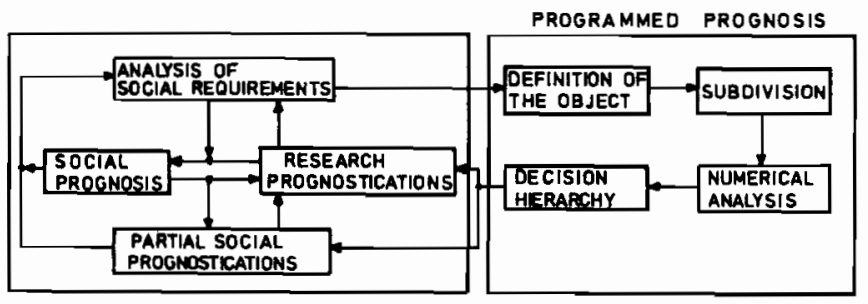

FIGURE A 1 .

${ }^{2}$ optimization is to be understood here in the sense of the choice of the best variant. 
According to the classification of G. M. Dobrov, our approach is the program prognosis method. The hierarchy of qualitative prognosis elements as the central part of this method is based upon the concepts of aspect, prognosis element, and a graph of length 1 .

In Figure A2 a graph of length 3 is represented (symbol $R(3)$ ). We define it as a directed, uncyclical centered graph, without double edges, in which every connection of two knots is of length 1 or is part of a connection of length 1 .

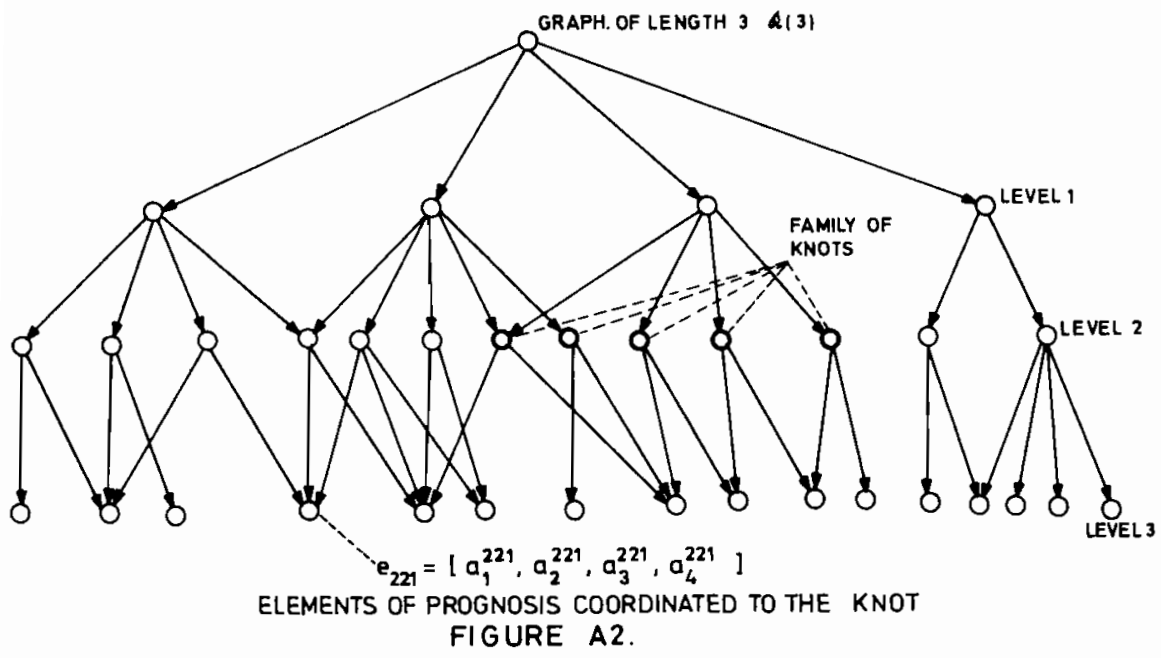

A graph $R(1)$ is free of loops; thus we speak about a tree of length 1 (symbol $B(1))$. These terms--taken from the theory of graphs or from set theory--serve a unified terminology. By adopting the method of relevance trees, methods of graph analysis or integrated element hierarchies according to a consistent generalization, methods were developed under various names--e.g. PATTERN, CPE--in several countries for programmed prognostication for science and technology (Jantsch, 1967; Nikolajev, 1969; and Autorenkollektiv, 1971).

In a further development, we attempted to make visible the arbitrariness or the specific particular laws during the transition from one level to another (downward) in an element hierarchy related to concrete prognosis, and thus to improve the objectivity of prognoses. Our point of departure was to renounce the practice of naming one classification feature only for the elements coordinated with the knots of a level of a graph $R(1)$, which we are going to call elements of prognosis.

It was not required, at any rate, that the classification features we cal1 "aspects" should apply for the whole level. Only, it must be taken into consideration:

1) that the features (aspects) apply to one family at 1east; and

2) that if the aspects do not apply to the whole level, then implications must be considered for applying numerical analysis. 
For the section of a hierarchy of unassessed elements of prognosis of structure $\mathrm{R}(4)$, already treated in the study, it was always possible to work with elements of prognosis described by the aspects

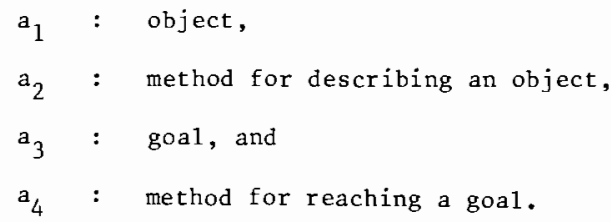

According to a prognosis to be worked out or, if necessary, to a family in the hierarchy of unassessed elements of prognosis, a specific choice of aspects can be made.

The transition from one level to another is carried out by splitting up an aspect according to one of the structural properties existing in a concrete set, for instance,
reduction of the degree of abstraction,
subdivision into subsets,
subdivision into the elements of a system,

to give only a few structural properties for occupying an aspect (in so doing, the subdivision procedure must be indicated for every structural property).

Furthermore, a number of questions are to be mentioned whose consideration led to the formulation of a general subdivision operator. Its application for setting up an element hierarchy of structure $R(1)$ of unassessed elements of prognosis limits the arbitrariness during transitions from one level to another, and makes it possible to recognize gaps in the subdivisions, thus allowing one to derive implications about the possibility of using numerical analysis.

Let us now turn to the first of these questions. Subdividing an aspect of an element of prognosis according to its structural property implies the necessity in many cases of subdividing further aspects of the element of prognosis according to certain structural properties. As an example, take the subdivision of a particular element of prognosis from the study: "Scientific Foundations for the Optimization of the Human Life Processes" (Fuchs-Kittowski et a1., 1971). This example consists of the following aspects:

1) Object: physical properties of the resource air;

2) Method related to the object: (formulated by naming the participating disciplines) biophysical sciences, technological sciences, architecture, urban planning;

3) Goal: keeping the resource air clean with parameters favorable to human life processes; and

4) Method of attaining this goal: protect the resource air from harmful influences.

Subdividing the occupancy of the aspect "Object" leads for the aspects and object to a family of occupancies, e.g. 
scientific foundations for measuring and controlling noise;

scientific foundations for preventing noise;

scientific foundations for radiation protection by measurement and control; and so on.

Clearly, the subdivision of the object also for the interpretation of a,--"Physical Properties of the Resource Air"--implies a subdivision in the system of the scientific disciplines concerned.

An analysis of well-known applications of element hierarchies and the work on this study led to the fact that levels existing in the hierarchy resulting from the logic of the subdivision are left out. Subdivisions in which $n$ levels are allowed, we call subdivisions of a higher order. The taking into account the order of the subdivision will lead to prognosis elements of equal level and thus to the possibility of employing horizontal numerical analysis.

We have indicated above that the aspects serve the purpose of classifying the prognosis elements of a level or of a family and that only in rare cases can all prognosis elements of an element hierarchy be described by the same set of aspects. To supplement the analytical apparatus, it is therefore necessary to take account of mappings that allow us to map an aspect before or after the subdivision into the interpretation of another aspect. By applying such an analytical apparatus the details can be more clearly arranged and, as is still to be shown, they can also be better assessed.

The application of numerical analytical methods of this sort, in one way or other involves the interviewing of experts. This is of particular ideological relevance. Ideological consistency in the basic problems of social development and toward the goals of society is an important point of departure of all the experts concerned.

It would be far beyond the scope of this paper to deal more closely with the resulting experience of social research to be considered which thrusts into the for eground such problems as

the composition of the expert groups,

the composition of the questions and the questionnaire,

the rules for the interviewer,

the validity and reliability of the methods, and so on.

From the results obtained so far, the necessity is stressed to continue research in the field of prognosis to work out extremely complex prognostications of science. The way has been shown for obtaining new insights into prognostic methods. 


\section{REFERENCES}

Autorenkollektiv (1971). Methodik der programierten Prognostizierung von Wissenschaft und Technik. (Moscow).

Friedemann, H., Thiele, H. J., and Tredt, H. J. (1970). Modellstudien für Vielfachreihenuntersuchungen als Grundlage eines umfassenden Systems der gesundheitlichen Betreuung der Bevölkerung--Eine Übersicht. Ztschr. ärzt1. Fortbildung 64, $1261-1267$.

Fuchs-Kittowski, K., Rosentha1, S., and Schlutow, G. (1971). Wissenschaftliche Grundlagen für die Optimierung der menschlichen Lebensprozesse. Humboldt University, Berlin, GDR.

Fuchs-Kittowski, K. and Rosentha1, S. (1972). Systemanalytischer Versuch zur Herausarbeitung des Gegenstandes der prognostischen Studie. Wissenschaftliche Grundlagen für die Optimierung menschlicher Lebensprozesse. DDR-Medizin. Report Jg. 1, Heft 6.

Jantsch, E. (1967). Technological Forecasting in Perspective. (Paris) $219-228$.

Nikolajev, v. (1969). Die Zielbaumethode. Technische Gemeinschaft 7, 3, $16-25$.

Rosenthal, S. (1972). Einfache Methoden der Entscheidungsfindung (Bewertung) in der prognostischen Tätigkeit. DDR-Medizin. Report Jg. 1, Heft 6 .

Rosentha1, S., Fuchs-Kittowski, K., and Lickert, G. (1972). Zu einigen ausgewäh1ten Fragen der Umwe1tproblematik vom Standpunkt der prognostischen Studie Optimierung menschlicher Lebensprozesse. Vortrag auf dem Akademiekolloquium der problemgebundenen Klasse, Optimale Gestaltung der Umwelt, über den Begriff, Umwelt. Wissenschaftliche Thesen. Jg. Heft 3 .

Schlutow, G. (1972). Integrierte Elementhierarchien, Methoden zur weiteren Objektivierung einer Klasse von Programm-Prognose-Verfahren. Dissertation. (Gesellschaftswissenschaftliche Fakultät, Sektion Wissenschaftstheorie und -organisation der Humboldt-Universität; Berlin). 


\section{Clarifications}

In response to questions from the floor, Messrs. Fuchs-Kittowski and Rapoport explained many points in the study reported in the paper:

a) that the objective was to describe modes and paths of collaboration between different disciplines in relation to health. The work comprised not so much a prognosis as a study identifying areas of potential value for research. Through simultaneous consultation with many disciplines, escape from disciplinary limitation of perspective was sought;

b) that between two and three hundred experts were consulted in the study; and

c) that study results were already being used to direct research funding. 


\section{INTRODUCTION TO THE FINAL SESSION}

Mr. Venediktov lauded the papers authors and their many discussants for bringing a large volume of information to the attention of the conference. The problem lying now before the participants was to draw conclusions from the vast mass of hypotheses, judgments, and facts. Of especial value would be suggestions that could guide the work of the IIASA Bio-Medical Project.

Mr. Raiffa echoed this plea for advice to IIASA work in the Bio-Medical area. He noted that extensive collaboration among projects was vital to the integration of Institute activities. Projects suggested for systems analysis in health should therefore not be formulated in isolation from other ongoing IIASA research.

Mr. Raiffa expressed his personal hope that the Bio-Medical area would continue to grow to become--in numbers and in output--one of the most significant sectors of the IIASA program.

From the floor, a question was raised on the difficulty in achieving continuity with limited-term appointments. Mr. Raiffa conceded that this is a problem, but one not without solutions. There is a distinct negative correlation--with consequent tradeoffs--between the quality of recruitable scientists and the length of time they can spend at IIASA. By devising innovative arrangements--such as continued visits from distinguished "itinerant scholars" after their stay at IIASA is over --this handicap can be surmounted.

\section{A COMMON IANGUAGE}

The immediate priority identified by several of the participants was the working out of a systems language that would be common across cultures and a means of communication among administrative planners, systems analysts, other scientists, and doctors. Frequently the experts at this Conference had used the same terms with different meanings. A possible extension of the language would be identification of universal units for measuring the input, output, processes, and efficiency of health systems.

Another member argued that the Conference had constituted a useful initial attempt to settle upon a new language, or at least a new dialect. He stressed though that the utility of applied systems analysis as a tool depends upon its simplicity and comprehensibility to large numbers. With the development of the discipline, the uncertainties among experts that came to light in the discussion of models will be reduced. This will increase the willingness of administrators to use systems analytic studies. The compilation of a glossary of systems terms in bealth planning was urged.

One participant reflected upon the conference and identified two distinct families of papers. The first assumed--without recourse to economics--that adequate health care is a basic right and then examined the means of its provision. The second family considered similar, specific problems where systems analysis might point the way to better or more cost-effective care. He argued that IIASA should work in the latter area. The projected glossary of systems analysis might well set forth a standard or code of practice that would promote clear exposition of systems methods used. One frequent failure of clarification he noted was that the boxes in systems diagrams are always explained but the lines between them only rarely.

It was suggested that the primary objective of a systems glossary should be clarifications of such concepts as "plans," "models," and "prognosis." of these, the first is central and most important. Plans presently differ across many nations and are addressed to various sectors and levels of the health system. Thus, there is planning of services, planning of manpower, planning of capital investments, and planning of finance. Somehow integration of these levels must be achieved. 
Perhaps this can optimally be done by clearly defining the main system goals. Important subsequent steps would then include delineating the information flows required and finally deriving operational details and guidelines.

\section{THE BROAD FRAMEWORK OF IIASA INTERESTS}

IIASA has adopted the goal of providing useful guidance to decision makers. Alternative ways of achieving this goal can be suggested for both the short- and long-term. In the inmediate future, it was urged that IIASA work upon case studies that would guide the use of systems analysis. For the longer term, a detailed elaboration of systems techniques should now be initiated. A proffered categorization of targets for analysis in the health field included: 1) demand; 2) systems modules; 3) regional characteristics; 4) effects of screening; and 5) cost effectiveness. Specific projects might address: 1) the overall health system; 2) health care in rural areas; 3) regional health care; and 4) health education.

One participant had recently read a US news magazine in which conservative and liberal critics agreed that all public programs have laudable purposes but too few justify the actual expenditures of public monies. With better indices and definitions of health status, program accountability could be enhanced. He suggested that IIASA work on specific projects to improve the measurability of health program aspects.

\section{SPECIFIC TASKS RECOMMENDED FOR IIASA}

Many participants brought forward specific problems to which IIASA might devote its attention:

a) systems nodels of pathogenic processes in the individual--explaining the natural history of diseases and their reactions to treatment;

b) modelling of the influence exercised by new medical technologies upon natural histories of diseases;

c) analysis of the benefits, or lack of such, achieved by intensive care treatment;

d) critical evaluation of the benefits wrought by new technologies; and

e) analysis of transplant procedures--the system for obtaining transplantable organs and the net benefits.

\section{CONCLUDING REMARKS BY MR. VENEDIKTOV}

For an operational definition of applied systems analysis (ASA), Mr. Venediktov referred to the brochure, "IIASA: Background Information." Here Mr. Raiffa states that:

Our Institute interprets Applied Systems Analysis not as a technique or even a set of techniques but as an embracing rational approach to the resolution of complex problems. ASA is a framework of thought designed to help decision-makers choose the desirable (or in some cases a "best") course of action.

This definition suggests a broad range of useful applications for systems analysis in the health field.

The basic goals of public health systems have been well expressed by many observers. One appealing formulation is given in Figure 1 . In the center are the measurable indicators of health status--denographic, morbidity, and mortality skatistics. These must be understood as imperfect surrogates for the true optimand! the positive health life of the population. In the ring surrounding are the four major classes of factors influencing health: 


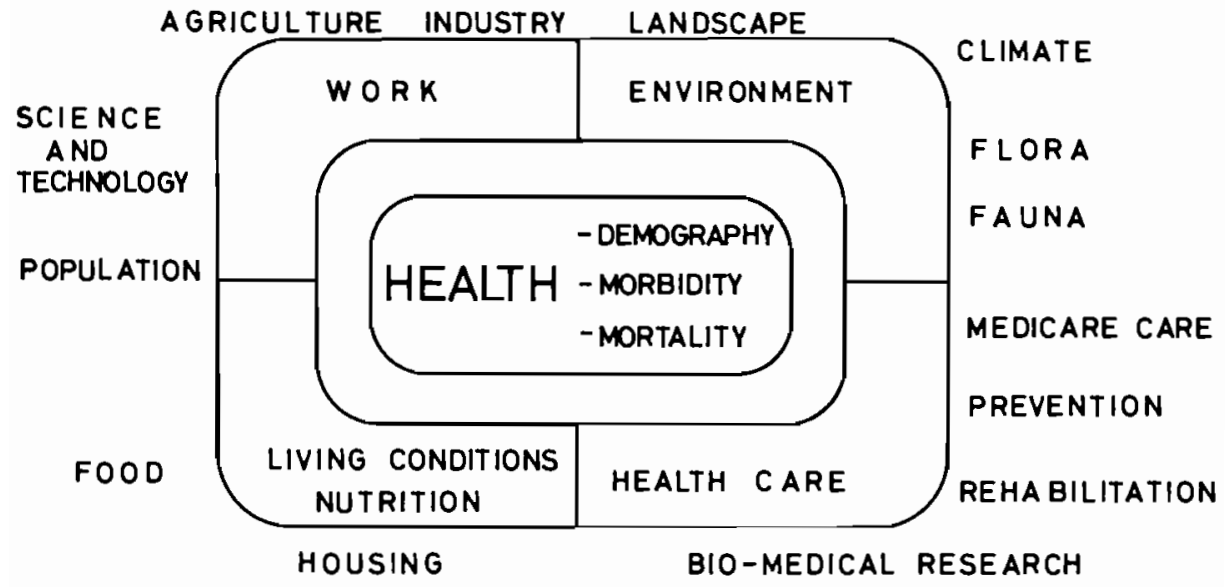

FIGURE 1. THE GOALS AND ENVIRONMENT OF PUBLIC HEALTH SYSTEMS. 
1) living conditions and nutrition,

2) the environment,

3) work, and

4) health care.

Outside these are indicated their various components.

Health planning begins with a clear conception of its goals, progresses through the drawing up of the plan, proceeds with its implementation and evaluation, and continues with feedback into the next cycle of planning. The Conference has stressed the importance of evaluative feedback and the necessity of deriving the best possible plans from inevitably deficient information. Planning requires obtaining the best projection of the future, recommending courses of action, and considering the managerial aspects of the health system.

Plans may be laid on a sectoral basis or they may be comprehensive. Present trends in all countries are leading to a more comprehensive planning approach. The time horizon may vary from days or weeks to decades. Plans often have a definite hierarchical structure backed by centralized authority but must allow for flexibility of adaptation at the local level. In socialist countries plans acquire the status of laws, yet flexible accommodation must be made to such events as autbreaks of cholera.

With an eye upon the overriding four goals, planning seeks to optimize the entire system and to put to use fallow resources. Work should go forward to determine the optimal set of needs. The concepts of system and sub-system efficiency must be made more clear. Much planning is addressed to the establishment of appropriate norms and standards. In the Soviet Union many studies seek to derive from existing needs, desires, and demands the proper standards.

The present compromised and discredited state of cost-benefit analysis has been brought out by the Conference. Nevertheless, planners cannot avoid such basic economic questions as the proper amount of governmental monies to spend upon health and the best allocation of those monies. Systems analysis should undertake the strengthening of the quantitative methods that can be addressed to such issues.

Both the need for health models and their methodological and presentational shortcomings had been brought out by the Conference. The models were of many different types and their clarity suffers from the lack of common typologies and denominators. The drawback, of reliance upon linear modelling had been pointed out. Mr. Venediktov sensed the need for multi-sectoral models implicitly incorporating feedback.

One diagrammatic model of the health system is given in Figure 2 . At the bottom are the different units comprising the health system which should be allocated and channeled by the next node higher--that of management. Management, together with the neighboring nodes of scientific knowledge, personnel, and support resources, individually and in combination feed into the specific activities of the health system: prevention, rehabilitation, and treatment. The activities are structured and planned to promote the highest node of the system, the best health of the population.

To be effective, the IIASA Bio-Medical Project must work closely with wHO and with national health ministries. The best use of IIASA's limited resouces may lie in concentration upon the methodological problems faced by these institutions. Another attractive possibility would be to work out a holistic and functional scheme of public health services. IIASA might be able to break through the methodological barrier that has hitherto prevented the application of hard analytic techniques to the soft values of health conditions, science, and life. Many projects of clinical evaluation seem to float and require the anchorage of a sound analytic methodology. All these projects would be furthered by a compiled glossary of systems analytic terms. We want to demonstrate to wHO and to other health organizations just how structured analysis can help them. 


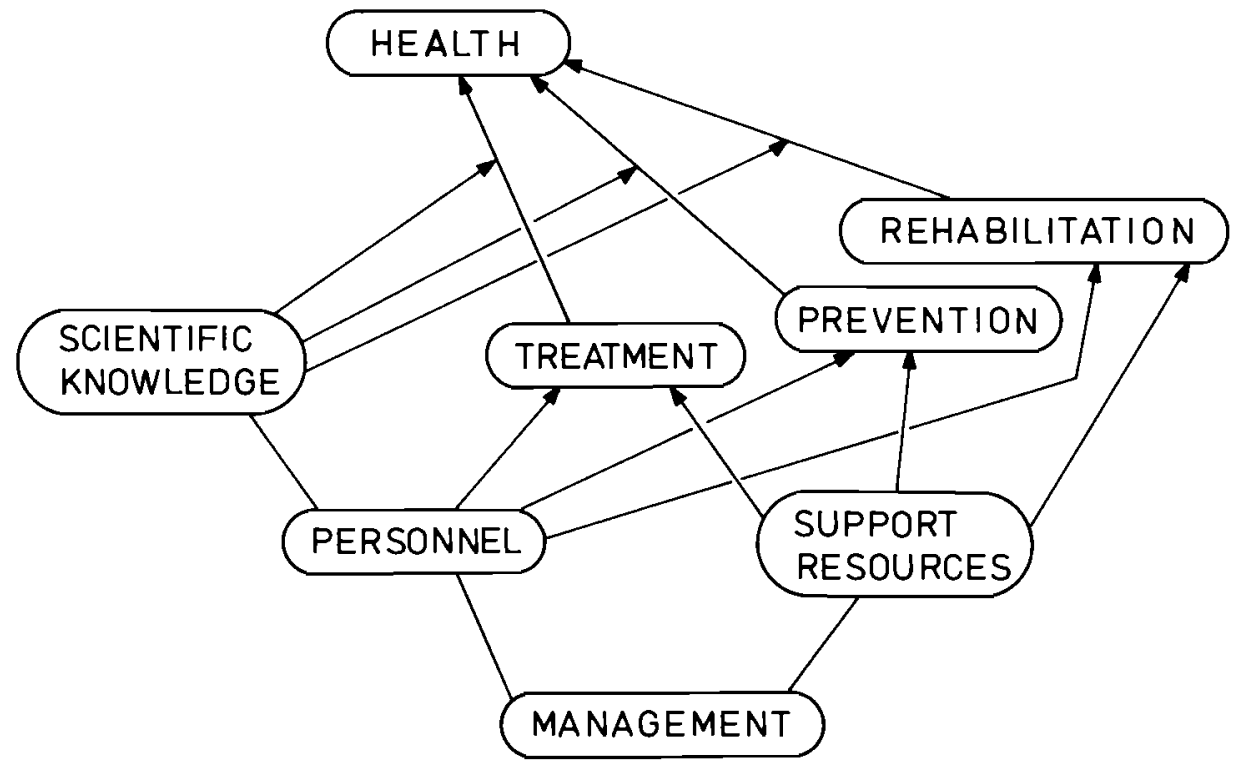

\begin{tabular}{|l|l|}
\hline RESEARCH \\
FACILITIES
\end{tabular} PREVENTIVE HOSPITALS

FIGURE 2. SOCIAL ORGANIZATION TO ACHIEVE HEALTH. 
Choice of specific projects must be tempered with a realization of our limited resources. Our efforts should be directed toward probleins of international interest so that it may not be said that our work could as easily have been performed in Moscow or in Harvard. In accordance with the IIASA philosophy reflected in its definition of systems analysis and with the imperatives of the moment, the Bio-Medical Project must address decision problems of the real world. Purely academic results, however scintillating, will not suffice. We all are infected with enthusiasm for the potential of IIASA. The time has come to channel that spirit into effective research.

\section{CONCLUSION}

Mr. Bailey thanked Mr. Venediktov for this summarizing statement and for his assistance in moderating discussion. He had enjoyed his role as chairman and noted a purposeful focusing of IIASA's efforts over the year that he has known the Institute. An important unchanging attribute of IIASA has been the graciousness and efficiency of its secretaries and other supporting personnel.

Mr. Raiffa expressed his hopes to welcome many conference participants to two further workshop sessions to be held on the morrow in Schloss Laxenburg. He appreciated the breadth of scope the Conference discussions had enjoyed but noted that distillation of far-reaching research dreams into a feasible initial program would be the immediate order of business. With the inauguration of Mr. Venediktov's term as Project Leader and with the helpful spirit of cooperation shown by WHo, the future looks bright. Mr. Raiffa thanked participants for their contributions and Mr. Bailey for the fair and unobtrusive manner in which he achieved a smocth pacing of the Conference. 
A.A. Afifi, J.H. Bigelow, and N. Glass

This excursion attempts to briefly define some of the more commonly used terms in systems analysis and its application to health problems. The authors have drawn freely on existing literature, without attempting citations. By no means is this meant to be a comprehensive glossary. Rather, it is a freewheeling exercise which presents what we believe to be the common connotations of various often used and misused words. The preceding papers in this volume present a plethora of examples.

A system is an aggregation of objects or components united by some form of interaction so as to perform a specific function. A system is usually a part of a larger system and consists of molecular subsystems. A modular system is one in which the component objects are standardized for flexibility, so that they may be deleted, replaced or exchanged with components of other systems.

An information system is one in which the components are devoted to storing, aggregating, processing and displaying information. The purpose of an information system is often to aid decision makers in reaching the most adequate decisions.

Without intending sarcasm, the best definition of systems analysis may be that it is the analysis of systems. It may be viewed as the systematic examination of a problem of choice in which each step of the analysis is made as explicit as possible. After perceiving the problem, the steps of analysis may include:

- defining and bounding the extent of the problem area--to simplify the problems to the point of analytic tractability and at the same time to preserve all vital aspects affected by possible solutions;

- identifying a hierarchy of goals and objectives and examining value trade-offs;

- generating appropriate decision alternatives for examination;

- modelling the complex, dynamic interrelationships among various facets of the problem, taking cognizance of the uncertainties inherent and realizing that decision rules incorporating feedback mechanisms can be employed;

- evaluating potential courses of action and investigating the sensitivity of the results to the assumptions made and to facets of the problems excluded from the formal analysis; and

- implementing the results of the analysis.

Editor's Note: One perhaps inevitable finding of the Conference was that certain systems terms took on different meanings for different scientific and cultural perspectives. It was widely felt that a useful first action in enhancing further exchange among scientists and practitioners of many nations would be the compilation of a glossary of systems terms. Accordingly, three members of the IIASA Bio-Medical Project have made a list of terms which arose during the Conference and have explained their most frequent usages. Their'glossary is included in this volume as a possible aid to the reader. Such an exercise in definition is inevitably subjective but here, we think, represents a good first step toward distilling the common core of understanding which the Conference members thought necessary. 
Objectives and goals are the ends we aim to achieve. Goals are long term while objectives are short term. Each goal consists of one or more objectives. In a hierarchical organization, the objectives of one level become the goals of the level immediately below it.

A plan is a strategy consisting of a set of steps to achieve goals or objectives. A plan may be considered as a method of controlling the activities or levels of those components of a system which are amenable to control.

Implementation is putting a plan into practical effect. Systems implementation is the process of bringing systems or their subsystems into operation. Prognosis is an estimate of the likelihood of success of a given plan. The term is used most often in medicine where the plan is the regimen of treatment. Projection is an estimate of future possibilities based on current trends. The possibilities do not necessarily relate to the success of a plan, but rather to the probable course of events in the absence of active intervention. A prediction is an estimate of the value of a variable, or the outcome of an event, based on available information regarding related factors. A forecast is a set of predictions calculated for a future point in time on the basis of present and past information.

Next, several terms used in mathematical programming are discussed. A mathematical program consists of a set of variables, a set of equations or inequalities, called constraints, involving these variables and a function of the same variables, called the objective function. The purpose of the program is to choose certain values of the variables, i.e. feasible values, which satisfy the constraints and also maximize or minimize, i.e. optimize, the objective function. The chosen values, if they exist, constitute the optimal solution. The process of finding optimal solutions is called optimization. A mathematical program is most often based on an incomplete representation of the rea1 world. Therefore, the "optima1" solution is optimal only within this restricted context. In a larger context, it is only suboptimal. In a hierarchical organization, optimal solutions of one level are often suboptimal for a higher level. Many decision makers believe that the real world is so different from the available representation of it that it is too much to hope for an optimal or suboptimal solution. Thus they are content with a satisfactory solution, i.e., one which meets certain minimum criteria and is known to be an improvement over the present strategy. This pattern of behavior is called satisficing.

Resource allocation is a term used to describe the process of distributing available material and personnel among a set of uses. Systems analysis is a valuable aid in improving resource allocation. A problem in which one wishes to maximize the benefit obtained from fixed amounts of resources, or to minimize resources required to achieve a given benefit, is called an optimal resource allocation problem. Such problems are often formulated as mathematical programs.

Evaluation is the process of determining the value or amount of success in achieving a predetermined objective. It includes at least the following steps: Formulation of the objective, identification of the proper criteria to be used in measuring success, determination and explanation of the degree of success, recommendations for further program activity. Feedback is the return to a point of origin of evaluative or corrective information about an action or process. It is one of the basic concepts of cybernetics. In policy-oriented systems analysis, the point of origin is often the decision maker or evaluator.

Indicators and indices describe the activity or condition of a system. Indices are quantitative integrative measures which attempt to describe the total activity of the system. On the other hand, indicators may or may not be quantitative and of ten reflect only limited aspects of the system. Effectiveness is the degree to which an objective or goal is achieved. Efficiency refers to the degree of economy in the use of resources, broadly defined, toward the achievement of a task. Thus it is possible that a system or subsystem may be efficient but ineffective, or vice versa. Indeed, much of the acumen in systems analysis consists in determining the trade-off between effectiveness and efficiency. 
A model is a representation of reality. Models may be descriptive, i.e. qualitative or quantitative. In systems analysis, models are usually of the mathematical kind, $i$.e. the relationships among relevant variables and parameters are expressed in the form of mathematical equations or inequalities. Parameters and variables are both deteminants of the state of system, and it is to some extent arbitrary which determinants are called parameters and which are called variables. Generally, however, the choice is made so that parameters change less frequently than variables.

There are many ways to categorize models. One is to classify them as positive vs. normative. While positive models merely describe the system in its present state, normative ones attempt to determine how the system should operate in order to satisfy certain criteria. Another independent classification is whether the model is dynamic or static. A dynamic model describes the entire path of the system until it reaches a stationary equilibrium state. A static model, on the other hand, is concerned only with the stationary state itself. A third independent classification is deterministic vs. stochastic. A deterministic model involves only factors whose values are possible to predict with certainty, or at least within tolerable error. Stochastic models involve one or more factors whose values are determined according to a probabilistic distribution, i.e. they include random error terms. In systems analysis, where optimization is usually the overriding concern, normative models occur more frequently than positive models. Static and dynamic models are frequently simultaneously developed. The static model determines the desired state of the system while the dynamic prescribes the required path. Once a model has been constructed, it should be verified and cross-validated. A model is verified when it is able to reproduce the factual information upon which it was based. It is cross-validated when it correctly describes the system under a different set of circumstances.

Next, we consider some of the economic terms used in systems analysis. A utility function is a function relating the utility derived by an individual or group to the goods and services which it consumes. Much of the analysis of micro-economics is based on the notion of consumers or groups maximizing the value of their utility function subject to an income constraint. In recent years there have been attempts to give an empirical basis to this notion and to cope with the problems posed by multi-dimensional utility functions.

Cost-benefit analysis is an attempt to apply to public investments the sort of investment appraisal applied to private business decisions. It attempts to incorporate concerns wider than those of the private decision maker. Many of these concerns are not normally measured in money terms. Discounted values are attributed to the benefits and costs so that a judgment can be made about the value of a proposed project when compared with possible alternatives. Costeffectiveness analysis attempts to circumvent some of the problems raised by cost-benefit analysis. It concentrates on finding the least-cost method of carrying out a given objective rather than trying to compare (often incomensurable) costs and benefits (e.g. the value of life compared with improvements in the physical environment).

Inputs are the resources used up by a project; outputs are the use that a project makes of these resources. Inputs and outputs may be measured in physical or money terms. Some outputs, termed intermediate outputs, are in turn inputs into a further system having outputs more directly related to ultimate goals. Externality effects are benefits or costs which an agent imposes incidentally on others. These effects may lead to a divergence between "private" cost and "social" cost. Examples might be the pollution of a river by a firm or noise caused by traffic. Recent theoretical work attributes the existence of externality effect to the imperfect definition of property rights and the presence of transaction costs. The existence of externality effects is often cited as a justification for public intervention in social or economic life. 
Costs and benefits of programs very often occur not all at once but spread over time. This poses the problem of comparing effects which occur later with those which occur sooner. The magnitude which relates the value of such effects through time is referred to as the discount rate and is normally expressed as a rate per annum, e.g. 6\%. Much theoretical work has concentrated on the basis for choosing one or more discount rates. Opportunity cost is the best alternative which is foregone when a particular course of action is chosen. This foregone alternative represents what one must give up in order to attain a particular objective. The opportunity cost of a new operating theater may, for example, be a new ward or outpatient suite. Trade-offs refer to possibilities of exchanging one set of benefits and costs for others.

The notions of Pareto optimality and efficiency are identical. In welfare economics they are used to designate economic states in which no member of a group can be made better off without making at least one other member worse off. Thus they represent the most efficient use of resources for a given distribution of income and wealth. In general, a different distribution will give a different Pareto optimal or Pareto efficient state. The term is derived from the writings of Vilfredo Pareto, the nineteenth-century Italian economist and sociologist.

Demands are quantities of commodities or services which consumers would purchase at a specified price. Price is not necessarily defined in terms of money alone. Need is a notion capable of many definitions and is often loosely used to mean "want" or "demand." The use of need should, however, imply that this particular good or service must be supplied before all other goods and services not classified as "needs" and up to the level at which it ceases to be a need. This still leaves undecided the vexed question of who is to decide what is a need and what is to be done in situations where the sum total of so-defined needs exceeds the capacity or willingness of society to supply the necessary goods and services. In most cases the notion of "need" is a political rather than a scientific concept. Wants are amounts of goods and services which a person would choose if the good or service were free or if, which atnounts to the same thing, his income were infinite. Market signals are the prices, profits, queues thrown up by a market which indicate the preferences of consumers and scarcity of resources within a given market. Their use as planning figures is dependent on views about the perfection of the market, the distribution of income and wealth and the importance to be attached to consumer preferences.

A standard is something established by authority as a rule for measuring quantity, weight, extent, value or quality of something. The thing may be an activity, e.g. a surgical procedure; a material substance, e.g. a drug, or competence of a professional; e.g. a physician. In systems analysis, constraints often require that the standards be met and sometimes penalties are imposed for violating them. A norm is a form of a standard which is based on the average behavior or quality of a group of objects. For example, when several workers are producing quantities of a given item, a standard of production may be set independently of their output. A norm, on the other hand, might be the mean or median level of their output.

To quote the World Health Organization, positive health status is "a state of complete physical, mental and social well-being and not merely the absence of disease or infirmity." The word health when used to denote a goal, aim or objective is a synonym for positive health status. The definitions and extent of a health care system vary widely. At one extreme, it may be understood to encompass only institutionalized medicine, e.g. hospitals, outpatient clinics and solo medical practices. At the other extreme, such a system has as components every segment of society connected in any way with health of the individual. This would include political, economic, social, cultural, recreational, technical, psychological and environmental factors, in addition to medical care. This latter definition would seem to equate the health care system with the totality of human environment. The authors will not attempt to select a "middle-ground" definition. 


\section{AUTHOR INDEX}

A

Acton, J., 22

Ahamad, B., 161

Ahuwalia, 199

Aleta, C.R., 290

Andersen, R., 55

Andersen, O.W. , 55

Anokhin, P.K., 31

Antonovsky, A., 264

d'Arge, R.C., 285

Attinger, E.0., 264

Auston, R., 277

Avtzyn, A.P., 35

$\underline{B}$

Bailey, M.J., 284

Bain, A.D., 213

Bartholomew, D.J. , 161

Bergner, M. , 237

Berki, S., 161

Berry, R.E., jr., 169

Bland, M. , 161

Blohmke, M. , 264

B1um, H.L., 288

Blumberg, M.S., 161

Boaz, R.F., 161

Boyes, D.A., 199

Brockington, F. , 20

Brown, B.W., jr., 55

Bunker, J.P., 55

Burnett, M., 35

C

Candau, M.G., 20

Chaklin, A.V. 35

Charnes, A., 288

Cleary, E.J., 288

Cochrane, A.L., 237

Cooper, W.W. , 288

Cox, G. 213

Coyl, E., 41

du Credoc, D.E.M., 277

Culyer, A.J., 282, 285
D

Danyushevsky, S.M., 28

Demset2, H. , 289

Desplanques, G., 277

Dobrov, G.M., 39

Doll , 199

Donabedian, A., 161

Dowl ing, W.L., 161

Drabek, L., 162

Draper, P., 213

Dubinin, N.P., 31

Dupuy, J.P., 277

E

Easson, E.C., 199

Egeberg, R.O., 237

Eliastan, M. , 162

Elinson, J., 237

Engelhart, V.A., 31

F

Fein, R., 55, 161

Feldstein, M.S., 55, 161

Ferry, J., 277

Fidler, H.K., 199

Fleissner, P., 264

Freeman, A.M., 285

Friedemann, H., 333

Friedman, B., 55, 161

Fuchs-Kittowski, K., 333

Fürst, E., 264

$\underline{G}$

Gardner, M.J., 277

Gerasimov, I.G., 39

Gobson, V., 20

Goldberger, A.S. 264

Golladay, F.L., 162

Golovteyev, V.V., 28

Grossman, M., 55 
Gvishiani, D., 39

Guillaume, H., 284

Gustafson, S.A., 286

Guterman, A.V., 213

$\underline{H}$

Hansen, W.L., 161

Hareman, R.H., 285

Harper, P., 35

Helmer, O., 41

Higginson, J., 35

Hitch, C.J., 282, 284

Hughes, E.F.X., 161

$\underline{I}$

Intriligator, M.D. , 162

$\underline{J}$

Jantsch, E., 333

Jones, N.H., jr., 161

Jones-Lee, M. 284

$\underline{K}$

Karsenty, S., 277

Kedroc, B.M., 31

Keeler, E.B., 55

Kimbe11, L.J., 162

King-Hilley, D., 31

Kinlen, 199

Kirillin, V.A., 34

Klein, L.R., 264

Kmet, J., 35

Kneese, A.V., 285

Knox, E.G., 199

Koltre1, A., 4 I

Kortanek, K.O., 286

Kosa, J., 264

Kostrzewski, J., 237

Kushlik, A., 213

$\underline{\mathrm{L}}$

Laver, R.J., 282, 285

Leeds, A., 41

Leveson, J. , 277

Levein, R. , 22
Levy-Lambert, H. , 284

Lickert, G. , 333

Löschner, E., 264

Lowe, C.R., 237

Lüth, P., 264

$\underline{M}$

Mabubi, E., 35

Mahler, H., 20

Majone, G., 280

Maki, D.R., 161

Maroyama, 35

Marston, R. , 39

Marx, K., 19

Mattis, 31

Maurizi, A., 161

McGinty, L., 284

McKean, R.N., 282, 284

McKeown, T., 199

Meadows, D., 264

Menzel, G. , 41

Mesarovic, M., 264

Metelitza, L.V., 35

Miller, M., 162

Milunsky, A., 213

Mirskaya, E.z., 41

Monsma, G.N., jr., 161

Mundlak, Y., 161

$\underline{N}$

Naschold, F., 264

Neligan, G., 213

Newhouse, J., 55, 161

Nikolajev, v., 333

Nugmanov, S.N., 35

$\underline{0}$

Orr, R., 41

$\underline{\mathrm{p}}$

Pauly, M.V., 162

Pfeifer, Z., 34, 35

Phelps, C.E., 55, 162

Pickering, J., 35

Pole, J.D., 213

Popper, L., 264

Popov, G.A., 279, 282

Powell, S.F., 35 
Pryce, D., 34, 41

$\underline{\mathrm{R}}$

Raab, V., 35

Raiffa, H., 167

Reinhardt, V.E., 162

Reisman, A., 264

Rimlinger, G.V., 162

Robertson, L., 264

Roemer, M.J., 55

Rösch, G. , 277

Rosenthal, S., 333

Rosh, 237

Rozenfeld, I.I., 162

Sarachek, D., 277

Schäfer, H. , 264

Schebeck, F., 264

Schelling, T.C., 284

Schleicher, S., 264

Schlutow, G. , 333

Schober, B., 264

Schultze, C.L., 289

Schwartz, W.B., 55

Schwödiauer, G., 264

Serebrov, A.I., 35

Shabad, L.M. , 35

Shain, M., 55

Shorin, M.V.G., 183

Shuman, 10

Silver, M., 264

Skhvatzabaya, I.K., 35

Sloan, F.A., 162

Smith, A.R., 161

Smith, K.R., 162

Smith, 31

Somer, A., 162

Speas, 10

Spofford, W.o., jr., 286

Steele, H.B., 162

Stefani, P., 161

Stein, Z., 213

Struve, C.A., 161

Susser, M., 213

Sutherland, G. , 213
$\underline{T}$

Taylor, G., 31, 35

Thiele, H.J., 333

Thomas, H.A., 284

Thompson, G.L., 288

Tilling, J., 31

Tinakov, V.D., 31

Tiyius, 35

Toffler, 0., 35

Torfs, M., 237

Tredt, H.J., 333

$\underline{\mathrm{U}}$

Uyeno, D.H., 162

$\underline{\mathrm{V}}$

Vikhert, A.I., 34

$\underline{W}$

White, P.D., 35

Williams, A., 213, 282, 285

Winter, H. , 264

Wiseman, J., 213

Wolff, K.H., 264

Worms, G., 277

Worth, A.J., 199

Wynne-Griffith, G., 213

$\underline{Y}$

Yett, D.E., 162

Yost, E., 162

$\underline{Z}$

Zeckhauser, R., 162

Zola, I. , 264 



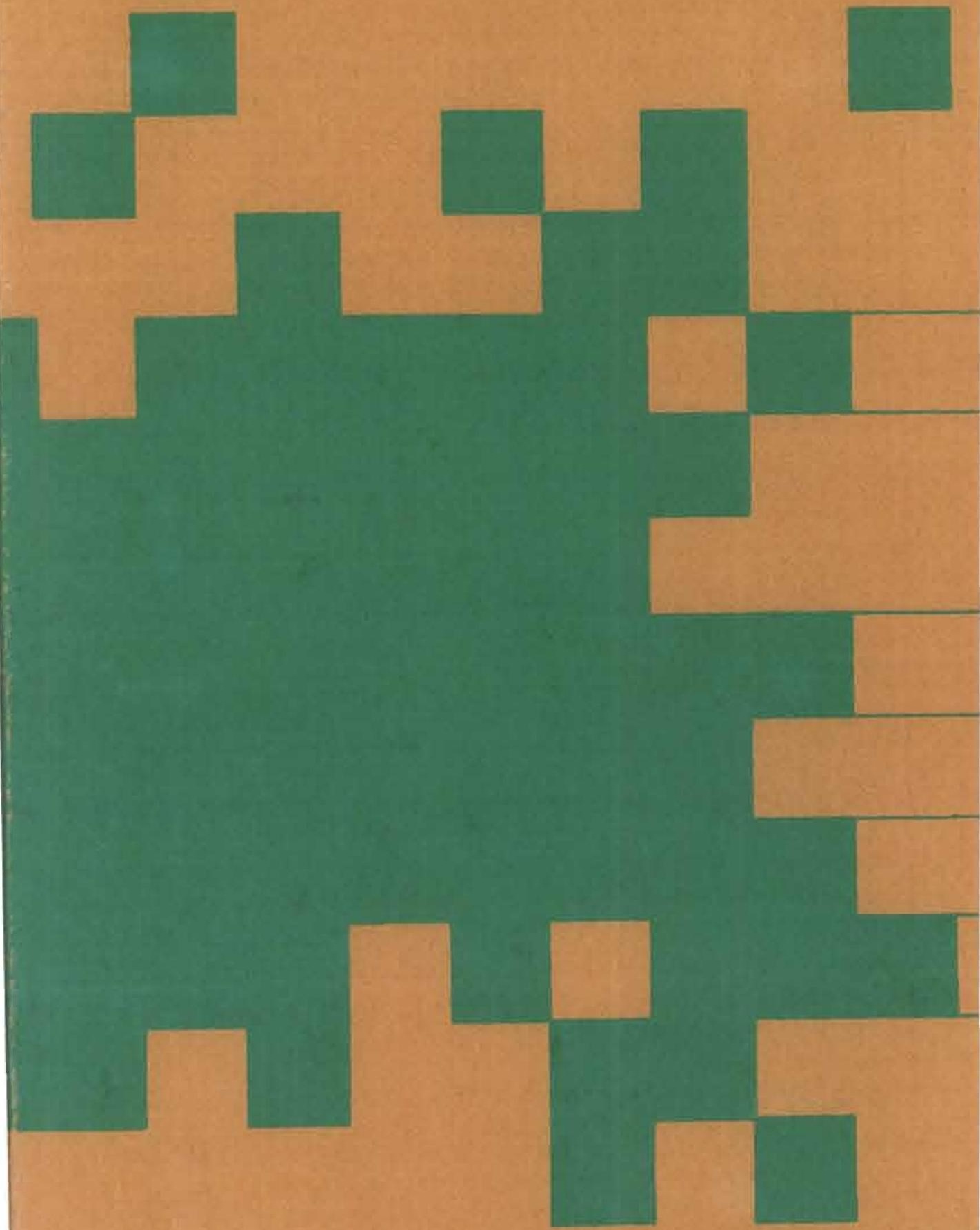